


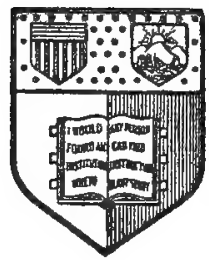

招ew 胃ork

State College of Agriculture At Cormell antiversity

3tbaca, 刍. 2 .

Zibrary 
QK 45.Cornell University Library

Nature and development of plants.

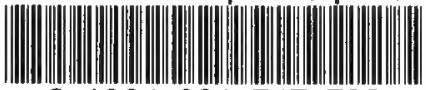

3 1924001747793

Date Due

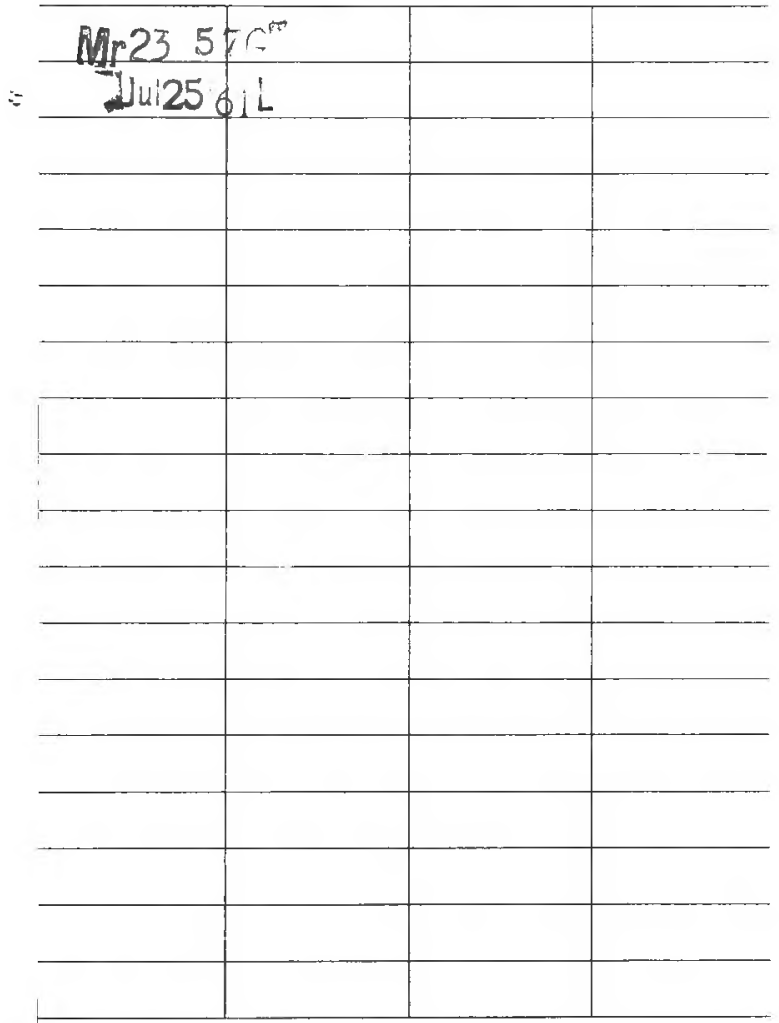

Library Bureau Cat, No. 1137 


\section{NATURE AND \\ DEVELOPMENT OF PLANTS \\ CURTIS}




\section{Cornell University Library}

The original of this book is in the Cornell University Library.

There are no known copyright restrictions in the United States on the use of the text. 


\section{NATURE AND}

\section{DEVELOPMENT OF PLANTS}

BY

CARLTON C. CUnRTIS, A.M., PH.D.

Professor in Botany in Columbia University

FIFTH EDITION-REVISED

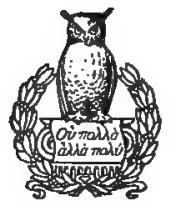

NEW YORK

HENRY HOLT AND COMPANY 


$$
\begin{aligned}
& \text { QK } \\
& 45 \\
& 686 \\
& 1916 \\
& 8119
\end{aligned}
$$

Copyrighted I907, I9I0, I9I4, I9I5, I9I6 by HeNRy Holt and COMPANy 


\section{PREFACE}

In the present volume an attempt has been made to present the more important aspects of botanical science, not only as they are related to pure biological science, but also as they are connected and associated with our daily life and interests. The general reader will find here a discussion of the laws and principles that control and direct plant life and of the importance of this life. The author also has had in mind the difficulties that the student experiences in entering a new field. To make the subject more approachable, many of the technical terms have been eliminated and an easily comprehended terminology has been maintained throughout the book. The text is designed especially for the benefit of the student who is beginning the subject. We trust that a study of it will bring him to the class room prepared for a discussion of the topics and we also trust that this work of preparation will tax him to the full measure of his intellectual capacity. The author is old fashioned in his. ideas of education. Work that simply entertains or imparts information and that does not create the sufferings associated with mental effort can be of little permanent value or make for any considerable development. Finally the book will fall short of its real purpose unless used in the laboratory in connection with the plants themselves. Detailed directions are not given for the laboratory work-these of necessity must vary with the instructor and with the locality-but the text gives the student sufficient guidance and understanding to enable him to find out for himself the principles and facts in the material to which he has been directed.

Acknowledgments are due to Professors C. B. Atwell, J. H. Schaffner, F. D. Kern, Ira D. Cardiff, Jean Broadhurst, C. A. Darling, A. H. Chivers, B. O. Dodge, R. C. Benedict, G. W. Martin and several others for valuable suggestions, in the prepa- 
ration of various portions of the text. The author desires to express his especial indebtedness to his good friend, Mr. H. O. Hanson, for the preparation of many of the illustrations; to $\mathrm{Mr}$. W. A. Andrews, for microscopical studies from which drawings have been made, and to Miss Mary L. Williams, for the execution of many of the studies. Special mention is also made of the author's indebtedness to the assistance and collaboration of his former pupils and present associates, Drs. E. Altenburg and $\mathrm{H}$. J. Muller.

Columbia University,

Carlton C. Curtis. June, I915. 


\section{CONTENTS}

PAGE

INTRODUCTION . . . . . . . . . . . . . . . . . I

\section{PART I \\ Nature of Plants}

I. The Leaf. . . . . . . . . . . . . . . . . . . 7

II. ThE RoOT........................ 46

III. The Stem. . . . . . . . . . . . . . . 7 I

IV. The Flower, Fruit and Seedling. . . . . . . . . . I I 5

PART II

The Development of Plants

V. Classification of Plants................ I46

VI. ThallophYTA. . . . . . . . . . . . . . . . I49

VII. BRYOPHYTA.. . . . ............... 269

VIII. PTERIdophYTA................... 3I I

IX. Spermatophyta. . . . . . . . . . . . . . . . 352

X. Angiospermae (Spermatophyta concluded) .... 378 



\section{NATURE AND DEVELOPMENT OF PLANTS}

\section{INTRODUCTION}

I. The Nature of the Plant.-It is a familiar fact that most plants have, stems, leaves and roots and that these organs are variously modified. Why have such organs been developed? Why do they assume such varied forms and arrangements? How does it come about that the stem reaches up in the air and that the branches and leaves are arranged in a very definite order while the root penetrates the soil and grows toward moisture and other soil material? Is a plant, like an animal, conscious of its surroundings, seeking suitable foods and avoiding unfavorable conditions? It is evident to the casual observer that the plant is sensitive to its surroundings; some plant organs bend toward a light that we recognize with difficulty or react to a touch that we cannot appreciate. Has the plant a nervous system and faculties like ourselves that enable it to adjust itself to its surroundings? To answer these questions it will be necessary to

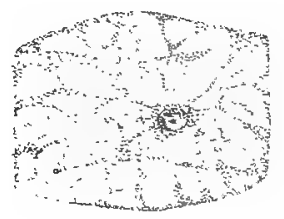

FIG. I. Diagram of a cell showing its three dimensions; mesh-work of granular cytoplasm which incloses colorless cell sap, the vacuoles, and a denser dark body, the nucleus.

consider the nature of the living substance of the plant. The plant body is composed of cells that are like boxes of living matter having length, breadth, and thickness (Fig. 1). While the cells assume various forms and perform different work or 
functions, they all possess cell walls which contain during the life of the cell a substance termed protoplasm. This substance resembles somewhat the white of an egg, being viscid and rather tenacious. The protoplasm is not of uniform consistency. The larger portion of it is finely granular and is called the cytoplasm while a denser rounded part is termed the nucleus. Other bodies, plastids, also denser than the cytoplasm are of common occurrence. Such plastids as contain a green pigment, chlorophyll, are called chloroplastids or chloroplasts, and these produce the green

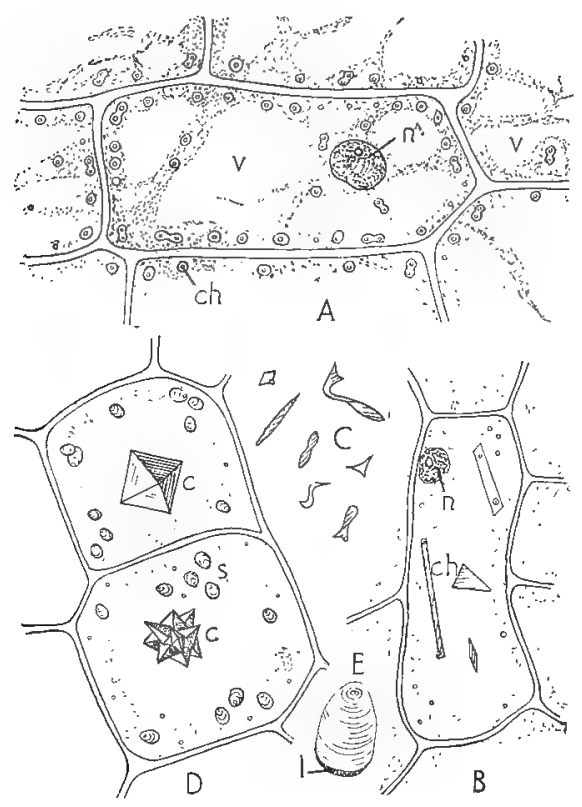

FIG. 2. Structure of the cell: $A$, cell ditch-moss, Philotria; $n$, nucleus $v$, vacuole, $c h$, chloroplast. $B$, cell of carrot; $c h$, yellowish chromoplasts, $n$, nucleus. $C$, reddish chromoplasts from rose hip. $D$, cells of Begonia; $s$, starch grains, $c$, crystals of lime. $E$, leucoplast, $l$, of potato forming a starch grain.

color of the vegetation (Fig. 2, A). Still other plastids, the chromoplasts, contain red or yellow pigments that give the color to many fruits and flowers, as the tomato, rose-hip, squash, nasturtium, etc. (Fig. 2, B, C). Colorless plastids, leucoplasts, often 
occur in cells hidden from the light. One group of these leucoplasts forms the starch that appears in underground storage organs as in the potato (Fig. 2. E Usually spaces or vacuoles, that appear as cavities also in the granular cytoplasm (Fig. 2, $A, v$ ). In reality they filled with watery solutions of various substances, the so-called cell sap. Many pther structures (Fig. 2, D) appear in the protoplasm to which attention will be called later. It is well to remember that these visible structures do not represent the real composition of the protoplasm. A variety of units beyond the range of visibility, grow, multiply, and build up the various structures which we recognize as constituting the protoplasm. The cell walls make up the body of the plant and give stability to its various organs but the living part of the cell is the protoplasm. This substance reaches through delicate pores in the cell wall to the protoplasm of adjacent cells so that all the living substance of the entire plant body is in contact and forms one united mass.

2. The Nature of the Living Substance of the Plant.-The protoplasm possesses most remarkable powers. It can absorb various fluids and gases, decompose them into simple elements, reunite them into foods or discharge from the cell such substances. as are not required. Furthermore the protoplasm effects those changes termed growth by transforming the foods into the substances that compose the cell walls and other parts of the cell, as the protoplasm itself. How are these changes brought about? Every substance is composed of elements. Water consists of two elements, hydrogen and oxygen. The elements that composeany substances are held together with great energy, owing to their mutual attraction for one another. When two different substances are brought together, it may happen that the attraction of certain elements of one substance is greater for one or more of the elements of the other substance than for its own elements. The result is, that the elements will be torn away from their respective substances and united into new combinations. We say that a decomposition and a re-combination has been effected, or, that a chemical reaction has occurred. We see an illustration of these chemical changes when iron-ore is heated with charcoal. 
The ore is composed of the elements iron and oxygen and the charcoal consists of carbon. In the presence of heat the carbon has a stronger attraction for the oxygen than the iron has. Consequently the oxygen is drawn away from the iron and unites with the carbon, forming a new combination of carbon and oxygen, and leaving the iron free. This decomposition and re-combination is only a part of the chemical change that takes place, but it will serve to illustrate the nature of many chemical reactions. The energy that was required to hold the oxygen and iron together begins to be set free as soon as the decomposition starts and it contributes to the rise of temperature during the reaction. The living substance of the plant is composed of a great variety of chemical substances that are very readily decomposed by gases and other substances which it absorbs. Light, heat, gravitation and moisture are even more powerful in producing these changes. These substances and forces are often referred to as stimuli (sing. stimulus) because they start the chemical changes referred to above. So the various substances and forces in nature stimulate or cause chemical changes in the living substance of the plant and the energy thus set free is used by the protoplasm in the performance of its work. The cells of a seed have no power of their own to grow or perform any duty. It is not until a certain amount of heat, moisture, gases or other stimulating forces have acted upon the protoplasm or substances contained in it and so aroused chemical changes that it is furnished with the requisite energy to begin growth. Furthermore, these forces exert a very definite influence upon the protoplasm and cause it to accomplish very definite results. This is due to the fact that not all portions of the protoplasm of the plant body are equally influenced by, or we may say equally sensitive to heat, light, and other forces and consequently the various parts of the plants do not respond alike. The force of gravity, for example, acts upon some stems and the living substance is influenced by this stimulus so that a growth is aroused that bends the stem into an upright position. The protoplasm in the cells of the root, however, is so constituted that the stimulus of gravity causes a growth that bends the root down into the soil. Light 
stimulates the mustard plant in such a way that the stem grows toward the light and the root away from it. So the living substance of the plant while forming one united whole varies in its sensitiveness in various parts of the plant. In this respect the various parts may be compared to the receiving stations of a wireless telegraphy system. The receiving stations may have instruments sensitive to certain intensities of electrical currents and other currents do not affect them. So the various organs of the plant are sensitive, each in its own peculiar way, to certain stimuli. As a result of this adjustment the various parts of the plant, being attuned or sensitive to certain forces, are led or induced to grow so that they come into the most helpful and beneficial relation to these forces. Thus the leaves, branches, and roots are stimulated to grow and develop so that each part becomes properly related to light, moisture, gravity, etc. The broad blades of the majority of leaves are exposed to the direct rays of light. This arrangement is of the greatest benefit because they are using the light in the manufacture of foods. This position is assumed, however, because they are sensitive to light, gravitation and other forces which direct and cause the arrangement. This is the most noteworthy feature about the sensitiveness of the protoplasm. Forces stimulate to growth in such a way that the results are helpful and the greatest good comes to the plant. In other words the reactions are purposive. These growths are so elaborate and beneficial that they often appear as the result of reason and will. The bending of the root into the soil brings it into contact with water and other foods; the tendril coils about a branch and binds the plant firmly to the support. The plant, however, does not direct these adjustments. These reactions do not involve consciousness. These movements and all others are absolutely directed and controlled by the various forces which act upon the sensitive protoplasm. A definite reaction follows a stimulation which the plant has no.power to alter or control. The root will bend down into a dish of mercury with the same energy and directness as that with which it penetrates the soil, and the tendril will clasp your finger or a branch of its own body as firmly as a serviceable support. 
We shall now proceed to study the plant from this standpoint, giving attention to the fitness or adaptation of the leaf, root and stem, to the conditions under which the plant lives, and to the work which it performs; and finally we will be interested to learn how the seed is formed and how the plant lives from year to year. 


\section{PART I \\ THE NATURE OF PLANTS}

\section{CHAPTER I}

\section{THE LEAF}

3. The Work of the Leaf.-Each plant has a character or a personality of its own. What is it that gives this individuality to the plant? When the work that it performs is understood it will be seen that this character is very largely due to the adaptation of the leaves to the performance of certain duties. The
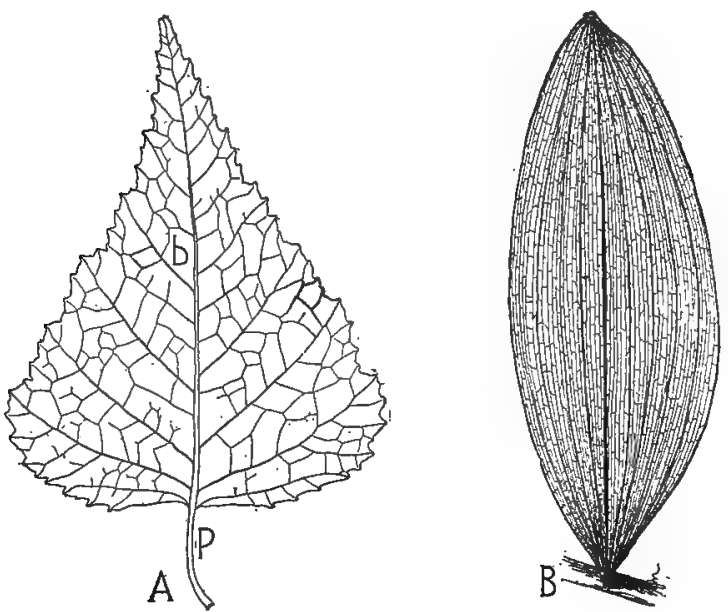

FIG. 3. Forms of leaves: $A$, leaf of white birch with netted veins- $p$, petiole; $b$, blade. $B$, leaf of Solomon's seal with parallel venation and blade clasping stem without petiole.

leaves bring the plant into harmony with its surroundings and give to it a subtle individuality owing to the perfection of their arrangements, structures and forms for the work in hand. The 
more important work performed by the leaves is the construction. of foods, the giving off of water or transpiration, and breathing or respiration. The magnitude of this work far exceeds the energy expended in all the industries of the world. The leaves, however, accomplish this work so quietly and economically that most people are scarcely conscious of it.

In order to understand the purpose of the petiole and green blade (Fig. 3) or the significance of the various forms and arrangements of leaves it will be necessary to examine the structure of the leaf and see the character of the apparatus that is used in the performance of its work. The blades of the majority

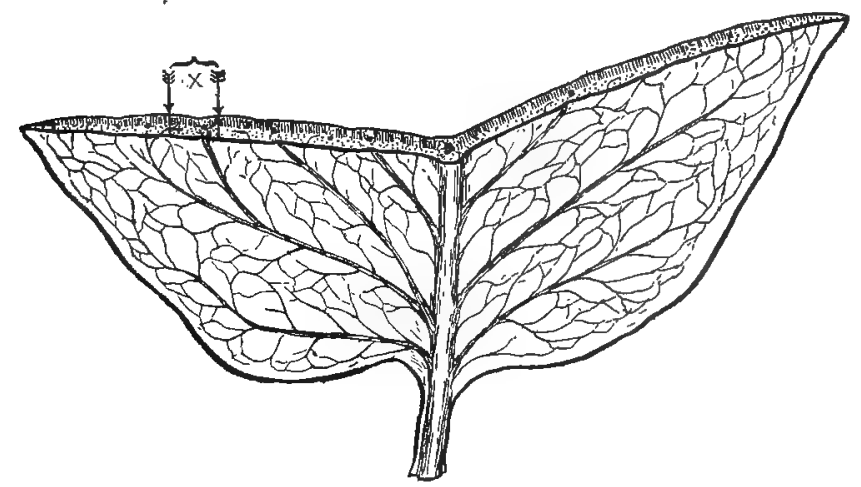

FIG. 4. Blade of lilac leaf cut across, showing the more compact arrangement of cells upon the upper side of the leaf.

of leaves are flat. A section through such a blade, cut as in Fig. 4 so that we can look into the end of the blade, shows that the leaf is composed of a complicated arrangement of cells. Fig. 5 is a greatly enlarged view of Fig. 4 taken at $X$.

4. The Epidermis.-It is now seen that a layer of compact cells (Fig. 5,e) surrounds the leaf on all sides. In fact such a layer covers all parts of the plant body. This layer of cells, the epidermis, is provided with minute openings or stomata (sing. stoma), Fig. 5, s. The stomata are especially abundant in the epidermis on the under surface of the leaf and often quite lacking from the upper surface. A better idea of these openings and of the epidermal cells may be gained by stripping off the epidermis 


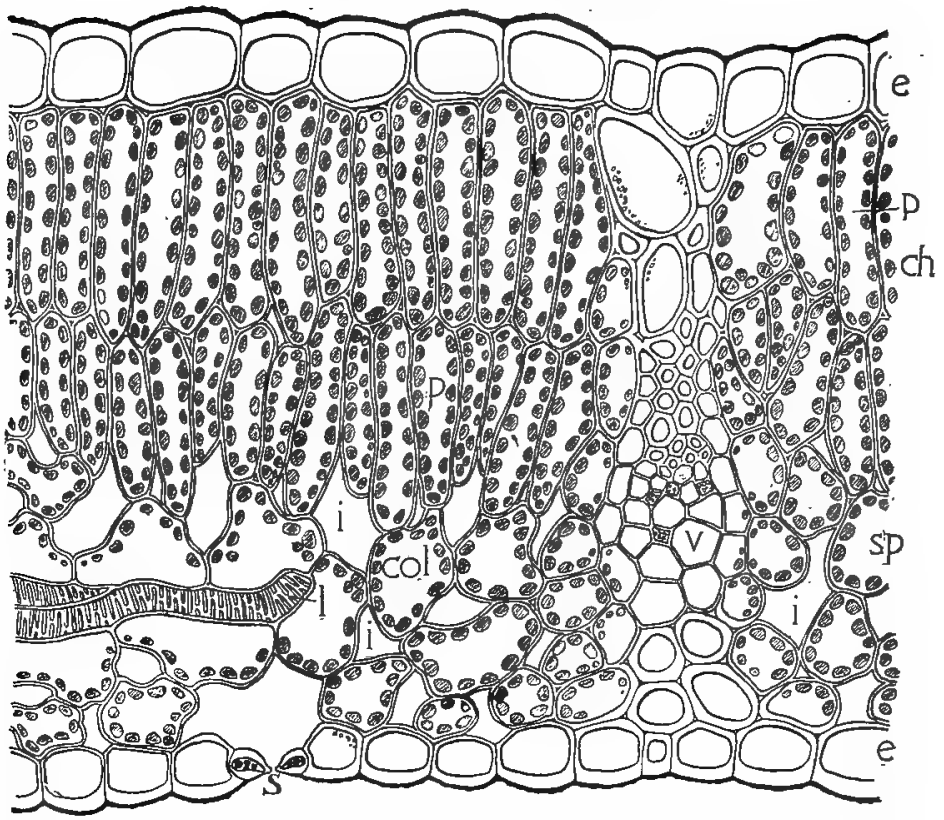

FIG. 5. Greatly enlarged view of region $X$ in Fig. 4: $e$, epidermis; s, stoma; $p$, palisade mesophyll; $c h$, chloroplast; $s p$, spongy mesophyll; $i$, intercellular spaces; $v$, small vein cut across; $l$, end of vein seen from the side, consisting of elongated and banded cells (tracheids); col, collecting cells that transfer material to and from the palisade cells.-H. O. Hanson.

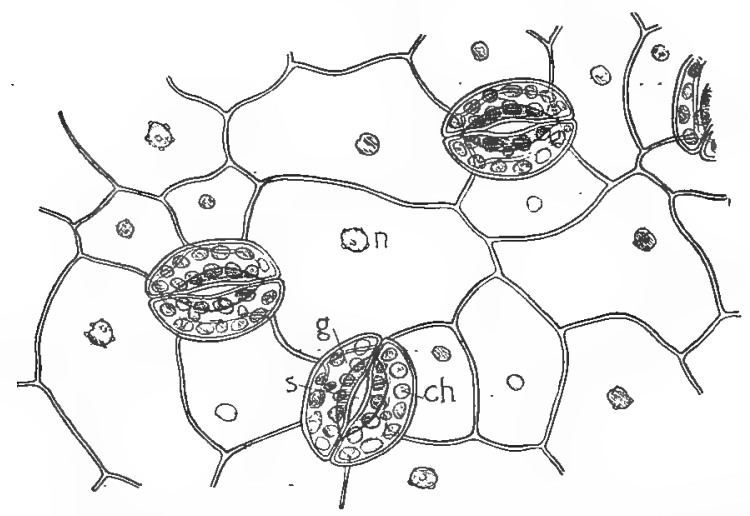

Fig. 6. Surface view of epidermis of lilac leaf: $g$, guard cell; $s$, stoma; $c h$; chloroplasts; $n$, nưcleus.-H. O: Hanson. 
from such leaves as the live-for-ever, blue flag or hyacinth. The cells of the epidermis are very compactly put together and may be stripped off by means of a penknife as a thin white skin. Examined under a microscope, such preparations show the stomata as minute openings guarded by two rather lens-shaped cells, termed the guard cells (Fig. 6). Chloroplasts usually occur only in the guard cells, the other epidermal cells having a watery, colorless cell content. In addition to these features, Fig. 7 shows that the outer portion of the walls of the epidermal cells is modified so as to form a delicate, skin-like layer over the outer sur-

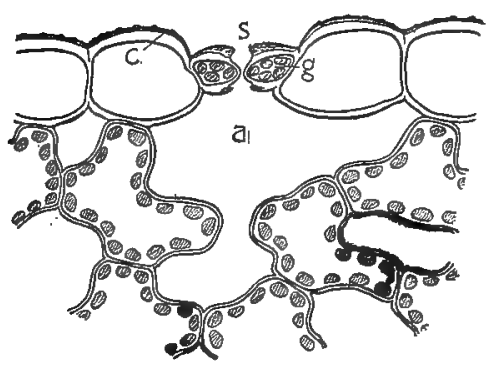

FIG. 7 .

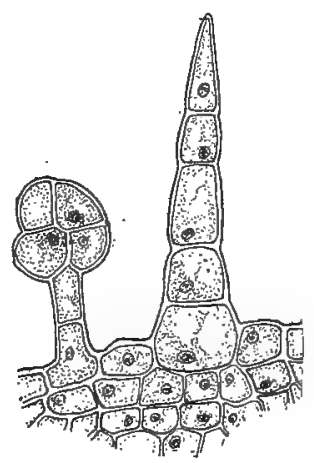

FIG. 8 .

FIG. 7. Section across a stoma shown in Fig. 6: $s$, stoma; g, guard cell: c, cuticle; $a$, air chamber.-H. O. Hanson.

FIG. 8. Hairs from the epidermis of squash leaf.

face of the epidermis. This part of the cell wall is called the cuticle. It contains a fatty substance, cutin, that renders the epidermis nearly impervious to gases and fluids, so that the leaf is entirely surrounded by a water- and gas-proof coat. In many leaves hairs of various forms grow out from the epidermal cells (Fig. 8).

5. The Mesophyll.-The cells within the epidermis have, for the most parts, a greenish color due to numerous green bodies, chloroplasts, contained in the cells (Fig. 5, ch). These green cells of the leaf, termed the mesophyll, consist of one or more layers of rather elongated and compact cells on the upper side of the leaf (the palisade mesophyll, Fig. 5, $p$ ), and below they 
are joined to rather irregular and loosely arranged cells (the spongy mesophyll, Fig. 5; $s p$ ). Numerous air spaces extend in all directions through this spongy mass of cells reaching up to and between the palisade cells and down to the stomata (Fig. $5, i)$. Bundles of small cells also appear here and there between the palisade and spongy mesophyll (Fig. 5, v, l). These structures are the so-called veins that appear as fine lines in the majority of leaves (Fig: 3 ). These veins or vascular bundles branch again and again and so extend to all parts of the leaf. In Fig. 5, v one of the veins has been cut square across while at $l$ the end of a small vein is shown, having been cut in half lengthwise. The walls of the mesophyll cells are smooth, thin, and elastic and composed of a substance called cellulose. Thin places or pores are often formed in the walls which appear as openings owing to the extreme thinness of the wall at such places. The term parenchyma is applied to all cells possessing the character of walls noted in the mesophyll cells. In the vascular bundle, however, a portion of the cells have thicker walls which are more rigid, hard and woody. Such cells are often referred to as prosenchyma.

What is the significance of the peculiar and varied arrangements of the cells in the leaf? We naturally anticipate that these different structures are adapted to performance of special duties. Attention will first be directed to the work performed by the green portion of the leaf, the mesophyll. Similar cells containing chloroplasts are of common occurrence in various parts of the plant, being often found in stems and unripe fruits. In the leaf such a tissue is termed mesophyll but a more general term, Chlorenchyma, includes all chlorophyll-bearing tissue wherever found.

6. The First Function of the Leaf, Photosynthesis.-Chlorenchyma is the most important tissue in the plant since it has for its special function or work the construction of carbohydrates, such as sugars and starches, which are among the most important foods of the plant. The construction of these carbohydrates by the chlorenchyma is called photosynthesis. This work easily ranks as the leading wonder of the world because its processes are so complicated and of such magnitude and importance in the 
economy of this world of outs. It will be seen that this tissue not only keeps the air in a wholesome condition for breathing and so makes life possible upon the earth but that all animal life is absolutely dependent, either directly or indirectly, for food upon the products built up by the chlorenchyma. Let us see how these foods are formed. Various substances are absorbed by the roots, and the vascular bundles, which extend throughout the plant body, transfer them to the chlorenchyma. This absorbed material is in large part water, but various mineral substances are dissolved in it. Various gases, as carbon dioxide; also find their way through the stoma to the chlorenchyma. All of these absorbed substances are composed of elements. Thus water consists of two elements, hydrogen and oxygen, in the proportion of two parts of hydrogen to one part oxygen. This composition is indicated by the abbreviation, $\mathrm{H}_{2} \mathrm{O}$. So the gas, carbon dioxide, contains one part of carbon and two parts of oxygen, indicated thus $\mathrm{CO}_{2}$. Chloroplasts have the power under suitable conditions of decomposing or tearing apart these compounds and of reuniting their elements into new compounds that are quite different from the original ones. In this way $\mathrm{CO}_{2}$ and $\mathrm{H}_{2} \mathrm{O}$ are decomposed and the elements reunited intó complex compounds or foods consisting of carbon, hydrogen and oxygen. Such complex foods as cane sugar, consisting of twelve parts of carbon, twenty-two of hydrogen, and eleven of oxygen are formed in this way. This very commion food is expressed by the formula $\mathrm{C}_{12} \mathrm{H}_{22} \mathrm{O}_{11}$. So also other foods are formed, as grape sugar $\mathrm{C}_{6} \mathrm{H}_{12} \mathrm{O}_{6}$ and starch usually indicated as some multiple of $\mathrm{C}_{6} \mathrm{H}_{10} \mathrm{O}_{5}$. The cellulose walls of the parenchyma cells have the same composition as starch. It will be seen that all these foods have carbon united to hydrogen and oxygen in the same proportion as it exists in water. Cane sugar has carbon united to eleven times $\mathrm{H}_{2} \mathrm{O}$, and starch five times $\mathrm{H}_{2} \mathrm{O}$. It was supposed that these substances were a combination of carbon and $\mathrm{H}_{2} \mathrm{O}$. For this reason they were called carbohydrates. This name is still applied to these foods although it is known that the base is not $\mathrm{H}_{2} \mathrm{O}$ but the hydroxyl $\mathrm{OH}$. The actual changes that are effected in the formation of these various carbohydrates are not known. 
It has been suggested that $\mathrm{CO}_{2}$ and $\mathrm{H}_{2} \mathrm{O}$ enter into solution forming carbonic acid $\left(\mathrm{H}_{2} \mathrm{CO}_{3}\right)$. This change is represented by the equation, $\mathrm{CO}_{2}+\mathrm{H}_{2} \mathrm{O}=\mathrm{H}_{2} \mathrm{CO}_{3}$. By giving off one part of oxygen this acid is changed to formic acid $\left(\mathrm{CH}_{2} \mathrm{O}_{2}\right)$, i. e., $\mathrm{H}_{2} \mathrm{CO}_{3}$ $=\mathrm{CH}_{2} \mathrm{O}_{2}+\mathrm{O}$. A similar decomposition is effected in the formic acid which results in the formation of formaldehyde $\left(\mathrm{CH}_{2} \mathrm{O}\right)$, i. e., $\mathrm{CH}_{2} \mathrm{O}_{2}=\mathrm{CH}_{2} \mathrm{O}+\mathrm{O}$. The two parts of oxygen pass from the cells and escape through the stomata as a gas. In the presence of certain alkalies and acids, formaldehyde increases the number of elements which compose it, thus six times $\mathrm{CH}_{2} \mathrm{O}$ would give $\mathrm{C}_{6} \mathrm{H}_{12} \mathrm{O}_{6}$ or grape sugar. This is but a theory based upon the facts that $\mathrm{CO}_{2}$ and $\mathrm{H}_{2} \mathrm{O}$ do unite in nature to form $\mathrm{H}_{2} \mathrm{CO}_{3}$ and that this acid may decompose as stated above, and finally that formaldehyde can be detected in plant cells and it is possible to produce sugar from this substance by treating it with alkalies and acids. All that can be definitely stated about the changes going on in the leaf, during the formation of the carbohydrates relates solely to the beginning and end of the process. Water and carbon dioxide enter the chlorenchyma cells. A series of changes follows, the nature of which can only be conjectured. Finally, as the end result, sugar appears in the cells and oxygen is set free, escaping as a gas.

These complex changes are brought about in the leaf in so subtle a way that we are not conscious of them or of the great amount of energy that is required to effect them. It requires the energy expressed by a temperature of $1300^{\circ} \mathrm{C}$. to decompose $\mathrm{CO}_{2}$ into its elements. Where does the plant obtain the energy to bring about the decompositions and recomposition? This work is accomplished by the energy of the sunlight acting upon the chloroplasts. The chloroplasts of the seed plants are minute, rather lens-shaped grains, and increase in number by the division of the plastid into two equal parts (Fig. 9). These bodies are denser portions of the cytoplasm and like it are nearly colorless. In the presence of light a green, oily substance, chlorophyll, is formed in the plastids, thus producing their green color. Chlorophyll is rarely formed except in the presence of light. Plants grown in cellars or in the dark are of a pale color owing to the 
absence of chlorophyll in the plastids. Similarly green plants lose their chlorophyll when placed in the dark. This is the principle employed in the blanching of celery. The stalks are surrounded by earth or the light is excluded from them by some other means; chlorophyll disappears from the plastids and fails to develop in the new cells that are formed in the dark. Plants in which the chlorophyll is not developed are said to be etiolated. The plastids are in the cells, however, for if an etiolated seedling is removed from the dark to the light the chlorophyll will begin to appear in a few hours. The greening of potatoes when removed from the ground and left in a strong light is a familiar example of this. It is evident that the formation of chlorophyll is usually closely connected with the action of light. Another important point regarding the influence of light is the fact that such a food as starch is not usually found in the leaf in the absence of light. This may be easily. verified by cutting the initials of your name in rather large letters in a strip of black paper or smooth tin-foil and fastening the strip in the early morning to the upper surface of a well-sunned leaf of a starch forming plant. After a few hours remove the leaf from the plant and place it in alcohol. This will dissolve the chlorophyll and the leaf will become quite white in a few hours. Now place the leaf in a tincture of iodine which turns starch to a blue or blueblack color. Wherever the light was excluded from the leaf there is only a pale yellow color but all portions of the sunned leaf show an abundance of starch as revealed by the blue or blueblack coloration. Consequently the letters appear black on a yellow background which marks the limits of the strip of paper. No starch can be detected as a rule in leaves taken from plants that have been growing in the dark for twenty-four hours. Plastids that do not contain chlorophyll, examples of which are found in the cells forming the white bands or blotches in many variegated plants, do not form starch in the light. It is evident from these facts that the chlorophyll and light co-operate in some way in the formation of starch. It is known that chlorophyll absorbs a certain portion of the sunlight. If a beam of sunlight is caused to pass through a prism it is separated into 
seven colors, i. e., red, orange, yellow, green, blue, indigo and violet. When, however, a beam first passes through an alcoholic solution of chlorophyll or through a green leaf a portion of certain colors and all of other colors do not appear. The chlorophyll has taken up or absorbed certain of the light rays especially portions of the red, blue and violet. It is reasonable to suppose that the energy in these rays is utilized in part by the plastids in effecting the changes noted above in the formation of foods. The sun gives to the earth great quantities of energy in the form of light. A portion of this light is taken up by the chlorophyll, and the plastid uses the energy of the light to bring about the recombination of $\mathrm{CO}_{2}$ and $\mathrm{H}_{2} \mathrm{O}$ and the formation of sugars, starches, and other carbohydrates. Because of the importance of the sunlight in the formation of carbohydrates this process is called photosynthesis. This term means the putting together by means of light.

7. The Magnitude of the Work of Photosynthesis.-Carbon is an important element in the composition of plant foods and also in the walls of the cells. It forms one half of the dry weight of the plant. All the carbon appearing in the plant is derived solely from the $\mathrm{CO}_{2}$ in the air, of which it forms a very small part, only about three parts in ten thousand. Furthermore the carbon comprises only $3 / 1$ I by weight of the $\mathrm{CO}_{2}, 8 / 1$ I being oxygen. A square meter of leaf surface, however, can withdraw all the $\mathrm{CO}_{2}$ from 2500 liters of air in one hour. Such a volume of air would be a space one meter square and $2 \frac{1}{2}$ meters high. This would furnish sufficient carbon for the construction of one gram of starch. In this way such large quantities of $\mathrm{CO}_{2}$ are drawn into the chlorenchyma cells as to make possible each year the harvest and the renewal of vegetation of the earth. In the United States alone in this way there was in 19I4 built up over 734 millions of pounds of cotton, $89 \mathrm{I}$ million bushels of wheat, I 39 million bushels of oats, etc., representing a value for all crops of 7 billion dollars. Our leading crop is corn which amounted to nearly $2 \frac{3}{4}$ billion bushels and valued at about $\mathrm{I} / 4$ billion dollars. The gold and silver coin and bullion of the country are not of greater value. This corn came up and matured in I20 
days, consequently these coin plants were manufacturing food at the rate of over I 5 million a day. These figures represent only a small portion of the work performed, since the grain is but a part of the plant, and furthermore the larger portion of the land is covered with forests and other forms of vegetation. The fact must not be overlooked that this process of photosynthesis is of vital importance to our welfare in another way. Owing to the large volumes of $\mathrm{CO}_{2}$ that are constantly formed by fires and the respiration of animals such an excess of this gas would accumulate in the atmosphere that all animal life would eventually cease were it not for its absorption in photosynthesis. So balanced are the rates of formation and absorption, however, that the percentage existing in the air does not materially vary.

8. The Construction of Proteids.-A second group of foods formed by plants are called proteids. These differ from the carbohydrates in that they contain nitrogen in addition to carbon, hydrogen and oxygen. They are more complex compounds than the carbohydrates and may contain sulphur and phosphorus in addition to the four elements mentioned above. Less is known about their formation than of the carbohydrates. It is probable that they are largely formed in the leaves and by a process similar to that of photosynthesis. The sulphates, phosphates, and nitrates absorbed from the soil are decomposed and the elements of nitrogen, sulphur or phosphorus are united to simple carbon compounds and complex proteids are the result. Light probably does not co-operate directly in this construction although it may do so indirecily. These foods are formed in much smaller quantities than the carbohydrates but they are of the greatest importance in the nourishment of the plant. This is especially true as regards the living substance, protoplasm, which resembles somewhat in composition some of the more complex proteids.

9. The Distribution of the Foods. - Let us now consider what becomes of these foods. A small part is consumed on the spot by the manufacturing cells themselves, a larger portion is transported through the vascular bundles to all the living and growing cells of the plant body, but as the plant approaches the completion of its annual growth a larger and larger part of the food 
is transferred to special parts of the plant, such as buds, roots, seeds. Here it is stored as a reserve food to meet the needs of the plant at such times as it is not able to manufacture food. This transfer of foods is slow and consequently the rapidly constructed sugars gradually accumulate in the chlorenchyma during the day. This would result in the saturation of the cells with sugar and so stop the work of photosynthesis were it not for the fact that the chloroplasts quickly change the sugar to insoluble starch, thus leaving the cells free to receive more sugar. If chloroplasts of well-sunned, starch-forming leaves are examined in the afternoon, they will be found to contain minute glistening bodies, the starch grains (Fig. 9, s). The chloroplasts have the power to absorb sugar and secrete starch. The construction of

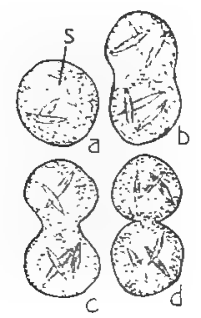

FIG. 9. Greatly enlarged chloroplasts from leaf of moss: $a$, plastid with three starch grains, $s ; b$, plastid elongating preparatory to division; $c, d$, later stages in division.

sugars and their transformation into starch is effected with surprising rapidity. If some plants of pond scum are placed in the dark for twenty-four hours so that all sugars and starches may be consumed, starch will re-appear in the cells in these plants in from three to five minutes after their return to the light. Consider the absorptions, decompositions, recompositions, and transformations that have been effected in this short time. Is it surprising that the exact nature of the changes effected in the manufacture of foods is not known? It is evident as a result of the rapid formation of sugar that starch must accumulate in the plastids during the day. At night sugar is no longer formed but the transfer of food continues as in the day. The insoluble starch is now dissolved by means of a ferment or enzyme into 
sugar so that by morning the cells are quite emptied of the sugar and ready for another day's work. This accumulation and transfer of foods can easily be demonstrated by cutting off in the afternoon leaves from clover, bean or other starch-forming plant and placing them in alcohol. When blanched and tested with iodine the blue or blue-black color shows that they have accumulated a large amount of starch. Test in the same way leaves taken from these plants early in the morning. No starch reaction will be seen because the cells have been freed from their starch during the night. The formation of starch is often used as a test for photosynthesis, but it must be borne in mind that photosynthesis first results in the formation of various sugars and that starch only appears when the sugars have reached a certain percentage in the cells and indeed that some plants do not form starch at all. So when starch appears in a leaf it is simply the measure of the excess of carbohydrate manufacture over transportation. Furthermore starch will form in the cells in the dark if a plant is supplied with an excess of carbohydrate.

ro. The Storage of Foods.--It has been stated that the foods not required for the nourishment and growth of the plant are stored in the region of buds, the growing portions of stems,

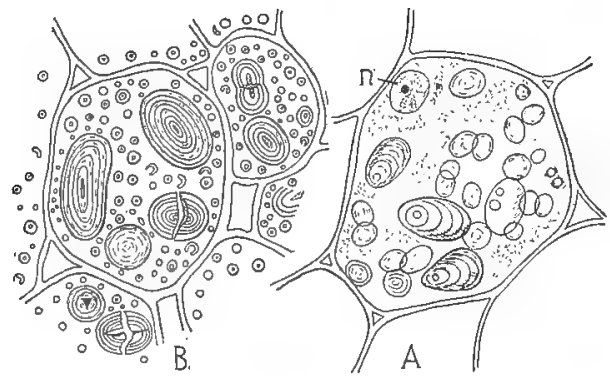

FIG. Io. Storage food: $A$, starch grains in cell of potato- $n$, nucleus. $B$, cells of bean, the smaller particles being proteid grains.

in bulbs, in roots, in seeds, and in fruits. These are the socalled storage foods and they remain in these regions for considerable periods or until the conditions are favorable for a renewal of growth. They generally assume much more definite 
forms than the products constructed in the chlorenchyma which were designed for immediate use or translocation to other parts. If we examine a potato the cells will seem to be filled with very regularly constructed starch grains (Fig. Io, $A$ ). In the pea seed and in wheat and other grains proteid granules are associated with the starch grains (Fig. IO, B). These starch grains are formed by rather colorless plastids called leucoplasts (Fig. 3,E) that closely resemble the chloroplasts. The starch grain first appears in the leucoplast as a minute point. Its stratified structure is due to the successive deposits of starch by the leucoplasts. If the grain is built up equally on all sides by the leucoplasts it will possess regular and concentric strata as in the bean (Fig. II, $A$ ). If the bulk of the leucoplast lies on one side of the grain, this side of the grain will receive more material and consequently the starch grain will become more or less one-

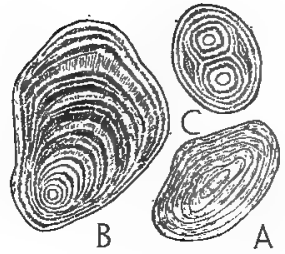

FIG. II.

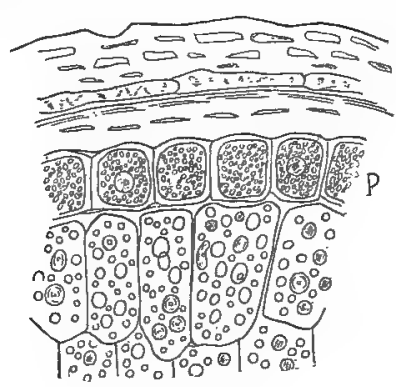

FIG. I2.

FIG. II. Starch grains: $A$, from bean. $B$, from potato. $C$, compound grain from potato.

FIG. I2. Section of the outer portion of a grain of wheat: $p$, cells containing proteid grains. The larger cells are filled with starch.-After Strasburger.

sided as in the potato (Fig. II, B). Frequently two or more grains originate in one leucoplast and compound grains result (Fig. I I, C). Proteids and other foods are likewise transported in solution to the storage organs where they may or may not be deposited in solid form. This is usually effected directly by the protoplasm of the cell without the aid of any plastid. Animals have learned to use the foods stored in these organs just as does the plant. It is interesting, however to note that we 
cannot use them as economically as the plant does. In the wheat, for example, the proteid material is largely confined to the outer portion of the grain (Fig. I2). This layer is of a darker color and in the "best flour" it is excluded in the milling process, leaving the flour very white. So the most nutritious part of the wheat does not appear in white bread, but it should be remembered that white bread is better than the much exploited "whole wheat" products because the proteid material is digestible to only a slight degree. These reserve foods are made available to the plant in the same way as to the animal. They are first put into solutions by ferments or enzymes. Ptyalin in the saliva of animals and diastase in the plant are common examples of enzymes which change starch into sugar. So there are enzymes which transform each reserve food and render it capable of transport and incorporation into the substance of the plant body. These enzymes are formed by the living substance of certain cells and resemble in many ways the living matter itself. They are most extraordinary in their action and behavior. The decomposition of the substances upon which they react is effected by the mere presence of the ferment-at least there is no permanent union between ferment and the substance. Consequently a very small amount of a ferment may effect a decomposition of an almost unlimited amount of a given substance. More commonly water enters into the composition of the substance as a result of the presence of the enzyme. As a result its stability is upset and it breaks down into simpler compounds. This decomposition due to the incorporation of water is termed for this reason hydrolysis. We say that diastase hydrolyzes starch into simpler compounds, as maltose and dextrines. Some enzymes appear to effect decompositions without the cooperation of other substances. Still more remarkable is the action of these ferments in that some of them appear to have a reverse action, $i$. e., the power of building up again complex material from the parts into which they have separated it. In many ways enzymes behave like living matter, being quickened in their activities by suitable temperatures, the concentration of the fluid or by the presence of certain acids and alkalies; or 
retarded by solutions containing copper or mercury which also poison living matter. The distribution of foods made possible by enzymes has been compared to the currency of a country; the storage foods are the bank reserve while the sugars and other solutions are the circulating currency.

I I. Significance of the Leaf Structure.-We now begin to understand the significance of the structure and form of the leaf. The broad blade is a device to catch the energy of the sunlight. The stomata afford access of $\mathrm{CO}_{2}$ and escape of oxygen. The intercellular spaces in the spongy mesophyll all lead to the stomata, thus bringing about a quick distribution of the gases and they also increase the area for the absorption of $\mathrm{CO}_{2}$ and excretion of oxygen to such an extent that the internal surface of the leaf exceeds the external many times. It will be noticed that the cells of the spongy mesophyll vary in character. This is because of the different functions that they perform. The collecting cells (Fig. 5, col) are closely applied to the palisade cells and collect the sugars and other foods from them while the elongated conducting cells transport this food to the cells of the vascular bundles.

I2. The Second Function of the Leaf.-Respiration or breathing is a second function of leaves. While work of this kind is performed by all living cells it may be considered at this point because in the leaves the nature of the work is very well illustrated. The work of respiration is usually associated with the absorption of oxygen and the giving off of $\mathrm{CO}_{2}$. Animals and plants are constantly taking in oxygen and giving off $\mathrm{CO}_{2}$. This interchange of gases is the reverse of that occurring in photosynthesis. Furthermore respiration goes on all the time when conditions are suitable for life while photosynthesis only is possible in the light. Let us consider the significance of this interchange of gases. Why do animals and plants breathe? The construction of the foods to which attention has been called may well be termed the storing up of the energy of the sunlight. When the chlorophyll absorbs certain rays of light it does not destroy any of the energy in those rays. The energy is changed to another form and it still exists in the sugars and other com- 
pounds that are built up through its power. The energy is locked up, so to speak, in the foods and finally it is lodged in the compounds that are constructed from the foods, $i . e$, in the living substance and in the tissues of the plant. If now any of these compounds are decomposed into their constituent parts then the energy will be set free unimpaired. Oxygen is the principal agent in carrying on this decomposition. It has a great attraction for nearly all the elements occurring in the plant and so it is able to detach one element from another and so effect decomposition and the liberation of the locked up energy. You are not to think of the oxygen entering directly into combination with the foods or with the substances formed from the foods, but rather with the decomposition products that are 'brought about by the living matter. It is probable that respiration starts in the living substance. Some agent, other than oxygen and possibly enzymic in nature, inaugurates these decompositions and then oxygen comes in at some stage in this breaking down process and makes possible a further reduction. As evidence that the oxygen does not combine directly with the more complex substances mention may be made of the fact that the absorption of oxygen is quite independent of the amount of oxygen present. The plant respires at the same rate in an atmosphere of pure oxygen as in an atmosphere containing one twentieth part of the oxygen in the air. Furthermore the amount of oxygen absorbed is independent of the amount of 'foods stored in the plant. So respiration is not a simple and direct process like combustion where the percentage of oxygen and the amount of material present determine the reaction.

In the majority of cases oxygen causes a continuation of the decomposition processes until such simple substances as $\mathrm{CO}_{2}$ and $\mathrm{HO}$ compounds, such as water, are formed-in a word until the very substances utilized in photosynthesis are formed. Some of these simple products, such as $\mathrm{H}_{2} \mathrm{O}$ and $\mathrm{CO}_{2}$, escape from the stomata as gas and water vapor. Accordingly respiration is usually indicated by the absorption of oxygen and the giving off of $\mathrm{CO}_{2}$ and $\mathrm{H}_{2} \mathrm{O}$. Some plants, however, have sufficient oxygen in their tissues to enable them to breathe for considerable 
periods without absorbing oxygen from the air and on the other hand in some plants $\mathrm{CO}_{2}$ is not always given off because the decomposition is not carried so far as to result in the formation of so simple a product. We eat in order to gain possession of the energy locked up in the foods. We breathe in order that the oxygen may assist in the decomposition of these compounds and set free this energy which gives us power to work and move and keep our bodies warm. The plant lives in the same way. It only differs from the animal in that it has the added power to build up the complex food compounds from crude material. By the decomposition of the products formed from these foods it gains energy to grow and carry on its other vital functions. The work of respiration is carried on more economically by green plants than by animals since in the animal the $\mathrm{CO}_{2}$ escapes in the breath as a waste product, while the plant uses this $\mathrm{CO}_{2}$ during the day time for the construction of foods. Consequently the escape of $\mathrm{CO}_{2}$ can only be observed during the night and cannot be detected in the light unless an examination of very rapidly growing organs be made. If a jar be nearly filled with opening buds of dandelions or rapidly growing shoots and then closed air tight, sufficient $\mathrm{CO}_{2}$ will be respired in a few hours to extinguish a light that is lowered into the jar. In such instances as these very rapid respiration is necessary to furnish the required energy for growth and the volumes of $\mathrm{CO}_{2}$ expired exceed many times the volume of $\mathrm{CO}_{2}$ utilized in photosynthesis. A handful of germinating peas or beans placed in a closed jar for a few hours better illustrates the giving off of $\mathrm{CO}_{2}$ because here there is no green tissue to absorb any of the $\mathrm{CO}_{2}$. Plants are often considered unhealthful in sleeping rooms at night because of their exhalation of $\mathrm{CO}_{2}$. It is well to remember that the amount of $\mathrm{CO}_{2}$ expired by a plant is small and that a gas jet would furnish more $\mathrm{CO}_{2}$ to the air than a window full of plants. A square meter of leaf surface gives off about .I2 gm. (6o c.c.) of carbon dioxide per hour at $20^{\circ} \mathrm{C}$.

We are now in a position to understand the importance of photosynthesis and respiration. Photosynthesis keeps the air pure for breathing, decomposes the simple inorganic compounds 
and recombines them into foods which represent a certain amount of stored-up energy. Respiration breaks down the products formed from these foods and liberates the energy necessary for the growth and activities of the plant.

13. The Third Function of the Leaf, Transpiration.-This function refers to the giving off of water by the plant. While other parts of the plant assist in transpiration, the leaf is the principal organ upon which this very considerable work devolves. Water is given off from the plant as a vapor and for this reason transpiration is a more familiar phenomenon than photosynthesis and respiration, where we are dealing with an interchange of invisible gases. We see the vapor from plants growing in a window precipitated on the cool window panes in the form of drops. On hot summer days the leaves of plants droop. This is because they have transpired so much water that their cells are no longer distended by the water, consequently the cells shrink and the leaves contract or wilt. When plants are covered by a bell jar or placed in a tight glass jar the water given off soon saturates the air and collects in drops on the sides of the jar. The amount of water transpired by a plant is surprisingly large and it is probably safe to state that usually it amounts daily during the hot summer months to more than the plant's weight. An oak with seven hundred thousand leaves was estimated by Ward to transpire from June to October 244,695 pounds of water. A birch with 200,000 leaves transpired 700 to 900 gallons on hot summer days. This means that an acre of such trees would give off in the course of the season 3,I68,000 pounds of water. From careful measurements of the amount of water given off by grass plants it has been calculated that six and one-half tons per acre may be transpired daily during the summer. It is estimated that from 200 to $500 \mathrm{lbs}$. of water is transpired in the construction of one pound of dry substance and that a square meter of leaf surface evaporates about $50 \mathrm{gms}$. per hour.

The question naturally arises why are such large volumes of water transpired? This depends in part upon the size of the leaf and external conditions, the size of the leaf being determined by the relation of transpiration to photosynthesis. Conditions mak- 
ing possible vigorous photosyntheses would result-in extensive growth and leaf development. An extensive leaf area, however, may not necessitate a heavy transpiration; the amount of water given off will depend upon external conditions. In warm moist climates conditions are favorable for photosynthesis but not for transpiration, which is reduced in amount by the moist air. So growth is vigorous, the largest leaves are developed and transpiration is feeble. In warm but dry climates, on the other hand, while conditions are favorable for photosynthesis the dry air promotes excessive transpiration. This interferes with photosynthesis, consequently very small leaves develop and the volume of water transpired is correspondingly reduced. Under conditions of moderate temperature and moisture as in most temperate climates, the leaf assumes a size intermediate between these two extremes because these conditions favor vigorous photosynthesis and the resulting growth is not materially checked by transpiration. So we see that the extensive transpiration in temperate regions is in part the result of the large leaf development and that this leaf area is dependent upon a vigorous photosynthesis.

Only a small part of the water absorbed by the plant is required to furnish the necessary mineral substances and the water utilized in its growth. The surplus is forced out of the cells and finds its way in the form of vapor along the intercellular spaces in the spongy mesophyll through the stomata to the air. The transpiration of these large volumes of water must be of importance in keeping down the temperature of the plant during the burning summer heat. Transpiration is often compared to the evaporation of water from a dish. While it is controlled to a limited extent in the same manner as evaporation, it should be borne in mind that the giving off of water is intimately associated with the vital activities of the cells and that the loss of water is to a degree under the control of the plant. The cuticle, which is practically impervious to water and gases, extends as a coat over all parts of the plant body, and materially assists in controlling the amount of transpiration. The thickness of this protective coating depends upon external conditions, being developed in 
proportion to the ratio of transpiration to absorption. So we find that it becomes thicker as the volume of water given off comes nearer and nearer to the volume absorbed. In this way it serves as a very effective check in preventing a fatal loss of water. As a result of this water-proof coat the vapor can only escape from the leaf through the stomata. These minute openings are one of the most interesting features of the leaf. When there is an adequate supply of water the elliptical guard cells are drawn apart and give free exit to vapors and gases. However in cases of drought when a continued loss of water would prove harmful to the plant, or when an interchange of gases is no longer required then the guard cells close and so offer such a barrier against further loss of water that only the severest conditions, such as prolonged heat and drought, can overcome. It has been claimed that the stomata do not regulate transpiration because it has been observed in some cases that the stomata are not closed when wilting begins or fully opened at the time of maximum transpiration. Further observation is required to settle this question and for the present we must believe that so elaborate a mechanism as the guard cells is of significance. The stomata in the majority of cases range in size from $.0002 \mathrm{sq} . \mathrm{mm}$. to $.0008 \mathrm{sq}$. $\mathrm{mm}$. so that in comparison a needle prick would appear as a huge hole, but they are so numerous, 40 to 300 to the sq. mm., as to comprise about I per cent. to 3 per cent. of the area of the leaf surface. It might be questioned if this extent of opening is sufficient to permit the entrance and exit of the large volumes of gases and water handled by the plant. It has been shown that a membrane pierced by sufficiently small openings which are separated from one another by a distance of at least ten times their diameter, permits.diffusion of gases as readily as though there were no membrane at all. The structure of the epidermis is an admirable example of such a perforated membrane and it is so perfectly adjusted to the work in hand that it could accomplish much more than the necessities of the plant demand.

I4. Noteworthy Features of Leaves.-Now that some idea has been gained of the nature and extent of the work performed by the leaves we are prepared to comprehend the meaning of the 
large extent of the leaf surface and of the arrangement, structure and modification of the leaves. The broad blades are devices for gathering or absorbing as much of the sunlight as possible and they increase the surface of the plant many hundreds of times. Contrast the extent of surface of a tree in full foliage with the bare branches of the winter. A mature maple develops annually from one to two thousand square yards of leaf surface.

One of the most noteworthy features about the leaves is their arrangement or "hang" on the branches. In some plants they are arranged in two vertical rows, in other instances three, four, five, eight or more rows. By fastening a thread to a leaf and winding it about the stem so as to touch the petiole of each succeeding leaf the arrangement of the leaves becomes more obvious. Some plants have their leaves opposite in two rows or ranks, others opposite in four ranks, each succeeding set of leaves being at right angles to the lower set. This latter arrangement is called decussate (Fig. 13). More commonly the leaves are spirally arranged and the thread passed once, twice, thrice, five, eight, etc., times around the stem before a leaf is reached that is exactly over the one from which we started (Fig. I4). The number of leaves passed before reaching one that stands over the first leaf indicates the number of rows or ranks of leaves on the stem. This variation in the arrangement of the leaves is simply a device to bring the leaves into the light and prevent the shading of one leaf by another. In opposite two ranked leaves each succeeding leaf is over the one below it but the cutting off of the light is prevented by lengthening the internodes and thus separating the leaves. The decussate arrangement of the leaves is a more economical arrangement because more leaves can be developed on a given length of stem without danger of shading. The spiral distribution of leaves is still a better device since each succeeding leaf is placed a little above and to one side of the next lower leaf. By this means the maximum of leaf surface can be exposed to the light in a given length of stem. No one can look at the leaves of the maples, dogwoods, ailanthus, creeping and climbing vines, etc., and not be impressed with the fact that the leaves are arranged so as to catch the most favorable light without shading 
or interfering with one another. Furthermore the arrangement is such as to occupy practically all the space about the stem that

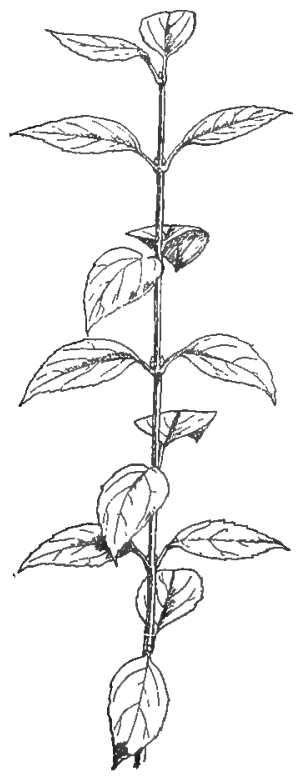

FIG. 13 .

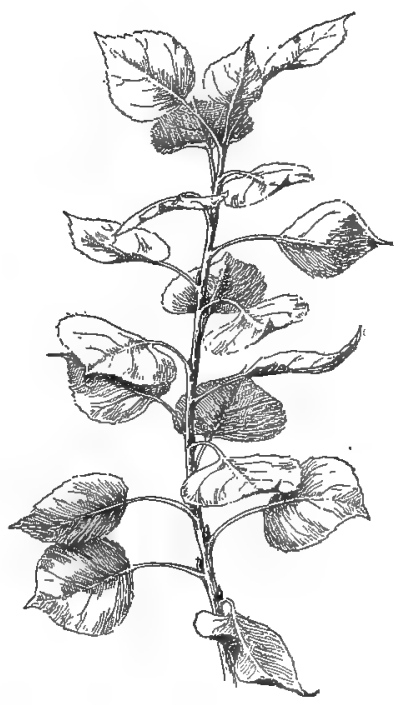

FIG. I4.

FIG. I3. Branch of Forsythia, leaves decussate, in four rows.

FIG. 14. Branch of poplar with leaves spirally arranged in five rows.

receives light. This becomes very noticeable if we look directly down upon a shoot or better if we stand under a tree and look up into the branches. It will be seen that very little direct sunlight finds its way through the branch, so nicely are the leaves adjusted to each other. Some plants like the hickories, catalpa, etc., occupy all the available space with a few large leaves at the tips of the branches. In other cases, as in the willows, some lilies, etc., the same result is accomplished by many small leaves that can be arranged along the stem for considerable distances without shading. The nicety of leaf arrangements is especially noticeable in many horizontal and creeping stems. In such cases the leaves can only be exposed on the sides of the stem and consequently the stem may become twisted or more usually the 
petioles are variously elongated and curved in order to bring the leaves into proper relation to the light (Fig. I5). Notice the

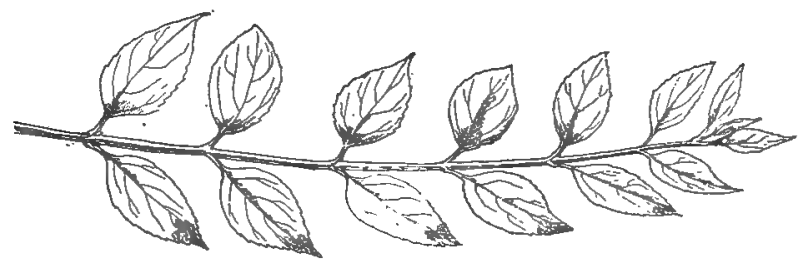

Fig. 15. Horizontal branch of Forsythia with leaves in two rows owing to the alternate twisting of each internode, assisted by the curving of the petioles. Compare Fig. I3.

change in leaf arrangement in horizontal and erect stems of maple. In an example like the maple if the leaves could not change their position they would all be standing edgewise to the light on horizontal branches and therefore receive little of it. They not only place their blades at right angles to the light but owing to the greater elongation of each succeeding petiole from the apex toward the base of the stem, all the leaves are arranged one beyond another so as to overlap very little. This same device is noticed in many plants that produce their leaves close to the ground in rosettes, as mullein, wood betony, plantain, etc. (Fig.

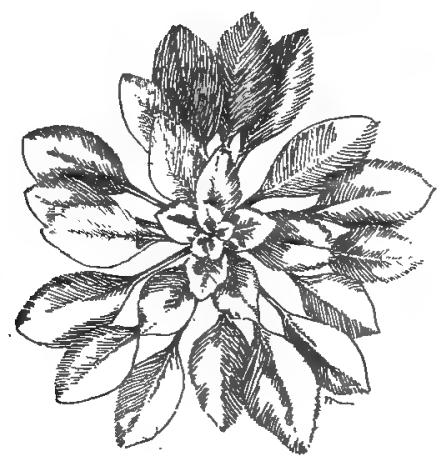

FIG. I6. Leaf rosette of evening primrose. Each leaf blade has a longer petiole than the one above it, so that the leaves are not shaded by one another.

16). Compare the erect and horizontal branches of a variety of plants noting by what devices the leaves are brought into the 
light. Especially instructive are the leaf arrangements of plants growing in windows or creeping over trellises, etc., where complicated twisting and elongation of stems and petioles are necessary to adjust the leaves to the one-sided illumination. The angular leaves of some begonias furnish excellent illustrations of this. Perhaps so many plants bear angular leaves because they can be better adjusted and fitted together without loss of space than would be the case in rounded leaves, and smaller leaves can also be more advantageously introduced between the larger ones (Fig. I7). The lobing and branching of leaves has become a characteristic of many plants because such variations permit the

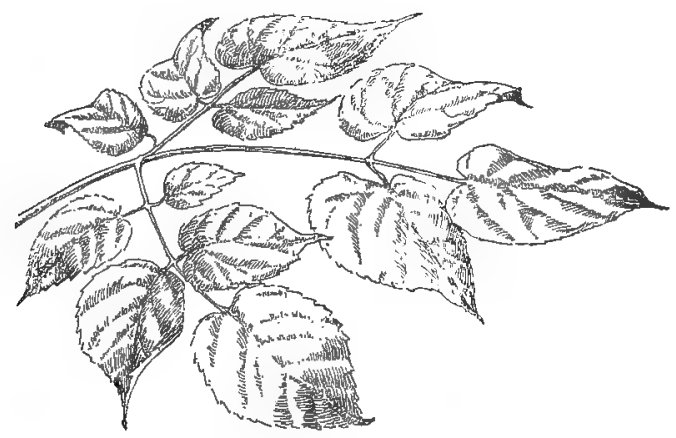

FIg. I7. Leaf of Aralia. Note the angular shape of the leaflets and the smaller ones filling the space between the larger ones.

illumination of a larger leaf surface. This is particularly noticeable in our oaks where the outer leaves are often deeply lobed, thus permitting considerable light to pass through to the underlying leaves. Observe also that these lower leaves are larger and less lobed, thus catching as much as possible of this rather feeble light (Fig. I8). In many plants the lobing extends quite to the middle of the leaf and the lobes are often attached to the midvein or midrib by a petiole. In this latter case the leaf is said to be compound (Fig. I9). All such modifications permit the development of numerous leaves upon the branches without the danger of shading. If there is still any doubt as to the perfection of this light-catching arrangement of the leaves, try to substitute the somewhat similar leaves of two different trees as the birch and elm 
or the water beech (Carpinus) and the beech, noting how the leaves of one fit when placed upon the branch of the other. This subject of leaf form and arrangement may be summed up by the statement that these features are devices for exposing the maximum leaf surface without one leaf interfering with another. This is in accord with the fact that light is practically of no value in photosynthesis after passing through two leaves.

Another interesting feature about the leaf is its relation to the

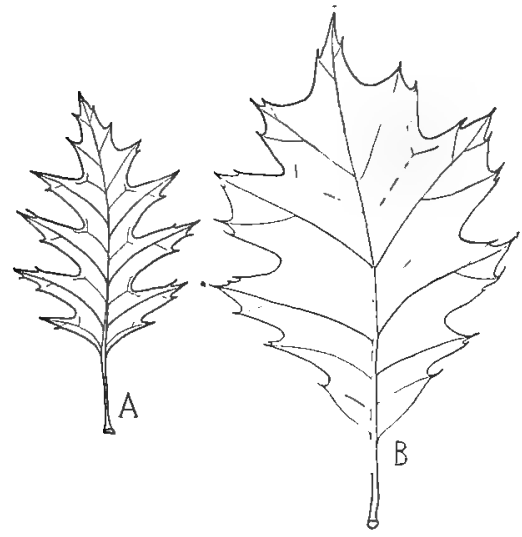

FIG. I8.

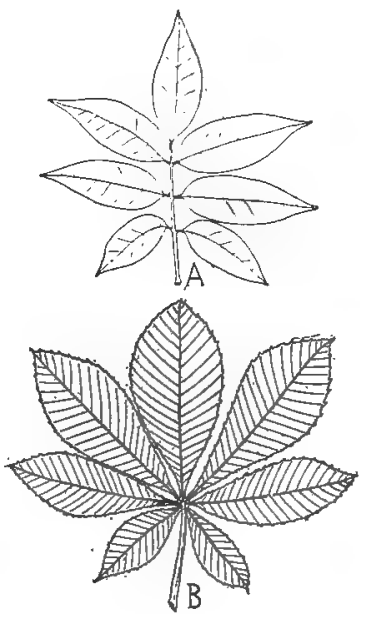

FIG. I9.

FIG. I8. Leaves of red oak: $A$, sunned leaf. $B$, shaded leaf.

FIG. I9. Compound leaves: $A$, red ash. $B$, horse chestnut.

intensities of light. Some plants demand the full intensities of sunlight while others can tolerate only a small fraction of it. Some lichens will grow in a light only $1 / \mathbf{I}^{6}$ part of the full intensity while many plants, as the grasses, will endure the strongest illumination. Beech, maple and spruce are tolerant of shade and oak, hickory and chestnut are intolerant. This relation of plants to light is an important factor in controlling their associations and we frequently speak of plants as sun loving, partially so, shade, and deep shade plants.

The coloration of leaves is often of significance. In addition to the green color, of which we now have some understanding, 
a variety of other colors often appears. One of the most common is red. Young shoots of the rose, grape vine and so much of the early spring vegetation are tinged with red. So in the fall our vegetation takes on a greater wealth of coloration than is seen in any other land. And finally there are leaves variegated with yellow, white and red, colored fruits and.other organs, and the endless hues of the flowers. These colors are caused by pigments or by chromoplasts (p. 2) that are developed in certain cells and which either transmit or reflect to the eye their particular colors. The white blotches of variegated leaves are caused by the absence of chlorophyll, thus allowing the light to pass practically unchanged, or in some cases these areas are characterized by large intercellular spaces filled with air. Such a structure would tend to reflect the light and so contribute to the white appearance of the area ( $\dot{p} .39$ ). In some cases these colors may be of service to the plant. The red probably functions as a screen to young organs, shielding them from the intense light that would otherwise decompose the forming chlorophyll and otherwise interfere with the vital processes. Red is also a strong absorber of the heat rays in light, and in some cases it may be of service in ensuring a higher temperature in the organs and so expedite their work. Many plants, some tradescantias, hawkweeds and spatter dock, have in their mature leaves layers of cells, frequently the lower epidermis, filled with a red pigment. So many evergreens assume a brown or reddish hue in the winter owing to the formation of a reddish pigment. However, too much emphasis should not be given to this matter of coloration. The colors of flowers, to be sure, are of service in guiding insects when close at hand, to the proper approach to the flower, and there is probably a significance in the coloration of the algae (p. I73) but in general it is not possible at present to offer an explanation for the variety of colors that characterize so many leaves, especially noticeable in tropical plants, and fruits and other organs, as the radish, and beet. The copper beech grows slower than our green-leaved beech and so doubtless in the case of many plants that have survived not because of their coloration but in spite of it. In many instances the colors are due to the acidity or alkalinity of the 
cell sap. Red cells often indicate acidity and they become blue in weak potash solutions. So violet and blue indicate an alkaline condition and such cells change to red in weak acid solutions. This is essentially the explanation of the changing tints in the autumn. The changing character of the cell sap is attended with a gradual decomposition of the complex chlorophyll and other materials that results in the formation of a series of substances that are characterized by a variety of colors. Here again the matter of coloration has been over emphasized. While nitrogen, phosphorus and potassium are transported from the leaves before they fall, the coloration does not effect so complete an emptying of the leaves as was previously believed, if indeed it is of any service.

I5. The Cause of Lieaf Arrangement.-How is the perfection in the arrangement of the leaves accomplished? The leaf or any other organ does not remain in a fixed position during its growth and development but owing to the fact that first one side and then an adjoining side of the organ is growing faster than any other part it comes about that the organ is bent from side to side by the more rapidly growing cells and the apex of the organ is often caused to travel through a rather irregular circle. These growing organs are sensitive to light, gravity, moisture and other stimuli. As a result of these movements the organ is brought into relations with various intensities of light, heat, etc. In certain positions the stimuli are not favorable and they cause it to grow away from this position while in other positions the stimuli act in the most favorable way and the organ is stimulated to its best growth. So during the development of the organ it is brought into varied relations with the forces which affect it and as a result of this experience the leaf or other organ is directed by the stimuli and at maturity finally comes to rest in a fixed position that is the most advantageous. The leaf ordinarily so reacts to these stimuli that its blade is exposed at right angles to the rays of light, but in the iris, many grasses and rushes the blades are nearly erect. Quite a large number of plants bear their leaves edgewise. The giant trees of Australia (Eucalyptus) and the so-called compass plants are familiar examples (Fig. 
20). Possibly these blades are driven into this position because they are more sensitive and the direct sunlight upon the broad surface of the blade would be injurious. This certainly appears to be the case in young leaves when emerging from the bud. Note the character of the foldings and the erect positions of such leaves (Fig. 2I). The leaves of the horse chestnut assume at

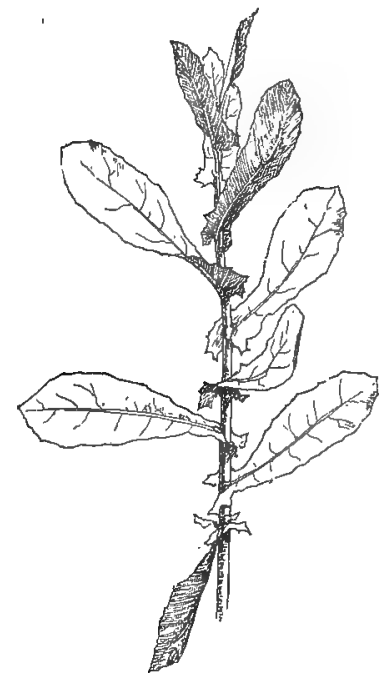

FIG. 20.

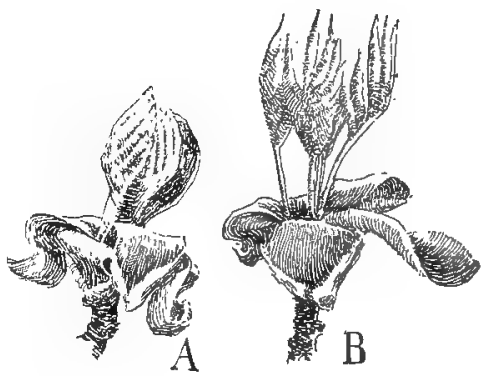

FIG. 2 I.

FIG. 20. Shoot of wild lettuce, Lactuca, with leaves turned edgewise to the light.

FIG. 2I. Position of young leaves of hickory: $A$, scales of bud curving back showing the tightly folded leaves. $B$, later stage, leaves unfolding but still erect.

least three different positions during their growth. The folding of such leaves and their erect positions expose less surface. They consequently lose less heat and moisture, and the delicate growing cells are better protected against the intense sunlight. You must notice as the cells mature and become better protected that their irritability changes and they respond in a different way to light and gravity, etc. They begin to unfold and turn away from their erect positions and at maturity assume a fixed position to light, etc., that is quite different from the original posi- 
tion. The position of the leaves of our pines and several other evergreens is not controlled by light and as a consequence they assume a variety of angles to the incident rays.

The leaves of many plants do not have a fixed position but show more or less motility during their entire life. Interesting examples are seen in the sensitive plants and in members of the bean and oxalis families where marked changes result in the position of the leaves from alterations in the intensity of light, temperature, or moisture. Many of these plants fold their leaves when the temperature falls at sundown. Many flowers close in the same way. These changes are popularly termed sleep movements. They are caused not only by the changes in the intensity of the light but also by changes in temperature and moisture. In the case of these leaves the cells in the swollen organ (the pulvinus) at the base of each leaf are kept full of water so long as the temperature and external conditions exert a suitable stimulus upon the plant, but when the conditions are unfavorable certain of the cells on one side of the pulvinus lose water and contract while the cells on the opposite side of the pulvinus remain rigid; consequently, the leaves droop and fold in various ways. This is due in part to the fact that the contracted cells of the pulvinus are no longer capable of assisting in the support of the leaf and also to the fact that the rigid cells continue to exert a pressure which bends the pulvinus towards the side where the contracted cells are situated (Fig. 22). This folding of the leaves materially reduces the area exposed to the atmosphere and consequently will lessen transpiration. Many of our sensitive clovers (Meibomia, Lespedeza), sensitive peas (Cassia), sensitive plant (Mimosa), are able to check the excessive loss of water on hot dry days by the folding of their leaves. As soon as the loss of water becomes detrimental some of the leaves begin to fold and the reduction of leaf surface continues until the loss of water by transpiration is met by root absorption. Very commonly leaves that do not have this power of adjustment are able to accomplish the same results by a rolling of the leaf. This is particularly noticeable among the grasses, which, on hot, dry days, roll up their leaves so tightly as to rhange the appear- 
ance of the plants. Observe a corn field during a dry period. The interesting feature of all this is that these reactions and adjustments are purposive but not intelligent. The movements are not called forth by consciousness but by stimuli to which the irritable living substance is attuned or sensitive.

I6. The Significance of Certain External Leaf Structures.Many features connected with the structure of the leaf furnish admirable illustrations of the fitness of the leaf for the perform-

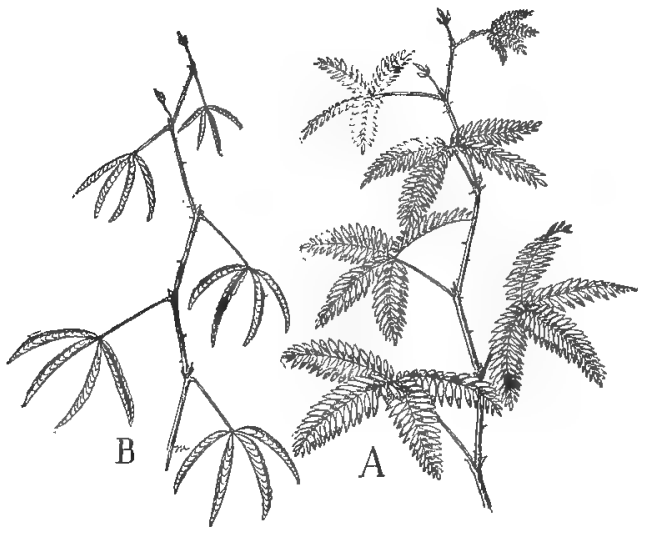

FIG. 22. Leaf position of the sensitive plant, Mimosa: $A$, in light. $B$, in darkness. The same movements occur as a result of unfavorable temperatures and humidity.

ance of its work. The stimulus of light and moisture have a marked influence upon the external structure and form of leaves. The epidermis is strikingly modified by such forces. In shade plants the epidermis consists of a rather delicate layer of cells with very thin cuticle. This gives sufficient protection to such plants, but in leaves exposed to intense sunlight and a hot and dry air, the epidermal cells become greatly thickened and often of two or more rows, while the cuticle may often form the larger part of the outer cell wall or even extend in between the cells (Fig. 23, c). Cell walls that are filled with cutin in this manner are said to be cutinized. This development of cutin gives the tough leathery aspect to many leaves. Such fèatures are partic. ularly noticeable in desert plants, in long-lived leaves of many 
evergreens, as laurels and rhododendrons, in the needles of conebearing trees, and in all plants that are exposed to the hot, dry air of summer or the drying winds of winter. Such leaves may be further protected and strengthened by thick-walled elongated cells, stereome (Fig. 23, st). Coatings of wax, mucilage and lime are also frequently developed upon the cuticle to further reinforce the impermeability of the epidermis.

The stomata are also so developed as to meet the conditions under which the plant grows. In dorsiventral leaves they are more numerous on the under side of the leaves because they are less liable to be filled with water by rains and with dust which would prevent the interchange of gases. The plugging of the

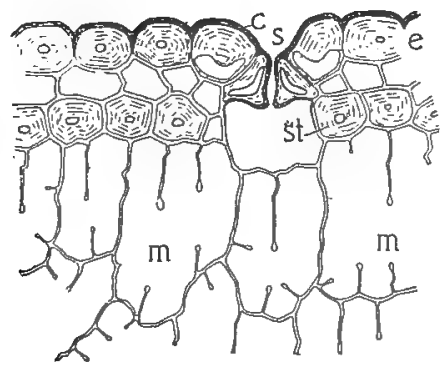

FIG. 23. Cross-section of the outer cells of a leaf of pine, showing the firm character of the outer cells of the tough leaf: $s$, stoma; $e$, epidermis; $c$, cuticle; st, stereome; $m$, mesophyll cells.

stomata by dust is one of the causes of the sickliness of plants in homes. The arrangement of the stomata on the under side of the leaf is also of especial advantage because the direct light does not fall upon them and cause an excessive loss of water. The stomata of floating leaves, however, are upon the upper surface and their stoppage with water is prevented by waxy coatings, as can be easily demonstrated by dipping a leaf of a water lily or spatter dock in the water. When the leaf is removed the water runs off of the waxed surface without wetting it. Some leaves are more or less erect, as the cattails, rushes and grasses, and these have the stomata developed more or less evenly on both surfaces. Doubtless the intense light of midday is not beneficial to these leaves and the blade of the leaf is consequently placed parallel 
with the sun's rays. This arrangement of the leaf permits a direct illumination of the leaf only in the morning and afternoon when the intensity of the light is feebler.

The position and character of the stomata in relation to external conditions show many interesting relations. Plants living in the shade or in the presence of an abundant soil-moisture develop

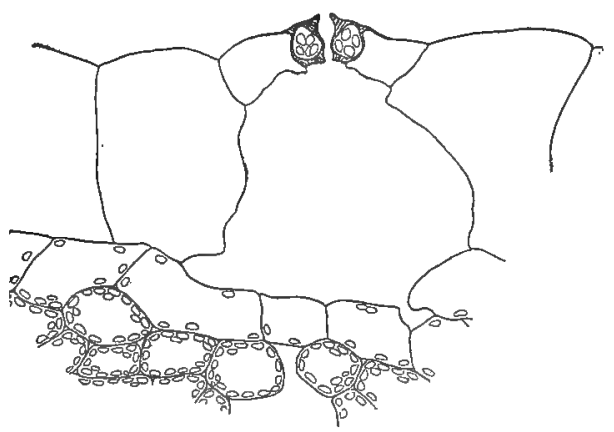

FIG. 24. Cross-section of a leaf of the inch plant, Tradescantia, showing the delicate character of the cells and the raised stoma of this shade plant.

the stomata on a level with the leaf surface (Fig. 24), because there is no necessity of conserving the water supply. For the same reason some aquatics have lost altogether the power of closing their stomata. On the other hand plants that are exposed to arid conditions or drying winds develop the stomata well below the surface of the leaf, as in the cactus and in the needles of conifers (Fig. 23, s), or in furrows, as in certain grasses, or at the bottom of minute pores, as in the oleander. These depressions remove the stomata from the dry winds and prevent the direct contact of the moist air in the leaf with the dry atmosphere. The pores in the oleander contain hairs which would check transpiration just as a plug of cotton in the neck of a flask would lessen the evaporation of the fluid in the flask. The chief purpose of this arrangement, however, is to prevent the stopping of the stomata with water. This plant grows naturally along the banks of streams where it is subject almost nightly to heavy dews. When the stomata become filled with dew it re- 
quires several hours of sunshine to drive the moisture from these capillary openings. Consequently during this time there could be no interchange of gases and the vital functions of the leaves would be largely stopped. Many devices appear that prevent water entering the stomata. Attention has been called to the development of stomata on the under surface of leaves and to waxy coatings as protective features of this nature. Every one is familiar with the waxy appearance or bloom of many fruits, as the plum; or of leaves, as the cabbage; and of stems, as the raspberry. Water is unable to spread over the wax and enter the stomata because a thin layer of air clings to it. The silvery appearance of many grass leaves and of the jewel-weed when immersed in water is due to this thin film of air which reflects the light. Accordingly the water does not really touch the leaf and you notice that it is quite dry when it is removed from the water save for a few drops which readily run off. Protection against wetting is also obtained by the development of coatings of hairs. This is noticeable in many Alpine and polar plants where they are constantly exposed to heavy fogs, dews, and rains.

Plant hairs do not always serve this purpose. Desert plants and those living in dry localities are frequently characterized by hairy coatings. Such plants are frequently termed xerophytes in contradistinction to aquatics or hydrophytes and to plants living in moderately moist soils, which are called mesophytes. The hairy coatings of xerophytes give them their familiar silvery or hoary appearance as seen in the sage-brush, dusty miller, and mullein. The hairs are usually empty tubes or cells which reflect a large portion of the intense light and heat and consequently materially lessen the loss of water, just as straw sprinkled upon the ground keeps the earth below moist and cool. In many instances plant hairs develop mucilage or resinous secretions which protect as with a varnish growing regions as buds or young shoots and leaves of birches, alders, poplars, and peach. In this connection it should be noted that dense hairy coatings reduce the loss of water only when the plant is exposed to air currentsnot in still air. Cutin, wax and resinous deposits retard transpiration under all conditions. Oil and poisonous substances are 
also formed which repel by disagreeable odors or tastes, the attacks of animals. The nettles are shunned because of the burning sting produced by the plant hairs. The upper portion of these hairs (Fig. 25) is practically a delicate glass tube since the walls are filled with silica. The basal portion of the hair is composed of soft, yielding cellulose so that the fluid collecting in the hair distends this portion of it. The knob at the end is fastened to the hair by so thin a ring of wall, as seen in Fig. 25, $B$, that the least touch breaks it off. In this way the hair is

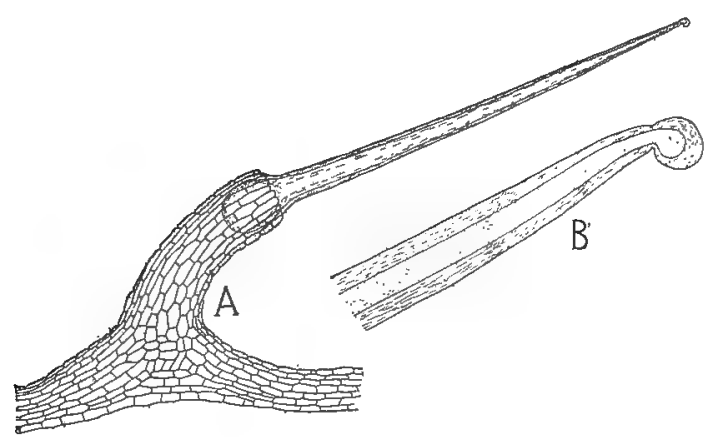

FIG. 25. Stinging hair of nettle: $A$, portion of epidermis bearing hair. $B$, tip of hair enlarged, showing easily detachable knob.-I. D. Cardiff.

transformed into a veritable hypodermic needle which easily punctures the skin while the distended basal portion contracts and forces out some of the fluid. The burning sensation or sting that immediately follows the puncture of the skin is caused by the injection of formic acid while a variety of other poisons produce the subsequent irritations. These poisons are so powerful in some of the East Indian nettles as to produce serious results, even a tetanus.

I7. Significance of Certain Internal Leaf Structures.-The changes or modifications produced in the chlorenchyma by various stimuli are quite as striking as in the case of the epidermis. The palisade cells are an excellent illustration of this point. These cells are developed as a result of the stimulating influence of light (Fig. 26). The photosynthetic activity caused by the light increases the pressure of the fluids in the cells. This 
tends to round them out. They are unable to expand laterally owing to the adjacent cells but are free to extend towards the looser cells below, and so they become longer and palisaded. Leaves growing in the deep shade show little indication of palisade

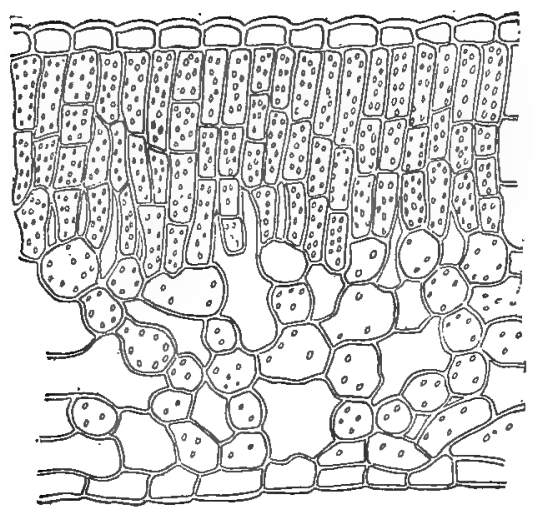

FIG. 26.

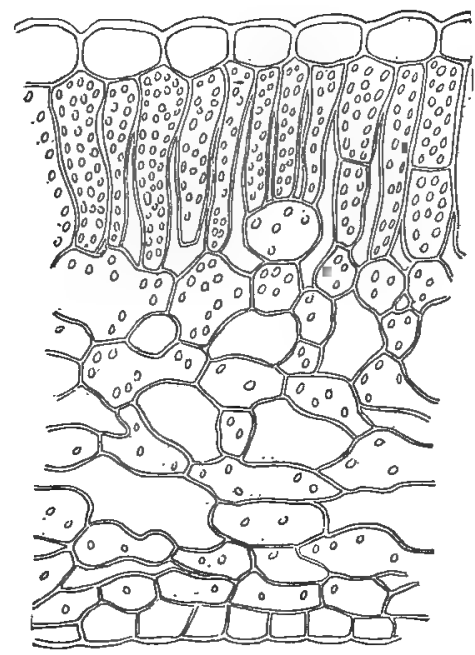

FIG. 27.

FIG. 26. Section of a leaf of Rhododendron. Note the compact palisade tissue which results from intense light.

FIG. 27. Section of a leaf of skunk cabbage, Spathyema. Note the poorly developed palisade tissue and the loose arrangement of the cells' of this plant which lives in moist, shaded places.

structure. Shade and moisture plants are not obliged to conserve the amount of water received and these two forces, feeble light and moisture, produce a larger and looser arrangement of tissues which is favorable to an interchange of gases (Fig. 27). Particularly is this noticeable in aquatics as in the water lilies and many rushes, etc., where the tissue is loose and spongy and permits a ready circulation of gases from the leaves to the roots and to all parts of the plant body even when submerged. This loose arrangement of tissues also renders water plants very buoyant and consequently they are less liable to injury from the currents of the water. Aquatic plants have little need of strengthening and conducting tissues because they are supported 
by the water. Neither do they require elaborate bundles for the conduction of the crude foods which may be absorbed by nearly all parts of the plant body. We now understand why shade leaves are thin and broad and soft whereas leaves of desert plants and those exposed to severe drying winds of summer or winter are thick, compact, firmer and often leathery and hairy.

One of the most interesting adaptive features of leaves is seen in the leaf fall of our deciduous trees and shrubs. In the tropics the leaves remain on the perennial plants often for long periods, but in temperate climates the severe winters necessitate the annual dropping of the leaves except in a comparatively few evergreens where the thick leathery leaves are able to endure such conditions. In our deciduous plants, when the conditions are no longer favorable for the performance of leaf work, the cells at the base of the petiole begin to divide and a delicate layer of cells, the separating layer, is formed across the petiole (Fig. 28). Various conditions induce this growth for there is more or less leaf fall at all seasons of the year. Doubtless lack of nutriment has much to do with it. If a leafy branch of horse chestnut is placed between moist paper in a few days the separating layer will have formed and the leaf will have dropped from the branch. The innermost delicate cells of the separating layer may become changed into cork cells just before or directly after leaf fall while the outer cells of this layer may break down through mucilaginous modification or they may become rounded off so that water collects in the intercellular spaces. Thus the leaf is attached to the stem chiefly by the veins since the delicate separating layer offers little support. If now the water in the intercellular spaces of the separating layer should freeze, the expansion of the water as it freezes would so rupture the remaining tissue that we would have the familiar sight of the leaves falling in a shower in the morning after a frost-either of their own weight or with the slightest breeze. It will also be noticed that owing to the formation of the cork layer or the drying up of the delicate cells of the separating layer, the scar formed by the fall of the leaf is nicely healed and closed against any loss of fluids or the entrance of any organism (Fig. 28, C). 
The casting off of the leaves reduces the area of the plant that is exposed to the unfavorable conditions to a minimum. This reduction of the surface is effected in one way or another by a great variety of plants. Much of our spring vegetation is possible by reason of it. The spring beauties, anemones, fawn lilies, jack-in-the-pulpits, etc., practically complete their growth

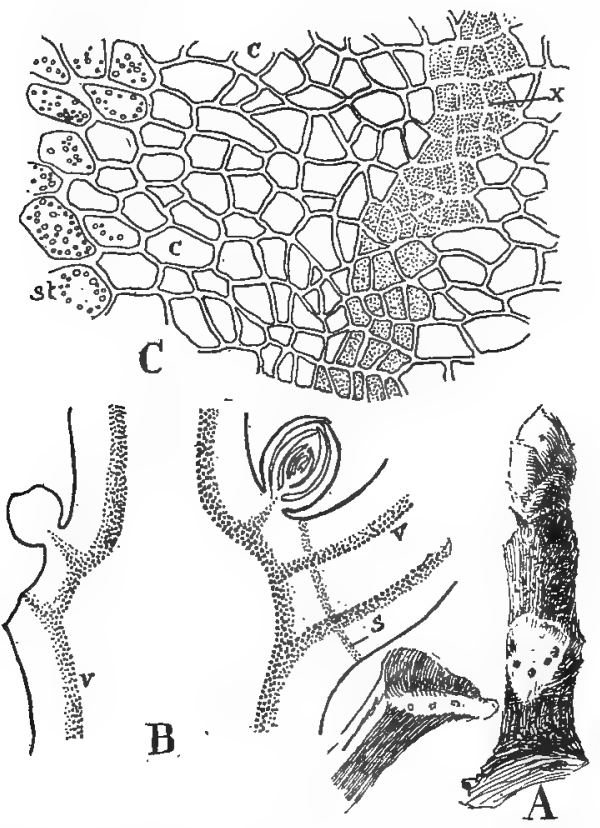

FIG. 28. Leaf fall: $A$, branch of horse-chestnut showing scar formed by the fall of the leaf. The dots on the scar show the position of the vascular bundles that are finally. broken by the weight of the leaf. At the left the base of the petiole is shown. $B$, diagram of a section through a twig of hickory $-s$, separating layer at base of petiole; $v$, vascular bundles. $C$, enlarged view of the separating layer-c, cork cells that heal the wound caused by the fall of the leaf. The granular cells are the outer region of the separating layer, and they are beginning to break down as seen in the upper part of the figure, at $x$, thus causing the fall of the leaf; st, cells of the stem containing starch.

before the larger summer forms appear. During this short period sufficient food is manufactured by the leaves to mature the seeds and fill the storage organs in the underground bulbs and stems. 
When the larger forms appear later in the season these plants are overshadowed, their leaves wither, and they are reduced to the small bulbs and stems hidden in the earth. In this condition they remain until the next spring when the abundance of stored food enables them to complete their growth before other competing forms appear.

This ability to reduce the surface of the plant body makes possible the existence of much of the plant life of arid and desert regions. During the short rainy seasons the stored foods enable the plant to quickly put forth the leaves which in turn manufacture the foods which are stored in seeds, stem and roots. Then practically all trace of these plants is destroyed by the drought. Only the seeds or a greatly reduced portion of the plant remain alive and this is often further protected by being hidden in the ground. A return of favorable conditions quickly awakens these plants to growth. Mr. Dan Beard relates an interesting experience in the desert regions of Texas that illustrates this feature of plant life. At the close of the dry season this territory was a bare, sun-cracked plain swept by hot, dry winds. Not a green leaf was to be seen. Heavy rains transformed this level tract of land into an inland sea. In a few days the water disappeared and one morning he was surprised to see green blades appearing everywhere and in a few days the barren earth was covered with an almost tropical profusion of vegetation of bright flowers. Many desert plants to be sure develop permanent aërial parts but here, too, the most.striking feature is the extreme reduction of the organs. Compare the areas of the Spanish bayonet, aloes, grease wood and sage with that of our leafy plants. The cactus represents one of the extreme forms of reduction. The leaves have been dispensed with entirely and are not represented save possibly by the spines. Consequently the work of the leaves devolves upon the stems. While desert plants receive very meager amounts of water, this is so effectually conserved that the plants are usually rich in water. Drinking water is frequently obtained in desert regions from cacti by pounding up the pulpy interior and squeezing out the water. Animals are well aware of this rich storehouse and will eagerly 
devour the cacti after the spines are burned off. The development of these storage cells accounts for the fleshy character of many alkaline, saline, and desert plants, many of which depend upon organic compounds lodged in their cells for the retention of water rather than upon the development of cutin. Curiously enough there are many examples of xerophytic plants living in bogs and marshes, as, for example, the rushes and sedges, the horse tail ferns (Equisetum), the lamb kill (Kalmia) and leather leaf (Chamaedaphne), etc. The cause of the association of these plants with aquatic forms is not known. In exposed moors and heaths these reduced forms would have decided advantage because of their protection against drying winds. Our sedges and rushes are exposed to very intense heat and light which may possibly cause so heavy a transpiration that these plants are not able to meet the loss by root absorption. This is the more probable because in many instances the absorption of water by plants living under such conditions is slow owing to lack of oxygen and to the concentration of the water in which the roots grow. 


\section{CHAPTER II}

\section{THE ROOT}

18. Character of Primitive Plants.-The first forms of life upon the earth were doubtless unattached unicellular plants that lived in the water or moist places. All the varied functions of the plant body, as the absorption of gases and material from the soil and the manufacture of organic compounds, etc., were performed alike by each cell. This was easily accomplished owing to the simplicity of the organism and also because the plant was surrounded by water which contained all the substances required in the construction of foods. Perhaps the first change produced in these plants by their surroundings was a modification of a part of a cell so that it served as an organ of attachment, or root, anchoring the plant to the substratum. As the plant continued to change and become more complex, and especially as it became more and more subject to drier conditions, special organs for the absorption of materials became a necessity. This change from an aquatic to a terrestrial life finally left the root alone in touch with the crude materials. Thus the root which at first was only an anchoring organ, came later to function also as the principal absorbing organ of the plant. Next to the leaf the root commands our attention because of its fitness for the accomplishment of this work. Practically all the water required by land plants, and all the elements, save carbon and oxygen, utilized in the construction of foods are absorbed by the roots.

I9. Root Hairs.-We will first be interested to examine the structure and nature of the absorbing apparatus of the root. If seeds of radish, mustard, or other plants are germinated upon moist sand or moist blotting paper it will be seen when the roots have attained a length of several $\mathrm{cm}$. that a portion of each root is covered with delicate hairs (Fig. 29, $A$ ). There are several interesting features about these root hairs. In the first place they are extremely delicate tubular outgrowths of the epidermal cells, 
scarcely more than one millimeter in length (Fig. 30). Note that they always begin to grow a few mm. back from the root tip and at the opposite end of the zone of root hairs the tubes are withering or dying off, leaving the older portion of the root covered only with the epidermis. If a root is marked into $2 \mathrm{~mm}$. spaces with India ink it will be found after 12 to 15 hours that only the portion below the root hairs is elongating. The first space from the tip has grown very little, the second and third

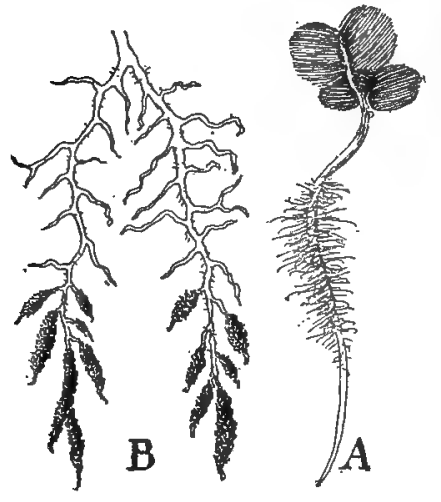

FIG. 29.

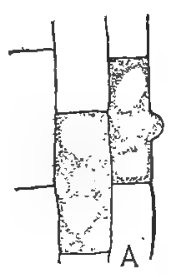

FIG. 30 ,

Fig. 29. The absorbing surface of roots: $A$, seedling of mustard showing extent of surface covered by root hairs. $B$, an older branching root, the shaded areas near the tip are due to particles of earth clinging to the root hairs. The remaining portions of the root are free hairs and take little or no part in absorption.

FIG. 30. Origin and character of root hairs: $A$, first appearance of a root hair due to the pushing out or growth of a definite portion of the surface of an epidermal cell. $B$, older hairs that have become irregular through coming in contact with soil particles.

much more, and in the other spaces there is a gradual retarding of the growth until 8 to $12 \mathrm{~mm}$. from the tip elongation has ceased. It is at the point where elongation has ceased that the root hairs begin to appear, but the total number existing on the root at any one time does not materially vary owing to the fact that they are dying off farther back on the root with the same rapidity that characterizes their formation near the tip (Fig. $29, B)$. Before the significance of these peculiar features can be 
understood it will be necessary to consider the nature of soils and the relation of the substances absorbed by the plant to the soils.

20. The Nature of Soils.-The soil is composed of minute particles derived from decaying rocks and of organic particles or humus derived from decaying plants and animals. The mineral particles furnish several of the important crude plant foods, as calcium, magnesium, potassium, phosphorus, sulphur, iron and small amounts of other elements. These substances occur in great abundance, comprising over thirteen per cent. of the earth's crust. It is a singular fact that two of the most abundant substances, silicon and aluminium, are utilized by only comparatively few plants, although it will be seen later on that the latter element is indirectly of great service to plant life. The remaining elements used by the plant, oxygen, nitrogen, carbon, hydrogen, are equally abundant. The first three may be obtained from the air while the hydrogen is a constituent of water and other compounds. It is an interesting fact, however, if rocks containing all these mineral elements should be ground up into the form of a good soil and the other necessary substances be added thereto that it would not support plant life at all. The reason is that these elements exist in the rocks in a form that the plants can not utilize. They are largely combined with an element silicon, of. which substance pure sand or quartz is largely composed. These compounds are termed silicates. The plant can only utilize these elements when they are combined with some element, other than silicon, and to which oxygen has been added. The potassium, magnesium, etc., must be combined with nitrogen, phosphorus, sulphur or carbon to which oxygen is also added in order to make a substance that the plant can utilize. These crude foods of the plant are termed nitrates, phosphates, sulphates and carbonates. It is only in this form that the necessary elements can be absorbed, silicates are rarely of service. The question naturally arises: how do the silicates become transformed into suitable compounds and how do the rocks become changed into the form of a soil. Several factors are concerned in the transformation and the reactions are complicated and very slowly effected. 
Water is the most important force in starting these changes. It dissolves, that is removes, several of the elements that appear in the silicates. Note also when water has taken up certain of these elements and compounds that its dissolving power is greatly increased. For example when water has absorbed carbon dioxide its power of dissolving calcium is increased 25 times. Furthermore the removal of an element by the water means that new chemical compounds are formed and these are frequently of such a nature as to lead to further chemical reactions. We say that the dissolving action of water upsets the chemical stability of the substances composing the rocks. Certain gases of the air, particularly oxygen, also enter into union with some of the rock elements, making them more soluble. So you can think of a series of chemical struggles going on between the silicon and other elements and compounds for the possession of the potassium, calcium, etc., and that in this way these latter elements are slowly removed from the silicon and united into new compounds suitable for plants.

The removal of these elements from the rock minerals forms cavities and as a consequence the rock tends to become honeycombed and finally begins to crumble and so approaches a soil condition. Two forces are therefore involved in soil making: the one chemical which is termed decomposition and the other mechanical, termed disintegration. Disintegration or the crumbling of the rocks is hastened by a number of factors, especially the force of running water. The power of water to break up the rock substance and distribute the particles thus formed is one of the most important factors in soil formation. Changes in temperature also constantly cause the contraction and expansion of the rock material and of the water occupying any of the spaces in the rock and so assist in the disintegration. Finally the force of the wind and the grinding action of moving ice are important factors in wearing away the rock surface and reducing it to a soil condition. By these slow and intricate processes compounds for plant uses are formed and the rocks are reduced to the condition of a soil. Such a soil, however, does not contain sufficient amounts of the crude food material to support the ordinary 
plant. So we find very simple plants, as the lichens and certain mosses, occupying such primitive soils. They are able to live upon such soils because they are small and slow growing and therefore demand meager amounts of the crude foods. Note the character of the first vegetation that appears on the slopes of mountains below the solid rock. These simple plants, however, are very important factors in effecting further decomposition of the minerals in the soil. Through the chemical activity of their absorbing organs and especially through the decay of the dead parts of these plants new compounds are formed so that more elaborate plants, as certain ferns, are now able to live upon the soil. These latter plants in turn carry on the work until the rock material is sufficiently changed to make a good soil. Do hot imagine that the work of soil formation stops here. You are to think of every growing plant performing the same work as noted in the lichens and mosses.

The soil is one of the most remarkable things in this world of ours and we must consider two of its more important features. The first of its important characteristics is its power to retain moisture. Water exists in the soil in three forms,-as hygroscopic, as capillary and as gravitational water. The first form is the water that condenses from the atmosphere as extremely delicate films about the air-dry soil particles. This water is not available to the plant because it is held so firmly by the soil particles. It comprises only a small per cent. of the total water in the soil. The capillary water also exists as films about the soil particles but it is not retained so tenaciously and it is this water that furnishes the chief supply to land plants. Capillary water may amount to Io per cent. of the dry weight of coarse sand up to 25 per cent. in clay soils. Gravitational water is not retained by the soil particles and it is therefore free to run down through the pores and spaces in the soil under the control of gravity. This water in the upper portions of the soil is not of value to the majority of plants because it fills the pore spaces in the soil and so deprives the roots of the air which is necessary to their existence. When gravitational water exists a few feet below the surface it often becomes of great value as a source of supply for the capillary water. 
Let us now consider how the root is related to the soil water. You have seen that the soil particles have an attraction for water. This attraction is due to a force termed surface tension. Each soil particle has a definite surface tension or capacity for retaining water that is dependent upon the extent of its surface. The retention of the hygroscopic water uses up a small portion of the particle's capacity and then it adds capillary water until no more can be retained. We say that the particle is in a saturated state. It is evident that the last water added to the particle will not be held very firmly and it is this water that the root hair can readily absorb. But now follows a very remarkable movement of water. No sooner has a particle lost some of its water than it is able to replenish its supply from adjacent particles that are in a saturated state. This transfer of water from particle to particle goes on for surprising distances, depending upon the amount of the surface tension. So we find particles four to six feet away from the root hair contributing a portion of their capillary water to replace the water thus absorbed. So you can think of the capillary water moving as films from particle to particle towards. the points of absorption. It is for this reason that the gravitational water may be of great value. If it is only a few feet below the absorbing roots it will furnish a constant supply of capillary water to the overlying soil particles. So one of the most important features about a soil is the size of its particles. The term texture refers to this condition of a soil and we speak of fine or coarse textured soils. The finer the particles the greater the surface exposed in a given unit of space; and consequently the greater the surface tension and water-holding capacity. A cubic foot of coarse sand can not retain as much water as a cubic foot of clay because the clay particles are 200 times smaller than the sand particles. A fine textured soil may lose some of its capacity to retain water owing to the compacting of its particles into larger ones. It is evident that two separate particles possess more surface area than when combined into one particle. This relation of the particles to one another is termed structure and we see that soil structure is of equal importance with soil texture. Now we can understand the chief advantage of tillage. Plowing 
and harrowing break up the compact structure and tend to keep the soil in a fine textural condition. It is surprising to note the amount of surface exposed by the particles of various types of soils. A coarse sand where the particles range from .I to $.5 \mathrm{~mm}$. in diameter has no less than 40,000 sq. ft. of surface exposed in each cu. ft. of soil and a clay soil where the particles are $.005 \mathrm{~mm}$. in diameter or smaller has over I40 thousand sq. ft. of surface per cu. $\mathrm{ft}$.

A second noteworthy feature of soil particles is their power to retain certain elements that are brought in contact with them in solutions. These elements are retained in some instances much after the manner of film water but in other cases retention is effected through chemical reactions. You see an illustration of this property of soils when colored solutions, such as the drainage water from stables, after passing through a soil comes out quite colorless. The old type of charcoal filter purified drinking water in this way. It is an important fact that many of the important elements and compounds utilized by the plant, such as potassium, ammonium, magnesium, calcium, phosphorus, etc., are retained in this way; and they are retained so firmly that only small percentages of them are leached out and lost through the action of running water. Certain aluminum compounds (see above), also iron, calcium and the humus compounds derived from dead plants and animals are very important factors in retaining the above mentioned elements.

2I. Relation of the Root Hairs to the Soil Particles.-We are now prepared to understand the significance of the structures noted in the root and their relation to the physical properties of the soil. In the first place we see that these microscopic root hairs can readily penetrate any cavity and they are so delicate and soft that they become moulded about any soil particle in their line of growth (Fig. 30, B). So firmly are they attached to these particles that it is impossible to detach them without injuring the root hairs (Fig. 29, $B$ ). This arrangement admirably adapts them to gathering up the water and other crude material in the soil. The tubes are filled with organic acids and other substances which have an affinity for water and such earth 
substances as the plant requires. In this way the materials in the soils are drawn through the delicate walls of the root hairs, a process termed osmosis. Some of the acids in the root hairs may also reach through the cell walls and so come in contact with the insoluble substances, dissolving them and thus rendering them capable of absorption by osmosis. Certain it is that $\mathrm{CO}_{2}$ is given off by the root hairs and as we have seen, this gas entering into the film water would enable it to dissolve calcium-a fact easily demonstrated by allowing the roots to grow over the clean surface of oyster shells or pieces of polished marble. Delicate grooves in the marble show where the roots have dissolved the calcium in the course of their growth. Some roots show an acid reaction, as is indicated by their ability to turn blue litmus paper red; but all roots do not react in this way and it is impossible to state whether acids, other than carbonic acid which would result from the elimination of $\mathrm{CO}_{2}$, are excreted.

We are now prepared to understand why the root hairs are developed just back of the zone of elongation. Any disturbance of these delicate absorbing organs, such as the extension of that part of the root to which they are attached, would result in tearing and killing them.

22. Familiar Facts About Roots. - The character of the root and its relation to the physical properties of the soil explain many familiar phenomena of plant life. We see why plants must be repotted. The root hairs, which only live for a few days or a few weeks, are constantly being formed back of the growing zone and dying off behind. This would result in not only placing: the new root hairs in new soil but they would also be removed in a measure from any harmful substances that may have arisen through the activity of the older root hairs. In this connection note should be made of the suggestive work that is being accomplished today tending to show that roots give off substances, probably of organic nature, which are toxic in character and so, render the soils unfit for plant growth. These substances are readily oxidized and rendered harmless. The presence of oxygen and certain fertilizers increases the oxidizing power of the roots. While this theory is far from being established it is pos- 
sible that we may have a new explanation for the sterile condition of some soils; also plowing and the use of fertilizers may have a new meaning. Consequently when a potted plant shows signs of starvation it is removed from the jar, the tangled mass of roots next to the jar is cut off together with a portion of the earth and then repotted with fresh earth. In this way room is given for the rootlets to grow out into the earth and develop a new absorbing surface and additional materials are placed at the disposal of the root. This relation of the root hairs to the soil particles explains to us why transplanted seedlings usually wilt. Many of the root hairs have been killed and the seedling does not revive until new root hairs have been developed. So also it is clear why most shrubs and trees should be transplanted in September or October or in the early spring in order to permit the rootlets which renew their growth very early in the spring to establish in the soil new absorbing surfaces before the leaves develop and bring about an excessive loss 'of water through transpiration. Why are plants often pruned or cut back in transplanting? Why is nursery stock frequently transplanted, generally a year before it is to be permanently planted?

You have often noticed that fields of grain and other crops turn yellow and die during a long rainy season. This is due to the fact that the air spaces between the earth particles become filled with water and there is no longer possible an interchange of gases. At least two-fifths of the space in these capillary pores should be filled with air to insure healthy plants. This is particularly noticeable in clay soils which are referred to as cold, wet, and sour soils. The reason of this is that the earth particles of such soils are very fine and, owing to their enormous surface, they hold the water with great tenacity. In this way acids from decaying vegetation as well as other substances accumulate in excess and render the soil unwholesome. Therefore heavy clay soils, which are richer in plant foods than other soils, require an admixture of sand and an adequate drainage to render them sufficiently porous for a proper circulation of air. Sandy soils are made of coarser particles and therefore looser. For this reason the capillary water is not retained for any considerable 
time and the soil is properly aërated. Injudicious sprinkling of lawns, gardens, or potted plants will result in the formation of a compact surface crust. This acts exactly like a clay soil and draws the water away from the region of the roots to the surface of the soil where it is lost by evaporation. Potted plants are best watered by standing the jar in the water until the soil is wet. Further watering is not required until the jar sounds hollow when tapped. So gardens and lawns should be thoroughly soaked during the night. The ordinary sprinkling only moistens the surface and leaves the soil in a worse condition for holding the moisture than before, because on drying it bakes and the hard crust draws up the water to the surface where the dry air readily evaporates it. A light shower in the summer time may produce the same injurious effect. On the other hand when the surface of the soil is loose and air dry, so that the capillary water does not extend from the surface to the deeper strata, then a shower may do harm in quite another way. By supplying the upper particles with films of water it reëstablishes capillary connection with the lower lying particles so that the film water now begins to move again towards the surface of the soil. This explains why the top soil should be harrowed and hoed during periods of inadequate rainfall. The loosely arranged particles quickly become dry and the capillary films leading to the water supply below are thus broken at the surface and further loss of water through evaporation is in part checked. A mulch of straw and leaves upon the surface of a soil has the same result as harrowing. Sometimes it is desirable to have a compact surface layer of soil, as for example in sowing a field to grain or grass. This is accomplished by rolling the field, which not only gives a smooth surface to facilitate the cutting of the crop but also makes a compact stratum at the surface which draws the moisture up to the grains, causing them to grow. Otherwise the surface of the soil containing the grains would be so dried out by the winds often in a single day, as to prevent their sprouting.

23. Extent of the Root Surface.-It may seem surprising that the roots are able to take up the large volumes of water that are lost daily through transpiration. The spread of the root, how- 
ever is much more extensive than we think, usually quite equal to that of the branches, so that the absorbing portion of the root is beneath the drip of the branches or exposed to the rains and dews. Furthermore, when we come to add together the lengths of the numerous rootlets, the extent of the total root system is still more surprising. The total length of the roots of an oat plant has been estimated at I54 feet; of a corn plant, at I 320 feet; and of a squash plant at fifteen miles. These roots in ordinary soil reach a depth of from three to five feet, but in dry regions sometimes much greater depths are attained; for example, alfalfa 3 I feet and mesquite 60 feet. The most important increase in the extent of the root system is due to the root hairs, 480 having been estimated on $.0 \mathrm{I}$ in. of a root of corn $\mathrm{I} / \mathrm{I} 7 \mathrm{in}$. in diameter, and 230 on a square mm. of a pea root. By this means the absorbing surface of roots may be increased from five to ten times.

24. The Structure of the Root.-You have noticed that only the apical portion of the root elongates and it may be well to first examine the structure of this region in order to see how growth is brought about and what changes are effected by it. The tip of the root is composed of very delicate cells. Certain of these cells are rapidly dividing by forming new walls through the middle of the cells, thus dividing each cell into two new cells. The division of a cell is effected in a very elaborate manner. The first indication of this growth appears in the nucleus. This organ of the cell enlarges (Fig. 3I, $A$ ) and we now see that it has a very complex structure, consisting of a protoplasmic mass surrounded by a delicate membrane and traversed by a network of delicate threads (linin) and containing one or more large granules (nucleoli). The most important portions of the nucleus are the minute particles (chromatin) which are associated with the linin threads. It has been supposed that this substance controls to a considerable extent the activity of the cell and determines the kind of cell that shall be formed and the work that it shall perform. As the nucleus enlarges the chromatin increases in amount and often forms a ribbon-like structure (Fig. 3I, $B$ ) which finally contracts and divides, thus forming numerous small masses of chromatin, called chromosomes (Fig. 3I, C). At this stage in the 
division delicate colorless strands begin to appear and ultimately grow into a spindle as shown in Fig. $3 \mathrm{I}, D$. There are two sets of these strands or fibrillae; an inner and an outer series. The outer fibrillae, in some way not understood, arrange the chromosomes in the center or equator of the spindle (Fig. 3I, D) where each
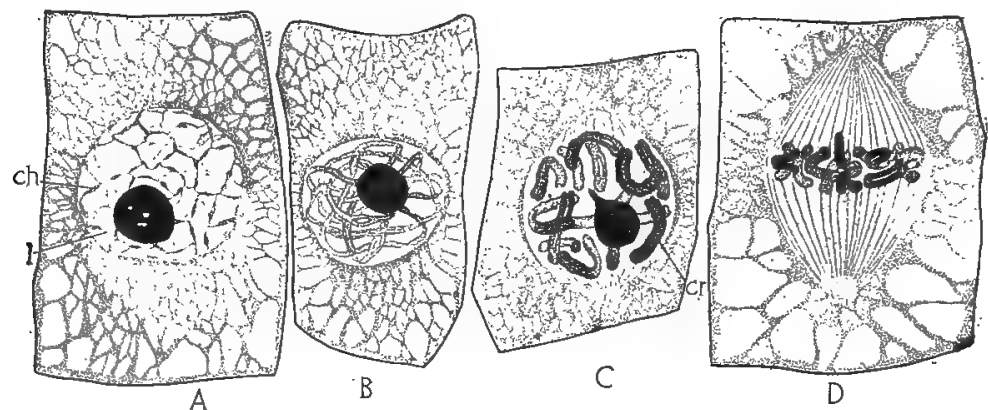

FIG. 3I. Cell division in root of corn: $A$, cell with nucleus enlarging preliminary to division- $l$, linin; $c h$, chromatin. The central dark body is the nucleolus. $B$, later stage, the chromatin has increased and appears as a ribbonlike skein. $C$, formation of the chromosomes, $c r . \quad D$, formation of the spindle and the arrangement of the chromosomes in the center of the spindle.I. D. Cardiff.

chromosome divides by a longitudinal division into two equal parts. The fibrillae now separate the two halves of each chromosome and pull them to the opposite poles of the spindle so that each pole receives a half of every chromosome (Fig. 32, E). The chromosomes now become rearranged at the poles and two new nuclei are gradually formed like the original nucleus (Fig. $32, F, G$ ). In the meantime the inner fibrillae of the spindle have shortened and become thicker at the equator (Fig. 32, G). This thickening goes on assisted by the addition of new fibrillae at either side of the spindle until a delicate line (the cell wall) reaches across the old cell (Fig. 32, H), and the division of the mother cell into two daughter cells is completed. In this way new cells are being constantly added to the root. It will be noticed, if a longitudinal section through the middle of the root is examined, that various regions of the elongating root may be recognized owing to the difference in the character of their growth. In such a section (Fig. 33) we see that the tip of the root is covered with 
a mantle of cells, the root cap. This cap protects the delicate cells within like a thimble so that they are not exposed or injured as the root extends through the soil. At the tip of the root, just within the root cap, the cells are actively dividing and adding new cells to the end of the root and some cells are also added

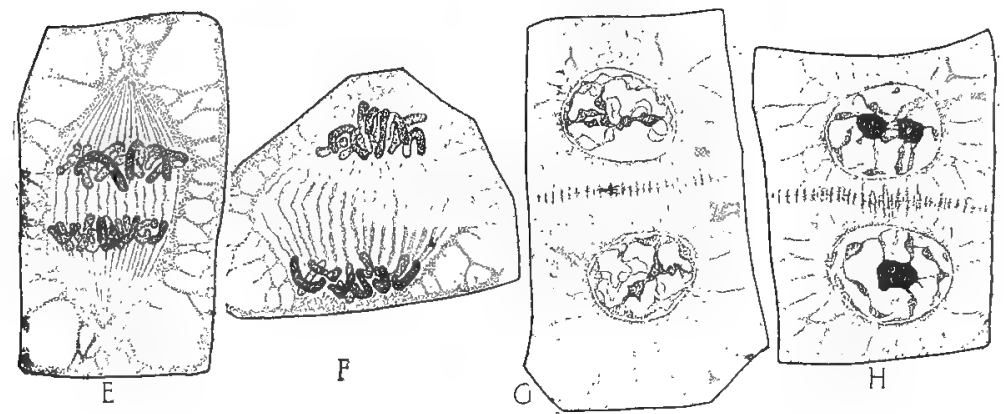

FIG. 32. Later stages in the division of the cell: $E$, the fibrillae pulling the separated halves of the chromosomes to the opposite poles of the spindle. The inner series of fibrillae are now seen at the equator between the two groups of chromosomes. $F$, the chromosomes arranged at the poles and the inner fibrillae increasing in size and number. $G$, the fibrillae have increased in number until they nearly reach the opposite walls of the mother cell. Their thickening at the equator is the first indication of the wall separating the two new cells. $H$, position of the new wall clearly indicated.-I. D. Cardiff.

to the inner side of the root cap (Fig. 34). Owing to this unique arrangement it does not matter if the outer cells of the cap are injured or destroyed as the root pushes through the soil, because the cap is constantly being renewed from within, and so always furnishes adequate protection to the delicate cells within. The cells that are added to the tip of the root divide several times after their formation, so we find that the tip of the root for a distance of one or two $\mathrm{mm}$. is composed of small cells that are in a process of division but that are enlarging to only a slight degree (Fig. 34). This region is called for this reason the formative region of the root. Back of the formative region for a distance of two or four $\mathrm{mm}$. the cells are dividing to a less degree but are elongating very rapidly and changing in form (Fig. 35). This is the region of rapid elongation. Still further back elongation has ceased, but the walls of the cells are becoming thicker 
and the cells are changing in character, so that they perform different duties. This is illustrated in the cross section of the root (Fig. 36), where we see that the outer cells have become modified, forming an epidermis with root hairs for absorption. Within the epidermis is a broad zone of cells, the cortex, often used for the storage of manufactured foods, while in the center of the stem are the vascular bundles. The woody portion of the bundle, or xylem, radiates outward from the center and the soft portion, or phloem, alternates with it (Fig. $36, x, p$ ). The materials absorbed from the soil are largely transported up to the stem and leaves through the xylem, and the foods manufactured by the leaves reach the root by means of the phloem cells. The branches of the root originate in a very curious way from the cells just outside the xylem. These cells by repeated divisions form lateral roots which gradually destroy the tissues in their way and finally grow out to the surface of the root (Fig. 37). By this arrangement they are provided with a root cap and fully prepared to enter the soil on emerging from the old root.

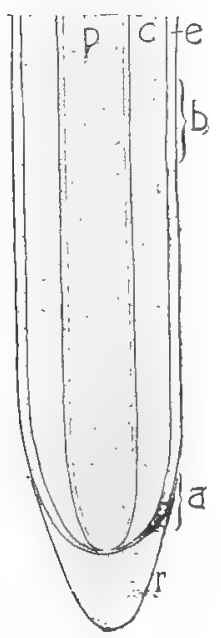

FIG. 33. Diagram of a section taken through the center of a corn root: $r$, root cap; $e$, epidermis; $c$, cortex; $p$, central region.

25. The Transport of Water in the Root.-The inner layer of the cortex, the endodermis (Fig. 36, end), consists of a layer of cells which, in the older part of the roots, forms a very compact and more or less cutinized ring of cells. This tissue is supposed to function in preventing an undue loss of water from the conducting strands of xylem to the cortex. It should be stated here that the root hairs not only absorb fluids but also force out the absorbed substances into the adjoining cells of the cortex. All living cells have this power of absorbing and expressing fluids. So it comes about that the absorbed fluids are forced by the root hairs into the cortical cells and by them they are passed on to the cells of the xylem when by some force not known they are drawn up the stem into the leaves. The force exerted by these myriad 


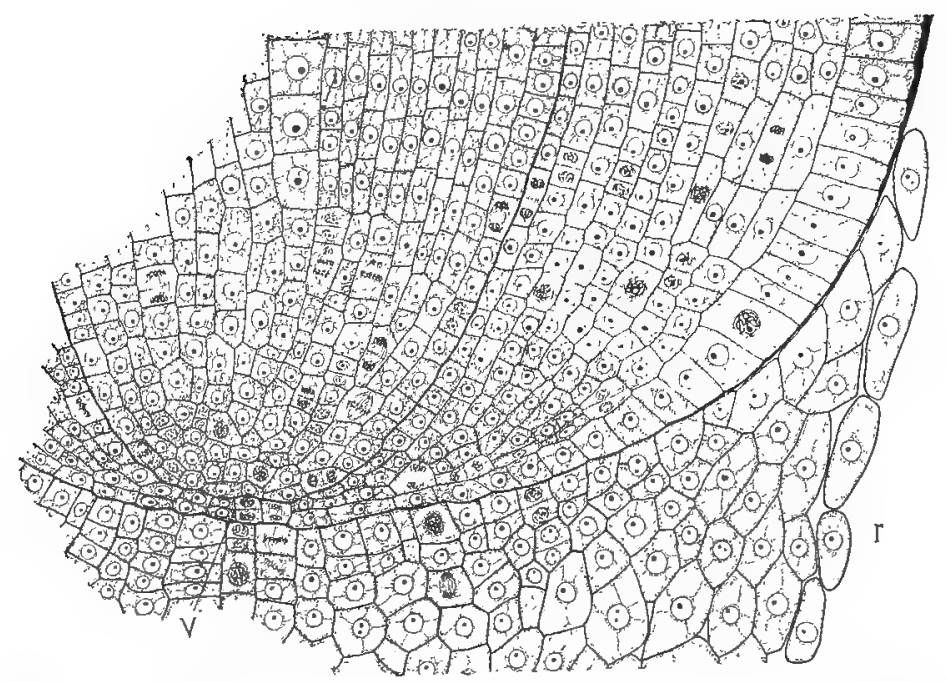

FIG. 34. Portion of the formative region of the root taken at $a$ in Fig. 33: $r$, root cap; $v$, cells which by repeated division add new cells to end of root and to inside of root cap. Note the numerous dividing cells and their uniformity in size.-I. D. Cardiff.

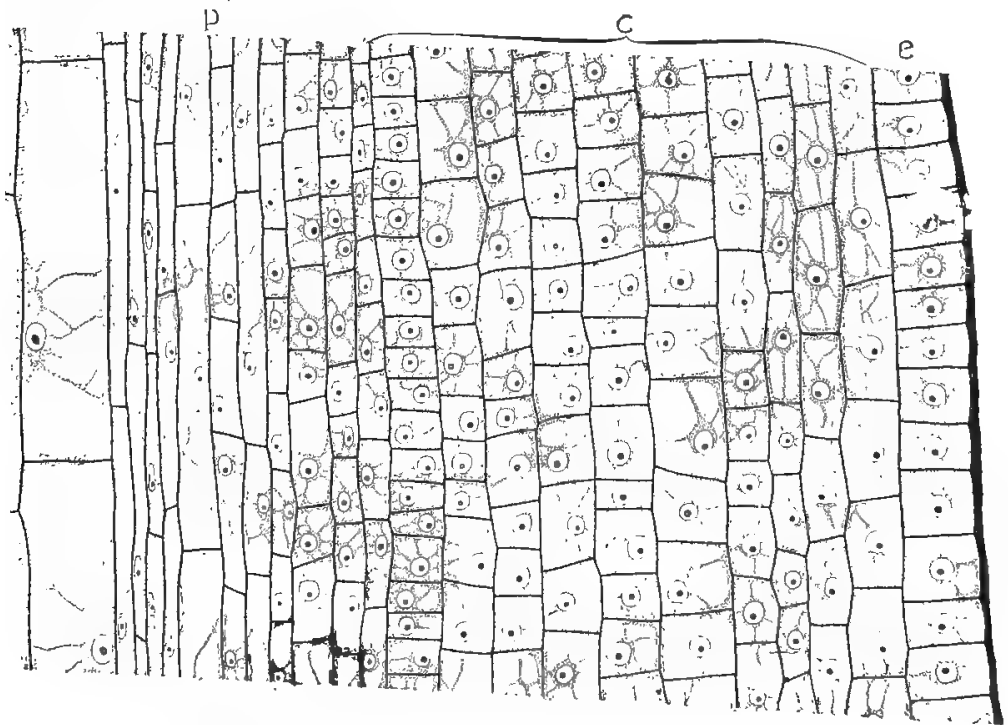

FIG. 35. Portion of the region of elongation of the root taken at $b$ in Fig. 33. Note the larger size of the cells, increase in cell sap as indicated by the larger vacuoles and absence of cell division; $e$, epidermis; $c$, cortical region; $p$, central region.--I. D. Cardiff. 
number of cells in the root exerts a pressure that often amounts to considerably more than one atmosphere, $i$. e., I5 lbs. to the square inch. It is the steady expressing of fluids by these cells that causes the familiar phenomena of the "bleeding," or flow of water from stumps in the spring; likewise the "bleeding," of injured branches, or the flow of sap, for in the stem the living

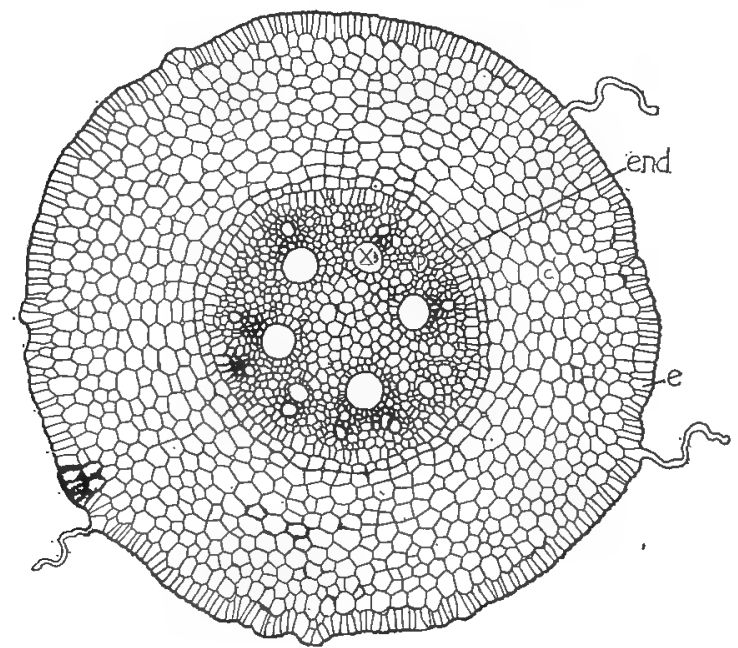

FIG. 36. Cross-section of root taken above section shown in Fig. 33:e, epidermis with root hairs; $c$, cortex bounded on inner side by endodermis, end. Within is the central region containing vascular bundles; $x$, xylem; $p$. phloem. - I. D. Cardiff.

cells are constantly absorbing and giving off water as in the root. In the summer, stumps and stems do not "bleed" as a rule because the water lost by transpiration nearly empties the cells, whereas in the spring before the leaves appear they become filled with fluid.

26. The Sensitiveness of the Root.-We may now ask how does this elaborate root mechanism become so perfectly adjusted to the soil. If the root of a pea or bean seedling is placed horizontally in sawdust, after one or two hours it will begin to curve down toward the earth center. No matter in what position it is placed the result is always the same. We are so familiar with the downward growth of roots into the soil that we never 
stop to consider how they gain their sense of direction. Gravity is the stimulus that acts upon the irritable protoplasm of the cells. and so brings about a growth reaction that sends the root in the right direction. When roots are placed in a horizontal position and slowly revolved on their longitudinal axes, no curvature results, since all parts of the cells are stimulated alike; but when allowed to rest a curvature results because possibly heavier particles in the cells fall to the lower sides of the cells and so pro-

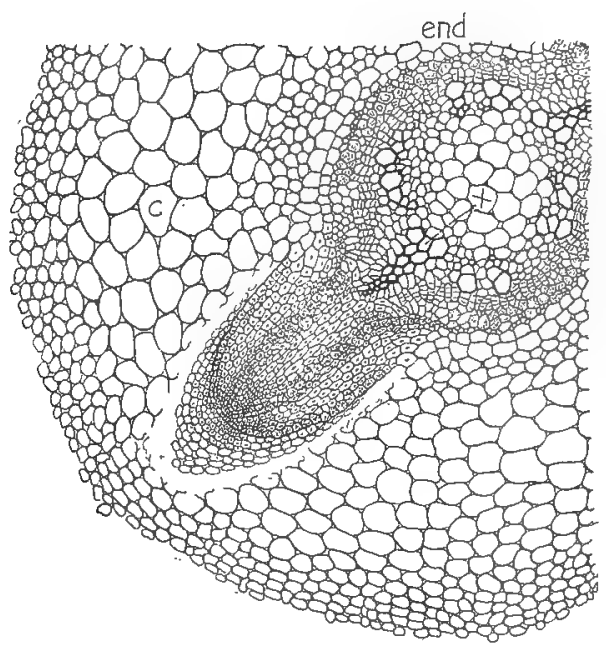

FIG. 37. Cross-section of a root of lupine showing the origin of the lateral rootlets. Lettering as in Fig. 36.--H. O. Hanson.

duce an irritation through their unusual position. The cells in the first millimeter and a half of the root tip, or possibly in the root cap, are sensitive principally to the stimulus of gravitythe other cells much less so. If this region of the root is carefully removed with a very sharp razor the root is no longer capable of responding to gravity although it may curve in various directions owing to the irritation produced by cutting. Furthermore, while the tip alone perceives the stimulus of gravity, the curvature occurs two or three mm. back of the tip, $i . e_{.}$, in the region of rapid elongation, so that we have the transmission of the impulse somewhat after the manner of our. own nervous system. To be sure there are no specially con- 
structed cells for conveying this impulse comparable to the nerves, but it has been shown that chemical changes are set up that extend from the tip to the region of curvature where a more extended growth of the cells on the upper side of the root is induced than on the lower side. This results in bending the root down into the soil. These reactions apply to the main or tap root. The lateral branches, or secondary roots, tend to grow more or less at right angles to the stimulus of gravity, while the short tertiary branches radiate out in all directions. Why the stimulus of gravity causes a more extended growth on one side of the tap root than on the other or why the lateral roots are so differently affected can not yet be answered, but the nicety of these reactions in enabling the roots to reach in all directions and thoroughly explore the soil in their quest for food, is very apparent. The cells of the root tip are also sensitive to touch or contact. This enables the root to avoid obstacles and grow around rocks and stones. In this case the irritation of the root tip produces a more considerable growth in the zone of curvature on the side where the root is irritated with the result that the tip of the root is bent from the object. In this way roots work their way through the soil and avoid obstacles and grow around rocks, for as soon as the irritation of the obstruction is removed by the curvature, gravity will cause the root to grow down again.

The cells of the root tip also react to light intensities and to definite percentages of moisture and mineral foods. Roots avoid light and as a consequence they grow down into the earth where they are directed in their growth, owing to the peculiar sensitiveness of their cells, so that they come to lie in soils containing suitable moisture and crude food materials. Every one is familiar with the fact that roots are caused to curve towards and follow the course of decaying tree trunks, being stimulated by the moisture and food contained in them. Numerous instances might be cited where roots are attracted to wells, drains, etc., even surmounting considerable obstructions in order to reach the water. This localization of the sensitiveness to all external conditions that affect the root at the very tip is altogether ad- 
mirable, because it enables it at the very start to come into the most helpful relations to its surroundings. It was a very clever fancy of Darwin to compare this localization to a brain center as found in certain low orders of animals.

27. Other Root Relations.-While 70 per cent. of our plants develop roots adapted to absorbing substances from the soil there are several interesting modifications of the structures noted above. The roots of aquatics may not develop root hairs because the roots are so finely divided and delicate as to enable them to absorb their crude materials directly from the water. Many plants develop roots in the air. These are sometimes simply clinging devices, as in the poison ivy; or they may be true absorbing organs, in some cases reaching down to the ground or to cup-shaped leaves that hold water, as in many tropical climbing plants. One of the most interesting of these modifications is found in the orchids (Fig. 29I) that live on the damp tree trunks or on dripping rocks of tropical countries. Here the root is covered by a thick mantle of cells that are capable of holding the water that comes to them either in the form of dew or drainage or rain. Such plants, called epiphytes, are able to flourish in the air without the assistance of soil roots. ' Quite a large number of plants, parasites, depend entirely, or in part, upon other plants for their foods. The mistletoe is an example of this. The sticky seeds are carried by birds to the branches of oaks and other trees where they germinate, the roots penetrating the branches and withdrawing the necessary foods. The mistletoe withdraws largely crude materials from the branch because it has pale green leaves and is therefore capable of manufacturing some food on its own account. Our common dodder (Cuscuta) is entirely dependent upon other plants and illustrates the results that follow from the disuse of any function. It has lost its chloroplasts, the leaves are reduced to inconspicuous scales and the stem resembles a coarse yellow string while the root has disappeared entirely. The seeds produce a small thread-like shoot which soon perishes unless it comes in contact with a plant upon which it can live. These thread-like plants are sensitive to touch and so coil about the branches of any plant that they may chance to hit 
in their growth. If this plant happens to contain foods suitable to the dodder then a second stimulus is aroused which causes rootlike branches to form. These organs penetrate the branches upon which the dodder is growing and absorb foods from it. Many plants live as parasites on the roots of a variety of herbaceous and woody plants, as the beech drop, orobanches, broom rape, etc.

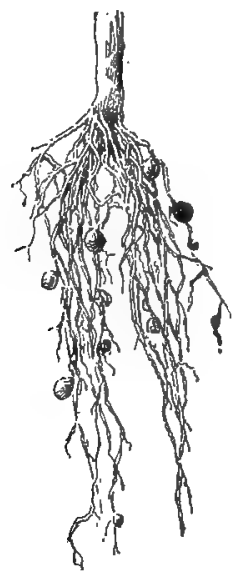

FIG. 38. Tubercles formed on roots of lupine by nitrogen fixing bacteria.

One of the most remarkable features of roots and one of the most important in the economy of the earth is seen in that large family of bean or leguminous plants that are characterized by flowers and fruit like those of the pea. Minute plants, bacteria, gain access to the roots of these plants through the root hairs and cause wart-like enlargements, tubercles, on the roots (Fig. 38). These bacteria have the power of combining the nitrogen of the air with other elements, termed the fixation of nitrogen, and so forming a nitrogen-bearing compound that can be absorbed by the plant. To give an idea of the importance and work of these bacteria, it is estimated that an acre of clover yielding two tons contains Ioo lbs. of nitrogen-74 lbs. of which has been derived from the air. The fixation of this amount of nitrogen by the bacteria in the roots of the clover would nearly suffice for the production of 50 bushels of corn and 30 bushels of wheat. Nitrogen is one of the very essential elements re- 
quired in the construction of the living substance of the plant. Strangely enough, though the atmosphere contains over 70 per cent. of this gas, the plant has no way of utilizing it directly but only in compounds, such as ammonia and nitrates, etc. Compounds of this kind exist in very meager quantities upon the earth. The only sources of supply of any consequence are the decaying animal and vegetable life; manures; small amounts that are formed in the air and that are then carried to the earth in rains; the guano deposits, now practically consumed; and the saltpeter beds of Peru and Chile, which will be exhausted by 1925 . Consequently widespread alarm has arisen lest famines ultimately result through lack of these nitrogen compounds, and the situation becomes the more serious since from one half to two thirds of the nitrogen compounds placed on the soils are lost annually in various ways, especially by the leaching out of these substances by rains and drainage waters. Naturally of late years much attention has been directed to devices for uniting the nitrogen of the air with other elements in order to find a substitute for the rapidly disappearing nitrogenous compounds. Working upon the fact that nitrogen compounds are formed in the atmosphere by electrical discharges, several countries are now manufacturing by electrical processes large quantities of nitric compounds. One of the valuable substances thus formed is calcium nitrate. Nitrogen is first combined with oxygen by utilizing the high temperature of the electric arc $\left(2500\right.$ to $3000^{\circ}$ C.) and the nitric oxide gas thus formed is passed through milk of lime, thus forming calcium nitrate. Another nitrogen compound, valuable for certain soils, is calcium cyanimid. It is formed by passing nitrogen into closed retorts containing powdered calcium carbide heated to a temperature of $\mathrm{IIOO}^{\circ} \mathrm{C}$. Under this temperature the calcium carbide (this substance forms acetylene gas when placed in water) unites with the nitrogen, forming calcium cyanimid and carbon. The cyanimid slowly decomposes in the soil, yielding ammonia which can be either directly or indirectly utilized by the plant. While the value and general utility of these artificially formed nitrogen compounds has not been thoroughly tested, it is not to be ques- 
tioned that products and processes will be improved so as to meet the rapidly increasing demands for nitrate.

Much study has also been given to the nitrogen-fixing bacteria as a further source of supply for nitrogen compounds. Failure attended the numerous attempts to cultivate these important plants with practical results, although our own department of agriculture has met with a limited success in making cultures of bacteria that are sold to farmers for mixing with their clover or other leguminous seeds. "See Bulletin 71, I905, U. S. Dept. of Agriculture. There are many difficulties in the way of introducing these forms, such as keeping them alive, supplying the proper conditions for their growth and the variety of forms that must be dealt with. Although there is possibly but one species of these bacteria, they have become so changed through association with the various kinds of leguminous plants that there are numerous varieties, each adapted to one or a few species of plants. Soils in one section may have the forms suitable for one kind of plant and be totally deficient in forms required for other plants. At present the only sure way of inoculating sterile soils is by mixing with them soils containing the desired bacteria-a laborious and expensive method. Quite recently very promising results have been obtained by growing the desired bacteria in soils until they have so multiplied and permeated it that a small amount of this soil will suffice to inoculate a large area. Without doubt means will be devised for cultivating the various forms of these bacteria so that they may be sold for mixing with the soil or seeds. Thus the farmer will be able to raise a crop that contains a large amount of nitrogen derived from the air and by plowing under this crop or better still, if conditions permit, by feeding it to stock and utilizing the manure, he will be able to add a valuable nitrogenous fertilizer to the soil. In this way the soil is prepared for another crop, as wheat, which is dependent for nitrogen upon nitrogenous compounds. This alternation of crops is of prime importance in successful farming. Each kind of plant takes from the soil certain elements in large amounts and' for this reason the alternating or succeeding crop should be of such a kind as to require other elements. As these elements are 
removed from the soil suitable fertilizers containing nitrogen, phosphorus, lime, potash, etc., must be added to the soil to replace the absorbed crude foods.

The majority of plants do not absorb materials from the soil in so direct a way as is illustrated in Fig. 29. They are dependent for certain of their materials at least upon a low group of plants termed fungi. These fungi more commonly consist of delicate cobwebby threads (termed hyphae), such as are seen on mouldy bread. This fungal group, known collectively as mycorrhiza, comprises a number of forms or species, only a few of which have as yet been identified. These delicate plants spread through the soil and their hyphae enter either the outer cells of the roots or form a mantle of more or less closely interwoven threads about them or the hyphae may sustain both of these relations to the root. It has been demonstrated in many instances that they transfer to the plant various substances derived from the humus. Certain forms, probably a much larger number than is now known, have the power to fix free nitrogen much after the manner of the bacteria. It is also probable that they sometimes take over the normal absorbing function of the root hairs for frequently roots associated with Mycorrhiza develop root hairs sparingly or not at all. This relationship is not always one sided in its benefits for the fungus receives carbohydrate material from the green plant. This state where two or more plants live together is termed symbiosis. All stages in the symbiotic relationship of the fungi and the green plants may be seen. The green plant may not be benefited or even injured by the fungus. This symbotic relationship is termed parasitism. The symbionts may be equally benefited and not all injurious the one to the other. This relationship is termed commensalism. The majority of our poplars, willows, beeches, heaths, orchids and evergreens have attained this state and do not flourish in soils where suitable fungi do not abound. Perhaps this explains why it is so difficult to transplant certain shrubs and trees. The fungi are easily injured and do not become established in the new soil soon enough to keep the plant alive. This mutual relationship has gone so far in some species 
that the seeds are unable to grow unless they come in contact with the hyphae of the fungus. Finally some plants have become so adapted to these fungi as to receive all necessary foods from them. Accordingly, their green leaves and roots have largely disappeared since they are no longer of service. Examples of this are seen in the white Indian pipe and pine-sap and in the coral root orchid. In these latter examples the relationship of the two plants is completely turned about for we see that the plant has become a parasite upon the fungus.

28. Roots as Store-houses for Foods. - In all the cases heretofore considered the root has functioned in one way or another as an organ for the temporary reception and transmission of materials from the soil. It may also serve in other capacities, one of the more important of which is as a storage organ. Such roots become fleshy and filled with foods and are of great economic importance, furnishing a variety of nutritious vegetables, as the sweet potato, beet, turnip, etc. Many of these valuable plants are biennials. During the first season the plant develops only leaves and stores up food in its fleshy roots which is utilized in the following season in the production of flowers and seeds, after which the plant perishes. It is noteworthy that the biennial habit has veen induced in many of these plants by cultivation. If they are left to themselves in a wild condition they will soon revert to an annual growth, $i$. e., producing seed and perishing during the season. Perennial plants live on from year to year. As to whether some plants behave as annuals, biennials, or perennials depends in some cases upon the place or time of planting. The castor bean with us is an annual but in warm countries it becomes a perennial. Winter wheat on the other hand has acquired a biennial habit owing to the late planting of summer wheat types.

29. Anchoring and Supporting Roots.-Roots also play a very important role in anchoring and supporting the plant. Excellent examples of the supporting roots are seen in the Indian corn where numerous roots spring from the stem a short distance from the ground and reach out on all sides like guy ropes steadying the plant in the ground. Similar devices appear in our elms, 
maples, and beeches where enlargements of the roots at the base of the trunk rise up like girders, bracing the tree against winds. More marked illustrations appear in many tropical plants, as the stilt roots of the mangrove and screw pines, and the buttressing roots of one of the Indian rubber plants (Ficus), etc. In the banyan tree of India the branches have an almost unlimited lateral growth owing to the fact that they are supported by a succession of roots that reach from the branches to the ground. Kerner cites an example of one of these trees with 300 large and 3 ,ooo small prop roots. This tree sheltered a village of Ioo native huts and an army of 5,000 men.

30. Binding Action of Roots.-The landscape would be constantly subject to great change either by erosion or through the action of winds were it not for the solidifying and binding action of roots upon the soil. The difficulty of breaking up the prairies and the turf of abandoned fields or meadows indicates the extent and completeness of the ramifications and interweaving of the roots. Miles of sandy reaches are held from shifting through the restraining action of roots and stems of grasses and other plants. The little town at the end of Cape Cod would have been submerged long ago by the shifting sand dunes had not suitable plants been planted to hold in check the loose sands.

Roots not only bind the soil together but the older portion of the root usually possesses the power of contraction. This property results in the pulling down and fixing of the stem in the ground. You must have often wondered how stems and bulbs become so deeply buried in the soil although the seeds are scattered on the surface of the soil. This is also well illustrated in the tips of raspberry bushes which come in contact with the soil through the bending of the stalk. Roots strike out from the tip and when thoroughly established in the earth the older portions contract and bury the tip in the soil. In the same way seedlings of various plants are slowly pulled down into the earth so that they finally become planted at considerable depths. It is this contraction of the roots that keeps the slowly elongating stems of the dandelion, dock and many other plants buried in the soil and that binds many creeping plants such as certain clovers and knot weeds firmly to the earth. 


\section{CHAPTER III}

\section{THE STEM}

3I. The Function of the Stem.-The stem has for its chief function the production and display of the leaves and roots and the conduction of the materials which these organs are especially concerned in handling. It serves as a connection between them, carrying up the material absorbed by the roots and distributing the various substances received from the leaf. Like the traffic of a city this material is received at many stations and transported along various channels to many points. At one place some of it is used in the manufacture of food, at another point material is required for the nourishment and construction of the cells. Here a portion is stored, or again, there is the useless or waste material to be carried away.

32. Character of the Stem.-In order to comprehend the nature of the work performed by the stem it will be necessary to examine its external form and its internal structure. While stems vary greatly in character we may gain a general understanding of their more important features by studying some woody twigs or branches as they appear in winter (Fig. 39). The most striking features in such twigs are the buds, the leaf scars (see page 43), lines of fine scars forming rings about the stems at varying intervals, minute roundish or lense-like elevations (the lenticels), and finally the character of the branching. Thie buds of the hickory, horse chestnut, Norway maple, lilac, cherry, etc., are excellent for study. In these buds, as in most examples, the outer part consists of a series of leathery, closely overlapping scales or modified leaves. These function to protect the delicate parts within against injury and especially against loss of water. By carefully removing the scales with a sharp pen knife we find within the ordinary green leaves, stem and also in some buds the flowers that will appear next year. These organs are so small and crowded that they appear to arise from a single point. 
They have, however, the same arrangement as in the mature shoot of the summer time and you should observe for a few days in the spring the opening of a variety of buds, noting how this crowded arrangement of the organs of the bud gives place to that of the mature shoot. The formation of buds possibly came about owing to climatic changes. The earlier vegetation of the earth was subject to a uniform tropical climate but the formation of high mountain ranges and other factors caused cold currents of air to sweep over the earth and also produced variations in the humidity of the atmosphere. These factors resulted in producing a season favorable for growth and one in which growth would be stunted or checked. The latter condition induced many changes in the plant, of which the bud is an important example. The great majority of woody plants are characterized by these two phases: a period of rapid growth up to about the middle of July, during which time all the organs of the season as well as the buds are formed, after which they continue to manufacture food and store it up in the buds and other organs until September or October; and a period of dormancy in which the plant is in a resting condition until the spring. Such a method of growth is termed definite and should be distinguished from the indefinite growth of a few plants such as the raspberries, locusts, some honeysuckles, etc., where the growth goes on until the fall frosts, with the result that the more recently formed, delicate parts are killed off each year. But even in these cases we have essentially the same rhythm of growth as in the first case because the older portions of the shoot have perfected their tissues and developed their buds and so prepared for the dormant period.

Whatever may be the causes that have resulted in the formation of the bud, certainly its closely united scales which are often reinforced with resinous, mucilaginous or hairy coatings, are an admirable device for protecting the delicate parts within against winds which would rob them of water at a time when none could be obtained from the soil. It is quite natural to think of these devices as protection against cold, but strangely there is no adaptation known among plants that serves primarily as a protection against low temperatures, and there is no cold upon the earth 


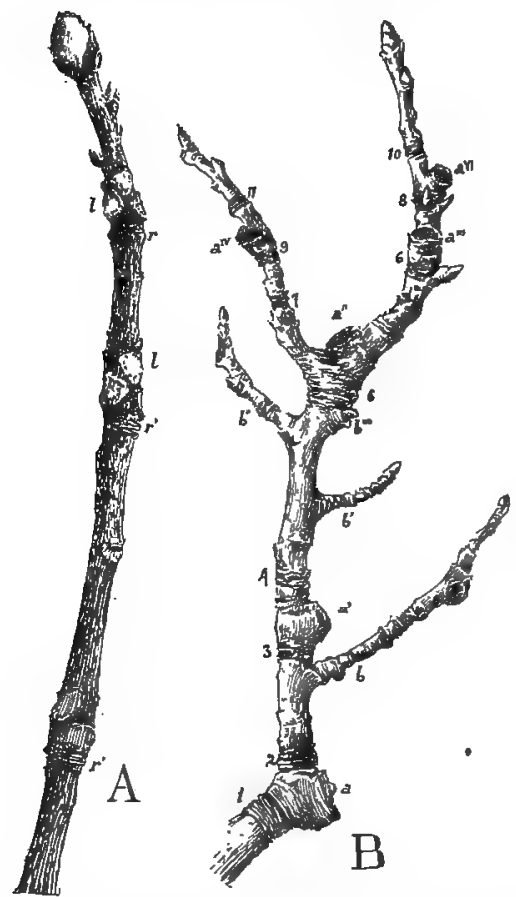

FIG. 39. Types of stems: $A$, branch of hickory showing a large terminal bud and several small lateral buds that were developed in the axils of the leaves of the past season. The branch is three years old, as shown by the three rings, $r, r^{\prime}, r^{\prime \prime}$, of the bud scars which mark the successive positions of the terminal bud during the past three seasons; $l$, leaf scars. $B$, branch of pear-after Bailey. The ring at $\mathrm{I}$ shows the position of a bud which produced the next year a pear, as is indicated by the large scar and swollen branch at $a$. A short lateral branch was also developed the same season with its terminal bud at 2. The next year this bud produced a branch that extended to 3 , bearing several leaves (note leaf scars) and of course axillary buds-one of which, $b$, we see grew in the following seasons. No fruit was developed this season. The bud formed at 3 behaved the next season very much as the one previously noted at $I$, forming a pear at $a^{\prime}$ and a short lateral branch that reached to 4. Note also that the axillary bud, $b$, of the previous season grew a little and its subsequent history can be followed by the annual bud scars. In the following season bud 4 developed a vigorous shoot reaching to 5 . No fruit was formed but three buds survived, $b^{\prime}, b^{\prime \prime}, b^{\prime \prime \prime}$, thus nearly duplicating the growth of bud 2. Bud 5 develops the next season fruit at $a^{\prime \prime}$ and also two lateral shoots that extend to 6 and 7 respectively. The three buds below 5 had only a feeble growth during this and the succeeding seasons and bud $b^{\prime \prime \prime}$ evidently perished during its first period of growth. Bud 6 produces the next year a pear at $a^{\prime \prime \prime}$ and a lateral shoot reaching to 8 and bud 7 at the same 
so intense that it may not be endured by many plants, if this were the only unfavorable factor.

Buds are usually found singly in the axils of the leaves and as a rule only a few that are favorably situated as regards the light ever develop. The development of the buds brings about the characteristic appearance or habit of the plant. This growth is not controlled alone by the favorable position of the buds but also by the interaction or correlation of all the growing parts. As a result in some trees we find a single terminal bud that is larger and better developed than all others. This bud will produce the longest shoots and consequently such trees will have spire-like stems as in the spruces, larches, etc. In other cases this same type of growth may continue for a time but eventually terminal buds of equal vigor will be developed upon several branches and consequently equal growths or diffuse types of branching will result as in the maples, elms, etc. Buds that are not favorably located generally perish after a few years but not infrequently they remain alive and become overgrown by the increase of the stem. In such cases the bud grows slowly and maintains itself near the surface of the wood. These buds growing and often branching in the wood produce those curlings and twistings in the grain that are commonly known as bird's-eye wood. Somewhat similar markings are also produced by minute outgrowths on the surface of the wood. These do not have, however, the darkened center characteristic of the curl caused by the bud growth. Dormant buds sometimes develop into normal branches, as when a portion of a tree is removed and

time only develops a leafy shoot reaching to 9 . Buds 8 and 9 both produce fruit the next season $\left(a^{i v}, a^{v i}\right)$ and short lateral branches reaching to Io and I I. These buds during the present season only formed leafy shoots.

Buds are formed in the axils of all the leaves that appear on the shoots of a season's growth, but notice that but few or none at all develop. Some have a thrifty growth, others remain small and perish after one or more years. This is true of the fruit. Some of the pears mature, as is indicated by size of the scars, while others drop off after one or more months. Note also the almost regular alternation in the production of shoots bearing fruit and leaf shoots. Bud 6 is the only exception to this succession. Observe that the branches assume different positions and that the extent of the elongation of the shoot from year to year varies. Can you explain these facts? 
consequently an additional supply of food stimulates them to growth. Buds may also arise upon any part of the stem, root or leaf. These are the so-called adventitious buds and their formation upon roots often accounts for the colonial habit of many trees, plants and shrubs, as in the poplars, Ailanthus, sumacs, etc. They appear to rise naturally in some cases, but in other instances their formation is due to the stimulus of a wound or some other cause and like the dormant bud they serve to prolong the life of the plant. Richards has shown when living cells are exposed to the oxygen of the air, owing to a wound, that these cells are stimulated as a result to renewed activity. This doubtless explains the formation of callus and the healing of wounds, as well as the formation of adventitious buds in many cases. Common examples of buds due to wounds are seen in the vigorous shoots that spring up from the stumps of hardwood trees, pollarded willows, etc. Some buds become fleshy owing to the storage of the food and dropping from the plants serve to propagate new individuals. Examples of this are seen in the fleshy buds on the tips of the branches or in the axils of the leaves of the stone-crop and some lilies and in the flower clusters of some onions. Many aquatic plants have the habit of forming similar buds on the approach of winter. These being compact and heavy with food sink to the bottom of the ponds in the fall and renew their growth in the spring.

The rapid unfolding of the bud in the spring is a constant source of surprise but when we recall that it contains usually an abundant supply of food and practically all the organs that will appear on the stem during the season we can understand how the bud opens and elongates into a shoot bearing leaves and flowers during the first few weeks of spring. The part of the stem bearing the scale leaves of the bud does not elongate materially since these leaves are of service only during the winter or dry season and soon fall off after the opening of the bud. Consequently the scars formed by the fall of these protective scales form a ring (Fig. 39, r) each year about the stem which marks the position of each successive bud. These scars are therefore known as annual rings and by counting the number of 
these rings on a twig you can ascertain its age and observe the extent of elongation during each season. The minute dots or lenticels consist of loosely arranged cells that permit an interchange of gases between the living cells within the stem and the atmosphere, functioning in much the same way as do the stomata of the leaves.

We are now interested to learn something of the internal character of the stem. By cutting with a sharp knife across the stem between the terminal bud and the first annual ring we see that there are several regions in the stem. On the outside is a very thin brown layer, largely composed of cork cells, which prevents loss of water and which in old stems becomes quite thick and variously split. Within is a zone of rather delicate tissue. The outer part of this region, termed the cortex contains more or less chlorenchyma-at least this is true of small stems-and functions as in the leaf; while the inner rather colorless portion of this region serves to conduct foods manufactured by the leaves and it also frequently serves as a storehouse. The third zone is made up of thick-walled, compact cells, regularly arranged. This is the wood or xylem portion of the stem. It gives stability, conducts the water and crude materials absorbed from the soil and also serves as a storage organ for the reserve foods of the plant. The center of the stem, known as the pith, consists of delicate cells which conduct water for a short time and soon die.

33. The Anatomy of the Stem.-We are now desirous of seeing how this complex structure of the stem comes about and of studying in more detail the character and operations of the apparatus.

If thin sections are made across the stems of seedlings, as of the castor bean, the tissues will resemble the arrangement shown in Fig. 40. It should be stated that the vascular bundles (Fig. $40, v)$ do not appear as separate strands in the earliest stages of the development of the stem. This vascular tissue appears rather as a more or less continuous circle of tissue surrounding the pith. Very early in the development of the stem this circle of vascular tissue is broken into segments or vascular bundles. This separation of the ring of vascular tissue into segments is 
caused by strands of it here and there extending out into the leaves, thus forming gaps in the circle. All seedling stems show this arrangement of tissues and consequently there appears more or less clearly three regions; an epidermis, a cortex, and a central region surrounded by the cortex, an arrangement already noticed in the roots. The epidermis does not materially differ in structure, modification, or function from that already noted in the leaf, see page 8 . The cortex is largely composed of parenchyma and extends from the epidermis to the endodermis which it includes. The endodermis is not so well marked as in the root and owing to the rapid growth of the tissues in this region it is

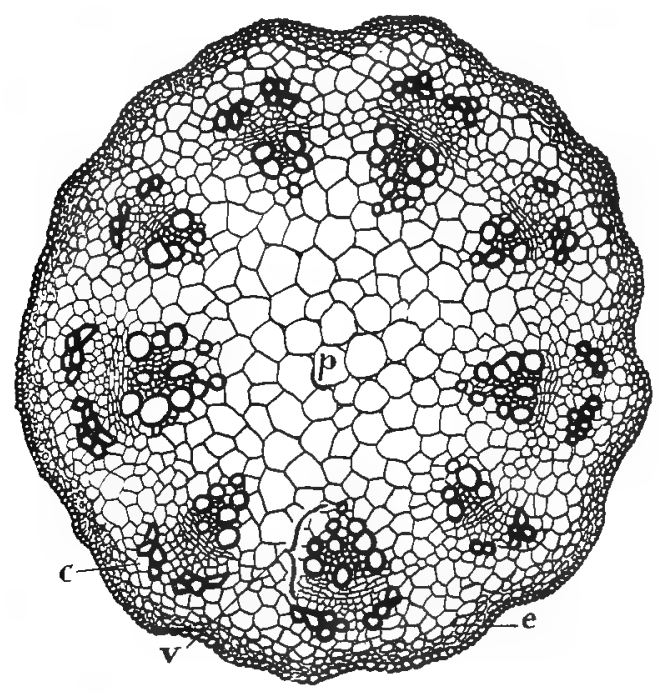

FIG. 40. Cross-section of young stem of castor bean: $e$, epidermis; $c$, cortex; $p$, pith or inner portion of central cylinder; $v$, vascular bundle, arranged in outer part of central cylinder.-H. O. Hanson.

often impossible to detect it. The cortex assists the leaves in photosynthesis, the outer portion as a rule being well supplied with chloroplasts. In old stems that become covered with a thick layer of bark the chlorophyll quite disappears, owing doubtless to its exclusion from air and light. The cortex also serves as a storehouse for foods. Particularly is this true of the endodermis and adjoining cells which are often temporary 
eceiving stations for the carbohydrates during their transport through the stem. The cells in the outer portion of the cortex frequently become thickened and more or less elongated to give strength to the stem. One of the most common modifications of this kind is shown in Fig. 4I, $A$. This tissue, collenchyma, is characterized by the thickening of the cells at the angles or on all sides and by the silvery luster of the walls. The walls, though very elastic and tough, are capable of growth and so they are especially adapted to the support of the young elongating stems. In older stems, where elongation has ceased, other greatly elongated cells, called stereome fibers or sclerenchyma
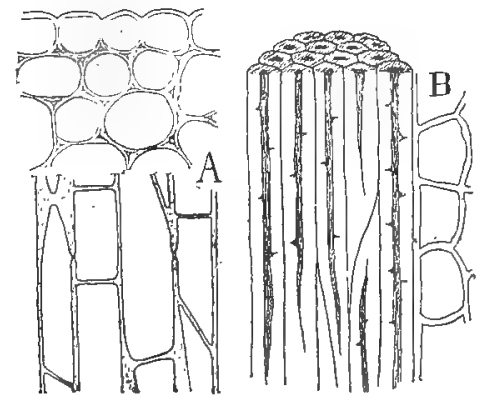

FIG. 4I. The stereome or strengthening cells of the cortex: $A$, collenchyma cells in growing stem of Begonia, showing above the cells in cross-section and below in longitudinal section. $B$, a group of elongated thick-walled cells, called sclerenchyma fibers or stereome fibers, from the stereome of mature flax stem.

fibers, are often formed. These cells have thick walls and tapering ends which interlock and bind the cells very firmly together (Fig. 4I, B). These strengthening cells form a compact zone about the stem or they may be arranged in separate bundles. In this latter case they often appear to the eye as light colored bands extending along the surface of the stems of many herbaceous plants. The central region of the stem is characterized by a mass of parenchyma with several vascular bundles arranged in a circle (Fig. 40). The central mass of parenchyma is called the pith.

34. The Vascular Bundle.-The vascular bundle contains three distinct regions; an inner thick-walled portion (the wood or $\mathrm{xy}$ - 
lem), an outer thin-walled portion (phloem), and between these two regions a delicate layer of cells, the cambium (Fig. 42). The transport of all substances is largely confined to the vascular bundles, the xylem conducting principally the crude materials while the bulk of the organic substances passes through the phloem. We are now interested to study the character of these cells and note their adaptation to the work in hand. In the xylem occur various large spaces, the vessels or ducts (Fig. $42, v)$, and smaller spaces, wood cells of different kinds. The

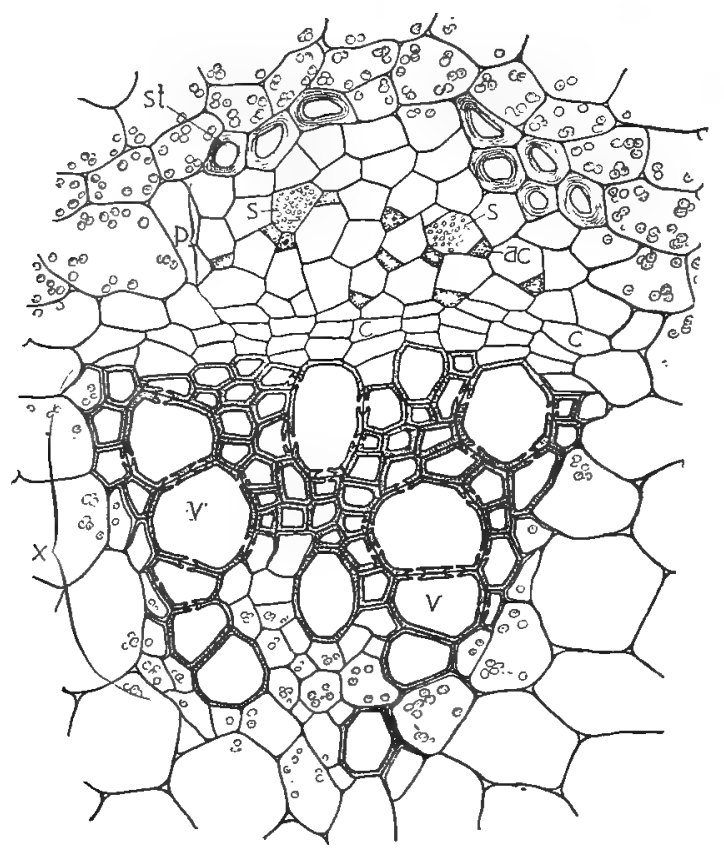

FIG. 42. One of the vascular bundles shown in Fig. 40 enlarged: $x$, xylem; $v$, vessels or ducts; $p$, phloem; $s$, sieve tube; $a c$, accompanying cell; $c$, cambium; st, stereome.-H. O. Hanson.

cells of the phloem are much smaller, thinner walled and less numerous than those of the xylem. Therefore very thin sections are necessary in order to make clear all the different tissues. Sections from a squash stem may well be studied for this purpose because the various cells of the phloem are comparatively large 
and easily distinguishable. It should be stated that the bundle of the squash is peculiar in that a phloem region is developed on both sides of the xylem. The phloem, like the xylem, is also characterized by large cells, which are here known as sieve tubes, because these cells are tube-like structures with the cross walls perforated like a sieve (Fig. $42, s$ ). A small cell, the accompanying cell, is associated with the sieve tube. Usually a varying amount of parenchyma also occurs in the phloem and often thick walled stereome fibers (Fig. 42, st). Between the xylem and phloem is a region of very delicate and regularly constructed cells, the cambium (Fig. 42, c). The growth of the bundle in diameter and, in fact, of the entire stem is brought about very largely by the formation of new cells through the division of the

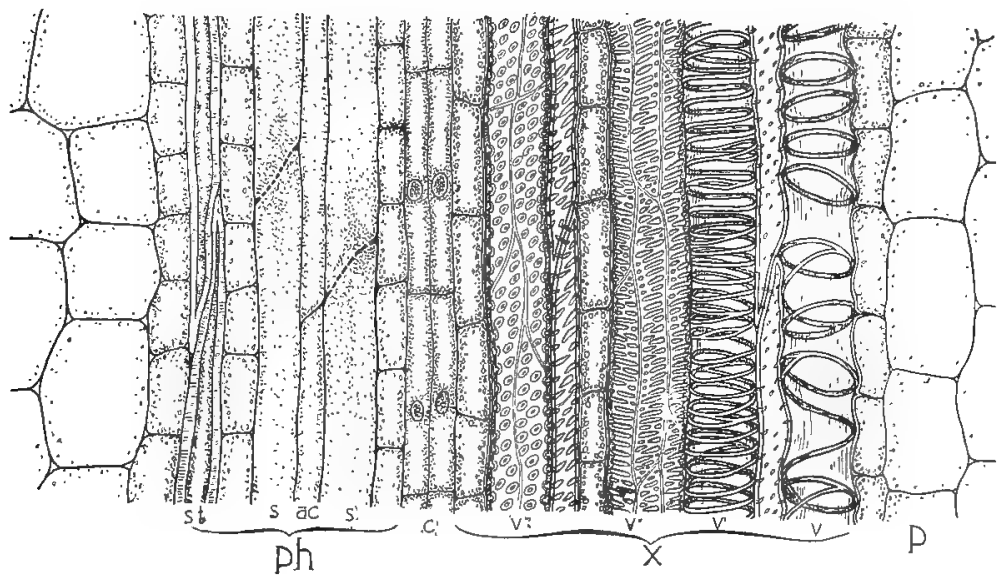

FIG. 43. Longitudinal section of the bundle shown in Fig. 42: $x$, xylem; $p h$, phloem; $p$, pith; $v-v^{\prime \prime \prime}$, annular, spiral, scalariform and pitted vessels; $c$, cambium; s, sieve tubes; $a c$, accompanying cells; st, stereome.-H. O. Hanson.

cells in the cambium. The cross section of the bundle reveals the arrangement and distribution of the various tissues but it will be necessary to examine a section taken parallel with the length of the stem, $i$.e., a longitudinal section, in order to arrive at an understanding of the structure and character of the cells themselves. Fig. 43 shows such a section of a bundle. The 
vessels are now seen to be tubular structures with peculiar thickenings of their inner walls that assume the form of rings (annular vessels), spirals (spiral vessels), or the spirals may branch more or less (reticulate vessels), and often to such an extent that they cover the entire surface of the wall with the exception of numerous small spaces, pores, thus forming the pitted vessels (Fig. 43, $v^{\prime \prime \prime}$ ). These peculiar sculpturings prevent the crushing in and closing of these tubes and the annular and spiral thickenings also permit considerable elongation of such ducts which would not be possible if the thickening were more uniform over the wall. It will be noticed that the later formed ducts are characterized by reticulate or pitted walls since this type of thickening must occur after the elongation has taken place. The ducts are composed of elongated cells but owing to the absorption of the majority of the cross walls the ducts finally come to resemble hollow tubes that of ten run for considerable distances through the stem without any cross walls at all. The smaller cells of the xylem assume various shapes. Some of them, the tracheids, have pointed ends and are characterized by markings similar to the ducts. Strengthening fibers, similar to those noted in the cortex, are of common occurrence and also short cells with blunt ends, wood parenchyma. The ducts and tracheids soon lose their cell contents but continue to function in the conduction of water. The wood parenchyma and other living cells retain their vitality for several years and generally function as storage cells. It is not improbable that they may furnish some of the energy required to force the water through the ducts and tracheids. It is significant that living tissue is always associated with these water-conducting cells of the stem. Passing now to the phloem we see that the sieve tubes are made up of elongated cells with perforated or sieve-like cross walls (Fig. $43, s)$. These minute openings adapt these cells to the transport of albuminous substances which do not readily diffuse through cell walls. The accompanying cells (Fig. 43,ac) which are cut off from the sieve tubes probably assist them in this work. At any rate they have abundant cell contents and contain nuclei, whereas, singularly enough, the nuclei of the sieve tubes soon dis- 
appear although the rest of the protoplasm of the cells remains active for one or more seasons. Elongated parenchyma cells are associated with the sieve tubes and accompanying cells, serving chiefly for the transport and the temporary storage of the more readily diffusible carbohydrates. Fibrous cells, stereome, are also of common occurrence in the phloem (Fig. 43, st). The cambium is composed of very delicate cells, owing to the fact that in this region cell division is taking place and the cells consequently have not yet attained their characteristic form (Fig. $43, c)$. We may best gain an idea of the growth of the cambium if we consider it as a single layer of cells between the xylem and phloem. Each of these cells divides into two daughter cells (Fig. 44), usually the inner cell ( $i . e$. , the cell next to the xylem) develops into a duct, tracheid, or other element of the xylem, while the outer cell, after increasing to the original size of the cambium cells, divides into two cells as at first. This process is repeated again and again, usually the inner cell growing into one of the cells of the xylem while the outer cell retains the

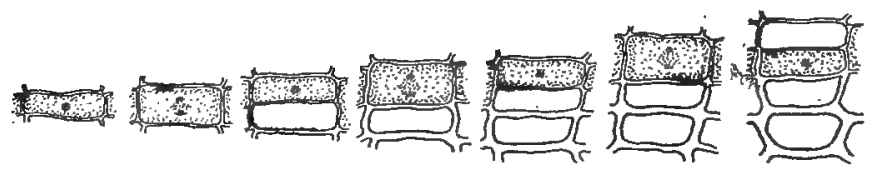

FIG. 44. Diagram showing the mode of division of the cambium cells. The cambium cell is shaded to distinguish it from the cells derived from it. Note in the last division at the right that the inner daughter cell becomes the cambium cell while the outer develops into a phloem cell.

power of further division. Less commonly the reverse method of growth takes place and we have the outer cell enlarging and forming one of the cells of the phloem while the inner cell acts as a cambium cell. In this way new cells are added to the xylem and phloem and the enlargement of the vascular bundle is effected.

35. The Conducting System of the Plant.-These vascular bundles extend from the root up through the stem and branches to the leaf where they divide again and again, reaching all parts of it. In this way the bundles become much reduced in size, the free end of the vein often consisting of a single tracheid to 
conduct the crude materials to the surrounding cells and elongated parenchyma cells to collect the manufactured foods (Fig. $5, l)$. We now see how admirably the vascular bundles are adapted to the transport of fluids. The xylem carries the substances received from the root hairs to all parts of the plant body quickly and with a minimum expenditure of energy because of the elongated character of its cells and the absorption of many of the cross walls of its cells. So the manufactured foods located at any point in stem or leaf are gathered up and distributed by the phloem, the more soluble and diffusible substances being handled in part by the thin-walled parenchyma, while nondiffusible, albuminous substances can readily be transported from cell to cell through the perforations of the sieve tubes.

\section{The Strengthening Tissues of the Stem.-Attention may} be directed at this point to the perfection of the arrangements that give rigidity to the stem. The delicate cells of very young stems or of any other part of the plant are distended by fluids which they absorb. In this way a very considerable force, known as the turgor of the cell, is exerted that may amount to over 200 pounds to the square inch. This pressure at first gives sufficient rigidity to the rapidly elongating stem, but as it increases in

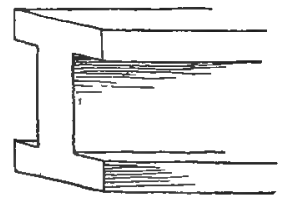

FIG. 45. Common form of girder.

size and the strain upon it becomes more considerable, thickwalled collenchyma cells are formed that keep pace in their growth with the elongation of the stem. When elongation finally ceases, tough fibers of stereome appear which are able to meet the increasing strain upon the stem due to the formation and development of its various organs: These strengthening tissues, with which must also be included the tissues of the xylem, are arranged with the same mechanical effects as are employed in the construction of buildings, bridges, etc. In bending a beam 
the strain falls especially on the convex and concave surfaces. The cells will be compressed on the concave side and stretched on the convex side, while the tissues in the center will be subject to the least disturbance. For this reason girders are strengthened on the surfaces receiving the strain and weakened in the center (Fig. 45). So also given a certain amount of material
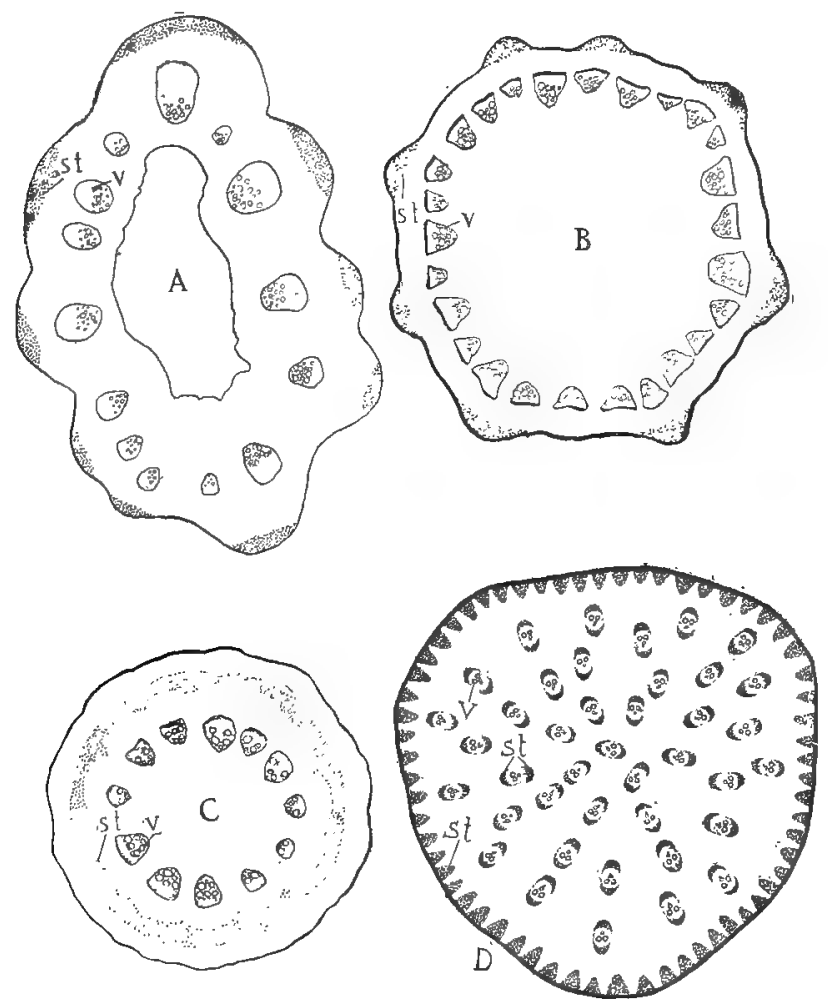

FIG. 46. Cross-section of stems showing arrangement of strengthening tissues: $A$, burdock with strands of collenchyma-st, at periphery; $v$, vascular bundles. $B$, sweet clover, showing a similar arrangement. $C$, moonseed showing cylinder of stereome fibers outside of vascular bundles. $D$. rush with strands of stereome fibers at periphery of stem and also on inner and outer sides of the bundles; v, vascular bundles; st, stereome.

this is more effectively distributed in the form of a hollow column than in a solid column since less strain falls upon the center of the column. Therefore in stems we find the strengthening tissue 
very economically distributed at the periphery either as bands or strands of collenchyma and stereome fibers and these structures are frequently reinforced by additional mechanical tissue in the phloem or just outside of it (Fig. 46). The vascular bundles themselves frequently furnish excellent examples of the girder, masses of stereome being found on the outside of the phloem and on the inside of the xylem (Fig. $46, D$ ). The resistance of these tissues to cutting and breaking affords abundant evidence of their hardness and rigidity. It may be surprising to note that the sustaining strength of the stereome fibers is equal to that of the best wrought iron or hammered steel while their ductility is ten to fifteen times that of iron. The superior quality of these tissues and the perfection of their arrangement result in structures that can not be approximated in any of our buildings. The height of the tallest chimneys scarcely exceeds the diameter of their bases more than fifteen times but many stems of rushes and grasses exceed the diameter of their bases from 200 to 500 times. It would be impossible with any metal to construct a column of the same length and weight and having the same rigidity, elasticity, and resisting power as these stems. We gain an idea of the toughness and durability of these fibers when we consider that linen, rope, matting, etc., are manufactured from them. In stems that increase greatly in diameter, as our trees, the mechanical tissues are confined to the wood or xylem. These are to be sure nearly solid columns, but even here there is sufficient strengthening tissue in the xylem at the periphery of the stem to support the trunk, as is often attested by the sturdy character of trees that have become hollow through decay.

37. The Secondary Growth of the Stem.-The arrangement of the tissues as outlined above, termed the primary growth, remains practically unchanged in some annual plants but in such forms as live on from year to year or that increase materially in diameter there results extensive alterations in the structure of the stems owing to the formation of new tissues, especially in the region of the cortex and in the vascular bundles. The epidermis furnishes sufficient protection to such stems as do not 
increase materially in size, such as the majority of our annual plants; but in long lived stems, as shrubs and trees, where growth goes on from year to year the epidermis is not able to keep pace with the growth.

38. Cork Tissue.-To meet this condition a new tissue, the cork, is developed from certain cells called the cork cambium, usually situated near the epidermis (Fig. 47). The cells of the cork cambium divide much after the manner noted in the cambium of the vascular bundle, but there is this difference, the outer cell of the two daughter cells becomes a cork cell while the inner cell remains capable of further division. Only rarely does the outer daughter cell act as the cambium cell while the inner cell develops into one of the cells of the cortex. As soon as the cork cells have reached their growth, a substance called suber

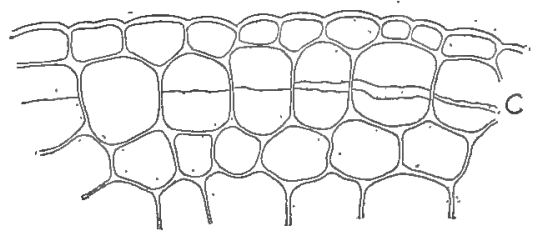

FIG. 47. Cross-section of the outer part of the stem of geranium. The ncork cambium, $c$, originating in the cells immediately below the epidermis.

begins to be deposited in their walls. This completely changes the properties of the cellulose walls and renders them impervious to fluids and gases. So the cork cells have the same physical properties as the cuticle of the epidermis and owing to the continued activity of the cork cambium they are able to keep pace with the growth of the stem. It is evident that the cork cells must die as soon as they become impervious to fluids, and it must also follow that all cells lying outside of these cork cells will die since no fluids can reach them from the vascular bundles. These dead cork cells give the characteristic aspect to the outer bark of trees and we would naturally come to think of the coarse, dark bark as composed of rather thick cells. As a rule, however, the cork cells are quite delicate and compactly put together (Fig. 48 ) and the dark color is more usually due to a discoloration of their walls or to the dried remains of the cell contents. The 
furrows and seams that occur in the bark of most trees are caused by the continued activity of the cork cambium and the cambium of "the vascular bundles which adds each season new cells to the stem and so pushes out the cork cells. In this way it comes about

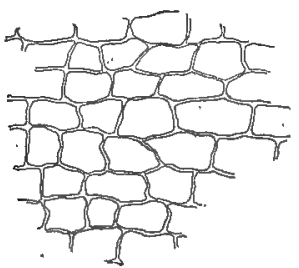

FIG. 48.

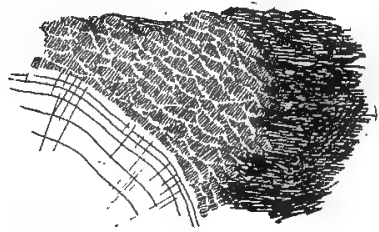

FIG. 49.

FIG. 48. Cross-section of cells of bottle cork showing the delicate character of cork cells.

FIG. 49. Scale bark of pitch pine. The crescent-like lines in the bark show the successive positions of the cork cambium.

that the cork cells are pushed further and further from the center of the stem and since they are not capable of dividing they are pulled apart, forming the characteristic furrows in the bark. It will often be noticed that the bark of some trees, as the conebearing trees, sycamore, etc., cleaves off in shell-like scales. This is due to the formation of a new cambium that joins on to

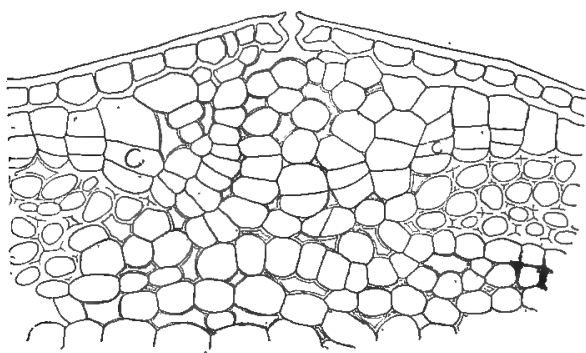

FIG. 5o. Cross-section of the outer part of a stem showing the early development of a lenticel. Note the irregular character and loose arrangement of the cells below the stoma and the cork cambium, c, extending out on either side of the lenticel.

the old cambium in the form of crescents (Fig. 49). Consequently as this bark is pushed out it breaks along these successive crescent shaped cambiums and finally cleaves off in scales. In 
some trees the cork cells break off about as fast as they are formed, so that a comparatively thin layer of cork cells remains attached to the trunk. Such trees have a smooth bark, as in the beech. In other cases the cork cells are formed in great abundance, and owing to the adhesion of the cells, thick layers of cork are formed, as in the oaks, and giant trees of the Pacific.

It is evident that this mantle of impervious cork cells would tend to prevent the access of the atmosphere to the stem. We have seen that all living cells respire. In many instances the air spaces extending from the leaves to all regions of the stem are

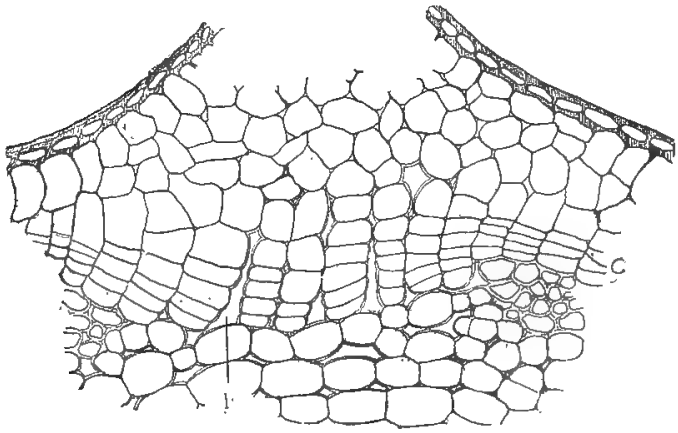

FIG. 5I.

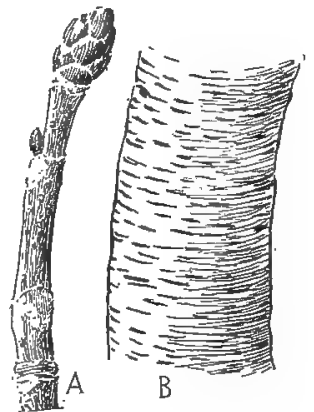

FIG. 52.

FIG. 51. Later development of a lenticel: $c$, cork cambium; $i$, intercellular space.

FIG. 52. Surface view of lenticels: $A$, lenticels on branch of horse-chestnut appearing as minute brownish swellings. $B$, old lenticels on white birch appearing as dark lens-shaped streaks.

sufficient to bring about an adequate interchange of gases but in young stems where growth is vigorous and where therefore respiration is considerable, special devices are required to bring the living cells of the stem into more direct communication with the air. This work is effectively accomplished in herbaceous stems by the stomata, but in stems characterized by the formation of cork it is noticed that the cells just below the stomata begin to divide and form a rather loose mass of cells that lift up and finally rupture the tissues about the stomata, thus forming a small, lens-shaped outgrowth on the surface of the young stem, called a lenticel (Figs. 50; 52, $A$ ). Soon this growth becomes 
localized in a layer of cells situated on the inside of the lenticel (Fig. 5I). This layer of cells is a part of the cork cambium, but strangely enough only loose cells are added to the lenticel during each year's growth and consequently a passage way is kept open to the living cells within the stem. The lenticels appear as minute points upon the surface of young stems but upon old trunks they often become greatly elongated, forming the characteristic bands on the bark of the birch and cherry, etc. (Fig. 52, B). In bottle cork, derived from the cork oak of the Mediterranean, the lenticels appear as minute lines often erroneously referred to as worm holes. Usually as the cork layer increases in thickness the cortical cells become less active, lose their chlorophyll and the cork cambium closes the lenticels by forming compact cork cells instead of the loose cells of the lenticels. This same closure of the lenticels is frequently seen in the fall but the renewal of growth in the spring results in the formation of new loosely related cells which rupture the overlying cork layer and so open the lenticels. So it seems probable that the lenticels arise owing to the active respiration and transpiration of the cortical cells and, when these functions diminish, that the lenticels become closed and finally fail to develop further.

39. The Cambium Cylinder.-Let us now consider the changes that are effected in the vascular bundles through the activity of the cambium. The increase in the diameter of the stems of many annual plants and especially of our trees and shrubs is largely brought about by the formation of new cells derived from the cambium. While the vascular bundles are very small it will be noticed that the parenchyma cells separating the vascular bundles begin to divide so as to form a line of cells connecting the cambium of each bundle (Fig. 53). In some cases these divisions are at first somewhat irregular but soon the growth results in the formation of cells with parallel walls and in this way a line of regular cells is formed which in cross section appear as a band or ring of cells but in longitudinal extent they constitute a cylinder. These cells are therefore termed the cambium cylinder and they continue to divide as already noted in the cambium 
of the bundles (Fig. 54). Consequently new cells are now added not alone to the vascular bundles but also along the entire extent

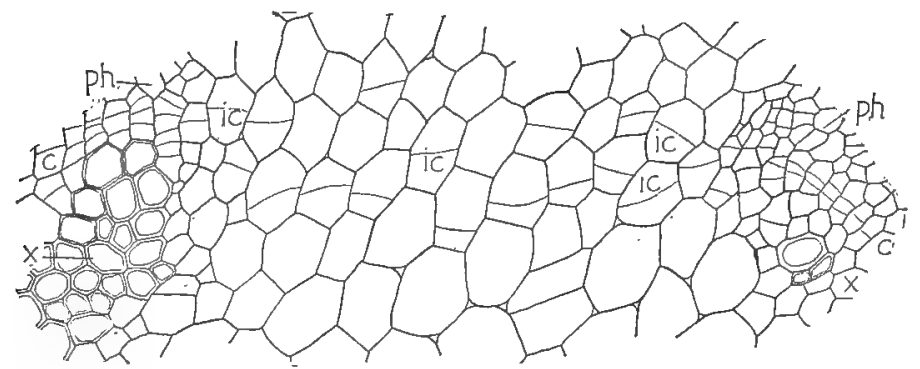

FIG. 53. Cross-section of a stem of castor bean showing the formation of the cambium between two vascular bundles: $x$, xylem; $p h$, phloem; $c$, cambium of the bundle. The faint lines, $i c$, are the first divisions of the parenchyma cells between the bundles that result in the formation of the cambium cylinder.

of the cambium cylinder. This growth results in the formation of a layer of xylem on the inside of the cambium cylinder and a layer of phloem on the outside, and so brings about the principal

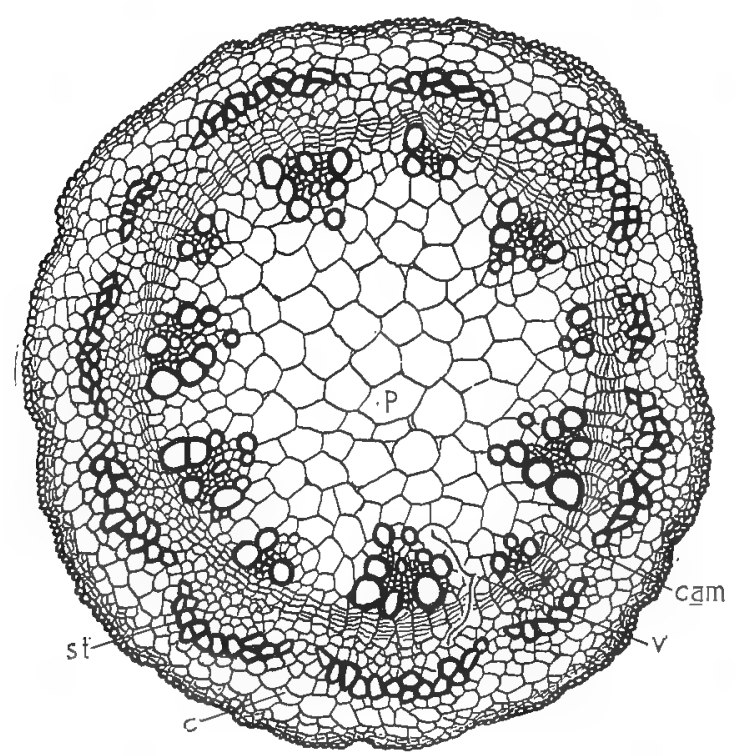

FIG. 54. Cross-section of a stem of castor bean in which the formation of the cambium cylinder, cam, as a ring of regular cells, has been completed; $p$, pith; $v$, vascular bundles; st, stereome; $c$, cortex. Compare Fig. 40.H. O. Hanson. 
enlargement of the stem (Fig. 55). This growth is repeated each spring in such plants as continue to enlarge from year to year, as in the shrubs and trees. The majority of all the cells that are to be formed in a year's growth are cut off from the cambium cylinder early in the spring, usually by the last of April. The majority of these cells become xylem cells while comparatively only a few of the cells are added to the phloem. Consequently the

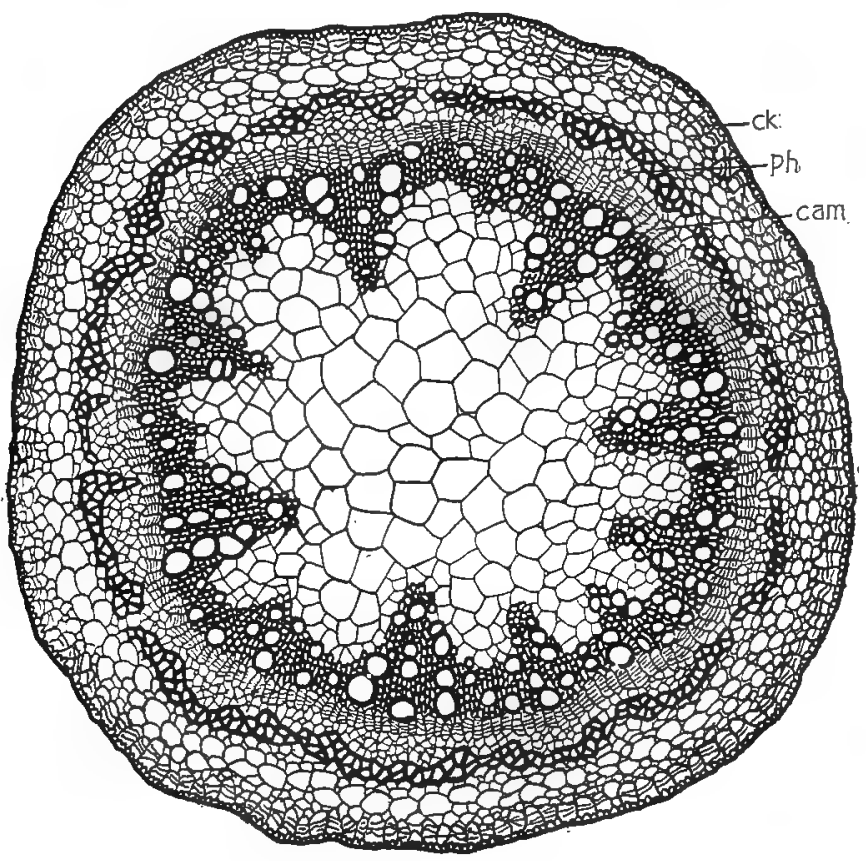

FIG. 55. Cross-section of stem of castor bean three weeks older than one shown in Fig. 54. Note the changes that have occurred in the stem and especially the numerous cells that have been added to the xylem. $c k$, cork; ph, phloem; cam, cambium cylinder.-H. O. Hanson.

xylem increases faster than the phloem and forms the bulk of the tissues of the stem. The amount of the xylem added to the stem each year is generally indicated by bands or annual rings (Fig. 56). This is due to the fact that the first cells formed in the spring have thinner walls and often contain a great many ducts, whereas the later formed cells are for the most part small and pro- 
vided with thicker walls. So there is a sharp contrast between the small thick-walled cells of the summer wood and the thinner walls and larger cells of the spring wood (Fig. 57). This appears to the eye as a band, the annual ring (Fig. 56). The difference in the structure of the cells of the spring and summer wood is doubtless due to the large volumes of water that are transported to the rapidly growing shoots, flowers, and leaves each spring. Later in the season a lesseried volume of water

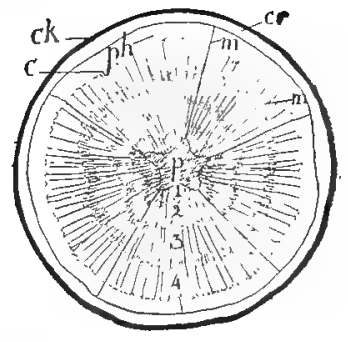

FIG. 56.

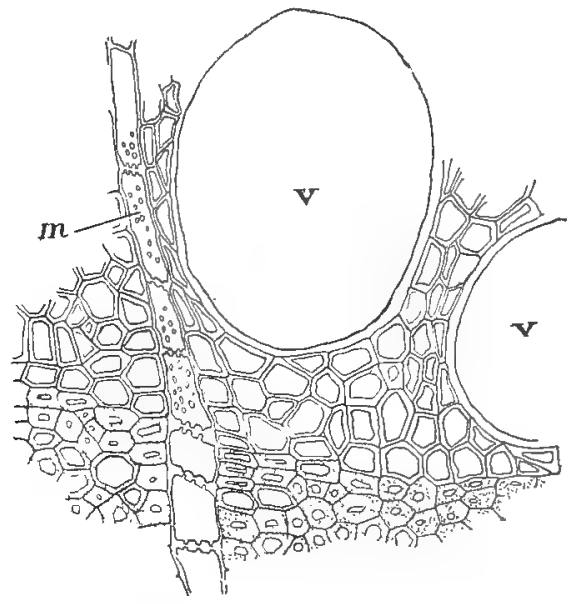

FrG. 57.

FIG. 56. Diagram of a cross-section of a stem of black oak four years old; $p$, pith; $1,2,3,4$, annual rings of xylem; $c$, cambium cylinder; $p h$ phloem; $c r$, cortex; $c k$, cork; $m$, medullary rays.

FIG. 57. Magnified view of a portion of one of the bands of black oak in Fig. 56, showing the thick-walled summer wood succeeded by the thinnerwalled cells and vessels. This association of cells causes the banded appearance of the annual rings of growth. $m$, medullary rays; $v$, vessels in the spring wood.

produces firmer and denser tissues. The age of a tree can generally be ascertained by counting the annual rings. However, two rings may be formed in one season owing to the checking of the growth by fire, severe drouth, depredations of insects and the subsequent recovery and renewal of growth. These annual rings also reveal the life history of the tree, broad bands indicating favorable seasons and narrow bands telling of fires, 
drought, transplanting, and other factors that limit the annual growth. They also show that the development of the plant is subject to the same rhythm of growth as is seen in the animal.

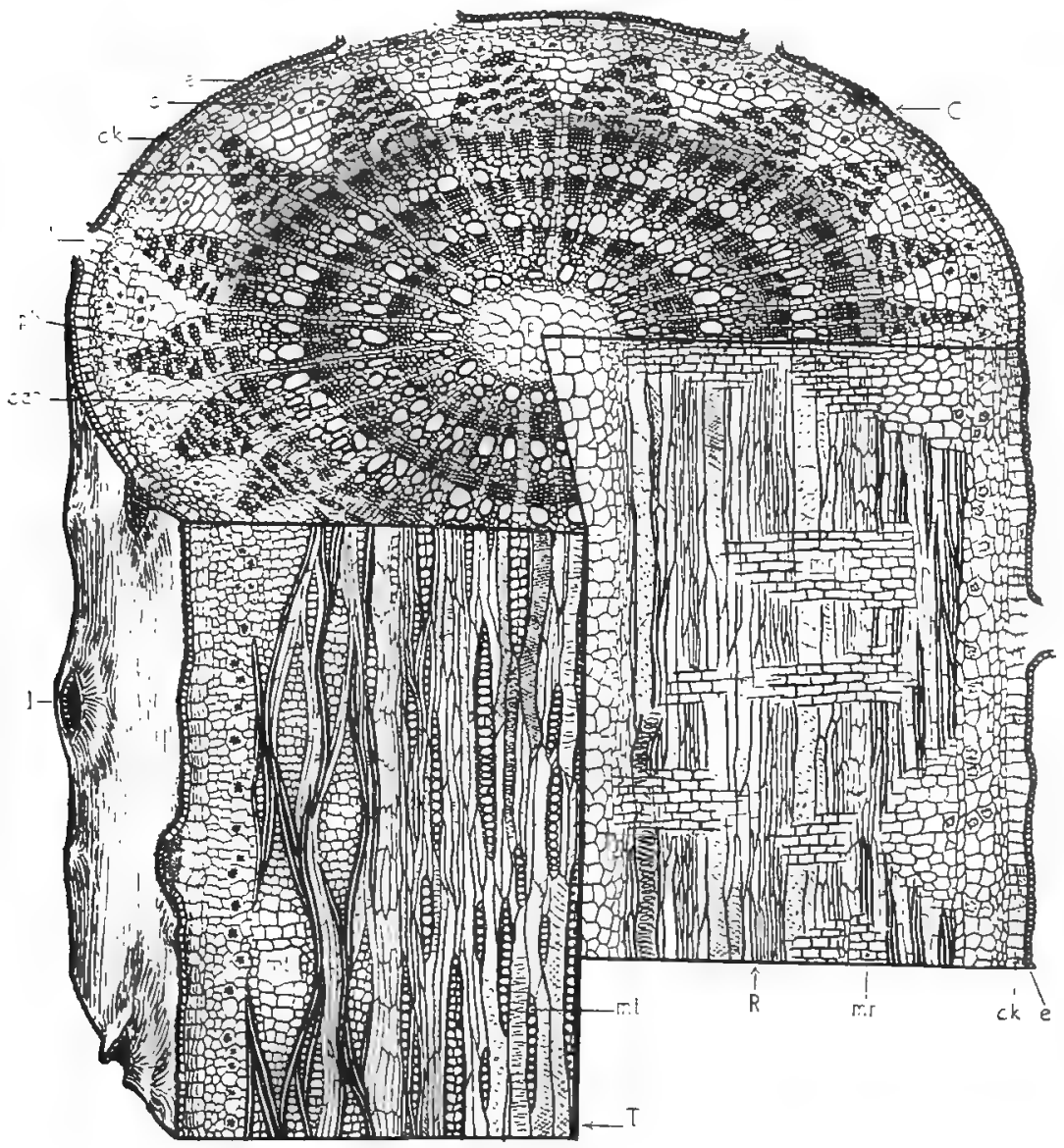

FIG. 58. Diagram of a three-year-old stem of basswood cut so as to show the structure in cross-section, $C$, in radial section, $R$, and in tangential section, T; $c$, cortex; $c k$, cork; $p h$, phloem with darker bands of stereome; mc, medullary ray in cross-6ection; $m r$, ray in radial section; $m t$, ray in tangential section; $l$, lenticels; cam, cambium cylinder; $p$, pith. - H. O. Hanson.

Namely the thickness of the rings increases yearly up to a certain age, after which time there is a gradual retardation. So the tree has its youth, maturity and old age. 
40. The Medullary Ray.-Another characteristic of most woody stems as seen in cross section is the series of delicate lines, the medullary rays, that radiate from the center of the stem (Fig. 58, mc). Some extend from near the pith through the phloem and others originate in the various annual zones of the xylem and extend partially through the phloem. When magnified these medullary rays are seen to consist of rather thinwalled, oblong cells and varying in width from one to a few cells (Figs. $57, m ; 58, m c$ ). In a longitudinal section cut parallel to the rays, called a radial section, they appear as bars of oblong cells running at right angles to the elongated cells of the xylem (Figs. 58, mr; 59, A), while in longitudinal sections cut at right

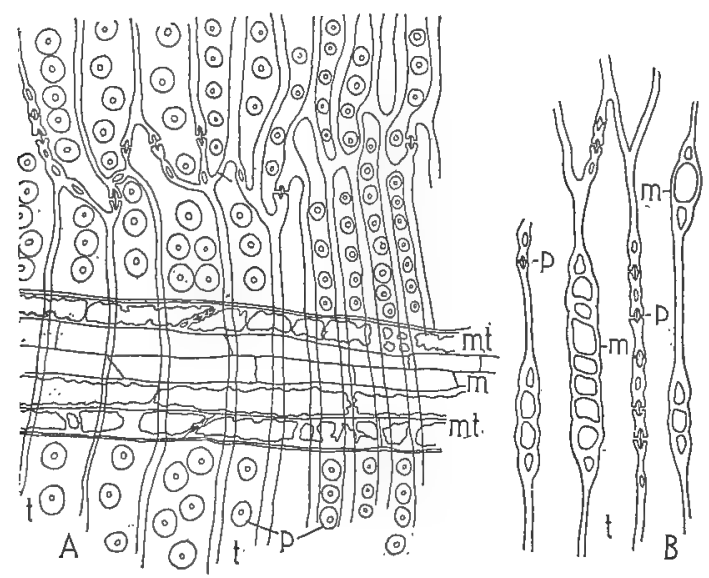

FIG. 59. Relation of the medullary rays to the xylem cells in pitch pine: $A$, radial section showing the elongated cells or tracheids, $t$, marked by circular, thin places on bordered pores, $p ; m$, medullary ray of two cells accompanied by tracheids, $m t$. $B$, tangential section showing medullary rays one cell broad and three to nine high- $p$, bordered pores.

angles to the rays, called a tangential section, we see that the cells of the rays are arranged in a lens-shaped group (Figs. 58, $m t_{\text {; }}$; $59, B)$. The medullary rays are of great importance in the distribution and often also in the storage of foods. Their structure and arrangement in the stem are admirably adapted for this work. Their thin walls can readily withdraw from the ascending current in the xylem as much water as is needed for the phloem and cor- 
tex. Tracheids are often associated with the medullary rays to further increase their absorbing power (Fig. 59, $A, m t$ ). Particularly is this true in the spring wood where the ray cells also often become greatly enlarged in order to absorb the large volume of water required at this time of year. In the same way the carbohydrates and albuminous substances transported through the phloem are withdrawn through the medullary cells and conveyed to the active cambium and the growing cells of xylem.

The value of oak and other woods for interior decoration is materially increased by the medullary rays. The trees are sawed into timber in such a way as to expose the medullary rays to the best advantage, a process called quartering (Fig. 60). Conse-

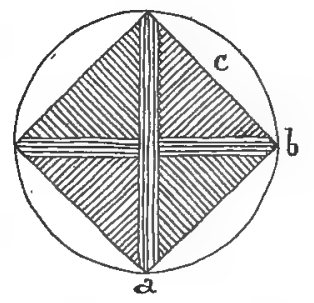

FIG. 60. Diagram showing a common method of sawing in producing quartered oak. The log is first squared to remove the sap wood and then a number of boards, depending upon the size and grain of the tree, are removed at $a$ and $b$. These are the best boards obtained from the log, being broad and approximately radial and therefore showing the medullary rays to good advantage. The remaining portions of the log are cut radially, as shown at $c$. One of the ends of quartered lumber is oblique and must be squared, as shown in the diagram.

quently the rays appear as flecks and bands upon the surface of the board and vary greatly in character owing to the angle of cutting and to the irregularities of the trunk. The medullary rays can always be detected in the grain of wood because they run across or at right angles to the xylem. cells (Fig. 58, $m r$ ). As a rule the wood cells of the stem remain alive for only a few years. This fact is usually apparent in any log or stump where it will be seen that the outer annular rings are of a lighter color, the sap wood, and the older parts are of a darker color, the heart wood. The sap wood is active in the transport of water and contains many living cells. For this reason it is not so valuable 
for lumber. The heart wood is composed of dead cells and while the most serviceable for building purposes, it is of little use to the tree as we often see a vigorous tree whose heart wood has been largely destroyed by decay. We ought not to leave this vascular system of the plant without again emphasizing the perfection of it. First there is the completeness of the system, extending from the root to all parts of the leaf. As soon as the root hairs begin to form and function there is already at that point the beginnings of one of the terminals of the system while the other terminal is also appearing in the leaves while they are forming and still concealed in the buds. Then the elongated cells, those of the xylem being in addition largely without living cell contents, ensures a rapid transport of material. The weak feature of this system is the terminals for here the materials must not only pass through the numerous walls of the short cells but also through the still more impermeable membranes of the living matter of these cells. But once the material is landed in the elongated cells, then follows a rapid transport. Therefore it is the development of this system that makes possible the stature of plants. Without it, plants must remain small and in close reach of their crude supply.

4I. Other Types of Stems.-The cone bearing trees, such as the pines and spruces, have essentially the same arrangement of tissues and mode of growth as noted above in the dicotyledons. The xylem, however, consists entirely of tracheids (Fig. 59) with the exception of a few small spiral vessels that are formed as the first cells of the vascular bundles.

The monocotyledons, plants distinguished usually by their parallel veined leaves and single seed leaf, like the palms, lilies, grasses, etc., are characterized by stems that do not increase materially in diameter. Growth is largely confined to the top of the stem and consequently it can only elongate, forming a very regular, columnar trunk. The reason of this is apparent when cross sections of such stems are examined (Fig. $46, D$ ). The vascular bundles are more or less scattered throughout the stem. The cause of this arrangement is seen in the seedling stage of the plant. Here we see the vascular bundles arising 
through the opening up of the vascular cylinder just as in the case of the dicotyledones, page 76 . The vascular bundles thus formed, however, do not long pursue a uniform course through the stem, some soon turning into the pith and others bending into the cortex. It is also especially noteworthy that there is usually no cambium separating the xylem and phloem. It will be seen by examining Fig. 6I, that the tissues of the bundles are

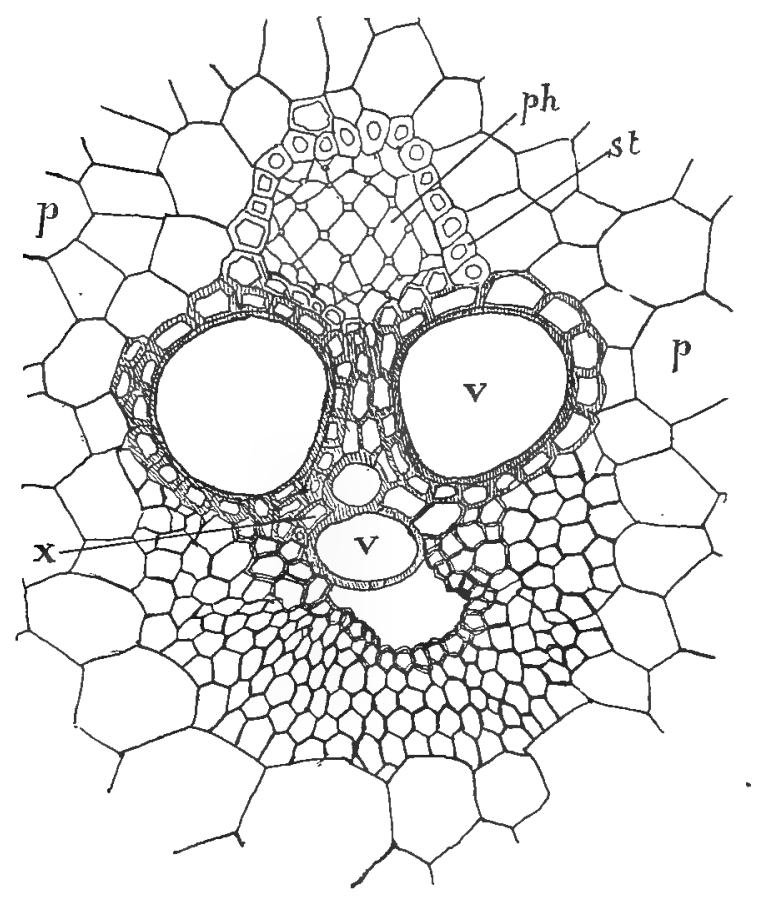

Fig. 6r. Cross-section of a single vascular bundle of corn stem: $p h$, phloem; $x$, small cells of the xylem; $v$, vessels of xylem; st, stereome that forms a sheath about the bundle; $p$, parenchyma of the stem.

of a similar character and have the same arrangement as in the dicotyledons (Fig. 42) save for the absence of the cambium which prevents the addition of new cells to the xylem and phloem. Consequently there can be no considerable increase in the diameter of the stem and no necessity therefore for the protective layer of cork cells. 
42. Apical Growth of the Stem.-All stems are characterized by a more or less extended apical growth. The changes produced in stems by the growth of the cambium only result in increasing their diameters but the elongation of all stems is effected by the formation of new cells at the apex of the stem. Fig. 62 shows the general features to be noticed in the tip of a stem as seen in longitudinal section. New cells are being formed at the apex by division just as in the case of the root. Below this formative region is the zone of elongation in which the cells gradually change in character so that the cortical and central regions are apparent and in certain elongated cells we note the first indication of the vascular bundles (Fig. 62, $x$ ).

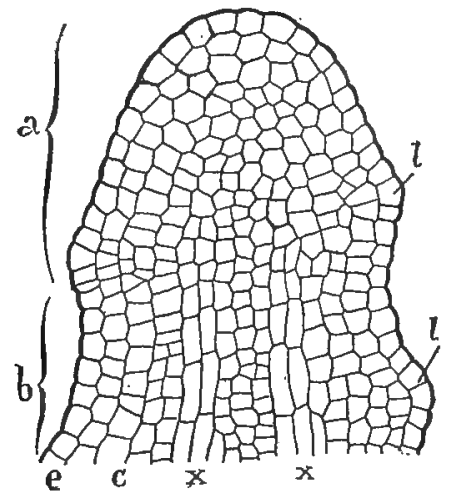

FIG. 62. Longitudinal section of the tip of a growing stem: $e$, epidermis extending over surface of the entire tip; $a$, formative region; $b$, upper portion of the zone of elongation; $c$, cortex; $x$, cells of the central region that by further growth form the vascular bundles; $l$, first appearance of the leaves.

The leaves also originate in this region through the active division of the superficial cells of the stem. The branches of the stem develop somewhat later in the axils of the leaves, and more deeply located cells in the cortex co-operate in their formation. This relationship of the leaves and branches to the stem is shown in Fig. 63, which is a diagtam of an elongating stem, showing the relation of the apical region of the stem ( $a$ in Fig. 62), to the lower and older portion. The cells in these young leaves and branches by rapid division and growth soon form the character- 
istic tissues already noted in the leaves and stems; while a corresponding growth in the cortex and adjacent regions results in the formation of vascular bundles that connect the vascular bundles of the stem with those of the leaves and branches. When a leaf falls off, the ends of these vascular bundles can be easily seen in the leaf scar (Fig. 28, $A$ ) but owing to their minuteness

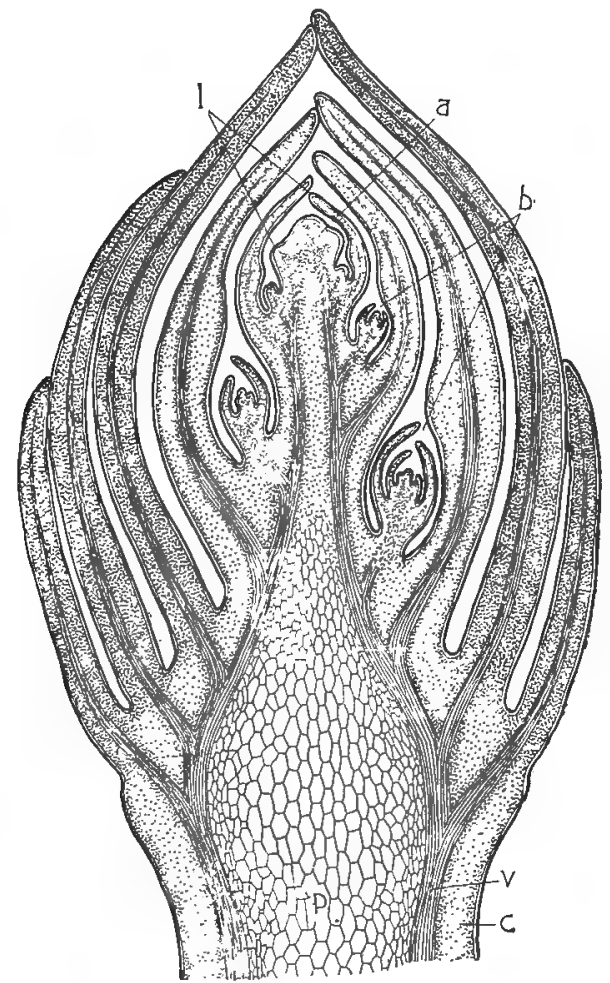

FIG. 63. Diagram of the tip of a stem as seen in longitudinal section: $a$, formative region corresponding to the part shown in Fig. $6 \mathrm{I} ; l, b$, leaves and branches in various stages of development; $v$, vascular bundles; $c$, cortex; $p$, pith.

it is not an easy matter to trace them through the stem to the point where they join on to the bundles of the stem. In the branch, however, owing to its size and woody character, the union with the stem is very manifest. Fig. 64 shows several very small branches that continued to keep pace for one or more 
years with the growth of the stem, but eventually they were killed by the overhanging branches and in time became overgrown with the annual layers of xylem. If the branch is favorably situated so that it continues to live then a cone-like structure is developed (Fig. 64, a) since the branch increases in girth each year in the same manner as the stem. These branches running through the xylem are the cause of knots that appear in lumber. If the branch is living the tissues of stem and branch

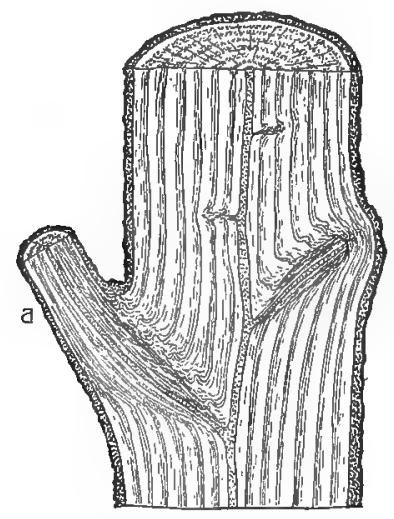

FIG. 64. Section through the trunk of basswood showing relation of ibranches to main stem. In the upper portion of the figure are three branches that were killed after a few years' growth by shading and that have been 'overgrown by the annual rings of the wood. The branch shown at $a$ has remained alive and increased in size after the manner of the main stem.

are closely bound together and we have a solid knot, but it not infrequently happens that branches after living several years die and begin to decay before they are overgrown. Such a limb will produce in the lumber a knot that is often black and shaky or it may fall out, forming a knot hole. The lower branches of trees growing in a forest are quickly pruned off by the shade of the upper branches. This causes straight, clean trunks to develop and the lumber is free of knots.

It follows from what has been said above that in pruning trees the limbs should be cut off close to the trunk. Painting the cut surface does not promote the healing of the wound though it may exclude organisms causing decay. When a wound 
is made that extends across the cambium as in the cutting off of a limb or by a cut into the trunk that removes the tissues as far as the xylem it will be noticed that the exposed cambium is stimulated to form a mass of delicate cells, the callus, that gradually extend over the wound if this is not too large. While the callus is still forming its outer cells become changed to cork cells which join onto the old cork while a new cambium layer is also developed on the inner side of the callus, which unites with the old cambium, thus continuing the cambium of the stem over the surface of the wound (Fig. 65, A). In this way wounds are covered or healed

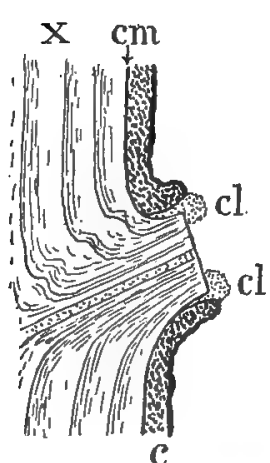

A.

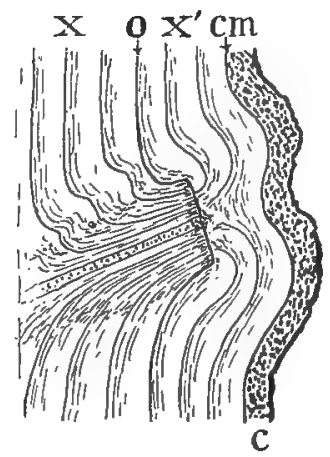

B.

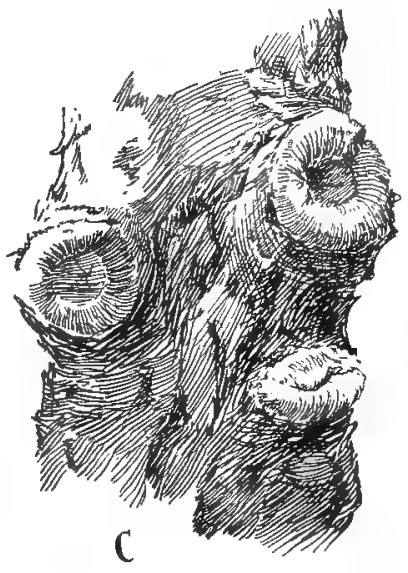

FIG. 65. Section of a portion of a stem showing the healing of a wound caused by the cutting off of a lateral branch: $A$, formation of the callus, $c l$, owing to the renewed activity of the living cells exposed by the wound; $c$, cortex; $\mathrm{cm}$, cambium; $x$, region of the xylem. $B$, a similar stem three years later- $c$, cortex; $c m$, cambium; $x^{\prime}$, xylem added since the wound was made; 0 , position of the cambium at the time the branch was cut off; $x$, original xylem of the stem. $C$, trunk from which three branches have been removed, showing the gradual covering of the wounds by new tissue.

and the tissue exposed by the cut is gradually-buried deeper by. the annual addition of new tissue derived from the cambium (Fig. $65, B, C)$ : Grafting is made possible owing to the formation of callus that unites the tissues of the scion and stock (Fig. 66). While grafting is performed in a variety of ways the process consists essentially in all cases of bringing the cambium and cortex of the cutting or scion in contact with the corresponding 
region of the stock. The junction of the scion with the stock is sealed with grafting wax to prevent decay and the drying out of the exposed cells while the callus is joining together the corresponding tissues in the two parts. When the wound is healed only a slight ring or swelling indicates the point where the scion was inserted-so complete is the union of the vascular and cortical regions. It is evident that pruning and grafting should be done at a time when the cambium is most active, $i$. e., in the spring. In the case of fruit trees it is now the practice to defer the pruning until some time in June, because the cambium is
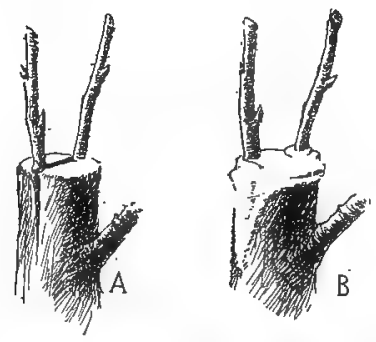

FIG. 66. A common method of grafting: $A$, insertion of two scions into cleft of stock at cambium region. $B$, wound protected with wax to prevesent drying out of tissues.-After L. H. Bailey.

still active at this season and especially since the buds are forming. By removing that portion of the branch which would only produce leaf buds a better development of the flower buds is ensured.

Although the organic union between scion and stock is complete, each part continues a separate and distinct existence. For example, a scion from a plum grafted upon a branch of a peach tree will develop a shoot bearing plums and the peach tree will also continue its normal growth. Ordinarily only closely related forms may be grafted, as tomatoes and potatoes, apples and quinces, etc. It must be inferred from the above statement that there is no interaction between stock and scion. Usually this is not sufficient to change materially the character of either but there are numerous instances showing that the chemical composition of the cells or even the form, coloration, and productive- 
ness of scion may be modified by the stock. Fruit growers take advantage of this in grafting the cuttings from seedlings that would not bear for several years upon fruiting trees, with the result that the scion comes into fruitfulness the next season. In the same way it is claimed that seedlings may be made to bear earlier than they normally would by grafting them with buds from fruiting trees.

43. Comparison of Stem and Root.-It will be noticed that the structure of the growing tip of the stem presents several striking departures from that of the root. In the first place a protective structure such as the root cap is not required (Fig. 62). The leaves, and consequently the branches are formed with great regularity from the superficial tissues of the stem, whereas the rootlets are deep seated in origin and irregularly distributed. Furthermore, the elongation of the stem is distributed over several centimeters, while in the root it is confined to a few millimeters. The leaves and branches are distributed over the entire zone of elongation, while lateral roots do not appear until elongation has ceased. This prolonged growth of the tip of stems is of great advantage in bringing about the proper adjustment of leaves and branches. These organs come into sharp competition with each other as well as with other plants, and so long as growth continues there is a possibility for them to become adjusted to the light without interfering with one another. The mode of elongation of stems and roots is essentially alike. Each has a formative region at the apex characterized by active cell formation and slight elongation, back of this is the zone of rapid elongation and following this is the zone in which elongation is gradually ceasing and the tissues are assuming their characteristic forms and functions. It is also important to note that the growth of the cells on one side of the stem or root is faster at a certain time than that of the other cells. This will cause the stem to be bent towards the opposite side. This condition of rapid elongation does not. continue on one side for any considerable time but slowly moves from point to point around the stem so that the stem is successively bent from side to side, thus causing the apex to travel in an irregular circle. By these constant movements, 
nutation, the stems and roots are more fully exposed to the various forces that influence their development and consequently they adjust themselves to the best advantage (see page 33 ).

As a rule the irritability or sensitiveness of the stem is not so localized as in the case of the root. It is evident that it is an advantage to have the entire growing surface of the stem sensitive to all those stimuli that influence its growth, because by this means it will be so influenced as to bring its leaves and branches into proper relations with the surroundings. In some plants to be sure the sensitiveness to stimuli is quite as localized as in the root; as, for example, the tip of the cotyledons of many grasses which have an appreciation of light almost the equal of our eyes. These cotyledons will turn toward a light too feeble to enable us to read the time of day on a watch. The significant fact to be noted here is that this keenness and localization directs the plant into a suitable place as soon as it emerges from the soil. Grass plants grow in thick colonies and therefore the stems come into sharp competition. Consequently it is a necessity that the young shoot on emerging from the soil should be able to appreciate the feeblest light and so be able to direct its growth through the smallest openings.

The reactions of the stem to various stimuli, such as light, gravity, etc., are quite as purposive as those noted in the root. Lateral light, as in the case of plants growing in windows, acts as a stimulus and causes a more considerable growth of the cells on the darker sides of the stem. This results in bending the stems towards the light and consequently in the exposure of the broad blades of the leaves to the light. So, also, when erect stems are placed in a horizontal position the stimulus of gravity awakens a more active growth on the underside of the stem, thus bending the tip into an erect position for securing light. Not all stems and, indeed, not all parts of the same plant body are similarly influenced by these forces. Many plants tend to arrange their stems at right angles to the action of gravity and light, as in the case of creeping and underground stems. So also the lateral branches are inclined at various angles to the stem. These adjustments are not to be looked upon solely as the direct response 
to one or more stimuli but as the resultant of numerous interactions aroused in the plant by various stimuli. The entire plant responds as a unit to these forces. Stimulation and the consequent growth in one part has its effects upon all other parts. As a result of this interaction there comes about a correlation in the growth of all the parts that is expressed in the symmetry of the plant body and in the perfect adjustment of roots, stem and branches, and leaves to its needs. Any window garden, forest, or field furnishes abundant evidence of the complicated and varied nature of these reactions. An illustration of this is afforded in the removal of the terminal axis of a tree. An adjoining lateral branch that heretofore has been stimulated to a more or less horizontal growth, now is so directed in its development that it ultimately becomes the terminal axis of the tree. So some parts are constantly being overshadowed and choked out while others are directed into favorable positions and perform the work of the destroyed parts. In this way there is brought about that weaving and twisting of stems and branches and the adjustment of leaves that so often suggest a conscious effort to reach favorable positions.

44. Modifications of the Stem.-In the above discussion attention has been called to the more common characteristics of the stem. It is well to remember, however, that variation is the law in the plant world. No two plants are alike. The environment of the plant is constantly stimulating it and causing it to vary. Frequently the variations are so minute as to escape our attention or totally distinct forms may arise. These departures from the parent type may be of no advantage to the plant and it may therefore perish. On the other hand the variations may be of such a character as to enable the plant to more successfully compete with other plants and as a consequence the plant with its helpful variations will survive. So it has come about that these changes going on during the past ages have resulted in many remarkable modifications. A few of the modifications of the stem that are of especial advantage to the plant and therefore spoken of as adaptive variations will be considered in the following paragraphs. 
45. The Climbing Type of Stems.-Climbing stems are characterized by being rather small and having greatly elongated internodes. Stems grown in the dark show a similar development. Perhaps this variation that we call the climbing type has been brought about by competition with larger plants. The feeble light has stimulated these stems so that they attain a very extended growth and finally are able to reach the light and display their leaves. Many variations in the structure and sensitiveness of the stem are associated with this elongation, all of which are designed in one way or another to enable the stem

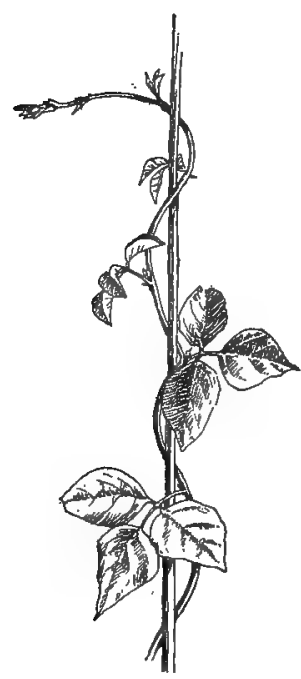

FIG. 67. Twining habit of wild bean. Note the horizontal position of the upper portion of the stem which results in the apex nutating through a wider circle. to reach the light. One type of these varia- . tions is seen in twining stems, as the morning glory, bean, hop, etc. Young twining plants behave quite like the ordinary plant. The stems are erect and actively nutating, the apex traveling through a rather large circle in one to three hours. When a certain height has been reached the stems are stimulated by gravity so that their upper portions grow more or less horizontally (Fig. 67). This position is a decided advantage since the stem is now revolved through a larger circle and has a greater chance of coming into contact with an object about which it can twine. As soon as the stem comes into contact with any support its nutation will cause it to wind or twine about it. The contact also acts as a stimulus, causing the stem to bend more energetically. Certainly in many plants the size and roughness of the support as well as other features, are important factors in inducing the twining. At first the coils are merely horizontal but owing to the elongation of the stem these coils are gradually pushed upwards and become steep and very firmly bound around the support. Twisting of the stems and reflexed bristles often assist in anchoring the plant to its support. It is interesting to 
note that in the majority of cases the stem twines about the support in left hand spirals or clockwise; less frequently right hand spirals are formed, as in the hop, some honeysuckles and knot weeds. Why the growth of the stem results in left or right hand twining is not known but the fact remains that the plants can not be induced to change their method of twining.

46. The Tendril Type of Stem.-One of the most interesting variations of climbing plants is seen in those stems that climb by means of tendrils. In this type almost any part of the plant may become modified so as to act as a tendril and bind the plant to a support; e. g., the petioles of nasturtium and clematis, stipule-like outgrowths in smilax, midrib of leaf in many members of the bean family, or modified branches as in the grape vine, etc. The ordinary tendrils as we see them in the gourd, passion flower, etc., are highly specialized stems that are very sensitive to touch. These organs are rapidly nutating, frequently completing two or more circles in an hour, and as they approach maturity they often become slightly curved and hooked (Fig. 68, $A$ ). Their sensitiveness to contact, which is often localized on the concave upper third of the tendril, also becomes so keen in some forms that a thread weighing one-fiftieth of a gram will cause a curvature of the tendril when placed upon it. In fact a much smaller weight if caused to vibrate will act as a stimulus, so that we have here an illustration of sensitiveness to weight that is keener than our own. When the sensitive part of a tendril is stroked by a pencil or comes in contact with any hard object, this acts as a stimulus and causes a very rapid growth upon the convex side of the tendril. As a result of this growth the tip of the tendril curves, forming a complete loop in from a few seconds to a few minutes. The contact of the tip of a tendril with any object acts as a continued stimulus and the tendril soon becomes tightly wound around it. As soon as the tip is firmly bound to the support a new impulse is frequently transmitted to the free portions of the tendril which in a day or so begin to assume the form of coils that are often reversed in the middle (Fig. 68, $B$ ). By this unique device tendril bearing stems are firmly fastened to their supports but at the same time the coiling of the tendrils 
Missing Page 
Missing Page 
develops in this way and with the dying off of the old stem a new plant is established, as in the houseleek (Fig. 70). In other cases, runners, almost any node may form buds and roots which become separate plants by the decay of the old stem, as in the strawberry, gill-over-the-ground, cinquefoil, etc. These new plants repeat the mode of growth of the parent plant and in

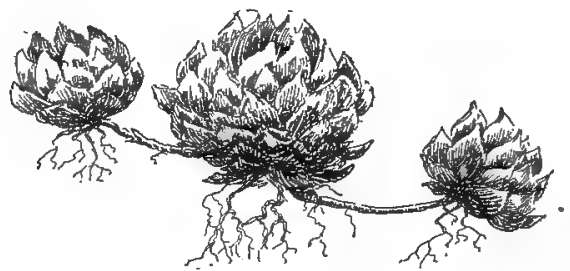

FIG. 70. Houseleek forming buds at the end of short branches or stolons.

this way many prostrate stems spread out over the soil, establishing new plants in wider and wider circles. If you will observe the number of new plants established and the distances traversed by some of these creeping stems each year you will see the reason for the common occurrence of the large mats and colonies of plants with prostrate stems.

48. The Rhizome Type of Stems.-In a third type; the stems have become so modified that they respond to the various stimuli in quite a different way from the forms noted above. They creep along in the soil and frequently resemble roots more than stems. For this reason they are called rootstocks or rhizomes. They are however, real stems, as is attested by the numerous leaves and often erect branches that spring from their nodes as seen in the ferns, sweet flag, cat tail, grasses, etc. Plants of this type are well protected against drought and fires, and like prostrate stems they are adapted to establishing new plants as is apparent in grassy meadows, colonies of golden-rod and daisies or reedy banks of cat tails, sedges, etc. These stems are also well adapted to propagating new plants because they generally serve as storage organs for food and are therefore often of a fleshy character (Fig. 7I). For these reasons it is sometimes very difficult to eradicate plants of this type. This is very well illustrated in the quack grass, often a troublesome pest in cul- 
tivated land. Plowing and hoeing only serves to break up the rhizome into numerous parts each of which may develop buds and roots from their nodes and so establish new plants.

49. The Condensed Type of Stems. - In many cases we find that the food is localized in special regions of the rhizome which consequently become enlarged and rather fleshy, such enlargements appearing at the end of the rhizome or scattered along its entire length. Such modified parts of a rhizome are called tubers, e. g., the potato and Jerusalem artichoke (Fig. 72). The potato

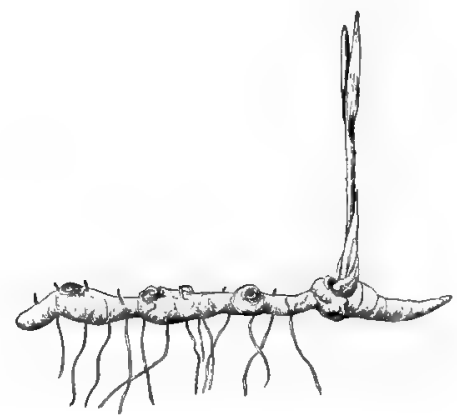

FIG. 7 I.

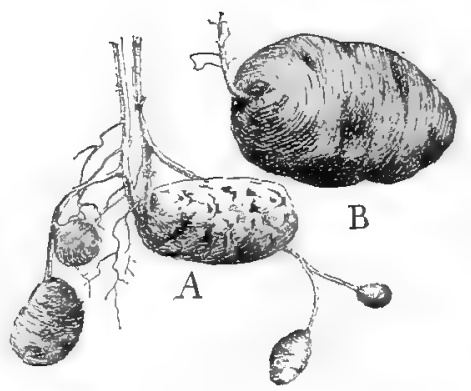

FIG. 72.

FIG. 7I. Rhizome of Solomon's seal with aerial shoot just emerging from the ground. The seal-like scars mark the successive shoots produced during the past three years.

FIG. 72. Formation of tubers: $A$, old potato or tuber with two shoots reaching up into the air and from the base of these shoots, rhizomes have been formed that are developing new tubers. $B$, mature tuber with spirally arranged buds, the so-called "eyes" of the potato.

is formed by the storage of foods in certain parts of the rather small rhizomes that branch out from the stem of the plant. The "eyes" are the buds that develop at each node of the rhizome and each is capable of forming a shoot, although but a few of them so function, as is the case in an ordinary branch of a tree. By passing a thread around a potato so that it touches each successive bud you will see that there is the same arrangement of the buds as appears in the leafy stem. There is considerable evidence to show that the tuber form of rhizome originated through association with fungi. Thus in the potato the rhizomes appear to have a vigorous normal growth through the soil until 
they are infested with fungi. This checks their elongation and possibly accounts for the change in their mode of growth, which is now characterized by the enlargement of the infested region and the accumulation of starch. It is well to remember that the organs of many of these plants are exceedingly plastic and controlled to a remarkable degree by conditions. As a single instance of this fact note the leafy stems originating from the "eyes" of the potato are inhibited in their elongation by strong light and dry air. A potato grown on a moist surface in intense light and dry air-develops short cactus like stems; but grown in the dark and in moist air they elongate vigorously after which their nature changes, for if now exposed to light they develop as the ordinary leafy stem. This is one reason for planting tubers several inches in the soil.

A great variety of plants develop only very short stems that are more or less buried in the ground. This type of stem modification has many of the advantages of the rhizome but not its power to spread through the soil and so spread the plant. The vital parts of such plants are only slightly exposed and consequently suffer little from grazing animals or other sources of injury, as in plantains, dandelions, etc. Frequently these short stems are associated with an abundance of foods that are stored in roots or other organs. Such plants can quickly send up and mature their flower stalks or leafy stems and thus avoid unfavorable conditions, as drought, competition with larger vegetation that will appear later, etc. These facts account for the common occurrence of this type of stem in arid regions where there are short rainy seasons. This habit has been made very conspicuous by cultivation in many plants, as the carrot, turnip, radish, and beet. But in nature the very short, almost flat stems and fleshy roots are also of common occurrence, e.g., the wild carrot, wood betony, dandelion, etc. In many cases the short stem itself is the storage organ and consequently it becomes enlarged and fleshy, as in the Jack-in-the-pulpit, garden crocus, spring beauty, etc. (Fig. 73, A). These short erect stems are termed corms and are suggestive of the tuber. In other plants the bases of leaves attached to the short stems function for the 
storage of food, as in the bulb type of 'stems of lilies, onions, etc. (Fig. 73, B).

It.is noteworthy that these special types of stems, the runner, rhizome, bulb, etc., are the most common. They represent the more recently evolved forms of stems and because of their advantages they have become the dominant forms. The geological

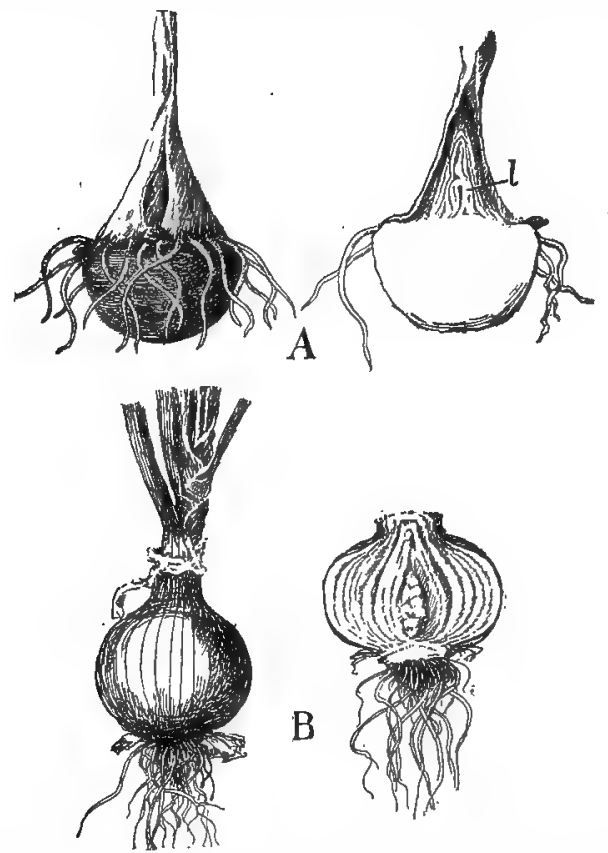

Fig. 73. Shortened types of stems: $A$, corm of jack-in-the-pulpit. At left surface view showing lateral buds, roots and sheathing leaf arising from top of shortened stem. At right sectional view with folded leaf, $l$, in bud at apex of stem. $B$, bulb type of shortened stems. At left bulb of onion showing the ensheathing leaves which are swollen at their bases with food, thus forming the bulb. At right, section of a bulb of hyacinth showing the fleshy leaves attached to the very short stem and in the center of the bulb a flower cluster.

ancestors of our seed plants were woody and tree like. The uniform climatic conditions of these past periods favored the tree type of stem with its admirable devices for leaf display. With the appearance of climatic changes upon the earth there resulted modifications in the stem: the medullary rays tended to 
increase in size and so serve as a storehouse, thus meeting the greater need of reserve material; the cambium also tended to form more and more parenchymatous tissue so that the stem became less woody and more of a storage organ. So you can think of the stem becoming reduced in size and finally prostrate through lack of supporting material. The contact of the stem with the soil exposed it to a variety of new factors which lead to further modifications, some of which have survived as seen in the runner, rhizome, corm as well as in the annual and biennial habit of plants. It is a striking fact that the majority of our primitive plants are woody and tree like (pines, willows and oaks) while the more recently evolved and higher types (daisies, dandelions and golden-rods) are characterized by various forms of these modified stems. 


\section{CHAPTER IV}

\section{THE FLOWER, FRUIT AND SEEDLING}

50. The Structure of the Flower.-We now come to the most interesting feature in the nature and life of the plant. All the energy of the plant is directed towards the perpetuation of its kind. Numerous examples have been noted where this is accomplished by bulbs, rootstocks, buds, etc. Among our common plants, however, new individuals are usually produced from seeds that are formed in the flowers. We will first examine the structure of a flower and see how it is adapted to the performance of this important work. A flower is a highly modified stem of the bud type. This is very noticeable before the flower opens or is in bloom (Fig. 74, A). A series of leaves usually of a greenish color envelop the delicate parts within and protect them, as in the case of the bud, against drying winds. These green leaves are known as the calyx and each individual leaf is called a sepal. As the bud opens a number of organs are disclosed, particularly noticeable are a set of more delicate and variously colored leaves, the corolla, each leaf of which is called a petal (Fig. 74, $B$ ). The corolla is of service to the flower in many ways. Like the calyx it may assist in protecting the other organs. Especially is it of importance in guarding them against dews and rains. For this reason the calyx and corolla, collectively called the floral envelop or perianth, in many flowers often close at night or on rainy days or the perianth may be so developed or inclined as to prevent the rain from falling into it. It will be seen later in the work that the perianth is of the greatest importance in assisting insects to visit the flowers in such a way that seeds may be produced. Within the perianth are two kinds of peculiar organs, the central flask-like ones are called pistils or, if united, carpels and surrounding them are the stamens (Fig. 74, B). These two kinds of organs are collectively known as sporophylls since their special work is to produce certain cells called spores. The 
sporophylls are the important organs of the flower. The calyx and corolla may be lacking but no seed can be formed without the sporophylls.

5I. The Structure of the Sporophylls.-Let us examine the structure of these organs and see how they co-operate in the formation of the seed. The stamens consist of a lobed sack or anther which is usually supported upon a stalk or filament (Fig.

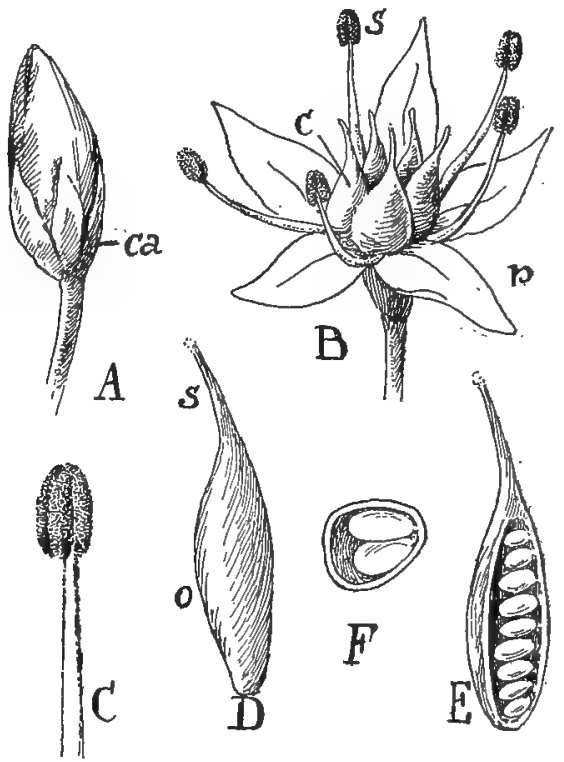

FIG. 74. Flower of the stonecrop, Sedum: $A$, bud stage of flower-ca, calyx showing three sepals. $B$, open flower- $p$, petals of corolla; $s$, stamens; $c$, pistils or carpels. $C$, stamen, consisting of a four-lobed anther supported on delicate stalk or filament. $D$, pistil or carpel-o, ovary; $s$, style which terminates in a small knob or stigma. E, longitudinal section of ovary showing row of ovules attached to wall of ovary. $F$, cross-section of ovary, ovules in two rows.

$74, C)$. If a young anther is cut across four cavities, containing minute or dust-like grains, the microspores, will be seen (Fig. 75, A). The microspores, also called pollen spores or grains, are minute cells, provided with a cell wall often variously sculptured and contain a nucleus and protoplasm like an ordinary cell (Fig. 79). At maturity the anthers break open in a manner 
that varies in different plants, exposing the microspores to the air (Fig. 75, B). The pistil or carpel is quite different in character. At or near the top is a more or less modified part, the stigma, below which is an elongated stalk, the style, that broadens out into a base or ovary. By longitudinal and transverse sections of a pistil we gain a better idea of its real character (Fig. 74, D-F). The ovary is now seen to contain a cavity from the walls of which one or more rather spherical bodies; the ovules, are developed. The structure of the ovule is very complicated. If a thin section 'is made through the center of one of them it will be seen to contain usually but one large spore, therefore called the megaspore (Fig. 76, $\mathrm{mg}$ ). This spore is

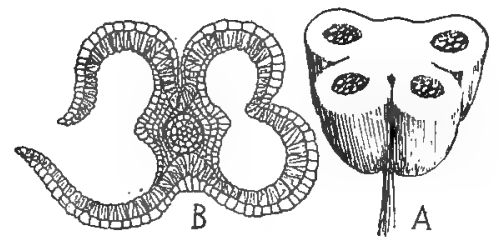

FIG. 75. Structure of the anther: $A$, diagram of the anther cut across, showing the four cavities, sporangia (sing. sporangium), flled with spores. $B$, cross-section of a mature anther. The tissue about the spores has broken down, thus forming two cavities and at the left the breaking open of the wall of the anther is shown.

developed in a mass of tissue, the nucellus, and the whole is surrounded by one or two coats, the integument, which grows. up from the base of the ovule but never quite surrounds it thus leaving a small opening or micropyle (Fig. 76, mi). The megaspore, unlike the microspore, is never set free but is retained permanently in the ovule.

It is not known how the sporophylls have originated but there are indications that they may have arisen through the modification of leaves for the purpose of forming spores instead of constructing foods. It is for this reason that these organs are called sporophylls, or spore-forming leaves, from phylon, a leaf. Those forming small spores are sometimes called microsporophylls instead of stamens and those forming large spores megasporophylls instead of pistils or carpels. Very many modifications of the sporophylls will be noted later in the work. 
52. The Germination of the Microspore and Megaspore.-The question now naturally arises as to the meaning of these peculiar structures. The important part of the sporophyll is the spore. A spore is a cell that is capable of germinating or growing under favorable conditions and thus producing some kind of a new organism, or we may say a new plant. You are always to think of a spore as having this power. In case of the spores under consideration very rudimentary plants are produced that consist of only a few cells. These minute plants are very important,

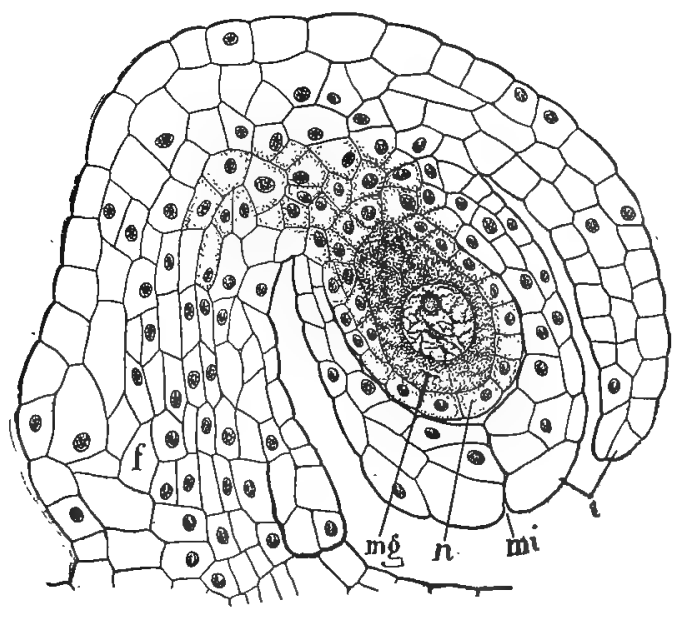

FIG. 76 .

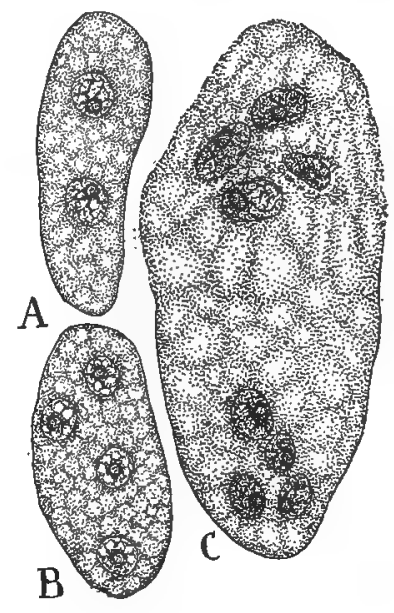

FIG. 77 .

FIG. 76. Section of the ovule of the Canada lily (greatly magnified): $m i$, micropyle; $i$, integuments; $n$, nucellus, here consisting of a single layer of cells, but it often forms a large mass of cells; $m g$, megaspore with large nucleus in center. This spore is about to divide; $f$, stalk or funiculus which attaches the ovule to the wall of the ovary.

FIG. 77. Germination of the megaspore: $A$, first division of the nucleus of the megaspore. $B$, second stage in the germination, four nuclei being formed. $C$, final stage in the division of the nuclei.

however, because they contain the male and female cells, or gametes, so called because they unite, thus forming a new spore, the gametospore, quite different from the micro- and megaspores. So let us not lose sight of the fact that these apparently insignificant micro- and mega-spores germinate and produce minute plants that are quite distinct from the plants that bore 
them. We shall first follow the germination of the megaspore and note the character of the plant that develops from it. As has been stated this spore is never discharged from the ovule within which its entire growth occurs. The first indications of germination are seen in the enlargement of the spore and the division of its nucleus into two nuclei, which are pushed to either end of the spore owing to the accumulation of water in the central region of the spore (Fig. 77, A). The food for the nourishment of the growing megaspore is derived from the cells of the nucellus which are dissolved and absorbed as the megaspore increases in size, and food is also conducted to it from the parent plant by means of the funiculus. Each of the two nuclei at the ends of the spore divides again, thus forming two nuclei at either end. This process is repeated once more so that we now find four nuclei at the ends of the spore which has become somewhat elongated (Fig. 77, B, C). The so-called polar nuclei, a nucleus from each end, now move toward the center of the spore and fuse, forming one nucleus. This completes the germination of the megaspore and we see that it has grown into a sac-like plant consisting of seven cells, or nuclei imbedded in a mass of protoplasm (Fig. 78). The cells of this minute plant differ in character and perform very different duties. For example, the larger cell toward the micropylar end of the plant is the female cell or egg cell. It will be called the female gamete because it unites with another cell, the male gamete. The two small cells near the female gamete are the synergidae or cells that assist in the nourishment and later development of the female gamete. The two cells fusing in the center of the plant form the endosperm nucleus which later by repeated divisions produces a mass of nourishing cells that fill the space within the sac. The three cells at the bottom of the sac, known as the antipodal cells; may increase in number and take part in the later growth, but as a rule they are disorganized and used for food. They are often provided with cell walls, the other cells consisting only of a nucleus and a varying amount of cytoplasm. This plant formed by the germination and growth of the megaspore is called the female gametophyte, because it contains the female gamete, and 
you will see that a corresponding plant appears in the ferns and other groups of plants.

Returning now to the microspore, we find that its germination also often begins while in its sporangium but in other cases growth begins after it has escaped from the sporangium and has

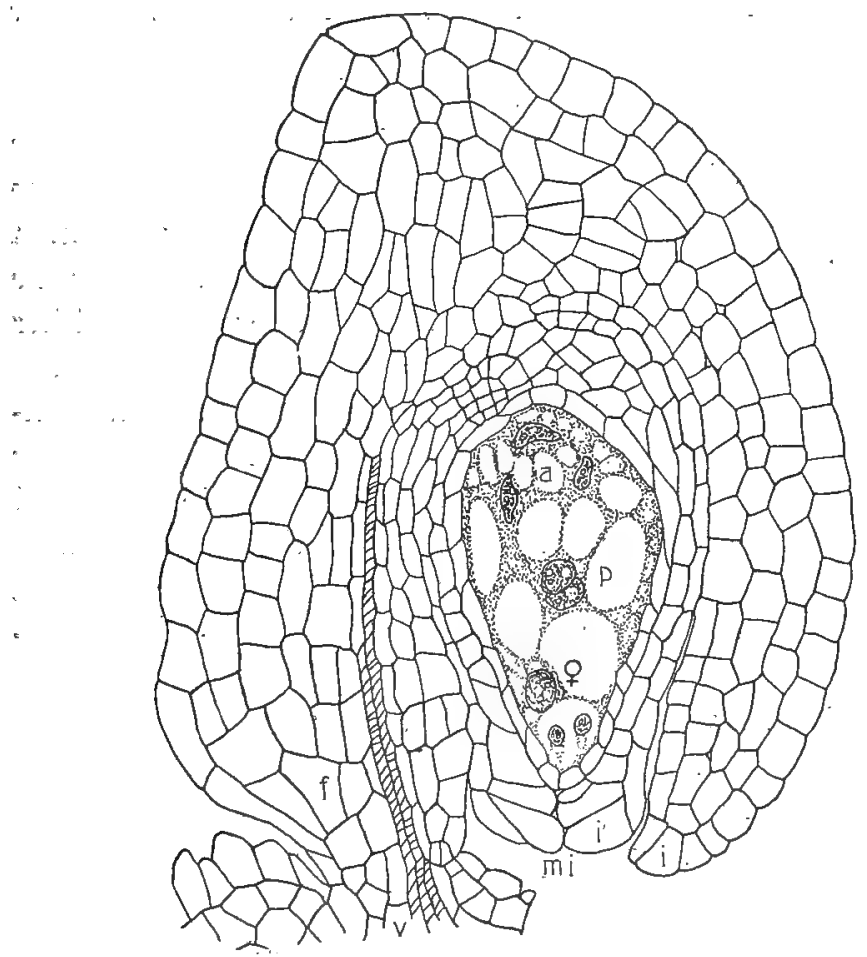

FIG. 78. The germination of the megaspore complete. The plant thus formed consists of a female gamete or egg cell, o , below which are two synergidae and in the center are the two uniting polar nuclei, $p$, while at the opposite end of the sac are three antipodal cells, $a ; m i$, micropyle; $i$, integuments; $f$, stalk or funiculus in which a vascular bundle, $v$, has been developed to transport food from the plant to the ovule.

been carried by the wind or some insect visiting the flower for food, to the stigma of the pistil. The stigma is admirably adapted to hold the microspores, being provided with minute outgrowths, and frequently sugary solutions are exuded which fasten the spores to the stigma. The real importance of these sugary 
solutions is to nourish the microspores. It is evident that these minute dust-like cells can not contain sufficient food to bring about any considerable growth. It is noteworthy that the strength and nature of the sugar solutions varies in different stigmas. and that the microspores are often able to grow only in solutions of such strength or in the presence of such substances as are found on the stigmas of their own kind of plant. So it results that the microspores are often unable to grow when carried to the stigmas of a different kind of plant from themselves. The germination of the microspore results in the division of its nucleus and the formation of a large and a small cell known as the tube and antheridial cell respectively (Fig. 79, $A, B$ ). The latter cell divides once, forming two cells, called the male gametes (Fig. 79, C). This stage in the germination of the microspore is reached either in its sporangium or after being transferred to the stigma. Nourished by the foods of the stigma the microspore continues its growth, the tube cell ruptures the outer wall of the spore and forms a tube-like growth. This tube cell grows down between the cells of the style into the cavity of the ovary where it usually curves out and enters the ovule by way of the micropyle. It now works its way through the tissues of the nucellus to the female gametophyte, into the cavity of which it enters by dissolving the wall. 'In the meantime the two male gametes have been carried down by the streaming movement of the cytoplasm to the end of the tube cell as it enters the female gametophyte (Fig. 79, D). The question will naturally bé asked, what directs the peculiar growth of this minute plant? In the first place the tube cell is repelled by the oxygen of the atmosphere, so as soon as it appears, it is directed away from the atmosphere into the stigma. Its course down the style to the ovary is very largely controlled by lines of loose tissue through which it can easily work its way and also by foods which are depposited in the cells just ahead of the tube cell so that it is led along rather straight pathways to the ovary. The curving out of the tube to the micropyle and its subsequent growth down into the female gametophyte can only be accounted for by some chemical stimulus that is located in the ovule and, 
female gametophyte. A similar attraction brings about a movement of the cytoplasm which carries the male gametes to the end of the tube cell. It will be seen that this peculiar plant (Fig. 79, D) consisting of a long tubular growth with three naked cells is more rudimentary than the plant derived from the megaspore. Because this plant produces the male cells or male

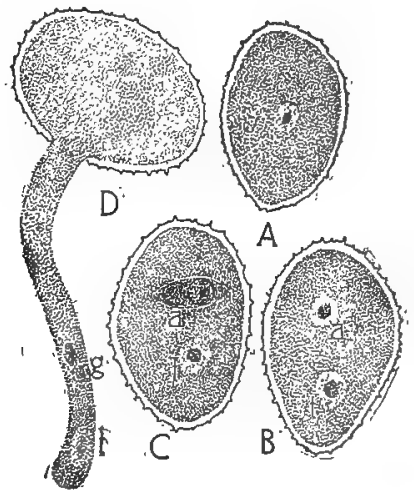

FIG. 79. Germinátion of the microspore: $A$, mature microspore. $B$, first stage in its germination- $t$, tube cell; $a$, antheridial cell. $C$, end of cell division- $t$, tube cell; $a$, antheridial cell forming two male gametes. $D$, diagram showing the formation of the tube which grows through the style and finally reaches the female gametophyte. The two male gametes, $g$, are shown passing down the tube; $t$, tube nucleus.

gametes we call it the male gametophyte. So we see that the flower forms two kinds of spores and that these germinate and form two kinds of plants, a male and a female.

53. Fecundation or Fertilization.-As soon as the development of these two plants is completed a very remarkable change takes place which starts an entirely new growth that is quite independent of the development of the male and female gametophyte. The end of the tube cell becomes distended through the accumulation of material and finally ruptures, discharging the male gametes into the female gametophyte. The chemical composition of the female gamete is such that one of the male cells is attracted to it (Fig. 80) and finally the two gametes unite forming a single cell. This body is a sexually formed spore or gametospore and like the ordinary spore has the power to germi- 
nate and produce a plant. The microspores and megaspores, however, were not formed by the union of sexual cells or gametes. Therefore we may distinguish them as asexual spores or simply spores. It has frequently been observed that the endosperm. nucleus also attracts the other male gamete and causes a similar fusion with it (Fig. 80). The union of the male and female

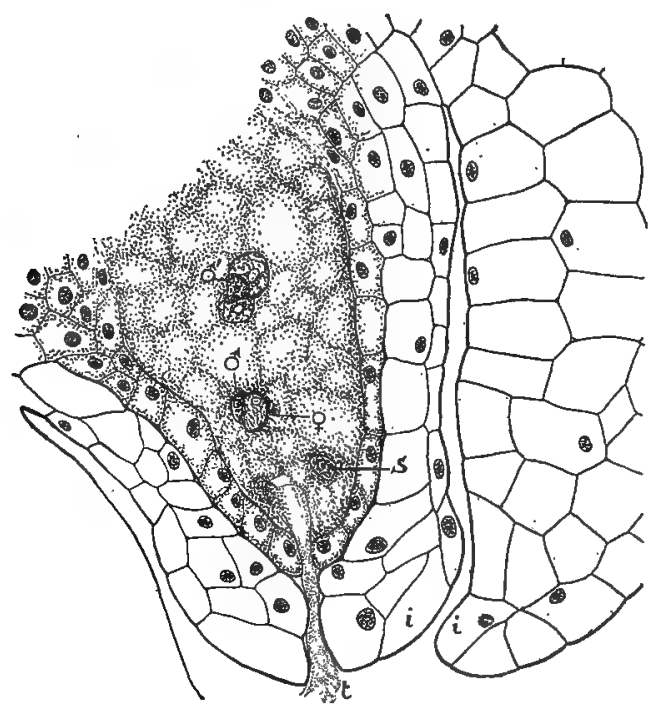

FIG. 80. The micropylar end of an ovule of Canada lily (sectional view), showing the process of fertilization or fecundation. The tube, $t$, has grown into the female gametophyte and ruptured, discharging the two male gametes. One, $\sigma^{7}$, is seen fusing with the female gamete, $o$, and the other one, $\sigma^{7 \prime}$, is uniting with the two polar cells, thus forming the endosperm nucleus; $s$, one of the synergids; $i$, integuments.

gametes is called fertilization or fecundation. Unless fertilization is effected the growth outlined above usually ends the history of the flower. But if fecundation is effected then a gametospore is formed that is capable of germinating and producing a plant whose growth and development are attained with most remarkable changes of the ovule and often of the surrounding parts.

54. The Germination of the Gametospore and the Formation of Seed.-The first indication of the germination and growth of the gametospore is seen directly after fertilization. It becomes 
surrounded by a cell wall and attached to one side of the female gametophyte, which is henceforth called the embryo sac (Fig. $8 \mathrm{I}, A) .:$ By a series of divisions the gametospore now forms a

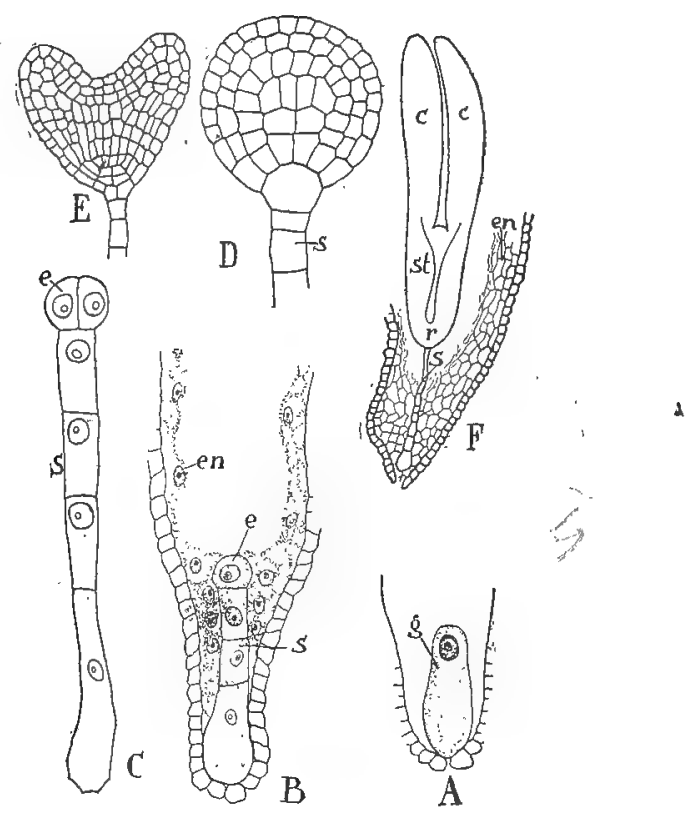

FIG. 8I. Germination of the gametospore of peppergrass, Lepidium: $A$ : micropylar end of the embryo sac showing that the gametospore, $g$ (fertilized female gamete), has developed a cell wall and become attached to the wall of the embryo sac. Compare Fig. $80 . \quad B$, later stage in the germination-e, embryo cell; $s$, suspensory cells; en, endosperm cells. $C$, the embryo cell has formed two cells. $D$, later stage. The embryo cell by further division has formed a spherical mass of cells, here shown in section. Note the appearance of an outer layer of cells, the epidermis, and a central or stem region, $s$, a few of the suspensory cells. $E$, still later growth. Two growing regions, the cottyledons are appearing on the side of the stem. $F$, the micropylar end of the embryo sac, showing the stage of development where the parts of a small plant can be clearly recognized-c, cotyledons; $s t$, stem ending in root, $r$, to which is still attached the supensory cells; en, endosperm cells, now provided with walls, are being absorbed as the plant or embryo enlarges. Note that the embryo and embryo sac are slightly bent to the left. This curvature is due to the fact that the ovule in a great many plants becomes curved in its development with the result that the embryo sac assumes a curved or $\mathrm{U}$-shaped form. This form of the ovule results in a complete bending over of the cotyledons against the stem, as shown in the next figure. 
number of more or less elongated cells, the so-called suspensor, and a terminal cell or embryo cell (Fig. 8I, $B, V$ ). In the meantime the endosperm cell has divided again and again and the resulting naked nuclei have become arranged around the sides of the embryo sac (Fig. 8I, B, en). This formation of endosperm cells continues until they more or less fill the embryo sac and they also become surrounded with cell walls. These endosperm cells are filled with food and serve to nourish the germinating gametospore just as the nucellus nourished the female gametophyte. While the suspensory cells usually soon cease to grow, the embryo cell divides very actively, as shown in Fig. 8I, $C-E$, and soon there is a clear indication of a minute plant'with root, stem and leaves (Fig. 81, F). This minute plant developed by the germination of the gametospore, is called the embryo. In the case of the plant under consideration the embryo, when fully formed consists of a stem with two laterally placed leaves, the cotyledons, and a root. The region of the stem above the attachment of the cotyledons is known as the plumule and frequently assumes the form of a minute bud. The region of the stem below the cotyledons is termed the hypocotyl and the root and root cap appear at its lower end (Fig. 82, $A$ ). The ovule containing the mature embryo is called a seed. The interesting feature about the seed is the fact that it is a structure in which growth has ceased and that it is capable, owing to a remarkable series of devices that will be noted directly, of remaining in this condition, $i$. e., dormant often for one or more years.

Great variation characterizes the germination of the gametospore in the different groups of plants, but the development outlined above is fairly characteristic of those plants that form an embryo with two cotyledons. Such plants are called for this reason dicotyledons. Other plants develop an embryo with but one cotyledon, as our grasses, lilies, etc., and for this reason they are called monocotyledons. Further variations will be seen in cone-bearing trees, ferns, etc.

It must be borne in mind that the formation of the seed is also attended with profound changes in the structure of the 
ovule, and often in the pistil and surrounding parts. Frequently the endosperm grows so extensively as to absorb and replace the cells of the nucellus and thus comes to occupy all the space within the coats of the integument, as in the castor bean, morning glory, onion, etc. (Fig. $85, B$ ). The embryo may remain comparatively
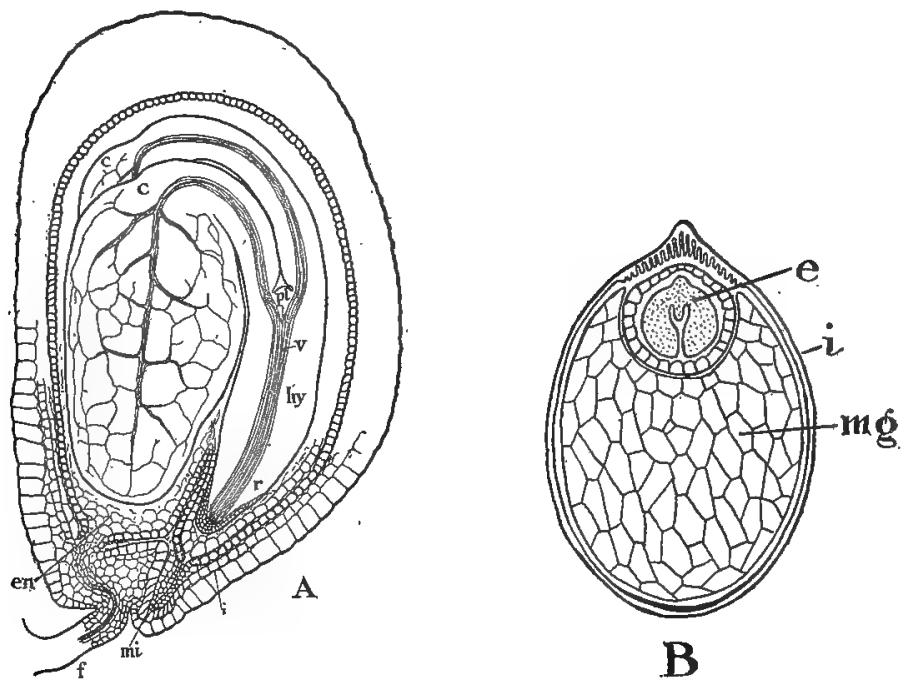

FIG. 82. Structure of the seed: $A$, section of an ovule of peppergrass in which the growth of the embryo is nearly complete $f$, stalk or funiculus attaching ovule to wall of ovary; $m i$, micropyle; $i$, integument; $e n$, remains of endosperm. The embryo consists of a stem which is differentiated into a hypocotyl, hy, that ends below in a root, $r$, and root cap, and above in the plumule, $p l$, and two cotyledons, $c$, which curve over and lie one upon the other. $v$, vascular bundles which extend up through the stem into the cotyledons where they subdivide, forming a network of veins. $B$, section of seed of water lily, after Conard- $e$, embryo surrounded by a layer of endosperm cells; $m g$, cells of the nucellus; $i$, integument.

small as in the cases just cited or it may in turn absorb and replace all the cells of the endosperm and so come to occupy the space within the integument, as in the bean, pea, etc. (Figs. $82, A ; 83, D)$. Various other arrangements may result; as for example, there may be remains of the nucellus and endosperm with the embryo (Fig. 82, $B$ ). The integument also undergoes various changes during these growths, of ten becoming hard or pa. 
pery or provided with hairs, hooks, spines, and smooth or pitted. Compare the bean, catalpa, cotton, milkweed, etc. Attention must also be directed to the growths that occur outside of the seed that are induced by fertilization and the germination of the gametospore. Very frequently the pistil becomes tough and hard and invests the seed like a second integument, as in wheat, corn, acorn, etc.; again it forms a sac about the seed as in the sedges and buttercups; or it may enlarge, forming the pods of peas and beans or the capsules of lilies. In other cases it becomes fleshy throughout as in the tomato and currant, or only the outer walls are fleshy while the inner part forms the pit or stone as in the peach and plum. Frequently wings and hooks grow out from the pistil as in the maple, Ailanthus, etc. Even the end of the stem, the receptacle, which bears the various organs of the flower, may be induced to grow, as in the apple, where it surrounds the pistils (the core) with a fleshy coat, or the receptacle may enlarge, as in the strawberry, forming the fleshy part of the fruit. In other cases outgrowths below the flower develop, forming the burr of the chestnut, clotbur, beechnut, and the cup of the acorn. The entire growth that is associated with the formation of the seed is termed the fruit and we see that it may include a variety of modified organs. The term seed, however, refers only to the modified ovule and its embryo. Later in the work it will be noted that these growths are often devices to bring about a distribution of the seed or to protect it during its dormant period.

55. The Seed and its Growth.- Spores of all kinds germinate and produce new plants. Seeds do not germinate. They simply continue the growth of the embryo or plant which has been temporarily stopped. The falsely called germination of the seed is but the awakening or renewal of the growth of this plant. The seed is essentially a young plant that is supplied with a certain amount of food and that has temporarily stopped growing. The seed may be looked upon as one of the many adaptations found among plants to ensure their distribution and perpetuation. From a seed a single plant is developed that may produce many, often thousands of seeds, i. e., plantlets. We have already noted 
that these may be widely distributed and so spread and multiply the number of plants. Some seeds are so fine that they float away as a dust, as in the orchids. Other seeds and fruits are provided with hairs and wings that serve to buoy them up or promote their transport by winds, as in the case of pine seeds, milkweed, willow, and the fruits of maple, dandelion; etc. In other cases spines and hooks or mucilage glands are developed that attach them to any passing animal and so bring about a considerable distribution. Note the common devices of this nature, as in the burdock, stick tight, beggar lice, agrimony or the glands on the nightshade (Circaea) and twin flower. So also seeds are scattered by the spring of elastic stems and explosive fruits, as in many lilies, witch hazel, violet, touch-me-not, etc. But especially may seeds be looked upon as an adaptation to tide the plant over seasons unfavorable for growth. In this respect they may be compared to buds, which they also resemble in their renewal of growth when conditions are again favorable. There are some noteworthy exceptions to this statement, as in the mangrove, certain oaks, and many grasses. The seeds of the former plant begin their growth while still attached to the tree and a similar growth has also been observed in the acorns of the white oak. Grain often sprouts while in the sheaves and the seeds from green tomatoes produce earlier and larger fruits. However, the majority of seeds and fruits, as well as buds, do not renew their growth immediately after their formation. 'A longer or shorter resting or dormant-period is required during which time chemical changes occur that render the foods soluble and therefore available to the young plant or embryo. For example, in many seeds and buds the storage foods are in the form of starch. This food is insoluble and can not be used by the plant until it has been acted upon by an enzyme which changes it into a soluble and readily diffusible sugar. These enzymes are slowly formed during the resting period and a renewal of growth is not possible until they have begun the transformation of the insoluble foods into soluble forms. The changes thus effected are so considerable that growing tubers, rootstocks and seeds often have a sweet taste owing to the considerable amount of 
sugar present. So the seed may be looked upon as a variation in the growth of the plant that enables it to multiply and distribute its kind and to meet the various problems in connection with its existence, such as drought and sometimes even fires.

56. Conditions Necessary for Growth.-The external conditions necessary for starting the growth of the embryo are a suitable temperature, moisture, and the oxygen of the atmosphere. Light only in rare instances appears to be a contributing factor in the renewal of growth. Some seeds will sprout at near the freezing point, while others require a temperature between $10^{\circ}$ and $17^{\circ} \mathrm{C}$. It is interesting to note that the rising temperature together with other factors as the season advances from early spring bring out a regular succession in the awakening of various kinds of seeds. A suitable amount of moisture must also be supplied to the seed to assist in the solution and diffusion of the foods to the embryo. This is very necessary since the seed contains very little water. In fact the seed owes its vitality and power to resist long drought and severe cold to its dry condition. Seeds soaked in water cannot endure such extremes as in a dry state. Excess of water, however, is unfavorable to the renewal of growth, because it excludes the oxygen of the air. This is the cause of the failure to grow and of the decay of the seeds planted in the spring when the season is rainy. The air spaces in the soil become filled with water and as a consequence oxygen can not gain access to the seed and co-operate in those chemical changes that not only supply some of the foods to the embryo but also provide it with the energy for growth. An examination of a few seeds will show some of the more important structural features that adapt them to the conditions that they have to meet.

In the case of the bean the integument is tough and would appear to offer a rather effectual barrier to the entrance of water and air. You have noted that a minute opening, the micropyle, exists in the integument. This opening is seen near the scar or hilum that marks the point where the seed was attached by a minute stem to the walls of the ovary (Fig. 83, B). This opening permits the entrance of the air and water as does the 
looser structure of the hilum. This can easily be demonstrated by placing beans in water, when the spread of the water from the region of the micropyle will be indicated by the swelling and wrinkling of the integument (Fig. 83,C). After a time the entire integument becomes quite soft and water is readily drawn through it owing to the fact that the storage foods in the embryo are in close contact with it and draw the water through by osmosis. Carefully removing the integument from a soaked bean
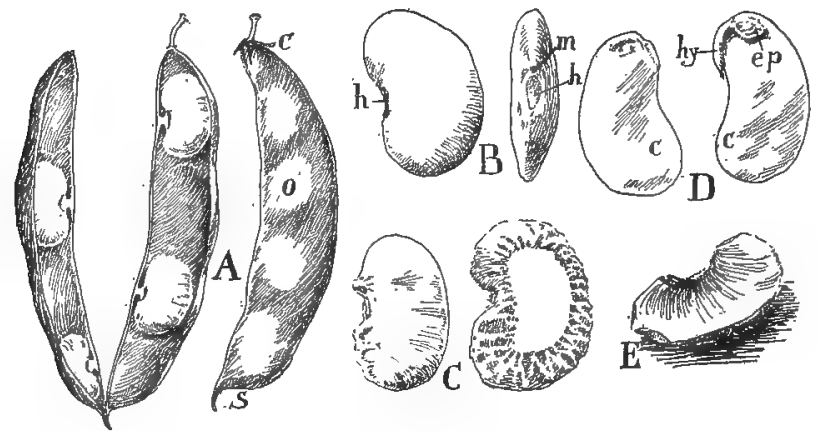

FIG. 83. Fruit and seed of the bean: $A$, mature fruit or pod: $s$, style; $c$, remains of calyx; 0 , ovary. At left the pod has been opened, showing four seeds attached to the walls of the ovary by funiculus. $B$, two views of a seed- $h$, hilum or scar marking attachment of funiculus to seed; $m$, micropyle. $C$, wrinkling of seed coat caused by the entrance of water through the micropyle and hilum. $D$, embryo of seed after removal of integument- $c$, cotyledons. At right one of the cotyledons has been removed to show the plumule, $e p$, and the hypocotyl, hy. $E$, half of the membranous integument.

we note that the embryo is well developed, consisting of two fleshy cotyledons and a short stem (Fig. 83, D,E). The plumule is well developed, bearing two leaves, and the short hypocotyl and root are enclosed in a sheath formed from the integument. Note that the hypocotyl and root are situated near the micropyle. How does this arrangement work to the advantage of the embryo? Allow the seed to germinate and it will be noted that the absorption of water first causes the embryo to expand and rupture the integument. This is immediately followed by the growth and elongation of the lower part of the hypocotyl which results in the pushing out of the root (Fig. 84, A). Thus it happens that the very part of the embryo that shows the first signs of growth is in 
close proximity to the water as it enters the seed and doubtless the sheath also assists in retaining water in this region. We are already familiar with the properties of the root which direct its growth in such a way that no matter how the seed may be placed the root will ultimately grow into the soil and toward water and the soil foods, page 6r. It is noteworthy that many seeds are so fashioned that they naturally assume such a position on the ground as to bring the root as it emerges into direct contact with the soil. Such an arrangement is equally advantageous for the absorption of water. How many seeds can you find that will naturally lie upon the soil in such a way as to cause the root on

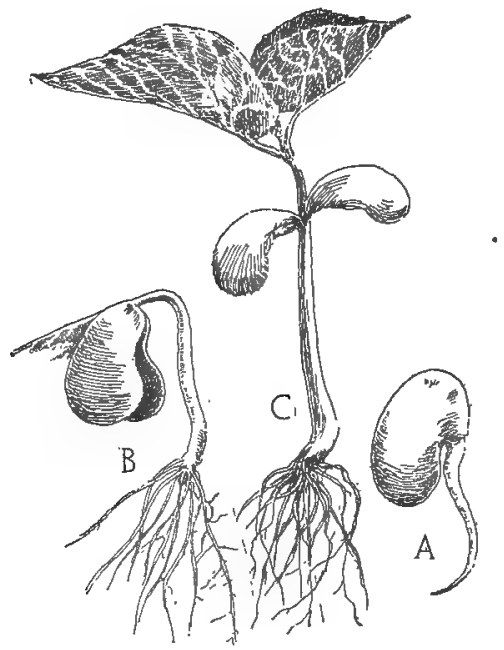

FIG. 84. Renewal of growth of the bean seed: $A$, basal region of fypocotyl elongating and pushing the root into the soil. $B$, upper region of the hypocotyl elongating, lifting the cotyledons and epicotyl above the soil. $C$, hypocotyl erect and epicotyl expanding, forming the first normal leaves.

emerging to be directed away from the earth? Thus at the very start the growth of the seed is of such a character that the young: plant is anchored to the soil by the root and brought into proper relation with the water and other materials necessary for the construction of foods. As soon as this work is well under way the upper end of the hypocotyl begins to elongate, pushing up into the air cotyledons and plumule (Fig. 84, B). Here we 
see that the upper end of the hypocotyl reacts to gravity like a stem and consequently grows away from the earth. This growth is attended with a curving and constant nutation of the hypocotyl which enables it to work its way through the ground to better advantage than would be the case if it were pushed passively up. Darwin compares this work of the seedling in emerging from the soil to the struggles of a man who is prostrate and attempting to arise with a heavy load on his back. The ability of the hypocotyl to overcome obstacles in its way and crowd through small openings is due to the power generated in the enlarging cells. In this way a force is often created that may exceed 80 pounds to the square inch, over five times the atmospheric pressure. In many seeds only the region above the cotyledons elongates, leaving the cotyledons in the ground, as in the pea, acorns, walnuts, etc. The elongating region is called the epicotyl. This behavior is doubtless associated with the storage of food. In some seeds the cotyledons serve only as storage organs and in such cases the position of advantage is in the soil where they are better protected and in contact with moisture which will assist in the solution and diffusion of the foods. In many cases the cotyledons perform a dual function, first as storage organs and later expanding and developing into the first green leaves of the plant, as in the squash and many of our common plants. In any of these cases it is evident that the young plant requires a certain amount of food to enable it to get established in the soil. It is not until considerable growth has taken place that it develops its first green leaves and so begins to be self supporting. In the case of the bean and in many other seeds and fruits this need is amply met by the abundance of food that is stored in the fleshy cotyledons (Fig. 84, C). These organs remain attached to the plant even after it is well established, and it is only after the food has been withdrawn that the shriveled cotyledons drop off. As the young plant becomes established the plumule unfolds like a bud and develops the stem and leaves and finally the flowers and fruit with which you are familiar.

The castor bean shows quite a variation from the structure of the bean. The hilum and micropyle are more or less con- 
cealed by a fleshy outgrowth, the caruncle (Fig. 85, $A$ ). Removing the hard integument we find within a white, oily mass of cells which are attached to the horn-like coat only at the hilum. Cutting across this mass of cells it will be seen that two thin leaves are imbedded in the center. Taking two other seeds and cutting them longitudinally, one at right angles and the other parallel to the leaves we see that the embryo consists of a very small stem and root and two delicate leaves imbedded in an oily tissue, the endosperm (Fig. 85, B). In the bean the seed consisted of

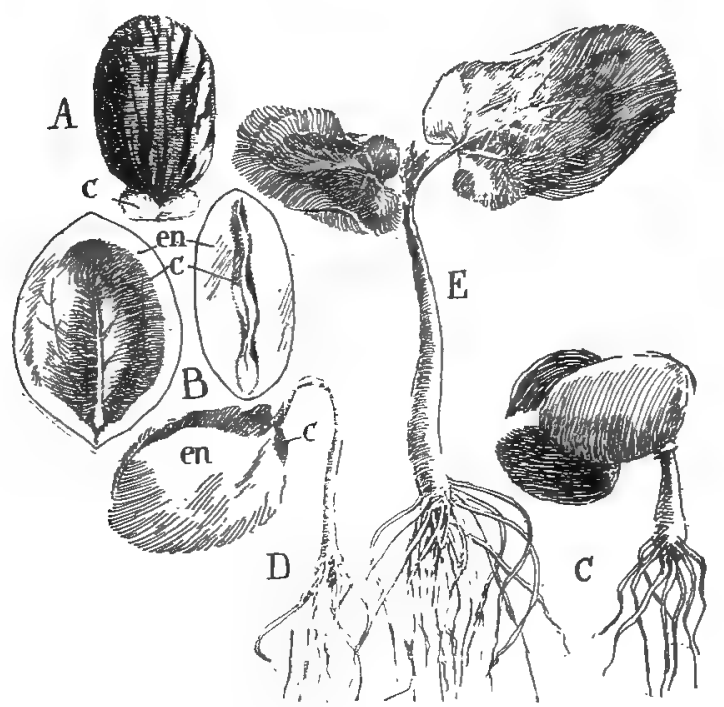

FIG. 85. Seed and seedling of the castor bean: $A$, the seed with fleshy outgrowth, the caruncle, $c$, at base. $B$, section of seed. At right showing the two cotyledons, $c$, and short hypocotyl in center of the endosperm, en. At left the seed is split parallel to the surface of the delicate white cotyledon. $C$, early stage in the growth of the seedling. The hard integument is being thrown off but the cotyledons are still entirely buried in the endosperm. $D$, later stage. The cotyledons, $c$, still absorbing food from the endosperm, en, are beginning to appear and to develop chlorophyll. $E$, the cotyledons and plumule are expanding, the endosperm being entirely absorbed.

an embryo and integument. In the castor bean, the endosperm forms the bulk of the seed, since it has been only partially consumed by the embryo. It would naturally be inferred that the hard coat would prevent the access of water and gases. Observe, 
however, that the caruncle readily absorbs water and that the embryo and endosperm are in direct contact with this region of the seed. Many devices will be observed among seeds serving to convey water to the growing parts. Note the mucilaginous coats on flax, quince, many mustard seeds, etc., or the spongy rinds of the fruits of the walnut, cocoanut, etc. It is well worth your time to submerge in water colored a deep red with eosin widely different seeds and examine them from time to time, noting the period required for the penetration of water and the lines along which the water enters and is distributed. It will be found that many seeds and fruits exclude water and oxygen very effectively for one or more years with the result that the renewal of growth is delayed until the decay of the parts permits their entrance. The breaking of the integument would appear as a serious obstacle to the growth of the embryo. However, the power gerierated by the cells owing to their expansion through the absorption of water is quite sufficient to rupture the seed coat. The early growth of the embryo of the castor bean is similar to that of the bean. The elongation of the lower end of the hypocotyl pushes the root into the soil, while the upper end of the hypocotyl, arching and twisting as it elongates, works the cotyledons and endosperm through the soil into the air (Fig. 85, C). In this seed the food is without the cotyledons. Consequently, although the cotyledons gradually enlarge and become green, they remain in contact with the endosperm until all its food is absorbed and but a papery skin remains (Fig. 85, D).

A grain of corn will illustrate another modification of the seed. In this case the pistil remains in such close contact with the seed that it appears to form an additional integument. Such a fruit is called a grain and may be compared to a bean pod with a single seed. We can still see upon the grain (Fig. 86, A) at $s$ the position of the style while at $p$ appears the remains of the stem that fastened the sporophyll to the cob. The long threads, often called the silk, that project from the ears of corn are greatly enlongated stigmas for catching the microspores. While the outer parts of the grain of corn are very hard, if it 
is treated with the eosin solution referred to above it will be seen that at first the water enters by way of the little stalk just as did the food that was supplied to the growing grain. In this way water is supplied directly to the root of the embryo which lies near the stalk as shown in Fig. 86, $B$. If two seeds are soaked until soft and then sectioned so as to cut one across and the other longitudinally through the embryo it will be seen

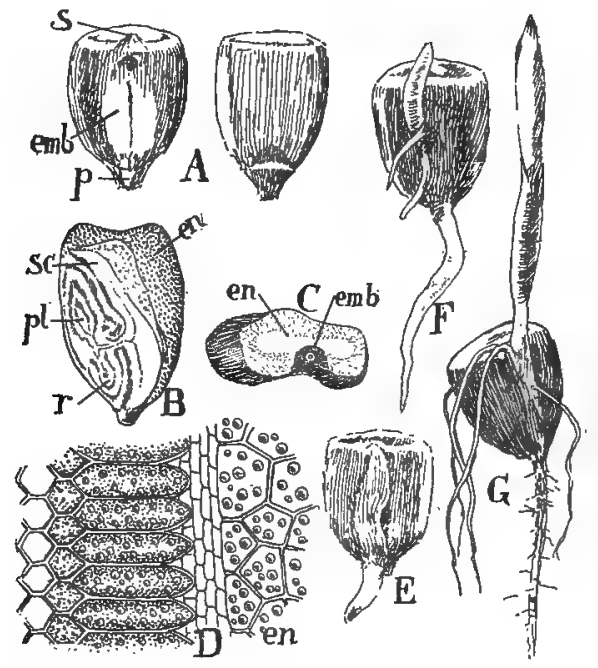

FIG. 86. Grain and seedling of corn: $A$, two views of a grain-s, point of attachment of style; $p$, stalk attaching the grain to cob; $e m b$, location of embryo. $B$, longitudinal section of a grain. The embryo consists of a plumule, $p l$, root, 7 , and scutellum, $s c$. en, endosperm. $C$, cross-section of a grain showing endosperm, en, surrounding the embryo, emb. $D$, diagram of the outer cells of the scutellum, showing the elongated cells that bring about a solution and absorption of the foods stored in the endosperm. $E-G$, stages in the growth of the seedling.

that the endosperm forms the larger part of the grain and that the embryo is relatively small, consisting of a stem and root, a plumule of several closely wound leaves, and a shield-like organ, the scutellum (Fig. 86, B, C). The entire embryo may easily be removed from the endosperm with a knife if the seed is thoroughly soaked. Unlike the two preceding examples the corn is a monocotyledon and many regard the scutellum as a modified cotyledon. This organ forms the enzymes which put into soluble 
form the food in the endosperm and it also functions as an absorbing organ of the embryo (Fig. 86, D). Similar devices for absorbing the storage foods and transferring them to the embryo are seen in the wheat, onion, date, and cocoanut. The early growth of the embryo goes on as in the preceding examples. The root first emerges and anchors the grain in the soil. The plumule of closely rolled leaves forms a sharp bodkin that reaches up through the soil with ease. This modification of the plumule would appear to be of a decided advantage and you will notice that this method of emerging from the soil is followed by a great many plants with underground stems; see the large leaves of the skunk cabbage, may apple, Solomon's seal, etc. The rest of the grain remains in the ground as in the case of the pea.

57. The Two Phases in the Life of a Plant.-As has been stated the plumule unfolds in all these cases like a bud and gradually develops into the mature plant. This may be effected in one year or several years may be required to complete the work. At some time in this growth flowers will appear bearing sporophylls and spores and thus we arrive again at the starting point in the life history of a plant. There are two distinct phases or generations in the life of a plant. The formation of the megaspores and microspores marks the beginning of the sexual generation or gametophyte which ends when the male and female gametes have been developed. The formation of the gametospore marks the beginning of the asexual generation or sporophyte which ends in the sporophylls when those cells, called the spore mother cells, appear which produce the micro- and megaspores. These two generations are also sharply distinguished from each other by the number of chromosomes, page 56 , which their cells contain. The cells of the gametophyte generation contain only one-half the number of chromosomes found in the cells of the sporophyte generation. If the nuclei of male and female gametes contain twelve chromosomes (the number varies in different plants) the gametospore which marks the beginning of the asexual generation, will contain twenty-four chromosomes. This number will be found in all the cells of the embryo and continue to characterize the subsequent development of the sporo- 
phyte. When, however, the spore mother cells appear in the anthers and ovules it is to be noted that these cells in dividing to form the micro- and mega-spores reduce the number of chromosomes by one-half so that the nuclei of these spores and of all cells derived from them contain but twelve chromosomes. For this reason the division of the spore mother cell is referred to as the reducing division. The significance of this difference in the number of chromosomes is not known but it furnishes a basis for the sharp separation of the two generations.

A sexual and an asexual phase or generation characterize the life history of nearly all the higher plants and the succession of these two phases is called the alternation of generation. In the case of the bean we have as the most important features of the sporophyte or asexual generation, (I) the gametospore, (2) the seed, and (3) the flowering bean plant. The microscopic plants that comprise the gametophyte or sexual generation are characterized by (I) the micro- and mega-spores which develop respectively into (2) a tubular growth of three cells and (3) a sac-like growth of seven cells, each of which contains one or more (4) sexual cells or gametes. These two phases are called respectively the sporophyte or asexual generation, and the gametophyte or sexual generation, since in the first phase mother cells are developed which form spores, $i$. e., this is the spore forming or asexual generation and in the second phase gametes or sexual cells are produced.

58. Significance of Fertilization. - Let us now stop to conside the meaning of the complicated process that we have termed fertilization. No satisfying explanation has been offered. Some see in these changes only a process of nutrition and chemical stimulation. The gametes are lacking in certain materials that are essential to their further growth. According to this view the male gamete is the complement of the female and by the union of the two all the substances are supplied that are necessary for growth.

It has also been suggested that the growth culminating in fertilization is attended with the removal of impurities from the sexual cells. Every cell has its growth, maturity, and senescence 
when it loses its power for further growth and division. The reduction division and the subsequent formation of the gametes results in the removal of substances that prevent their continued activity and as a consequence they are restored to a youthful condition which appears in the growth of the gametospore.

Much attention has been directed in recent years to the process of fertilization as a method of controlling the character of offspring. You have already noted, page 56 , that granular bodies or chromosomes are constant features of every nucleus. These complex bodies determine the type of plant that shall be developed. In other words the chromosomes contain the hereditary substances, termed factors, that cause each plant to develop in a certain definite way or to follow a certain pattern in its growth. The chromosomes derived from the parent plants cause the offspring to resemble them in growth. The micro- and mega-spores are formed in the sporophylls, and these spores must therefore contain the same kind of chromosomes or factors as the plants bearing the sporophylls, $i$. e., the parent plant, since they have been derived directly from the parent plant by cell division. Therefore gametes derived from the germinating spores must also contain the same factors as the parent plants. In fertilization we have the fusion of the gametes. This means that the hereditary substances in the gametospore will be of a dual character since it has been derived from the male and female gametes (Fig. 80). Consequently there is now lodged in one body, the gametospore, all the possibilities of growth that each gamete inherited from the parent plant.

Let us now examine some of the evidence indicating that the hereditary substances or factors are distributed in a very definite way from parent to offspring and that these factors are associated with the chromosomes. In the common garden plant, fouro'clock, we find some plants bearing only white flowers, others only red flowers. Here we have evidence of two factors; the one causing the white color, the other causing the red color. If these two plants be crossed the resulting offspring is pink or intermediate between the two parents. This offspring is a hybrid, meaning thereby an individual derived from parents that differ 
from one another in one or more factors. If now one of the hybrid four-o'clocks is crossed with the pure white, one half of the resulting offspring will be pure white and one half pink like the original hybrid. The reason for this variation in the offspring will be apparent by studying the diagram, Fig. $86 \mathrm{~A}$. Here we see that each parent ( $R R$ and $W W$ ) produced gametes having the same color factor as itself and when two gametes

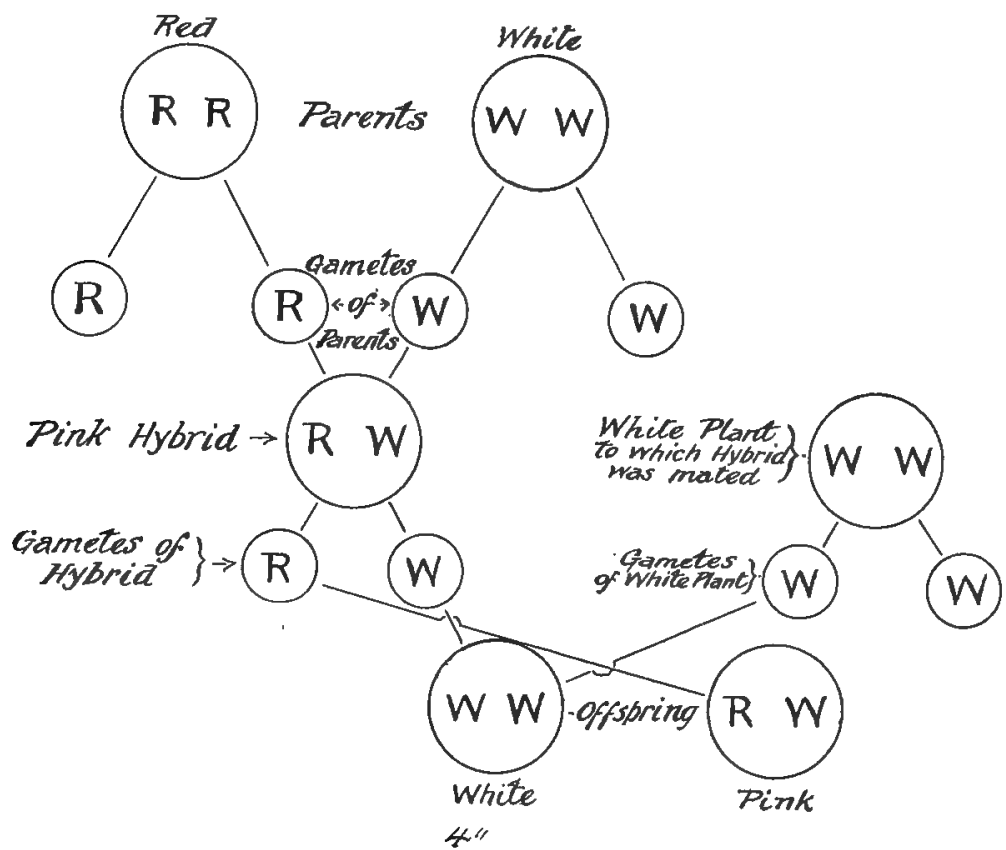

FIG. 86A. Diagram showing distribution of the factors for red $(R)$ and for white $(W)$ in the cross of the red and white four-o'clock; and the subsequent cross of the pink hybrid with the white form.

derived from these parents unite the resulting hybrid $(R W)$ must contain the color factors of both parents. Note, however, that the hybrid produces gametes like those of the parents, $i . e_{\text {., }}$ gametes with the red factor or with the white factor. This is due to the fact that in the formation of the gametes there is a separating out of the factors so that the gametes are never. hybrid. They only contain the factors of one or the other of the original parents. The lower part of the diagram shows how 
the results of crossing the pink hybrid ( $R W$ ) with the pure white (WW) come about. The white form can only produce gametes with the white factor but we have seen that the hybrid produces gametes, one half of which contain the white factor and one half the red factor. Therefore in the cross between the pink hybrid and the pure white there are only two possible combinations of gametes. A gamete from the hybrid bearing the white factor may fuse with a gamete from the white four o'clock, giving a pure white offspring or a gamete from the hybrid bearing the red factor may fuse with a gamete from the white four o'clock, giving a pink hybrid.

It is now known that the hereditary substances or factors are associated with the chromosomes and that they are separated in a very definite way during the cell divisions that result in the formation of the gametes. These chromosomes are associated in pairs and in the division of the cell one member of a pair goes to one daughter cell and the other member of this pair goes to the other daughter cell. If now the factor for red is in one member of a pair of chromosomes and the factor for white is in the other member of this pair, it must follow in the above cell division that one daughter cell will contain the red factor and the other daughter cell will contain the white factor. Therefore the gametes derived from these two daughter cells must contain respectively the red factor and the white factor. This distribution of the factors will be more manifest by examining the accompanying diagram, Fig. $86 \mathrm{~B}$. In figure $\mathrm{I}$ is shown a nucleus with three pairs of chromosomes, one pair very small, another somewhat larger and a third pair in which the factors for red and white are indicated by the letters $R$ and $W$. Of course it is not to be supposed that any factor is visible to the eye. In the second figure the two members of each pair of chromosomes is seen drawing together preparatory to cell division. In the third figure cell division is under way and the chromosomes still in pairs have been drawn to the center of the spindle, and in the fourth figure we see a member of each pair being pulled to the opposite pole of the spindle, where they will be organized into two daughter nuclei. The later appearance of these two daughter 
nuclei is shown at the right and left of figure four. In this way the red factor comes to be lodged in one of the daughter cells and the white factor in the other daughter cell. This separation. of the factors that appear in the two members of a pair of chromosomes is termed the segregation of the factors. It is one of the most important features in the cell divisions that result in the
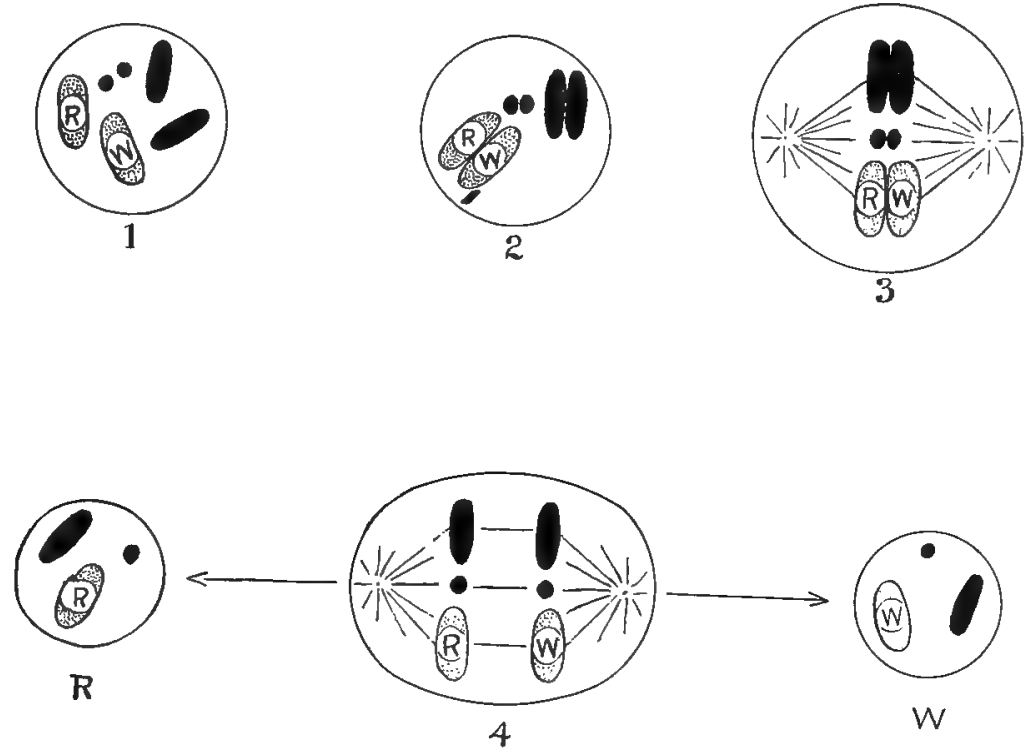

FIG. $86 B$. Diagram of a nucleus showing mode of division in gamete formation. See text.

formation of the gametes. The members of a pair of chromosomes are termed homologous chromosomes and the contrasting factors which they bear, in this case red and white, are named allelomorphs. We see that it is the behavior of the homologous chromosomes and their allelomorphic factors that determine the nature of the gametes.

The fundamental features to note in the above discussion is first that the factors remain distinct and show no indication of fusing with one another. The red and white factors appear unchanged in the gametes no matter how many crossings have been effected. The second feature is that these factors, though associated in pairs in the homologous chromosomes, undergo at a 
certain stage of cell division a separation or segregation. These two principles of non-mixing and of segregation of factors were discovered by Mendel and they are among the most important and fundamental facts in biological science. As a single illustration of this note that the success in breeding is solely based upon Mendel's principles of heredity. Desirable characters of one individual may by crossing be associated with the desirable characters of another individual and in the same way undesirable traits may be eliminated. These new combinations of characters may be effected in some cases with such certainty that horticulturists have advertised new forms, describing their characters and qualities before they have been bred. Late fruiting grains have been made to mature earlier, species susceptible to cold have become hardy, as in the case of wheat, which may now be cultivated in Canada many miles north of its former range, and non-resistant forms have become immune to disease. The annual loss from a single plant disease, one of the rusts, is estimated at 500 million dollars. In the same way the percentage composition of the reserve food in grains has been changed and the resulting yield greatly increased.

Another important feature in the tranismission of the hereditary factors is illustrated in the crossing of a blue-flowered tall sweet pea with a red-flowered dwarf sweet pea. In this case we have two pairs of allelomorphic factors instead of one as in the fouro'clock. One member of a pair of chromosomes contains the factor for blue and the other homologous member of this pair contains the factor for red. In another pair of chromosomes there is lodged in the same way the factors for tallness and dwarfness. When these two plants are crossed we find that the factors segregate as in the first example but the hybrids resulting from the cross are never intermediate between the two parents. It will be noticed in a hybrid from this cross containing the factors for tallness and dwarfness that the plant is always tall like the tall parent; so in a hybrid where blue and red are associated the flower is always blue. It would look as though the factors for dwarfness and redness in these cases had been obliterated. Such, however, is not the case. They have been inhibited in 
their action in some way by the opposite allelomorphic factor and reappear in the offspring when hybrid tall blue sweet peas are crossed among themselves. In cases of this nature where certain factors are suppressed and others are active, the inactive factors are termed recessive and the active ones are termed dominant. Tallness and blue are dominant factors, dwarfness and red are recessive factors.

In the above examples we see that the hereditary factors are segregated and distributed to the gametes in a very definite way. There is one important exception to this rule. A large number of instances is known where one factor is usually or always associated with another factor. That is, these two factors are not separated from one another in the formation of the gamete and consequently both are transmitted to the gamete. Factors that behave in this way are said to be linked and linkage is to be contrasted with the segregation mentioned above. One of the most striking illustrations of linkage is seen in color blindness. The factor for this characteristic is always linked with the factor for sex. Therefore this factor is distributed differently to the two sexes. The offspring of a color-blind male and a normal female would not show this characteristic at all because the sons are absolutely normal and the daughters, though having the factor for color blindness, do not show it, since this factor is recessive to the normal sight factor. The daughters, therefore, can alone transmit this factor, and one half of their sons by a normal male will be color blind.

In the above examples very simple cases have been taken in order to bring out more clearly the principles involved. We have spoken of only one factor being lodged in a chromosome. It is now known that many factors may be associated with each chromosome and the evidence at present makes very probable the belief that these factors are arranged in a line in the chromosome and are separated from each other by definite distances. The factors have also been spoken of as though they were the sole cause of the characters. The factor for redness is merely the deciding cause of this color. A great many factors are really necessary to cause the production of a given character, 
some being absolutely necessary, others having only slight effect upon it. The character is merely the end product of a series of reactions. Therefore you are not to think of these characters as definite chemical substances that are all lodged in the individual at the start of its life and that maintain their identity unchanged throughout its development. At the start of an organism a definite number of factors are involved-just enough to give direction to its growth and to cause it to follow a pattern of development that is peculiar to its kind. As growth goes on owing to the interaction of these factors and also owing to the action of the environment characters are constantly created and here and there in the organism characters appear that give us ocular evidence of the presence of the factors which are the deciding cause of a color, of a form, of a size, etc.

It will be seen from the above discussion that no cross can result in a new creation. All the work in breeding shows that the crosses result merely in new combinations of the old factors that already existed in the parent stock. How then does variation come about and new characters arise? de Vries has shown that one or more new characters may suddenly appear in the offspring through the influence of unknown causes. These sudden changes are termed mutations. It appears reasonable that the gradual accumulations of these mutations going on over a long period of time may have been the principal cause of the enormous number of variations that are seen in plant and animal life.

What then is the purpose of fertilization? We see that it is a process for effecting crossing and so bringing about a new combination of the characters and the variations that appear in the parent plants. Some of these new combinations will be of no value, others will give their possessors an advantage because they adapt them to the conditions under which they live. These latter forms will therefore tend to survive and to crowd out the less favored. This is natural selection, the environment bringing about the survival of the fit. As long as the environment remains constant and natural selection has picked out forms 
that are adapted to it, there is no need of further crossing. Indeed we see many plants that flourish without crossing. Owing to the changes, however, that have occurred on the earth since plants first appeared there has been a necessity for fertilization in order that new combinations might arise and adapt the offspring to the new conditions. 


\section{PART II \\ DEVELOPMENT OF PLANTS}

\section{CHAPTER V}

\section{CLASSIFICATION OF PLANTS}

59. The Method of Classifying Plants. - We have now arrived at an understanding of the nature of the plant and the work which it performs. In this study the most complex forms have been largely considered. There are, however, a great variety of very simple forms ranging from single-celled plants that often form the green coatings on trees up to the complex types. How have these different forms come about and what relation do they sustain to one another? We will also be interested to compare the life histories of these different forms and their modes of life. In approaching this subject it is first necessary to gain a knowledge of the system employed in grouping or classifying plants. Obviously many plants are closely related as the red, white, scarlet oaks. Such a group of closely related plants is called a genus (plural, genera) and the different kinds of individuals which compose the group are known as species. The red oak is one of the species of the oak genus. In scientific work the Latin or Greek names are used to designate the genera and species. In the case of the oak the genus is known as Quercus, an old Latin name for oak, and the red oak species as rubra, meaning red. Both the name of the species and the genus are employed in naming a plant and consequently the scientific name of the red oak is Quercus rubra. You will frequently see a letter or one or more abbreviations after the scientific name, indicating the person or persons who are responsible for giving the name now in use. Thus Quercus rubra L. indicates that this name was 
given by Linnaeus. So in other cases we can say white oak or Quercus alba, scarlet oak or Quercus coccinea, etc. The oak has several characters in common with the chestnut and beechnut genera, as for instance the fruit in each case is associated with outgrowths that appear as the burr in the chestnut and beech and as a cup in the oak. On account of these and other common characteristics these genera are supposed to be related and are therefore grouped together in one family. A family is composed of allied or related genera. The name of the family is derived from some characteristic genus in the group. In this case it happens to be the beech or Fagus. To distinguish a family from a genus the termination aceae is added to the base of the generic word, in this example making the family name Fagaceae. So we have the three allied genera, oak, beech, and chestnut forming the beech family or Fagaceae. In the same way it will be found that families are related and joined together into a still larger group known as the order. The flowers of the birch, alder, water beech, and hazel genera are very similar and consequently form a family known as the birch family or Betulaceae, Betula being the name of the birch genus. It will also be noticed that there is a similarity between the flowers of the Betulaceae and Fagaceae. This relationship is expressed by placing them in the same order known as the beech or Fagales, the termination ales being employed to distinguish the order just as aceae characterized the family. So also orders are related and grouped into classes. For example, the Fagales and many other orders are characterized by having seeds with two cotyledons. Several other orders have seeds with but one cotyledon. This relationship is expressed by grouping the orders into two classes, Dicotyledones and Monocotyledones. In both of these classes the seeds are inclosed within the pistil, but in the conebearing trees the seeds are exposed on a flat scale-like organ. All seeds producing plants belong to one or the other of these two groups. So we have two subdivisions, the Angiospermae, meaning seeds inclosed, and the Gymnospermae, meaning naked seeds. If now we stop to consider still larger groups than subdivisions, it will be noted that many plants do not produce seeds, as in the 
case of the ferns and mosses, etc. So a final grouping of plants into divisions or subkingdoms may be made. All seed-bearing plants form the division Spermatophyta, meaning seed plants; the ferns comprise the division Pteridophyta, meaning fern plants, etc. The termination of phyta, from phyton a plant, distinguishes the division from the other groups. To repeat, the division is composed of subdivisions which in turn are made up of classes. Frequently the division contains only classes. Classes consist of related orders. The orders are divided into families which include allied genera and these latter groups comprise closely related individuals or species. The vegetation of the earth is separable into four widely differing divisions: I., The Thallophyta, including among others the fungi and algae; II., The Bryophyta or moss plants; III., Pteridophyta or fern plants; IV., The Spermatophyta or seed plants. The character and relationship of these groups will be considered in the following pages. 


\section{CHAPTER VI \\ DIVISION I. THALLOPHYTA}

6o. Classification of the Thallophyta.-The Thallophyta comprise a multitude of plants that include the most primitive and simple forms of vegetation upon the earth. They range in size from single microscopic cells to forms that are comparable in bulk to some of our shrubs and trees. They are all of simple structure and do not possess roots, stems and leaves in the sense of the seed plants. Such a type of plant body is called a thallus and it assumes a variety of forms. The absorption and manufacture of foods is carried on, as a rule, by any and all of the cells and this is equally true of the reproductive process. This Division is not a natural one in that some of the subdivisions are not related so far as we know. Several of the groups represent distinct lines of development and they are placed together simply because they are all simple forms of plant life. So it is impossible to give in a short space a general idea of the nature and character of this division which includes many groups of widely different forms. For the purpose of study the Thallo phyta may be divided into five subdivisions:-(I) Myxomycetes or Slime Moulds; (2) Schizophyta or Bacteria and Blue green Algae; (3) Diatomeae or Diatoms; (4) Euphyceae or Algae; (5) Eumycetes or Fungi.

\section{Subdivision I. Myxomycetes or Slime Moulds}

6I. The Life History of a Slime Mould.-In one stage of their life the slime moulds have a motility and mode of feeding suggestive of some of the lower animals, while on the other hand the final stage of their existence is more suggestive of the fungi. For this reason it has often been suggested that they are intermediate between plant and animal life. These plants are widely distributed over the earth and may frequently be found on decaying logs and rotting twigs and leaves in forests. A common 
form, resembling a miniature, brownish puffball, is often seen on stumps and fallen logs (Fig. 87). Other kinds are illustrated in Fig. 88. They range in size from scarcely a pin head to nearly a foot in diameter and from spherical to cylindrical and cake-like masses. Not infrequently they are of great beauty owing to their coloration and lace-like structures. These small sacs or sporangia (sing. sporangium) as they are commonly called, represent but one stage in the life of the slime moulds. If we begin with an examination of the dust that floats away from these

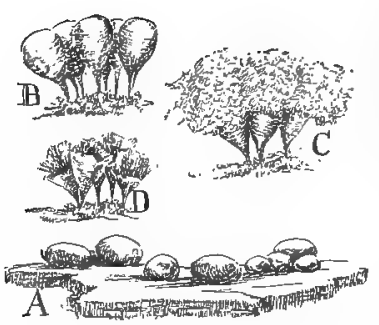

FIG. 87.

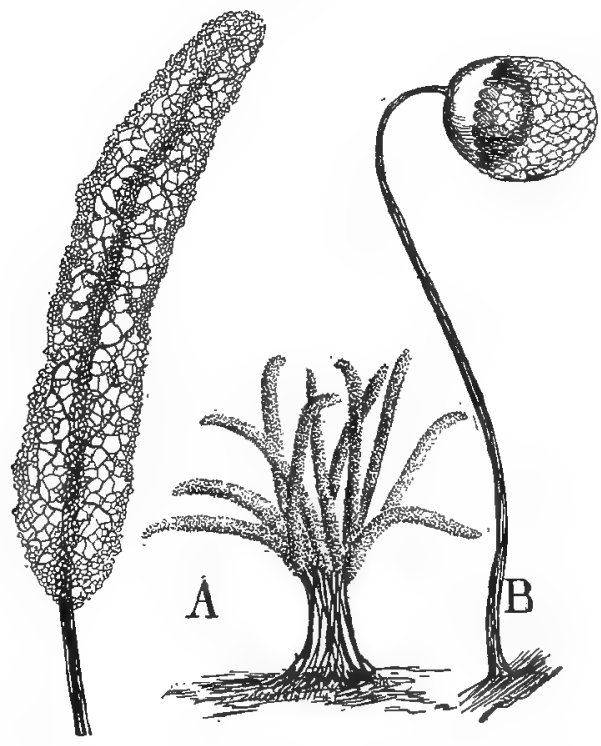

FIG. 88.

FIG. 87. The sporangial stage of two common slime moulds: $A$, Lycogala. $B$, Arcyria. $C$, sporangia rupturing, hair-like structures (the capillitium) and sfores protruding. $D$, sporangia emptied.

FIG. 88. Open types of sporangia: A, Stemonitis, at left a single sporangium enlarged, showing net-like structure formed by capillitium radiating from the central stalk of the sporangium. $B$, Cribaria.

sacs every time they are tapped, the life history will be found to be about as follows: Under the microscope the particles of dust are seen to be minute cells or spores (Fig. 89, A). You may think of a cell as a cube, a sphere or as assuming almost any form, 
frequently greatly elongated. It is bounded by a wall and within is the living substance or protoplasm. The more important parts of the living substance are a viscid rather watery material termed the cytoplasm and a minute denser body, the nucleus, which is immersed in the cytoplasm. A spore is a special kind of cell

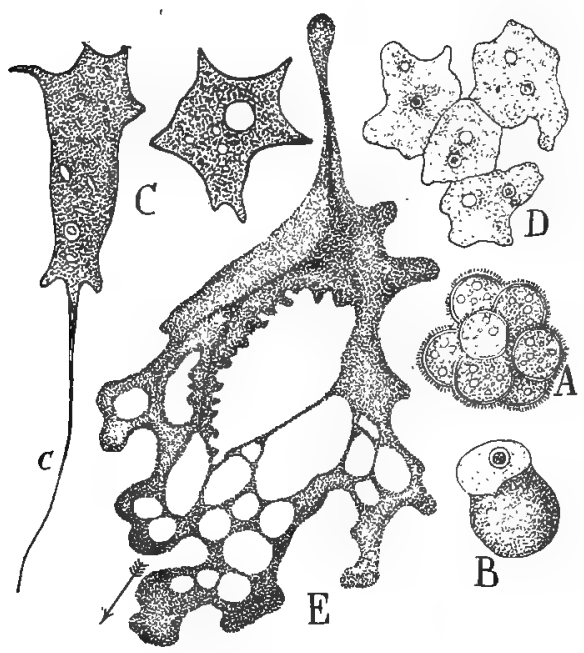

FIG. 89.

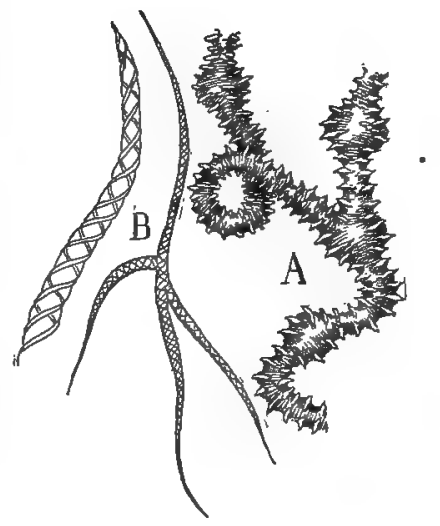

FIG. 90.

FIG. 89. Mobile phase in life of slime mould: $A$, group of spores. $B$, germination of a spore. $C$, two forms of zoöspores greatly enlarged. The right-hand one mobile owing to a streaming movement of its protoplasm and the left-hand one moves about owing to the rapid movements of the cilium, $c$. $D$, association of the zoospores preliminary to the formation of a plasmodium. $E$, plasmodium. The arrow indicates the direction of the streaming movement.

FIG. 9o. Character of the capillitium: $A$, in Arcyria. B, in Trichia, portion of thread enlarged on the left hand.

that is capable of germinating under favorable conditions and producing a plant. In this case it is advisable when germinating the spores to place them in a nutrient solution made by boiling in water bits of wood upon which the sporangia were growing. Germination will begin in about one day. As the spore wall ruptures the contents escapes as a naked bit of protoplasm (Fig. 89, B) which possesses a singular power of motion. This motility is due either to the slow creeping or streaming motion 
of the soft plastic body or more commonly the body may possess a delicate thread or cilium (plu. cilia) (Fig. 89, C). These ciliated bodies are called zoöspores. The cilium is a highly sensitive organ which by rapid and rhythmical movements, somewhat like the movements of the arms in swimming, beats the water and thus drives the body along. While in this condition the zoöspores are rapidly multiplied owing to the repeated splitting of the little bodies into two similar parts. Finally this greatly increased number of individuals begins to come together in small groups (Fig. 89, D) which in turn merge and so form large slimy masses termed plasmodia (sing. plasmodium) which . are quite destitute of all walls and consist of a great number of nuclei surrounded by a watery cytoplasm (Fig. 89, E). You will often find this plasmodial stage of the slime mould on the under side of rotting limbs or bits of wood in the forest as a sticky mass resembling in consistency the white of an egg. The mucilaginous character of the plasmodium accounts for the name slime mould popularly applied to these plants, also for the term myxomycetes, from myxos, slime, and myces, mould or fungus.

The plasmodium possesses a sensitiveness or capability of responding to external stimuli to a degree that is remarkable when we consider the extreme simplicity of these plants. For example, it avoids too strong a light and slowly moves toward moisture and food. This accounts for your failure ordinarily to notice it since it seeks the darkness and food in decaying logs or the under surface of sticks and leaves. The motion is brought about by little arm-like branches that flow from the jelly-like plasmodium and finally the entire plasmodium will slowly follow along these lines with a complicated streaming movement (Fig. 89, E). If bits of wood containing some of the plasmodium are placed in a damp chamber in the dark after a time the plasmodium will be seen creeping up the sides of the moist dish in a complex skein-like mass or if a glass slide, down which a very meager amount of water is slowly allowed to trickle, is brought in contact with the plasmodium it may be observed creeping up the slide toward the source of the water supply. The slime moulds do not contain chlorophyll and are therefore 
dependent upon organic food. Plants that feed in this way are called saprophytes. Since the plasmodium is not surrounded by a cell wall feeding becomes a simple matter. The jelly-like mass engulfs the decaying particles or other foods and after digesting the nourishing portions leaves behind the worthless parts as it creeps along. As the plasmodium approaches the final stage of its life, its nature appears to change completely, for now it avoids moisture and seeks the light. It creeps to the surface of the wood or leaves in which it has been growing and forms the characteristic bodies seen in Figs. 87, 88. These sporangia are formed by the outer part of the plasmodium hardening into a wall, while each of the inclosed nuclei, which have greatly increased in number by division, becomes surrounded by a wall, thus forming the spores. Usually a portion of the substance of the young sporangium is transformed into simple or branching threads or tubes, collectively called the capillitium (Fig. 9o). In several of the genera the capillitium forms a network within the delicate walls of the sporangia and owing to the early breaking down of the wall, the feathery frame alone remains (Fig. 88). These threads are hygroscopic and their constant motion assists in stirring up the spores and exposing them gradually to the wind as soon as the wall of the sporangium ruptures. A somewhat simpler type of slime mould lives as a parasite in the roots of turnip, cabbage and cauliflower, producing a destructive disease known as clubroot.

There are several groups of low types of plant and animal life that are suggestive of relationship with the slime moulds. The most important among these, the myxobacteriales, have been made known by Thaxter. They are minute plants, very suggestive of the next group, the bacteria, but associated in definite structures that resemble the sporangia of the slime moulds and also of certain fungi. On the other hand, certain aquatic forms, as Protomyxa, with a life history very. similar to that of the slime moulds, intergrade almost perfectly towards simple animal types, as the protozoans, of which the common amoeba is an example.

Thus we see that the life history of these plants is a very simple 
one. By the formation of sporangia numerous dust-like spores are produced that are capable of germinating and forming zoöspores that increase rapidly by division. The aggregation of the zoöspores results in the formation of the plasmodium which after a time completes the life history by creeping upon suitable dry objects and forming sporangia. The mingling of the zoöspores in the formation of the plasmodium is not a sexual process, since the nuclei do not fuse, but Olive has shown that the spores are formed in the same manner as in plants characterized by sexual reproduction and that therefore there must be a sexual fusion of the nuclei at some time in the life history of the plasmodium. The structure and life history of these plants is so simple that it is possible that they may have been derived from forms allied to the first forms of life upon the earth. The common occurrence among simple animals and plants of motile stages or zoöspores in their life history certainly suggests that possibly such forms may represent the first appearance of living matter.

\section{Subdivision 2. Schizophyta or Bacteria and Blue Green Algae}

As in the preceding group these forms are extremely simple and possess some characters suggestive of the lower forms of animal life. They have received the name of Schizophyta, meaning splitting plants, owing, to their common method of reproduction by division of the cell into two equal parts. There are two important classes of Schizophyta: A, Bacteria; B, The Blue Green Algae.

\section{Class A. Bacteria}

62. The Structure and Nature of Bacteria.-Bacteria are commonly known by such vague terms as microbes and germs. They are, however, unicellular plants that are of almost universal distribution, though more abundant about dwellings and less common in cold countries, at high altitudes and on the sea. They include the smallest and simplest forms of plants, ranging from scarcely I/50,000 in. to I/I0,000 in. in diameter (Fig. 9I). Such forms would have many times more room in a drop of water than a whale would find in New York harbor. So minute and 
simple in structure are the bacteria that the real nature of the plant body is somewhat a matter of dispute. The plants are unicellular and surrounded by a delicate thin wall which incloses a colorless and slightly granular protoplasm (Fig. 9I, $A, \mathrm{I})$. There is no nucleus comparable to that of the higher

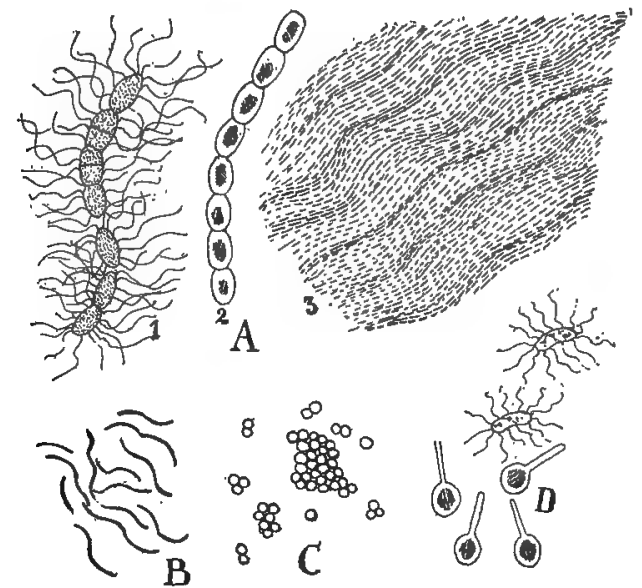

Fig. 9I. Forms of Bacteria: A, Bacillus subtilis, a form common in hay infusions. I, motile state; 2, cells with spores; 3, slimy mass of bacteria, the zoöglea condition, that appears on the surface of infusions, cooked vegetables, etc. $B$, Spirillum. $C$, a coccus form that appears in pus. $D$, mobile and spore stage of lock-jaw bacillus.

plants, although indications of it are seen in a few scattered chromatin grains. The cell content is very simple and totally lacking in plastids and other differentiations with which you are familiar. The slimy appearance of bacteria noticeable where they grow together in colonies is due to the mucilaginous excretion from their bodies which is often brightly colored. Bacteria range from globular to rod-like and curved forms (Fig. 9I). Many are motile by means of cilia, as in the case of the zoöspores of the Myxomycetes, which project singly or in tufts from the ends of the cells or in varying numbers from all sides.

(a) Reproduction of Bacteria.-This is a simpler process than in the slime moulds and much more rapidly effected when the conditions are favorable for growth. This process consists of 
forming a partition through the middle of a cell when the two daughter cells thus formed separate at once or they may remain attached, forming ultimately a chain of cells, since these two new cells continue to grow and repeat the dividing process. This method of multiplication goes on with great rapidity, frequently within a half hour, so that many millions of plants may be formed in a day from a single bacterium. This accounts for the rapidity with which solutions, as beef tea, in which bacteria thrive, become turbid and also for the gelatinous masses and wrinkled scum that appears upon cooked foods and soups, if allowed to stand undisturbed for a day or more (Fig. 9I, $A, 3$ ). Conn estimates that a single bacterium, if allowed to develop under perfect conditions, would produce in three days a mass of bacteria weighing 4,700 tons. When the conditions are unfavorable for growth many species of bacteria have another form of reproduction and form small bodies, called spores, within the cell (Fig. 9r, $A, D$ ). These spores are exceedingly resistant to unfavorable conditions but germinate readily, producing bacteria when conditions are again suitable for growth. Some spores will stand boiling for more than an hour. This peculiarity of the spore, while of great advantage to the bacteria, renders them very difficult to exterminate.

(b) Exclusion of Bacteria.-The various devices for preserving fruits and meats and sterilizing utensils and instruments in surgery is based upon some method of killing these organisms and preventing the entrance of others. This is the purpose of boiling and canning foods and of salting or drying fruits and meats. The boiling, if thorough, effectually sterilizes, while the canning excludes all organisms and the material will remain unchanged indefinitely. Smoking or drying, with addition of salt in the case of meat and of sugar in fruits, is effectual since bacteria flourish only in the presence of moisture. This is the reason that seeds and other structures are not speedily destroyed by bacteria. Seeds are naturally dry and protected by coats that tend to exclude the moisture for some time. Sugar is used as a preservative because bacteria cannot endure over 40 or 50 per cent. of it. Salt for the same reason is useful in preserving 
meat because it is injurious to bacterial life and smoking also introduces volatile products that prevent their growth. So too acids are generally harmful to bacteria. You have heard much regarding the use of salicylic acid, benzoate of soda, etc., in preserving foods and certain beverages. Whether these substances are harmful to us or not, certain it is that they are fatal to the existence of bacteria. So also meats, fruits and vegetables are kept in a wholesome condition for considerable periods in ice boxes and for months in cold storage since the bacteria grow more slowly as the temperature is lowered and their activity ceases at the freezing point. It should be remembered, however, that no amount of cold will kill all of the bacteria and that food spoils very quickly when removed from cold storage.

(c) Economic Importance of Bacteria.-Insignificant and simple as are the forms and structures of bacteria it is safe to say that no plants are so vitally related to our welfare. Numerous forms are instrumental in effecting changes in various substances termed fermentation; others assist in the decay of dead plants and animals; a comparatively small number of species build up or construct substances that are of vital importance to plant life; finally many diseases of plants and animals are due to bacteria. The work performed in all the above mentioned processes, save the third, is of the same nature. These plants have the power of breaking down into simpler compounds the various substances with which they may be brought in contact. Thus vinegar is formed through the decomposition of certain alcohols into simpler substances, as acetic acid and a gas, carbon dioxide. These changes are effected by substances, termed ferments or enzymes, that are excreted by the bacteria. These enzymes are very remarkable compounds. They do not enter into permanent union with any substance but by their presence cause it to break down into some of its component parts. When this decomposition is attended with the liberation of gas, as in certain sugar solutions, we term the process fermentation but when in an exactly similar way bacteria break down the substances composing the bodies of plants and animals we term the process decay. So also in disease bacteria simply cause the decomposition of 
certain of the compounds that make up the body. In some cases these simpler products that result from the activity of bacteria are very poisonous and in disease it is these substances, toxins, that often cause the principal danger. Let us now consider the more important of these operations.

I. Fermentation.-A very large group of bacteria, in common with some fungi, live upon sugars and other carbohydrates, causing a decomposition known as fermentation. Vinegar is due to the decomposition of the alcohol in cider and other weak alcoholic solution by numerous species of bacteria which appear as slimy masses and are popularly known as mother of vinegar. Milk sours and coagulates through the agency of bacteria which reduce the sugar to lactic acid, which in turn coagulates casein. The beverages known as zoölack, kumiss, etc., are milk preparations soured by special kinds of bacteria or yeast. The Metchnikoff tablets contain bacteria that are especially active in this way and they are also supposed to live in the lower alimentary tract where they form decomposition products that are injurious to the harmful bacteria that live in this same region. So also butyric acid, necessary in the manufacture of cheese, is produced by bacteria. It will be seen from this that the products of decomposition are not necessarily harmful. It is interesting to note that some of the flavors of cheese and of high grade butter are due to the products of decomposition and the excretions from bacteria. It is evident that this might be true in the case of limburger cheese and rancid butter but also remember that species of bacteria are cultivated and used to impart certain flavors to cheese and also to a less extent to butter. It is altogether probable that this will become a common practice in our dairies.

2. Decay.-The great majority of bacteria live as saprophytes upon dead plants and animals. They begin their work of decomposition immediately upon the death of the organism. In the case of plants they are generally assisted at first by various fungi. There are numerous classes in this group, each kind doing a special work in bringing about the decay. The first steps in the decomposition are quickly performed and then the simpler compounds, though mostly still quite complex, are 
acted upon by an entirely different class of bacteria that carry on the work to a further stage of decay. So you can think of many different kinds of bacteria each taking up the work where it was left by its predecessor and carrying it a step farther. In this way the complex compounds that make up the living organism are broken down into very simple ones, such as water $\left(\mathrm{H}_{2} \mathrm{O}\right)$ or gases as carbon dioxide $\left(\mathrm{CO}_{2}\right)$, ammonia $\left(\mathrm{NH}_{3}\right)$, methane $\left(\mathrm{CH}_{4}\right)$, sulphureted hydrogen $\left(\mathrm{H}_{2} \mathrm{~S}\right)$, nitrogen $(\mathrm{N})$, etc. It is not to be understood that all of these simpler substances arise only in the final stage of decay. Some of them may arise very early in the process, as ammonia and carbon dioxide, or they may be set free at later stages in the decay. Some of these gases are the cause of the foul odors associated with decay and it should be added that certain of the rather simpler products of decomposition, termed ptomaines, are exceedingly poisonous. The ptomaines found in fish, cheese, ice cream, are decomposition products formed by the bacteria of decay. Unfortunately these substances are without taste or odor.

This process of decay is of importance from two standpoints. First, it prevents the accumulation of organic matter upon the earth. Were it not for these changes every plant and animal would remain unchanged after death and so prevent further continuation of life. Second, we see that the successive steps in decay result in the formation of simple compounds that are either directly or indirectly utilized by plants in the formation of their tissues. Thus $\mathrm{H}_{2} \mathrm{O}$ and $\mathrm{CO}_{2}$ are used by the plant in forming sugars and starches which furnish the materials that go to make up the cell walls and also assist in building up the living substance. So also the $\mathrm{N}$ and the $\mathrm{S}$ that we have seen set free as elements or simple compounds are utilized in the formation of the living matter of the plant, though not directly, as we will see below.

3. Construction or Synthesis. - In sharp contrast to the above mentioned forms stands a rather small group of bacteria that possess the remarkable power of taking certain of the simpler products of decomposition and adding other elements to them. These forms, therefore, are quite different in their work from other 
bacteria. They build up substances instead of breaking them down. This work of combining two or more elements is termed synthesis and we may term these forms the synthetic bacteria. These bacteria are of great economic importance and those kinds that have the power of combining nitrogen into a form in which it can be used by plants are of first importance. Nitrogen, as it appears in the process of decay is in a form that the plant can utilize either not at all or only to a limited extent. There are several bacteria that have the power of combining nitrogen with other elements and so constructing a nitrogen compound, termed a nitrate, that is the most valuable crude food product of plants. Among these forms may first be mentioned the nitrifying bacteria. They have the power of adding another element to nitrogen compounds. They are able to add oxygen $(\mathrm{O})$ to ammonia $\left(\mathrm{NH}_{3}\right)$, that is to oxidize it, and thus transform it into a nitrate. This synthesis is accomplished in a truly remarkable manner; no less than two forms working together are required to accomplish the work. The first form adds two atoms of oxygen to the NH compound, thus changing it to a nitrous or nitrite state while the second form adds to the nitrite an additional atom of oxygen, thus completing the formation of the nitric or nitrate condition. The reactions caused by these two forms may be expressed as follows:

$2 \mathrm{NH}_{3}+3 \mathrm{O}_{2}=2 \mathrm{H}_{2} \mathrm{O}+2 \mathrm{HNO}_{2}$ (nitrous form of nitrogen), $2 \mathrm{HNO}_{2}+\mathrm{O}_{2}=2 \mathrm{HNO}_{3}$ (nitric form of nitrogen).

These two organisms work together, each doing its special work, and they are so efficient that a solution of ammonia poured upon soil will show no trace of the ammonia in the solution after it has percolated through the soil. Fully 65 per cent. of the nitrification is effected in the upper twelve inches of the soil and very little below a few feet. It is probable that the Chilian saltpeter beds, previously referred to, are the remains of inland seas where great growths of seaweeds accumulated. Owing to the drying out of these bodies of water and the decay of the vegetation ammonia was formed which became changed to nitrates as outlined above. Were it not for these organisms the ammonia compounds would quickly escape from the soil as a gas and thus 
the principal source of nitrogen in nature for the plant would be lost.

You have noticed that free nitrogen (N) may also appear in decomposition. A few forms of bacteria have been discovered that are able to synthesize this gaseous element into a compound that is of use to plants in a manner quite as remarkable as in the case of the nitrifying bacteria. Because they are able to fix the free gaseous element nitrogen in a stable compound these bacteria are referred to as the nitrogen-fixing bacteria-in contradistinction to the nitrifying bacteria that only act upon nitrogen when it is already in combination, as in ammonia. The most important of the nitrogen-fixing bacteria are those that live in the roots of plants belonging to the bean family. They cause minute gall-like swellings, termed tubercles, upon the roots of beans, clovers, alfalfa, etc., and are able to combine the free nitrogen of the air into a nitrogenous compound suitable for the nourishment of the plant. These bacteria are of inestimable value in maintaining the fertility of the soil (see page 65). Less important economically than the tubercle-forming bacteria but more wonderful biologically are those forms that live in the soil quite independent of higher plants and effect a somewhat similar fixation of free nitrogen. In this work they are associated with two other forms that take no part in the fixation of nitrogen but simply remove the oxygen and probably the organic matter, for only in the absence of these substances can these remarkable bacteria live. In this manner they are able to fix the nitrogen and build up complex compounds, probably of a proteid nature, which are subsequently decomposed and eventually converted into available nitrates by other bacteria.

As a final example of these synthesizing bacteria mention should be made of the iron and especially of the sulphur bacteria. They are able to oxidize simple compounds of iron and sulphur so that deposits of these minerals may often be seen as slimy white, red or yellow masses in springs and streams. The sulphur bacteria are of especial interest because they are able to oxidize one of the products of decomposition, $\mathrm{H}_{2} \mathrm{~S}$, into a sulphate-one of the valuable crude plant foods. These plants are practically 
independent of organic matter for their support, deriving the necessary energy for their growth from the decomposition of inorganic matter. This also is absolutely the case with the nitrifying bacteria which are unable to live upon organic matter and it should be added that these latter forms effect the same decomposition of carbon dioxide as noted in photosynthesis (see page 12). This is an important fact, for we see that there are two methods for effecting the storing up of eniergy. Green plants are the principal agents in this work. They build up, synthesize, such substances as sugars by utilizing the energy of the sunlight - for this reason the process is termed photosynthesis. Certain bacteria also build up compounds by utilizing the energy of chemical reactions. This process is therefore termed chemosynthesis.

We should now stop for a moment and consider what the real significance of these bacterial forms is. Green plants build up complex substances from certain elements and simple compounds. In the first steps of this work they may be assisted by certain bacteria and fungi. These complex compounds are now reduced by other bacteria to their original state so that they may be used again by the green plant. This in a word is the story of the organic world. Certain substances in the air and in the soil are going through an endless rotation or cycle of chemical changes-ever changing from simple to complex, from a complex state back to their simple form. So then the green plant is a temporary carrier of certain elements that, owing to their combinations, represent a certain amount of stored up energy. We and the plant and the bacteria utilize these substances in the same way. We eat them, $i$. e, decompose them. This is practically the only way that life can be maintained and the end result of this eating, this decomposition, is that the elements making up the compounds are returned unchanged to the earth, to go again through the cycle of changes.

4. Disease.- In contrast to the kinds of bacteria mentioned above there is another group that live as parasites on plants and animals producing disease either by destroying the tissue and sapping the vitality or by the production of poisonous 
compounds, toxins. Among the more terrible of these infectious bacteria may be mentioned those producing consumption. These affect especially the lungs of animals and cause, according to data now available, from 150 to 200 thousand deaths annually in the United States. It is altogether probable with complete returns that the death rate will exceed by 50 thousand the higher figure mentioned above. Consumption is no longer considered so fatal a disease as formerly. A person of ordinary constitution, if suitably nourished, can be cured by living in the open air. This pest could probably be wiped out within ten years, if the habit of spitting could be stopped. The spores and plants are readily carried away in the air from the dried sputum to be inhaled again and so spread the disease. The bacteria causing lockjaw, or tetanus, are especially abundant in the soil in certain localities. Through wounds they are carried into the system. These forms, like others previously noted, are peculiar in that they can not grow in the presence of oxygen. Consequently the dangers of infection are great in deep wounds. An immediate cauterization of the entire surface of the wound will kill the organisms. Other well-known bacterial diseases are pneumonia, diphtheria, erysipelas, Asiatic cholera, typhoid, and splenic fevers and grippe. It should be noted that many diseases, as smallpox, malaria, hydrophobia, yellow fever and probably scarlet fever, etc., are due to a low order of microscopic animal life. Disease-producing bacteria are either localized, as in the lungs, throat, intestines, or are generally distributed throughout the system. The symptoms of the disease are largely due to the products of decomposition caused by the growth of the bacteria or by secretions from the bacteria themselves, all of which act as poisons and are commonly referred to as toxins. In other cases the toxins are formed by the infected animal owing to the disturbance of its growth and nutrition by the bacteria in its tissues. In the same way bacteria are the cause of many diseases among the plants, as in corn, melons, many fruits, etc. See Bacteria in Relation to Plant Disease, by Erwin F. Smith.

These bacteria are constantly finding their way into our bodies by means of the breath but so long as the system is in a healthy 
condition there is only slight danger of the organism gaining a foothold. Just how the system is able to combat the growth of these plants is now the subject of earnest investigation. Certain diseases, as mumps, measles, whooping-cough, smallpox, etc., usually occur but once and it is probable that substances are formed in the body as a result of the presence of the bacteria or animal organisms that prevent a second growth of the germs and the individual thus becomes immune to further attacks. The formation of such a substance is known to occur in the case of diphtheria. The bacteria of this disease occur in the upper air passages of the throat and secrete a poison or toxine that affects the entire body. Gradually the system forms a substance called an antitoxine that stops the growth and eventually kills the bacteria. The vigor of the system and the virulence of the bacteria decide whether the disease shall prove fatal before the antitoxines are formed in sufficient quantity to destroy the bacteria. Note that these disease-producing bacteria vary in their power to produce toxine. Sometimes, as in epidemics, they are so virulent as to attack with fatal results the strongest individuals. In other cases the bacteria appear to be degenerate and only proaduce mild symptoms of the disease. This is the principle of vaccination. The little animals causing smallpox are cultivated runder conditions that weaken them and render them less virile. Consequently when they are introduced into the system they produce only mild symptoms of the disease. The history of the study of bacteria constitutes one of the most interesting and fascinating pages in science. Pasteur was the first to demonstrate that fermentations and putrefactions, and later that certain contagious diseases, were due to bacteria and animal organisms. His work is now commemorated by a tablet on the rue Pasteur in Paris with the inscription: Here stood Pasteur's laboratory. I857 Fermentations; I860 Spontaneous Generation; 1865 Diseases of Wines and Beers; $188 \mathrm{I}$ Virus and Vaccini; I 888 Silk-worm Distempers; I864-I888 Hydrophobic Remedies. To-day every state and government has its corps of workers and every city its expert bacteriologists who are studying the nature of bacteria and their relation to plants and animals. 


\section{Class B. Blue Green Algae or Cyanophyceae}

63. The Structure and Nature of the Cyanophyceae.-These plants are very simple organisms that have many features in common with the bacteria. They are unicellular plants, although the cells are more commonly joined into rows, forming a thread or filament (Fig. 92, $A, B$ ). In some cases these filaments may be regarded as multicellular plants since they branch and because the various cells perform different functions. They form slimy, blue-green, black, yellow or violet masses and, like the bacteria, appear to be dependent to a degree on organic material. At least they are especially abundant in the presence of decaying organic matter, as in the drainage from stables and watering troughs, or in pools, puddles and damp places where there is an abundance of filth and decay. The enormous increase of these plants often produces a discoloration of the water, as in the Red Sea, and they are often the cause of the foul odors of muddy ponds and streams and reservoirs and of the pollution commonly known as water-bloom or working of ponds. Like the bacteria also they are associated with varying amounts of gelatinous substances derived from their walls or excreted from the cells and in both cases the walls may become colored with various pigments. Doubtless the mucilaginous character of these plants enables them to retain moisture and so adapts them to dryer conditions than would otherwise be possible: The Cyanophyceae differ radically from the bacteria in possessing chlorophyll which is distributed in the outer portion of the protoplasm, and in the possession of a more definite nucleus. A blue pigment, phycocyanine, is associated with the chlorophyll and for this reason they are called the blue-green algae or cyanophyceae. Cell division follows the ordinary method noted in the higher plants, at least this appears to be true in those cases that have been accurately studied. These plants accordingly show a decided advance over the preceding forms not only in the differentiation of the cells but especially because they are capable, to a degree at least, of manufacturing food from inorganic substances by reason of their chlorophyll.

In addition to the multiplication of individuals by cell divi- 


\section{I66 REPRODUCTION OF THE CYANOPHУCEAE}

sion, as in the case of the bacteria, many of the thread-like forms have another interesting method of increasing their numbers. A few of the cells, termed a hormogonium, become separated

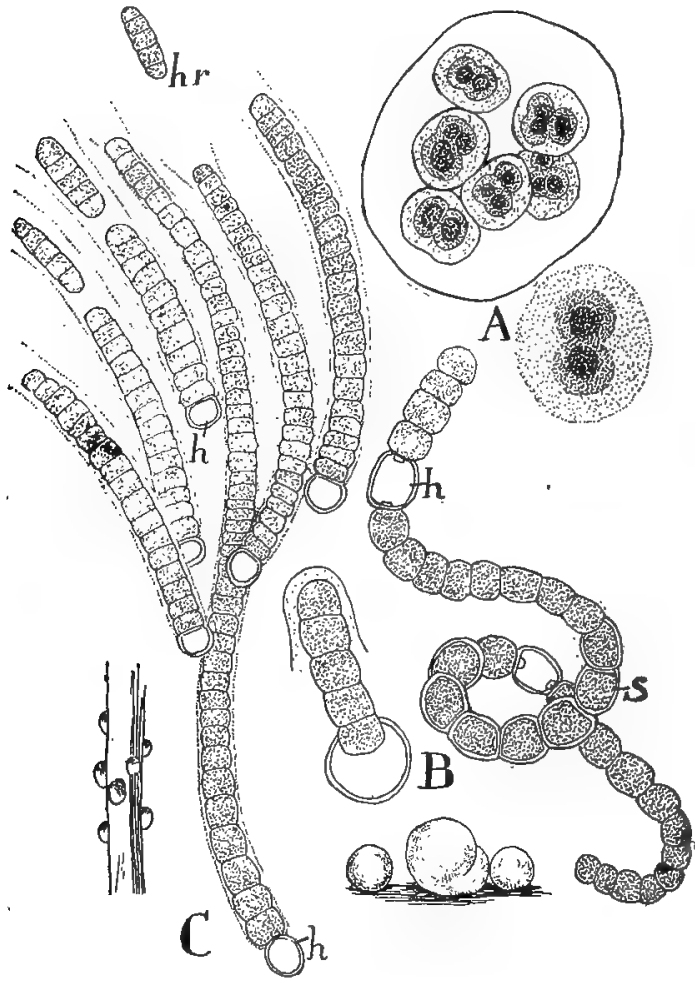

FIG. 92.

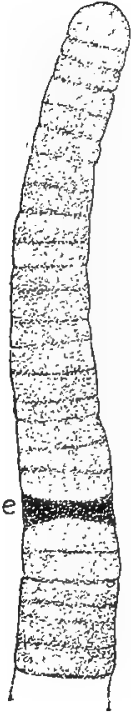

FIG. 93.

FIG. 92. Forms of the Cyanophyceae: A, Gleocapsa. At the right a cell has divided, but the two daughter cells are held together in a gelatinous mass. Above numerous divisions have occurred, but all the cells are surrounded by a mucilaginous envelope. $B$, Nostoc. Below appear the gelatinous, spherical masses of the plants as they appear floating upon the surface or resting on the bottom of ponds. At the right a plant enlarged$h$, heterocyst; $s$, thick-walled resting cells or spores. At the left a spore has germinated, producing five cells. C, Rivularia. At left gelatinous mass of plants attached to stem of water plant. At right view of a few of the plants - $h r$, hormogonium; $h$, heterocyst.

FIG. 93. One of the most common forms of the Cyanophyceae, Oscillatoria. The different sizes of the cells show that cell division may occur in any of the cells of the filament- $e$, a decaying cell which will ultimately free the cells below it as a hormogonium. 
from the other cells and frequently possess for a time a slight motility that enables them to move away from the parent filament (Fig. 92, $h r$ ). In some species one or several rather large, colorless cells, heterocysts, appear in the filament and may serve to separate it into hormogonia (Fig. 92, $h$ ). In Oscillatoria (Fig. 93) the filaments into which these hormogonia grow permanently retain their power of motion. No cilia have been observed for a certainty in any of these forms and the cause of the motion has been ascribed to the interchange of fluids attendant upon the absorption and digestion of foods. A simple type of spore production is also to be found in the majority of forms. This consists merely of a slight enlargement and thickening of the walls of the ordinary cells (Fig. 92,s). These simple spores are able to tide the plant over unfavorable conditions and germinate, forming new plants when conditions are again suitable.

The Bacteria and Cyanophyceae are evidently very primitive and ancient forms of life. The fact that they frequently occur in hot springs and that they can endure greater extremes of heat than higher plants may indicate that they are related to forms that appeared upon the earth when just such conditions existed and at a time when the environment was not suitable for the development of higher types. It has been stated on page 162 that certain bacteria are independent of organic foods and that they affect the decomposition of $\mathrm{CO}_{2}$ as in photosynthesis while in the purple and in the red sulphur bacteria we have pigmented forms that are perhaps in a transition state to chlorophyll-bearing plants. It seems altogether probable that the earliest forms of life could build up organic compounds without chlorophyll and in such forms as these bacteria we have perhaps an illustration of a tendency towards the acquisition of chlorophyll as seen in the higher plants.

\section{Subdivision 3. Diatomaceae or Diatoms}

64. The Nature and Structure of Diatoms.-The diatoms are among the most common and widely distributed plants (Fig. 94). While microscopic, they exist in such large numbers as to form the familiar brown coatings on the bottom of ponds and 
sluggish streams and often render sticks and stones in the water slippery with slimy deposits. They are widely distributed on damp soil and in fresh and salt waters. Note should also be

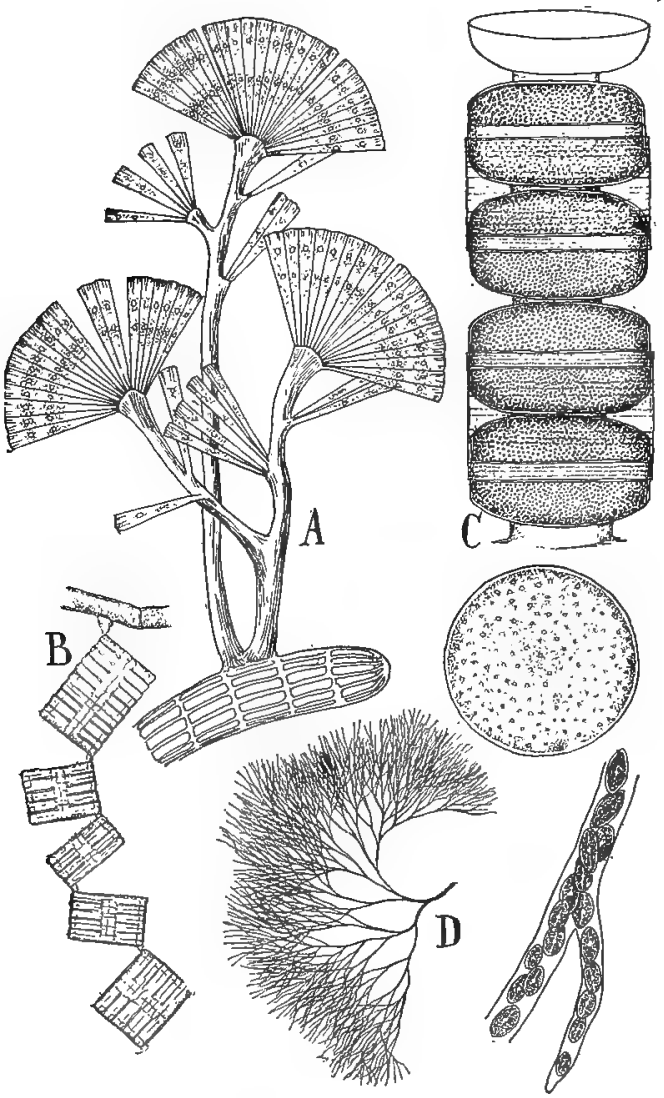

FIG. 94. Common forms of diatoms: $A$, fan-shaped colonies of diatoms, Licmophora, attached by gelatinous stalks to seaweed. The repeated division of a solitary diatom gradually builds up the fan-like colonies. $B, T a b e l$ laria, forming colonies grouped in zig-zag blocks. C, Melosira, cylindrical pill-box-like diatoms, arranged in chains. Below end view of the diatom. $D$, a species of Navicula arranged in gelatinous branches. At right enlarged view of a branch in which the diatoms glide back and forth.-After Wm. Smith.

made of the peculiar species that float upon the surface of the ocean and form the larger part of that organic life known as 
the plankton (Fig. 95). This is especially abundant in northern waters and has been compared to great pasture lands, since it furnishes the principal food of surface feeding fishes and other marine life. The Diatoms are unicellular plants and exhibit
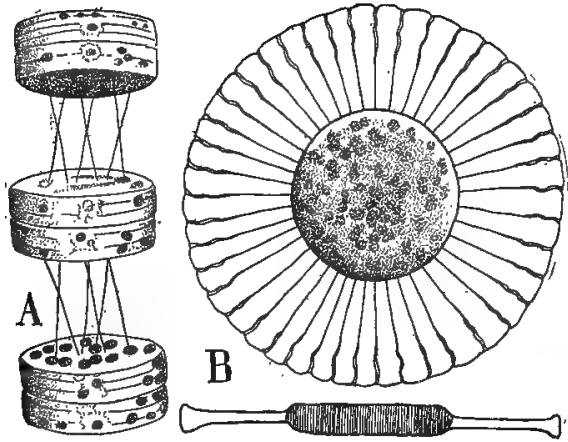

FIG. 95.

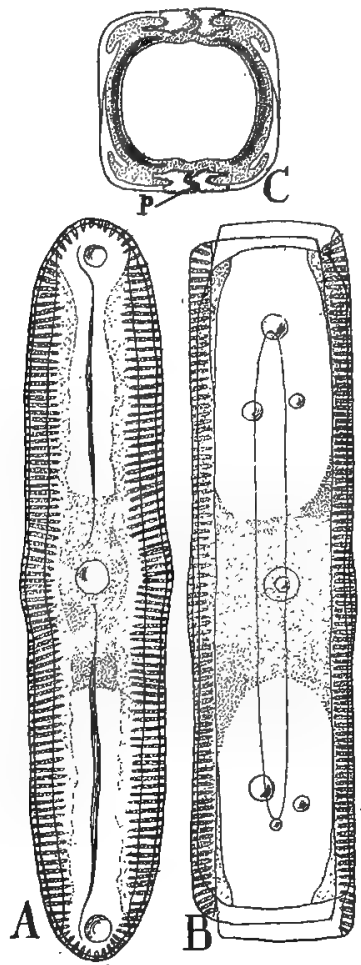

FIG. 96.

FIG. 95. Plankton forms of diatoms: A, Coscinodiscus, B, Planktoniella. Below seen from side.-After Gran.

FIg. 96. Structure of the diatom, Pinnularia: $A$, valve view. $B$, girdle view. $C$, cross-section, the two dark bands showing the position of the chromoplasts in the diatom- $p$, pore in wall which appears as a line in $A$, running from the ends towards the center of the valve.-After Lauterborn.

a great variety of forms as circular, elliptical, rod or wedgeshaped, curved or straight. They are equally variable as regards their association. Some are solitary and free swimming, others are attached by stalks; some form bands or ribbons or zigzag 
chains, while others are imbedded in a gelatinous mass of a more or less regular form (Fig. 94, D). The cells are covered by two valves, one of which overlaps the other like the cover of a box. Therefore a diatom presents two quite distinct appearances - the top or valve view and the side or girdle view (Figs. 96, 97). This difference is further intensified by the sculpturing of fine lines that appear upon the walls. An interesting feature about these valves is the fact that they are com-
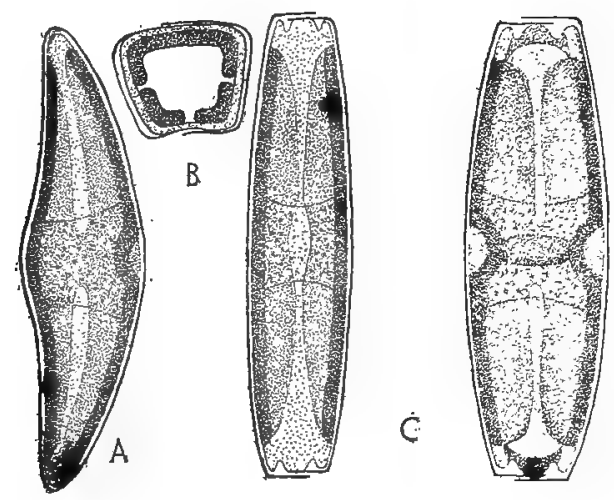

Fig. 97. Structure of Cymbella: $A$, valve view. $B$, cross-section showing the difference of the two sides of the diatom. $C$, the two girdle views. -After Pfitzer.

pletely infiltrated with silica, a substance resembling glass. If a diatom is burned in a flame on a strip of platinum or placed in acid to remove the organic substance the appearance of the valves remains unchanged.

The glass-like valves are quite transparent and it can be readily observed that the cell contents is much more highly differentiated than in the preceding group. The chlorophyll is deposited in plastids of definite form, although this color is often masked by a brown pigment which causes the characteristic appearance of these plants when associated in masses. The oil drops seen in the cells are the product of photosynthesis-starch not being formed. Some species, however, can live upon decaying organic matter and in consequence contain colorless plastids. In the free swimming forms the motion consists of an irregular 
gliding movement and this is supposed to be due to the expansion and contraction of minute strands of protoplasm that project through the pores of the valves (Fig. $96, C, p$ ).

(a) Reproduction of the Diatoms. - It will naturally be asked how can these plants living in glass houses, grow? As the valves become changed to silica naturally any increase in size must cease. Nevertheless the cells reproduce with great rapidity and in a very interesting manner. Through the growth of the living substance the valves are pushed apart and the cell contents divides, forming two diatoms with but one valve each. A new valve that fits into the old valve is soon developed on the uncovered side of each diatom and two complete diatoms are thus formed ( $\mathrm{F}$ ig. 98) which may become free at once or remain at-

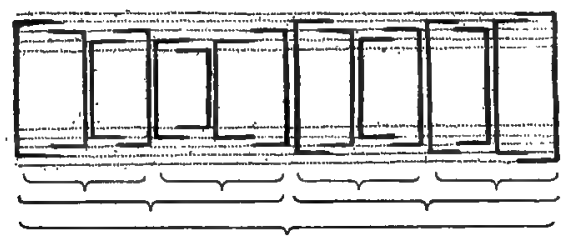

FIg. 98. Diagram illustrating the divisions of a diatom and the resulting reduction in size. The brackets connect the two diatoms that were formed by each successive division.-After Pfitzer.

tached and by further division form the odd groupings or colonies shown in Fig. 94. Since the valves are of unequal size, $i . e$., one fitting into the other, the two diatoms formed by the division must vary in size and it will be seen that the majority of the offspring will become greatly reduced in size as a result of the rapid and repeated divisions. That this reduction may not go on too far, when a certain minimum size has been reached the cell contents, with or without dividing, throws off the valves entirely and grows to the full size of the diatom, when new valves are formed and the diatom is ready to repeat the dividing process. In some cases we find quite a different method of reproduction. Two diatoms become enclosed in a jelly-like mass, into which the cell contents, with or without dividing, is discharged. These naked cells now unite in pairs and the bodies thus formed finally grow into diatoms (Fig. 99). This latter 
method of reproduction is termed sexual reproduction. The two fusing cells are looked upon as male and female cells or gametes, although in these simple plants there is no indication of sex that would enable us to recognize them as such. In the preceding groups, multiplication in numbers or reproduction has been effected by the division of the cells or by the formation of more or less modified cells, termed spores. All such methods of reproduction are called asexual, since but one cell is utilized in the process. In sexual reproduction a cell is formed by the union of the contents of two cells. The nuclei and protoplasmic contents of each unite so completely that a cell with but one nucleus and protoplasmic contents results. These sexually produced cells are called gametospores because they are formed by the
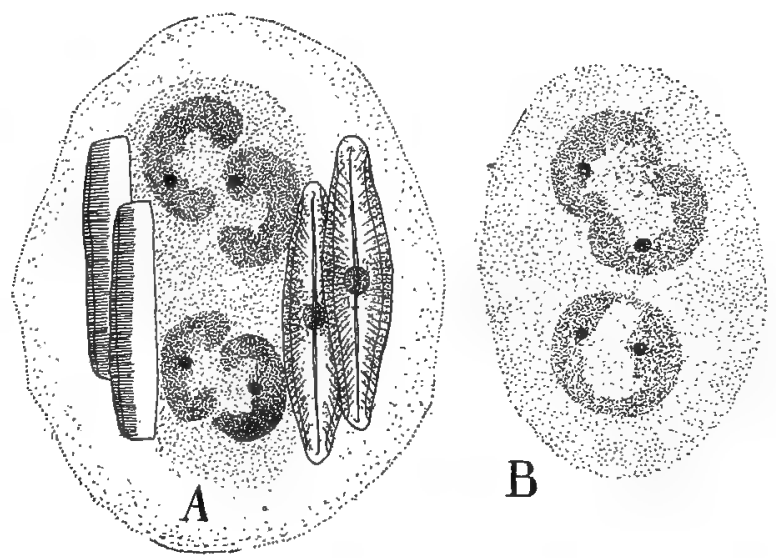

FIG. 99. Sexual reproduction of Pinnularia: $A$ two diatoms, enveloped in a mass of jelly. The valves have been thrown off and the content of each diatom has divided into two sexual cells or gametes. $B$, the fusion of the gametes.-After Karsten.

union of two gametes and are capable of forming a new plant in the same way as do spores. We may distinguish the spores derived from single cells as asexually formed spores or we may call them simply spores, while the spores formed by the fusion of the two cells or gametes may be termed sexually formed spores or gametospores. Both kinds of spores are devices to enable the plant to increase in number or to meet some other problem 
in life, such as conditions unfavorable for growth. The spores are especially to be looked upon as devices to bring about a rapid increase in the number of individuals while the gametospores more usually serve to carry the plant over periods of drought or extremes of temperature which would prove fatal to the plant. For this reason the gametospores are often provided with thick walls and dense cell contents which enable them to remain in a dormant state until conditions are favorable for growth. The gametospore is often called a resting spore for this reason.

So rapidly do the diatoms multiply that the larger part of the soil and rocks in many localities is composed of their remains. The constant casting off of the valves through reproduction or death results in vast deposits, known as silicious earth, on the bottom of ponds and in the sea. Beds of silicious earth formed in this way are often seen in districts where ponds and lakes have dried up. Sometimes these beds reach enormous proportions, the city of Richmond, Va., being built upon such a deposit. Some of the western beds are quite 300 feet in thickness and yet it takes about 40 million of these plants to make a cubic inch. Silicious earth is used as polishing powders and as absorbents in the manufacture of some explosives.

\section{Subdivision 4. Euphyceae or Algae}

65. General Features. - This subdivision includes a large number of plants that live chiefly in fresh or salt water. These plants, popularly known as Algae, vary greatly in form and structure and range from microscopic unicellular forms to some of the largest and most highly constructed plants found among the Thallophyta. Their advance over preceding groups appears especially in their well-marked walls and distinct plastids and nuclei (Fig. IO0, I04). Chlorophyll is always present in the cells, although in certain groups it is masked by brown or red pigments. These latter pigments are supposed to adapt the plant to varying intensities of light. This is supported by the fact that the marine Algae exhibit a zonal distribution in the water. Forms living near the surface of the water are predominantly green, at depths where they are alternately exposed and covered by the 
tide, they are more commonly brown, while in the shade of the brown Algae, or below tidal limits, red forms occur. The Algae appear to have developed along three lines, which are indicated by the green, brown and red colors, although the basis for this classification rests upon structural and reproductive characters. These three classes are: A, Green Algae or Chlorophyceae; B, Brown Algae or Phaeophyceae; C, Red Algae or Rhodophyceae.

\section{Class A. Green Algae or Chlorophyceae}

66. The More Important Orders of the Chlorophyceae.-The Chlorophyceae are one of the most interesting groups of the Algae, because they contain primitive forms that are at least suggestive of low animal types and they also exhibit a gradual modification of the plant body and reproductive processes that help us to understand how variations arose and how complex types have been evolved from very simple forms. These plants are doubtless the most primitive survivors of a line from which the higher land plants have been derived. Starting with unicellular motile forms, the green algae appear to have diverged along several lines. Among the more important of these may be mentioned the following orders: (a) Volvocales, largely unicellular green Algae; $(b)$ The Zygnematales or conjugating green Algae; (c) Chaetophorales or filamentous green Algae; (d) Siphonales or tubular green Algae.

67. Order a. Volvocales or Unicellular Green Algae.-The lower members of this order represent a very primitive type of plant. Their motility, certain features of their life history and delicate cell walls are suggestive of some of the preceding groups, as well as of low forms of animal life. Sphaerella (Fig. roo) is a familiar example of this group, of ten appearing in rock hollows as blood-red stains. If some of this red material is examined in water, the plants appear as spherical cells with dense red protoplasmic contents and thick walls (Fig. Ioo, $A$ ). This condition represents the resting state of the plant. If the plants, after being dried, are allowed to stand in water for a few hours, the nucleus will divide, forming usually from 4 to I 6 daughter 
cells (Fig. I00, $B$ ) which escape by the rupturing of the old mother wall and swim actively about by means of two cilia. These cells, or zoospores, remain motile for varying periods, during which time they increase in size, but finally the cilia are

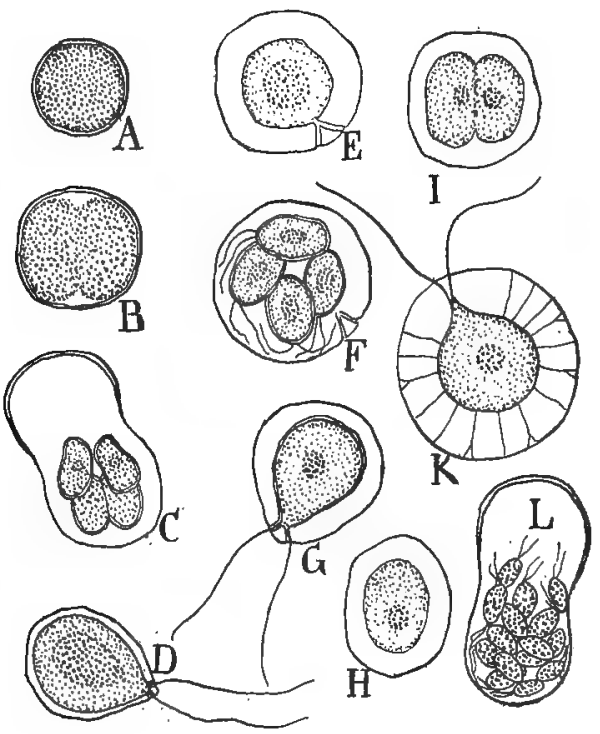

Fig. roo. Stages in the life history of Sphaerella: $A$, resting state of the plant. $B$, first division. $C$, second division, the four cells are about to escape from the mother plant. $D$, one of the cells of $C$ after escaping. This is a zoöspore of the first generation. $E$, zoöspore at rest. $F$, forming four new zoöspores. $G$, one of these zoöspores of the second generation. Note that the red material, represented by the shaded area in the center of the cell, has become greatly reduced and that the wall is becoming distended and separated from the granular cytoplasm. $H$, third resting stage. $I$, cell dividing. $K$, zoöspore of third generation with greatly distended cell wall and small red area. Delicate strands of cytoplasm connect the cell wall and the central protoplasmic body. $L$, a resting cell dividing into a large number of zoöspores which are consequently smaller.-After Hazen.

retracted and the plants remain in a quiescent state for a short period (Fig. IOo, $E$ ). A division of the nucleus now results again in the formation of two or more zoöspores (Fig. IOO, F) which repeat the life history noted above. This method of reproduction may occur again and again and thus rapidly bring about a great increase in the number of plants. During the 
divisions, the red coloring matter is usually rapidly replaced by chlorophyll until but a red speck remains and the zoöspores soon appear as rather ovate green cells surrounded by delicate walls which become widely separated from the chlorophyll owing to the accumulation of water (Fig. I00, G). Nearly all zoöspores that occur among the algae are characterized by a small red body, known as the eye spot, which is located near the ciliated end of the zoöspore. It has been supposed that this body is sensitive to light and gives the zoöspore a sense of direction. While this is questionable, since the eye spot may be lacking (as in Sphaerella), it is certain that these beautiful bodies swim about, ciliated end foremost, with a rotary motion from right to left and adjust themselves to a suitable illumination. It can easily be demonstrated that the zoöspores of Sphaerella are keenly sensitive to different intensities of light by placing them in a glass dish by a window when the zoöspores will congregate on the illuminated side unless the light is too intense, when a reverse action takes place.

Thus we see that the life of the plants is largely a motile one, each generation being characterized by a short resting stage during which division occurs and a longer motile zoöspore stage. In fact, the zoöspore may be looked upon as the original state of these plants, while the resting condition is a departure due to changes in the environment or the condition of the organism. This common occurrence of motility in the lower types of life indicates that possibly such was the condition of the first life upon the earth.

(a) Conditions Affecting the Life of Sphaerella.-Changes in the surroundings sometimes produce remarkable variations in the life of the plant. This fact is well illustrated in Sphaerella. If the water dries up, a thick wall is formed about the central protoplasmic body which becomes dense and of a deep red color while the delicate distended wall and cilia disappear. This variation adapts the plant to conditions unfavorable to growth, such as drought and severe temperature. The so-called red snow is due to a certain species of these plants that are swept off from the rocks in this resting condition by the winter winds and falling 
to the earth produces red streaks in the snow. Hazen has been able to show that a most suggestive change in the mode of life of the plants may also be induced by low temperature or by a reduction of the volume of water in which they live. Under such conditions, bodies are formed that resemble zoöspores, but that are not capable of motion owing to the lack of cilia. This helps us to understand how the motionless or stationary forms of plant life came about and how the motile stage became less and less conspicuous. Owing to such causes as these and many others, plants become stationary. At first, perhaps, simply an aggregate of motionless cells, but finally there resulted chains or filaments of cells owing to the repeated division of the plants in one plane. By division in two planes, membranous expansions resulted and the more complex types arose by the division of the cells in three planes and by modification of the cells.

One other feature appears in the life of the Sphaerella that indicates clearly how sexual reproduction came about. When the conditions for growth are unfavorable, as for example, through lack of moisture or low temperatures, there result plants that are not so well nourished, or at least they appear to lack some of the qualifications that characterize the plants giowing under favorable conditions. The same condition often arises in these plants after several generations have been formed. Such plants, which may be characterized as weaker, or, at least, lacking in certain material, do not give rise to the ordinary zoöspores, but to much smaller though similar bodies that are lacking in cell walls (Fig. Ioo, $L$ ). These small zoöspores usually perish or produce small plants unless two of them meet, when a fusion may occur and thus a plant is formed that is capable of repeating the life history of Sphaerella. By suitable nourishment, however, these small zoöspores may sometimes be made to develop into the normal plant. It is very evident that these small zoöspores are lacking in some substance that is essential to their growth. This is rarely furnished to them in nature except when two of the bodies fuse. From numerous examples appearing among different groups of Algae, it appears that sexuality arose in this way. Owing to certain conditions of light, temperature, 
food, etc., zoöspores were formed that were incapable of further growth. But, by the union of two of these zoöspores, a cell was formed possessed of renewed vigor and capabilities of growth. So we can think of the sexual cells or gametes as zoöspores that are lacking in the materials essential to growth and of the sexual process as a union of the two bodies for the purpose of bringing together the missing material and supplying the necessary energy for growth.

A closely allied genus, Chlamydomonas (Fig. IOI) has a life history very similar to that of Sphaerella but the formation of the gametes reveals a variation that gives us an understanding of how these bodies came to differ and finally became distinguishable as male and female gametes. In some of the species of Chlamydomonas, to be sure, the gametes are similar and can not be distinguished as male or female (Fig. Ior, $B$ ). This stage of sexuality is called isogamous, meaning similar gametes. In other species, there is a decided variation in the size of the gametes, certain cells or plants producing large and less active cells that are termed female gametes, while other plants produce numerous minute male gametes that swim actively about (Fig. IOI, $C, D$ ). This stage of sexuality, where the gametes differ in size is called heterogamous, meaning unequal gametes. This variation in the size of the gametes which we call the differentiation of sex is due to the amount and nature of the material stored in them, the male gametes being formed in a cell in larger numbers than in the case of the females. These heterogamous gametes do not differ in nature from the isogamous gametes. They are also lacking in some substance that renders them incapable of growth unless fusion of two gametes is effected.

(b) Colonial Unicellular Algae.-The various stages in the evolution of sex are also well illustrated in several genera of unicellular green algae that live together in colonies. These colonial forms are also of interest in that they help us to understand how unicellular plants became associated-at first quite independent of one another-and this led to the dependence of one plant upon another and finally to a distribution of work among the plants of the colony, so that certain plants or cells 
would be largely concerned in reproduction and others in the manufacture of foods, etc. This is essentially the state reached by our higher plants which may be spoken of as a colony of cells. Pandorina shows the earlier phases of the differentiation of the gametes. This plant is really a spherical colony of about 16 , prac-

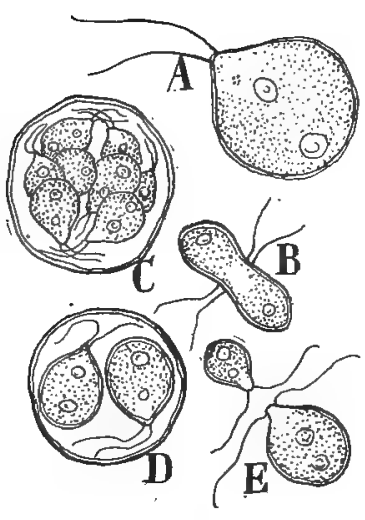

FIG. IOI.

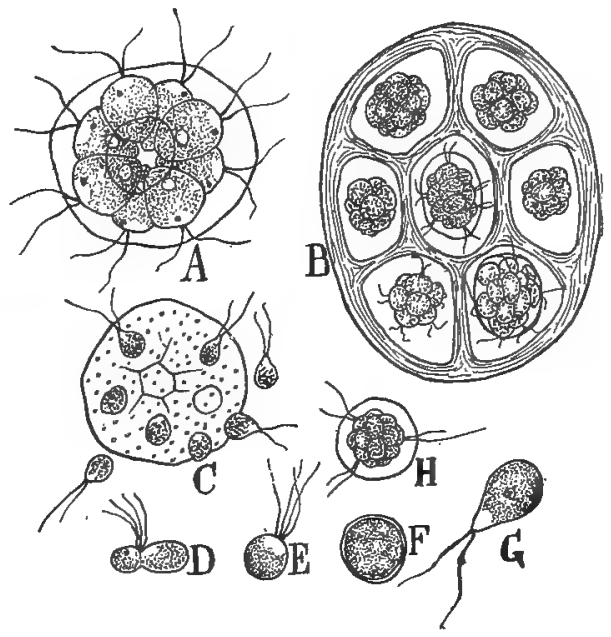

FIG. 102.

FIG. 10I. Features in the life history of Chlamydomonas: $A$, character of the motile plant. $B$, conjugation of isogamous gametes. $C$, a plant dividing to form numerous small male gametes. $D$, a plant forming two large female gametes. $E$, male and female gametes about to conjugate.

FIG. 102. Features in the life history of Pandorina: $A$, a colony of plants. $B$, each plant of the colony dividing to form a new colony. $C$, the plants of a colony escaping as gametes. $D$, the conjugation of two gametes of unequal size. $E$, later stage in the conjugation. $F$, gametospore or resting spore. $G$, large zoöspore formed from the gametospore. $H$, a colony formed by the division of the zoöspore, $G$.

tically independent, motile plants, each one similar to Sphaerella but held together in a mucilaginous mass (Fig. I02, $A$ ). These beautiful colonies multiply by each plant or cell dividing into 16 daughter cells which finally become an independent colony (Fig. I02, B). The gametes are formed in essentially the same way as the colonies, save that the 16 daughter cells finally escape as free swimming bodies (Fig. 102, C). The mother plants or cells producing these gametes differ in size, owing, doubtless, to 
the amount of nutriment which they receive. Consequently, the gametes formed from them must also differ in size. It is also possible that the mother plants may produce gametes of different sizes because some divide a larger number of times than others. The larger the number of divisions in a cell, the smaller will be the gametes. It is interesting to note that these gametes fuse quite regardless of their size, although there may be a slight tendency for the small and more active gametes to fuse with the larger and slower moving ones. Thus we have an illustration of the first appearance of the differentiation of sex although the sexuality of the gametes is not thoroughly established. The gametospore, resulting from the union of the gametes, develops a thick cell wall, the contents assumes a reddish color and it passes into a resting stage (Fig. I02, F). When conditions are favorable, it germinates as shown in Fig. 102, $G-H$. In the beautiful spherical colonies of Eudorina and Volvox (Fig. 103) the differentiation of the gametes is complete. Certain cells produce but one large female gamete that remains motionless in the mother cell while other cells form numerous small motile male gametes which are yellowish in color. In Volvox, over 200 male gametes may be formed from a single cell (Fig. IO3, $D, E)$. Volvox also shows that the association of plants in colonies resulted in an interdependence among the plants and also in a specialization in the work performed by these plants. Fig. I03, $C$, shows that the thousands of plants that make up the colony are in communication with one another and they doubtless give and receive material in accordance with the needs of the colony. Furthermore a few of the cells of the colony receive more nourishment than the others and these cells increase in size, divide and form new colonies as in Pandorina. Finally there is to be noticed that certain cells function in the production of gametes. So we see here in a simple way some of those specializations and distributions of labor that will appear as the most characteristic features in higher forms.

The tendency among the algae to form gametes of different sizes is manifestly of great advantage. The great number of male cells increases the chances of fusion of the gametes and their 
smallness promotes their movements through the water. Note also that these results are obtained without any additional expenditure of material-the 200 male gametes being produced from a cell no larger than Sphaerella where only a few are found. The increase in the size of the female gamete renders her movements more difficult, but the storage of food in this gamete provides for the better nourishment of the next generation. Finally the nourishing function becomes so strongly developed that the female ceases to move at all and remains protected in the mother

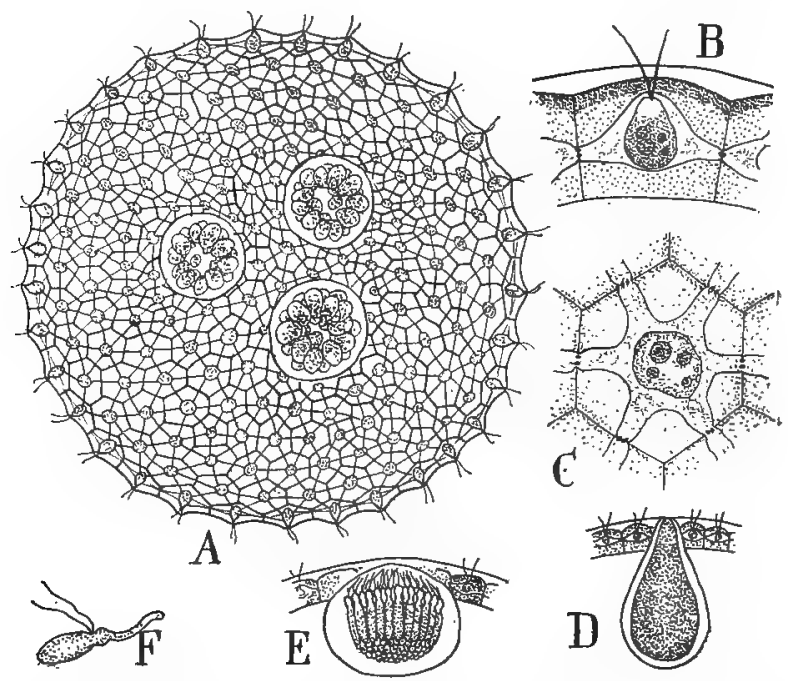

FIG. 103. Features in the life history of Volvox: $A$, a colony which may contain as many as 20,000 plants. The three central groups are young colonies which may arise by the repeated division of any of the plants. $B$, side view of one of the plants showing the canal-like connections with the neighboring plants. $C$, surface view of a plant with canals radiating out to the adjoining plants. $\quad D$, a plant enlarging and forming a single motionless female gamete. $E$, a plant forming numerous small male gametes. $F$, male gametes enlarged.

cell. Thus we see that sexuality may have arisen among plants. as the result of definite stimuli as heat, moisture, light, food and: other conditions that occur in the environment. These stimuli produce enfeebled zoöspores that are incapable ordinarily of: growth unless a fusion of two of them is effected. So sexuality: 
arose from the asexual state of the plant as a result of the influence of the environment and differentiation of sex appeared owing to the variation in the amount and kind of material in the gamete producing cells.

(c) Motionless Unicellular Algae.-In contrast to these motile plants, there is a large group of the Volvocales that have lost their motility and spend a large part of their life as stationary plants. We have already noticed how this condition may have

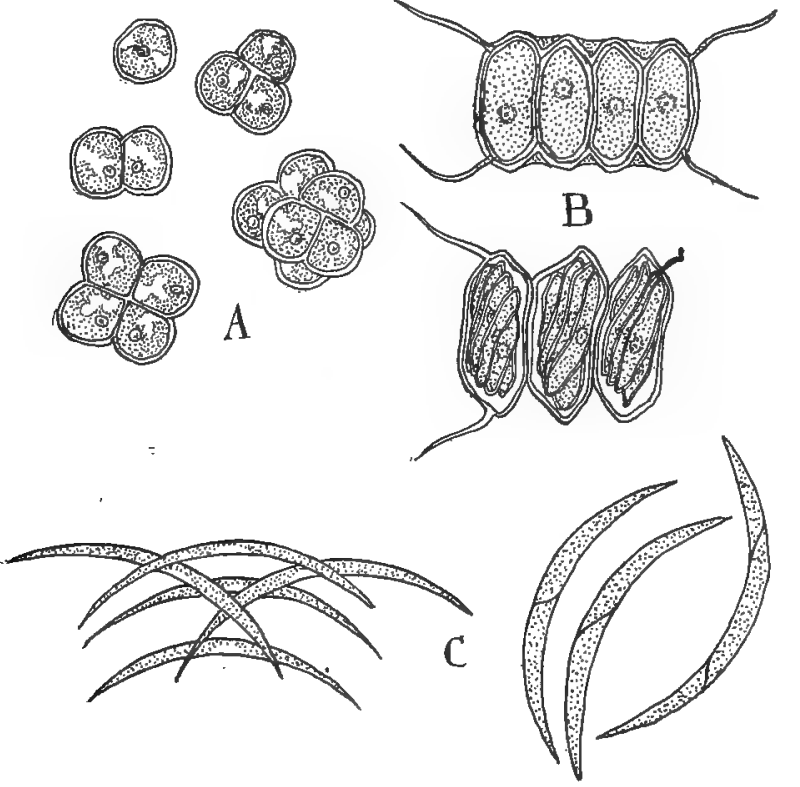

FIg. I04. Common forms of stationary unicellular green algae: A, Pleurococcus showing stages in the division of the plants, the nucleus and the irregular chloroplast. $B$, Scenedesmus. Below three of the plants are shown dividing. $C$, Ankistrodesmus. At right three plants in process of division.

come about, owing to the temperature and moisture conditions that were unfavorable for the motile existence. Pleurococcus (Fig. I04, $A$ ) is one of the most common of the green algae and illustrates many of the features in the life history of the stationary forms. These plants often cause the green coating that appears upon the shaded or moist side of tree trunks, fences and buildings. If a bit of this material is examined under 
the microscope, it will be seen that the plants are rather spherical cells provided with nucleus, cytoplasm, chloroplasts and well marked walls. This latter feature is characteristic of stationary algae and forms a sharp contrast to the delicate walls of the motile forms. These plants increase in numbers by the formation of a wall through the middle of the cell. The two daughter cells or plants grow to the size of the mother plant and repeat the process in division by forming a wall at right angles to the old wall. It will also be noticed that cell division may occur in three planes. The plants adhere together for a considerable period, or become detached shortly after the division of the mother cell. In this way they multiply with extreme rapidity and so come to form extensive green coatings. It has been noted in allied genera and reported in certain species of Pleurococcus also, that changes of temperature and amount of water, etc., will cause the contents of the cell to divide and form zoöspores which are of the same nature and behave in the same way as in Sphaerella. Thus we see how changes of the environment may cause these stationary plants to return to the motile condition of simpler types. It is interesting to note in this connection that Livingston was able to change the stationary condition of certain algae to the motile condition at will by diluting the solutions in which they were living. Fig. I04, $B, C$, illustrates several other forms of stationary green algae that are common in the drinking water and in ponds and streams. Interesting forms for study may be obtained by tying a woolen sack to a water faucet and allowing the water to run into it for several hours. Invert the sack into a glass, washing off the material that collects on the inside of the sack in the water of the glass. By means of a pipette, a drop of the material that collects at the bottom or sides of the glass or forms on the surface of the water may be transferred to a slide and examined under a microscope. Some of these forms are free, some attached and others aggregated in a mucilaginous mass.

There are a great many of the stationary genera that show the same habit of uniting into colonies that we noticed among the motile genera. These colonies may be very simple and com- 
posed of a few loosely aggregated plants forming flat discs or star-shaped plates (Fig. I05, $A$ ). In other cases, we find spherical and net-like colonies. The water net, Hydrodictyon, is a common illustration of this latter arrangement (Fig. I05, D, E). These plants occur in ponds and sluggish streams, forming saclike nets from a few inches to a foot in length, that are constructed

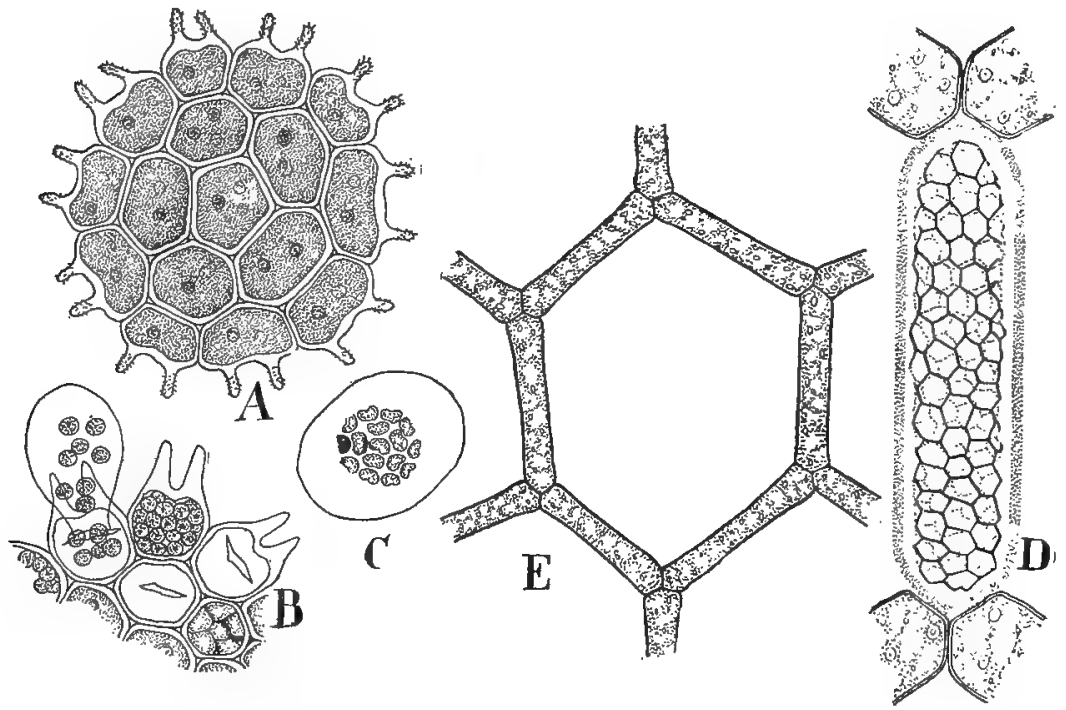

FIG. 105. Colonial forms of unicellular green algae: $A$, Pediastrum, the plants of the colony being arranged in a flat plate. $B$, a view of the outer cells of the colony showing the formation of a new colony. $C$, one of these new colonies. $D$, a plant of the water net containing a young colony. $E$, enlarged view of one of the meshes of a net showing the geometrical arrangement of the plants.

in a very regular manner. The reproduction is quite characteristic of many of the Volvocales. Zoöspores are formed in large numbers in any of the plants and after a period of motility, they come to rest and arrange themselves into a new net inside of the mother plant (Fig. I05, D). The walls of the mother plant soon break down and the new colony is set free. Under different conditions, smaller but similar bodies are formed which escape from the mother plant. These bodies are gametes and incapable of growth unless a fusion is effected between two of them. 
Especial interest attaches to the study of this plant because Klebs was able to change the reproductive character of the plant by subjecting it to certain definite conditions. By exposing the plants to bright light, slight increase of temperature and inorganic culture solutions of definite composition, zoöspores are produced. On the other hand, plants growing in solution of cane sugar in subdued light or darkness formed gametes.

These reactions are of great importance in helping us to understand the nature of plant life. They demonstrate that definite factors may change motile plants to a stationary condition and in Hydrodictyon we see that measurable factors, as light, heat and concentration of the solution may bring about the motile condition of the plant and may also cause a variation in the motile condition which we call sexuality.

68. Order b. Zygnematales or Conjugating Green Algae.This order includes the most common and attractive forms of green algae (Figs. 106, I08). They are of very general occur-
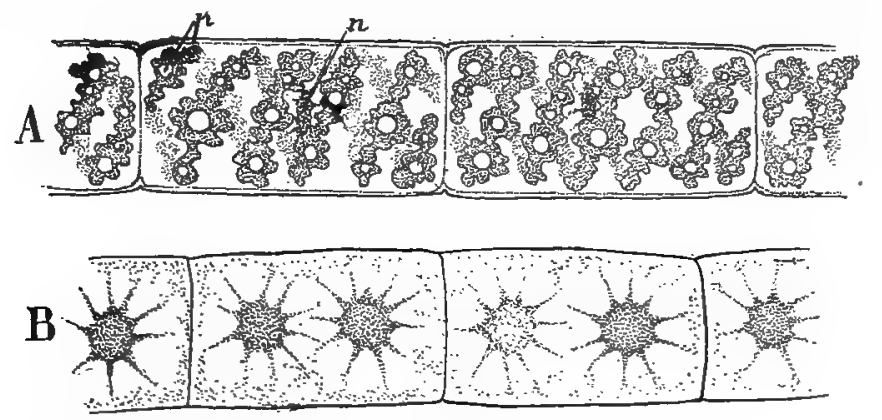

FIG. I06. Two common forms of the Zygnematales: $A$, Spirogyra$n$, nucleus; $p$, pyrenoid. $B, Z$ ygnema.

rence in the still waters of ponds and streams, where they often form the large floating and frothy green masses popularly known as pond scum or frog spittle. They can usually be recognized by their slimy nature which is due to the copious exudation of a gelatinous substance from the cell walls. In one group of this order the plants are multi-cellular (Fig. I06), the cells being attached end to end and forming a filament-though it should be stated that each cell is practically independent in its life process 
and the organism may therefore be regarded as a colony. Such a type of plant would have originated in the case of Pleurococcus if the two daughter cells had remained attached and continued to divide in but one plane and parallel to the first division wall. This is exactly the mode of growth in these filamentous plants. Any of the cells may divide into two daughter cells which grow to the original size of the mother cells. In this way the length of the plant is increased. The most characteristic feature about the Zygnematales is the remarkably large and attractive chloroplasts. In Spirogyra (Fig. I06, $A$ ) these appear as bands, from one to several in each cell, spirally arranged just within the cell wall. In Zygnema (Fig. I06, B) they assume the form of stars and in other genera they appear as plates, bars and variously modified bodies. Imbedded in the plastids are denser protoplasmic bodies, the pyrenoids, that appear to be connected with the secretion of starch; at least a layer of starch can be detected about the pyrenoids by testing with iodine (Fig. 106, pr).

The filaments are fragile and readily become dissociated into smaller portions. In this way, the plants may multiply, since the fragments continue to grow after the manner of the original filament. Singularly, there is no indication of a return to the motile condition in the life history of these plants. No zoöspores or motile gametes are formed. Sometimes the walls of a cell become thickened and after a dormant period, as through the winter, may germinate and grow into a new plant. With this rather rare exception, the asexual reproduction of the plant by spores does not occur. The sexual reproduction is of a peculiar character. This is very well illustrated in Spirogyra. When filaments of this plant chance to lie side by side, under certain conditions, tube-like processes from opposite cells begin to grow out towards each other (Fig. I07, $A$ ). These tubes finally meet, when the walls at the point of contact are absorbed, forming an open passage between the two cells. While this growth has been going on, the contents of the two cells have contracted somewhat and finally the contents of one cell passes through the tube and fuses with the contents of the other cell. Several modifications of the reproduction process outlined above will occa- 
sionally be noted, such as the development of gametospores in either filament or the fusion of the adjacent cells of a filament by means of lateral tubular outgrowth. In other genera, there is a considerable modification in the process, as in some species of Zygnema, where the fusion is effected in the middle of the tube.

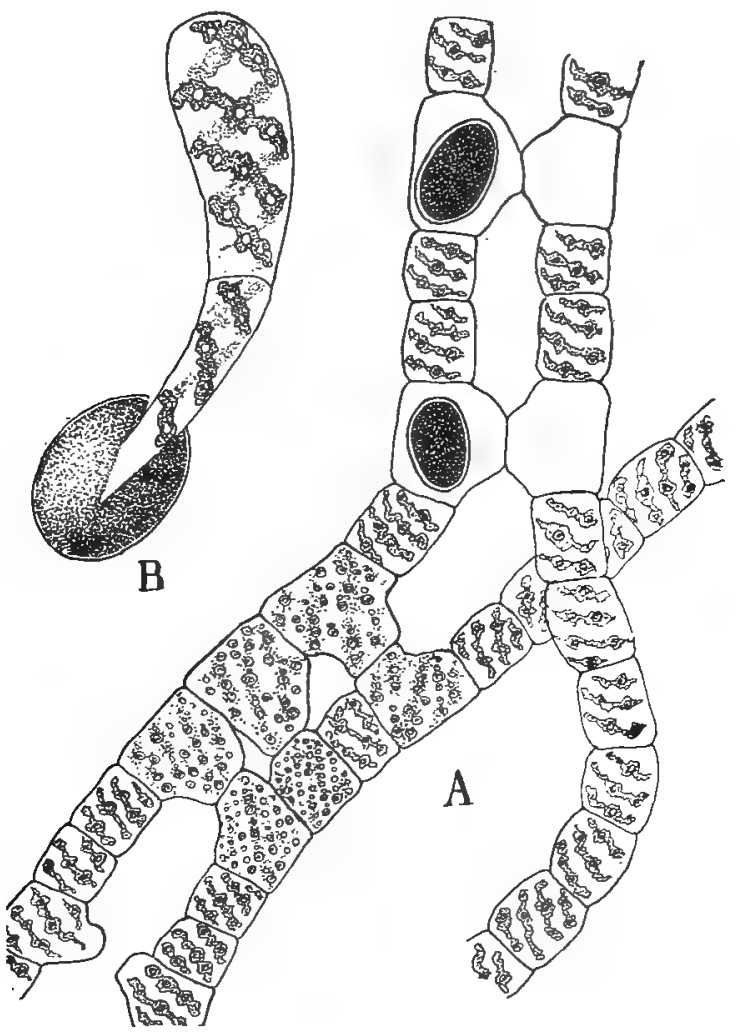

FIG. 107. Sexual reproduction of Spirogyra: $A$, in lower portion of figure the formation of the tubes between the opposite cells of the filaments is shown. Above the contents of two cells have united with two cells of another filament, forming two gametospores. $B$, germination of a gametospore.

This is only a different form of the sexual process with which you are familiar, the difference being, that but one gamete is formed in each cell and these bodies are motionless or at least not provided with cilia and do not escape from the mother plant. When the fusion of the gametes has been effected the resulting 


\section{I88 GERMINATION OF THE GAMETOSPORE}

gametospore becomes surrounded by a thick wall and in this resting condition it tides the plant over seasons, such as the winter or drought, unfavorable for the growth of the plant. When conditions return that permit the growth of the plant, the gametospore germinates by rupturing the outer wall and pro* truding the inner wall of the spore as a delicate tube (Fig. 107, $B$ ). Early in this germination the nucleus divides, forming four cells, the outermost of which only continues to grow and so ultimately forms the new plant. Note that the gametospore, therefore,

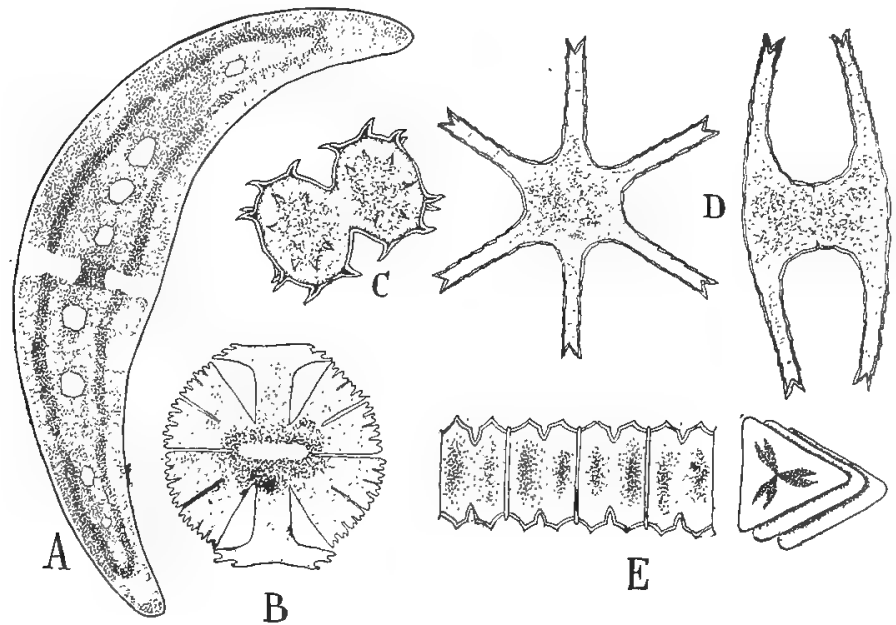

FIG. 108. Common forms of Desmids: A, Closterium. B, Micrasterias. $C$, Xanthidium. D, Stourastrum. At left top view, at right side view. $E$, Desmidium forming a chain of plants. At right, end view of chain.

does not grow directly into the parent type of plant. This behavior of the gametospore is one of the most fundamental features in plant life. It appears in the preceding groups but it is mentioned now for the first time because we see here a clear demonstration of its character. The gametospore is different in its nature and possibilities of growth from any one of the cells of the parent plant. It can not produce the spirogyra plant. It can only produce four cells and from one of these cells there will develop the spirogyra plant. Further consideration of this feature in the life history of the plant will be deferred to later 
examples, where it will become still more obvious. The loss of motility in the reproductive process in this order may possibly be associated with their exposure to terrestrial conditions. They are often exposed to the soil, owing to the drying up of the water and it has been suggested that they have consequently lost their motility. Their mucilaginous coatings would be of great service in enabling them to meet such conditions by retaining moisture, and indeed, they are often able to flourish in many damp places without the aid of surface water.

The Desmids.-A second group of the Zygnematales are strictly unicellular plants known as Desmids (Fig. I08). They are the most attractive of unicellular plants and are of common occurrence associated with coarse algae. The desmids are elaborately and variously fashioned but can readily be recognized by the

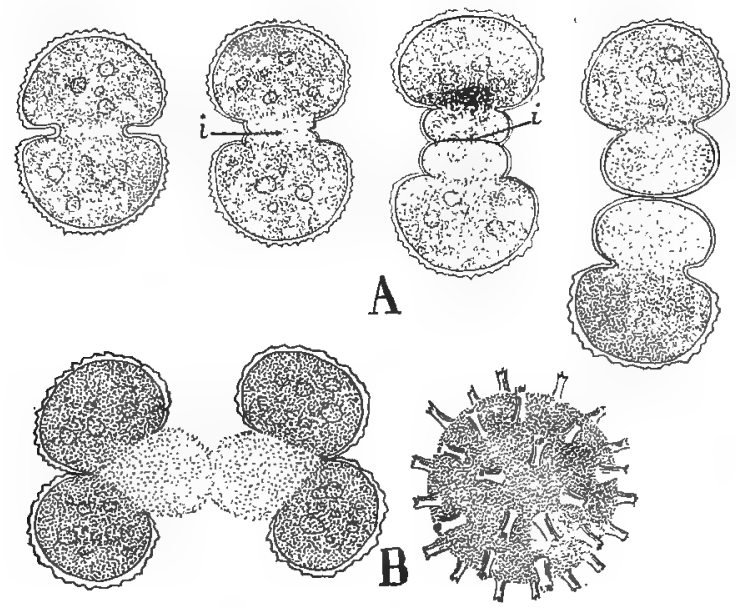

FIG. I09. Reproduction of Cosmarium: $A$, a sexual reproduction, showing the elongation of the isthmus, $i$, and its gradual enlargement and division to form the new lobes of the desmids. $B$, sexual reproduction. At the left the cell contents of two desmids fusing to form a gametospore. On the right the mature gametospore covered with a spiny coat.

fact that they consist of two similar halves (Fig. I09, $A$ ). The structure of the cells and the sexual method of reproduction is essentially the same as in the filamentous forms which have doubtless given rise to these unicellular plants. The asexual 
method of reproduction, however, is rather peculiar. The region connecting the two halves (Fig. I09, $A, i$ ), called the isthmus, becomes somewhat elongated and swollen. Soon a constriction appears midway between these two halves which deepens until the desmid is cut in half. Each desmid now consists of one of the original halves and one half of the isthmus. This latter part gradually enlarges and forms the second half of the desmid. Owing to the gelatinous character of the cell walls, the desmids often become aggregated in masses and form chains of cells (Fig. 108, E).

69. Order c. Chaetophorales or Filamentous Green Algae.Here belong a great array of green algae that grow attached to various objects and appear as simple or more usually as branched filaments which frequently end in hair-like tips. They are of common occurrence at the bottom or margins of springs, wells, streams and ponds. Ulothrix may be taken as an example of one of the simple forms of the Chaetophorales. Fig. I Io shows that it consists of a simple chain of cells that divide and so bring about the growth of the plant as in Spirogyra. However, it is important to note that we have here a higher type of vegetative structure than in any of the algae heretofore studied. This advance appears in the one or more rather colorless cells at the base of the plant which serve to anchor it to the substratum. In other words, there is apparent a distribution of labor or the performance of definite duties by special parts or cells of the plant body. The evolution of higher forms comes about in much this way. So long as each cell of the plant performs the same function, there can be little variation in the form and structure. But as these cells are differently stimulated by their environment, they tend to vary in character and so become adapted to the performance of different functions. Perhaps in Ulothrix the contact of the substratum acted as a stimulus, as Pierce found to be the case in many algae. Thus the plant comes to consist of different kinds of cells, each of which performs a different kind of work. The complexity of the plant is due to the variations of its cells which are thereby adapted to the performance of special duties. In Ulothrix, we have one of the simplest modifications 
of this nature, one or more of the basal cells becoming slightly changed in form and contents and so adapted in anchoring the plant. The other cells of the plant are practically alike, each containing a single nucleus and chloroplast and therefore capable of manufacturing food and forming the reproductive bodies which are of the same simple type as noted in Sphaerella.

(a) Reproduction of Ulothrix.- The contents of any of the green cells may divide into two or more cells which escape as

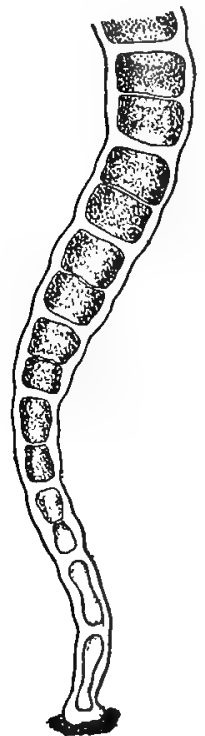

FIG. IIo.

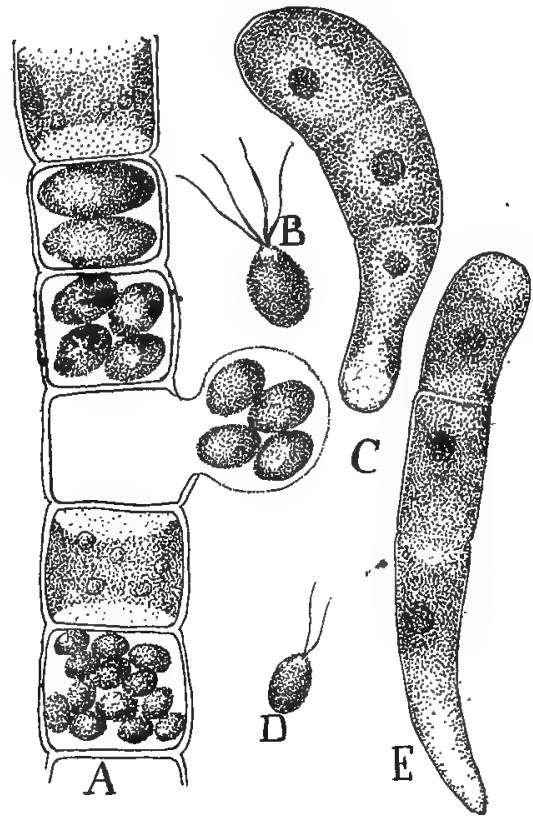

FIG. III.

FIG. I Io. Lower portion of Ulothrix, the basal cells are somewhat modified and the lowest one acts as an anchoring organ. Each of the upper cells contains a girdle-like chloroplast.

FIg. III. Asexual reproduction of Ulothrix: $A$, a few cells of a filament in the upper cells of which the formation and escape of the large zoöspores are shown, while in the lowest cells a large number of small zoöspores appear. $B$, a large zoöspore. $C$, a young plant formed by $B . \quad D$, a small zoöspore. $E$, a young plant formed from $D$.-After West.

zoöspores through an opening formed in the cell wall (Fig. III, $A$ ). The cells in which the zoöspores are formed are called 
sporangia. The zoöspores resemble the motile plants noted above, but after a short motile period they return to the stationary condition and grow into new plants (Fig. III, C). In this way, the number of plants is rapidly multiplied. The point must not be overlooked that this phase of the life history is the same as that of Sphaerella, the difference appearing in the shortening of the motile period and in the lengthening of the non-motile period. During the resting stage the cells of Ulothrix to be sure may divide in one plane forming a filament but remember also that non-motile cells of Ulothrix may divide, forming a mass of cells that become detached or loosely associated-the so-called palmelloid state-which behavior we have seen suggested in the non-motile cells of Sphaerella. It should be stated that the asexual method of reproduction may be looked upon as a means of bringing about a rapid increase in the number of individuals of a species while the conditions for growth are favorable. When new conditions arise, such as changes of temperature, food, etc., that would interfere with the normal growth of the individuals then a modification of the contents of the cells and its mode of division results. The cells of Ulothrix as a consequence of such alterations divide into a larger number of motile bodies which are consequently smaller than in the case of zoöspores (Fig. II2, A). These bodies may behave as gametes and unite, forming gametospores. The cells in which gametes are formed are called gametangia, sing. gametangium. Thus, Ulothrix is controlled in the same manner as Chlamydomonas and Hydrodictyon. It is interesting to note, however, that these small bodies frequently behave as zoöspores and develop into small and weak plants, which fact accounts for the common association in this genus of puny and vigorous plants (Fig. I I I $C, E$ ).

These small bodies of Ulothrix represent a curious intermediate condition between a zoöspore and a gamete where the sexual character is not strongly enough developed to overcome completely the zoöspore character. Thus, we see again in Ulothrix that definite environmental conditions caused motile bodies to be produced that are lacking in some essential substance and consequently do not have the energy for growth, or at least can only 
develop into feeble plants. This weakness is overcome by the fusion of two gametes which results in the formation of a cell or gametospore with renewed energy for growth. We also note how these departures in the behavior of the organism are of advantage to it. The zoöspores effect a distribution of the species while the gametospore ensures a continuity of the species by tiding it over unfavorable conditions.

The gametospore germinates after a period of rest somewhat as in the case of Spirogyra. The contents of the spore, instead of giving rise directly to a new plant, divides, forming several zoöspores (Fig. II2, E, F) which after a period of motility

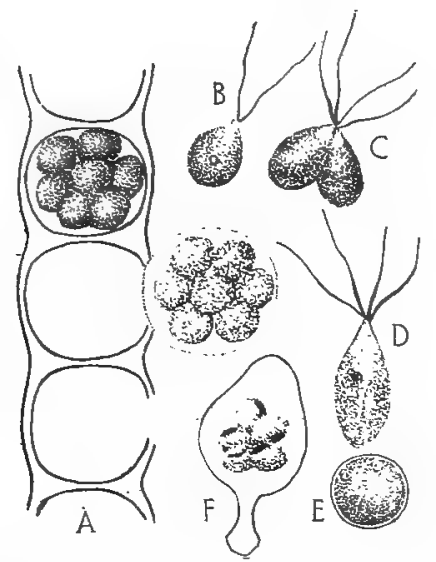

FIG. II2. Sexual reproduction of Ulothrix: $A$, a few cells of a filament showing the formation and escape of the gametes. $B$, gamete. $C, D$, stages in the union of the gametes. $E$, gametospore. $F$, gametospore germinating and forming the sporophyte or așexual generation, which is a sac-like plant containing several zoöspores.

become attached to some object and grow into a new plant. The cause of this peculiar behavior of the germinating gametospore is not known. Some change has occurred in it that renders it incapable of developing directly into a new plant. This variation in the growth of the gametospore marks the beginning of one of the most important departures in the evolution of plant life and it will become more and more significant as the work proceeds. It is evident that the formation of 
several zoöspores, each of which produces a new plant, is a decided advance over those types in which the gametospore develops directly into but one new plant. Note also that in Ulothrix there are two kinds of zoöspores, one formed from the Ulothrix plant and the other from the gametospore, the former being frequently called zoögonidia to distinguish them from the latter. This distinction is of great importance, because most plants have two distinct stages or generations in their life history. One is represented by the plant that bears the sexual cells or gametes and therefore called the sexual plant or sexual generation, or, in short, the gametophyte. The real nature of this plant is to produce gametes, although it may for a time produce zoöspores. The other stage is derived from the gametospore and is called the asexual plant, asexual generation or sporophyte, since this plant can only produce zoöspores. Among the green algae this distinction is not very manifest, the Ulothrix plant for example being the sexual plant or gametophyte and the gametospore or the little plant derived from it (Fig: II2, F) is the asexual plant or sporophyte, in this case being merely a single cell. It is very manifest, however, that this single cell or plant is decidedly different from the Ulothrix plant because it cannot develop into the Ulothrix plant, but can only produce zoöspores. So we see that there are two generations in the life history and that they differ radically in their natures and possibilities of growth. In higher types of plant life it will be seen that the gametospore tends to develop into a more and more complex body or plant and it will be one of the most intresting features of the work to watch the evolution of this asexual plant.

The higher members of the Chaetophorales illustrate the same gradual differentiation of the gametes, as has been noted in the motile forms of the Volvocales. The female gametes become distinguishable because of their larger size and shorter period of motility, while the male gametes are small, owing to the large numbers that are found in a cell or because of the small size of the cells in which they are developed. Finally, in several of the genera we find but a single female gamete which remains motionless in the cell. This condition is very well illustrated in one of the genera of the next order. 
70. Order d. Siphonales or Tubular Green Algae.-This order includes a large number of odd forms that are filamentous in character and they differ from algae previously noted in that the filaments contain numerous nuclei, but with rare exceptions no cell partitions. Such plants are called coenocytes. They assume various forms and often resemble a small plant with stem, root and leaf, but in all these cases the plant is essentially a huge cell or tube without partitions and containing numerous nuclei. Most of the Siphonales are marine, but one genus, Vaucheria, is well represented in shallow streams, damp places and on the earth of flower pots in greenhouses, where it forms rather coarse green felt-like masses. The plant body consists of long tubular threads, often branching and anchored to the ground by colorless

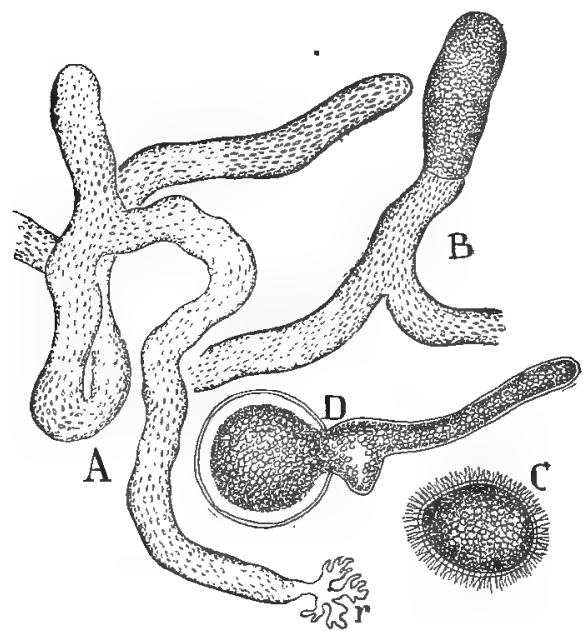

FIG. II3. Structure and asexual reproduction of Vaucheria: $A$, portion of a plant showing the branching tubular filament and colorless root-like outgrowth, $r, B$, end of a filament enlarging to form a zoöspore. $C$, zoöspore. $D$, germination of a zoöspore.

outgrowths (Fig. II3, $A$ ). The protoplasm forms a thick lining layer on the inner wall of the filament and embedded in it are numerous minute chloroplasts, nuclei and oil drops. A watery cell sap fills the center of the tube. Partitions only appear when reproductive bodies are formed or to close a wound in case of 
injury to the filaments. Asexual reproduction is effected by very large zoöspores which are developed in the enlarged extremities of the filaments (Fig. I $13, B$ ). These tips are cut off by a transverse wall and a single zoöspore escapes through an opening in the tip of the sporangium thus formed. The entire surface of the zoöspore is clothed with cilia arranged in pairs, each pair being associated with a nucleus so that the zoöspore resembles the motile colonies previously noted (Fig. II3, C). After a very short motile period, the zoöspore comes to rest and grows into the characteristic tubular plant (Fig. I I $3, D$ ). When the plants are exposed to too dry conditions, the tips of the filaments often

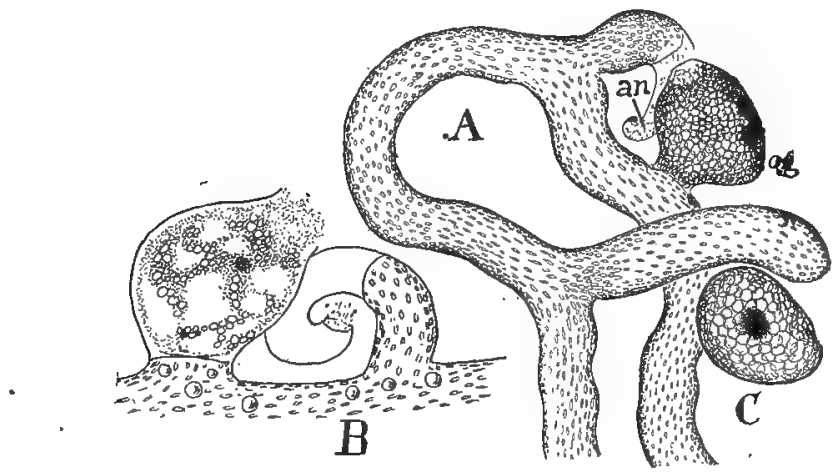

FIG. I14. Sexual reproduction of Vaucheria: $A$, portion of a filament that has formed two branches which have grown into a male, an, and female, og, gametangia. $B$, later stage, the gametangia have opened, permitting the escape of the male gametes and the fertilization of female gamete. $C$, gametospore detached from the filament.

enlarge and finally become detached as motionless spores that germinate when conditions are again favorable.

The male and female gametes are produced in gametangia that are formed from short branches. The males are developed in large numbers in curved branches that become cut off from the filament by a cross wall (Fig. II4, $A$ ) and the gametes finally escape through an opening that forms at the apex of the branch. A gametangium that produces clearly differentiated male gametes is called an antheridium (plu. antheridia) and the gametes are frequently called antherozoids or sperms. A single female 
gamete is found in a similar branch which becomes rather eggshaped and at maturity opens at the beaked end (Fig. II4, B). A single-celled female gametangium is called an oögonium and the female gamete is frequently referred to as the oösphere or egg. The male gametes are discharged a few minutes after the oögonium opens, when they swarm about the open end of the female gametangium and readily enter it. As soon as fusion has been effected the gametospore becomes invested with a thick wall and in this condition can endure a limited drought. In germinating it develops directly into a new plant. This feature of the

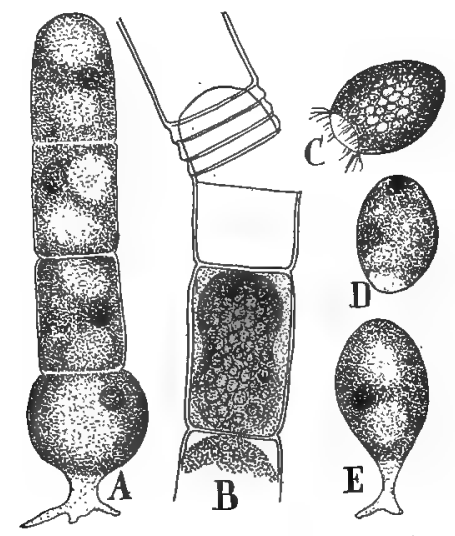

FIG. II5. Growth and asexual reproduction of Oedogonium: $A$, young plant showing basal cell modified as a hold-fast. $B$, two cells of a filament, in one of which a zoöspore is forming and the other cell has opened, permitting the escape of the zoöspore shown at $C$. D, zoöspore at rest. It becomes attached to an object at its colorless, ciliated end. $E$, later stage in the germination of the zoöspore.-After West.

life history of Vaucheria, therefore, appears as of a more primitive nature than in the case of Ulothrix. In the following studies you will repeatedly notice variations of this nature. In the development of plants advances are often confined to one or another feature of their organism which may become highly developed and specialized; at the same time one or more features may be retained that have been subject to little or no variation and which, therefore, remain in a primitive state.

7I. Other Members of the Green Algae.-There are several 
orders of the Chlorophyceae, some of which are marine, that cannot be considered at this time. Two genera, however, deserve attention because they show significant advances in the evolution of plant life. In Oedogonium, a member of a small order, the Oedogoniales, we find a still higher form of the sexual reproductive process. These plants are of very common occurrence in ditches, streams and springs where their filaments form for a time greenish masses and coatings upon various objects, but finally become detached and free-floating (Fig. II5, A). Any of the cells of a filament, save the basal one, may form a single zoöspore, which are large pear-shaped bodies with a narrow

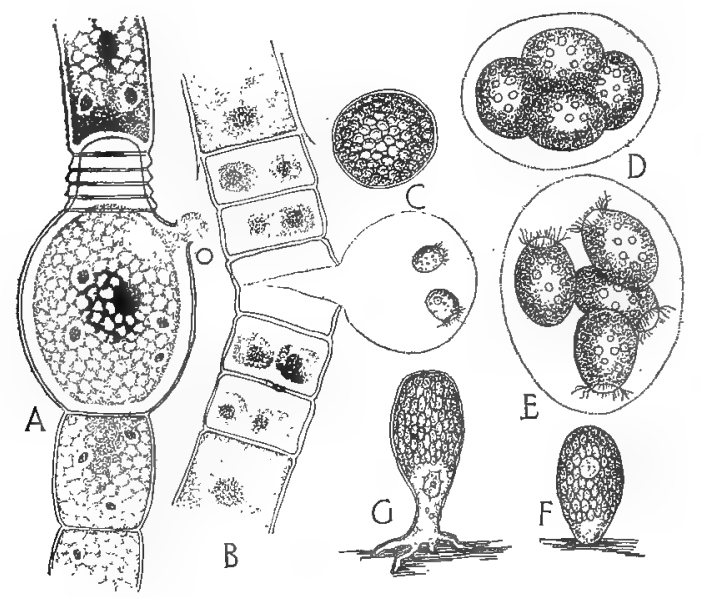

FIG. II6. Sexual reproduction of Oedogonium: $A$, portion of a filament in which a female gamete has been formed-o, opening in cell wall for entrance of male gamete. $B$, portion of filament showing formation and escape of male gametes. $C$, gametospore free from mother cell. The germination of this spore results in the rupture of its outer wall and the protrusion of the contents of the spore as four cells which are for a time retained by the delicate inner wall of the spore, as shown in $D$. $E$, the four cells have become mobile zoöspores and the delicate inner wall of the gametospore is greatly distended and about to rupture. $F, G$, stages in the germination of the zoosspore. -After Hirn.

colorless end around the base of which arise a circle of numerous cilia (Fig. II5, B,C). These zoöspores develop into new plants (Fig. II $5, D, E$ ) as in previous cases: The sexual reproduction presents a high degree of specialization. The male gametes are 
usually formed in pairs in small cells and are similar to but smaller than the zoöspores, while the female gametes are developed singly in the ordinary cells of a filament which become greatly enlarged and spherical or void in form (Fig. I16, $A, B$ ). The female gamete is motionless but the colorless region on one side of the gamete certainly suggests the idea that this body is

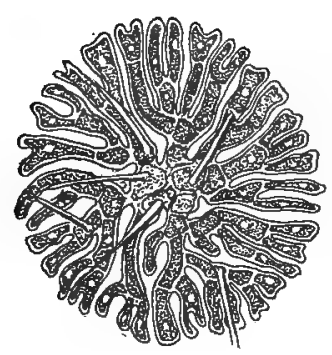

FIG. II7.

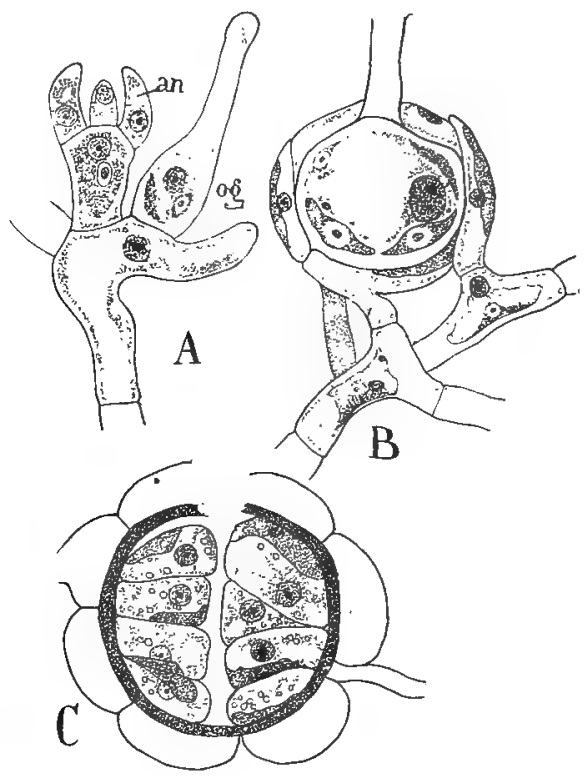

FIG. II 8 .

FIG. II7. Coleochaete, showing the radiating filaments and hair-like outgrowths of the cells.

FIG. II 8. Sexual reproduction of Coleochaete: $A$, end of a filament bearing the male, $a n$, and female, og, reproductive organs. $B$, the gametospore is being enveloped by the adjacent filaments of the plant. $C$, gametospore germinating. Eight cells have been formed, rupturing the walls of the gametospore.-After Oltmann.

related to the zoöspores and male gametes, but that it has lost its cilia. At maturity, openings of various kinds appear in the oögonium through which the male gametes enter and one fuses with the female (Fig. I I6, $A, o$ ). The thick-walled gametospore that results from this union is set free by the decay of the ooggonial walls and germinates after a resting period very much as in the 
case of Ulothrix. The contents of the gametospore is extruded through the ruptured wall as a delicate sac and then divides, forming four zoöspores which produce new plants (Fig. II6, $C-G$ ) -thus we see again an illustration of the peculiar nature of the gametospore as in Spirogyra and Ulothrix. The question will naturally arise as to the force that brings these and other gametes together. The frequently observed aggregation or swarming of the male gametes about the females renders probable the view that some substances, as organic acids, etc., are developed in the gametes that serve to draw them together whenever they come within a certain distance of each other.

The consideration of Coleochaete, a plant of the same order as Ulothrix, has been deferred to this point because it presents several interesting departures from previous types which indicate that a higher point has been attained in some respects by this plant than by any other of the green algae. The filaments of Coleochaete have a pronounced apical growth and are usually associated together in a radiate manner, forming small discs or cushion-like masses on the stems and leaves of water plants (Fig. II7). The advance of this type is indicated not only by the localization of growth at definite points, but also by the formation of the zoöspores and gametes in definite regions, i. e., in special cells which are usually located at the end of the filaments. The zoöspores are produced singly from such cells, and from smaller pear-shaped cells single male gametes are formed. The female gametes are developed singly in large flask-shaped cells, access to which is afforded by an opening that appears at the end of the long neck of the flask (Fig. I I8, $A$ ). The gametospore develops a cell wall and becomes enveloped by the adjoining cells of the filaments (Fig. II $8, B$ ). In this condition the winter is passed and in the spring it germinates, forming neither a plant like the parent type nor zoöspores as in Ulothrix and Oedogonium, but instead, the gametospore forms a number of cells. This growth ruptures the coat of the spore and finally from each cell a rather irregular zoöspore (Fig. II 8, c) is derived that develops into a small plant. The plants thus formed multiply solely by zoöspores until finally, after several generations, larger plants 
are produced that bear gametes, thus completing the life history.

72. Noteworthy Features of the Chlorophyceae.-Two features in the study of green algae should be kept clearly in mind, because they are closely connected with the tendencies that will appear in the development of the mosses. First: The gametospore is essentially a dormant or resting cell that tides the life of the plant over the conditions unfavorable for growth. Second: In passing from lower to higher types, the gametospore tends to vary in its nature and possibilities of growth. At first it forms directly a sexual or gamete-bearing plant as in Sphaerella but in higher types, it develops a generation of zoöspores from which the sexual plant is derived as in Ulothrix and Oedogonium. Finally in Coleochaete, we find a further advance in that several non-motile cells are formed by the gametospore. These cells, to be sure, are essentially like the zoöspore because they develop directly into zoöspores, but this condition emphasizes the fact that the nature of the gametospore is steadily departing from that of the gamete-bearing plant.

This development could be summarized by saying that there is a tendency to separate the life history of the plant into two stages; a sexual or gametophyte generation and an asexual sporophyte generation. These two generations follow each other in the life history of all the higher plants. This peculiar relationship is called the alternation of generations and the reason for it will be more apparent when we come to study the mosses.

\section{Class B. The Brown Algae or Phaeophyceae}

73. General Features.-With few exceptions the Phaeophyceae are marine plants. They are commonly known as brown algae, owing to the brownish pigments which conceal in a measure the chlorophyll, thus producing their characteristic brown or yellow color. They are of common occurrence along rocky shores and attain enormous dimensions in the northern and southern seas and on the Pacific Coast. As a rule, the plant body is better differentiated than in the green algae and shows a higher type of specialization than yet seen. It would appear 
probable that the brown algae have been derived from green algae but there is no satisfactory evidence of a series of unicellular forms leading up to the rather complex types that are representative of the simplest of the Phaeophyceae. The majority of these lower forms have already reached the filamentous stage and many of the higher genera exhibit a differentiation of the plant body suggestive of the higher plants, as for example, a definite axis with branches and leaf-like outgrowths and rootlike organs that anchor the plants to the substratum. Likewise, the tissues of these higher types often reveal many of the features already noted in the epidermis, cortex and central region of terrestrial plants. The life history of the brown algae indicates that they have undergone the same evolution as the Chlorophyceae. For purposes of comparison we will consider only two groups of the brown algae.

(a) The Simpler Brown Algae.-Ectocarpus may be taken as an example of this group. It is a filamentous branching form that is almost universally distributed along the sea shore (Fig. Ir9). The zoöspores are developed in certain cells of the upper branches. It is important to note in the brown algae, that the reproductive cells are generally confined to special parts of the plant and not promiscuously developed as in the green algae. This marks a decided advance in the evolution of the plant. The tissues are becoming more specialized and the work performed by the plant is apportioned to special cells and organs. The zoöspores have essentially the same structure and mode of growing into new plants as noted in Ulothrix. The cilia, however, are laterally attached and this is a characteristic feature of the zoöspores of the Phaeophyceae generally (Fig. II9, $A, g$ ).

The sexual reproduction of Ectocarpus exhibits some of the most instructive variations to be found in all the algae. The gametes are formed in gametangia that become divided into great numbers of very small cubical cells, each one of which produces a single gamete (Fig. II9, B). Thus the origin of the gametes is more specialized than in the case of the green algae where numerous gametes were formed in a single cell. You are to remember this feature of the gametangium because 
some of its characteristics will reappear in Bryophyta. The gametes themselves, however, show the same range of variations as previously noted. In the simpler types of this genus they are quite alike and on the same p'ane of differentiation as

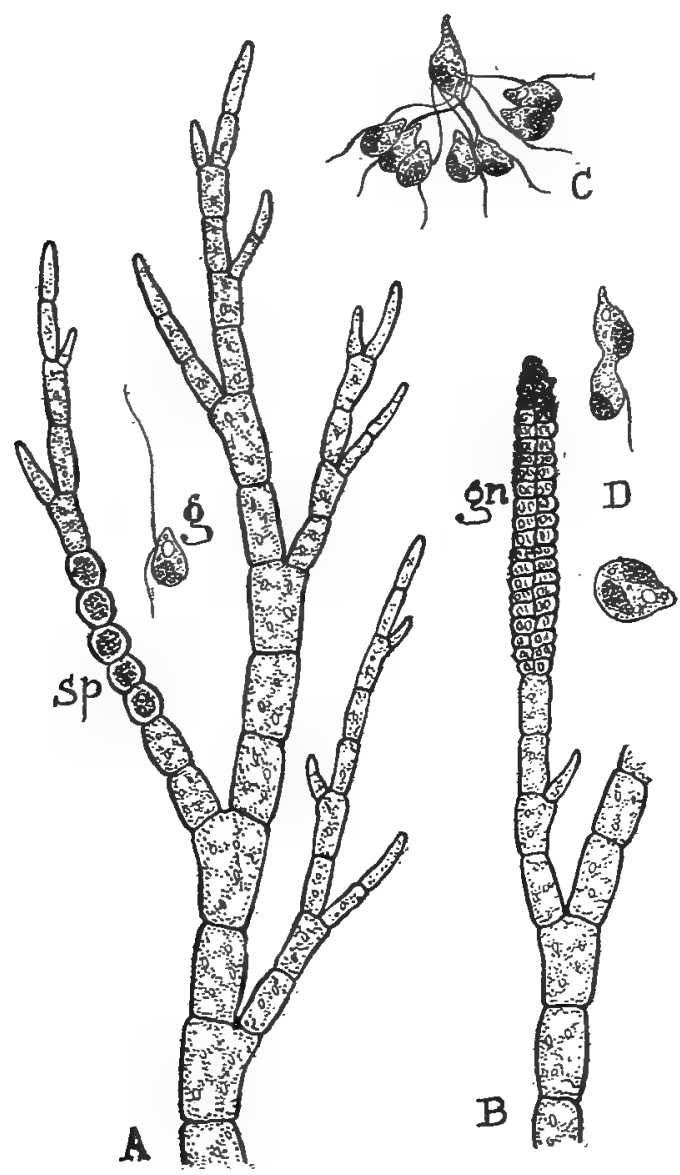

FIG. II9. Reproduction of Ectocarpus: $A$, branch bearing several sporangia, $s p ; g$, zoöspore enlarged. $B$, branch bearing gametangia, $g m$. $C$, the upper motionless gamete (female) surrounded by several still motile gametes (males). $D$, fusion of the gametes, below the resulting gametospore.

in Ulothrix, since they sometimes develop as zoöspores, directly forming the plant, or they may behave as gametes and fuse to 


\section{SEXUAL REPRODUCTION OF ECTOCARPUS}

form a gametospore. The nature and character of these bodies is so imperfectly established that their behavior is entirely determined by external conditions. Low temperatures and bright light tend to develop these bodies as zoöspores, whereas, high temperatures cause them to behave as gametes. (See Pandorina and Hydrodictyon.) Other species of Ectocarpus show an advance over this stage. The gametes are alike, but it has been observed that certain ones, the female gametes, have a shorter period of motility and after coming to rest they attract the still motile gametes, the males, and cause one to fuse with them (Fig. II9, C, D). This is the simplest distinction that can be pointed to as indicating a difference in the nature of the gametes which we call sex. This variation in the period of motility of the gametes must be due to an essential difference in the material or substance of which they are composed, although there is no external evidence of this. Certain species of this same genus also reveal a variation in the size of the cells from which the gametes are derived. In these species, the sex is clearly indicated by the larger size of the female cell and it is noticeable that there is a decided tendency for the smaller gametes to fuse with the larger and more slowly moving females. It is also worthy of note as these gametes become differentiated and their sex more evident that they are less able to behave as zoöspores and grow directly into new plants. When the gametes produced by the plant are all alike they may readily be made to grow into new plants, but this is rarely the case where they can be distinguished as male and female. Thus, in Ectocarpus, we have a most remarkable series of variations that indicate how sexuality has arisen from the asexual condition and also how sex finally became characterized by a shorter motile period in the female gamete. The character of the female finally became more pronounced, owing to its better nourishment and consequent increase in size and slower movements. A more perfect illustration of the evolution of sex is not found in nature.

The differentiation of reproductive parts, as will be frequently noted, does not keep pace necessarily with the evolution of the plant body. It is evident that sexuality has arisen independently 
at different levels in the plant world and in groups in no wise connected. We have noted the same state of sexuality in some of the motile green algae, $i$. $e$., in Chlamydomonas and in nonmotile forms as Hydrodictyon and Ulothrix, and now again in Ectocarpus although these plants are widely separated as far as relationship is concerned and exhibit a marked variation in the development of the plant body. It is also frequently to be noted that plants may get along very well indeed with only a sexual or an asexual method of reproduction.

(b) The Coarser Brown Algae, the Kelps.-Under this head we may consider two groups, illustrated by the kelps and rockweeds. The kelps are related to Ectocarpus and include the largest and most highly organized forms of all the algae. Indeed some of these forms are quite comparable in size with our shrubs and trees. The Laminarias (Fig. 120, $A$ ) of our Atlantic coast

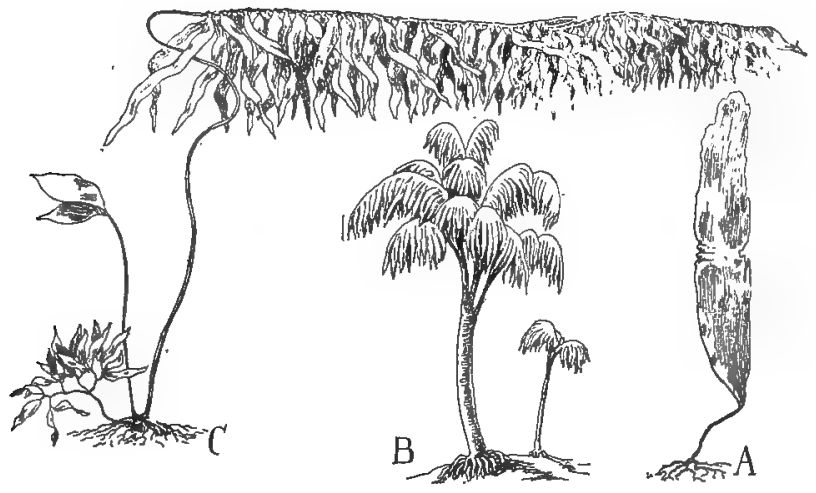

FIG. 120. Three of the larger brown algae: $A$, Laminaria. B. Lessonia. C, Macrocystis.

have stalked blades ten to twenty feet long. The great bladder kelps of the Pacific, Nereocystis and Macrocystis, attain great dimensions, the latter genus reaching a length of 500 to 900 feet and Lessonia with trunk-like stems and leaf-like segments forms veritable submerged forests in the Antarctic Ocean (Fig. I20, $B, C)$. These highly organized plants, however, do not show any advance in sexual reproduction over the simplest form noted in Ectocarpus. Much attention has been directed to the kelps 
as a source of potassium (see page 48), from 23 to 48 per cent. of their dry weight being potassium chloride. It is estimated that there is between 600 and 800 sq. miles of these plants on our Pacific coast and that they should yield annually one million tons of potassium chloride, valued at 40 million dollars.

The rock weed or bladder wrack (Fucus) and the gulf weed (Sargassum) are representatives of the second group, Fucaceae, that contain the most specialized of the brown algae (Fig. I2I). The Sargassum with its stem and leaf-like organs which may become modified into air sacs and reproductive organs bears the closest external resemblance to the higher plants of any of the algae (Fig. I2I, $A$ ). It forms the major portion of that floating

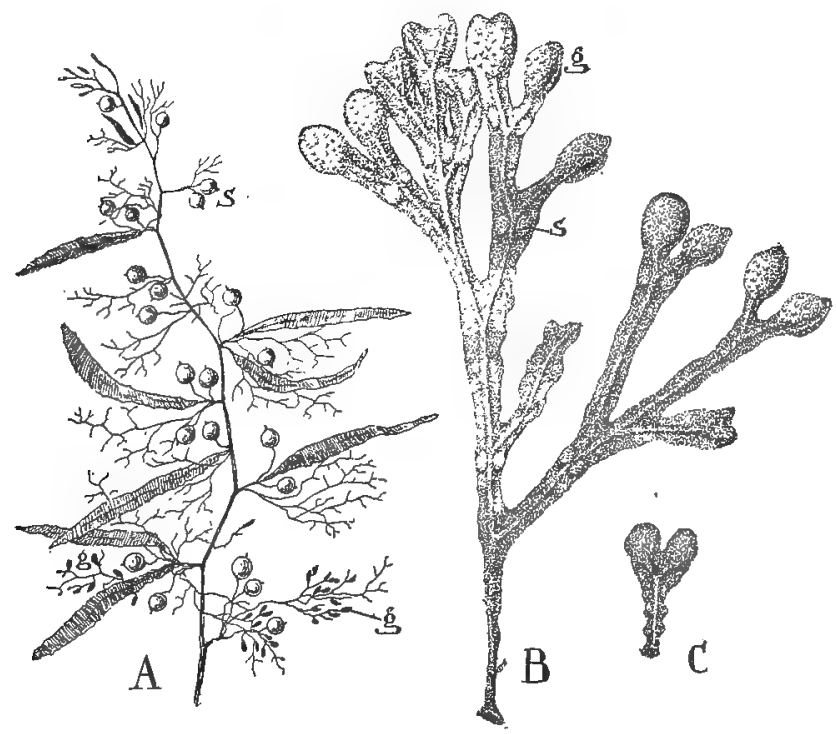

FIG. I2I. Two common forms of the Fucaceae: $A$, Sargassum, the stemlike axis bearing air sacs, $s$, and leaf-like organs; $g$, reproductive branches. $B$, Fucus-s, air sacs; $g$, reproductive branch. C, young plant.

vegetation in the Atlantic known as the Sargasso Sea. The bladder wracks may be found firmly attached to the rocks by disc-like holdfasts in almost all colder, temperate and northern seas (Fig. I2 I, B). The elongation of the flat leathery stems is largely localized in a terminal cell and results in a regular 
forking of the stem into two equal parts, a method of branching called dichotomy in contradistinction to the axial branching characteristic of the majority of our flowering plants. Fucus, like many of the gross brown algae, contains air cavities or bladders which buoy it up in the water; this feature accounts for its popular name of bladder wrack. A cross section of the stem shows that the tissues of these plants have attained a considerable differentiation (Fig. I22, $A$ ) as is attested by a rudi-

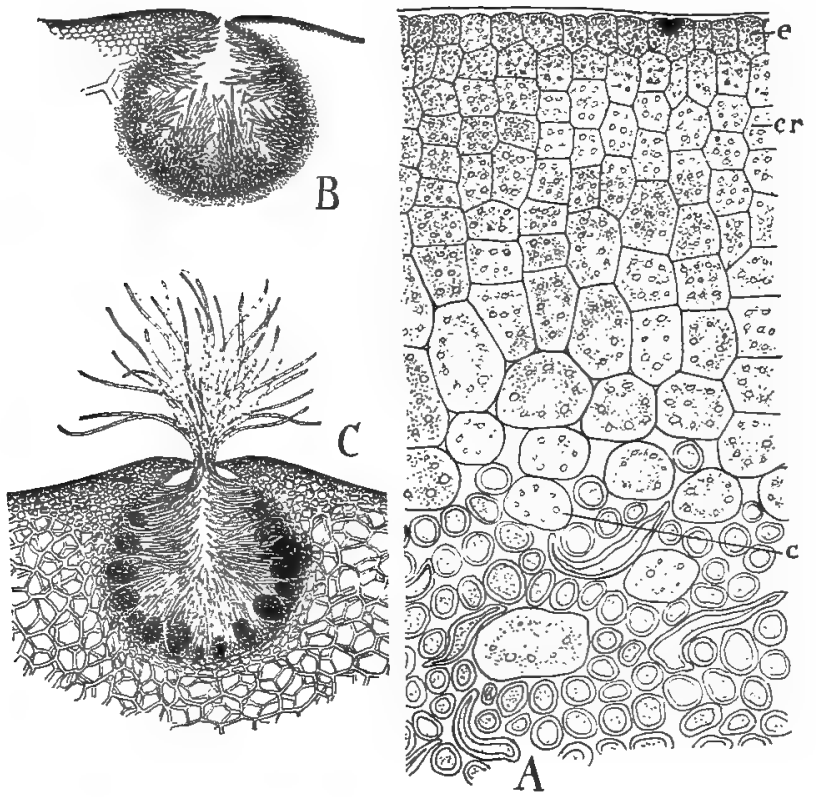

FIG. I22. Structural features of Fucus: $A$, cross-section of a portion of the central stem-like part of the plant, showing an epidermal, $e$, cortical, $c r$, and central region, c. $B$, section of one of the cavities that appears to the eye as a dot. See Fig. $12 \tau, B, g$. This cavity contains only male gametangia. $C$, section of a cavity from another plant contains only female gametangia.-After Oltmann.

mentary epidermal, cortical and central region, the latter often containing well-marked sieve tubes. These elongated cells of the central region promote the rapid distribution of materials and doubtless account in part for the size obtained by the kelps and rockweeds. 
The most characteristic feature of these plants, however, and the one separating them sharply from "the Laminarias appears in their method of reproduction. None of the Fucaceae develop zoöspores, although an asexual reproduction may be effected by the detachment of small branches from the plants. Sexual reproduction is a step in advance of any of the preceding types of the brown algae, in that the female gamete becomes still larger and loses entirely the power of motion. The reproductive organs, or gametangia, are developed in specialized branches or enlarged tips of the thallus. In Fucus (Fig. I2I, g), these organs are contained in small pits or cavities that appear as minute points, or as dots when the enlarged tip of a branch is held up to the light. A magnified section taken through such a branch shows the nature of the cavities (Fig. I22, $B, C$ ). In some species, the male and female gametangia are found in the same cavity, or they may occur separately and on different plants. The male gametes are developed in enormous numbers in numerous little sacs, or antheridia, borne on branching filaments of cells

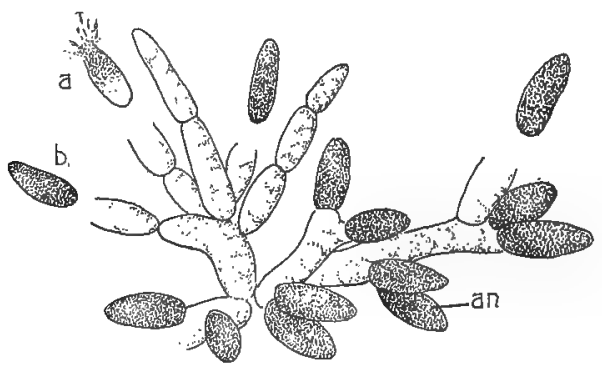

FIG. 123. One of the branching filaments from Fig. I22, $B$, greatly enlarged. Some of the antheridia, an, have discharged the male gametes, which are still retained in the inner wall of the antheridium, as at $b$. At $a$ this wall is ruptured, freeing the gametes.

which grow out from the sides of the cavities (Fig. I23). The female gametes are produced in larger sacs or oögonia, which are each supported on a single cell and associated with hair-like chains of cells, paraphyses (Fig. I24, $A$ ). Usually eight gametes are developed in each oögonium. The gametes when first discharged from the antheridia and oögonia are enclosed in a delicate 
cell wall which later ruptures and sets them free (Fig. I24, B). The female gametes are without cilia and as they float away in the water they appear to attract the male gametes which swarm about them and finally fertilization is effected by one of the male gametes working down to the nucleus of the female and fusing with it (Fig. I24,C). In an allied form not only is an attractive substance formed in the female gamete, but probably a repellent

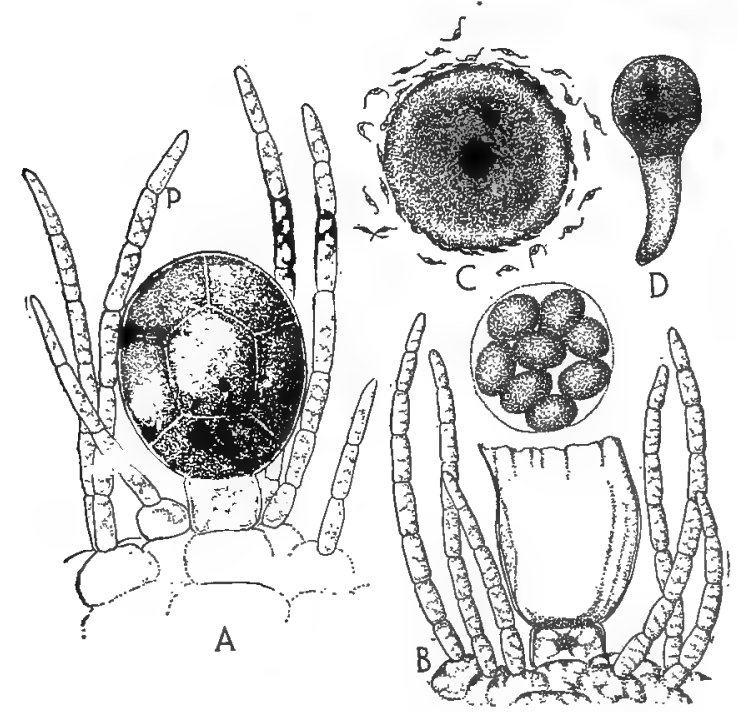

FIG. I24. Female gametangia: $A$, greatly enlarged view of one of the oögonia shown in Fig. 122, $C$. The oögonium is dividing and forming the female gametes; $p$, paraphyses. $B$; the female gametes discharged but still retained in the inner wall of the ooggonium. $C$, greatly enlarged view of a gamete which is surrounded by male gametes, some of which are seen as dark bodies penetrating the cytoplasm of the female gamete. $D$, early stage in the germination of the gametospore. See later stage, Fig. I2I, C.-After Thuret.

one after fertilization is effected, for Farmer observed that the male cells swarm about the female cells for a time and then suddenly swim away "like a flock of frightened birds." As soon as fertilization has been effected, the gametospores become invested with a cell wall and attached to the rocks. Cell division now proceeds rapidly and soon establishes the characteristic thallus of the plant (Figs. 124, D; 121, C). Fucus is a very prolific plant 
and the reproduction process can be observed at àlmost any time. After the plants have been exposed for several hours by the low tide the male and female gametes. will often be found forming orange yellow and olive green drops at the mouth of the cavities. In this condition the entire process of fecundation and early stages of germination can be studied by transferring a bit of these two fluids to a drop of sea water on a slide and studying them under a microscope. The differentiation of the gametes of Fucus is an interesting one because it represents the stage where the female gamete has become motionless, but is not retained in the mother cell as in Vaucheria and Oedogonium.

No resting spores are found among the brown algae. This may be connected with the more uniform conditions that obtain in the sea where also they are not exposed to the dangers of desiccation as in fresh water forms. It is noteworthy, that although the reproductive organs are, on the whole, more complex, fertilization is of a more primitive character than among many of the green,algae, in that the fusion of the gametes is effected outside of the gametangia.

\section{Class C. Red Algae or Rhodophyceae}

74. General Features.-The Red Algae are largely marine plants. Unlike the brown algae, they reach their greatest development and abundance in the warmer waters of the temperate and tropical seas and are usually found attached to various objects below tidal marks. Their red pigments probably adapt them to the feeble illumination of the deep waters in which they generally occur. They range through a great variety of forms, from delicate filaments or flattened ribbon-like bodies to structures with cylindrical axes and leaf-like branches (Fig. I25). The elegant symmetry of their branching together. with the delicacy of structure and richness of coloration has always attracted attention and made them the most familiar of all the algae. They are popularly though inaccurately known as sea mosses.

Reproduction of the Red Algae.-The reproduction of the Rhodophyceae, particularly the sexual method, presents so many modifications and specializations that only the general features 
can be pointed out. Singularly both the spores and gametes, have lost their motility. The sexual method of reproduction is the most complicated among all the algae, and even in the simplest form is far in advance of any method heretofore noted.

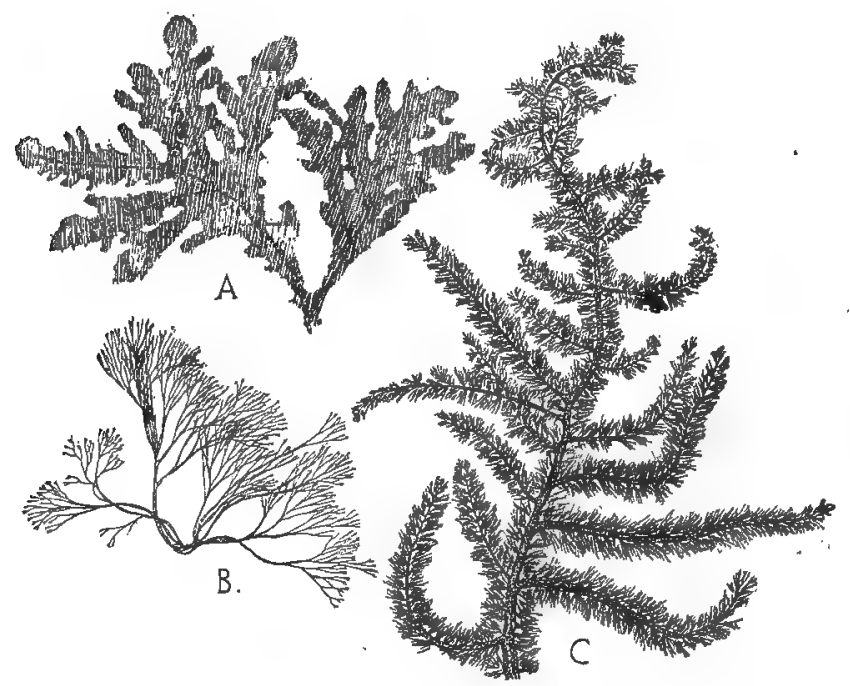

FIG. I25. Common forms of the Red Algae: $A$, a leaf-like form, Delesseria. $B$, a branching thread-like form, Ceramium. $C$, a branching form covered with delicate hairs, Dasya.

The female gametangium resembles a flask with a long neck and is usually developed at the end of a branch (Fig. I26, $A$ ), see Coleochaete. The single female gamete is found at the base of the flask. The male gametes are produced singly in small cells also at the ends of branches and they are often closely aggregated in dense clusters (Figs. 126, an; 127; $A, B$ ). After the discharge of the male gamete, they are carried by the currents of the water to the long tube of the female organ. The wall of the tube at the point of contact is now absorbed and the male gamete passes down the tube and fuses with the female. The gametospore does not germinate and produce a new plant similar to the one that bore the gametes. On the other hand, it produces a number of branches (Fig. I26, B, C), the terminal cells of which develop as spores (Fig. I26, D). The mode of sexual repro- 
duction outlined above is complicated in the majority of the red algae, owing to the fusion of the germinating gametospore with adjacent cells that contain storage foods and from certain of these storage cells the characteristic spore producing branches are developed. In this way, the formation of a larger number of spores is made possible by a single fecundation. Frequently
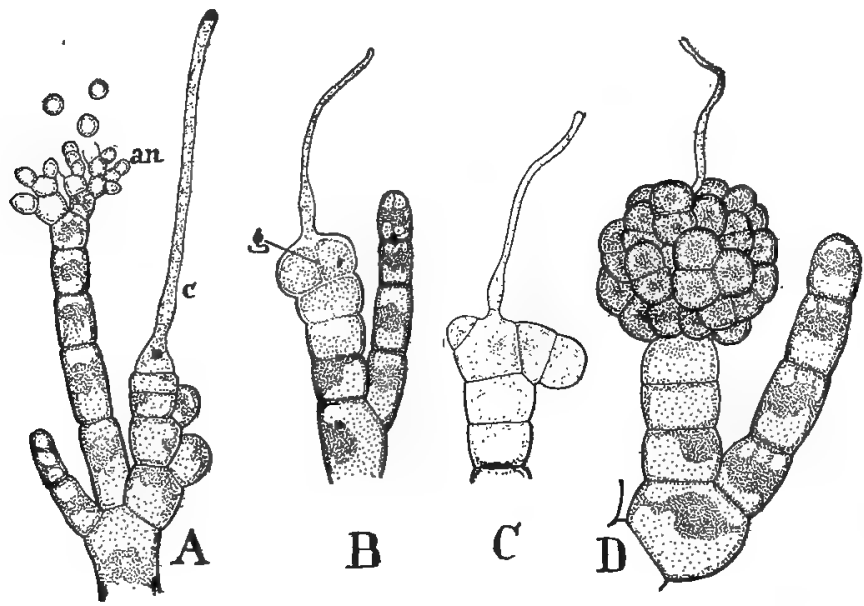

FIG. 126. Sexual reproduction in Nemalion: $A$, tip of branch bearing female gametangium, $c$, and cluster of male gametangia, $a n$, from some of which the motionless male gametes are escaping. $B$, first division of the germinating gametospore, $g$. $C$, later stage showing the early formation of the branches from which the spores will be developed. $D$, spores forming at the ends of the numerous branches.

a sac-like structure, the cystocarp, is developed about the spores owing to the outgrowths of the adjacent cells (Fig. 127,C). Attention should be fixed upon the form of the female gametangium and the sac-like structure of the cystocarp because you will see these features reappear in certain groups of the fungi.

The spores formed from the growth of the gametospore are finally set free and grow into plants resembling the gamete bearing red algae but singularly these plants only produce spores-never gametangia. These spores are formed in fours in a single cell (Fig. r28) and therefore called tetraspores. These spore-forming cells arise singly on the surface or in the tissues 


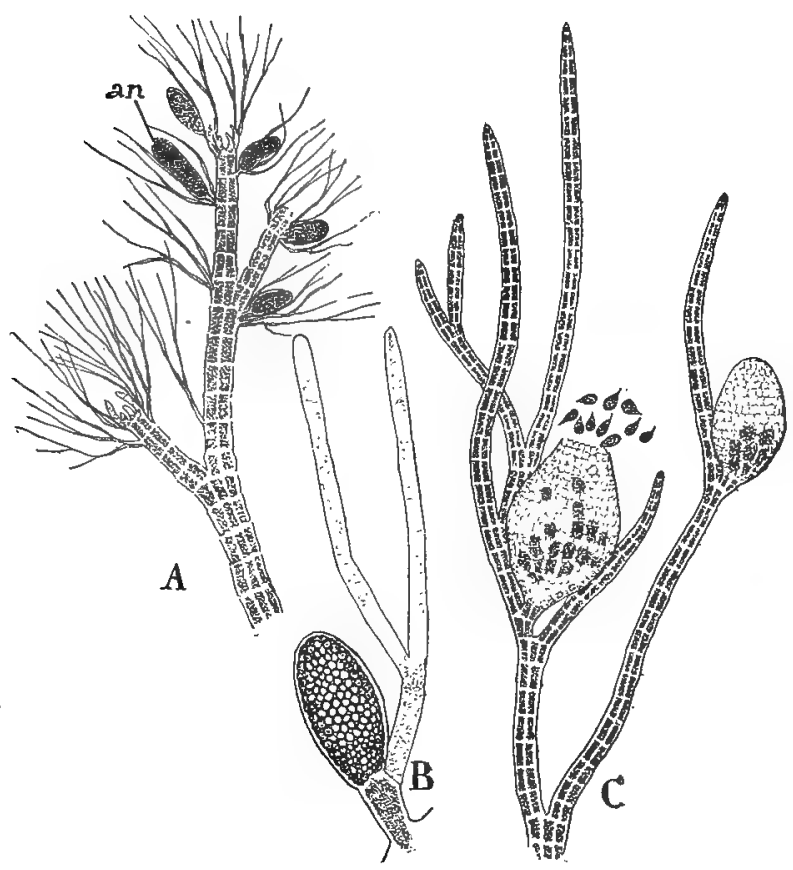

FIG. 127. Features in the reproduction of Polysiphonia: $A$, branch off the plant bearing clusters of male gametangia, $a n$. $B$, one of the clusters: enlarged, showing the numerous small gametangia. $C$, branch on which the spores derived from the gametospores are enveloped by a sac. From one of these bodies, called cystocarps, the spores are escaping.

of the plant, or they may be associated in conspicuous groups. The spores escape from the mother cell as naked bodies and

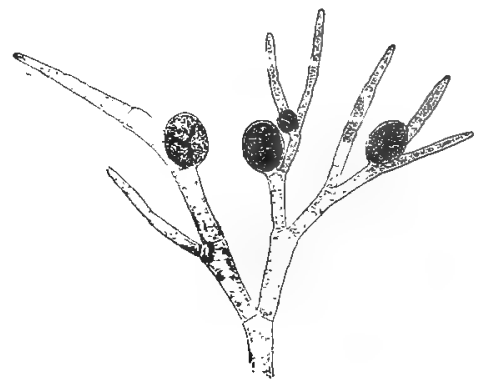

FIG. I28. A branching filament of Callithamnion, showing the spore mother cells forming tetraspores. 
finally secrete cell walls and develop into new plants. These plants, however, normally bear only gametangia and not tetraspores. So in this life history we have two similar plants appearing but they are manifestly different in nature as one produces tetraspores and the other gametangia.

The red algae are of considerable economic importance. Irish moss, Chondrus, is used in the manufacture of jellies, and agar-agar is obtained from several species of algae. Many tons of various kinds of red algae are annually dried and consumed for food in the East. The swallow's nest, of which you have heard so much as an article of food in the Orient, is constructed of algae.

75. Significant Features in Life History of the Algae.-The germination of the gametospore in the Rhodophyceae is a noteworthy departure in two respects. Unlike previous cases, it is retained on the plant, where it is nourished during its germination and grows practically as a parasite. This relation of the gametospore to the mother plant will become more noticeable among the fungi and the mosses and lead to pronounced changes in the life history of the plant. In the second place, we notice that the gametospore in the red algae produces a number of cells before the spores are formed. In the green and brown algae it either developed directly into a plant similar to the mother plant, as in Vaucheria and Fucus, or zoöspores were first formed which developed into a plant similar to the parent, as in Ulothrix and Oedogonium. What is the significance of this variation in the germination of the gametospore? Attention has been directed in the study of Spirogyra and Ulothrix, p. I93, to the fact that there are two phases in the life history of a plant, a spore-bearing phase or generation, and a sexual phase or generation. This is doubtless true of all forms characterized by a sexual reproduction. On page 136 you have noticed that these two phases or generations are also sharply distinguishable by the number of chromosomes appearing in the nuclei of the cells, the sexual generation having only half the number found in the asexual. This change - in the number of chromosomes occurs at two points in the life history, first, when the gametes unite to form the gametospore, 
at which time the number of chromosomes is doubled, and, secondly, when the spore mother cell of the asexual generation divides to form the four spores, the number of chromosomes is reduced by one-half. The two generations are generally not apparent in the Green and Brown Algae, because the asexual generation is greatly reduced and often does not produce spores, as in Vaucheria, etc., where the asexual generation consists of a single cell, the gametospore. This gametospore, however, must have twice the number of chromosomes as the mother plant, since it is formed by the union of the chromatic substance of two gametes and it will doubtless be found that its first divisions in germination are attended with a reduction of the chromosomes to the original number found in the mother plant. This remark applies also to Ulothrix and Oedogonium, where it is reasonable to suppose that the formation of the four zoöspores by the germination of the gametospore results in the reduction of the chromosomes to the number found in the mother plant. This has been found to be the case by Allen in the division of the germinating gametospore of Coleochaete, and Yamanouchi reports that the reduction of the chromosomes in the Red Algae does not occur until the mother cell divides to form the tetraspores (Fig. 128) and the same reduction has been reported in Spirogyra in the germination of the gametospore. The red algae give us the best illustration of this relationship yet seen. Here the gametospore gérminates, producing a small spore-bearing plant, enclosed in the cystocarp, which is parasitic upon the sexual plant. This plant is a part of the asexual generation, as all its cells contain the double number. of chromosomes. The spores from the cystocarp form plants externally similar to the sexual plants, but these plants are really different, being characterized by cells with the double number of chromosomes and also by the fact that they bear tetraspores. The formation of the tetraspores, however, is attended with a reduction of the chromosomes by one-half, and these spores produce plants characterized by the reduced, number of chromosomes, and also by the fact that they bear the sexual organs. So in the Red Algae we have very clearly brought before us the two generations in the life of the 
plant, the sexual generation, characterized by the reduced number of chromosomes and the production of the sexual organs, and the asexual generation, characterized by the double number of chromosomes which appear in two spore-bearing plants, $i . e$., the minute plant in the cystocarp and the tetraspore-bearing plant. The distinction between the sexual and asexual generation is emphasized at this point because we see in the algae how it gradually became more and more conspicuous, and in the mosses and succeeding groups it will be noticed that the relation of these two generations is intimately associated with the evolution of the higher types of plant life.

\section{Subdivision 5. Eumycetes or True Fungi}

76. The Nature of Fungi.-The Fungi are the largest group of the Thallophyta and include such familiar forms as moulds, mildews, toadstools and mushrooms. The absence of chlorophyll is the most striking feature of these plants. They are unable therefore to form sugar, starch and other foods from the elements of the soil and air and must obtain them already manufactured. Consequently, they are either saprophytes living upon decaying organic matter, or parasites preying upon living organ- . isms. It is quite possible that this mode of life is responsible for the disappearance of the chlorophyll. You have seen that the accumulation of sugar in the chlorophyll bearing cells stops their activity. So here the absorption of organic material from plants and animals may have had the same result and so led to the disappearance of chlorophyll. The majority of fungi procure their food from decaying plant and animal matter, and in this relation many of them are of the same economic importance as the saprophytic bacteria. Other forms exist as parasites upon living plants and animals. In this relation fungi cause almost incalculable loss annually to the country and frequently crops over large areas are ruined by their depredations. The parasitic forms gain access to the host through a wound, stoma or the delicate tissues of seedlings or young parts of the plant; and in other cases the fungus forms a ferment that dissolves the cell walls and thus opens the way for the entrance of the pest. The 
cultivation of plants has doubtless weakened their resistance in many cases to the attack of the parasites, and like ourselves the plant may inherit a weaker constitution that is more subject to disease. Nearly every state now employs experts to study the diseases caused by these fungi and to devise means for killing them and to develop more resistant plants.

The fungi are of very simple structure because they live upon foods already manufactured for them. There is no longer a necessity for a plant body that is complex, because each part is adapted to the performance of one or another of the many functions that coopperate in the construction and distribution of the organic substances. Consequently, the fungi do not exhibit many of the characteristics of chlorophyll-bearing plants. Their cell walls are thin and inclose a watery, colorless protoplasm in which are usually dispersed many small nuclei (Fig. I29). What-

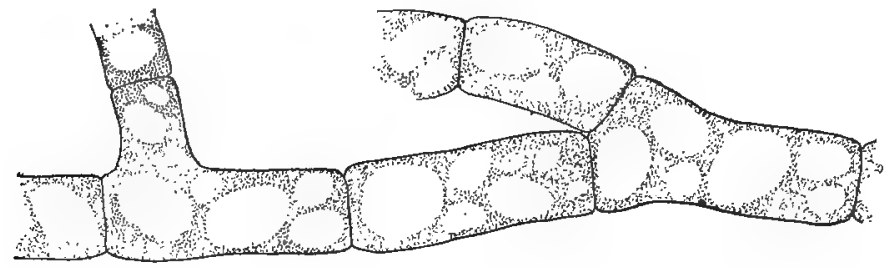

FIG. I29. A few cells from a branching filament of green mould, Penicillium, showing the granular character of the cytoplasms and the absence of plastids. The colorless areas in the cells, vacuoles, contain principally water.

ever form the plant body may assume, it will usually be found to consist of filaments of delicate cells or tubular growths, called hyphae (sing. hypha). These fine filaments or tubes are the essential portion of any fungus and as they spread over the substance upon which they feed they form a branching and interwoven mass of threads collectively known as the mycelium. This structure is well illustrated in the hyphae that spread over bread and fruits, forming a cobwebby mass or mycelium that is commonly known as mould or mildew. Bodies of various forms arise from the mycelium which are often mistaken for the fungus itself, as the mushroom, but this mushroom sustains the same relation to 
the fungus proper (the nincelium) as does an apple to the apple tree. The mushroom is simply a rather compactly interwoven mass of hyphae that arise from a mycelium in the ground. We shall expect to find remarkable departures in the fungi from previous types because of their peculiar manner of obtaining food and also because they are largely terrestrial plants and therefore exposed to a much wider series of conditions than in the case of the algae. This will tend to cause variations and so bring about new structures that are in harmony with the conditions under which the plants live. As a rule, these variations have been so extensive and have so completely changed the character of the plant as to render it impossible to state whence many of the groups have been derived or what relationship they sustain to one another. It may be stated, however, that the lower fungi show unmistakable evidence of relationship with certain of the green algae, while an intermediate class have evidently branched off from the red algae. In nearly all cases it will be seen that their parasitic and saprophytic mode of life has led to reduction and degeneration. The fungi may be divided into three classes: A, Phycomycetes or Alga-like Fungi; B, Ascomycetes or Sac Fungi; C, Basidiomycetes or Basidia-bearing Fungi.

\section{Class A. Phycomycetes}

77. Alga-like Fungi.-Some of these plants show such a strik: ing resemblance to certain algae, both in the structure of the plant body and in their reproductive processes, that they are called the Phycomycetes from phycos, alga, and myces, mould. Attention will be called to three orders of this group:

- 78. Order a. Saprolegniales or Water Moulds.-These fungi are either saprophytes, living upon dead animals and plants, or parasites. In this latter relation one form causes a destructive disease in fish while another genus produces the damping off and decay of seedlings. They are all microscopic plants and many are aquatic. Common examples of this order are seen in the whitish masses that form around decaying insects in the water and in fluffy or mould-like outgrowths that often appear upon the bodies of fish in aquaria. The plant body consists of branch: 
ing tubular threads without partitions but containing numerous nuclei and thus resembling Vaucheria save for the absence of chloroplasts (Fig. I30). The sporangia are also formed by the cutting off of the tip of one of the branches by a transverse wall. The contents of a sporangium, however, generally breaks up into a very large number of biciliate zoöspores (Fig. I30, C). In the species that cause so much damage to fish, the spores come to rest upon the fish and form tubular outgrowths that readily penetrate the tissues of the fish, especially where a scale has been rubbed off. Some of the hyphae also extend outward

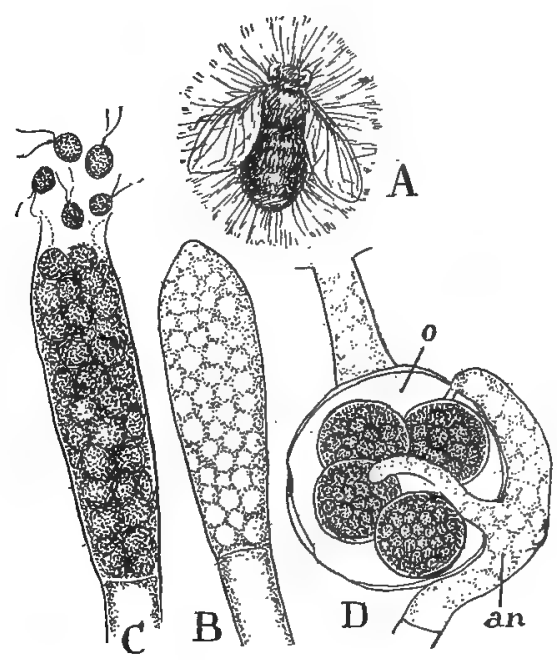

FIG. I30. Features in the life history of the water moulds: $A$, fly infected with Saprolegnia, showing the tubular threads of the fungus radiating out from its body. $B$, tip of a tube magnified, showing an early stage in the formation of the sporangium. $C$, sporangium discharging zoöspores. $D$, Reproductive organs of a rèlated fungus, $A \operatorname{chlya-0}$, oögonium containing four female gametes; an, antheridium with tubes penetrating oögonium for transport of male gametes.

from the body, causing the mould-like blotches on the infected fish, and from the tips of these branches the sporangia mentioned above are formed. Most of the species of Saprolegnia also form sexual organs as in Vaucheria, from one to several gametes being formed in an oögonium (Fig. I30, D). The antheridia, however, develop several non-motile male gametes. This peculiarity of 
the gametes is perhaps due to their exposure to atmospheric conditions, as would be the case when growing upon terrestrial or floating organic matter. The lack of water for the transport of the male gametes is nicely met by a tubular outgrowth of the antheridium which penetrates the oögonium when it ruptures, discharging the male close to the female gametes (Fig. I30, D, an). In the majority of the species, singularly enough, the female gametes germinate without being fertilized. The gametospore germinates as in Vaucheria.

It should be stated that, in related forms, large multiciliate zoöspores, like those of Vaucheria, are formed and also motile male gametes. It is also important to note that there are several parasitic algae closely related to these alga-like fungi and this remark applies to the Sac Fungi as well. Their parasitic habit and partial loss of chlorophyll clearly indicate that they are in a transition state from the algae to the fungi. It is therefore safe to state that in this group we have evidence of the derivation

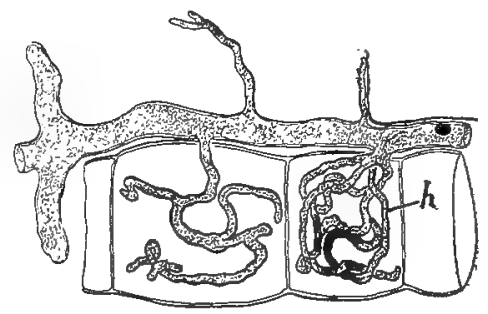

FIG. I3I. Hyphae of Peronospora extending through the tissues of a plant and absorbing food from the cells by means of haustoria, $h$.

of the fungi from the algae. This helps us to understand how fungi arose. Plants and animals live upon organic materials. These substances through chemical and physical reactions cause the absorbing orgàns of the plant to grow towards them. Consequently the green plant though capable of forming organic substances may through chemical stimulation be brought into contact with these materials in other plants and animals and as a result it becomes a fungus.

79. Order b. Peronosporales. Downy Mildews and White Rusts.-These forms are parasites upon the higher plants espe- 
cially and include two of the most destructive fungi, the potato and the grape vine blight. Phytophthora infestans causes the potato rot. This disease was widespread in the eastern United States in I90I, causing the entire loss of the crop in some sections. It would be difficult to imagine a pest more perfectly adapted to a destructive career. Let us begin the life history with the germination of a spore which has fallen upon a leaf. This spore forms a hypha which enters the leaf and quickly spreads through its tissues, sending into the cells short lateral branches called haustoria (Fig. I3I), which absorb the cell contents and thus supply the fungus with food. In severe cases this produces a withering and decay of the leaf. The hyphae continue their growth into the stems and all parts of the plant, thus causing the black discoloration of the potato and its early decay in bad cases of infection. This habit of many parasitic fungi of establishing themselves in those organs of the plant which live on from year to year, is one of the most serious difficulties in combating these pests. For with the renewal of growth of these organs the hyphae spread and reëstablish the disease. Thus the planting of infected potatoes is sure to result in the appearance of the potato blight if conditions are favorable. As soon as the mycelium has become well established in the leaf, numerous branching hyphae extend out through the stomata and form at their tips little sacs or sporangia (Fig. I32, A). The formation of the sporangia is effected in a few hours, when they drop off and are carried by the wind to other plants, where they germinate at once, forming a tube that penetrates the leaf and rapidly spreads the disease. If the sporangia chance to fall upon leaves that are wet by dew or rain, the contents breaks up into several zoöspores (Fig. 132, $B-E$ ) which finally come to rest and develop the characteristic tubular hyphae of the fungi. This behavior of the sporangium is doubtless a survival of the zoöspore stage seen in the algae. It is equally suggestive that definite changes in the environment, as the dry air, causes the sporangium to germinate as a nonmotile spore, whereas the presence of water causes the sporangium to produce several zoöspores. The potato blight is largely confined in our country to the northeastern states and usually it 


\section{REPRODUCTION OF THE DOWNY MILDEWS}

does not appear until the latter part of July. It only becomes of serious importance in sultry 'weather, when a short period of rain will result in the formation of the sporangia and whole fields will be devastated in a few days.

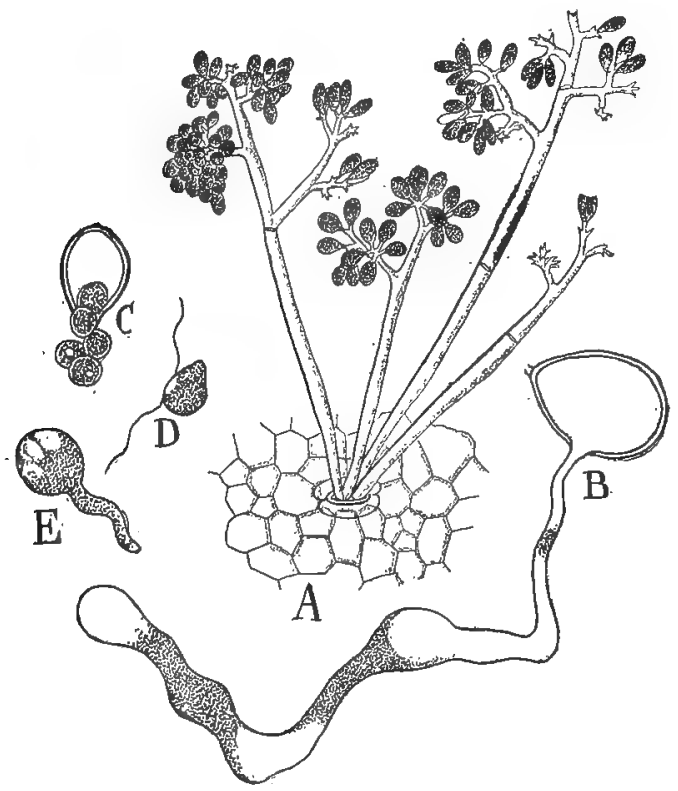

FIG. I32.

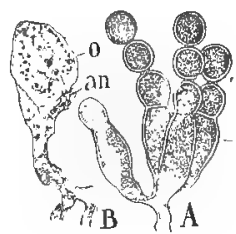

FIG. I33.

FIG. I32. Asexual reproduction of the mildew: $A$, hyphae of Plasmopara emerging from a stoma and bearing numerous sporangia. $B$, enlarged view of sporangium of Peronospora germinating on a dry leaf. In this case the sporangium behaves as a spore sending out a hypha that will penetrate the tissues of the leaf. $C$, sporangium of Phytophthora germinating in the water and forming zoöspores. $D$, zoöspore enlarged. $E$, zoöspore has come to rest and is forming a tube that will penetrate the tissues of the leaf as in the case of $B$.

FIG. I33. Reproduction of the white rust, Albugo: $A$, asexual stage, showing several erect hyphae forming spores. $B$, sexual stage which is characteristic of the Peronosporales in general-o, gametangium containing a single fermale gamete which is being penetrated by tube from male gametangium, an.-After Wager.

Very similar in character is the grape blight, Plasmopara viticola. This disease causes a browning of the leaves and the stunting of the fruit, which become brown or gray, and, finally, the 
death of the infected parts. This pest caused the abandonment of entire vineyards before the method of killing the fungus by spraying the plants with copper salts was discovered. In both of these pests and in allied genera the sporangia-bearing hyphae are produced in such numbers as to cause a downy, mould-like appearance on the leaves, thus accounting for their. popular name, Downy Mildews.

In a related genus, Albugo, the sporangia are formed by the repeated cutting off of the tips of the hyphae, as shown in Fig: I33, $A$. In this way, not one, but a chain of sporangia, are formed from the ends of the hyphae which do not project from the leaf, but grow up in dense masses just under the epidermis; producing glistening white blotches ot blisters on the leaves. This growth finally ruptures the epidermis when the spores are scattered by the wind and germinate as in the preceding cases. This fungus, known as white rust, is very common on mustards, pigweed and other plants.

The sexual reproduction of the Peronosporales is suggestive of Vaucheria. Gametangia are cut off from the ends of the hyphae, as shown in Fig. 133, $B$. The male gamete gains access to the female gamete, which is usually formed singly, by means of a tube as in Saprolegnia (Fig. I33, B, an). The thick-walled gameto-. spore, as in many of the algae, tides the plant over the winter, and being set free by the decay of the surrounding tissues it germinates in the spring, starting anew the life of the pest. It may germinate directly (see Vaucheria) into the fungus; or zoöspores are first produced, as in Oedogonium.

These two orders are more suggestive of the algae than any others that we shall study and it is well to note the modifications that have been induced in these plants as a result of their change from aquatic to terrestrial conditions. Removed from the water, special root-like organs and haustoria are evolved for the absorption of foods. The absence of water brings about a lack of motil ity in the male gametes and the formation of a tube to conduct them to the female. For the same reason, the zoöspores are reduced to light motionless spores that are developed upon elon: gated hyphae that expose them to the air currents for distribution. 
The ability of these spores, or sporangia, to produce zoöspores is doubtless the survival of a trait inherited from their algal ancestors.

80. Order c. Mucorales or Black Moulds.-These are among the most common of the fungi and they are almost sure to appear upon any cooked food or decaying matter that is exposed to the air even for a very short time (Fig. I34). The mycelium has practically the same structure as noted in the preceding groups, but the black moulds have lost all motile reproductive bodies and their relationship to any group of the algae is not known. Some of the hyphae of the mycelium creep over the food supply and send into it short branches which serve as organs of absorption while other rather thicker hyphae grow away from the mycelium and reach up into the air (Fig. I34). The tips of these erect

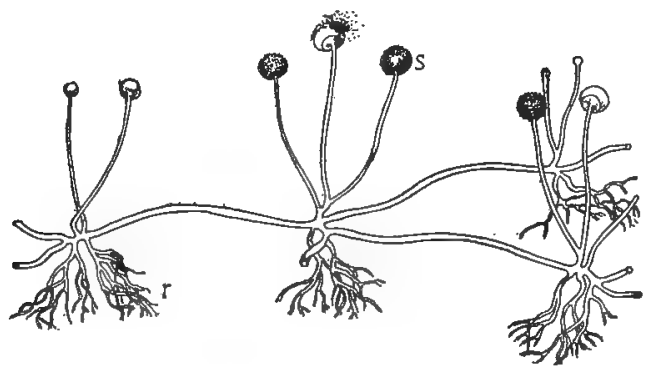

FIG. I34. Habit of growth of the black mould, Rhizopus: s, sporangia; $r$, absorbing branches of the mycelium.

hyphae enlarge owing to the accumulation of protoplasm and numerous nuclei in them, and finally become spherical, forming the sporangia. The contents of the young sporangia differentiate into a denser peripheral portion containing the bulk of the nuclei and a more watery central and basal region. A layer of large, round vacuoles now appears between these two regions and, owing to the flattening out and fusion of these vacuoles, a cleft is formed that ultimately separates the peripheral from the central protoplasm. Next furrows advancing inward from the sporangial wall and outward from the cleft divide the peripheral protoplasm into numerous small portions, each part containing several nuclei. hese bodies round off, secrete a rather thick smoky black wall 
and so become spores (Fig. I35). The numerous sporangia filled with dark spores are the principal cause of the black color of these fungi.

During the development of the spores a wall is constructed over the central protoplasm, thus often forming a dome-like structure in the sporangium known as the columella (Fig. I35, E). The walls of the sporangia (save at the region in contact with the stalk) readily dissolve in the presence of moisture, owing to their mucilaginous character, and thus allow the spores to float off in the air as an invisible dust. The spores will germinate at once and produce a new plant under suitable conditions of moisture and food, or they will retain their vitality for months if kept dry. As the spores are disseminated, the dome-like struc-
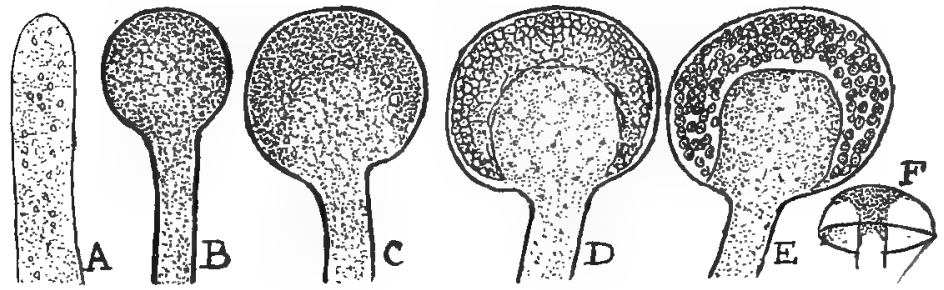

FIG. 135. $A, B$, early stages in the development of the sporangium of Rhizopus. $C$, the formation of the vacuoles which separate the denser peripheral protoplasm from the more watery central region. $D$, the vacuoles are flattening out and the denser protoplasm is becoming separated into multinucleate segment, $E$, the multinucleate segments are rounding off to form the spores and a wall has formed over the columella. $F$, the sporangium has ruptured, permitting the scattering of the spores and the columella has formed an umbrella-like structure owing to the loss of its watery contents.-After Swingle.

ture in the sporangium relaxes, owing to the loss of its watery contents, and assumes an umbrella shape, as seen in Fig. I35, F. You can readily understand why these black moulds are so common by counting the number of sporangia on a small bit of mycelium and then estimating the number of spores in a sporangium. So numerous and light are the spores that they are carried everywhere. It is only necessary to expose a bit of moist bread for a few moments to the air and then enclose it in a damp chamber to secure a luxuriant crop of these plants. An interesting variation 
in this mode of scattering the spores is seen in a related form, Pilobolus, which is of common occurrence upon horse dung. Here the wall of the sporangium, unlike Rhizopus, is quite firm and becomes mucilaginous only at the point of contact with the stalk that bears it. Owing to the accumulation of water in the stalk such a pressure is finally set up as to rupture it at the mucilaginous point and so the sporangium with its contained spores is hurled considerable distance-often quite one meter. The sporangia bearing stalks are also sensitive to light. If a glass jar covered with black paper so as to exclude all light is

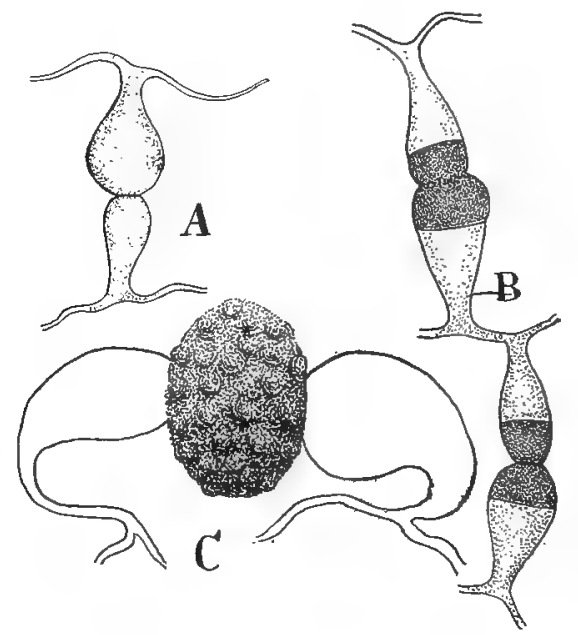

FIG. 136. Sexual reproduction in the black mould: $A$, the meeting of the tips of two hyphae. $B$, later stage, the lower part of the figure shows the cutting off of the tips by transverse walls and in the upper part of the figure the fusion of the contents of the two gametangia thus formed has begun. $C$, mature gametospore.

placed.over a colony of these plants and a minute opening is now made in the paper, you will be surprised to note with what accuracy each sporangium is shot off and hits this opening. The results are the same no matter where you make the opening.

Under certain conditions the sexual method of reproduction is effected by the union of two club-shaped hyphae, as shown in Fig. 136, A. As these hyphae meet, the tip of each branch is cut off by a wall and the contents of the two tips fuse, forming a 
thick-walled gametospore (Fig. I36, B, C). After a resting period, this gametospore grows directly into a new mycelium. In some of the black moulds Blakeslee has made known that reproduction is only effected by the union of hyphae from different plants which must differ therefore in their nature, just as you found to be the case in some species of Spirogyra.

81. A Fly Fungus.-An interesting form allied to the mucors is seen in the parasitic fungus Empusa, that produces an epi-

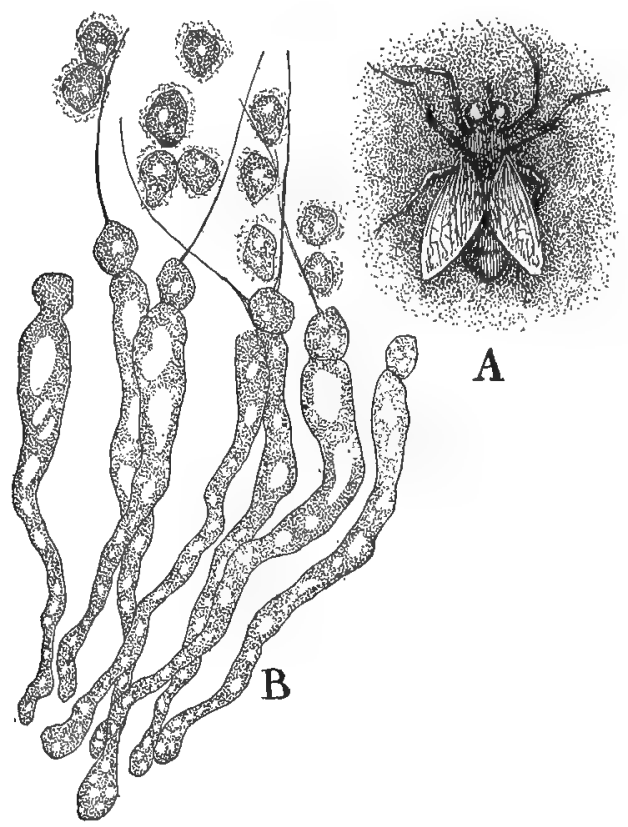

FIG. 137. A fungus, Empusa, parasitic upon flies: $A$, fly surrounded by a mass of discharged sporangia. $B$, enlarged view of several hyphae, showing the discharge of the sporangia which are surrounded by a mucilaginous substance.-After Brefeld.

demic among flies at certain seasons when they may be seen dead and clinging to the woodwork and window panes surrounded by a white halo (Fig. I37, $A$ ). This appearance is caused by the discharge of numerous white sporangia that are found at the ends of the hyphae that project from all sides of the fly's body (Fig. I37, B). If; by chance, a fly should come within range 
of these discharging sporangia, it would become infested and later, branches of the hyphae would project from its body and repeat the process of sporangia formation.

\section{Class B. Ascomycetes or Sac Fungi}

82. General Characters.- The Ascomycetes are the largest and most variable group of the fungi. They are illustrated by the powdery mildews which affect the leaves of a variety of plants; the brown and blue moulds that occur on preserves, decaying fruit, old leather, etc. (Fig. 138); the cup fungi and morels (Figs. I39, I4I); the black knot of the cherry and plum trees (Fig. I49), and the ergot of rye, etc.

The plant body or mycelium resembles in structure that of preceding orders, but its hyphae are composed of numerous cells instead of being tubular or with few cross walls as in the Phycomycetes (Fig. 138). The sporangia (Fig. I52) are reduced in

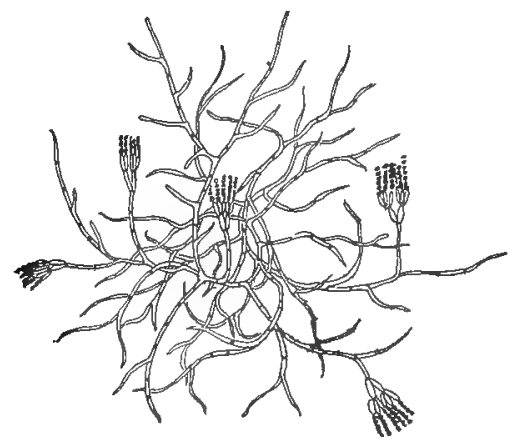

FIG. I38. The green mould, Penicillium, one of the most common of the Sac Fungi. The hyphae of the branching mycelium is composed of cells and the spores or conidia are formed in chains that are arranged in brushlike clusters at the ends of the erect hyphae.

size and contain but a single spore each, which is never discharged from the sporangium. This body will be referred to in the future as a spore or conidium (plu. conidia).

The gametangia are suggestive of those noted in the red algae (Fig. I40), though in many forms they appear to be greatly reduced or even lacking. The fusion of the gametes results in the formation of a gametospore which germinates at once, forming in 
the simplest cases one or more sacs. These bodies are known as asci (sing. ascus) and they contain more frequently eight spores, called ascospores (Fig. I60), which must be distinguished from the spores or conidia mentioned above. The gametospore germinates as a parasite on the mother plant as in the red algae; The sexual process results, in the majority of forms, not only in the formation of asci, but numerous hyphae from the mycelium are also stimulated to growth and become associated with the asci in various ways, recalling the cystocarps of the red algae. As a result fruit bodies of various forms, called ascocarps or perithecia, are developed which often become the conspicuous part of the fungus (Figs. I55-I58). The ascospores germinate immediately or after a period of rest and form a new mycelium. It should be stated that the ascocarps have not been connected, in many cases, with sexual processes, and it is inferred that sexuality has been lost along with other characters as a consequence of the degeneracy resulting from parasitic and saprophytic habits. Only a few of the more important orders will be discussed.

83. Order a. Pezizales or the Cup Fungi.-These plants are characterized by the formation of fleshy, leathery or gelatinous

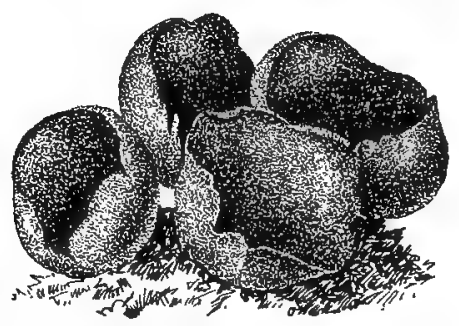

FIG. I39. One of the common cup fungi, order Pezizales, with broadly opened ascocarps. Common upon rich humus soil and decaying wood.

cup-like ascocarps that range in size from mere specks to forms four or five inches in diameter (Fig. 139). The mycelium lives upon the humus in the ground or on decaying plants and apparently in this and the next order frequently develops the ascocarps directly without a reproductive process. In Pyronema and many other forms, however, Dodge has shown that reproduc- 
tive organs are formed that are very suggestive of those of the red algae. The female gametangium in the simpler forms has an enlarged basal region with a long tubular outgrowth suggestive of Nemalion (Fig. I40). In the majority of forms this organ consists of several cells and often becomes coiled and greatly extended. The male gametangium is a somewhat enlarged hypha. These organs are developed here and there on the mycelium or several may be associated in a compact group.
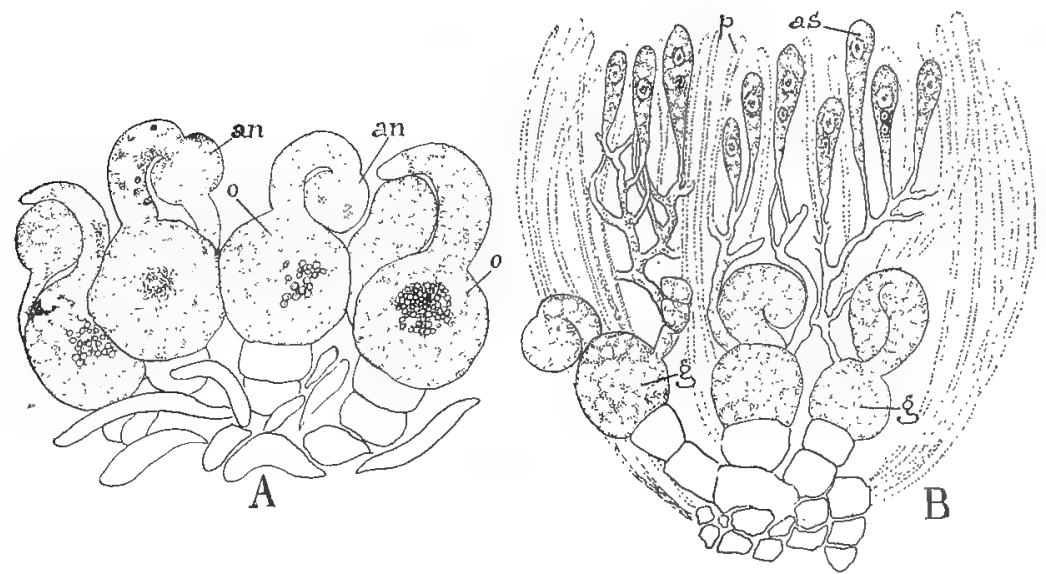

FIG. I40. Sexual reproduction of one of the cup fungi, Pyronema: $A$, the flask-shaped female gametangium, $o$, is seen in various stages of fusion with the male gametangium, an. This is effected by the curvature of the tubular outgrowth. $B$, the gametospores, $g$, germinating and forming branching hyphae which bear the asci, as. These asci are associated with hyphae or paraphyses, $p$, that arise from the mycelium. The asci and paraphyses constitute the hymenium.-After Harper.

Singularly the union between these two sex organs is effected by the female-its tubular part curves towards the male gametangium and effects a fusion with it. As to whether the male gametes pass over and unite with the females as a result of the fusion of the gametangia no general statement can be made at present, though in some forms there is evidence to indicate that such in the case. The basal portion of the female gametangium, or one of its cells in cases where the gametangium consists. of-several cells, behaves as though fertilization had been 
effected and a gametospore had been formed. It germinates by developing a number of erect sac-like hyphae or asci (Fig. I40, $B$ ). Adjoining hyphae grow up among the asci and around them, forming a cup-like structure resembling that shown in Fig. I39. A section through one of these cups reveals the asci intermingled with hyphae, also called paraphyses, in the form of a layer or stratum. Such an association of spore-bearing organs and paraphyses is called a hymenium. The spores are discharged to considerable distances, owing to the accumulation of fluids in the asci which finally rupture at their apices. They are formed in such enormous numbers that under favorable conditions they may be seen passing off as faint puffs of smoke. The bright scarlet cups of Sarcoscypha, common in the spring on decaying sticks and the gray cups of Peziza growing upon the ground and decaying wood, are familiar examples of the order.

84. Relationship of the Cup Fungi.-The Pezizales may be regarded as the typical representatives of the Ascomycetes. The sexual reproductive process as outlined above is fairly representative of the other groups of ascomycetes and will not be referred to again except in orders where noteworthy departures occur. The formation of spores or conidia are characteristic features of many of the groups but owing to the exceedingly diverse character and origin of these bodies attention will only be directed to some of the more familiar and common examples as illustrated in the two last orders. Diverging from these typical ascomycetes are several lines of fungi that show varying degrees of relationship to them. As an example of this divergence attention may first be directed to the Helvellales.

85. Order b. Helvellales.-These are fleshy forms like the cup fungi and grow upon the ground, but the reproductive process results in the development of oddly shaped ascocarps with the hymenium developed upon the upper exposed surface. Several common forms of these ascocarps are illustrated in Fig. I4I.

The morel or Morchella, in which the hymenium is spread over the pitted or honey-combed surface of the ascocarp, is one of the most highly prized of the edible fungi. The members of this order are largely saprophytic and often attain considerable 
size, forms of Morchella occasionally reaching the height of a foot and some species of Gyromitra weigh over a pound.

86. The Asco-lichens. - A second line of departure from the Pezizales includes a large group of plants known as the lichen. The great majority of these forms show strong evidence of rela-

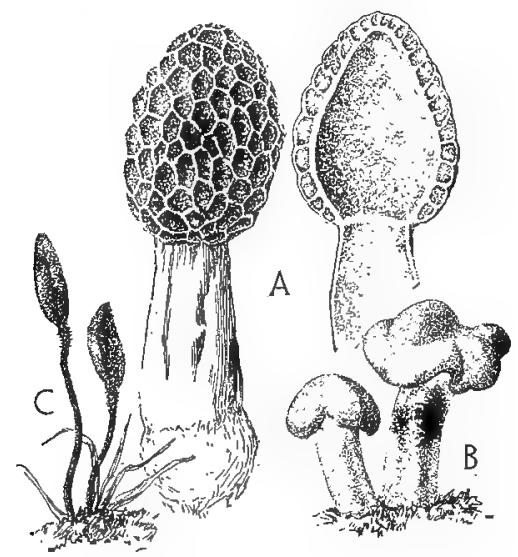

FIG. I4I. Common forms of the Helvellales: $A$, the morel, Morchella, surface view at left and in section at right. The asci and paraphyses form a hymenium over the honeycomb surface. $B$, Leotia, a small gelatinous form of a light, bluish-green color. $C$, Geoglossum, a black tongue-like form. In $B$ and $C$ the hymenium is confined to the upper enlarged portion of the fungus. Both are common in boggy ground.

tionship with the cup fungi in their reproductive processes and it should be added that the sex organs are more suggestive of the red algae than in any other group. A few species belong to the third class of fungi, the basidiomycetes, but these plants show the same general features as the asco-lichens and therefore a consideration of the entire group may be taken up at this point. These remarkable plants are of almost universal distribution upon tree trunks, rocks, old fences and buildings, and upon the bare earth, where they form variously colored incrustations or leaflike branching bodies (Fig. I42).

The lichen is one of the most extraordinary plants in the vegetable kingdom, since it is a union of two separate plants, a fungus and an alga. Naturally the relationship of the lichens to other groups of plants has been a matter of dispute, some 
regarding them as constituting an independent division, and by others they are looked upon as fungi. The fact that the fungus forms the bulk of the lichen and lives upon the alga somewhat after the manner of a parasite and is usually alone capable of forming reproductive spore bodies would lead to the latter

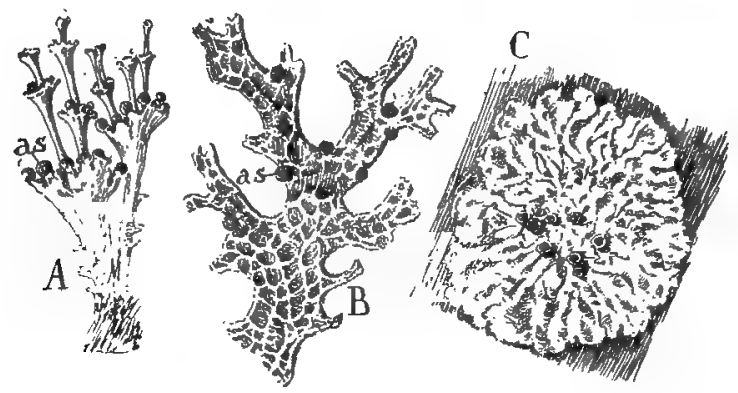

FIG. I42. Common species of Lichens: $A$, an erect branching form, Cladonia-as, ascocarps. $B$, a foliaceous lichen, Sticta. C, Parmelia spreading over the bark of tree. The centrally-placed ascocarps are surrounded by smaller pycnidia.

position. However, all degrees of relationship appear between the alga and fungus-from stages where their association is of little or no consequence to stages where their existence is absolutely dependent upon their association. The members of this curious co-partnership are largely ascomycetes and blue-green algae. Numerous species in each of these two groups of plants have become accustomed to living together. The formation of a lichen comes about through the attachment of a hypha of some fungus to one or more algal cells, as shown in Fig. I43, $B$. In this way, the food manufactured by the algae is absorbed osmotically by the hyphae. In some cases, the fungus obtains its food by means of haustoria which penetrate the algal cells. By the continued growth of the fungus and algae there finally results an interwoven mass of hyphae about the algae. The walls of the fungus are sufficiently transparent to permit the entrance of light and the color of the green algae can readily be seen when the lichen is moistened.

(a) Structure of the Lichen.-The bulk of the lichen is more usually composed of hyphae which show considerable regularity 
in their growth and the majority of the algae also are usually confined to a definite zone near the sunned surface of the lichen. Thus, in Fig. I43, $A$, which represents a cross-section of a lichen, it will be seen that the fungus forms a rather firm layer at the top and bottom of the thallus, while the algae are distributed near the upper surface, where they are exposed to the light, and can therefore carry on photosynthesis. Numerous hyphae projecting from the under surface of the lichen serve to anchor it to the substratum and also assist, doubtless, in the absorption of the earth substances. In some of the gelatinous lichens the fungi and algae are more promiscuously arranged.

While the fungus is dependent upon the foods manufactured by the algae, the latter are also benefited to an extent by this arrangement since they are protected by the strata of hyphae, and they are also provided with water and crude material which the fungus readily takes up and holds. This mutually helpful relationship of two organisms is a form of symbiosis, termed commensalism. The strange feature about this co-partnership is the marked change produced in the nature of the two symbionts. As long as they are independent of each other, very special conditions are necessary for their welfare, but associated, they form the most resistant plants known. This accounts for their distribution from the equator to the pole and their association upon crystalline rocks, baked earth, bark of trees and other places where no other plant life is possible. Under unfavorable conditions the lichen becomes dry and brittle, in which resting condition it is able to meet any extreme temperature and drought. With the return of suitable moisture and heat they become leathery or gelatinous and renew their growth with considerable rapidity. Thus they live on from year to year, but owing to the exposed places in which they are usually found, their growing periods are frequently very short and their total annual growth may not exceed a few milli. meters-see soils, p. 50 ,

(b) Reproduction of Lichens.-Reproduction of the lichens is brought about by means of fragments that are readily detached when the lichens are dry and brittle, or by means of soredia. These latter bodies consist of a few algal cells intertwined with 
hyphae, in fact, a miniature lichen (Fig. I43, C). In some species the soredia form a rather powdery or granular coating on the upper surface of the lichen, and in other cases they are developed within the lichen. These bodies are easily scattered by the wind when the lichens are dry and under favorable conditions grow into new lichens. Reproduction is also effected by means of ascospores that are developed as in the cup fungi. The female

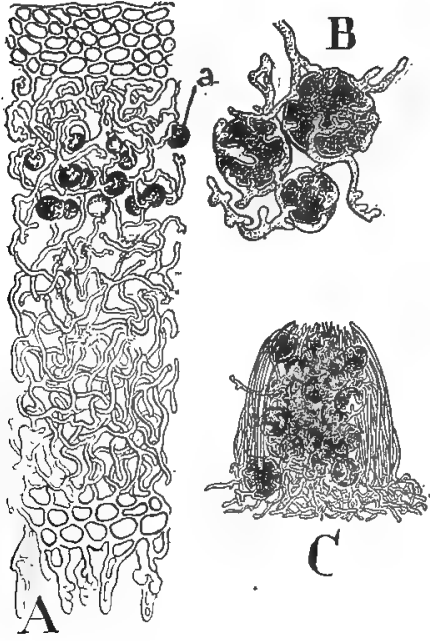

FIG. I43.

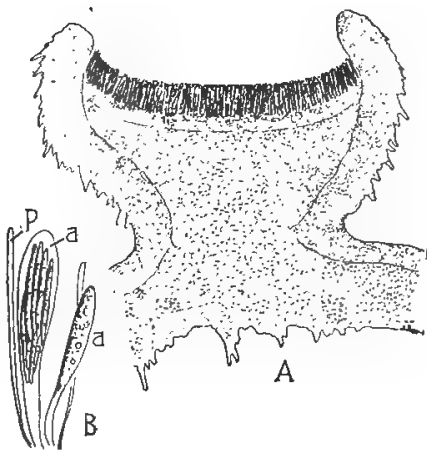

FIG. I44.

FIG. I43. Structure of the Lichen: $A$, section of a lichen, showing the compact arrangement of the hyphae at the top and bottom, also the anchoring fungal threads on the underside and the dark algal cells, $a$, near the top. $B$, enlarged view of the algae to show their relation to the hyphae. $C$, diagram of one of the powdery particles, soredium, appearing upon certain lichens, showing the hyphae and algae. These bodies are scattered by the wind and form new lichens.

FIG. I44. Sexual reproduction of the lichen: $A$, section of an ascocarp, the hymenium appearing as a dark band in the mouth of the cup. $B$, enlarged view of the asci, $a$, and paraphyses, $p$, of the hymenium.

gametangium is a coiled organ consisting of many cells as in some Pezizales but the male gametes are developed in ascocarplike bodies where they are formed at the ends of numerous minute hyphae-in their origin, therefore, being strikingly suggestive of the red algae. In one form, it should be added that a fusion between male and female gametangia has been reported. 
The ascocarps derived from this reproductive process assume a great variety of shapes (Fig. I42) but they all show the hymenial layer of asci and paraphyses (Fig. I44) or of basidia and paraphyses in the few forms belonging to basidio-lichens.

The ascospores germinate readily, producing hyphae which, however, soon perish unless they chance to meet an alga with which they can live. It should be noted that these fungi appearing in lichens cannot associate indiscriminately with any species of algae. Each species of fungus is adapted to one or more species of algae and is unable to live with any other form. As may be imagined, the real nature of the lichen was for a long time misunderstood, the algae, even being looked upon as spore bodies. The bitter dispute over the question was finally settled when a lichen was produced artificially by bringing together a suitable fungus and alga.

(c) Economic Value.-Lichens are of considerable economic importance in the world. Their service in hastening the decay and transformation of rock material has already been referred to. In many sections they form the characteristic vegetation of the country, as in certain alpine and desert regions and in the northern barrens, where they afford rich pasturage to reindeer and caribou. Their abundant growth in mountainous districts and subsequent distribution by winds and rains accounts for the showers of manna in biblical history. Certain species are still used in northern regions to lengthen out a meager food supply. Litmus, employed in acid testing, and various pigments are derived from lichens, as were also the famous purple and blue dyes of the East.

87. A Third Line Possibly Related to the Pezizales.-The following orders may not represent a single line of descent but there are certain features in their life history indicating that they may represent a line of departure from the Pezizales. These forms are mostly minute; parasitic, or saprophytic upon dead plants. The more epiphytic position of these forms may have been a factor in the reduction in size. Certainly the larger fleshy forms of the preceding orders are terrestrial in habitat. There are two quite distinct groups in this alliance, 
the one characterized by ascocarps that are only slightly opened so that the asci are not as freely exposed to the air as in the preceding orders and the other with closed ascocarps so that the asci are exposed only on the decay of the fruit body. The

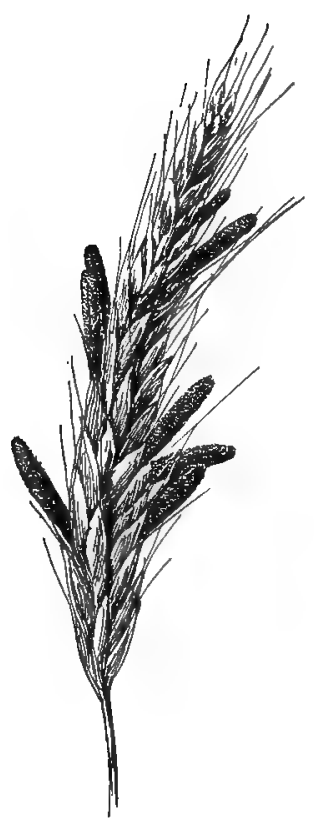

FIG. 145.

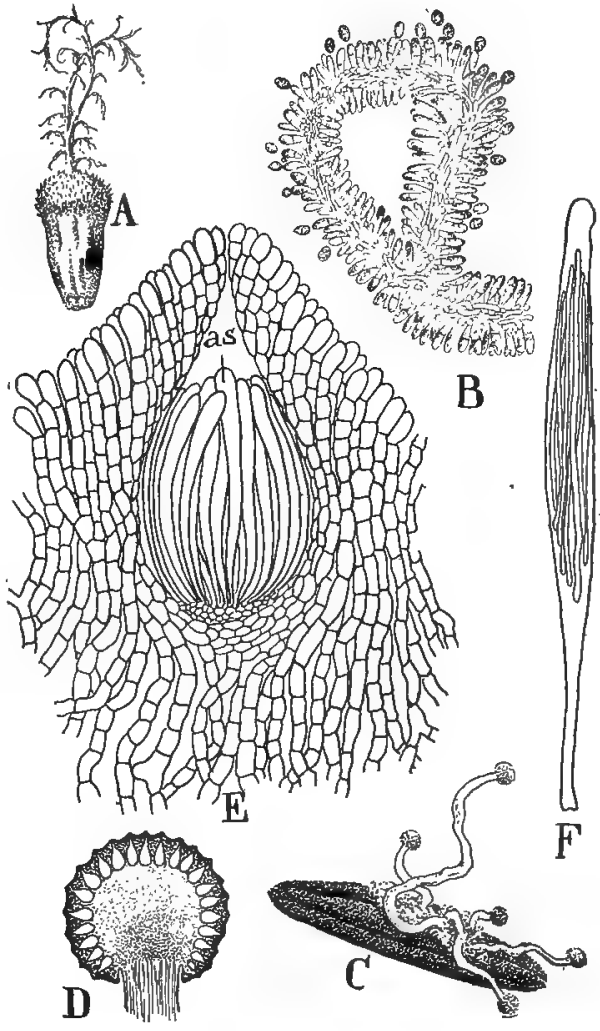

FIG. I46.

FIG. I45. Head of rye infested by the parasite, Claviceps, which has transformed several of the grains into black masses of mycelium known as sclerotia.

FIG. I46. Various phases in the life history of Claviceps: $A$, a young grain or pistil infested with the parasite. $B$, enlarged view of the mycelium as it appears on the surface of the pistil, showing the formation of numerous spores. $C$, the hyphae of a sclerotium growing out and forming several purplish stalks, each capped with knob-like clusters of ascocarps. $D$, enlarged sectional view of one of these knobs, showing numerous ascocarps on the periphery. $E$, one of the ascocarps enlarged. $a s$, asci. $F$, an ascus containing eight thread-like ascospores. 
first group is further characterized by the fact that the ascocarps are frequently associated with a more or less conspicuous growth of the mycelium in which the ascocarps are imbedded in varying degrees. This growth is known as the stroma and it may form a rather compact mass of hyphae. Only two orders can be considered in each of these two groups.

88. Order c. Hypocreales. - These fungi are distinguished by their rather fleshy or membranous ascocarps and stroma, which range in color from white to yellow, purple, scarlet and brown. Numerous species are saprophytic while others are parasitic upon higher plants, fungi and insects. Claviceps is a common example of this group, causing the disease known as ergot in the flowers of rye and other grasses (Fig. 145). The mycelium at first spreads over the outer part of the pistil, rapidly forming spores (Fig. I46, $A, B$ ) and exuding a sweet slimy juice, honey dew, which is eagerly eaten by flies. In this way the spores are carried away to infest other plants. The mycelium finally completely absorbs the substance of the grain and grows into a hard blue-black body several times larger than the grain (Fig. 145). This body, known as the sclerotium, remains dormant during the winter and in the spring groups of hyphae at various points in the sclerotium grow out into rose-colored stalks that terminate in globular heads (Fig. I46, C). These stalked bodies represent the stromata as it appears in this genus. Numerous ascocarps with minute openings are developed in the outer part of globular head of the stroma (Fig. I46,D). The ascospores germinate in the spring and infest the flowers of the grain. The Chinese wonder, Cordyceps, is a related parasite that attacks caterpillars, larvae of beetles and truffles. In the case of the forms living upon insects, the parasite does not usually appear until the spring, when they are in the pupa or cocoon stage. At this time, the mycelium which flourishes in the tissues of the host, sends up club-like bodies (Fig. I47), that bear the ascocarps as in the case of the ergot. Among the important pests included in this order are those causing the wilt disease of cotton, cowpea and watermelon; the disease on currant, apple and pear trees; and the claviceps of grain. 
89. Order d. Sphaeriales or Black Fungi.-This is the largest group of the ascomycetes, over 2,000 species being known in the United States alone. Scarcely a fallen twig or bit of old wood can be examined without revealing the minute ascocarps which

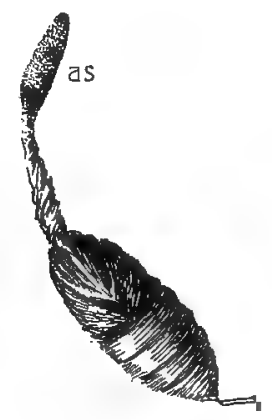

FIG. 147. The stroma of Cordyceps emerging from the pupa of a moth and forming a club-like organ with numerous ascocarps, as, in its apical region.

more commonly are hard and black in contradistinction to the Hypocreales (Figs. I48; I5I, $A$ ). Many of these fungi are quite conspicuous since the ascocarps are formed in large compact masses and also because they are often associated with a more or less conspicuous stroma (Figs. I49; I5I, D). The majority of the genera are saprophytic upon dead and decaying vegetation, though some of them are destructive parasites. The black knot, Plowrightia, the cause of a serious disease to plum and cherry trees, illustrates very well the characteristics of this order. The mycelium grows in the cambium and cortical regions of the branches, causing the bark to split open in the spring when spore bearing hyphae extend up into the air forming a velvety coating (Fig. I49, c). By the approach of winter, this mycelium has grown into the familiar black knotty mass in which are developed numerous ascocarp-like bodies (Fig. I50). The spores from these ascocarps are carried by the wind in the early spring to other branches and probably infest the budding trees. Other conspicuous forms are Xylaria and Daldinia, which develop an extensive stroma on stumps and trees that contains numerous ascocarps (Fig. I5I). In Hypoxylon, the stroma containing the 
ascocarps breaks through the bark of a large variety of trees and shrubs in the form of spherical or cake-like masses (Fig. I48). Among the more serious pests may be mentioned the very destructive black rot of grapes, apple and pear scab; bitter rot of apples; the sycamore blight, and the chestnut bark disease.

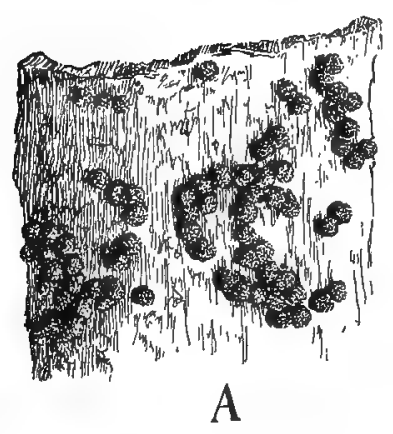

FIG. I48.

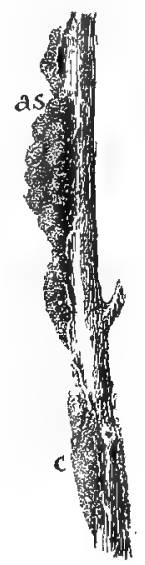

FIG. I49.

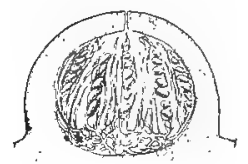

B

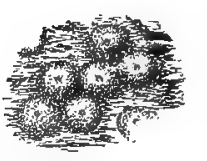

A

FIG. I50.

FIG. I48. A common black fungus, Hypoxylon: $A$, habit of the fungus as it appears on dead branches and logs. The round black bodies are an association of the mycelium, stroma, and numerous ascocarps. $B$, a single ascus enlarged, showing character of the ascospores.

FIG. I49. The black knot, Plowrightia, infecting a branch of cherry. At the bottom of the branch is shown the early summer or spore-bearing stage, $c$, and above a black warty mass of ascocarps, as, produced the previous season.

FIG. I50. $A$, several ascocarps enlarged, taken from region, as, in Fig. 149. $B$, diagram of an ascocarp as seen in section, showing the asci and the opening for the escape of the ascospores.

This and the following order represent possibly the consummation of those tendencies that we saw appearing in the third line of departure from the Pezizales. As stated they are characterized by their closed ascocarps.

90. Order e. Aspergillales or Blue-green and Brown Fungi.The Aspergillales includes perhaps the most widely distributed and familiar examples of the fungi. They occur as blue-green or brown moulds upon almost any organic matter, forming a delicate mycelium from which are developed numerous erect hyphae. 
In the common blue mould, Penicillium, these erect hyphae are broom like (Fig. I52, B) and the spores are formed from the tips of the branches very much after the manner of the budding. of the yeast cells. The tip of a branch buds out into a spherical cell that is finally cut off from the stalk, thus forming the spore (Fig. ${ }^{52}, C$ ). This process is repeated again and again just

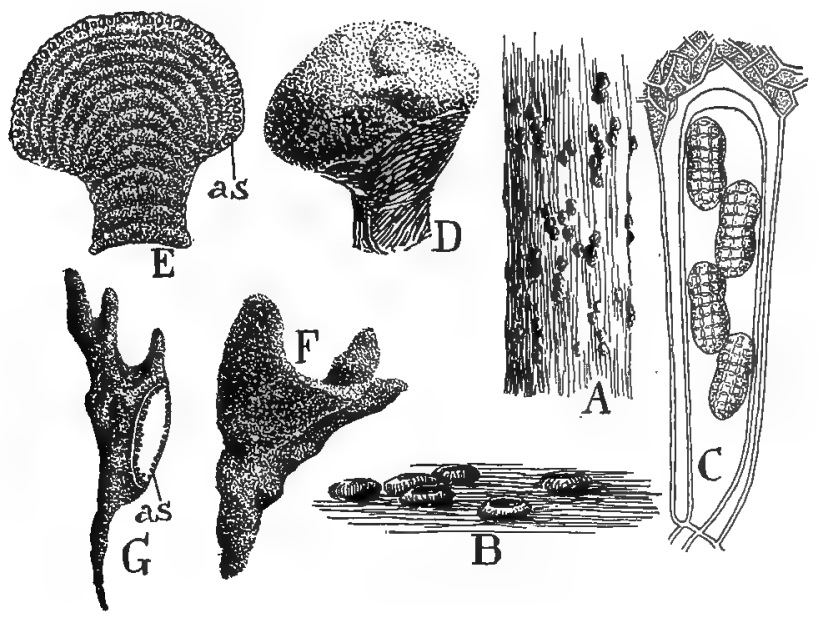

FIG. I5I. Other common forms of the Spheriales: A, habit of Hysteriographium, on a dead twig. $B$, ascocarps enlarged. $C$, ascus enlarged, showing character of ascospores. $D$, Daldinia. $E$, section of the same, showing that the stroma forms a concentric stratum of ascocarps, as, each year. $F$, $X y$ laria. $G$, the same with branch cut off to. show the layer of ascocarps on the periphery of the stroma.

below each successive spore and in this way chains of spores are formed. It will be noticed that many single spores are found instead of a large sporangium which contains many spores as in the case of Mucor. These spores are sometimes regarded as sporangia which have become reduced in size and contain but à single spore. In Aspergillus, a furigús common upon preserves and upon herbarium plants that have not been sufficiently dried, the spores are developed from very short branches that arise from a bulbous swelling at the apex of the erect hyphae (Fig. I52, $A$ ). The color of the spores, as in Mucor, is the cause of the characteristic blue or brown color of the fungi. 'These ex- 


\section{SEXUAL REPRODUCTION OF ASPERGILLALES}

tremely small and numerous spores float off in the air as an invisible dust and quickly germinate under favorable conditions, forming new mycelia.

The male and female gametangia have departed considerably from the form shown in the cup fungi. They now appear as short, slightly modified branches of the hyphae and have lost the tubular outgrowth so characteristic of the Pezizales and red

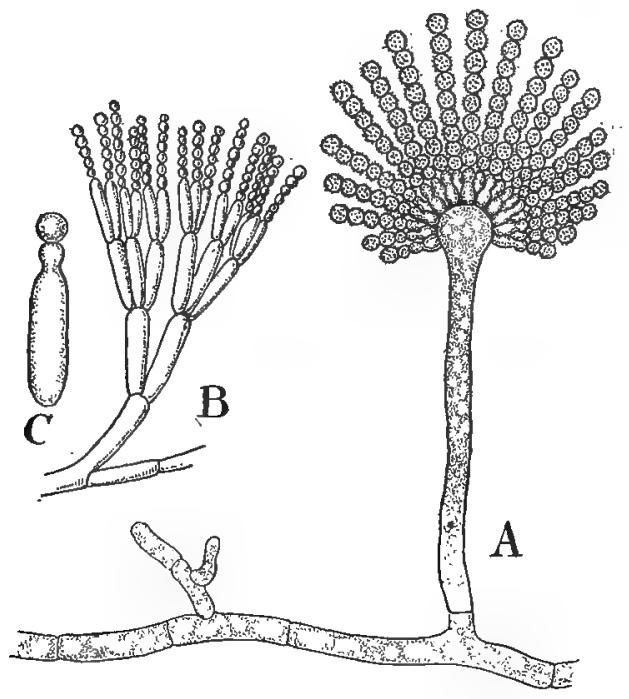

FIG. I52. Formation of spores or conidia in the Aspergillales: $A$, sporebearing hypha of Aspergillus. B, hypha of green mould, Penicillium. $C$, one of the terminal branches of $B$ enlarged, showing manner of spore formation.

algae. However they become closely intertwined (Fig. I53) and the ends of the branches meet, thus the mingling of the gametes is made possible through a dissolution of the separating walls at the tips of the gametangia. The resulting gametospore remains attached to the parent plant and germinates at once, forming an irregular hyphal outgrowth (Fig. I53, B, s) which becomes completely overgrown by the hyphae of the mycelium (Fig. I 53, B, C). Thus is formed a solid ascocarp or perithecium (plu. perithecia), that appears to the eye as a minute grain of sand. During this growth numerous lateral branches arise on the hyphae derived from the gametospore and become trans- 
formed into asci as shown in Fig. I54, $A, B$. The ascocarps finally decay and 'set free the ascospores which develop a new plant or mycelium. Thus the entire life history in these forms as in other fungi is suggestive of the algae. While conditions are
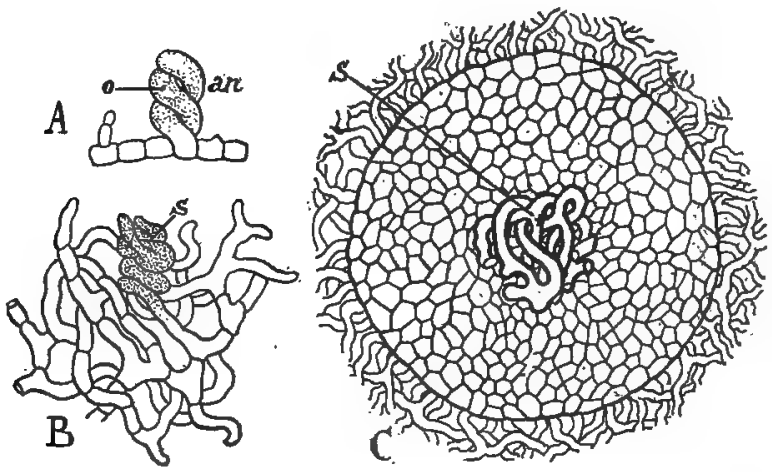

FIG. I53. Sexual reproduction of the Aspergillales and the formation of the ascocarp or perithecium: $A$, meeting of the male, an, and female, $o$, gametangia. $B$, early stage in the development of the ascocarp. The gametospore has formed a series of branches, $s$, which are being surrounded by hyphae (unshaded in the figure) from the mycelium. $C$, later stage seen in section. The gametospore has formed a much-branched body, $s$, which is surrounded by a closely interwoven mass of hyphae that appear in section as cells. After Brefeld.

favorable for growth these plants are rapidly multiplied and disseminated by conidia. Changed conditions cause the development of sexual organs and the consequent formation of the game-1 tospore. The gametospore germinates at once, living on the parent plant like a parasite just as in the case of the red algae.' Note also another resemblance, the gametospore first develops a mass of cells, in this instance of a hyphal character, on which later the spore-containing asci arise as lateral branches.

The truffles are a curious group of related fungi that live for the most part entirely under ground. The mycelium of many forms is supposed to live in contact with the roots of oaks and other trees as a mycorhiza. The fleshy tuber-like ascocarp; often as large as a walnut, is a highly prized delicacy in Europe where dogs and pigs are trained to locate the truffles by smell. This industry amounts to more than $\mathrm{f}, 000,000$ annually in France and Italy. 
9r. Order f. Perisporiales or Powdery Mildews. - This name is given to a common and widely distributed group of largely parasitic fungi that form cobwebby mycelia on the under surface of the leaves of the eim, maple, willow, lilac, rhododendron,

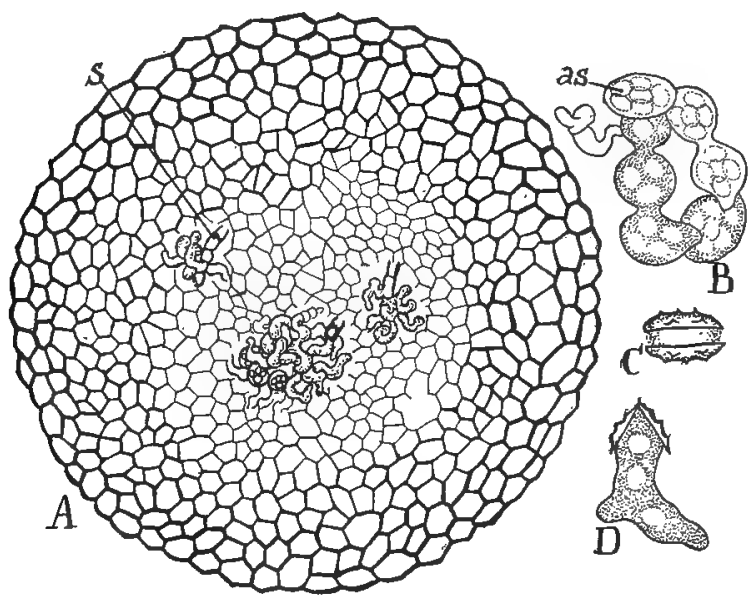

FIG. I54. Further development of the ascocarp: $A$, sectional view, showing the branches, $s$, derived from the germinating gametospore, that are forming numerous lateral branchlets. $B$, one of the branchlets enlarged, showing how it divides into cells which round off, forming the asci, as. $C$, ascospore. $D$, germinating ascospore.-After Brefeld.

Virginia creeper, etc. (Fig. I55), and a great variety of herbaceous plants, as the dandelion and cocklebur. The majority of them do not seriously interfere with the health of the plant, but others produce serious diseases in young cherry and plum trees, hop vines, gooseberry, etc. These parasites are external and obtain their food by means of short branches, haustoria, which dissolve the cell wall and absorb the cell contents as shown in Fig. $156, h$. The members of this order are of special interest in that they throw considerable light upon the nature of parasitism. Frequently one and the same form will grow upon a wide variety of plants, just as we will see to be the case in another group, $i$. e., the rusts. Erysiphe graminis, for example, is found upon barley, wheat, rye, oats and several genera of grasses. But the form growing upon any one of these kinds of plants will 
not infest any of the others. It would seem that the parasite becomes changed and specialized, although there is no visible evidence of this, and so after a time is able to live upon but one kind of plant. These specialized forms are termed biological species, in contradistinction to the general or morphological species which include them all. Evidently there is something within the plant that not only attracts these parasites, but also changes them, so that after a time they can only live upon the

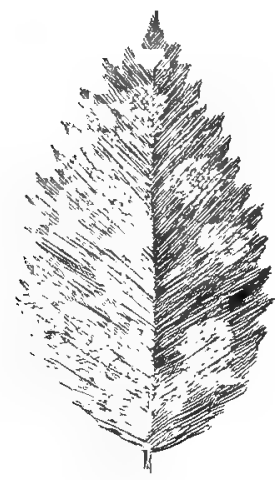

FIG. I55.

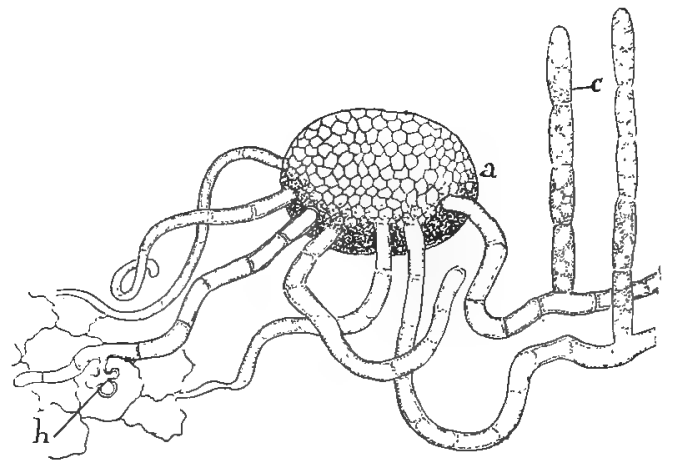

FIG. 156.

FIG. I55. Appearance of one of the powdery mildews, Uncinula, on leaf of elm.

FIG. 156. Enlarged view of the mycelium, ascocarp, etc., of one of the mildews, Erysiphe: $c$, erect hyphae forming spores or conidia; $h$, haustoria penetrating epidermis of leaf; $a$, ascocarp or perithecium.

plant having these substances. If this material is absent from the plant then it is immune and it has been shown in a few cases where individual plants were not subject to a plant disease that this was due to the lack of a substance which the infested plants had or to the presence of a new substance which was repellent to the parasite. The relation between parasite and host is strikingly brought out by Massee's experiment, in which he claims that a purely saprophytic fungus was induced to become a destructive parasite upon the leaves of a species of Begonia by injecting the leaves with a sugar solution. The fungus flourished upon the leaves treated in this way and produced spores. These spores were sown upon leaves similarly treated and this was repeated for 
twelve generations, at which time he states that the spores would grow upon the untreated leaves. Perhaps this is the explanation of some epidemics or the occasional sudden appearance of a plant disease. A variety of circumstances might cause plants to form substances attractive to the parasite or to fail to develop repellent

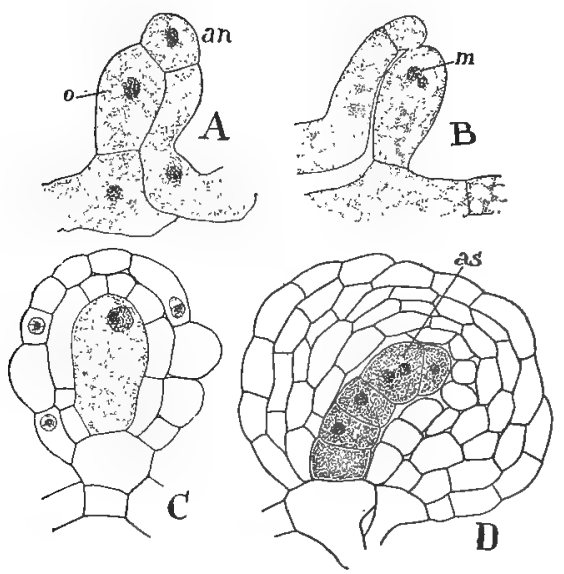

FIG. I57. Sexual reproduction of a powdery mildew: $A$, meeting of the male, $a n$, and female, $o$, gametangia. $B$, fertilization, the male gamete, $m$, is seen approaching the female. $C$, section of young ascocarp showing the early germination of the gametospore, which has become surrounded by thyphae derived from the mycelium. $D$, later stage, the gametospore has developed several cells and the second cell from the end, as, will produce ithe ascus.-After Harper.

materials. In either case they would become susceptible to the disease.

The spores are formed in chains (Fig. I56, c) from the end of the erect hyphae that project from the surface of the leaf in thick masses, causing the powdery appearance and the popular name of these parasites. These spores germinate quickly and rapidly spread the fungus.

The reproductive organs have in this group become still further reduced and appear as short branches as shown in Fig. I57, A. The solution of the walls at the point of contact of these organs permits the male gamete to pass over and fuse with the female (Fig. I57, B). The growth of the gametospore forms a limited number of cells and one of them, usually the 
second from the end, will develop one or several asci (Fig. I57, $C, D)$. As in Penicillium, this growth becomes enveloped by a mass of hyphae that originate from the hyphae bearing the gametospore and from adjacent strands of the mycelium. These ascocarps appear at maturity as black specks and in the majority of forms they are provided with hair-like outgrowths that are very regular and characteristic of the genera (Fig. I58). The ends of these hairs are rather mucilaginous and may assist in the dissemination of the ascocarps. The ascospores are resting

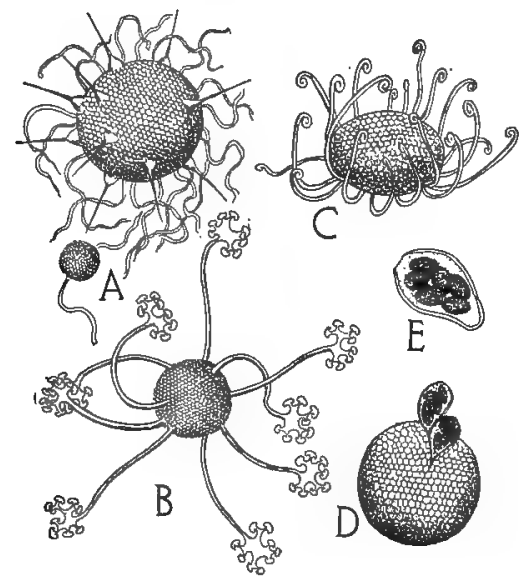

FIG. I58. Forms of ascocarps found among the powdery mildews: $A$, Phyllactinia with needle-like appendages enlarged at the base. $B$, Microsphaera, appendages dichotomous at apex. $C$, Uncinula, appendages coiled at apex. $D$, Erysiphe without appendages and crushed to show escaping asci. $E$, an ascus containing six ascospores.

spores adapted to enduring drought and cold as in Penicillium, which they resemble in their discharge and germination.

92. Reduced Ascomycetes.-Space will only permit the consideration of two other groups from this enormous alliance of the Ascomycetes. These forms are here considered partly because of their economic importance and partly because they illustrate the reduction that may go on in the plant body. These two groups of fungi have become so changed and simplified in their structure and life history as to render impossible a guess as to their relationship to other forms. 
92A. Order g. Exoascales or Peach Curl.-This group includes a small number of parastic fungi that are especially destructive to peach and plum trees, causing distortion of the leaves and fruit, known as leaf curl and bladder plum (Fig. I59). There is apparently no trace of a reproductive process, the mycelium spreading through the leaf develops directly a rudimentary hymenium of numerous asci beneath the cuticle, which is finally

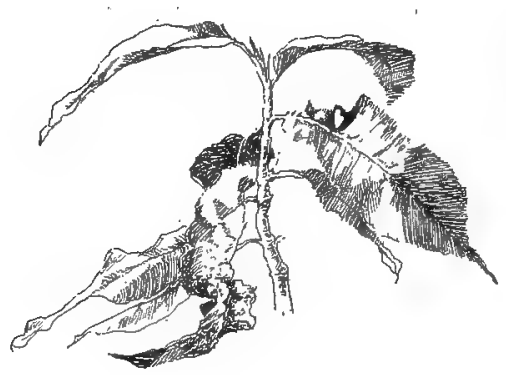

FIG. I 59 .

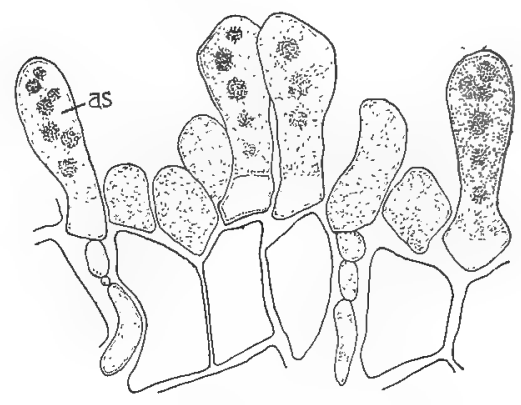

FIG. I60.

FIG. 159. A branch from peach tree, showing the distortion of the leaves caused by the fungus, Exoascus.

FIG. I60. Section of a leaf showing numerous cells rupturing the cuticle and developing into asci, as.

ruptured by their growth (Fig. 160). The ascospores are discharged into the air by the bursting of the asci and carried by the wind to other plants. The damage in the United States to peach trees alone is estimated at $\$ 2,000,000$ to $\$ 3,000,000$ annually.

93. Order h. Yeast or Saccharomycetes.-These fungi are unicellular plants with little suggestion of mycelial growth، Ordinarily they consist of rather oval cells which multiply rapidly by a budding suggestive of conidia formation in preceding orders (Fig. I6I). The new cells that push out from the side of the mother cell readily drop off, but in rapid growth they may remain attached in chains (Fig. I6I, D). Under certain conditions, as the exhaustion of the food supply, the cells become transformed into asci and the contents of each cell rounds off into one or more ascospores (Fig. I6I, E). The ascospores are 
freed by the decay of the ascus and when conditions are favorable; grow into the characteristic yeast cells, as shown in Fig. I6I, $F$.

(a) Fermentation.- These microscopic plants must be numbered among those plants that are of the greatest economic value. Their importance is due to the fact that they decompose sugars upon which they feed into $\mathrm{CO}_{2}$ and alcohol, a change called fermentation. The extensive brewing and distilling industries all

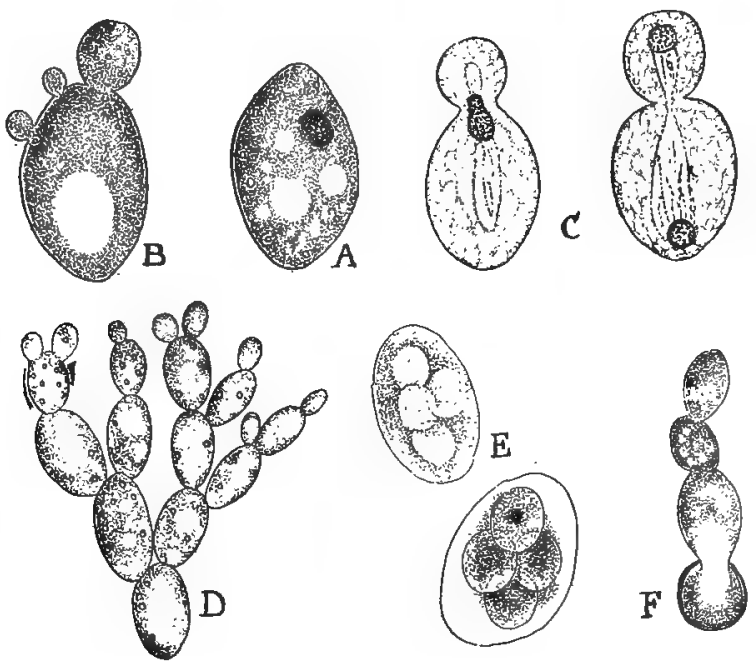

Fig. I6I. The yeast plant, Saccharomyces: $A$, single plant, $B$, plant producing three buds. $C$, section of two plants showing buds and nuclear division. $D$, chain of plants due to rapid budding and growth. E, formation of ascospores. $F$, germination of an ascospore and the formation of new plants by budding.-After Wager.

over the world are dependent upon the growth and peculiar action of these microscopic plants. When yeast plants are placed in solutions containing sugar in the form of molasses or preparations of rye, corn, barley, potatoes, etc., and slightly warmed, the growth of the yeast produces a vigorous fermentation. Carbon dioxide rises to the surface, forming a frothy scum while the alcohol accumulates in the fluid. Beers and ales are fermented beverages of this nature, while whiskies, brandies, alcohol, etc., are obtained from the fermented mass by removing a part of the water by distillation. Wines and cider are weak alcoholic bev- 
erages formed by the yeast plant from the sugars in the juices expressed from grapes and apples. In this case, the yeast is generally allowed to find its way naturally into the fluids. So minute are these plants that they are distributed in the air throughout the world and no weak sugar solution can be exposed for any length of time without being inoculated by them-a fact that has been apparently taken advantage of by man in all times and places. When these fermented beverages are bottled before the decomposition of the sugar is complete, then a further generation of $\mathrm{CO}_{2}$ sets up a pressure in the bottle or cask that causes the popping of the cork when the bottle is opened and the sparkle of the fluid owing to the escaping gas. These forms show the same range of variability in the work which they perform as noted in the bacteria of decay. In the case of cider our government experts have separated several forms of yeast that are now offered for distribution and which give distinctive flavors to cider. So in brewing and bread making enough has been done to show that there are numerous forms of yeast that differ materially in their power to induce fermentation as well as in the nature of the fermentations that they bring about.

(b) Bread Making.-The most important use of the yeast plant is its application to the "raising" of bread. Flour contains, in addition to starch, a little sugar, and this amount is increased in bread making by a ferment, diastase, in the flour which changes starch into sugar. The flour is mixed with water containing yeast plants into a dough and placed in a warm place, when it begins to rise. This means that the yeast plants begin to grow and decompose the sugar into $\mathrm{CO}_{2}$ and alcohol. The dough prevents the escape of the gas which collects in bubbles in the dough, causing it to swell. Baking further expands the gas and also drives off the water and alcohol, leaving the bread light and porous. There are many forms of yeast plants which differ in their power of producing fermentations and in the flavor which they impart. Consequently, different forms are used for different purposes. Bread yeast is a form that has been selected because of the quickness of its action and the flavor that it imparts to bread. Bread yeast is grown in large vats and put up with starch in cakes, known as compressed yeast. 


\section{Class C. Basidiomycetes or Basidia-Forming Fungi}

94. General Features.-This class contains two important groups of fungi; one of which includes very destructive parasites, and the other comprises those conspicuous and familiar saprophytes known as mushrooms, bracket fungi, puff balls, etc. The striking feature of the class is the formation of spores on club-like hyphae called basidia (sing. basidium) (Fig. I71, D). These organs are often developed in rather complex outgrowths of the mycelium which may be fleshy or woody, as in the mushroom and bracket fungi (Figs. I70; $173, B$ ). There is no known sexual reproduction, save possibly in the first order mentioned below where a vegetative union of cells appears to have been substituted for a fertilization process which was originally like that seen in the red algae. The more important orders are the following:

95. Order a. Uredinales or Rusts.-These parasites are well known by the streaks and blotches of yellow or black rust which they produce on the leaves and stems of a great variety of plants. About 2,000 species are known in the United States. They are among the most destructive parasites, causing great damage to wheat, oats, apples, quinces, roses, carnations, etc. The yearly loss from grain rust alone is estimated at considerably over $\$ 18,000,000$ in the United States. They exhibit a degree of variation not paralleled among other plants, more than five different kinds of spores being formed by some species in their life history. This is due, doubtless, to the influence of the climate, the spores varying with the season (spring, summer and fall) and the plants upon which the fungus grows, for one and the same fungus may grow upon different plants, producing one or more kinds of spores on each. Forms infesting different species of plants are said to be heteroecious and those living upon but one species are termed autoecious.

(a) The Life History of Puccinia.-Several species of this genus infest wheat and illustrate the many forms that may appear in the life history of a rust. One phase of the life of this parasite appears upon the leaves of the barberry. During May and June the mycelium growing in the leaves forms roundish 
bodies which rupture the epidermis and finally open out into cups filled with chains of yellowish spores. An examination of Fig. I62 shows that these spores are formed in rows at the end of hyphae and surrounded by a layer of rather thick-walled hyphae. This stage of the rust is known as the cluster cup or aecial stage and the spores are called aeciospores. Often smaller spore-bear-

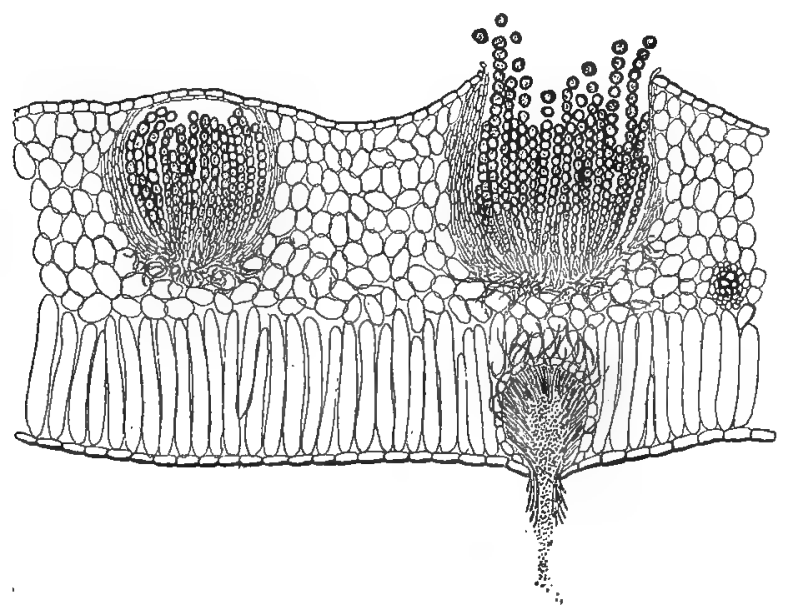

FIG. 162. Cluster cups as seen in section of leaf of spring beauty, Claytonia. At right one of the cups is ruptured, exposing the aeciospores. Below a small cup, pycnium, is discharging pycniospores that are possibly functionless male gametes.

ing cups, known as pycnia (sing. pycnium), are associated with this phase of the fungus. These small spores, while capable of germinating, do not appear to enter into the life history of the fungus by producing a new parasite. They have been looked upon as male gametes that originally effected fertilization in a female organ from which developed the spore-bearing cluster cup, the process being similar to that noted in the Red Algae. On the other hand they are regarded by some authorities as spores that have lost their power to germinate and so breed the fungus asexually. The process of spore formation in the cluster cup, as will be seen from the outline given below, is so different from that of the algae and is known in so few forms that any interpretation of the phenomena should be deferred for the present. 
The spore-producing hyphae in the young aecidia form a rather loose stratum of somewhat elongated cells (Fig. I62, $A, \mathrm{I}$ ). These cells divide, forming an upper series of cells which are smaller and narrower than the lower or basal cells. These upper cells are sterile, ultimately disappearing, and they have been compared
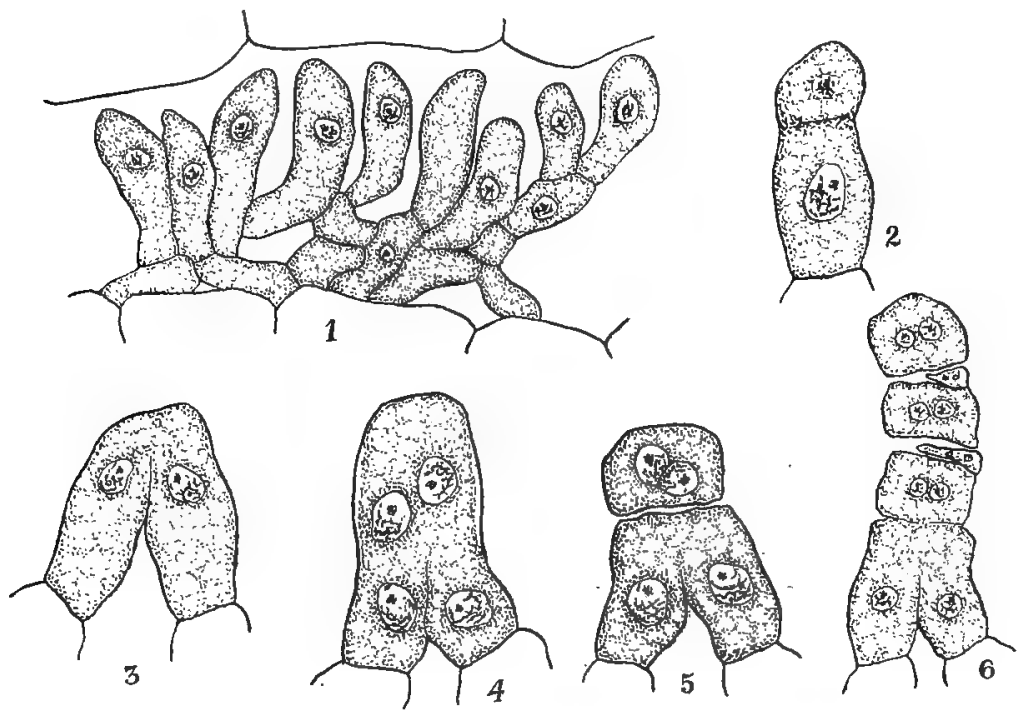

FIG. I62A. Spore formation in a cluster cup: $\mathrm{I}$, appearance of the hyphae in a young cup. 2, one of the cells from Fig. I, after it has divided into the sterile cell and the large basal cell. 3, early stage in the fusion of the basal cells of two adjacent hyphae. 4, the two nuclei of the fused cells have divided and two of them are passing to the base of the cells and two into the fused region of the cells. 5, the upper portion of the fused area is cut off, forming the spore mother cell. This cell will divide once, forming a spore and a small sterile cell. 6 , a chain of spores and sterile cells is being formed as noted in 5.-After Christman.

to remnants of the tubular outgrowth of the female gametangium noted in the red algae.

The basal cells enlarge, become inclined towards one another in pairs and finally meet at their upper ends, the walls dissolving at the point of contact. The nuclei of the two cells now pass to the fused region of the cells and divide, forming four nuclei. Two of these wander back into the base of their respective cells, while the other two pass to the upper portion of the fused area 


\section{FORMATION OF SPORES IN THE RUSTS}

and become separated from the basal nuclei by a transverse wall (Fig. 162, $A, 3-5$ ). The upper cell formed in this manner is the spore mother cell and it divides at once, forming an aeciospore and a small intercalary cell. As soon as this process is completed the two nuclei at the base of the fused cells move up again into the fused portion of the cells, which region has elongated in the meantime, and divided as before. In this way a chain of binucleate aeciospores is formed, separated by small intercalary cells (Fig. I62, $A, 6$ ) that soon disintegrate.

As soon as the cluster cups are ruptured the aeciospores are scattered by the wind, and singularly, will only germinate and infest the seedlings and young leaves of the wheat in which they develop a mycelium similar to that of the barberry, but note that the cells of this mycelium are binucleate like the aeciospores. However, this mycelium forms in place of cluster cups, groups of erect hyphae at the ends of which single reddish spores are formed (Fig. I63, C). This growth ruptures the epidermis, exposing the spores in rusty lines of blotches (Fig. I63, B). These yellowbrown blotches account for the popular name of Rusts given to this group of fungi. This is the summer or uredinal stage of the parasite. The spores are known as urediniospores. This phase of the fungus is a very destructive one, for the spores are formed in great numbers and provided with thin walls. They are widely distributed by the wind and germinate at once (Fig. I64, A) on other wheat plants which soon show the rusty brown streaks of urediniospores. In this way, the pest spreads with great rapidity from a single center of infection. This formation of urediniospores goes on during the summer, sapping the vitality of the plant and, in severe cases of infection, materially interferes with the maturing of the grain.

Later in the season, this same mycelium forms in the leaves of the wheat quite a different type of spore. They are formed in the same manner as the urediniospores but are provided with thick dark walls and from one to several spores are developed at the end of the hyphae (Fig. I63,D). Consequently, when the epidermis is ruptured, these spores form rusty black blotches on the leaves. This third stage is known as the telial, since it ends 
the season's growth. These spores, called teliospores, are resting spores and tide the fungus over the winter. Furthermore these spores are uninucleate. The two nuclei which have characterized all cells from the aecial stage on, actually fuse, forming one nucleus as the teliospores mature. Some regard this as a delayed fertilization. The teliospores germinate in the spring quite

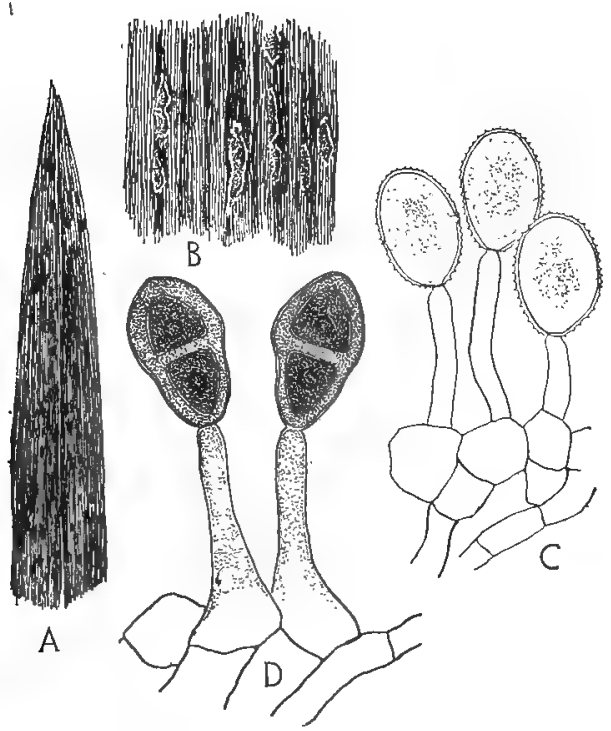

FIG. I63.

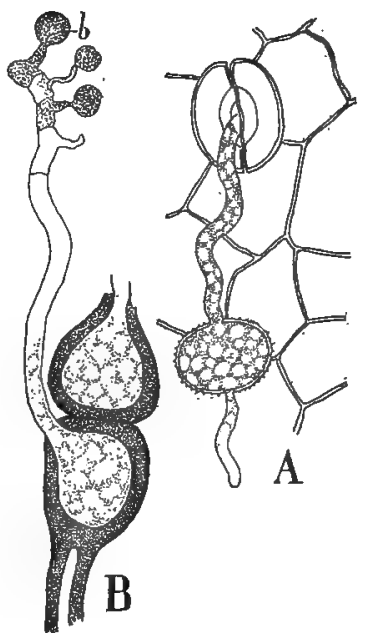

FIG. I64.

FIG. I63. The summer and fall stages of a rust, Puccinia: $A$, rust blotches on leaf of wheat. $B$, portion of leaf magnified, showing rupturing of the epidermis due to the formation of spores. $C$, urediniospores or the summer spores which effect a rapid distribution of the parasite during the summer. $D$, teliospores or fall spores which are dormant during the winter.

FIG. 164. Germination of uredinio- and telio-spores: $A$, the thin-walled urediniospore sending out hyphae from thin places in its wall. This is effected as soon as it is carried by the wind to a moist leaf. $B$, teliospore germinating in the spring and forming a short hypha, from the end of which four cells have been cut off that are forming the basidiospores, $b$.

independent of any plant and being dependent upon the food stored in the spore, they only form short hyphae which usually become divided into four cells (Fig. I64, B). This structure is known as the basidium. Each cell of the basidium sends out a delicate tube into the end of which the cell contents passes, thus 
forming a small spore, known as the basidiospore. This basidial stage completes the life history of the fungus for the basidiospores are carried to the leaves of the barberry and begin again the life cycle of the parasite by forming the cluster cups. It is held by many that this sequence in spore formation represents an alternation of generation. According to this view the aecium is the result of a sexual process. Therefore the aeciospore would be the beginning of the sporophyte or asexual generation, which terminates in the teliospore. The germination of the teliospore marks the beginning of the sexual generation and it is interesting to note that we have four cells produced as in the tetraspores of the red algae.

It is not surprising that this story was not unravelled for a long time and that these different stages of the parasite were known as distinct species. The first clue to the relationship was gained in England where it was observed that the wheat fields to the leeward of the barberry bushes were especially infested with rust. For this reason, a law was passed early in the history of Massachusetts compelling the destruction of the barberry bushes. This suggestion of relationship between the cluster-cup stage of the barberry and the rust of the wheat finally led to the inoculation of wheat plants with aeciospores and this resulted after a week or more in the appearance of the characteristic rusty streaks on the leaves of the wheat.

(b) Features in the Life History of Other Rusts.-Considerable variation characterizes these rusts, not all of them having so elaborate a life history as that outlined above. One of the most common species of Puccinia affecting the wheat is perennial in the wheat and possibly in other grasses where it.produces urediniospores in the spring, thus, the aecial, telial and basidial stages are eliminated. In the apple rust, the uredinial stage is missing. This disease produces on the leaves of various members of the apple family, yellow patches in which are formed tube-like cluster cups (Fig. I65, A). The aeciospores are only capable of infesting the juniper, in the branches of which they produce gall-like swellings (Fig. I65, B) known as cedar apples and also sometimes bushy outgrowths known as witches' brooms. In the 
spring, variously shaped masses of hyphae bearing numerous teliospores radiate out from these galls and in the early spring rains these strands swell up, forming conspicuous yellow, jellylike masses. The basidiospores are developed in the jelly and infest the leaves of the apple, thorn, shadbush, etc. In some of the genera of rusts all the stages appear upon the same plant as in the May apple and jack-in-the-pulpit. In the early spring

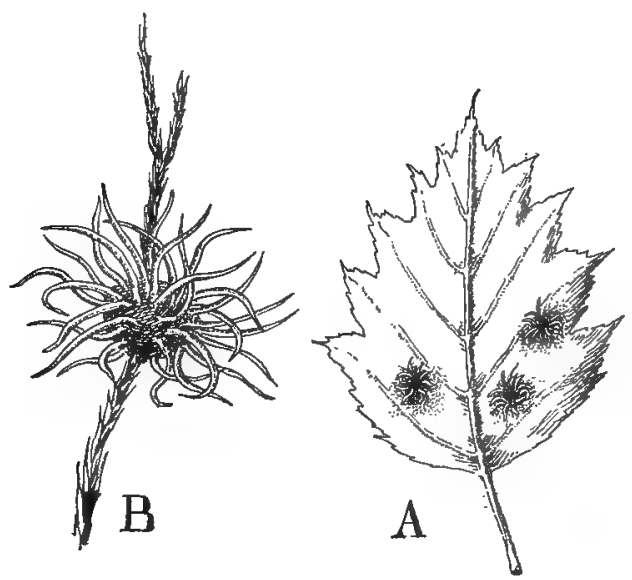

FIG. 165. A rust, Gymnosporangium, that infests the juniper and members of the apple family: $A$, cluster cups on leaf of thorn apple. $B$, teliospore stage on red cedar, juniper.

the stems and leaves may often be seen infected with the yellow cluster cups which are followed later by the dark-colored teliospores. In other cases, teliospores only are produced, as in the hollyhock, and this was doubtless the original form of the spore. Numerous physiological species have been reported among the rusts as in the case of the powdery mildews, and in both groups we find some of these specialized forms able to grow' upon different plants if an intermediate plant is used to "bridge" them over. Thus a physiological species that grows normally upon the oat but not upon rye or wheat may be made to do so by first growing it upon barley. Spores derived from the barley will now infest rye or wheat.

96. Order b. Ustilaginales or the Smuts. - These parasités are more primitive than the rusts to which they are doubtless 
related. They produce very generally but one form of spore that may possibly be compared to the teliospore. They are common and exceedingly destructive parasites, affecting especially the flowers and fruits of corn and other cereals as wheat, oats and barley (Fig. r66). The damage by smuts to the corn crop

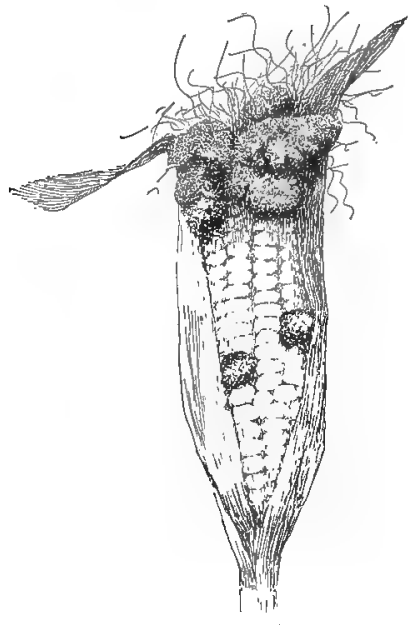

FIG. I66.

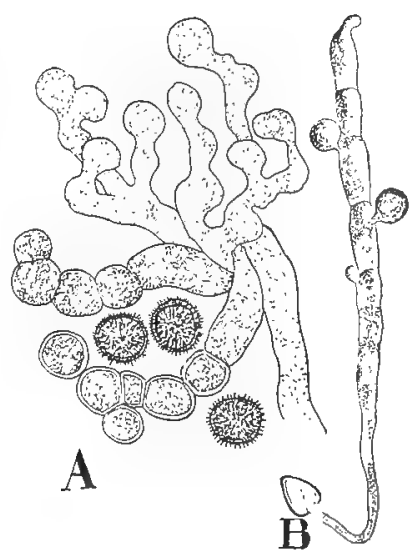

FIG. I67.

FIG. I66. A common smut, Ustilago, transforming the kernels of corn into sooty black pustules.

FIG. 167. The formation and germination of the spore of a smut: $A$, the formation of the spores from the mycelium in the kernel of corn. $B$, germination of a spore and the appearance of the basidiospore.

of the United States exceeds $\$ 2,000,000$ annually. In the case of corn, the parasite keeps pace with the growth of the plant without producing serious damage until the flowers appear, when the mycelium increases greatly in the affected ears and "tassels". producing sometimes enormous malformation, especially in the ears, which appear as glistening white blisters or pustules. Later, these bodies change to a sooty black, owing to the transformation of the cells of the mycelium (Fig. I67, A) into black greasy spores. These spores are scattered in clouds upon the breaking of the pustules and germinate much after the manner of the teliospores of the rusts, infesting the young and delicate parts of 
other corn plants by means of their basidiospores (Fig. I67, B). In other cases, the teliospores germinate in the spring, infesting the seedlings. This appears to be always the case in the destructive wheat, rye, oat and barley smuts. Infection only takes place when the spores come in contact with the seed. Consequently, in these cases, the fungus can more readily be fought by treating the seed with some fungicide as formaline and copper sulphate.

97. Order c. Agaricales or Mushrooms and Toadstools.This is the most familiar group of the basidiomycetes and its I 2,000 odd species are commonly referred to as mushrooms and toadstools. These fungi are largely saprophytes, living upon the humus in the soil and upon decaying wood. Several of the genera are exceedingly destructive to trees and cause great loss to the lumber industry. In the majority of cases, the fungi appear unable to attack the living portion of the trees and only thrive upon dead tissues, as the heart wood, which they quickly disorganize and render worthless. As in all the preceding groups of fungi, the real plant body is a delicate mycelium that spreads through the soil or decaying substances, as may readily be demonstrated by splitting open a tree infested with one of the fungi (Fig. I68). The "spawn" that is sold in seed stores for planting in mushroom beds is a dried mass of decaying leaves and straw mixed with earth, in which the mycelium of the mushroom has been allowed to grow. Often the hyphae of the mycelium. lose their delicate character and become woven together, forming rather dense woody strands or plates, a development frequently seen in the timbers of mines and under the bark of decaying trees. In certain species the mycelium is phosphorescent and the cause of the pale light that sometimes appears upon moist decaying wood, the so-called fox wood. The mycelium bears at various places the complex fleshy or woody body commonly known as the mushroom or toadstool. If the mycelium grows in a regular manner, radiating outward in all directions, then the mushrooms. will have a similar arrangement. The older central portions of the mycelium will finally die off, while the newer portions continue to radiate outward and produce the mushrooms, whirh con- 
sequently appear in a more or less regular circle. In this way, the fairy rings, which are often held in superstitious awe, come about.

The Mushroom or Toadstool.-The common umbrella type of mushroom consists of a stalk or stipe and a cap or pileus, on

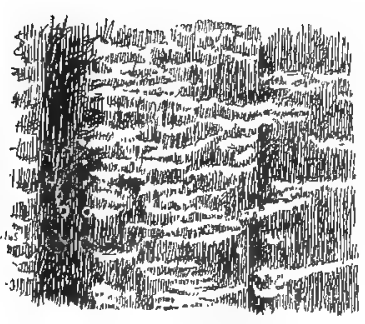

FIG. I68.

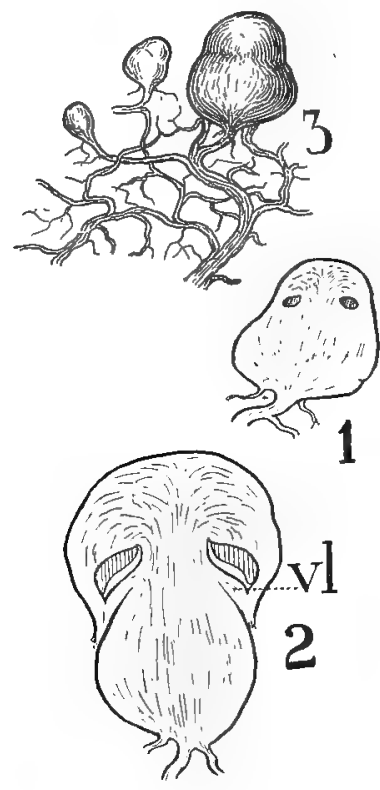

FIG. I69.

FIG. I68. The mycelium of one of the Agaricales forming white masses as its spreads through wood.

Frg. I69. Development of a mushroom: 3 , early appearance of the mushroom as a ball of hyphae on the strands of the mycelium. I, section of one of these spherical masses of hyphae, showing the circular openings in which the gills are developed. 2, a later stage with the gills formed and the velum, $v l$, appearing as a delicate membrane.

the underside of which are located radiating plates or gills (Fig. I70, $A$ ). This structure originates on a strand of the mycelium as a very small ball composed of a mass of interwoven hyphae (Fig. I69, 3). Soon, however, the hyphae of this mass begin to grow in a very regular manner. At first the growth results in the formation of a cavity in the upper part of the ball that extends completely around it (Fig. I69, I). Hyphae now grow 
down into this cavity in regular lines, forming the radiating plates or gills noted in Fig. I70. This development divides the ball of hyphae into an upper part or pileus and a basal region, the stalk or stipe. As this growth proceeds the mass of hyphae extending from the margin of the pileus to the stipe becomes

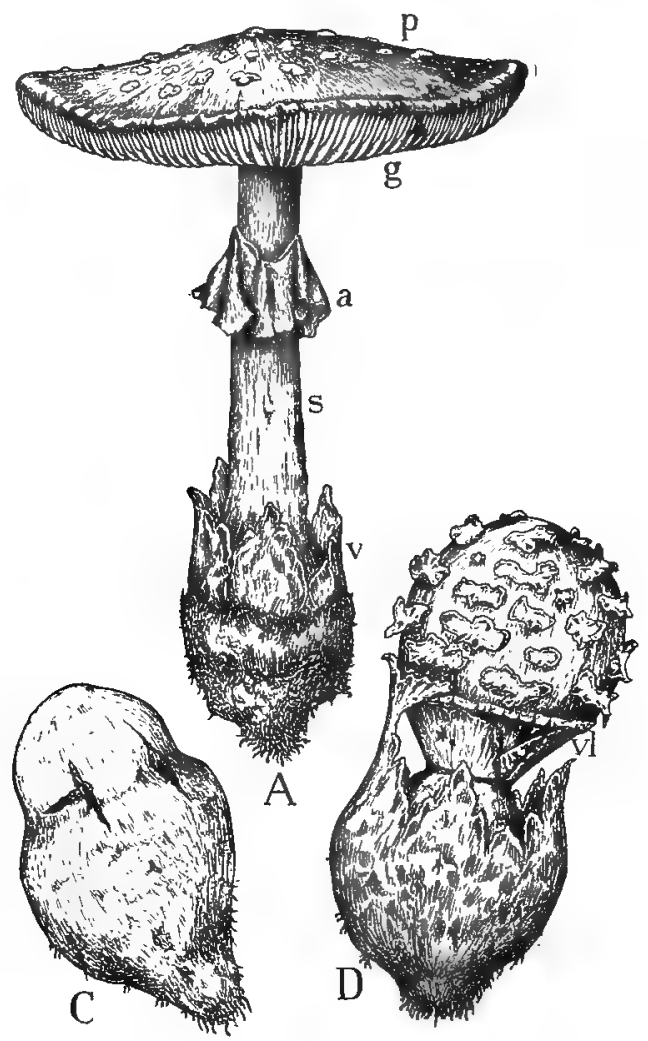

FIG. I70. Habit of a poisonous mushroom, Amanita: $A$, the mature mushroom $-s$, stipe; $p$, pileus; $g$, gills; $a$, annulus; $v$, volva, a part of which appears in patches on the top of the pileus. $C$, young form of the Amanita, the volva beginning to break. $D$, later development, the volva completely ruptured, disclosing the pileus, stipe and velum, $v$. - H. O. Hanson.

drawn out and ultimately forms a rather thin membrane known as the velum (Fig. I69, 2, vl). This entire growth is often enveloped by a sheath-like mass of hyphae, the volva (Fig. I 7o, $C, D)$. At this stage of development, the young mushroom is 
rather spherical in shape and so small that it is quite concealed in the ground or by surrounding vegetation. When conditions are favorable for further growth, as after a rain, each cell of this miniature fungus absorbs moisture and rapidly expands, thus causing the mushroom to spring up as by magic and reach its full growth in a few hours. As the stipe elongates, the pileus spreads out like an umbrella, rupturing the veil, a part of which clings to the stalk (Fig. I $70, A, a$ ) in the form of a ring, the annulus, and a part may also hang in the form of ragged filaments from the edge of the pileus. If a volva is formed, this is also ruptured by the elongation of the stipe, forming a cup at the base of the stipe, and usually portions also remain attached to the top of the pileus as scales and patches (Fig. I7o, $A, D$ ). The structure of the mushroom is very simple. The stipe consists of a mass of nearly parallel hyphae that show little modification save at the surface of the stem, where they are sometimes more compactly arranged (Fig. I7I, $A, B$ ). By cutting across the gills, so that we can look into the ends of them; it will be seen that the hyphae extend down the center of the gills and also continually radiate out on either side, forming a compact layer of rather elongated cells on the surface of the gills, known as the hymenium (Fig. I7 I, C). A magnified view of a portion of this hymenium shows that it is composed of paraphyses and basidia (Fig. I7I, D). These so-called paraphyses are potential basidia and continue to develop as such during the life of the mushroom. The basidia are not divided as in the smuts and rusts, but the spores are formed in the same manner at the end of two or four small tubes that grow out from the apex of the basidia. It should be stated that a series of intermediate forms exist that connect the divided basidia with the present form. The spores are mature and begin to drop off as soon as the pileus opens, when they are scattered by the wind and develop under favorable conditions into a new mycelium. If the pileus of a freshly opened mushroom is placed on a sheet of gray paper and tightly covered with a dish, so as to exclude all air currents, the spores will fall directly upon the paper and in a few hours form an exact copy or a spore print of the gill arrangement. There 
are several very widely distributed and familiar families of the Agaricales, distinguished by the arrangement and distribution of the jhymenium.

A.'Thelephoraceae.-These fungi form membranous, leathery

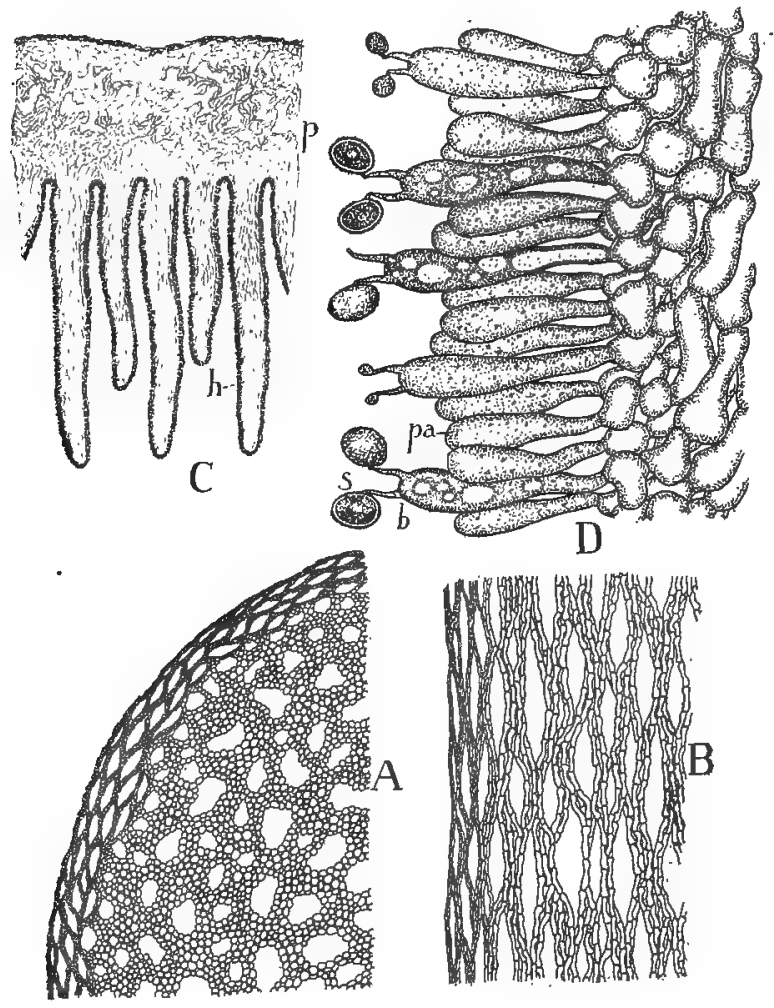

FIG. 17I. Structure of a mushroom: $A$ and $B$, cross and longitudinal sections of a portion of the stipe, showing the character and arrangement of the" hyphae that make up the mushroom. $C$, tangential view of the gills $-p$, pileus; $h$, hymenium appearing as a dark band on the surface of the gills. $D$, a portion of the hymenium enlarged $-b$, basidia; $p a$, paraphyses; $s$, basidiospores.

or woody incrustations or shell-like structures or branching bodies on soil or wood (Fig. I72, $A, B$ ). The hymenium forms a smooth or slightly wrinkled surface on the under side or exposed surface of the fungus. 
B. Clavariaceae or Coral Fungi.-This family includes the fairy clubs and coral-like fleshy masses of various colors (Fig. I72, C). The hymenium covers the branches.

C. Hydnaceae or Prickly Fungi.-These fungi form masses of widely various forms, but provided with spine-like outgrowths upon which the hymenium is developed (Fig. I72, D).

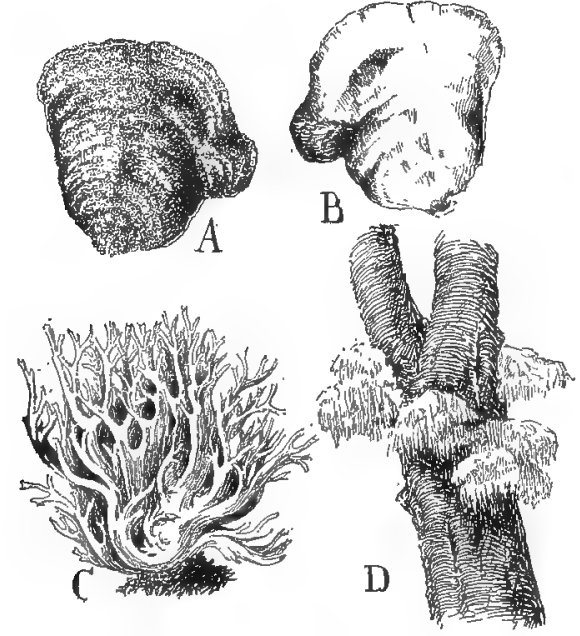

FIG. 172. Forms of the Agaricales: $A$, Stereum, top view. $B$, underside, showing the characteristic smooth hymenial surface of the Telephoraceae. $C$, a coral fungus, Clavaria, with hymenium confined to the tips of the branches. $D$, a prickly fungus, $H y d n u m$, with the hymenium on spine-like projections.

\section{Polyporaceae or Pore Fungi.-This group includes largely} leathery, woody or corky fungi in which the hymenium is developed on the surface of pores. They contain some of the most destructive of the timber-destroying fungi. Many of the genera of this family form shelf-like outgrowths on trees and are therefore known as bracket fungi (Fig. I73, $B-D$ ). Professor Buller estimated that a single pore in one species of this group which he found growing upon a decaying elm, produced no less than I,700,000 spores and that the entire bracket, about $250 \mathrm{sq} . \mathrm{cm}$. in area, formed over eleven billion spores. The combined annual output of the ten brackets growing upon this tree exceeded by fifty times the population of the globe. This enormous spore 
production is characteristic of nearly all of the Agaricales and it is not surprising that a bit of dead wood or piece of lumber can not be exposed without being infested with the spores.

E. Boletaceae or Fleshy Pore Fungi.-The members of this family are generally characterized by a stalk and a pileus which
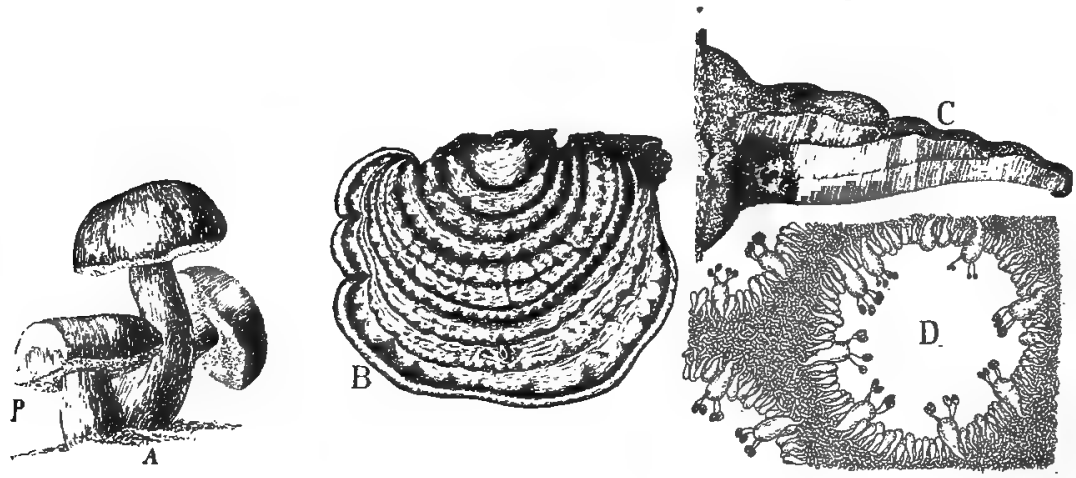

FIG. I73. Pore forms of the Agaricales: $A$, Boletus, showing fleshy porebearing layer, $p$. $B$, top view of a woody, bracket form, Elfvingia. The concentric lines represent the annual growth. $C$, section of a similar form, showing three layers of pores that represent three years' growth. $D$, enlarged view of under surface, showing one of the pores with hymenial layer.

bears pores, the latter being easily separable as a layer from the pileus (Fig. I73, $A$ ).

F. Agaricaceae or Gill Fungi.-These fungi more commonly assume an umbrella form, although some of them are of the shelving bracket type (Fig. I70). The hymenium is arranged on the surface of gills or plates. Many of them are highly prized for the table, though they contain comparatively little nourishment, and must be regarded as relishes rather than foods. While the majority of the 5,000 species of the family are edible, some of them contain the most deadly poisons. No rule can be given that will enable the collector to separate these fungi into the two mythical groups of poisonous toadstools and edible mushrooms. Each species must be known individually before it is safe to use them for food. All forms with a volva should be most carefully identified, because this is a feature of the deadly amanitas (Fig. I70), which are among the most poisonous plants known. 
The remaining orders of Basidiomycetes are characterized by the concealment of the basidia in cavities and are for this reason collectively known as the Gasteromycetes, meaning stomach fungi. Among the more common orders may be mentioned:

98. Order d. Lycoperdales or Puff Balls.-These familiar

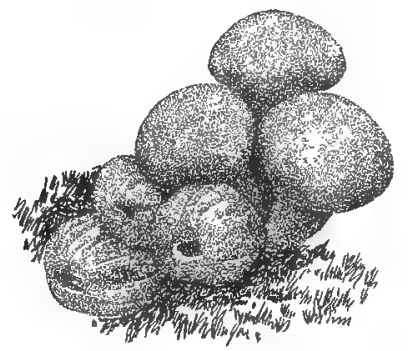

FIG. I74. Cluster of common puffballs, Lycoperdon. At left three older ones have opened, permitting dissharge of basidiospores.

fungi are developed, as in the Agaricales, on strands of the mycelium, which often form extensive net-like threads in rotten stumps, logs, sawdust and humus (Fig. I74). The puffballs vary in size from a pea to over a foot in diameter. When young, they consist of white cheesy masses of hyphae which form in

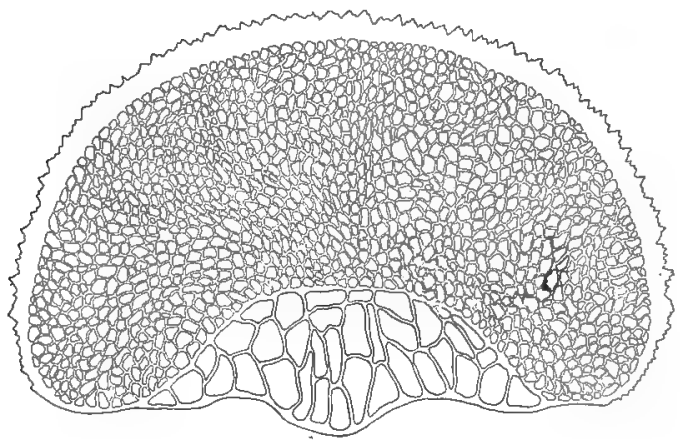

FIG. 175. Diagram of a section of one of the puffballs, showing the thick skin of periderm and the irregular cavities which are lined with basidia. At the base the larger, sterile cavities of the stipe are shown.

the interior of the puffball a series of irregular cavities lined with basidia and on the exterior, a rather firm skin or periderm (Fig. I75). At maturity, the inner hyphae break up, leaving only a 
dusty mass of spores and in some cases firmer hyphae, the capillitium. The skin ruptures in various ways, often by one or more pores at the top, and the least touch now causes the spores to sift out in smoke-like puffs, hence the popular name of puffballs. In the earth stars (Fig. I76) the outer layer of the peri-

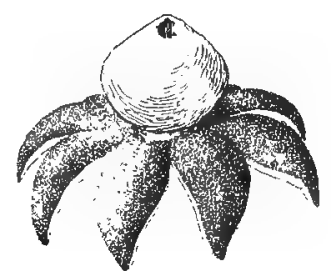

FIG. 176. One of the puffballs popularly known as "earth stars," show. ing the outer periderm splitting into star-like sections and the inner periderm opening by a pore.

derm splits into rather regular star-like segments or valves which are hygroscopic. In damp weather these valves roll back, in some species to such an extent as to lift the puffball from the ground, when it may be set rolling by the wind and thus bring about a better discharge of the spores.

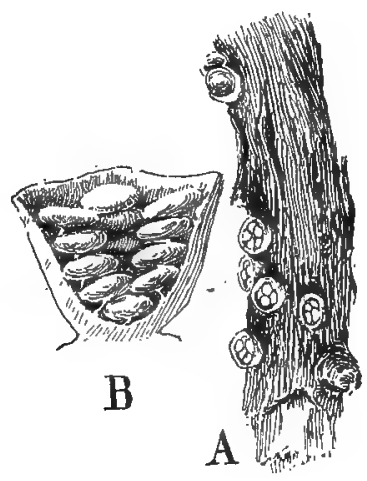

FIG. 177. A common bird's-nest-fungus, Cruicibulum: $A$, habit of fungus on branch of hickory. $B$, one of the cups in section, showing the tough hyphae surrounding the spore-bearing cavities.

99. Order e. Nidulariales or Bird's-Nest Fungi.-These minute and curious fungi may be found growing upon twigs or upon bare ground in old fields, or upon dried dung (Fig. I77, $A$ ). 
They differ chiefly from the puffballs in that the spore-bearing cavities are surrounded by tougher hyphae. Consequently, when the periderm of these little cup-shaped bodies opens, these tougher parts appear as minute eggs in a nest (Fig. I77, B).

Ioo. Order f. Phallales or Stink Horns.-These fungi first appear as egg-like structures on rather coarse strands of the mycelium which traverse decaying 'vegetation. These bodies consist of a white skin-like periderm which encloses a stipe and

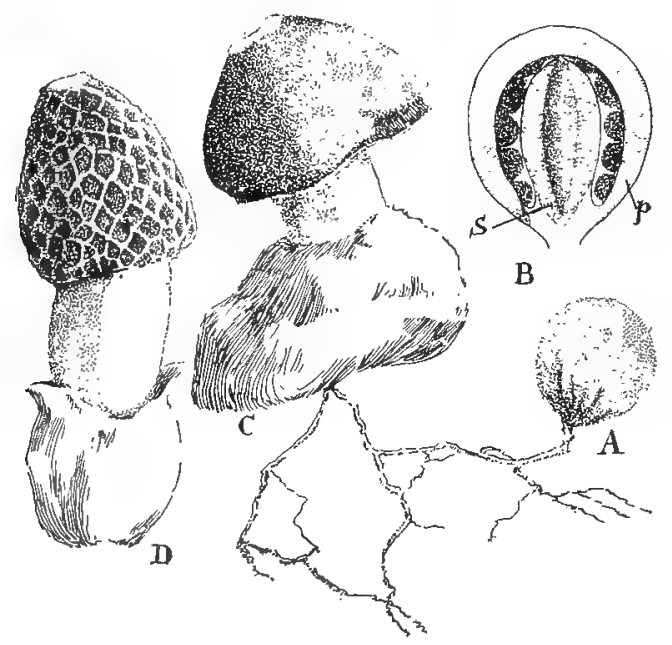

FIG. 178. A common form of the Phallales, Phallus: $A$, the so-called eggstage which in $B$, sectional view, is seen to consist of an outer periderm, $p$, and within is a central stipe, $s$, capped with a pileus. The spore-bearing cavities of the pileus are shaded. $C$, stipe and pileus have emerged from the periderm, which forms an irregular sac about the base of the stipe. $D$, later stage after the spore-bearing layer has dissolved, revealing the cavities on surface of pileus.

pileus (Fig. $\mathrm{r} 78, A, B$ ). The basidia are formed in honeycomblike cavities on the outer surface of the pileus. As soon as the spores are matured the stipe quickly elongates, rupturing the periderm and lifting the pileus into the air (Fig. I78, C). In structure and coloration, the Phallales are among the most attractive of the Basidiomycetes, but the majority of the forms are regarded with aversion, since the spore-bearing layer melts down into a slimy mass which emits a carrion-like stench. 


\section{CHAPTER VII}

\section{DIVISION II. BRYOPHYTA. THE LIVERWORTS AND MOSSES}

Ior. Adaptive Features of the Bryophyta.-We have now reached the point in the evolution of the plant where it has left the aquatic condition of its algal ancestors and become largely terrestrial. As has been stated, the fungi do not enter into the scheme of evolution of higher types. They are looked upon as a side line, derived doubtless from various groups of the algae, that have undergone a peculiar series of variation owing to their parasitic and saprophytic habits and that are in no way connected with higher plants. In the Bryophyta we take up again the line of ascent. Naturally we would expect that a change from the aquatic to terrestrial conditions would be attended with profound changes, tending to adapt the plants to the terrestrial conditions. The results of the stimulus of the new surroundings are seen in the production of hair-like outgrowths, rhizoids, that anchor the plant to the substratum and bring it into proper relation with the soil. So long as the plant lived in the water any of its cells might serve as absorbing organs, but it is evident that the provision must now be made for procuring the crude materials which are no longer in direct contact with the plant. The exposure of the plant to the atmosphere results also in the formation of a cuticle and of mucilage-producing cells which tend to retain the moisture and so adapt the plant to its drier environment. It will also be noted that modifications are beginning to appear in the arrangement of the chlorophyll-bearing cells, with the result that they are sometimes distributed in the same favorable positions for photosynthesis, as you have noted in the higher plants. However, the Bryophyta are only imperfectly adapted to terrestrial conditions and the entire plant body often assists in the absorption of moisture and mineral substances. For this reason most of them are moisture and shade plants, some indeed being still aquatic, and they remain rather small and inconspicuous, 


\section{CHARACTERISTICS OF THE BRYOPHYTA}

owing to the fact that they have not as yet varied and produced tissues that can supply them with an adequate amount of moisture and protect them against the climatic changes. Owing to their habit of growing together in colonies, they often become conspicuous and cover the bare earth, logs and tree trunks with swards and mats that constitute one of the most attractive features of the forest vegetation, and in northern regions they often form the most characteristic feature of the vegetation over large districts.

102. General Characteristics of the Bryophyta.-Certain groups of the Bryophyta are characterized by thalloid plant bodies, $i$. e., without distinction of stem, root or leaf, while many have developed into creeping or erect plants with leaf-like organs. All are distinguished by a marked localization of the growing zone, the elongation of the plant being due to the repeated divisions of a single apical cell. The reproduction of the Bryophyta shows such marked departures that we realize that a wide gulf separates even the simplest of them from the Thallophyta. Notable among these departures is the absence of zoöspores. Only in a single genus are nonciliated bodies formed and discharged from certain cells as in the case of zoöspores. In this connection it is worth your time to look back and note the trend of plant life. The lowest forms of the green algae were essentially motile. Then the stationary condition arose and the motile state represented by the zoöspores became less and less conspicuous. In the bryophytes we perhaps have in the spores, referred to above, an interesting example of the last trace of the motile phase of plant life. The suppression by the sexual plant of the spore method of reproduction is due to several causes. They are able to increase their numbers in a vegetative manner. Special branches or ordinary shoots become detached from the parent plant by decay of the older parts or by other means and develop into new plants. Buds, called gemmae, consisting of one or more cells, are also very commonly formed on various parts of the plant and becoming detached grow into new plants (Fig. r86). Possibly also the higher organization of the Bryophyta, which renders them more capable of meeting 
conditions that would be fatal to the lower forms, tended to make them independent of spore reproduction. But especially has this change been brought about by the fact that the gametospore in germinating develops an asexual plant or generation with enormous possibilities in the way of spore production, so that the increase and distribution of individuals is now fully provided for by the asexual plant and consequently largely removed from the sexual plant. This shifting of the responsibility for the increase in number of individuals from the sexual to the asexual generation is one of the most significant departures in the evolution of plants. We will be interested to note how this change came about and how it steadily gains in importance in the remaining divisions.

The sexual reproduction of the bryophytes reveals a series of variations that are only remotely suggestive of the algae, but that indicate very clearly relationship with higher plants. These features will be considered in the discussion of the various groups. There are two classes of Bryophyta: A, The Hepaticae or Liverworts; B, the Musci or Mosses.

\section{Class A. Hepaticae or Liverworts}

103. Classification of the Liverworts.-While these plants are the simplest and least conspicuous of the Bryophyta, they are the most interesting, because among them will be found reminders of the algae and at the same time they present many features that are suggestive of the mosses and ferns. They occur in very moist places and in deep woods, on rotting logs and moist shady banks. A few are aquatic, floating upon still ponds and streams, and some have become adapted to dry conditions. There are three orders: (a) Marchantiales or Thallose Liverworts; (b) Jungermaniales or Leafy Liverworts; (c) Anthocerotales or Horned Liverworts.

I04. Order a. Marchantiales or Thallose Hepatics.-The liverworts of this order are characterized by flat, prostrate and rather fleshy bodies which usually grow upon the earth, to which they are attached by numerous rhizoids. Owing to the frequent division of the apical cell of the thallus into two equal parts, there result two growing points which thus produce the equal forking 
or dichotomous branching of the thallus, so characteristic of these plants (Fig. I 79, $A, B$ ). The appearance of many of these hepatics is suggestive of the algae. Especially is this true of the aquatic Ricciocarpus and Riccia.

(a) Structure of Ricciocarpus.-An examination of the structure of one of these will show, however, that extensive changes have been induced in even the simplest forms. The new stimuli to which the terrestrial conditions expose them cause a remarkable series of transformations in the cells that are cut off from the

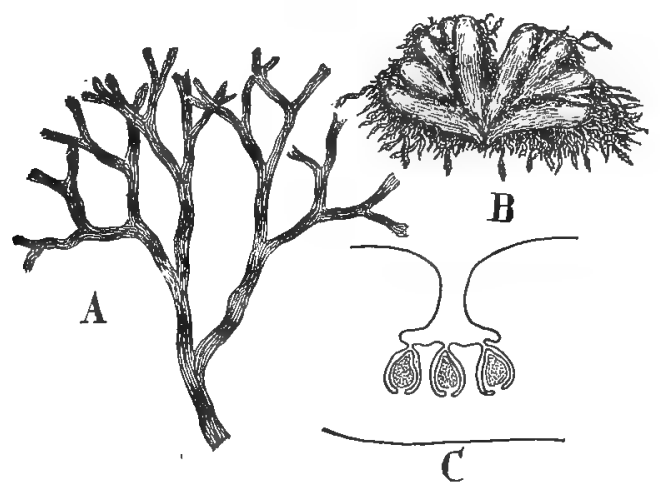

FIG. 179. Forms of semiaquatic Marchantiales: $A$, Riccia, showing the dichotomous branching of the thallus. $B$, Ricciocarpus. The sexual organs are concealed in furrows that appear as radiating lines in the center of the branches. $C$, diagram of a cross-section of a branch, showing the male gametangia in the bottom of one of the furrows.

apical cell. The upper cells of the thallus, as soon as they are formed at the growing point, are exposed directly to the air and light, and they develop chlorophyll and grow up into vertical rows or plates just as you have already noticed in the palisade chlorenchyma of the leaf (Fig. I80, $A$ ). At an early period these rows of green cells become separated so that air spaces arise between them, and thus the chlorophyll-bearing cells are brought into direct contact with the atmosphere and enabled to carry on photosynthesis to the best advantage. The terminal cells of these rows enlarge considerably and form a rudimentary epidermis. It is also interesting to note that the direct contact of the cells with the atmosphere results for the first time in the forma- 
tion of a cuticle. In móst species the air spaces arising among the upper cells of the thallus increase greatly in size and the epidermal cells by vertical divisions keep pace with this enlargement and thus arch over the air cavities, forming, however, a small opening in the epidermal layer that permits a free circulation of the air (Fig. I80, B). These openings are suggestive of stomata and function in the same way, though they have originated in an entirely different manner. The lower cells of the thallus are compact and doubtless serve as, storage cells, being nearly or quite destitute of chlorophyll. The stimulus of the soil causes

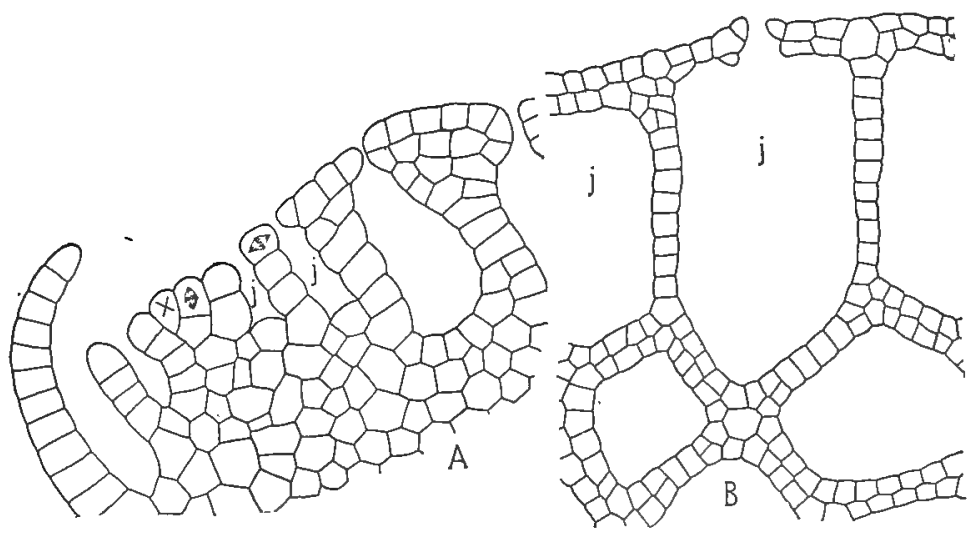

FIG. I80. Structure of the thallus of Ricciocarpus: $A$, section of the thallus, showing the apical cell, $x$, forming cells that by further division develop into plates of cells separated by air spaces, $j$. At the left the plates thus formed are seen curving over the apical cell. $B$, an older portion of the upper part of the thallus. The air spaces, $j$, are greatly enlarged and the upper cells of the vertical plates have divided, arching over the air spaces but leaving small openings which permit the entrance of air for photosynthesis.-I. D. Cardiff.

the lower epidermal cells of the thallus to form numerous smooth or pitted rhizoids that are suggestive of the root-hairs of the higher plants, anchoring the plant to the substratum and assisting in the absorption of the earth substances. Plates of cells similar in origin to those occurring on the upper surface are also found on the under side of the thallus (Fig. I80, $A$ ). These plates curve up around the growing point and doubtless protect it against drought, in which work they are assisted by the mucilage 
cells or glands. The development of these glandular cells on the plates, as well as on the other parts of the thallus, adapt the plants to the drier terrestrial conditions to which they are exposed, as was the case with the mucilaginous walls of the Schizomycetes and Zygnematales.

(b) Sexual Reproduction of Ricciocarpus.-The gametes are produced in more complex gametangia than we have as yet seen. These organs are developed upon the upper surface of the thallus

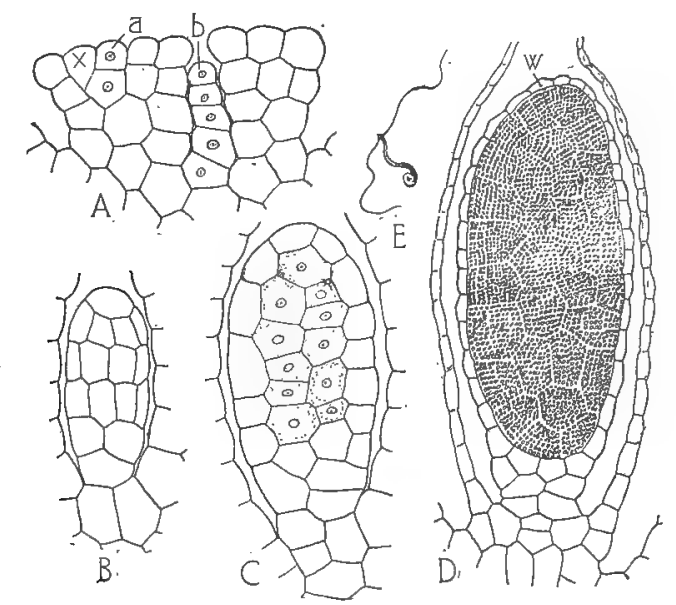

FIG. I8I. The origin and structure of the male gametangia or antheridia: $A$, section of the thallus, showing the apical cell, $x$, and the early stages, $a, b$, in the development of the antheridia. $B$, older antheridium with cells dividing vertically. $C$, later stage in which the wall cells are differentiated. $D$, mature antheridium of Marchantia, showing the numerous cells that develop the male gametes and the wall cells, $w$. E, greatly enlarged view of a male gamete after discharge from the antheridium.

and in some species appear as lines radiating from the center of the plant. The male gametangium originates from one of the superficial cells of the thallus, which at first continues to divide transversely after the manner of the vertical plates of chlorophyllbearing cells (Fig. I8I, $A$ ). The cells of these vertical plates soon begin to divide vertically and thus form an elliptical mass of cells (Fig. I8I, B,C). As this growth goes on the outer or wall cells become larger than the others and gencrally develop chlorophyll, while the inner cells divide repeatedly and become 
very numerous with dense granular contents (Fig. I8I, D). Each of the latter cells produces a single male gamete that is motile by means of two cilia (Fig. I8I, E). This complex gametangium is suggestive of the structure we have seen in Ectocarpus (Fig. I I9, $B$ ). The male gametangium is commonly called the antheridium, and the male gametes are often termed sperms or antherozoids. The gametes are discharged from the antheridium owing to the absorption of water by the walls of the cells in the upper portion of the antheridium which become mucilaginous at maturity and expanding, rupture this region of the antheridium, thus permitting the discharge of its contents. The walls of the gamete producing cells also become mucilaginous and by the absorption of moisture they may assist in the extrusion of the gametes. The pressure of the surrounding tissues upon the antheridium is also an important factor in this discharge. The mucilaginous mass that is extruded from the antheridium in this manner, rapidly dissolves in the water and sets free the male gametes or sperms. The female gametangium is also quite different from the single-celled gametangia which we have noticed among the algae and fungi. It originates as in the case of the antheridium, but develops into a flask-shaped body, consisting of a long neck of several rows of cells surrounding a central row, called the canal cells, and an enlarged basal region in which is developed the female gamete (Fig. I82). The female gametangium is commonly known as the archegonium and the fermale gamete is sometimes called the oösphere or egg. The female gamete presents essentially the same characteristics as seen in many of the algae, as Vaucheria, Oedogonium, etc., but it is surrounded by a jacket of cell which constitutes the basal portion of the archegonium instead of being contained in a single cell. Possibly the archegonium has come about from a multicellular gametangium as seen in the brown algae, owing to the sterilization of all but one of the cells. Archegonia, with two or more gamete-like cells, are sometimes found in the mosses and ferns and there is evidence tending to show that the primitive gametangia contained both male and female gametes. As soon as the female gamete is formed, the apical or lip cells of the neck open in the same manner as noted in the 
antheridium and the canal cells become mucilaginous, thus forming a passageway to the female gamete (Fig. 182, $F$ ). The male gametes, attracted, it is supposed, by cane sugar, developed in the archegonium, swim down the canal of the neck, and one unites with the female gamete, as shown in Fig. 182, $F$, where

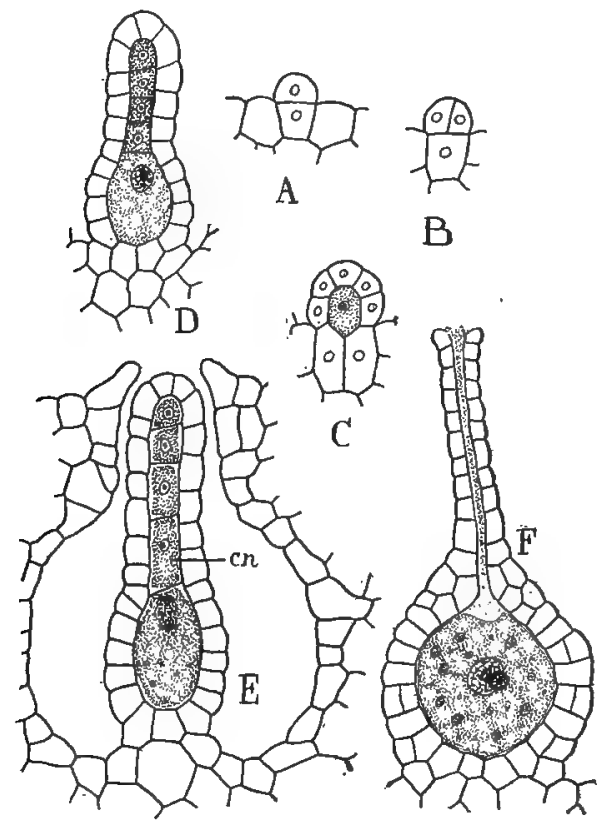

FIG. 182. Development of the female gametangium or archegonium: $A-D$, stages in the development of the archegonium from a single cell. $E$, nearly mature archegonium just before the female gamete is formed-cn, canal cells. $F$, lip cells have opened and the canal cells have dissolved, thus forming a passage way to female gamete. A male gamete has entered and is seen fusing with the nucleus of the large female gamete.-After Garber.

the two gametes are seen fusing. Note that mucilage retained in the neck protects the female gamete against loss of water and also that the attenuated form of the male is of advantage in enabling it to work its way through this substance.

(c) Germination of the Gametospore and Spore Formation.The gametospore, resulting from this fusion, becomes surrounded by a cell wall, but does not function as a resting spore as in some of the algae. It germinates at once and by repeated divisions of 
its nucleus forms a globular mass of cells, the capsule, within the archegonium which keeps pace with its growth (Fig. $183, A, B$ ). The wall cells of this capsule are soon distinguishable, owing to their watery contents and shape, from the other cells, which are rather cubical and densely granular. The growth and division of the granular cells continues until about 400 have been formed, when they round off, become separated from one another and increase greatly in size (Fig. I83,C). These large cells, called

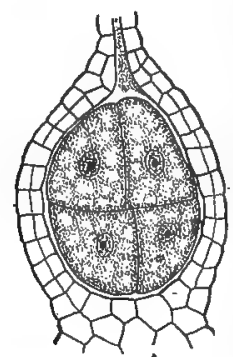

A
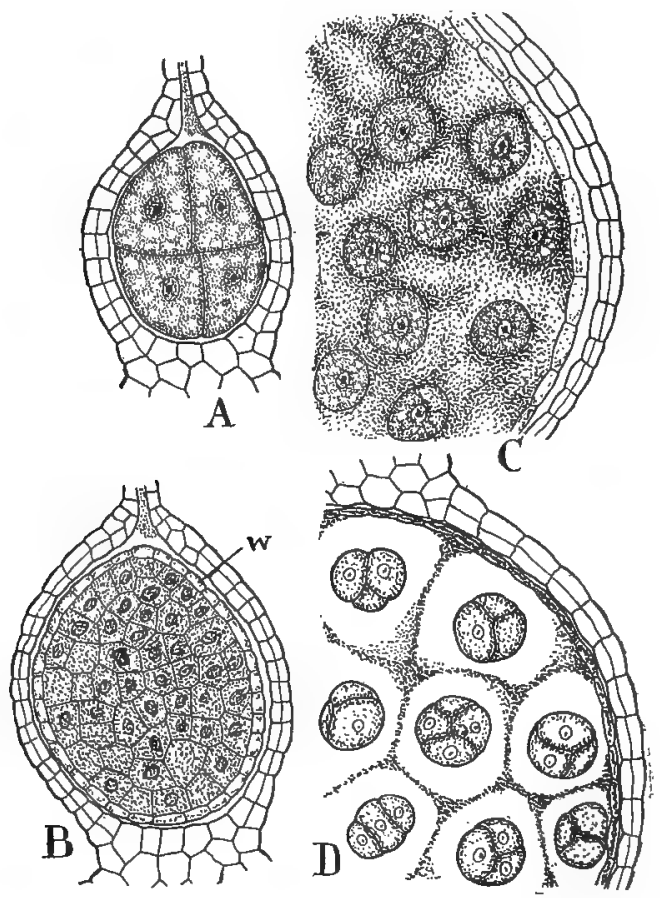

FIG. 183. Germination of the gametospore: $A$, basal portion of an archegonium, showing the germinating gametospore in the four-cell stage. $B$, later growth, forming a capsule with wall cells, $w$, which inclose large granular cells. $C$, a portion of the capsule, showing spore mother cells rounding off and floating in the fluid of the capsule. $D$, the mother cells dividing and forming four spores each.-H. O. Hanson.

spore mother cells, form four spores each, as in the tetraspores of the red algae (Fig. $\mathrm{r} 83, D$ ). The delicate walls of the capsule break down as soon as the spores are matured, leaving them 
free in the archegonium, and later they, are set free by the decay of the latter organ. These spores in some forms are provided with thick walls and are, therefore, resting spores adapted to carrying the plant over unfavorable conditions for growth. In other cases the spores have thin walls and germinate at once. The advantage of the transference of the resting stage from a single gametospore to the numerous spores derived from the gametospore is manifest.

(d) Germination of the Spore.-The germination of the spore is usually indicated by the formation of chlorophyll, and this is

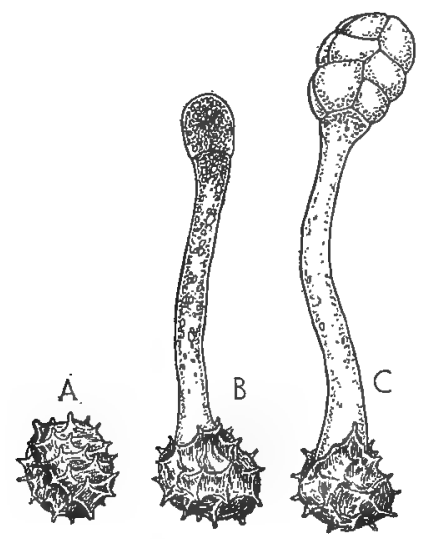

FIG. 184. Germination of the spores: $A$, spore. $B$, first division of the germ tube. $C$, early form of the thallus, due to the formation and subsequent division of the apical cell.

followed by the rupture of the outer spore coat and the protrusion of the inner as a delicate papilla or germ tube (Fig. I84). Usually from this tube a small, hair-like outgrowth is soon formed which penetrates the soil as the first rhizoid. The germ tube continues to elongate and often forms a chain of cells by successive transverse divisions, but eventually by oblique divisions an apical cell is formed that develops the characteristic thallus (Fig. I 84, C). Thus we arrive again at the starting point in the life history of these simple plants.

(e) Noteworthy Departures in the Life History.-It should be stated that the gametophyte of certain species of the Marchan- 
tiales may live for long periods without producing the gametes. In fact, it frequently multiplies by means of buds and branches which become detached and grow directly into new plants. However, as soon as conditions are favorable the sexual organs and gametes will appear. There are several features in this history that must be kept clearly in mind. In the first place, the gametospore is not discharged from the plant as in the case of the green or brown algae, but remains permanently in the archegonium, where it continues to be nourished by the plant during its germination and the formation of its spores. Therefore, it develops essentially as a parasite upon the plant, as is the case among the red algae. This retention and nourishment of the germinating gametospore in the plant is perhaps the most important of any of the variations that appear in plant life. Owing to this relationship the gametospore attains a larger growth with increased power of spore production. In Ricciocarpus the capsule is about 500 times as large as the gametospore. In this way the development of many new plants is made possible by a single fusion of gametes. This is a very significant feature in terrestrial plants, since the fusion of the gametes is effected with more difficulty, owing to the absence of aquatic conditions. Without doubt this change was induced by the transference of foods from the sexual to the asexual plant derived from the gametospore. This loss of food gradually prevented the sexual plant from producing spores or other bodies designed to multiply its numbers and we will finally see that the sole work of the sexual plant is limited to the production of gametes. Note also that the gametospore not only has a larger growth but a longer life. This is of the utmost importance because it became exposed in this way to a new series of stimuli that affected it profoundly and that resulted in the evolution of the higher types of plants. Among the green algae the actual germination of the gametospore is limited to a few hours at the most and this is effected in the water, where the conditions are exceptionally uniform. The germination of the gametospore in the case of the liverworts is prolonged over several weeks, and more important still is the fact that this growth occurs on the land where it is exposed to a 
wide range of stimuli that cause it to vary in a most remarkable manner. So we must bear in mind the character of this rather simple growth derived from the gametospore of Ricciocarpus and compare it with the variations that appear in the succeeding forms.

It is also evident that the fusion of the gametes in the simple liverworts results in the production of a cell, the gametospore, that is radically different in its nature and possibilities of growth from any of the cells of the parent plant or liverwort. This was not apparent in the simpler forms of the algae, where the gametospore produced directly a plant like the parent, as in Vaucheria and Fucus. In Spirogyra, Ulothrix, Oedogonium and Coleochaete, we saw the first indication of the real nature of the gametospore. It did not develop into a plant like the parent, but produced cells or zoöspores. The reason for this difference in behavior is possibly due to the higher organization of the gametospore. In the lower forms its first divisions result in the formation of cells that are of the same nature as the cells of the parent plant, but in higher forms its composition is more complex and as a consequence it forms a number of cells before cells like those of the parent plant are developed. For example, in the Red Algae, certain of the fungi and in Ricciocarpus the gametospore gives rise to a varying number of cells that are different from those of the parent plant, but finally spore mother cells are formed from which are derived spores that are of the same nature as those of the parent plant and that consequently produce new plants like the parent. As has been stated on page 138 , one difference between the cells derived from the gametospore and those of the parent plant is to be found in the number of chromosomes which they contain, the former having twice as many chromosomes as the latter. The doubling of the chromosomes occurs when the two gametes unite to form the gametospore and this number is retained during the germination of the gametospore until the division of the spore mother cells, which results in the formation of spores with only one half the number of chromosomes. In the lower algae this reduction must occur in the first divisions of the germinating gametospore, which therefore corresponds to the 
spore mother cell, but in the Red Algae and Ricciocarpus a considerable growth intervenes before the spore mother cells appear and the reduction of the chromosomes takes place. In other words, as we ascend the scale of plant life, the formation of the spore mother cells and the reduction of the chromosomes is preceded by an ever-increasing growth of the gametospore. This postponement in the formation of the spore mother cells, owing to the larger and larger growth of the gametospore, will steadily progress in the following studies.

These simple liverworts, like Ricciocarpus, show very clearly two phases or generations in their life history. The thallose

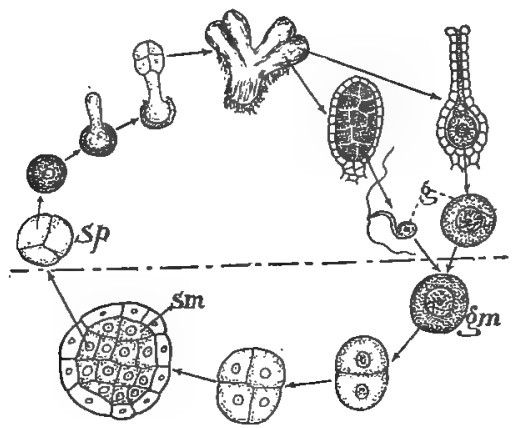

FIG. I85. Diagram of the life history of Ricciocarpus. The upper portion of the figure represents the sexual generation and the lower portion, the asexual. The former generation begins with the formation of the spores, $s p$, from the mother-cell and ends with the formation of the gametes, $g$. The asexual generation begins with the gametospore, $g m$, and ends with the spore mother cells, sm.

plant is the gametophyte or sexual generation because it bears sexual cells or gametes. The capsule is the sporophyte or asexual generation because it can only produce spores. The gametophyte begins with the spore and ends with the formation of the gametes. The sporophyte begins with the gametospore and ends with the division of the spore mother cell (Fig. I85). It may appear to you now as strange to regard the few cells of the capsule, the majority of which become spore mother cells, as a plant. But we shall directly see this microscopic plant assuming larger proportions as a result of its better nourishment and the stimuli to which it is exposed. It will form a larger and larger number 
of cells and the spore mother cells will not appear until late in its growth and they will be confined to definite regions and only constitute a small part of it. We now call the gametophyte the plant because it is many times larger than the sporophyte, but we shall see the sporophyte become quite as conspicuous as the gametophyte, as in the mosses, and finally it will become much larger, as in the ferns. Then we shall call the sporophyte the plant.

(f) Structure and Life History of Marchantia.-Let us now examine a higher type of the Marchantiales, as Marchantia, and note the advances that have been made over simple forms like Ricciocarpus. Marchantia (Fig. I86) is of common occurrence

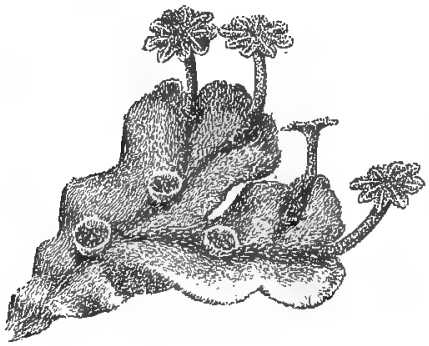

FIG. I 86.

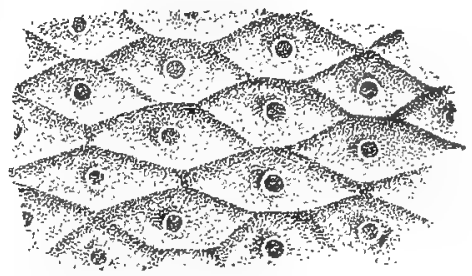

FIG. I 87.

FIG. I86. Thallus of Marchantia bearing three cup-like organs that contain buds or gemmae and also four erect branches that contain the antheridia in their upper surfaces in radiating lines.

FIG. 187. Portion of the surface of the thallus of Marchantia enlarged, showing the rhomboidal air chambers and air pores.

in moist places, often appearing in greenhouses on the earth of flower pots, and it also forms luxuriant beds on the damp ground, especially where logs and brush have been burnt. The thallus shows the same general features that we have noticed in Ricciocarpus, being rather fleshy and creeping over the ground, to which it is attached by numerous rhizoids. The simple air chambers noted in Ricciocarpus are much enlarged and appear as diamondshaped or rhomboidal plates on the surface of the thallus (Fig. I87). Thin sections across the thallus show that these air chambers have a complex structure (Fig. I88). They originate in the upper cells of the thallus and as they enlarge they become covered by a well-developed epidermis which forms a chimney- 
like pore over the center of each cavity. From the bottom of the chamber numerous delicate chlorophyll-bearing cells arise. This arrangement of the tissues is again suggestive of the chlorenchyma of the leaf and it is manifestly protective and adapted to photosynthesis. The structure of the lower cells of the thallus

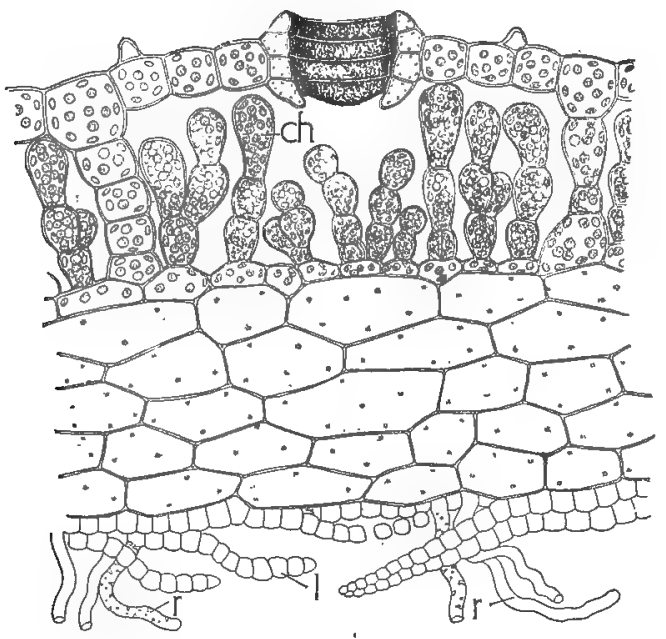

FIG. I88. Section through the center of the thallus of Marchantia, showing one of the air chambers and chimney-like pores in the epidermis-ch. palisade-like chlorenchyma arising from bottom of air chamber. The lower cells of the thallus are nearly colorless and filled with watery solutions or mucilage. $r$, rhizoids; $l$, leaf-like plates of cells.

and the distribution of the rhizoids and ventral plates are essentially as in Ricciocarpus.

Marchantia, as in many of the liverworts and some mosses, multiplies extensively by means of buds or gemmae. They are

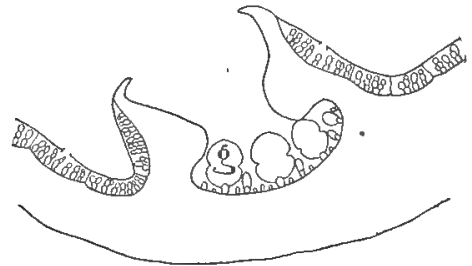

FIG. I89. Diagram of a section of one of the cups shown in Fig. I86-g, buds or gemmae associated with small glandular cells. 
borne in cup-shaped receptacles and consist of small lense-shaped masses of cells which are freed from the thallus by the swelling of the mucilage secreted by glandular hairs growing among them (Fig. I89). These minute bodies grow directly into new plants and so serve to rapidly multiply the plant.

The reproductive organs appear upon different plants which

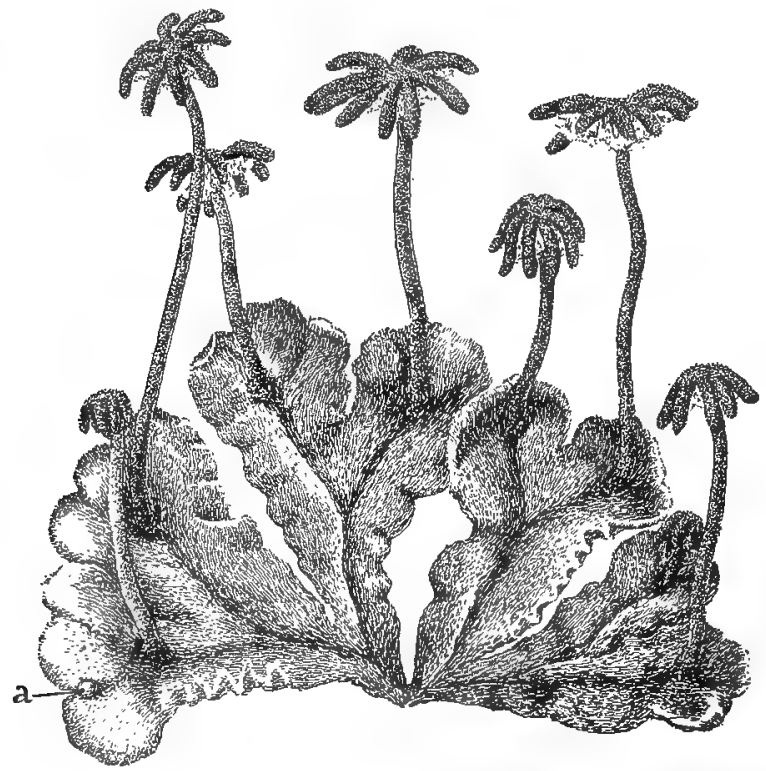

FIG. I9o. Thallus of Marchantia bearing several erect branches with lobed or umbrella-like tops. The archegonia are situated on the underside of the umbrella, between the lobes. $u$, the early appearance of a branch, in which condition fertilization is effected.

may therefore be distinguished as antheridial or male plants and archegonial or female plants (Figs. I86, I90). Such a distribution of the sexual organs is termed dioecious, meaning in two households, whereas Ricciocarpus and others are said to be monoecious, because the sexual organs are developed upon the same plant. The antheridia and archegonia are developed, as in Ricciocarpus, upon the upper surface of the thallus, but they are confined to special portions of it which appear at first as mushroom-shaped outgrowths (Fig. I90, a). These outgrowths, how- 
ever, are but modified branches of the thallus and bear the sexual organs upon their upper surfaces in lines radiating from the center of the branches. Fertilization is effected, as in all forms, by means of dews and rains which flood these organs with water. An examination of a young archegonial branch will show how admirably it is constructed to ensure fertilization. The archegonia radiating in lines have their necks strongly curved

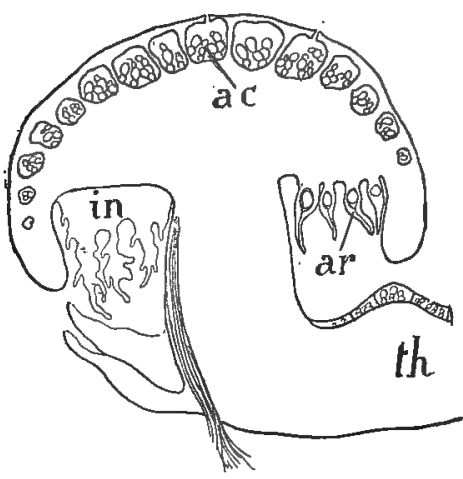

FIG. I9I.

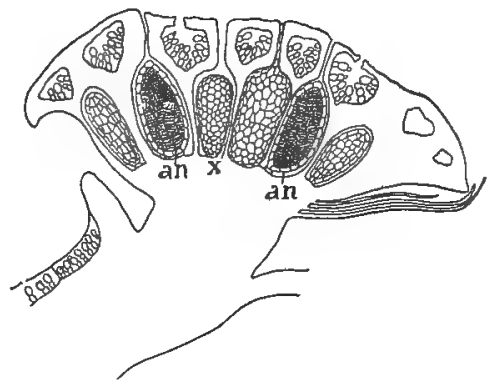

FIG. I92.

FIG. I9I. Section of an archegonial branch similar to $a$, Fig. 190-ar, archegonia; in, involucre or curtain that hangs down on either side of the rows of archegonia; $a c$, air chambers; th, thallus.

FIG. I92. Section of a young antheridial branch: an, antheridia sunken in cavities of the branch, which is also provided with air chambers similar to those of the normal thallus. Some of the antheridia have discharged their gametes, as at $x$.

upwards and away from the center of the branch. These lines of archegonia are separated by ridges which thus act as a watershed, deflecting into the upturned necks any water containing gametes that may chance to fall upon them. After fertilization these mushroom-shaped branches elongate, raising the sexual organs up into the air, where the antheridial branch assumes the form of a lobed disc, while the archegonial branch terminates in an umbrella-like structure (Figs. I86, 190). Owing to the extended growth of this latter branch, the archegonia come to lie on the under side of the structure between the finger-like outgrowths, where they are completely hidden and protected by fringed curtains, the involucre, that hang down from the fingers 
(Figs. I9I, I95, $A$ ). The antheridia retain their original position upon the branch, where they appear in cavities, as shown in Fig. 192.

The most important and significant departure in Marchantia is seen in the germination of the gametospore which divides into an inner and outer cell as in Ricciocarpus (Fig. 193, B). The inner

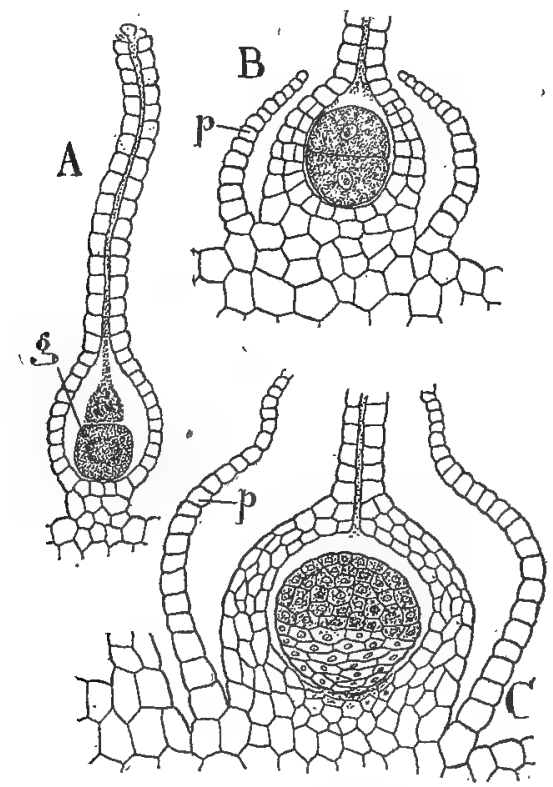

FIG. I93. Germination of the gametospore: $A$, section of a mature archegonium with canal cells dissolved, thus'forming a passageway to the large female gamete, $g$. $B$, sectional view of base of archegonium, showing the germinating gametospore in two-cell stage. The perianth, $p$, is seen growing up about the archegonium. $C$, later stage in growth of the gametospore. The lower cell shown in $B$ is forming stalk cells, while the outer cell has produced densely granular cells that will later by further division form spore mother cells and eläters.

cell, however, by a series of divisions, forms a rudimentary stalk and the lower part of it, known as the foot, comes into close contact with the tissues of the plant from which it absorbs nourishment (Figs. I93, I94). The outer cell divides, forming a spherical mass of cells that resembles the capsule of Ricciocarpus. Some of these cells of the capsule develop as spore mother cells, 
while others, known as elaters, elongate greatly and serve to conduct the foods absorbed by the foot to the spore mother cells, and finally they become spirally thickened (Fig. 194, C). These elaters arise through the sterilization of certain of the spore-

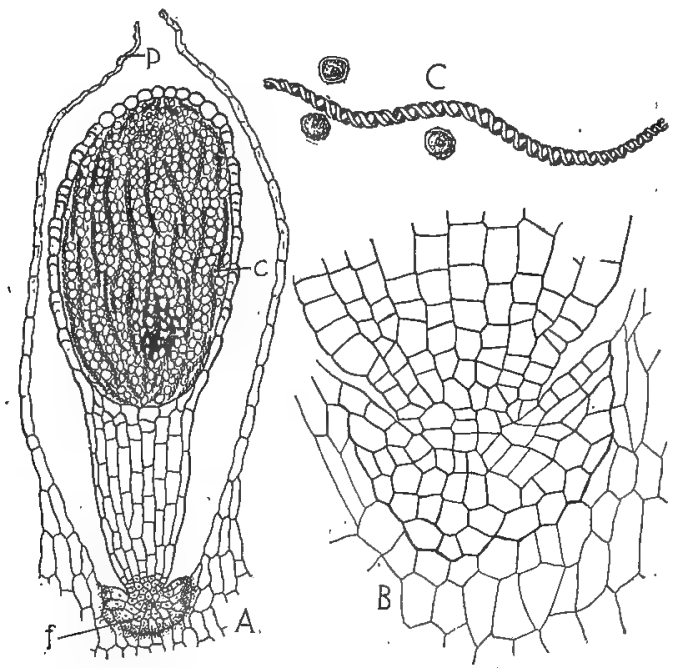

FIG. I94. Structure of the nearly mature sporophyte: $A$, continuation of the growth in Fig. 193, $C$, showing the formation of a foot, $f$, stalk, and capsules, $c$, which contain elongated dark cells, the elaters, and the spores. The archegonium has been ruptured by the elongation of the stalk and is not shown in the figure. $p$, perianth. $B$, enlargement of the base of $A$, showing the attachment of the foot (indicated by darker lines) to the tissues of the antheridial stalk. $C$, an elater and spores.

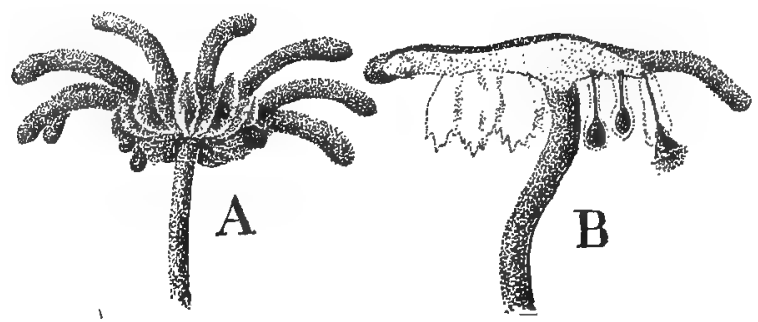

FIG. I95. Archegonial branch with mature sporophytes: $A$, branch with the dark capsules of several sporophytes projecting beyond the curtains of the involucre. $B$, diagram of a branch as seen in section. On the right one of the capsules of a sporophyte ruptured, exposing the elaters and spores. On the left the curtain-like involucre only is shown. 
producing cells. This is an important departure from Ricciocarpus and we see here the beginning of the tendency towards the sterilization of sporogeneous cells that becomes more and

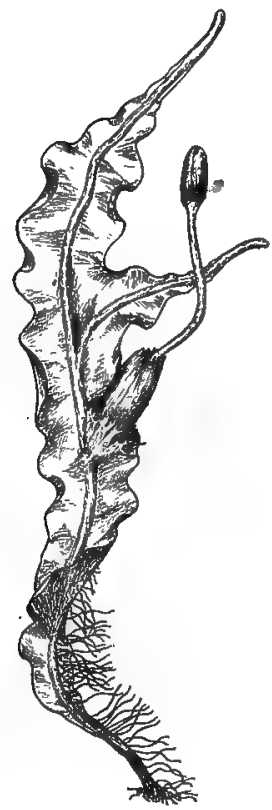

FIG. 196. One of simpler thalloid Jungermaniales, Pallavicinia, showing the rhizoidal growth on the under surface of the thallus and a mature sporophyte arising from a cuplike perianth which is surrounded at its base with involucrate leaves.-H. O. Hanson. more pronounced in higher forms and that plays an important part in the evolution of plant life. During the germination and growth of the gametospore, a delicate membrane (the perianth) grows up about the archegonium and doubtless assists the involucre in protecting it against drying winds (Fig. r93, $p$ ). When the spores are mature, the cells of the stalk elongate, rupture the archegonium and push the capsule beyond the curtains of the perianth and involucre, so that it is exposed to the air (Fig. I95). The capsule now ruptures, exposing the spores and elaters to the air. The elaters, a word meaning lifters, are very hygroscopic; they coil and uncoil with the least change in the humidity of the air and thus doubtless assist in the gradual exposure of the spores to the air currents. The spores germinate as in the lower liverworts. Thus we see that the sporophyte, consisting of a foot, stem and capsule, is more complex and larger than in Ricciocarpus. This is doubtless due to the better nourishment which it receives as a result of the development of a more efficient absorbing organ, the foot.

I05. Order b. Jungermaniales or Leafy Hepatics. - By far the larger number of hepatics belong to this order. They are especially abundant in moist tropical countries, where they often cover the stems and leaves with a rich vegetation, and with us they are of common occurrence on dripping rocks and in deep woods on the moist bark of trees and decaying logs or damp earth. In the lower form the thallus is very simple and delicate 
(Fig. 196). In other genera there are indications of a lobing in the thallus which becomes more pronounced in some forms and leads by gradual gradations to genera in which the lobes appear as distinct leafy organs arranged in two rows upon a stem-like

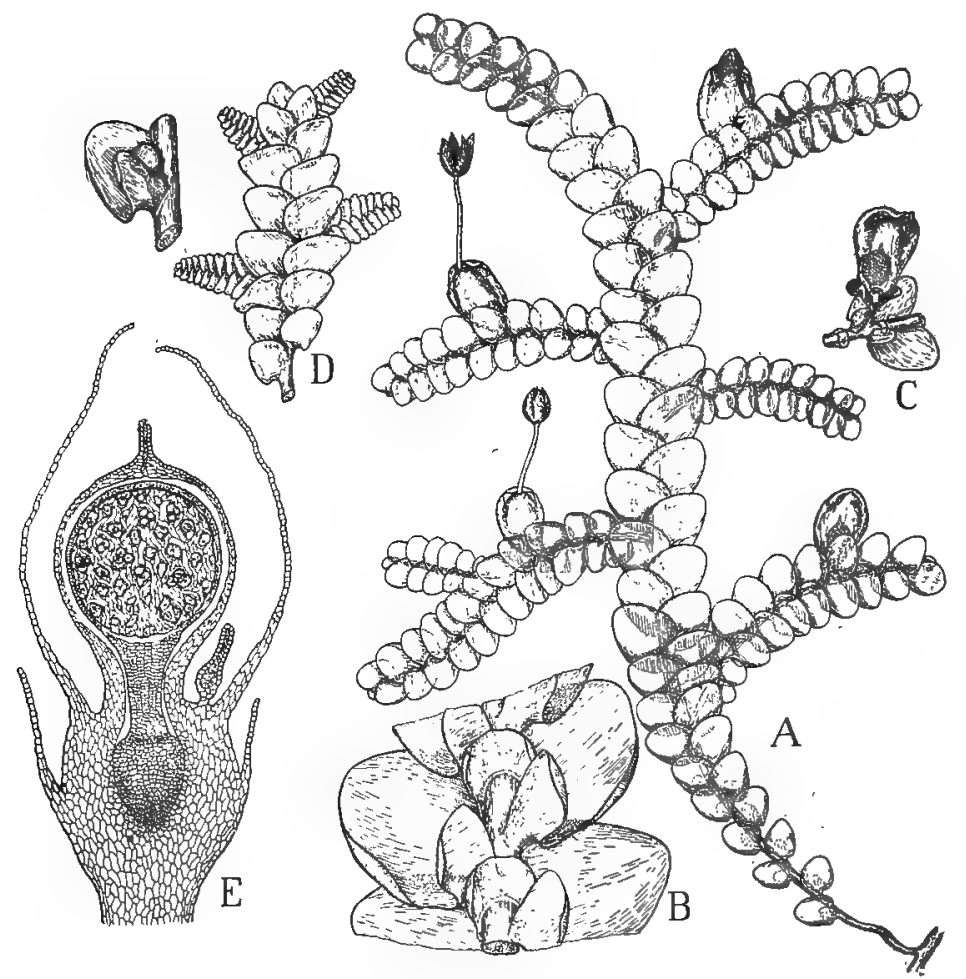

FIG. 197. One of the leafy Jungermaniales, Porella: $A$, branch of the plant bearing several sporophytes. $B$, under surface of a branch, showing the lobing of the leaves and a row of minute scale-like leaves. $C$, portion of a branch bearing an archegonium surrounded by cup-like perianth with minute involucrate leaves at base. $D$, branch with cone-like antheridial branchlets. At the left a single leaf is shown with globular antheridium in its axis. $E$, section of a branch similar to $C$. The archegonium is seen surrounded by the perianth and below the involucrate leaves. The sporophyte is nearly mature and ready to elongate. It consists of a round capsule containing elaters and spore mother cells that are dividing to form four spores each. Below the capsule is the stalk or seta which ends in a foot buried in the tissues of the branch. At the right is an unfertilized archegonium that shows the original position and size of this organ.-H. O. Hanson. 
axis (Fig. I97). Usually a third row of rudimentary leaves, associated with rhizoids, appears upon the under side of the thallus (Fig. I97, B). Although the Jungermaniales tend to become highly modified into a leafy body the tissues remain practically unchanged in all forms. Even in the leafy genera, which comprise the majority of forms in this order, there is little evidence of such a differentiation of the tissues as characterize the Marchantiales. Without doubt, the simple thallose Jungermaniales are the most primitive forms of the hepatics and probably stand nearer the ancestral type than any other form. The Marchantiales represent a line in which the tissues of the thallus have attained a considerable degree of differentiation, but in the present order, the evolution led to a marked change of form with but slight modification of the tissues. This is apparent in the highest forms where the leaves, consisting of little more than a single layer of chlorophyll-bearing cells, are arranged in two rather oblique rows upon delicate stems. The under surfaces of these leaves are generally lobed and often form sacs containing water (Fig. I97, B). This peculiarity of the leaves, together with the rudimentary third row of leaves that are associated with the rhizoids, makes a sharp contrast between the upper and lower surfaces and serves to distinguish them from the mosses, with which they are often confused. In fact, they are often called scale mosses, owing to the moss-like appearance of their dorsal surface and the close contact formed with bark or other surfaces over which they creep. This habit of pressing the leaves against the substratum tends to retain the moisture and also enables the leaves to absorb it directly through their delicate cell walls. The overlapping of the leaves in many genera, as well as their lobing, would serve the same purpose and enable the plants to live under drier conditions than would otherwise be possible. Doubtless, these departures have been of great advantage to the plants and in part account for the common occurrence of these leafy forms. It should be stated that the leafy hepatics are regarded as forms that have been evolved from the simple thallose forms in quite recent geological times and owing to their better adaptation to present 
conditions they have become the most numerous of all the Hepaticae. The cause of the differentiation of the tissues in the two groups is doubtless explained by their relation to moisture. The leafy hepatics are easily wetted and the entire plant body can readily absorb moisture. Therefore the tissues remain delicate and fewer rhizoids are required to absorb the moisture. The Marchantiales are not wettable, and as a consequence they must develop wick-like strands of rhizoids as well as the elaborate storage tissues of the thallus. Both groups, and indeed all hepatics, must remain prostrate, because they are dependent upon surface water and have not as yet developed an absorbing and conducting apparatus that will permit of any other position.

Reproductive Features of the Jungermaniales.-Asexual reproduction is of the same vegetative type as has been seen in the preceding groups. The archegonia and antheridia are also of essentially the same character as seen in Marchantiales. They are borne upon the dorsal surface of the thallus or upon more or less modified branches, the archegonia often arising upon the apex of the branch and the antheridia appearing as rather spherical bodies in the axis of the leaves (Fig. 197, C, D). The archegonia are developed in rather conspicuous cup-like or leafy outgrowths of the thallus. This structure, termed the perianth (Fig. 197, C), assumes very characteristic forms in the different genera and is generally associated with modified leaves, the involucre. By these devices the archegonia gain the same protection against drying out as was secured to them by the cavities in which they were developed in the preceding group. The gametospore develops after the manner noted in Marchantia, forming a capsule with elaters, but its stalk or seta reaches much larger dimensions, owing doubtless to the well-developed foot (Fig. I97, E). The majority of the genera also are characterized by having many of the cells of the capsule sterilized so that the number of spore-producing cells becomes further reduced. When the spores have been matured the seta rapidly elongates to several times its original length, rupturing the archegonium and lifting the capsule high in the air (Figs. 196; 197, $A$ ). The capsule usually breaks open into four valves which are hygro- 
scopic, closing over the spores in damp weather and opening in dry weather to expose them to the wind. These spores germinate and begin the life history of a new gametophyte. As in some of the Marchantiales a filamentous alga-like growth is first formed by the germinating spore before the characteristic plant is reproduced.

I06. Order c. Anthocerotales or Horned Liverworts.-This small group of four genera is the most interesting of any of the hepatics because it presents features that are suggestive of the algae and also of a relationship with the mosses. The thallus is of a primitive type, often with simple lobings and therefore, suggestive of relationship with the simpler Jungermaniales (Fig. I98). A peculiar feature of the order is the occurrence of mucil-

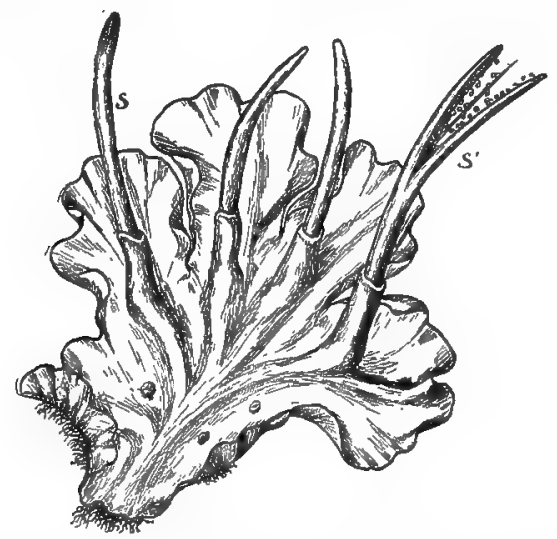

FIG. I98. One of the Anthocerotales, Anthoceros, bearing four pod-shaped sporophytes, $s$. The one on the right, $s$, has opened at the top and is discharging the spores, but elongation and the formation of spores continue below owing to its basal growth.

age cavities which communicate with the air through small openings on the under side of the thallus. These cavities are always occupied by one of the blue-green algae, Nostoc, which possibly assists the plant in the retention of water owing to their mucilaginous character. Another interesting feature of the order is the occurrence usually of a single chloroplast in each cell, as in Coleochaete and several other genera of the algae. The archegonia and antheridia, while resembling those of the preceding orders, 
are sunken in the tissues. This arrangement doubtless protected the reproductive organs just as did the involucre and perianth in the preceding groups.

The most suggestive variation of the Anthocerotales appears in the development of the sporophyte. We have noted that the asexual generation in forms like Ricciocarpus was a microscopic plant consisting of a delicate spore-bearing capsule. In Marchantia the sporophyte is still minute but differentiated into a foot, stalk and capsule, and in the Jungermaniales this becomes much more pronounced. In the Anthocerotales the sporophyte assumes a growth and differentiation that is much more extensive and complex and it also presents features that indicate a relationship with the mosses. Furthermore it shows certain features in its development that also arose in the ferns. The germination of the gametospore gives rise to a rather cylindrical or pod-shaped body (Fig. 199), in which all the cells have become sterile save a dome-shaped layer. The basal portion of the sporophyte develops into a massive foot, often provided with rhizoidal-like outgrowths, which serve as a very efficient absorbing organ. The upper portion of the sporophyte presents a remarkable series of differentiations. The outer part of it consists of chlorophyllbearing cells in which, for the first time, genuine stomata appear (Fig. 199, ch). Within this zone of chlorenchyma is a domeshaped layer of spore mother cells often alternating with sterile cells which in some genera develop as elaters. In the center of the sporophyte is a mass of rather elongated cells, the columella, which assist in conducting food from the foot to the forming spores. Directly above the foot is a region of rapidly dividing cells which causes the sporophyte to elongate by basal growth and push out of the archegonium before the spores are mature. This is a radical departure from the other liverworts in the mode of development of the sporophyte and we will see essentially the same manner of growth occurring in the mosses. As the sporophyte develops, the spores in the upper part of it mature and the sporophyte splits into two valves (Fig. I98, $s^{\prime}$ ), thus permitting the scattering of the spores. The lower portion, however, may continue to elongate for several months in some species, forming additional spores. 
It is evident that this sporophyte would become a self-supporting plant if its foot should reach through the gametophyte and absorb substances from the soil. In comparing the sporophyte

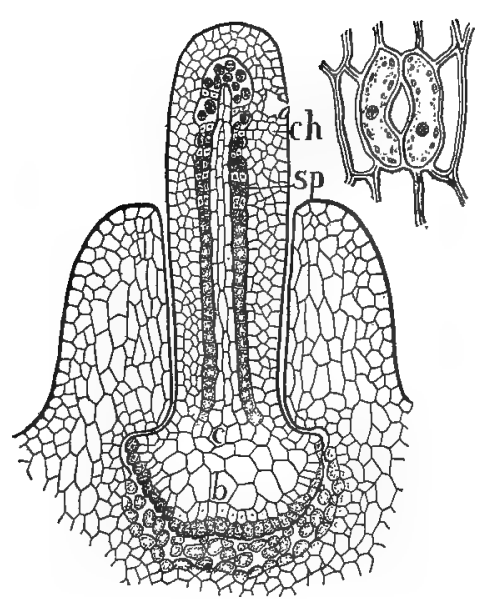

FIG. I99.

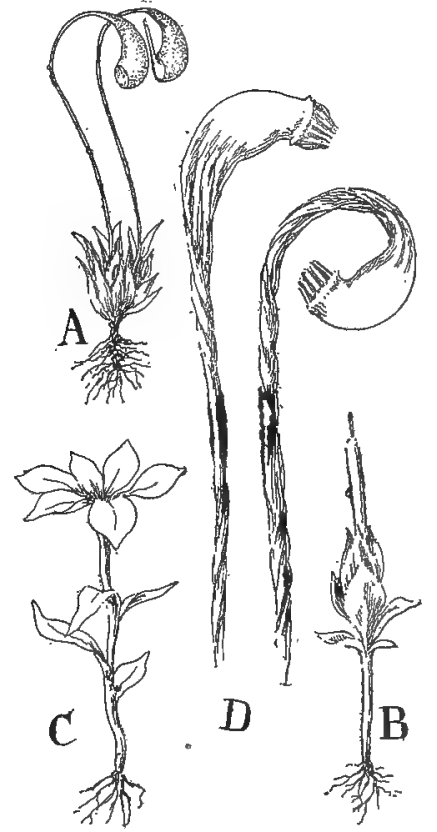

Frg. 200.

FIG. I99. Section of a young sporophyte of Anthoceros emerging from the involucre-like outgrowth of the thallus-sp, dome-shaped spore forming layer of cells; $c h$, chlorenchyma with stomata; $b$, foot or absorbing region; $c$, region of growth. At right, surface view of stoma.

FIG. 200. A common moss, Funaria: $A$, two plants with root-like rhizoids at base and radially arranged leaves. Rising above the leaves are the stalks or setae and capsules of two sporophytes. $B$, magnified view of a plant, showing the early appearance of the sporophytes as a delicate stalk still covered by the enlarging archegonium or calyptra. $C$, a plant bearing antheridia in a rosette of leaves at apex of stem. $D$, enlarged view of the upper portion of the sporophyte, showing the twisting of the stalk that assists in sifting the spores through the fringe of teeth, peristome, that encircles the mouth of the capsule.

in forms like Ricciocarpus, Marchantia and the leafy hepatics with Anthoceros, we see that it has undergone a gradual evolution and has finally reached a point where it only needs to 
come in contact with the soil to become an independent plant since it is provided with all the tissues necessary for photosynthesis and absorption. Note also that the growth of the sporophyte is becoming more prolonged, that the spore mother cells appear later in its development and comprise but a small portion of it, and finally, that the sporogenous and sterile tissues alternate, forming a dome-like zone of cells. Structures very suggestive of these features will appear among the mosses and ferns.

\section{Class B. Musci or Mosses}

107. General Characteristics.-The mosses are by far the largest group of the Bryophyta and show marked advances over the hepatics in the development of the gametophyte and sporophyte. Particularly noticeable is the size and differentiation of the sporophyte which now becomes among the majority of the genera of nearly equal importance with the gametophyte (Fig. 200). Variations appear in the mosses that have been successful in adapting them to a great variety of conditions, ranging from submerged aquatics to pronounced xerophytes that live upon exposed rocks. As a result, they are of common occurrence everywhere. The mosses, however, do not show any variations that have led to higher types of plants. In fact, they are regarded as a highly specialized group, like the Jungermaniales, that have branched off from the hepatics in recent geological times and become the dominant representatives of the Bryophyta owing to their better adaptation to present conditions upon the earth. This recent derivation of the mosses is indicated by the remarkable uniformity of structure that characterizes the entire group.

While the plants themselves are relatively small, they often form large swards or mats, owing to the extensive branching and prolonged growth of the stems and their rapid multiplication through the dying off of the older parts and the independent growth of the branches that are thus set free. Owing to this habit of growth and multiplication the mosses often furnish the conspicuous features of the vegetation. Especially is this true in northern regions and in bogs and barrens where great sections 
of the country are carpeted with them. The mosses are leafy stemmed plants like the Jungermaniales, but they usually possess the decided advantage of having erect stems and radially arranged leaves (Fig. 200). Even in the prostrate forms where but two rows of leaves can be developed, the resemblance to the leafy hepatics is only superficial. The moss leaves are not lobed and the central portion is usually traversed by a strand of cells which serve for conduction like the vascular bundles of higher plants (Fig. 206, B). The differentiation of the tissues of the stem also shows a marked advance over preceding forms/ A central conducting region of elongated cells that may be compared to a rudimentary vascular system and a cortical zone, often with thickened cells and rudimentary epidermis, are frequently to be seen (Fig. 206, A). Asexual reproduction is almost entirely confined to the detachment of branches as stated above. In only a few genera have the formation of gemmae been' noticed. The sexual reproduction and the development of the sporophyte present some interesting features that will be noticed in the following orders.

r08. Order a. Sphagnales. Bog or Peat Mosses.-A single genus, Sphagnum, of numerous poorly defined species is the sole representative of this order and in several respects it occupies an intermediate position between the hepatics and the mosses proper. These pale-green mosses (Fig. 20I) grow on bogs and moors and other places where they are subject to drainage containing organic matter, as humic acid, derived from the decay of plant and animal life. The majority of plants are unable to endure these conditions, which are popularly referred to as sour, and as a result, you will always find associated with the bog mosses a rather limited and peculiar variety of plants such as several genera of heaths, sedges, orchids, pitcher plants (Sarracenia) and other insectivorous plants like the sundew (Drosera). For some reason the ordinary plant is not able to procure its food from these sour bogs and this may explain the common occurrence in such places of insectivorous plants, and of certain trees and shrubs that are associated with mycorrhiza. The sphagnums grow luxuriantly in such places, the lower portions of the stem 
dying off and the upper portion branching and continuing the growth from year to year. In this way, ponds are gradually covered with a layer of mosses which become rather insecurely bound together by the subsequent introduction of other plants whose roots or stems traverse the covering formed by the mosses. So frail is this covering at first, that a very slight jar will cause the surface to tremble and for this reason these places are known

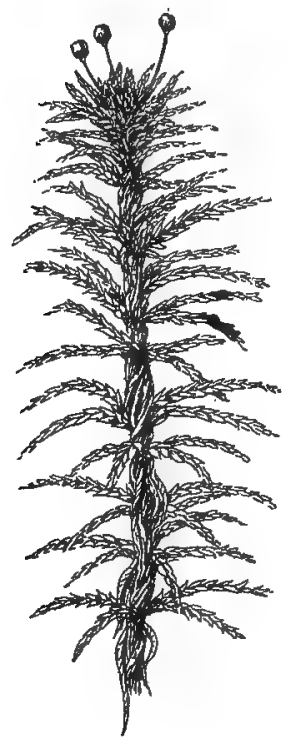

FIG. 20I.

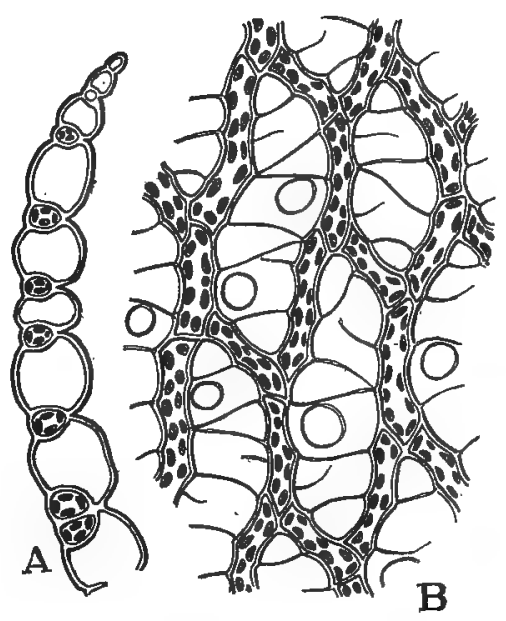

FIG. 202.

FIG. 20I. The bog moss, Sphagnum, bearing three sporophytes and numerous lateral branches covered with closely overlapping leaves. Note that some of these branches envelop the stem in wick-like strands.

FIG. 202. Structure of the leaf of Sphagnum: $A$, section of leaf, showing its single layer of cells that consists of large empty cells alternating with small chlorophyll-bearing ones. $B$, surface view of the cells, the larger empty cells being marked with spiral bands and often perforated with minute openings.

as quaking bogs. The constant dropping of the decaying vegetation to the bottom of the ponds, assisted by the drainage material, gradually fills them, and in time they may become quite dry. The acid character of these bogs prevents the entrance of those organisms which promote decay. As a result, plants 
and animals that fall into these bogs may only partly decay and remain for ages in a wonderful state of preservation as is shown by the recovery of skeletons of animals and clothing of men that belonged to a prehistoric period. It is because of this condition that the bog mosses are of great economic importance. The dead portions of the moss plants, as well as that of the associated plants, do not entirely decay, and consequently there is slowly formed a compact mass of material rich in carbon. This is cut or pressed into blocks, forming peat. This material is an important fuel in Europe and the vast deposits of it in this country will doubtless be utilized in the future. It has been recently shown that the material of some of these bogs is of great value as a source of pulp for paper.

(a) The Structure and Reproduction of Sphagnum.-The leaves of the bog moss are arranged in compact spirals around the stems and consist of a single layer of cells as in the leafy hepatics (Fig. 202, B). These cells, however, are of two kinds, large and empty cells with spirally thickened walls which are generally perforated with small pores and very narrow cells containing chlorophyll. This distribution of the cells explains the palegreen color characteristic of the sphagnums. Large and spirally marked cells, similar to those of the leaf, may also occur in the cortex of the stem. The closely packed leaves enable the bog mosses to take up water like a sponge and the sphagnums are of considerable commercial value for this reason, being extensively employed by. horticulturists to keep plants moist during shipment. They are also used extensively in stables in place of straw and they render them almost odorless owing to their absorption of liquids and gases. Perhaps these large cells may serve as floats, enabling the plant to bridge over ponds and they may enable the plant to endure the acid waters in which these plants grow. In this connection, it is noteworthy that rhizoids are entirely lacking and that water and other substances are absorbed by the outer cells of the stems and by certain branches which hang down in wick-like strands close to the main stem (Fig. 201).

The antheridia and archegonia are developed much as in the 
leafy hepatics, the former organs appearing as stalked bodies in the axils of the leaves on short cone-like branches and the archegonia originate on the tips of short branches. The gametospore germinates very much as in Anthoceros (Fig. 203, 6). It does not, however, have as prolonged a growth, and at ma-

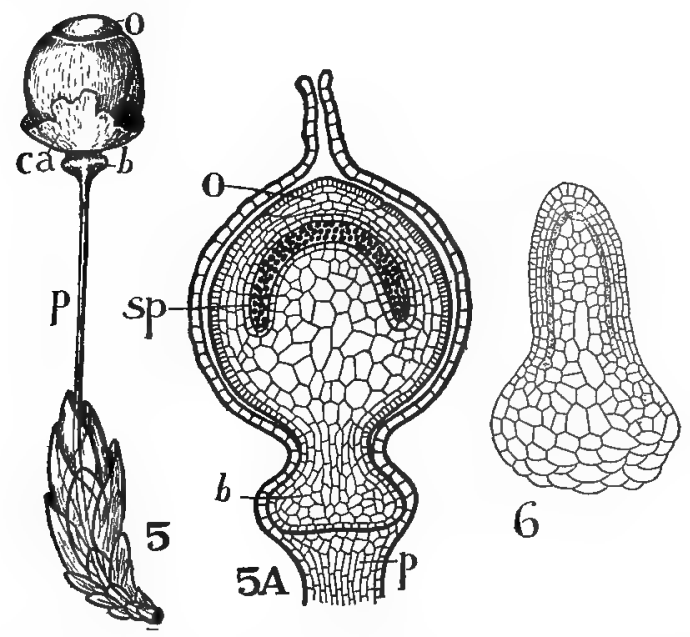

FIG. 203. The sporophyte of Sphagnum: 6, the young sporophyte separated from the archegonium with essentially the same differentiation of parts as noted in Anthoceros, Fig. I99. $5 A$, diagram of a later development of the sporophyte in the archegonium. The enlarged foot, $b$, is embedded in the apex of the moss branch, $p$, and the spores, $s p$, form a dome-shaped layer in the upper part of the capsule. 5, the naked stem, $p$, of the moss branch, surrounded at base with spirally arranged leaves, has elongated, lifting the mature sporophyte into the air. The enlargement of the stem, $b$, is due to the growth of the foot region of the sporophyte; $c a$, remains of the ruptured archegonium or calyptra; $o$, lid or operculum of the capsule. -After Schimper.

turity consists of a well-developed foot embedded in the tissues of the gametophyte and a spore-bearing capsule (Fig. 203, 5A). The stomata and chlorenchyma which were so conspicuous in Anthoceros are less perfectly represented, but the spore mother cells are still developed in a dome-shaped zone. This rather minute sporophyte at maturity barely breaks through the archegonium, known in this condition as the calyptra, which covers the capsule as a cap. The absence of a conspicuous stalk or seta 
in the sporophyte of Sphagnum is provided for by the elongation of the upper part of the moss stem which pushes the sporophyte above the leaves and exposes the capsule to the winds quite as

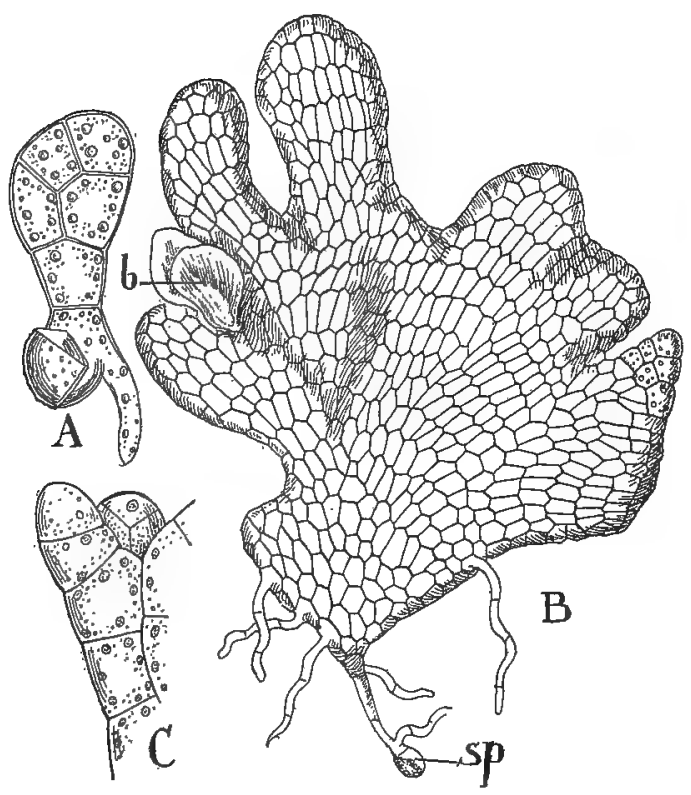

FIG. 204.

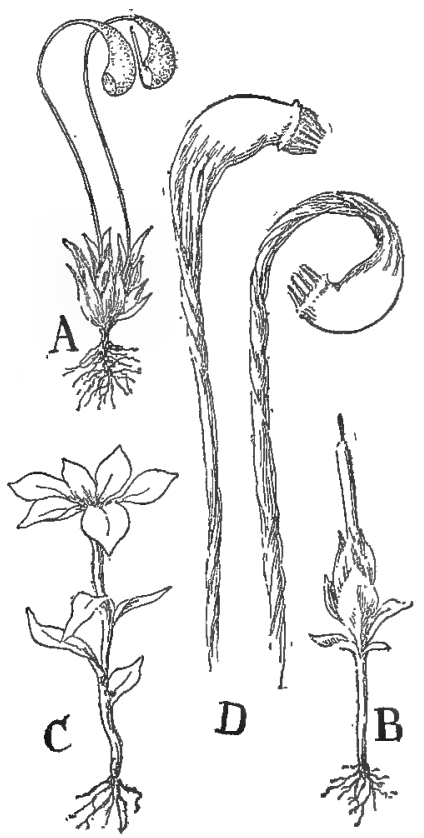

FIG. 205.

FIG. 204. Germination of the spore of Sphagnum: $A$, early growth of the spore. $B$, later development- $s p$, spore; $b$, bud developing into moss plant. $C$, margin of the thallus, showing the origin of the bud.-After Campbell.

FIG. 205. The twisted stalk moss, Funaria: $A$, two sporophyte-bearing plants, the remains of the archegonium or calyptra still attached to the capsule on the right. $B$, enlarged view of plant with the young sporophyte, still enclosed in the archegonium, just emerging above the leaves. $C$, the male plant bearing the antheridia in a conspicuous rosette of leaves. $D$, upper portion of the sporophyte, showing the twisting of the stalk or seta that assist in sifting the spores through the teeth, peristome, that encircle the mouth of the capsule.

effectually as the seta of the hepatics and mosses (Fig. 203, 5). The spores are freed by the forcing off of a circular lid, the operculum, as is the case among the majority of the mosses (Fig. 203, 0). This is effected by a ring of thin-walled cells, 
the annulus, that lies in the groove just below the operculum, As the walls of the capsule dry out at maturity they shrink. compressing the air within the capsule until the tension ruptures the delicate ring of cells and throws out the spores with an audible report. No elaters are associated with the spores in any of the mosses.

The germination of the spores results in the formation of a short chain or filament of cells which soon develop into a flat and rather irregular thallus consisting of a single layer of cells and attached to the ground by numerous rhizoids (Fig. 204). This thallus may produce from its marginal cells other filaments which behave like the original one and thus serve to increase the number of thalli. The archegonia and antheridia are not developed upon these thalli, but there are first formed as in most of the Jungermaniales, bud-like growths which develop into leafy stems of the sphagnum (Fig. 204, $b$ ). These stems soon become independent plants through the decay of the thallus and finally bear the reproductive organs.

I09. Order b. Bryales. The Higher or True Mosses.-The great majority of plants, commonly known as mosses, belong to this order. As a rule, these plants are of a higher type than any of the other Bryophyta (Fig. 205). The stems are frequently erect with radially arranged leaves and show considerable differentiation of tissues, as is apparent in the cross-section of the stem of one of the higher forms, shown in Fig. 206, A. Particularly noticeable are the thin-walled cells located in the central strand of the stem which serve to conduct the fluids and are therefore, comparable to the tracheal tissue of the higher plants. A similar conducting tissue is often seen in the central strand that appears in the leaves of the majority of the Bryales (Fig. 206, B). In connection with this higher development of the plant, attention should be directed to the more efficient organs of absorption. The rhizoids that spring from the base of the erect stems or from the under side of forms with creeping stems are often larger than those noted in the hepatics, and generally they are multicellular and often twisted together into root-like strands. (Fig. 206, C). These features doubtless account in part for the larger size that 
is attained by many of the Bryales. It is noteworthy, however, that the devices for absorption and conduction of water are not as yet sufficiently developed to enable these plants to attain any considerable height. Erect forms rarely exceed a few centimeters in height, but prostrate forms creep over the ground indefinitely. Some mosses are short lived and many are perennial, continuing their apical growth from year to year. Some can live only in the wettest of places or as submerged aquatics,

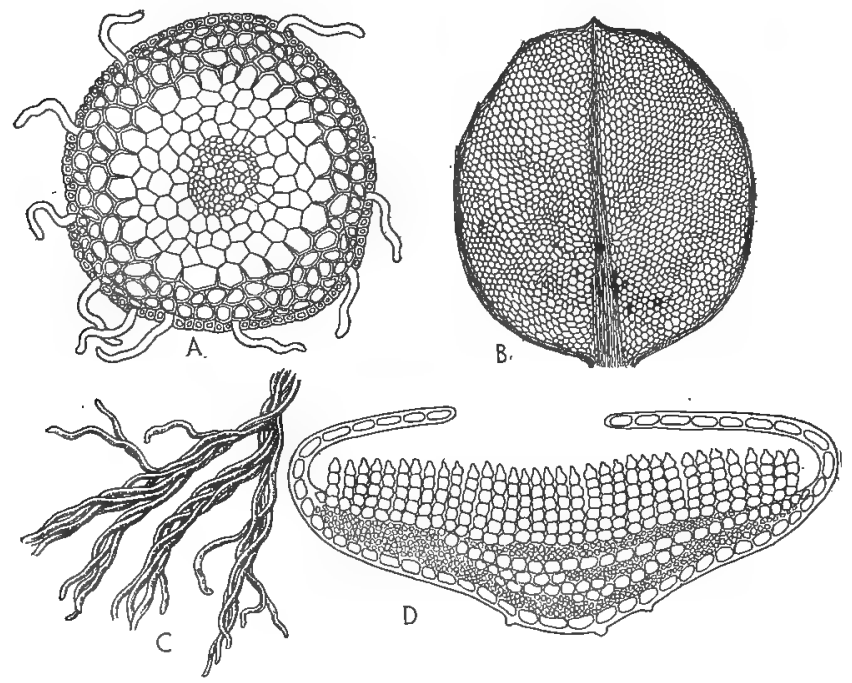

FIG. 206. Structural features of the moss plant; $A$, cross-section through the basal region of a moss stem, showing rhizoidal outgrowths from epidermis, cortical and central conducting tissues. $B$, leaf of Mnium with midvein of elongated conducting cells. $C$, rhizoids twisted together into rootlike strands. $D$, cross-section of a leaf of Polytrichum, showing the partial folding in of the margins of the leaf to protect the delicate plates of chlorophyll-bearing cells against drought.

while others are capable of enduring almost complete desiccation and revive quickly when moistened. An interesting device of service in adapting these plants to periods of drought appears in the leaves of some of the higher forms, as the hair cap moss, Polytrichum. Plates of green cells parallel to the midvein project from the upper surface of the leaves, thus greatly increasing the surface of the leaves for photosynthesis and also serving as water 


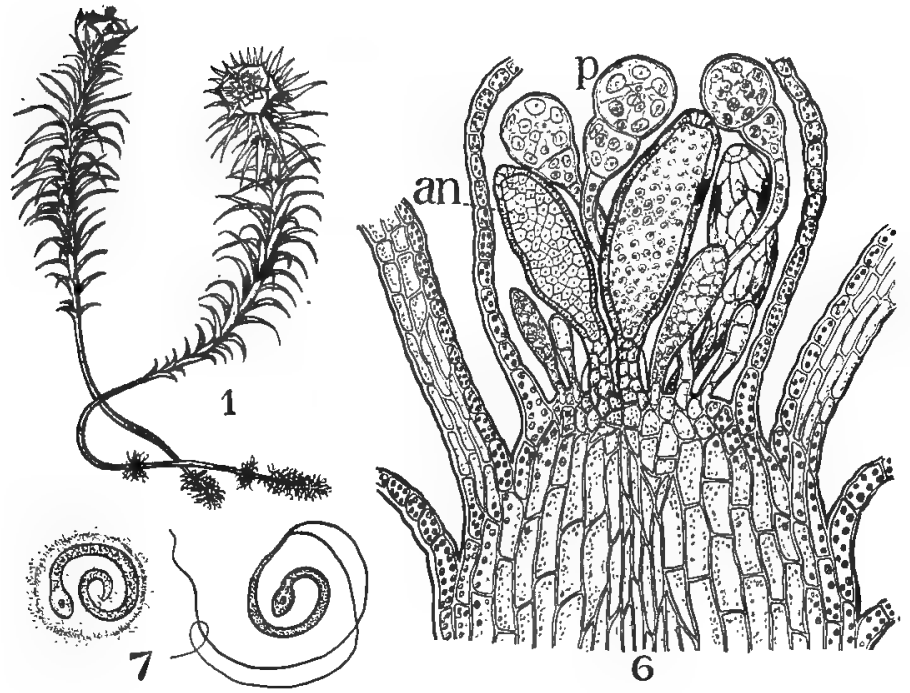

FIG. 207. Male reproductive organs: I, male plants of Polytrichum bearing antheridia in cup-like buds. 6, section of apex of stem of Funaria - an, antheridia; $p$, paraphysis. 7 , male gametes, the one at left still enveloped in mucilaginous remains of mother cell wall.
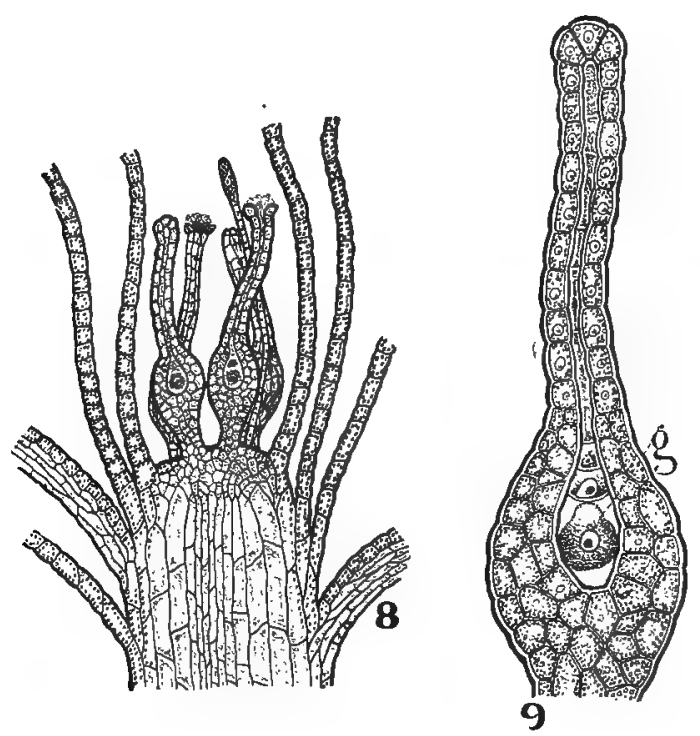

FIG. 208. Female reproductive organs: 8, longitudinal section of apex of stem, showing arrangement of archegonia. 9, archegonium enlarged, the canal cells just beginning to dissolve- $g$, the female gamete. 
reservoirs (Fig. 206, D). During drought, this delicate apparatus is protected by the coiling of the leaves into needle-like rolls which result in the exposure only of the thickened epidermal cells.

The sexual organs are developed on the apices of the main or lateral branches and they are protected by modified leaves which are often colored and form a more or less conspicuous bud or cup (Fig. 207, I). This is especially true of the antheridial buds, the plants being monoecious or dioecious. The antheridia and archegonia are essentially of the same structure as noted in

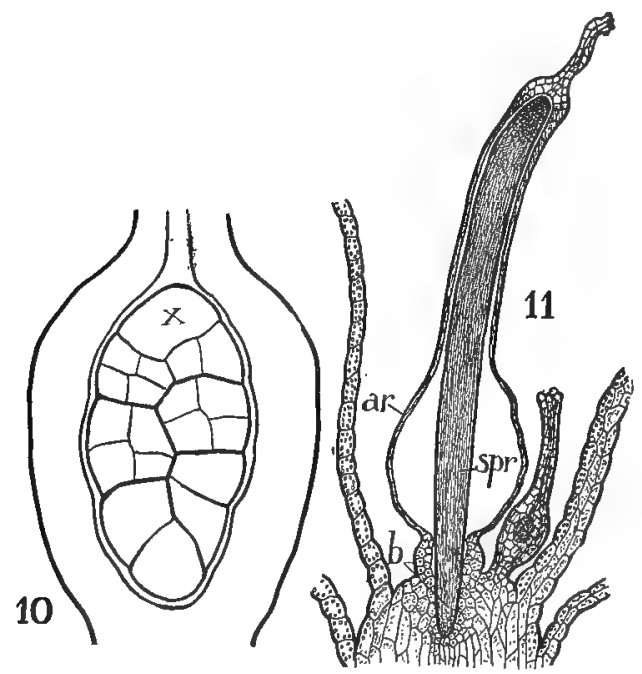

FIG. 209. Germination of the gametospore: 10, base of the archegonium in which the gametospore has germinated, forming a mass of cells with apical growing cell, $x$. II, later growth of the gametospore. The sporophyte, $s p r$, still enveloped by the archegonium, $a r$, appears as a cylindrical mass of cells with foot, $b$, penetrating the stem of the moss plant. At right an unfertilized archegonium. See Fig. 205, B.-After Sachs.

previous groups and they are usually associated with modified leaves known as paraphyses (Figs. 207, 6; 208). The germination of the gametospore and the development of the sporophyte, while presenting many features in common with the hepatics and Anthoceros in particular, shows a remarkable series of variations that are of decided advantage to the plant. The gametospore in its early growth forms a spindle-shaped mass of cells, 
the basal portion of which reaches down into the stem of the moss plant and forms a well-developed absorbing organ or foot, while the upper portion elongates by means of an apical cell (Fig. 209, 10). Later, the growth becomes basal as in Antho. ceros. For a time, the archegonium keeps pace with the elongation of the young sporophyte (Fig. 209, II), but finally it is ruptured and lifted up as a cap, called the calyptra, on the apex of the young sporophyte. This is one of the most essential differences between the mosses and hepatics. In the latter group, with the exception of the Anthocerotales, the spores were matured in the archegonium. In the Bryales, the spores are usually not formed until the seta has elongated considerably. As the sporophyte elongates, the upper part enlarges and finally forms a complex capsule which remains covered for a varying length of time by the calyptra. The hairy calyptra of Polytrichum (this name means many hairs) is due to the development of a felt of hairs upon the archegonium which forms a protective covering to the young sporophyte against the loss of water.

The capsule and calyptra assume various forms and positions. In some cases the capsule is quite erect and completely covered by the calyptra (Fig. 210, I), and again it may be more or less inclined or even pendulous and the calyptra laterally placed like a cap (Figs. 205, $A$; 2II, 5). Removing the calyptra you notice that a lid or operculum is situated on top of the capsule while at the bottom is a somewhat enlarged region, the apophysis, provided with stomata that communicate with the interior regions of the capsule (Figs. 210, 2; 2II, 5). When the operculum is removed a circle of minute teeth-like structures, the peristome, appears that more or less completely closes the mouth of the capsule (Fig. 205, D). In some mosses a delicate membrane, the epiphragm, lies just below the peristome, which assists in closing the mouth of the capsule (Fig. 210, 2B, 4A). We are now interested to know the meaning of these structures and to learn how they have come about. By examining a longitudinal section of the nearly mature capsule you will see that the sporeproducing tissue is relatively small and appears as a hollow cylinder. The progressive sterilization that we have seen going 
on has here resulted in the transformation of the upper part of the dome-shaped zone of sporogenous cells into vegetative cells (Figs. 210, 3; 211,6). The sporogenous tissue is usually sur-
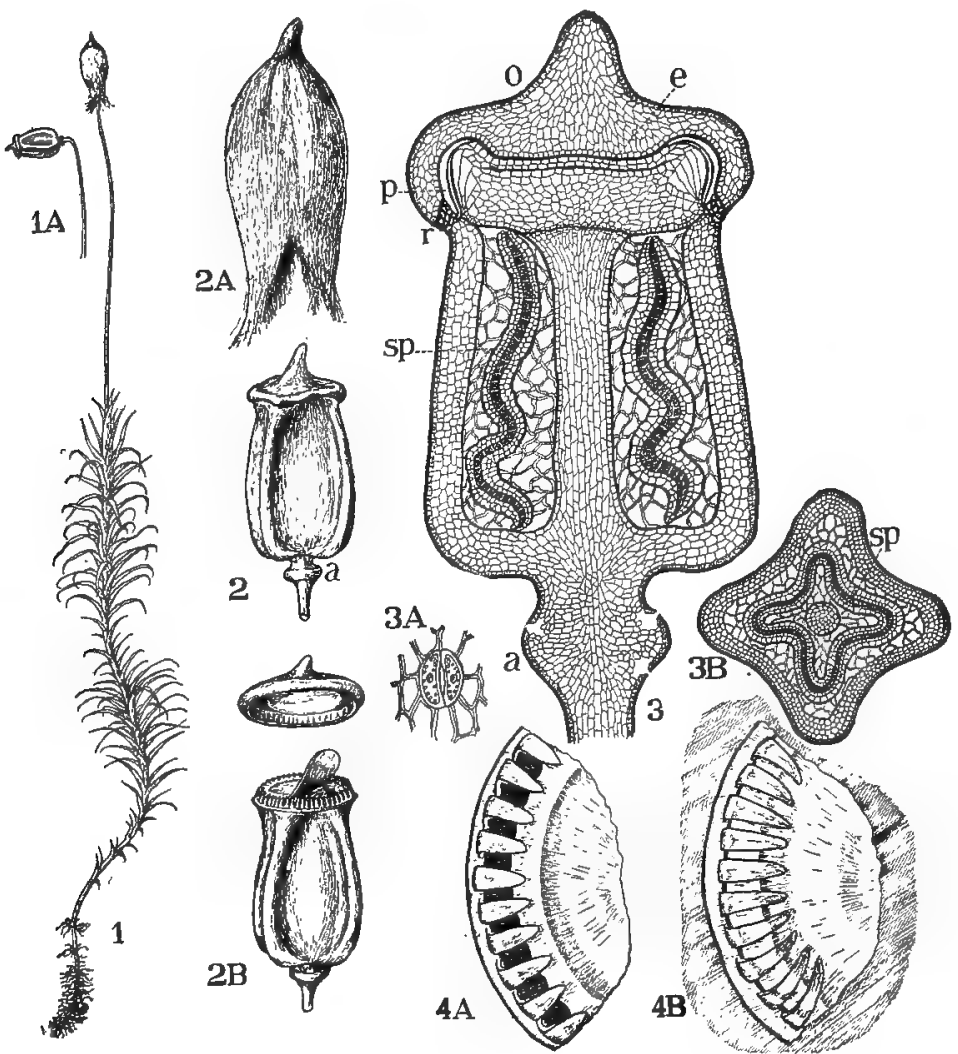

FIG. 2тo. The mature sporophyte of Polytrichum: I, moss plant bearing sporophyte. I $A$, calyptra removed, showing capŝule, which has curved to one side. 2, capsule, the calyptra, $2 A$, removed, showing the operculum or lid and the enlarged apophysis, $a$, at base. $2 B$, capsule with operculum re. moved, showing the teeth-like peristome and the epiphragm, which has been lifted up at one side. 3, section of nearly mature capsule- $s p$, cylinder of spore-forming cells that is surrounded on its inner and outer sides by loosely arranged chlorophyll cells; $o$, operculum; $r$, annulus; $p$, peristome; $e$, epiphragm; $a$, apophysis. $3 A$, stoma of apophysis. $3 B$, crosssection of capsule- $s p$, spore-forming cells. $4 A$, portion of mouth of capsule, showing position of peristome and epiphragm in dry weather. ${ }_{4} B$, peristome pressed down on epiphragm, closing the capsule in damp weather. -H. O. Hanson. 
rounded on the outside, and less commonly on the inside, by loose chlorophyll-bearing cells which extend down to the base of the capsule where chlorenchyma and stomata are developed. This lower region of the capsule, the apophysis, is often enlarged and provided with air spaces and stomata, thus constituting the chief photosynthetic apparatus of the sporophyte (Fig. 2 Io, $3 A$ ).

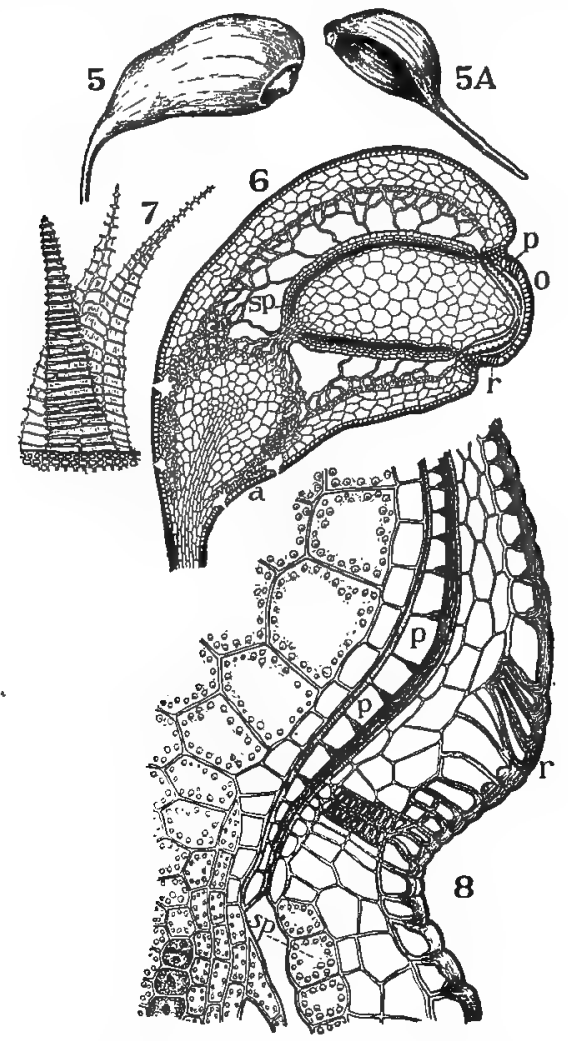

FIG. 2II. Structure of capsule of Funaria: 5, capsule with calyptra, 5A, removed. 6 , section of nearly mature capsule- $s p$, spore-forming cells surrounded on outside by loosely arranged chlorophyll-bearing cells; 0 , operculum; $r$, annulus; $p$, peristome; $a$, apophysis. 8, magnified view of a portion of the capsule, showing the annulus, $r$, and the thick-walled cells of the peristome, $p$, which are attached at their base to the epidermis by a double row of cells; $s p$, spore-forming cells, the dotted line should run to the four roundish cells at the left. 7 , the cells shown in $8, p$, have split apart, thus forming the inner and outer teeth-like segments of the peristome.-After Sachs. 
The entire surface of the capsule is protected by a well-developed epidermis but at the top a lid or operculum is cut off by a ring of rather delicate mucilage-bearing cells, the annulus, which swells at maturity and so assists in casting off the operculum (Fig. 2 I0, 3, r). Below the operculum a layer of cells, known as the peristome, extends across the capsule and becomes greatly thickened on its outer and usually on its inner walls. This layer of cells is firmly attached to the walls of the capsule by rather short thick-walled cells (Figs. 210, 3, $;$; 2 II, 6-8, $p$ ). When the spores are mature, the more delicate cells break down, leaving little more than a loose mass of spores and the peristome within the capsule. The cells of the peristome break apart into teeth-

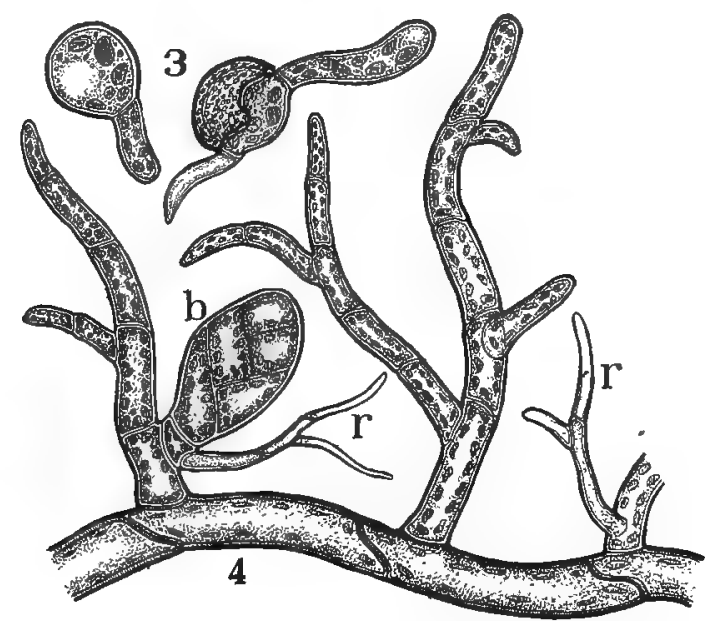

FIG. 212. Germination of the spore: 3, early stage in the germination. 4, character of the branching, alga-like filaments that are finally developed from the spore- $r$, rhizoids which penetrate the ground; $b$, bud which will develop into a leafy moss plant.

like segments (Figs. 2II, 7) and being very hygroscopic, cooperate with the contracting capsule in forcing off the operculum. After the removal of the operculum the mouth of the capsule is covered by the peristome which now appears as a fringe of teeth radiating out from the walls of the capsule (Fig. 2IO, 4). The teeth of the peristome are always in multiples of two and form one or more, usually two layers, accordingly as only the outer or 
both surfaces of the peristome cells are thickened. These teeth are so variously marked and fashioned that they furnish one of the most characteristic features of the various genera of the mosses. The peristome closes the mouth of the capsule in wet weather, but on dry days it opens in a variety of ingenious ways in the various species of mosses so as to effect a gradual scattering of the spores. The seta also contributes in the distribution, being very elastic and often hygroscopic (Fig. 205, D).

The spores germinate and produce profusely branching chains or filaments of green cells, called the protonema (Fig. 212). In a few instances, thalloid structures are developed as in Sphagnum. The protonema absorbs the earth substances through delicate rhizoids and spreads over the ground, appearing to the eye as a green mould or fine algal cells. Goebel presents some evidence tending to show that the mosses may have been derived from branching forms of the green algae. Buds finally appear on these branches at numerous places and develop the leafy stems of the moss plant (Fig. 212, b). This in part accounts for the dense colonies so characteristic of the mosses. As soon as the young plants are established in the soil by means of rhizoids that spring from the basal parts, the protonema withers away, although in some genera it is perennial and continues to produce new plants from year to year.

I 10. The Relationship of the Bryophyta.-It appears probable that there have been three lines of variation or evolution among the Bryophyta that have had their origin in some simple thalloid form most nearly related to the lower Jungermaniales. One line has resulted in the highly differentiated thallus of the Marchantiales with its simple sporophyte. Another, the Jungermaniales, retaining the simple structures of the primitive thallus has modified its form into a leafy plant and developed a more complex sporophyte, while the variations of the third line, or Anthocerotales, have resulted in slight alterations of the primitive type of the thallus but in profound modifications of the sporophyte. The variations of the sporophyte in the latter group appear to have been very advantageous to the present conditions upon the earth and perhaps led to the mosses. The important feature in this 
evolution, already noted among the algae, is the increasing importance of the sporophyte. Among the green algae it was dependent upon the amount of food stored in the gametospore. In the Bryophyta, it is better nourished, owing to its essential parasitic habit. This led to a larger growth and more complex development and it is especially important to note that the sporophyte became more profoundly modified by the stimuli of external conditions than did the gametophyte. For example, we see in the sporophyte of Anthoceros and of the mosses, a plant that is practically dependent upon the gametophyte only for water and the earth substances. So the way is prepared for a study of the next division where the sporophyte finally comes to absorb its crude materials directly from the soil and thus becomes an independent self-supporting plant. 


\section{CHAPTER VIII}

\section{DIVISION III. PTERIDOPHYTA OR FERNS}

III. Nature of the Ferns.-The members of this division differ greatly in character and live under a wide range of conditions, although, like the Bryophyta, they usually frequent moist and shady places, as glens, ravines and damp woods, or in tropical countries they often cover the moist rocks and tree trunks with a luxuriant and attractive vegetation. The most noticeable fea-

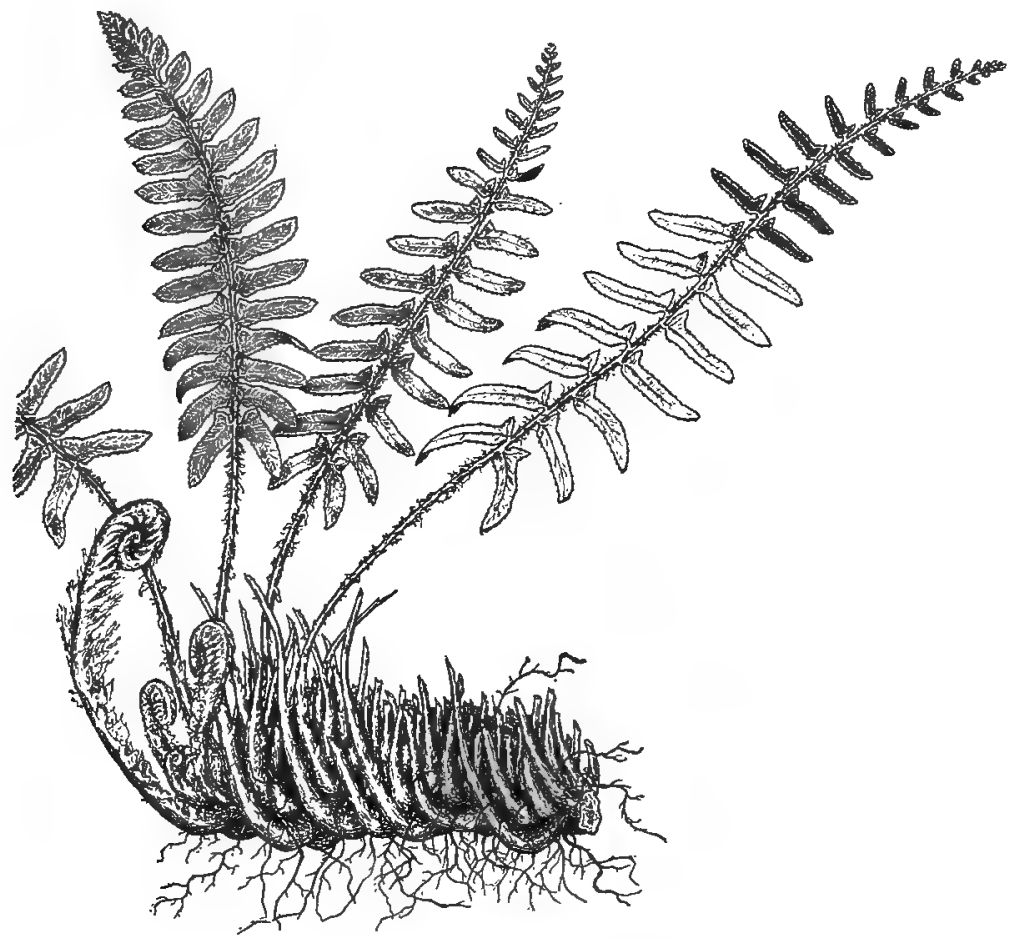

FIG. 2r3. The Christmas fern, Polystichum, with young leaves uncioiling in the spring at the tip of the stem and further back the fully developed leaves of the past season. The older portion of the stem is covered with the petioles of leaves that have died off and numerous roots are seen arising from the stem and bases of the petioles.-H. O. Hanson. 
true in the fern is the large development and complex character of the plant (Fig. 213). This is due to a more efficient absorbing and conducting apparatus, the root and vascular bundles. This conducting system was foreshadowed in the elongated cells that appear in the sporophyte of Anthoceros and of the mosses. Here the elongated cells are much more specialized and are united into large bundles, termed the vascular bundles, that appear in the leaves as "veins" and in the stems they are variously related and often constitute a conspicuous portion of these organs, as is the case in the higher plants, see page 76 . The fern plant does not correspond to the moss plant. 'It is the sporophyte which has become independent of the gametophyte. ${ }^{+}$The sexual generation is a small thallus, commonly called the prothallium, that is quite as primitive as the simplest Jungermaniales. Its chief function is the formation of gametes (page 282) and it is capable of nourishing the sporophyte only for a short time in the majority of ferns

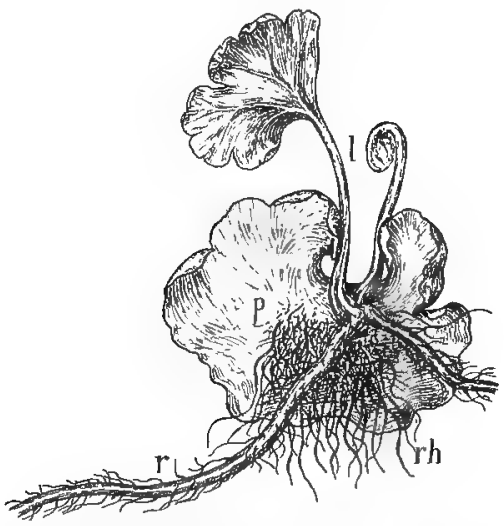

FIG. 2I4. The thalloid gametophyte or prothallium, $p$, of a fern from which a young fern plant is being developed. This sporophyte has already developed two roots, $r$, that penetrate the soil, and two leaves, $l$, are appearing, thus making the fern at an early age independent of the gametophyte; $r h$, rhizoids.

(Fig. 2I4). The gametophyte of the Bryophyta never attained any considerable proportions owing to its inability to vary and produce adequate absorbing organs and conducting tissues. This naturally limited the development of the sporophyte which 
was parasitic upon it. In the Pteridophyta, however; the sporophyte is not at such a disadvantage since it actually becomes independent of the gametophyte owing to the development of a root which puts it in communication with the earth substances. This radical departure in its mode of life acted as a profound stimulus and coöperated in inducing marked variations that were so beneficial in character as to cause the sporophyte to assume large proportions and become differentiated into a highly organized plant. The stem elongates through the repeated division of a single apical cell, as in the Bryophyta, but the stem and also the leaves and roots in addition contain vascular bundles and an arrangement of tissues already noticed in the higher plants.

The gametophyte in many of the Pteridophyta is very suggestive of the simpler thalloid hepatics. Owing to the fact that it is no longer permanently burdened with the nutrition of the sporophyte, it becomes greatly reduced in size and length of life. In fact, in several of the more specialized ferns, the gametophyte may be reduced to a few cells and the entire development may take place within a day. The reproductive organs and the germination of the gametospore are suggestive of the corresponding features noted in the Bryophyta. The more important orders of the Pteridophyta are: r. Ophioglossales. 2. Filicales or Common Ferns. 3. Equisetales or Horsetails. 4. Lycopodiales or Club Mosses. This sequence is followed because it brings out more clearly the trends or tendencies that arose step by step in the evolution of plant life. As a matter of fact the club mosses appear to be the most primitive forms and they are the most suggestive of the Bryophyta; while the common ferns are the most recent in development. Enough has been said to show that these forms are very remotely related to the ancestors of the Bryophyta and that these four orders of Pteridophyta are very distantly connected.

\section{Order I. Ophioglossales}

I12. General Characters of the Sporophyte.-This order contains three genera which are probably but a remnant of an earlier and widely distributed group. Only two, Ophioglossum 
and Botrychium, are of common occurrence (Fig. 215). They are of unusual interest because they present many features suggestive of the liverworts and also of the more specialized ferns and seed plants. This remark is not intended as necessarily implying relationship between the three groups, but that analogous structures have arisen in each, due either to inheritance from allied ancestors or to the operation of stimuli upon plants that are only slightly or not at all related. The sporophyte consists of a short stem with thick fleshy roots that are associated with mycorrhiza. The leaves are simple or divided and usually appear singly, ensheathing the apex of the stem which always remains in the soil. One of the most remarkable features about these ferns is the development in the stems, roots and leaves of the same tissues that we have noted in the higher seed plants. The vascular bundles have the same origin as in the seed plants. The woody portion (xylem) of the conducting system appears as a solid strand in the center of the very young stem and this is surrounded by the cellulose part (phloem) of the system. Early in the development of the stem delicate cells (pith) replace the central cells of the xylem so that the conducting system now appears as a hollow cylinder. As the stem elongates this cylinder is broken into segments by certain strands from it passing out into the leaves. The spaces formed by the departure of these strands are termed foliar gaps. The segments of the conducting system are termed the vascular bundles and since the phloem is outside the xylem they are known as collateral bundles. In some cases these bundles develop a cambium which adds new cells to the xylem and phloem so that the arrangement of tissues in the stem is strikingly suggestive of the dicotyledonous stem with its pith; concentric rings of xylem, cambium and phloem; medullary rays; cortex; cork; etc. (Fig. 216,40 ). It is noteworthy also that the cells added to the xylem by the cambium resemble those appearing in the pines. The stem structure of some of the simpler representatives of the next order resembles that of the Ophioglossales and it has been suggested that the ancestors of these two lines of Pteridophyta may have been the starting point of the seed plants. 
The spores are borne in peculiar modified outgrowths of the leaves that assume a cylindrical shape in Ophioglossum and become more or less branched in the species of the Botrychium (Fig. 2I5). The structure of these organs presents many features that recall the sporophyte of Anthoceros (Figs. 2I5, $B$; I99). The outer portion of the cylinder consists of chlorophyllbearing cells which communicate with stomata in some of the forms at least. The spore mother cells are also distributed as
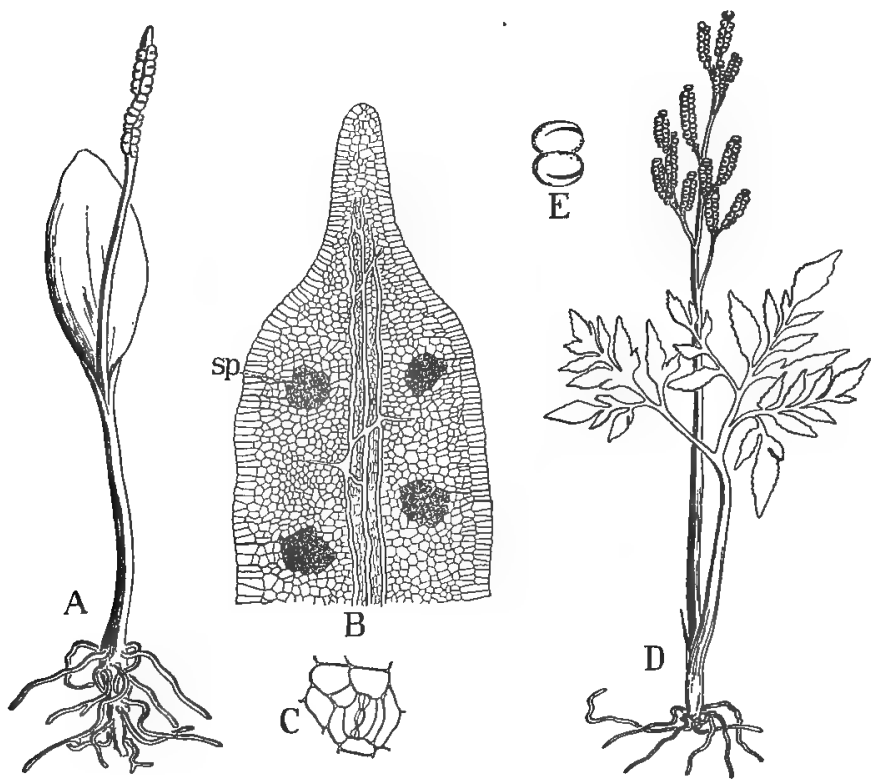

FIG. 215. The two common genera of the Ophioglossales: $A$, the addertongue fern, Ophioglossum, with single leaf ensheathing the short stem and producing a spore-bearing spike. $B$, section of the spike-sp, the sporeforming cells arranged in groups or sporangia. The spores are exposed by the breaking apart of the cells between the dark lines. $C$, stoma from epidermis of spike. $D$, the grape fern, Botrychium. The leaf is much divided and also forms a branched spore-bearing organ. $E$, two sporangia, showing the manner of opening for discharge of spores.

in Anthoceros, the essential difference being that they are separated by a larger number of sterile cells and a larger number of spore mother cells are also grouped together, forming rather conspicuous sacs or sporangia (Fig. 2I5,sp). The spores are formed 
from the mother cells as in the Bryophyta and are discharged from the sporangia through a trąnsverse cleft (Fig. 215, E). It is interesting to note in a closely allied order occurring in the

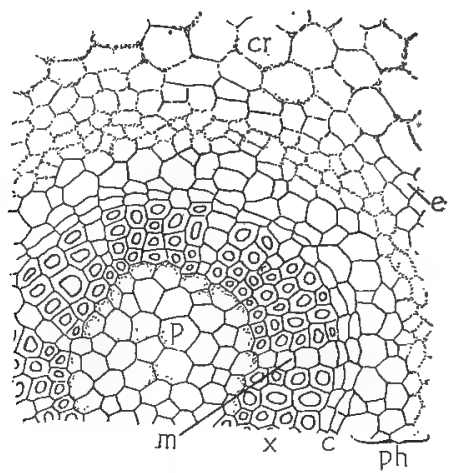

FIG. 216. Cross-section of a stem of Botrychium: $p$, pith; $x$, xylem; $m$, medullary ray; $c$, cambium; $p h$, phloem; $e$, endodermis; $c r$, cortex.After Jeffrey.

tropics, that the sporangia are developed directly upon the leaves (Fig. 2I7) instead of upon special branches and that they are sometimes associated together in groups, known as sori (sing.

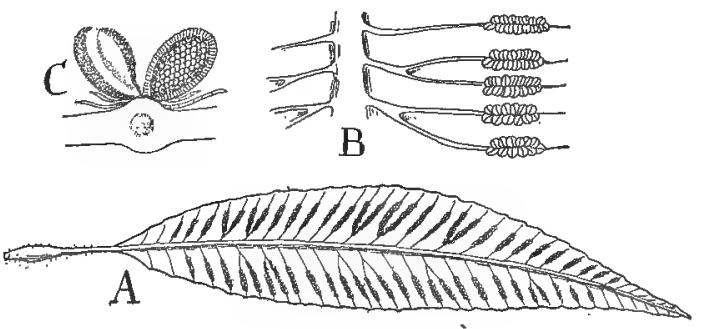

FIG. 2I7. Arrangement of the sporangia of an allied order, Marattiales; $A$, leaflet of Archangiopteris with sporangia on surface of leaf and arranged in groups or sori. $B$, magnified view of a portion of the leaflet. $C$, section of leaf, showing two sporangia, the left-hand one in section.

sorus) and provided with thickened cells, the annulus-characters that will become conspicuous in the next order. These sporangia originate, however, as in Ophioglossum and open by transverse clefts, which operation is promoted by the unequal drying of the thick- and thin-walled cells of the annulate forms.

(a) The Gametophyte.--The gametophyte or sexual genera- 
tion is not often met with, owing to the fact that, like the sporophyte, its development is associated with mycorrhizal fungi and consequently it is usually completely buried in the soil and usually quite devoid of chlorophyll. The various stages in the germination of the spores have never been observed, but the mature gametophyte of Botrychium was found a few years ago by Jeffrey

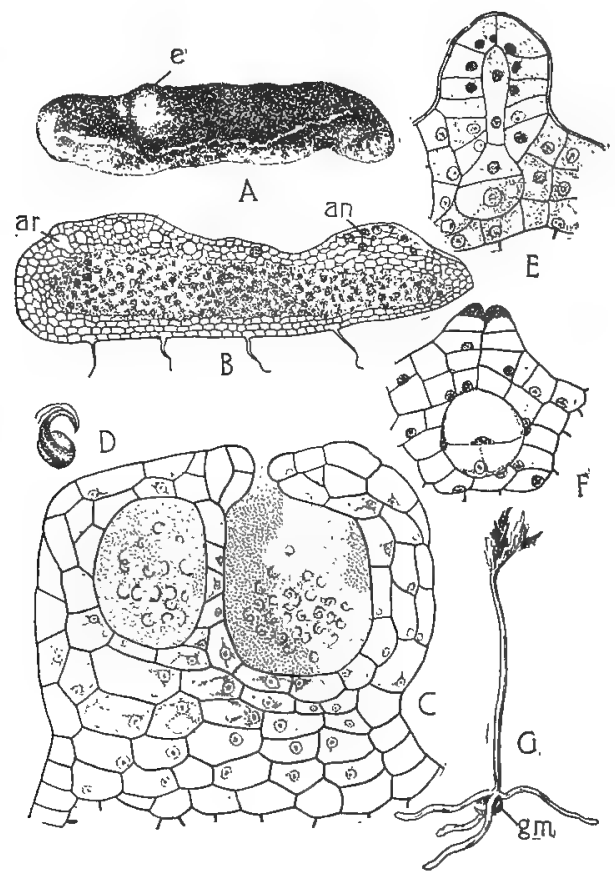

FIG. 218. The gametophyte and young sporophyte of Botrychium: $A$, tuberous appearance of the gametophyte- $e$, a young sporophyte or embryo developing in one of the archegonia. $B$, a section of gametophyte$a r$, archegonia; $a n$, antheridia. $C$, two antheridia in section. $D$, male gamete. $E$, archegonium before dissolution of canal cells. $F$, gametospore in two-cell stage of germination. $G$, young sporophyte with roots and first leaf developed but still attached by foot to the round gametophyte, $g m$. A. F.-After Jeffrey.

and carefully studied. It appeared as a rather tuberous body that is provided with numerous rhizoids and a growing apical cell as in the Bryophyta (Fig. 218, A, B). The archegonia and antheridia are usually borne upon the upper surface of the game- 
tophyte and in origin and appearance are rather suggestive of Anthoceros. The antheridia consist of a number of mother cells quite buried in the tissues of the thallus, being covered by one or two layers of cells which are destroyed or break open when the male gametes are mature (Fig. 2I8,C). These gametes are quite different from any yet seen, being spirally coiled and provided with numerous cilia (Fig. 2I8, D). The archegonia are similar to those noted in Anthoceros, consisting of a rather short neck with two central canal cells and a swollen base sunken in the tissues of the gametophyte (Fig. 2I8, E). The female gamete is formed at the base of the canal cells which finally become mucilaginous and thus form an open passage-way for the entrance of the male gametes as soon as the lip cells have opened. It has been shown in the common ferns that malic acid is present in this mucilaginous substance which strongly attracts the male gametes so that they crowd into the canal, of ten completely choking it. So we see that the gametophyte of this fern (though differing in form) is essentially of the same character as in the Bryophyta, its subterranean character and absence of chlorophyll being due to its association with fungi. It should be stated that lobes are produced from the end of the tuberous gametophyte of one of the species which become green on reaching the surface of the soil and in a closely allied order or tropical ferns, the sexual generation is normally a green thallus strikingly like some of the simpler Jungermaniales.

(b) The Germination of the Gametospore.-The early development of the sporophyte resembles Anthoceros in many respects. The gametospore divides into two cells (Fig. $218, F$ ), from the lower of which a large foot is formed, and from the upper cell the short stem and root arise. Later, the first leaf or cotyledon. is formed from the stem. This development of the sporophyte goes on very slowly within the archegonium where it lives as a parasite for a long time. Eventually the root ruptures the archegonium or calyptra and comes in contact with the soil. The cotyledon now grows upward and makes its appearance above the ground as the first green leaf (Fig. 2I8, G). The sporophyte thus becomes a self-supporting plant, although it probably re- 
mains in part dependent upon the gametophyte for several years. At this stage of development the young sporophyte is a very simple type of fern, but gradually more efficient roots are developed and each year the stem sends up a larger and larger leaf until the adult size is reached when the spore-bearing branch is formed (Fig. 2r5), thus making possible again a new series of gametophytes.

(c) Comparison of the Adder Tongue Ferns with Preceding Groups.-The most noteworthy difference between these simple ferns and the Bryophyta is the larger development of the sporophyte and its final independence of the gametophyte. This is doubtless due to the development of true roots which made possible a continuous and abundant supply of the crude materials from the soil. This change acted as a stimulus which promoted variations in the sporophyte while the light and various climatic factors also assisted to a very marked degree. Among the algae, the gametophyte is the dominant generation, the sporophyte being represented often by the gametospore. This is essentially the relationship among the majority of the Hepaticae where the gametophyte performs all the work of food construction and the sporophyte is a minute parasitic plant upon it. In Anthoceros and the mosses, the sporophyte is longer lived and more highly organized, but the gametophyte is still the more important generation as it performs the major portion of the work. Among the ferns, this relationship and the distribution of labor is completely turned about. The sporophyte becomes the larger plant and the principal center of photosynthesis, while the gametophyte remains small and gradually becomes very short lived.

There is also to be noted the longer postponement in the formation of the spores. In certain of the algae the gametospores produce the spores directly on germinating while in Ricciocarpus a small mass of cells is first formed and certain of these cells soon become spore mother cells. In Marchantia, a larger number of cells are formed by the gametospore and the spore mother cells originate after a few weeks in a definite region of the sporophyte. These features are more noticeable in the Jungermaniales and especially in the long-lived sporophyte of Anthoceros. Recall 
also the considerable growth of the sporophyte of the Bryales and the final development of the spore mother cells in a definite and restricted region in the capsule. In the Pteridophyta, the sporophyte not only becomes larger and more highly differentiated, but the formation of the spores is often deferred for years and the spore mother cells are localized in special organs. This postponement of the spore formation may appear at first sight as a disadvantage since the sporophyte is exposed to many dangers during the long period of preparation for its work. However, the delay is more than compensated for by the large number of spores that are finally formed and also by the fact that the sporophyte does not entirely perish as in previous cases, but lives on, sending up annually new spore-bearing leaves. It would appear that a point had at last been reached in the evolution of the sporophyte where it is so well organized as to ensure its existence. It can consequently with safety defer the formation of spores until well-developed roots, stems and leaves have been formed. The independent existence of the sporophyte brings out very clearly the two phases in the life history of the plant which we call the alternation of generations. The formation of the spores marks the beginning of the gametophyte or sexual generation, which ends with the formation of the gametes. The formation of the gametospore through the fusion of the gametes starts the sporophyte or asexual generation which ends with the division of the spore mother cells.

Why has not the gametophyte varied as well as the sporophyte? Perhaps the simplicity of its structure has become fixed by inheritance from a long line of algal ancestors. The occurrence in the Bryophyta and Pteridophyta of motile male gametes and the consequent necessity of water for fertilization, points to the inheritance of this peculiarity from aquatic ancestors. It is evident that there can be no considerable modification of the gametophyte, as long as this feature is retained, without greatly decreasing the possibilities of fertilization. Consequently the gametophyte must remain of necessity a primitive structure. The sporophyte, on the other hand, was accustomed from the first to terrestrial conditions, or to such conditions as were unfavorable 
to the growth of the gametophyte. Among the algae we have noticed that it may carry the plant over the more or less complete drying up of the water or unfavorable temperatures. Perhaps these exposures to a variety of stimuli which the gametophyte never experienced or in a lesser degree enabled the sporophyte to respond with more profound variations when it became parasitic upon the gametophyte and exposed directly to the light and air as was the case among the Bryophyta. Certainly we know that abundance of foods, light, temperatures, etc., are among the important stimuli in causing variations. The simple sporophyte of the Bryophyta was exposed to just such forces as these and steadily gained in complexity until in the Bryales it nearly equaled in importance the gametophyte. The sporophyte of the Pteridophyta, owing to the development of the root, experiences a new stimulus, $i$. e., that of the soil which, cooperating with the stimuli of the light, etc., causes it to assume much larger proportions than the gametophyte and become the dominant generation in the life history of the plant. Perhaps another factor played an important rôle in securing the supremacy of the sporophyte. We have seen in paragraph 58, The Significance of Fertilization, that the sporophyte is the result of the fusion of two gametes which may vary in character. The constant introduction of variant characters into the asexual generation in this way may have coöperated in its increasing complexity.

\section{Order 2. Filicales or Common Ferns}

II3. General Features.-The great majority of plants popularly known as ferns belong to this order. They are a highly specialized group that have branched off from some primitive fern stock in recent geological times and owing to their variations being highly adapted to present conditions upon the earth, they have become very numerous and widely distributed-probably exceeding 3000 species. In temperate climates the majority live upon the ground in moist and shady regions and some are aquatic or xerophytic. They attain their greatest abundance in the mountainous district of tropical countries where they occur in astonishing profusion and variety upon the moist rocks and 
trunks of trees, as well as upon the earth. The leaves are the most striking feature of the Filicales. They are usually large and divided and are characterized by being coiled when young (Fig. 219). This is due to the stronger growth of the outer cells which causes an inward rolling of the leaf. The growth of the leaf is very slow, of ten requiring three years for its formation in tem-

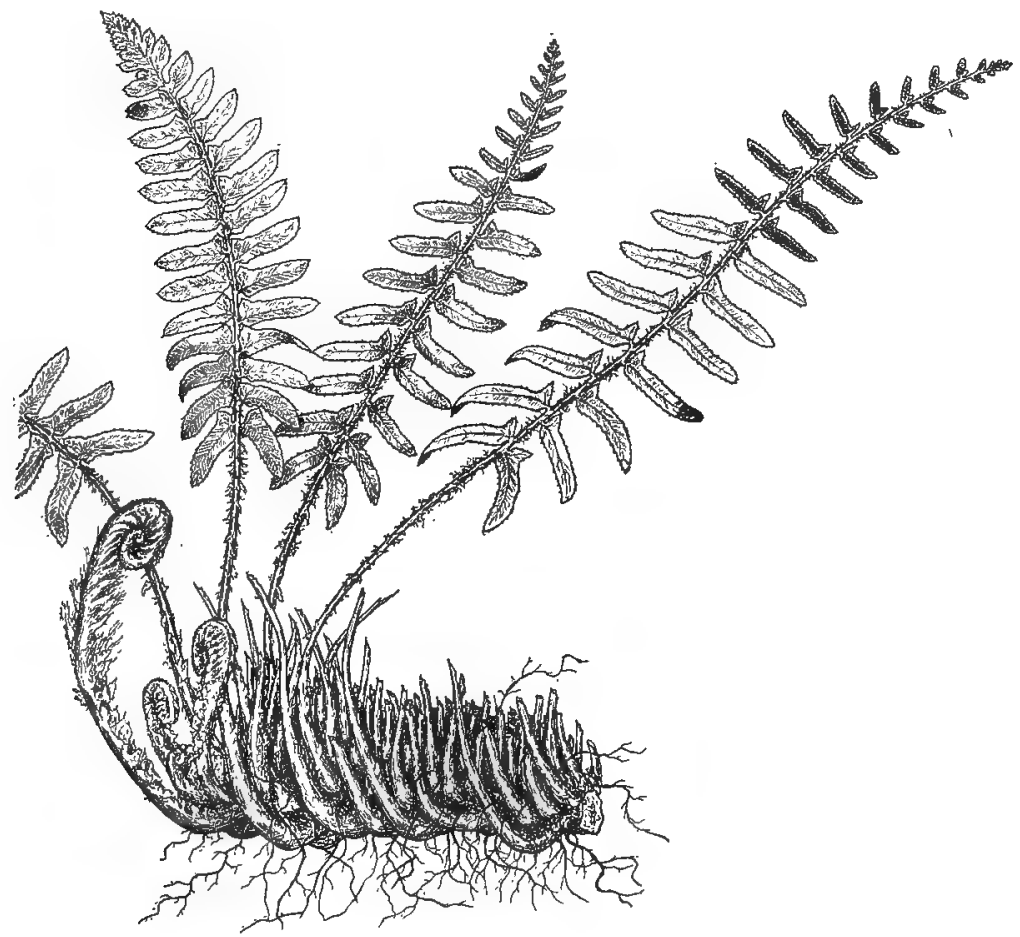

FIG. 2I9. Christmas fern, Polystichum, with prostrate stem bearing at the tip young coiled leaves covered with chaffy scales and further back large leaves of the previous season. The older portions of the stem are covered with the petioles of the dead leaves.-H. O. Hanson.

perate regions. During the season preceding its expansion, the petiole and blade are completely formed and appear in crosierlike coils more or less covered with chaffy scales (Fig. 220, c). This development enables the leaves to expand with surprising rapidity in the spring when the more rapid enlargement of the cells on the inner side of the leaf cause it to uncoil. There is 
another feature about these leaves that compels our admiration. Comparatively few leaves are produced annually from the tip of each stem-in the preceding order usually but one. This

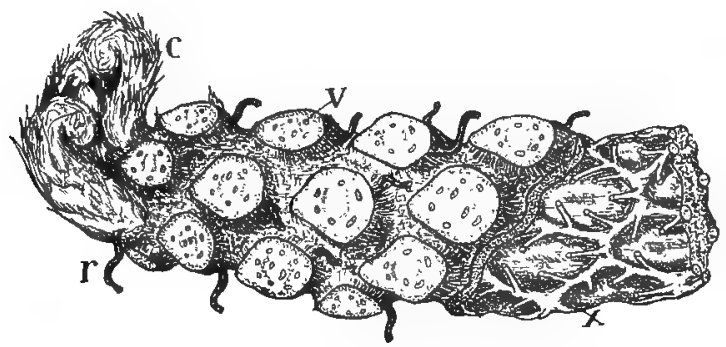

FIG. 220. Stem in early spring freed from all of its leaves save the young ones, $c$, near the tip: $r$, roots; $v$, vascular bundles in base of petiole; $x$, region from which the cortex has been removed to show the vascular bundles from the leaves uniting to form a lattice work.

appears to be the rule in underground stems, since the difficulty and danger of sending the tender young leaves up through the soil is minimized by the development of one or a few leaves which

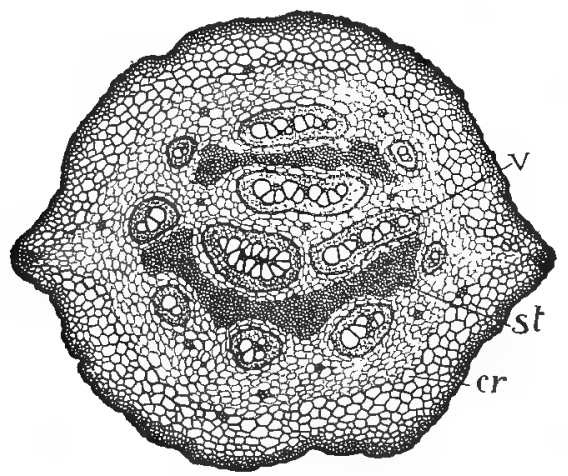

FIG. 22I. Cross-section of fern stem: v, a concentric vascular strand, the large cells of the xylem being surrounded by the phloem. Each strand is surrounded by a compact layer of cells, the endodermis; st, stereome; $c r$, cortical region.

form large blades after reaching the air. In the two remaining orders of Pteridophyta, branches of the underground stems rise above the ground and these bear numerous small leaves, also a rule for stems of this kind. The tissues of the leaves are differ- 
entiated into an epidermis, stomata, chlorenchyma and vascular bundles as in the higher plants (Fig. 223). The stems are more usually prostrate, creeping rhizomes that branch sparingly and so gradually give rise to colonies of ferns. One of the most attractive features of certain tropical districts is the tree ferns with erect stems of palm-like appearance which lift their great crowns of leaves 30 to 50 feet in the air. The vascular bundles are more commonly of the concentric type (Fig. 22I). Perhaps we should repeat that a bundle is composed of two types of elongated cells, thick walled woody cells (the xylem) and thin walled

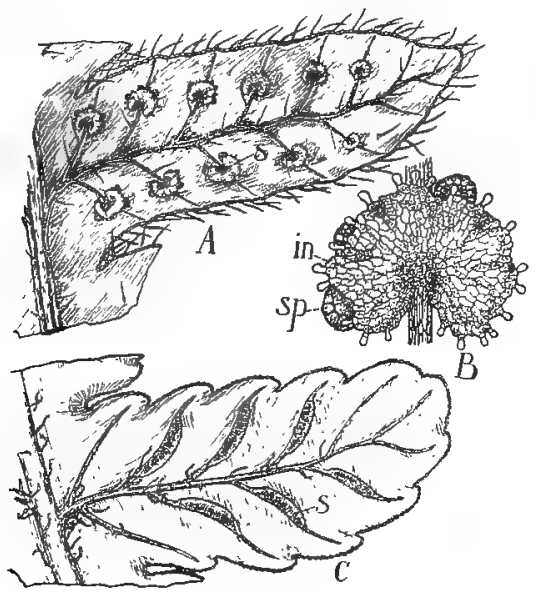

FIG. 222. Arrangements of the sporangia: A, lobe of leaf of Dryopteris with sporangia grouped in circular sori, $s . \quad B$, sorus enlarged, showing the shield-like membrane or indusium, in, covering the sporangia, $s p . C$, lobe of leaf of Asplenium with elongated sori, s.

cellulose cells (the phloem). In the fern type of concentric bundle the phloem surrounds the xylem. These bundles are united in the stem in a variety of ways. In the simplest case we find a central core of xylem surrounded by phloem which gives off strands or vascular bundles to the leaves and roots. In the majority of ferns this core of xylem is modified by the development of rather delicate pith-like cells in its center, consequently it appears as a ring in cross section or as a cylinder in longitudinal view. This ring is broken into segments owing to the fact that 
portions of it turn out here and there, thus forming the vascular bundles that extend into the leaves. Such an arrangement is seen in Botrychium (Fig. 216). These spaces formed in the ring, called foliar gaps, are often quite large so that the cylinder of vascular tissue in the stem presents the appearance of a lattice work - note the vascular tissue at the right-hand end of the stem in Fig. 220. In cross section such a cylinder would appear as a series of more or less widely separated strands (Fig. 22I). This latter figure shows that strands arising from the lattice-like cylinder may also extend into the pith-like region-note the three large strands in Fig. 22I, v. This explains the confusing arrangement of strands often seen in the cross section of fern stems and previously noted in monocotyledons, p. 96. Certain cells of the cortex and pith often become modified into strengthening cells of stereome (Fig. 22 I, st). Roots arise near the base of the leaves, and in some of the tree ferns form a thick mat-like covering on the stems. They originate from the endodermis of the bundles and possess a root cap and radial arrangement of the vascular bundles as in higher plants.

(a) Structure and Character of the Sporangia.-The sporangia, instead of being produced in the tissues of special branches as in Ophioglossum, are borne in curiously constructed capsules, usually situated on the under surface of the ordinary green leaves (Fig. 222). The sporangia-bearing leaves are usually called sporophylls, meaning spore-bearing leaves. In some cases the sporophylls are highly modified, being entirely given up to spore production and therefore quite different from the green leaves (Fig. 227). The sporangia are usually associated in groups or sori (sing. sorus) on the vascular bundles and protected by a membranous outgrowth of the epidermis, known as the indusium (Fig. 222, B). Each sporangium originates usually from a single epidermal cell, which by repeated divisions (Fig. 223) produces a capsule or sporangium that contains the spores. A sporangium of the shield fern contains 48 spores and there are fully 100 sporangia to a sorus and 20 sori on each lobe or pinna of the leaf. A well-developed leaf would have on an average 50 pinnae and a healthy plant would bear about to 
leaves. Therefore, Bower estimates that the shield fern produces annually upwards of 50 million spores. This makes a striking comparison when we consider the spore production in the Bryo-

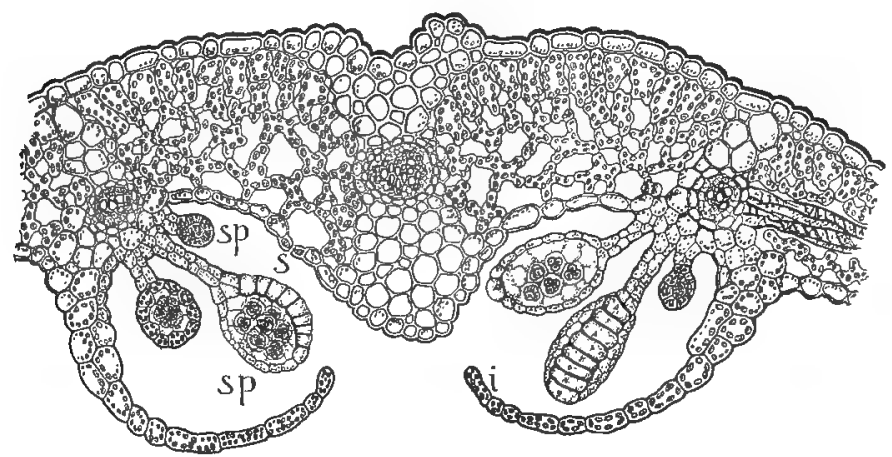

FIG. 223. Section of a leaf of Woodwardia, showing two sori: $i$, indusium; $s p$, sporangia arising from the epidermis and in various stages of development. Note the epidermis, stoma, $s$, palisade and spongy chlorenchyma. and vascular bundles, as in higher plants.

phyta, and it is evident that ample provision is made for the maintenance of the race notwithstanding the postponement and specialization in spore production.

The sporangia vary considerably in structure in the various

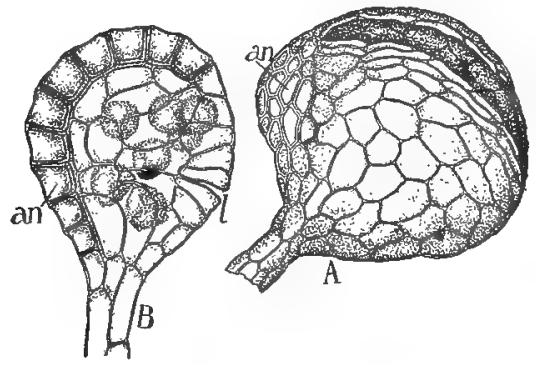

FIg. 224. Character of sporangia: $A$, simple type of sporangium of Osmunda with rudimentary annulus, an, of a few thickened cells. $B$, common type of sporangium-an, annulus; $l$, lip cells.

genera. In the simplest forms, they consist of a uniform layer of wall cells incløsing a mass of cells, the majority of which become spore mother cells, producing four spores each. In other cases, a few of the wall cells are thickened, forming a rudimentary 
annulus (Fig. 224, $A$ ), but in the majority of our common ferns, the sporangium consists of a delicate stalk, supporting a rather spherical spore-bearing capsule (Fig. 224, B). The walls of this capsule consist of a single layer of thin-walled cells except for a row of thickened cells, the annulus, that extends from the stalk over the capsule nearly to the opposite side (Fig. 224, B, an). At the latter point, the annulus ends in a few rather weakened cells, two of which, the lip cells, are conspicuous for their larger size (Fig. 224, $B, l$ ). It is to be noticed that the cells of the annulus are thickened on their inner and radial walls while the outer walls remain comparatively thin. When the spores are mature and lie loose in the capsule, the cells of the annulus that have been filled with water up to this time begin to dry out. As the volume of water in these cells lessens through evaporation, the cohesion of the water pulls upon the thin outer walls, causing them to bend in, assuming a U-shaped appearance. This tends to pull the two radial walls of each cell together and shorten the outer circumference of the annulus. This contraction pulls open the sporangium at the weak lip cells, the split extending back through the lateral cells of the capsule which is finally drawn back to such an extent that the annulus becomes nearly straight. Finally, when the water is nearly withdrawn from the cells, the tension becomes so great that air is drawn in through the thin walls of the cells. The entrance of air breaks the water adhering to the walls and which had kept them pulled in as described above and consequently each cell returns instantly to its original form. This causes the capsule to snap back to near its original position with a quick jerk, thus throwing out the spores to a considerable distance. This motion of the capsule can be approximated by mounting sporangia that have been soaked in a drop of water and watching them under a microscope while a drop of glycerine placed in touch with one side of the mount is drawn in with a filter paper applied to the opposite side. The denser glycerine will draw the water out of the cells by osmosis and set up a tension in the cells. of the annulus just as did the evaporation of the water.

The form of the sorus and its relation to the indusium and 
particularly the structure of the annulus are important characteristics to be observed in identifying the ferns. In the flowering ferns, Osmunda, the large slight-stalked sporangia are provided with a rudimentary annulus of a few thickened cells located at one side of the capsule (Fig. 224, A). The entire leaf or certain leaflets are completely covered with the sporangia, little more than the vascular bundles remaining (Fig. 225, A).

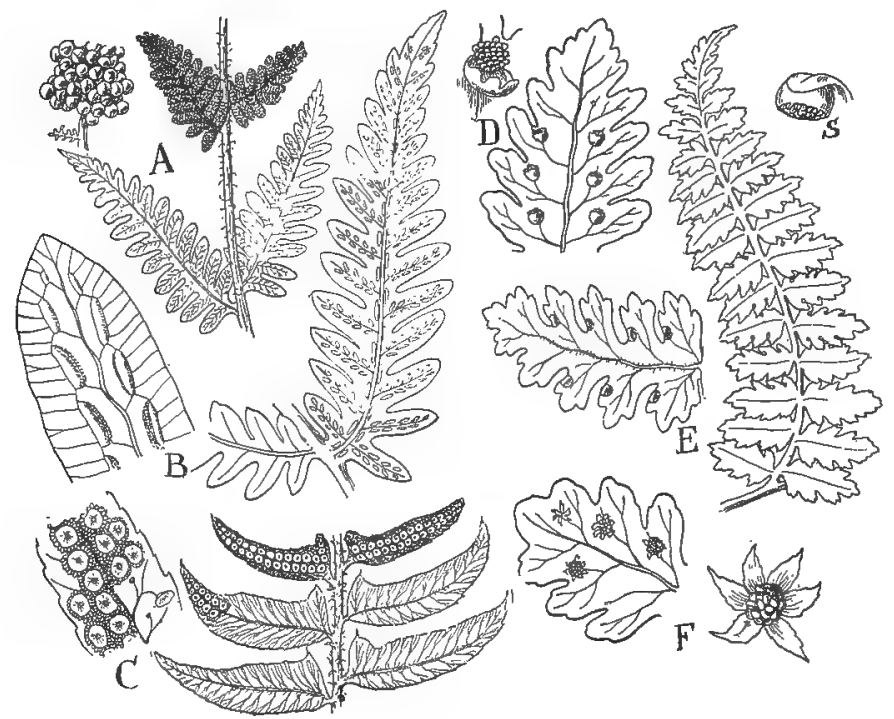

FIG. 325. Common forms of the Filicales: $A$, the flowering fern, $O s$ munda, showing below two green leaflets and above two sporangia-bearing leaflets. At left a cluster of sporangia magnified. The first leaves in the spring only bear sporangia; those appearing later have only green leaves. $B$, chain fern, Woodwardia. C, Christmas fern, Polystichum. $D$, bladder fern, Filix. $\quad E$, hay-scented fern, Dennstaedtia-s, sorus enlarged. $F$, Woodsia -After Sprague.

Osmunda belongs to the lowest group of the Filicales and shows certain analogies in the arrangement and structure of its collateral vascular bundles with the Ophioglossales. The majority of ferns in temperate climates are characterized by sporangia of the type shown in Fig. 224, $B$, and they are distinguished by the form and arrangement of the sori and indusia. The shield fern, Dryopteris, has a rather circular or curved sorus covered 
by an indusium that is laterally attached at a single point (Fig. 222, A). The Christmas fern, Polystichum, has a circular sorus with centrally attached indusium (Fig. 225, C). The spleenwort fern; Asplenium, is characterized by elongated sori arranged obliquely to the midrib upon the upper side of the veinlets. The indusium is attached on one side of the sorus along its entire length (Fig. 222, B). The chain fern, Woodwardia, differs from Asplenium in having the sori arranged in chain-like rows

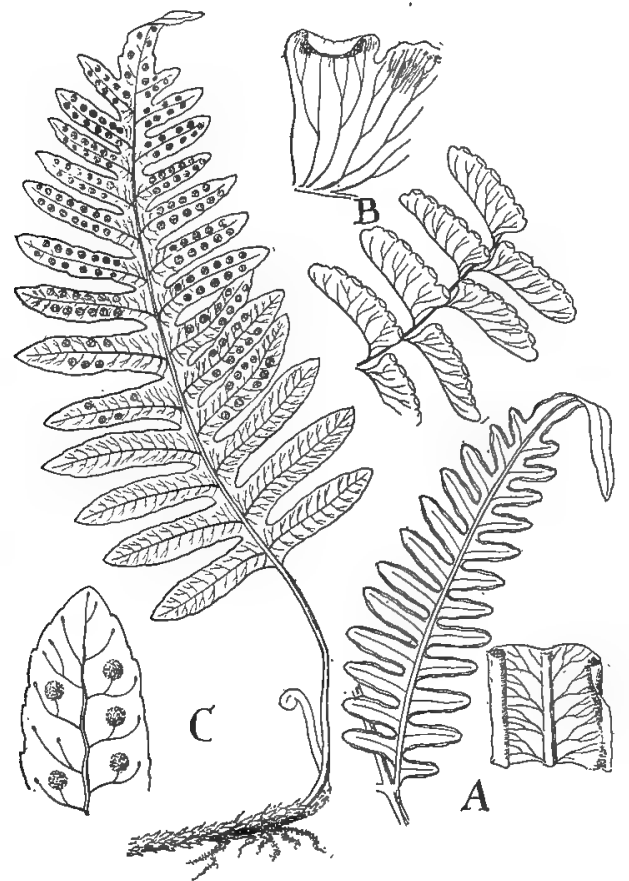

FIG. 226. Ferns without indusia or possessing false ones: $A$, leaflet of bracken fern, Pteridium. B, maiden-hair fern, Adiantum. C, polypod fern, Polypodium.-After Sprague.

parallel to its midrib (Fig. 225, B). In several genera of ferns the indusium is partly or entirely inferior. Thus in the bladder fern, Filix, the partly inferior indusium covers the circular sorus like a hood (Fig. 225, D), while it is wholly inferior in the hayscented fern, Dennstaedtia, forming a cup (Fig. 225, E) and in Woodsia the indusium is roundish or star-like (Fig. 225, F). 
Several ferns are distinguished by false indusia that are formed by the more or less modified margins of the leaf. In the bracken, Pteridium, the entire membranous margin of the leaf curves over the closely crowded sori (Fig. 226, $A$ ), and in the maiden-hair fern, Adiantum, the sporangia are at the ends of the veins and covered by reflexed portions of the leaf (Fig. 226, $B$ ). The indusia are lacking in some forms, as in the beech fern, Phegopteris, and in the polypody, Polypodium (Fig. 226, C). These genera are distinguished by the fact, among others, that the leaves of Polypodium drop off, leaving a scar as in our deciduous trees.

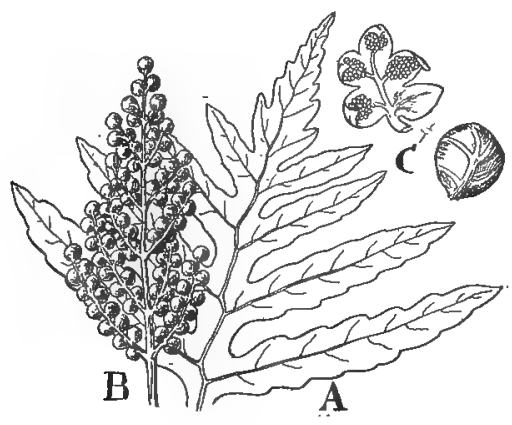

FIG. 227. The sensitive fern, Onoclea: $A$, portion of normal green leaf. $B$, a spore-bearing leaf. $C$, two views of one of the round lobes of $B$, showing the veins and the sori on inner side of the lobe.-After Bailey.

This feature is possibly due to its more or less epiphytic habit. This is the only really xerophytic fern of temperate regions. The sporophyll of the sensitive fern, Onoclea, bears a striking outward resemblance to Botrychium, but the sporangia-like bodies are really leaf lobes rolled up and each bears several round sori on its inner side (Fig. 227). In this and several other genera, see Osmunda, the work of photosynthesis is given over to large. green leaves that do not produce sporangia.

(b) The Gametophyte.-In the majority of ferns the spore germinates by rupturing the outer coats and producing a germ tube from which one or more delicate rhizoids are cut off. The germ tube elongates, forming a short chain of cells which soon develop by apical growth into a flat thalloid structure, commonly called the prothallium, that is attached to the ground by numer- 
ous rhizoids (Fig. 228). This gametophyte often becomes heartshaped (Fig. 228, C), owing to the more rapid growth of the cells that are cut off from the apical cell. In some genera branched filamentous or narrowly thalloid growths are developed that resemble the protonema of the mosses or the thallose hepat-

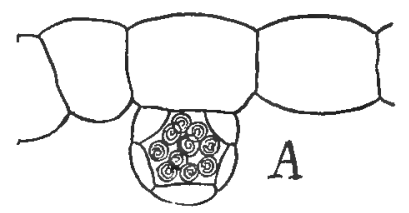

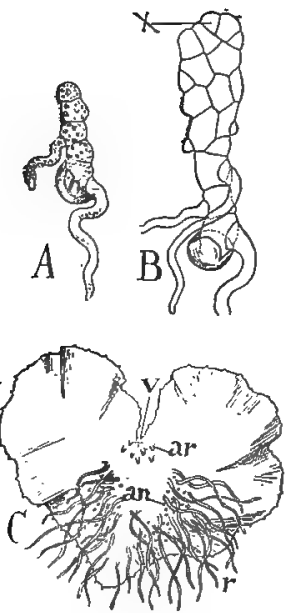

FIG. 228.
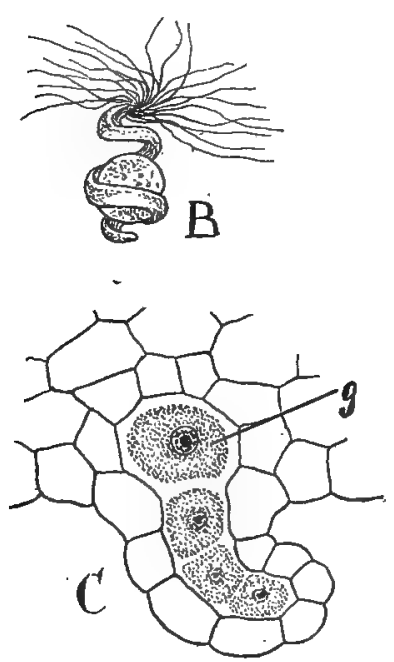

FIG. 229.

FIG. 228. Gametophyte of the Filicales: $A$, germination of the spore. $B$, early appearance of the thalloid structure of the gametophyte owing to the formation of an apical cell, $x$. C, mature gametophyte-an, antheridia; $a r$, archegonia; $r$, rhizoids; $v$, apical cell or growing point.

Fig. 229. Structure in reproductive organs: $A$, antheridium as seen in section, just before the discharge of the gametes. $B$, male gamete. $C$ section view of archegonium $-g$, female gamete.

ics. The gametophyte usually lives but a few months, although in some species they may endure for years, multiplying extensively by gemmae, and so form conspicuous mats upon the moist trunks and rocks. The archegonia and antheridia are usually borne upon the same gametophyte. Some genera, however, are 
strictly dioecious, producing small antheridial or male gametophytes and larger archegonial or female gametophytes. Small male gametophytes occur not uncommonly among any of the genera, owing doubtless to their poorer nourishment. The sexual organs are developed upon the under side of the gametophyte (Fig. 228, C), probably because this position is of advantage in keeping them in contact with any water that may fall upon the earth and thus preventing their drying out. The antheridia develop before the archegonia, often appearing while the gametophyte is quite small. They usually project from the surface of the thallus as spherical bodies covered with a single layer of chlorophyll-bearing cells which inclose usually from thirty-two to sixty-four gamete-bearing cells (Fig. 229, $A$ ). The male gametes are discharged as in the Bryophyta - the swelling of the antheridium causes the rupture or throwing off of the apical cell and the extrusion of the inner cells as a mucilaginous mass. The gametes are large spirally-coiled bodies provided with numerous cilia and the larger posterior coils enclose a delicate sac containing the remains of the nourishment stored in the mother cell (Fig. $229, B)$. The archegonia are developed on the older prothallia, usually just back of the growing point (Fig. 228, C). The neck of the archegonia, consisting of four rows of cells, projects from the under surface of the prothallium and is usually curved back from the growing point, while the basal portion containing the female gamete remains buried in the tissues of the prothallium (Fig. 229, C). When the female gamete is mature the canal cells become mucilaginous and the lip cells open as in the archegonium in the mosses.

(c) Germination of the Gametospore.-The gametospore germinates in a week or more after fertilization, usually dividing very regularly first by a vertical and later by a transverse division into four cells. Each of these cells forms a primary organ of the young sporophyte. Of the two outer cells, the one near to the growing point of the prothallium (Fig. 230, $A, c$ ) by repeated divisions produces the first leaf or cotyledon, while the other one forms the first root (Fig. 230, $A, r$ ). Of the two lower cells, the one directly below the leaf cell gives rise to the stem (Fig. 230, $A, s$ ) 
and the other one to the foot (Fig. 230, $A, f$ ). The growth of these four cells results at first in the formation of a rather globular sporophyte, but soon the growing point of the young
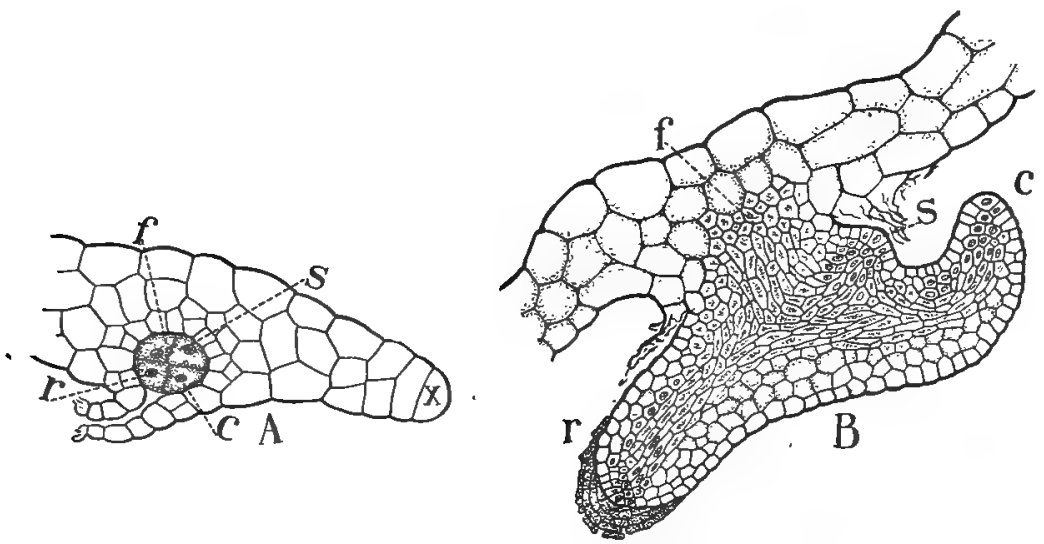

FIG. 230. Germination of the gametospore: $A$, section of archegonium, after fertilization, showing the four-celled stage of the germinating gametospore. The cell $r$ by repeated division forms the first root, $c$ forms the first leaf, $s$ forms the stem and $f$ the foot; $x$, apical cell of prothallium. $B$, later stage. The young sporophyte rupturing the archegonium or calyptra, lettering as in $A$.

root grows through the calyptra, turns downward and penetrates the soil (Fig. 230, B). This is followed by emergence

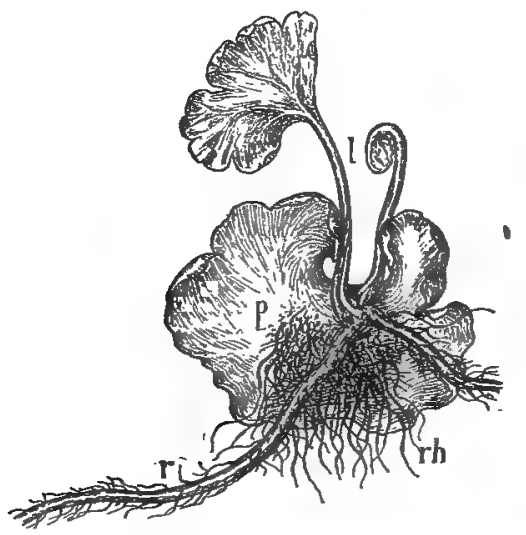

FIG. 231. Older sporophyte that has developed two roots, $r$, and is unfolding the second leaf, $l$, but still attached to the withering gametophyte or prothallium, $p ;$ th, rhizoids. 
of the cotyledon, which, however, curves upward and spreads out its blade to the light (Fig. 23I). Note in Fig. 230 that the necessities of the plant have determined the position of these four organs. The foot is formed in contact with the bulk of the food in the prothallium, the root next the ground which it reaches at once, the leaf easily reaches the light since the root has already ruptured the calyptra, and since the leaf is near the margin of the prothallium, and finally the stem is in a position of advantage (Fig. 230, B) for growing straight up or horizontally. The young sporophyte, which has up to this time drawn its nourishment by means of the foot from the gametophyte, is now in a position to care for itself. The prothallium soon withers, leaving the sporophyte an independent and self-supporting plant. The first leaf is small and usually bears little resemblance to those of the mature plant, but as the stem elongates, new leaves are formed which gradually become larger and each succeeding one resembles more closely the adult form. The foot disappears with the withering of the gametophyte, and this is soon the fate of the primary root, but numerous secondary roots are formed along the stems as it continues to creep along on or near the surface of the soil; This growth goes on from two to several years before the plant is prepared to develop sporangia upon the leaves, page 282 .

\section{Order 3. Equisetales. The Horsetails}

Ir4. General Characters.-This small group of Pteridophyta, comprising but a single genus of about twenty-five species, is but a remnant of an extensive group of plants that flourished in the coal period and that formed conspicuous features of the vegetation at that time. The structure of these earlier forms has been so perfectly preserver in fossil remains that they give a better idea of the relationship of the group than could be obtained from the living plants. Forms allied to Equisetum doubtless formed during the coal period of the earth large forests and attained a height of sixty to ninety feet and perhaps three feet in diameter. The species that survive to-day are rush-like plants that rarely exceed a foot in height, though a single tropical form supports its delicate stem upon other vegetation and so attains a length 
of over thirty-five feet. Species of Equisetum are of common occurrence in nearly all countries, living in shallow ponds, swamps, and marshes or drier soils.

At first sight they show little suggestion of fern relationship (Fig. 232) and impress one as being singularly out of harmony

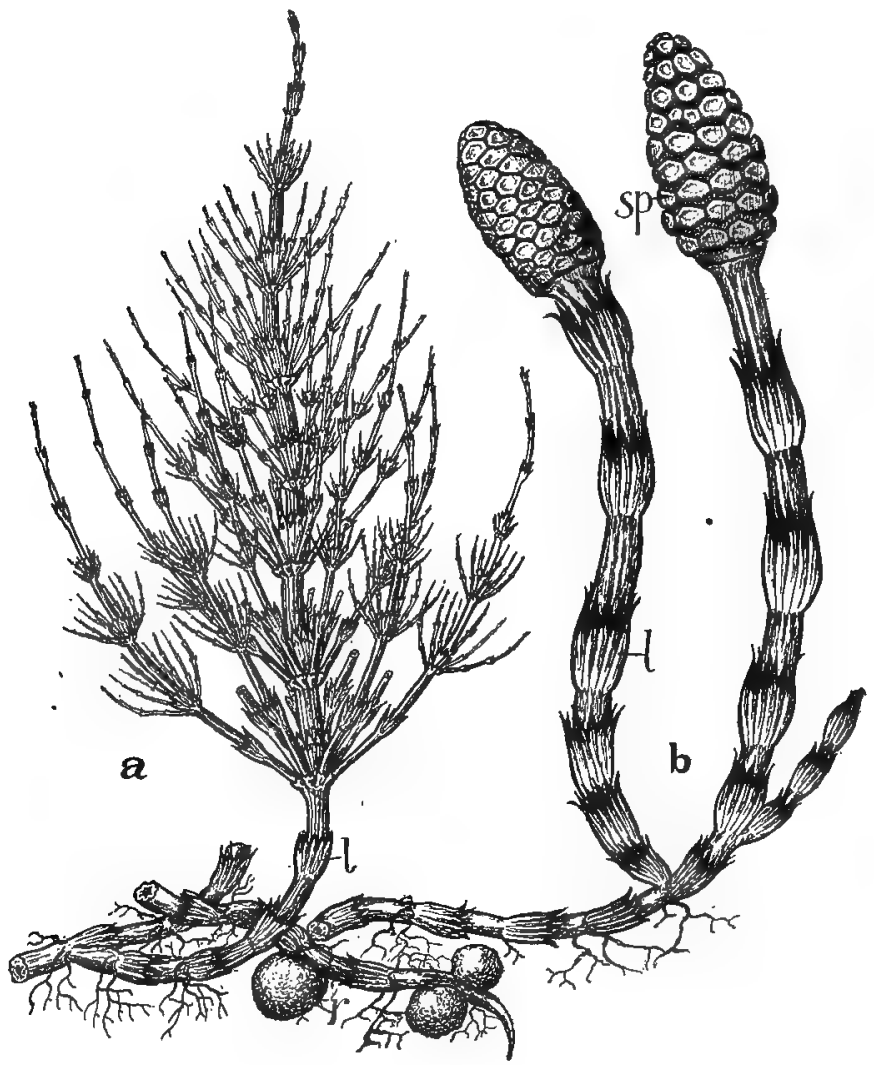

FrG. 232. A common horsetail, Equisetum arvense: $a$, the green branching plant that lives through the summer- $l$, scale leaves; $r$, rhizome or underground stem with tuberous storage organs. $b$, early spring shoot that bears a spike or strobilus of modified spore-bearing leaves, $s p$. This stem is of a light brown color and withers after the spores are shed.- $\mathrm{H}$. O. Hanson.

with our common plants, as though they were indeed relics of a past age. The large leaves, which were so characteristic of the Filicales, are reduced to minute papery scales in this 
and take little or no part in photosynthesis. These scale leaves are arranged with great regularity at the nodes of the stem, and owing to their close association they grow together, forming a papery sheath with teeth-like points about the stem (Fig. 232,l). It is noteworthy that in allied fossil forms large chlorophyllbearing leaves occurred.

The stems are of two kinds, subterranean rhizomes that branch

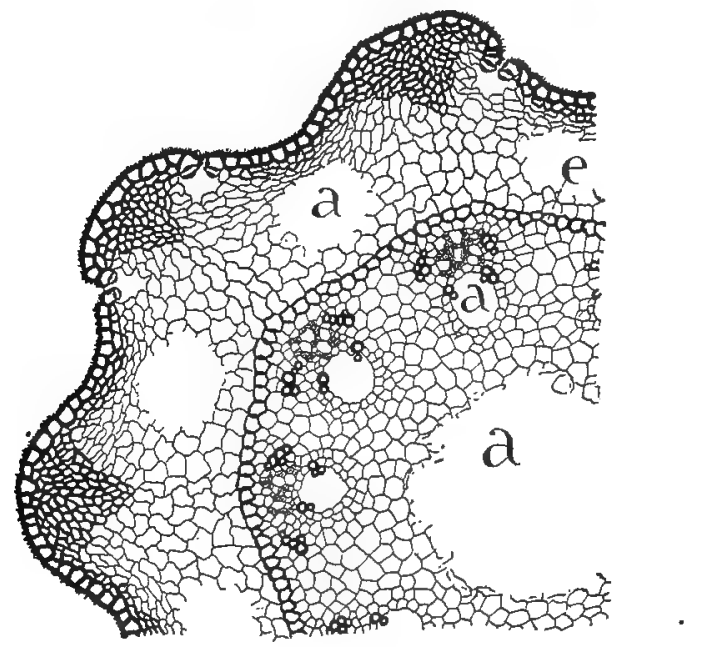

Fig. 233. Cross-section of a portion of the stem showing its grooved character and stereome confined to the ridges: $a$, air spaces; $\ell$, endodermis, inside of which are shown three bundles.

extensively through the soil, and aerial stems that arise as branches from the rhizomes. The aerial stem is simple or branched and is characterized by nodes made conspicuous by the sheathing teeth-like leaves and strongly furrowed internodes. In such species as branch, these organs originate with great regularity in the axils of the leaves and perforating the sheathing leaves produce a bushy symmetry that caused the name of Equisetum or horsetail to be applied to these plants. The epidermal cells are hard and rough, owing to the abundant deposit of silica in the cell walls. For this reason certain species were used in early times for scouring purposes and so they became popularly known as scouring rushes. Complete silicious casts of the epidermal 
walls and stomata can be obtained by treating the tissue as noted in the diatoms. The arrangement of the leaves and branches and the distribution of the vascular bundles and other tissues presents a mathematical regularity unexcelled in any plant. As in the Bryophyta, the elongation of the stem is effected by a single apical cell which cuts off with extreme regularity the cells from which the various tissues and organs of the plant are formed. The very rudimentary vascular bundles are arranged around a large pith (Fig. 233). They rarely show secondary growth through the activities of a cambium, although this was a marked feature of many of the extinct species. These bundles lie directly below each ridge of the stem and run downward through the internode to the next lower node, where they divide in to two equal parts. One of these branches joins a similar branch from the adjacent bundle and continues straight down to the next node, where the branching is repeated. The rudimentary bundles of the leaves also join on to the bundles of the stem at the node. Owing to this regularity of branching, the leaves and vascular bundles alternate in each succeeding node and the vascular system assumes a cylindrical form composed of oblong six-sided figures. Thick-walled stereome cells are developed in the ridges and constitute the principal mechanical tissue of the stem, while the stomata and the chlorophyll apparatus are largely confined to the grooves. The stems are very light, owing to absorption of the larger part of the pith and certain regions of the cortex (Fig. $233, a)$.

(a) The Spore-bearing Leaves or Sporophylls.-The sporangia are formed only upon special organs, probably leaves or sporophylls, that are arranged in a compact cone or strobilus (plu. strobili) at the end of the stem (Fig. 232, sp). In some species the strobilus is borne upon a special branch that does not contain chlorophyll, though variously colored, and that withers away as soon as the spores are shed (Fig. 232, b). In other cases the strobilus appears at the tip of the ordinary green shoot. This variation is doubtless associated with the season of the year at which the strobili appear. The species characterized by the special branches produce these early in the spring when the temperatures 
are not favorable for the work of the green shoots. Note in this connection the significance of the coloration. Species with the strobili upon the ordinary plants form these structures later in the season when the temperatures are favorable for photosynthesis. The development of the sporangia upon specialized sporophylls that are grouped together at definite points on the plant is one of the significant departures that appears in the evolution of the plant. This distribution of labor that is seen in the setting aside of certain groups of leaves for spore production will appear.in all the succeeding groups; and the arrangement and structure of the sporophylls will steadily become more and more complex until a point is reached where they are popularly called a flower, although this term can be just as correctly applied to the strobilus appearing in Equisetum and succeeding groups. The sporophylls of Equisetum originate at the nodes, as in the case of the scale leaves, but as they enlarge the apical portion spreads out like a shield. The internodes do not elongate and separate the sporophylls to any considerable extent, consequently the shields become six-sided through contact with the adjacent sporophylls.

(b) Character of Sporangia and Spores.-The sporangia appear as rather elongated sacs on the under side of the shields (Fig. 234,2 ) and at maturity open by a longitudinal cleft. The structure of the spores is of especial interest. The outer wall of these spores is thickened in spiral bands, and owing to the dissolution of the thin portion of the wall separating these bands, the outer coat uncoils and appears as four bands, with spoon-like ends, attached to the spore at one point (Fig. 234, 3). These bands or elaters are very hygroscopic and their movements assist in rupturing the sporangium, but their special significance is seen in the fact that the elaters become entangled and so several spores are carried away together by the wind. The meaning of this arrangement will appear directly.

(c) Germination of the Spore.-The gametophyte produced from these spores (Fig. 235) is an irregularly lobed thallus more suggestive of the irregular thallus of an hepatic or the leaves of a moss plant, or the lobed gametophyte of certain species of 
the Ophioglossales than of the prothallium of the Filicales. The most important feature about the gametophytes is the fact that they are as a rule dioecious and of two sizes, the smaller ones bearing only antheridia and the larger only archegonia. This difference in the nature of the gametophytes is largely due to nutrition as noted among the Filicales, the well-nourished ones being the female. In fact antheridia may appear upon the female gametophyte as a result of insufficient nourishment during its

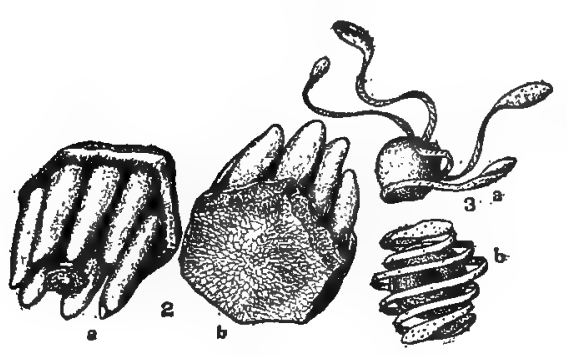

FIG. 234.

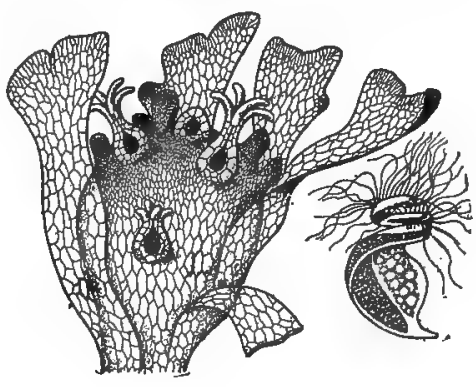

FIG. 235.

FIG. 234. Sporophylls and spores of Equisetum: 2, sporophylls viewed from outer and inner side, showing form and attachment of sporangia and the central stalk attaching the sporophyll to the strobilus. 3, spores with elaters expanded in $a$ and partially coiled in $b$.

FIG. 235. Female gametophyte of Equisetum bearing several archegonia and leaf-like lobes. At right male gamete--After Sadebeck.

later development. Thus we see that the germination of these spores, which are apparently exactly alike, is controlled by a definite stimulus, just as was the case in the formation of zoöspores and gametes among the lower green algae (page 185). It is noteworthy that some of the extinct species of this group actually stored more food in certain spores than in others, so that they came to differ somewhat in size. This habit is well established in some of the living Filicales and will also be noted in the next order. As a consequence of this tendency, the nature of the gametophyte developed from the spore is no longer a matter of chance. The larger spores, called megaspores, by reason of the more abundant food produce female gametophytes, while the smaller spores, microspores, form small gametophytes bearing only antheridia. The significance of this tendency to produce 
megaspores and microspores will be seen in the disussion of the fourth order, but attention is called to it here because the Equisetales show very clearly how such a condition came about. It would appear probable that the spores of Equisetum, although exactly alike as far as we can see, must have already undergone some physiological change which predisposes them to develop either male or female gametophytes. If this is not the case it would be difficult to explain the common occurrence of dioecious gametophytes in Equisetum and the rarity of such an occurrence among the Filicales. It would appear reasonable to suppose that the living substance in the spore of the Filicales is not so highly organized and therefore not so readily influenced by external con- ditions, while the composition of the spore of Equisetum is of such a nature that the amount of food placed at its disposal profoundly affects its germination and development. Perhaps this physiological differentiation of the spores led to their appropriating different amounts of food during their formation in the sporangium, and so they finally came to be distinguished as large and small spores, as noted above. The antheridia and archegonia present essentially the same features as were noted in the Filicales, and fertilization is effected in the same manner.

(d) The Germination of the Gametospore.-The most noteworthy departure in the germination of the gametospore is seen in the limited growth of the stem. The early stages are similar to those of the Filicales, but after the stem has formed a few nodes with three leaves each, it is replaced by a stem that develops at its base. This second stem attains a somewhat larger size, but is finally replaced in the same manner by a third shoot. In this way several stems are formed until finally one is developed that penetrates the ground and forms the characteristic rhizome of the mature sporophyte. These plants with their scale leaves reduced to protective organs, sunken stomata and chlorenchyma confined to the grooves of the internodes, present an extreme form of xerophytic structure and form a sharp contrast with the large and usually thin-leaved Filicales. While they occur in dry localities, to which conditions their structures admirably adapt them, they are of more common occurrence in moist and wet 
places. This peculiar distribution of the species of Equisetum has not been explained. It is evident that these plants, like the rushes and sedges of our marshes and shallow ponds, are often exposed to intense heat and light, which would cause an excessive transpiration. Possibly these plants are not able to absorb water rapidly owing to the limited amount of conducting tissues and to the exclusion of the atmosphere by the water which surrounds the roots (see pages 45,54 ), consequently they are at the same disadvantage and require the same protective devices as plants living in arid localities.

\section{Order 4. Lycopodiales. The Club Mosses}

I15. General Characters.-The members of this group are popularly known as the club mosses owing to their small mosslike leaves and the arrangement of the spore-bearing leaves into

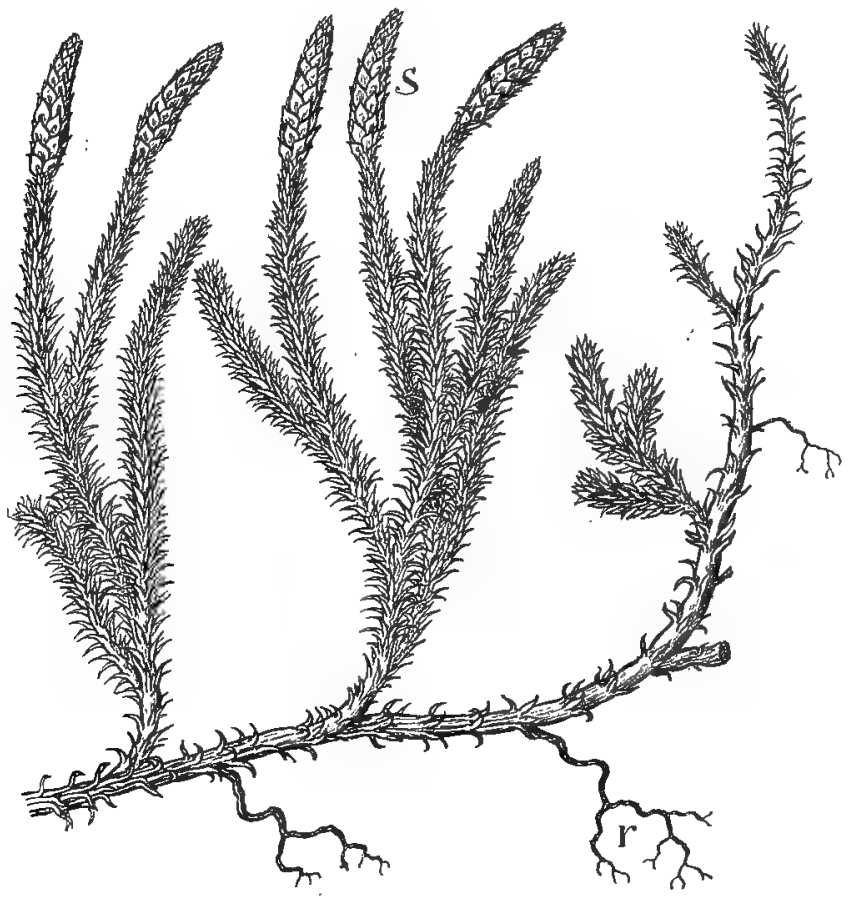

FIG. 236. A common club moss, Lycopodium annotinum, with creeping stem and erect branches covered with small moss-like leaves: $s$, strobilus $r$, roots.-H. O. Hanson. 
club-like strobili or cones (Fig. 236). The gametophyte or sexual generation is also suggestive of the mosses. Particularly is this true of the male gamete, which is small and not spirally coiled and it is apparently biciliate (Fig. 240).

The Lycopodiales are largely tropical, though a small number of forms are of common occurrence in temperate regions. The stems are erect or creeping and rather small, but owing to their prolonged growth and extensive branching they often form con-

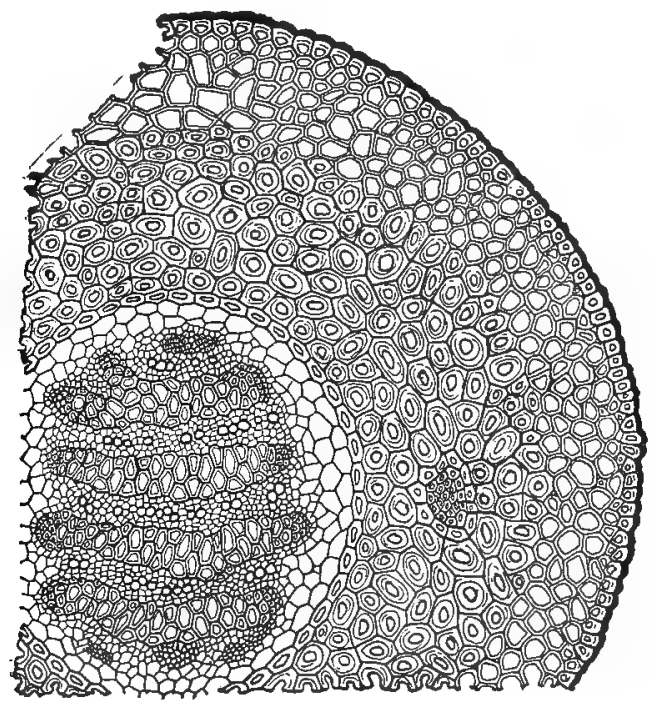

FIG. 237. Cross-section of a portion of the stem of Lycopodium, showing the centrally arranged vascular bundles.

spicuous and attractive colonies. The tissues of the stem do not materially differ from those of the common fern, though the vascular bundles from the leaves generally unite in the stem to form a central core of xylem surrounded by phloem. This solid core of xylem may be broken up in various ways by the development in it of masses of pith-like cells. Sometimes these pith cells form plates alternating with the xylem (Fig. 237). The work performed by the leaves, as in the Equisetales, is usually of two kinds, namely, photosynthesis by the green foliage leaves and spore production by the leaves that usually form 
strobili at the tips of certain branches. But a single sporangium is associated with each of these sporophylls (Fig. 239).

The club mosses are a very much larger group than the Equisetales, but like the latter group, they are a remnant of a highly developed and widely distributed race. Fossil remains indicate that the ancient allies of these plants were conspicuous features of an earlier vegetation, with palm-like trunks Ioo feet in height and three feet in diameter, and bearing a crown of long narrow leaves that attained a length of three feet. They reached their

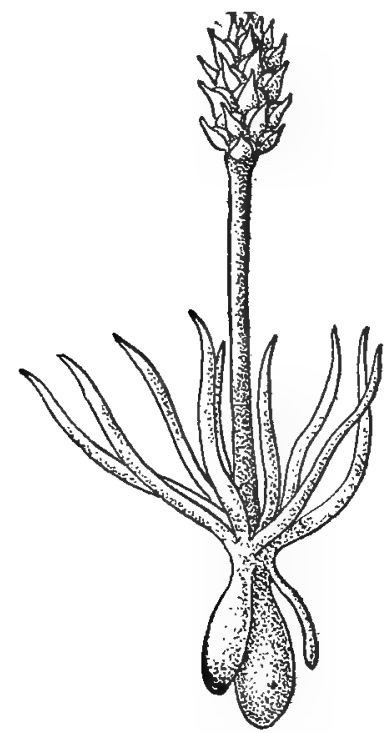

FIG. 238.

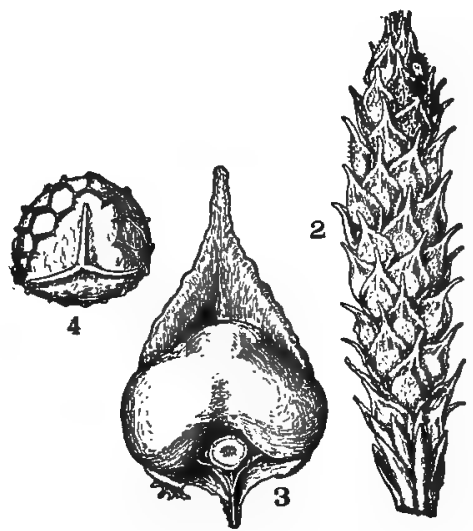

FIG. 239.

FIG. 238. Phylloglossum Drummondi.-After Pritzel.

FIg. 239. Strobilus and sporophylls of Lycopodium: 2, strobilus. 3, a leaf or sporophyll from the strobilus enlarged and showing attached sporangium. 4, a spore greatly magnified.

greatest abundance in the coal age and thence gradually declined, being crowded out by the more specialized seed plants. There are two important families of the Lycopodiales: I, Lycopodiaceae; 2, Selaginellaceae.

II6. Family 1. Lycopodiaceae.-With but one exception the members of this family belong to the genus Lycopodium, commonly known as the club moss, ground or running pine, ground 
fir or hemlock (Fig. 236). These plants are very well represented in our open woods, where they often form conspicuous colonies owing to the extensive branching and prolonged growth of the stems which creep over or through the ground, sending up numerous, erect branches and giving off roots that branch with great regularity. Various species of Lycopodium are extensively gathered for decorations since the aerial portions of the stems are thickly clothed with small moss-like leaves. The second genus of the family (Phylloglossum) contains but one species, which is found in New Zealand and Australia. It is of interest because it is the most simple fern known (Fig. 238), consisting of a few narrow leaves, rudimentary strobilus and poorly developed tissues. The simple strobilus of this plant is suggestive of the sporophyte of Anthoceros and it also recalls the spore-bearing spike of Ophioglossum. If the sterile cells separating the spore-forming cells in Anthoceros had increased in number so as to project somewhat and thus form rudimentary leaf-like outgrowths, then it would have resembled the strobilus of $P h y l$ loglossum. To be sure the sporangia of the latter plant are borne upon the leaves but in the next family they arise from the stem as in Anthoceros. Ophioglossum shows the increase of the sterile cells between the spore-bearing cells but this did not result in leaf development; so it occupies an intermediate position in this trend of development. It is certainly a striking fact that these three groups, though widely separated, exhibit the same type of development.

The sporangia of the Lycopodiaceae are large considering the size of the leaf, and usually appear on specialized leaves that are arranged in strobili on the ends of erect branches (Fig. 239). The sporangia open by a longitudinal cleft and the spores are produced in such quantities in some of the forms that they are of commercial importance, being used for flashlight effects and sold as lycopodium powder.

(a) The Gametophyte of the Lycopodiaceae.-The most interesting feature about the club mosses is the sexual generation, because it indicates that these forms may have been derived from the same ancestry as the mosses or at least from a very primitive 
stock. In certain species the spores produce a rather cylindrical erect gametophyte which terminates in a number of radiallyarranged green leaf-like lobes, among which the archegonia and antheridia are produced (Fig. 240). This structure has been compared to a miniature leafy moss plant. This suggestion of relationship is strengthened by the resemblance of the male gametes to those of the mosses, the sperms, so far as they have been observed, being small, almost straight bodies, and provided with two cilia (Fig. 240). The archegonia may also be more primitive than those of the ferns in possessing several neck canal

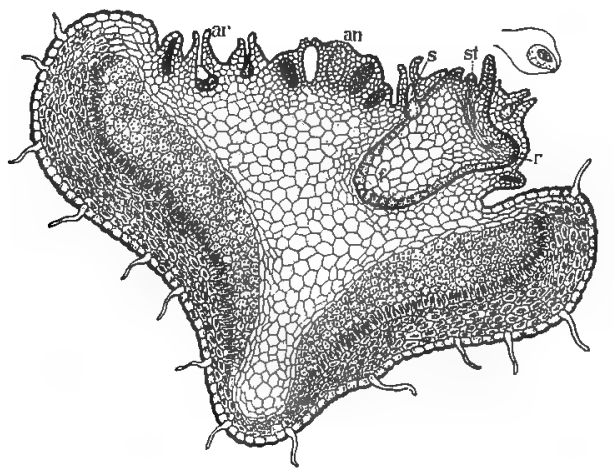

FIG. 240. Gametophyte of Lycopodium as seen in section: an, antheridia; $a r$, archegonia. The young sporophyte or embryo developed in one of the archegonia consists of a foot, $f$; a root, $r$; and a stem, st, bearing a leaf on either side; $s$, the suspensor, which has pushed the sporophyte early in its development into the tissues of the gametophyte. Above a single male gamete is figured.-After Bruchmann.

cells and five instead of four rows of neck cells. The gametophyte appears in all species examined to be associated with symbiotic fungi, as in Ophioglossales. The spores will not develop unless they come in contact with a suitable fungus and this has led in many forms to a subterranean and chlorophylless development of the gametophyte.

(b) The Germination of the Gametospore.-The germination of the gametospore is characterized by new departures that will continue on through the seed plants. The gametospore enlarges and divides into two cells by a transverse wall. The outer of 
the two daughter cells takes no part in the formation of the sporophyte, though elongating and often dividing several times. These cells are termed the suspensor (Fig. 240, $s$ ) and function in pushing the lower daughter cell down into the nourishing tissue of the gametophyte. The lower daughter cell, by a series of divisions that at first resemble the common ferns, forms the young sporophyte. This consists of a stem with one or two cotyledons, a massive foot and finally, at a late period in the development in the sporophyte, of a root (Fig. 240). The tardy development of the root has been cited as an indication of the origin of the lycopods from very primitive ancestors, in which the formation of the root had not become established. It may also be due to the abundant food stored in the gametophyte and hence the development of the root might well be delayed until this store is in part exhausted. The growth of the sporophyte is very slow and it remains as a parasite upon the gametophyte for a long time, even for years in some of the subterranean forms (see Ophioglossales). The elongation of the stem and root is effected by the division of several cells rather than by one apical cell, as in previous cases, a feature to be noted in the seed plants.

II7. Family 2. Selaginellaceae.-This family includes but a single genus, Selaginella, of over 600 species. - Only a few forms occur in the temperate regions, the majority being confined to tropical countries, where they often form one of the most attractive features of the forest vegetation owing to the symmetry of their branching and the rare delicacy of their foliage (Fig. 24I). For these reasons they are extensively cultivated and familiar objects in conservatories and florists' shops. The so-called resurrection plant, Selaginella lepidophylla, lives in the very arid sections of the southwestern United States, and during drought reduces its surface to a nest-like ball by rolling up its branches into tight coils. In this condition it appears as a brownish dead mass. When moistened, the absorption of water causes the branches to quickly uncoil and also renders the tissues translucent, so that the green color of the chloroplasts can be seen. These reactions occur even in the dead plants and so create the impression that they have returned to life. Many of the species 
of Selaginella have a creeping habit like that of Lycopodium, and the aerial stems are covered with leaves arranged in several rows, very frequently in four rows of two large and two smaller leaves (Fig. 24I, I $A$ ). Usually but a single chloroplast appears in each cell, as already noticed in several algae and in the Antho-

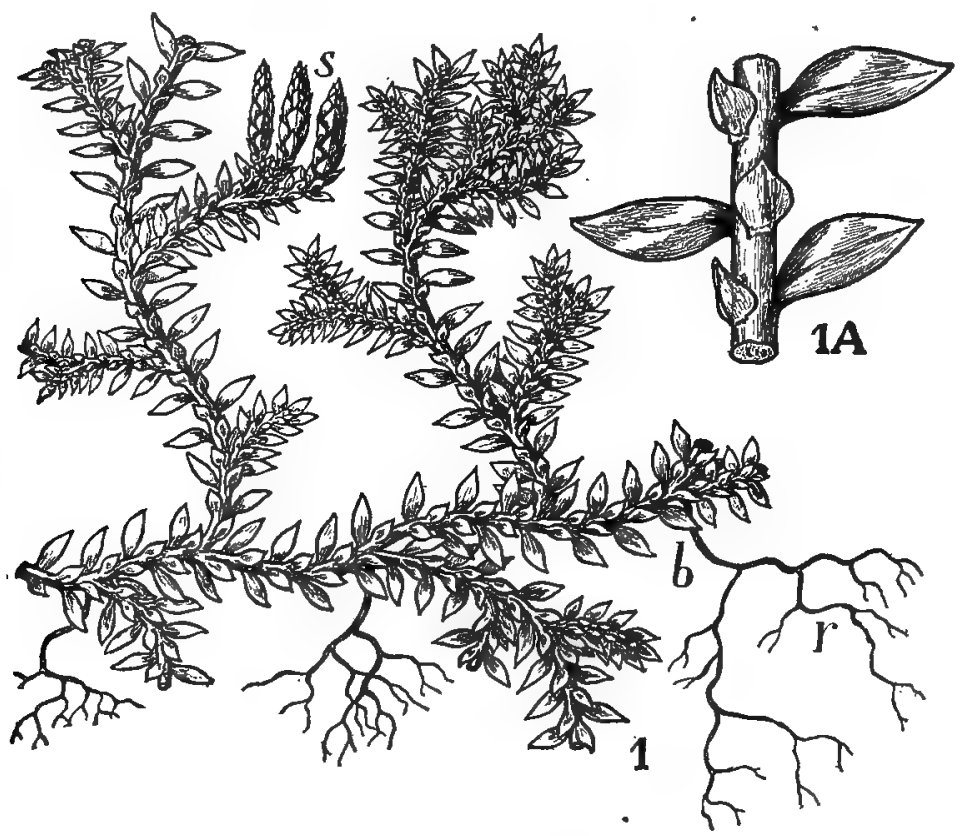

FIG. 24I. A common cultivated Selaginella: I, habit of the plant $-s$, strobili; $b$, a branch bearing roots, $r$. I $A$, portion of stem, showing leaf arrangement.-H. O. Hanson.

cerotales. The roots are frequently developed from the end of naked branches that extend from the stems to the ground (Fig. 24I, $r$ ).

(a) Sporangia and Spores.-The sporangia are borne on the stems in the axils of the leaves which form a strobilus, as in Lycopodium. However, they differ radically from those of the Lycopodium, in that two kinds of spores are formed, small spores or microspores and larger ones or megaspores. The formation of two kinds of spores, or heterospory, is not confined to the Lycopodiales. It occurs among certain genera of the Filicales 
and, as has been stated, characterizes some of the fossil Equisetales. The megaspores are generally formed at the base of the strobilus and the microspores occupy the upper sporangia (Fig. 242). The sporangia are called microsporangia and megasporangia accordingly as they contain small or large spores and for the same reason the leaves may be designated as micro- and

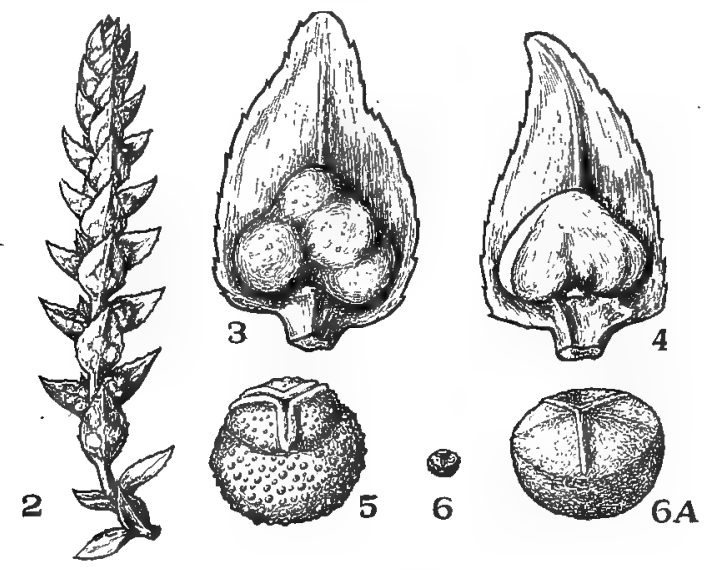

FIG. 242. Sporophylls and spores of Selaginella: 2, strobilus with lower sporophylls separated for spore dissemination. 3, megasporophyll with sporangium containing four megaspores. 4, microsporophyll. 5, megaspore enlarged. 6 , microspore equally magnified. $6 A$, more enlarged view of the microspore. The triangular surfaces of the spores show that these spores have been formed in tetrads from a spore mother cell as in previous groups.

mega-sporophylls. The two kinds of spores originate in the same manner as previously noted and the difference in size is due to the amount of food which they receive. In the case of the microspores, the numerous mother cells of the sporangia form four spores each in the usual manner: but in the megasporangia only one of the mother cells divides in this manner, and in some cases only one spore is formed. The other mother cells do not develop and are ultimately consumed in nourishing the megaspores. As a result of the large amount of food transferred to the megasporangium, both it and especially the one to four spores become much larger than the others (Fig. 242, 3-6). The physiological differentiation of the spores noted in Equisetum 
has here gone a step further. They are so constituted that they now appropriate all the food in their respective sporangia.

(b) The Germination of the Spores.-The most important and suggestive feature in the life history of Selaginella appears in the germination of the spores. The spores germinate in the sporangia and not after being shed, as in the other orders. This growth is somewhat different from previous cases in that at first there is no outgrowth of the spore but simply the formation of a varying number of nuclei within the spore. Later these nuclei develop cell walls and subsequent growth ruptures the spore. In this way the microspore forms two cells while in the sporangia, a small one often compared to a remnant of the male gametophyte or prothallium and a large cell which ultimately forms a single antheridium. At about this stage of germination the microsporangium opens by a vertical cleft, permitting the scattering of the spores. The larger cell of the microspores now forms a central mass of gamete mother cells which are surrounded by a single layer of wall cells (Fig. 243, I). The male gametes are of the same character as noted in Lycopodium and are set free by the disintegration of the wall cells. The megaspores begin to germinate even before they have reached their full size. The nucleus of a megaspore divides repeatedly, forming numerous nuclei which become arranged about the walls of the young spore. Subsequently walls are formed about the nuclei at the apex of the spore (Fig. 243,2) and by further division a mass of cells results, in the outer part of which the first divisions of the archegonia arise. At this stage of development, or earlier, the megasporangium opens by a vertical cleft permitting the discharge of the spores. It must be borne in mind that this origin of the gametophyte is of a radically different nature from any case previously noted. Heretofore the gametophyte always had an independent existence and the sporophyte for varying periods of time was a parasite upon it. In Selaginella you note the beginning of a reversal of this relation, for the sporangia remain green and continue to nourish the spores during their germination; in other words, during the early stages in the development of the gametophyte. We see that the gametophyte is becoming para- 
sitic upon the sporophyte (see page 28I). After the spores are shed they complete the growth of the gametophyte by forming the archegonia and filling the space within the spores with a solid mass of cells. This growth ruptures the spore walls at the apical regions, thus exposing the archegonia to the male gametes (Fig. $243,3)$. The archegonia are rudimentary structures consisting

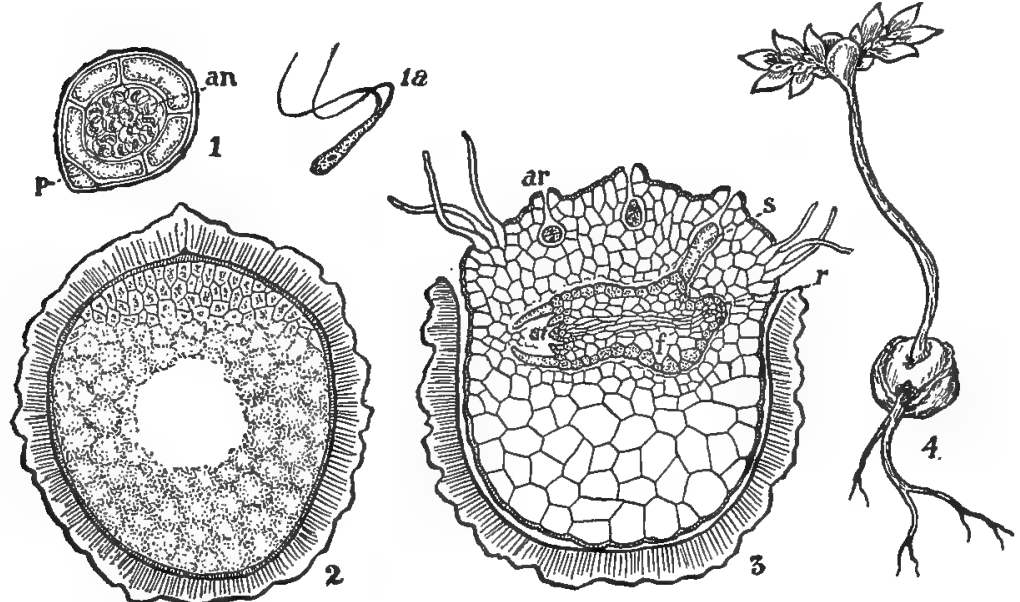

FIG. 243. Gametophyte and young sporophyte of Selaginella: I, section of a microspore that has nearly completed its germination- $p$, a single cell that is possibly a remnant of the large gametophyte or prothallium of previous groups of ferns; an, antheridium consisting of a layer of wall cells which enclose the gamete mother cells. $I A$, a male gamete. 2 , section of a megaspore, showing the stage of germination that is usually attained in the sporangium. 3, mature female gametophyte that has ruptured the wall of the megaspore, thus exposing the archegonia, ar, one of which has developed a young sporophyte or embryo with root, $r$; stem bearing two leaves, st, foot, $f$, and the suspensor, s. 4, young sporophyte with root, stem and leaves emerging from the gametophyte.

of but two neck cells, and a single canal cell leads to the female gamete.

It is evident that these variations are of great advantage in ensuring the perpetuation of the species. Especially is the nourishment of the young gametophyte by the highly organized sporophyte a distinct gain. In previous types the formation of the gametophyte was dependent upon favorable conditions, such as moisture, light, temperature, etc., and it should be said that 
only in rare cases do the spores fall in such favorable situations and meet with such suitable conditions as to enable them to mature archegonia and antheridia, and so provide for a new sporophyte. In Selaginella the formation of the gametophyte is ensured by the food supplied to it by the sporophyte. Thus the germination of the spore is practically independent of its surroundings and it can complete its growth under a variety of conditions, even in the dark. It should also be noted that this relationship of the two generations results in a marked reduction in the size of both the male and female gametophyte, since they are no longer burdened with the work of food construction. This reduction will proceed very rapidly as we advance through the remaining groups.

(c) Germination of the Gametospore.-The germination of the gametospore is very much like that of Lycopodium. The suspensor is much longer and the young sporophyte consists of a stem bearing two cotyledons, a well-developed foot and a root that is developed after the other organs (Fig. 243, 3). The foot continues to absorb food from the gametophyte after the stem and root have emerged, and in this condition the relation of the sporophyte to the gametophyte is strikingly. suggestive of a sprouting seed (Fig. 243, 4). In this connection it should be remembered that the young sporophyte of certain species remains in the gametophyte during the winter or during a drought in a resting or dormant condition, thus resembling very closely the seed structure to be seen in the next group. It may also be stated that fertilization and even the formation of the young sporophyte may begin before the spores are discharged from the sporangium, thus helping us to understand how it came about that the megaspores were permanently retained in the sporangium as is the case among seed plants. In one of the large groups of Pteridophyta that have become extinct, it is noteworthy that both the gametophyte and young sporophyte were retained in the sporangium so that the seed-like structures were formed. 


\section{CHAPTER IX}

\section{DIVISION IV. SPERMATOPHYTA OR SEED PLANTS}

I18. General Characters.-This is the largest group of the vegetable kingdom and includes all our common trees, shrubs and herbs. The relationship of these plants is very imperfectly understood and the various classes, orders, etc., into which they are divided are in part artificial and do not therefore represent completely the alliances of the groups. You have noticed that the porophyte is the most important feature in the life history of the fern and that the gametophyte, subordinate from the start, becomes very inconspicuous in some of the forms. This inequality of the two generations is more noticeable in the seed plants where a progressive series of variations result in a more and more complex external and internal differentiation of the various organs of the sporophyte and in a steady reduction of the gametophyte. Heterospory that appeared in several groups of the Pteridophyta, becomes a constant characteristic of the seed plants. The spores originate much as in the preceding group but the megaspore is nourished and permanently retained in the sporangium where it not only forms the female gametophyte (see Selaginella) but also develops the young sporophyte. At this point, the most characteristic feature of the Spermatophyta is seen. The young sporophyte or embryo usually ceases to grow while still in the gametophyte and passes into a resting or dormant condition and the sporangium which has become variously modified for the purpose of protecting the embryo is discharged from the sporophyte. This sporangium containing the embryo is called the seed. Contrast with these features two important differences that appeared in Selaginella. First: The spores of these ferns are retained and nourished in the sporangia only during the early development of the gametophytes. Second: The young sporophyte of Selaginella-it may also be called the embryo-does not normally pass into a resting state, but steadily grows on 
into the mature sporophyte. The seed plants are divided into two subdivisions based upon the relation of the megasporangia to the sporophylls: I. Gymnospermae, with sporangia, hence with the seed, on the surface of the sporophyll. 2. Angiospermae, with sporangia, hence with the seed, enclosed by the sporophyll. It should be stated that this association of these two subdivisions is artificial, the Gymnosperms being more nearly related to the Pteridophyta than to the Angiosperms.

\section{Subdivision I. Gymnospermae. Plants with Naked Seeds}

II9. Origin of the Gymnospermae.-This group is principally represented to-day by the cone-bearing trees. In very ancient geological times, several groups of primitive gymnosperms, now extinct, flourished and formed an extensive and varied forest vegetation. Fossil remains of these various groups have been wonderfully well preserved and show that they were undoubtedly related to the Pteridophyta. The modern group of gymnosperms has been derived from these ancient lines and but a remnant has survived the changes occurring upon the earth and the competition with the more highly specialized Angiospermae. A few genera, however, are well represented to-day and they are of great commercial importance as lumber. The sporophylls of the gymnosperms are arranged in a strobilus as in the Equisetales and Lycopodiales, but the microspores and megaspores are not associated, being developed in separate strobili. Attention will be directed to only two of the more important orders: The Cycadales or Cycads and the Pinales or cone-bearing trees.

I20. Order a. Cycadales or Cycads. - These plants are strictly tropical, though two genera are subtropical, Zamia or coontie in Florida, and Cycas, of ten called the sago palm, in China and Japan. Many of them are extensively cultivated in green-houses owing to their peculiar growth and attractive foliage (Fig. 244). The cycads include less than Ioo species of what was in geological times, a very extensive alliance. They are of special interest as showing unmistakable fern characters and because they are the most primitive of our extant seed plants. The stems of these plants are rather tuberous, though certain species are 
decidedly palm-like in appearance, with stems 12 to 60 feet high. The vascular bundles are collateral and arranged around a large pith as noted in Botrychium. A slight enlargement of the stem is brought about owing to the weak growth of the cambium of these bundles, but in some genera the principal increase is effected by the formation of new bundles outside of those first formed. Fern types of bundles also occur in the leaves, cortex and strobili of certain species. The foliage leaves are large and leathery and form a rosette, alternating with scale leaves, at the apex of the

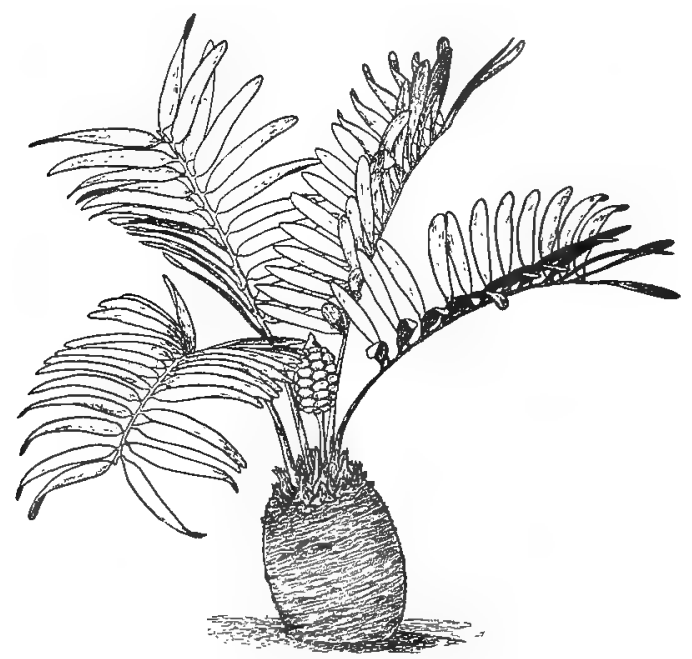

FIG. 244. Zamia, a cycad common in southern Florida, with strobilus of megasporophylls.-H. O. Hanson.

stem. The bases of these leaves form an armor-like plate over the surface of the stems. In certain genera, the young leaves are coiled as in the ferns.

(a) The Sporophylls and Sporangia of the Cycads.-The sporangia are borne on more or less modified leaves arranged in large strobili at the top of the stem, though rarely on the apex. Unlike preceding cases these strobili are of two kinds, the one bearing only megasporangia, the other microsporangia. Furthermore these two kinds of strobili are on different plants. The sporangia are either scattered over the sporophyll or arranged in 
groups suggestive of the sori of the ferns, in some forms even showing a rudimentary annulus. There is a considerable variation in the form of the sporophylls and the distribution of the sporangia. For example, in Cycas, the megasporophylls are loosely associated and only slightly modified, the sporangia being developed on their margins (Fig. 245, 3B). The microsporo-

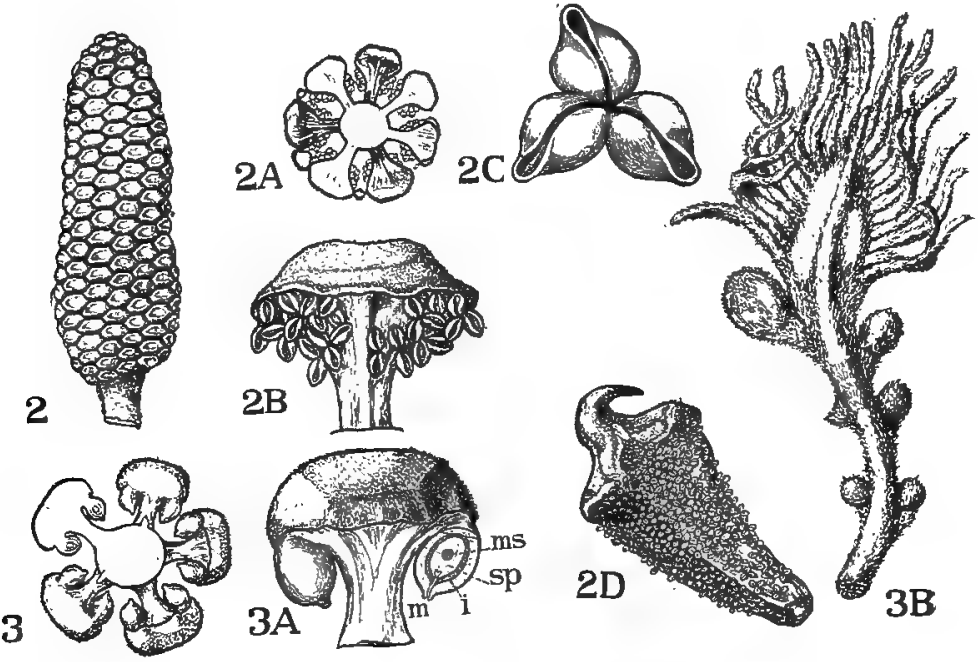

FIG. 245. Sporophylls and sporangia of the Cycads: 2, strobilus of Zamia. $2 A$, cross-section of strobilus of Zamia, showing arrangement of microsporophylls. $2 B$, microsporophyll enlarged, showing sporangia arranged in sori. $2 C$, sorus of three sporangia that have opened. $2 D$, microsporophyll of Cycas. 3, cross-section of a strobilus of Zamia, showing arrangement of megasporophylls. $3 A$, megasporophyll enlarged with two sporangia. The one on the right shown in section; $m s$, megaspore; $i$, integument; $s p$, sporangium; $m$, micropyle. $3 B$, megasporophyll of Cycas with laterally arranged megasporangia.-H. O. Hanson.

phylls are small and more compactly arranged, the sporangia being associated in sori on the lower surface of the sporophylis (Fig. 245, 2D). In Zamia, the strobili and sporophylls are quite suggestive of Equisetum, the sporangia being developed on the inner side of shield-like sporophylls (Fig. 245, 2-3A).

The microspores originate by the division of certain cells just beneath the epidermis and are discharged from the sporangium very much as in the Ophioglossales. The megasporangia, 
however, present several new departures that must be borne in mind. A rather thick coat or integument covers the sporangium save for a small opening called the micropyle (Fig. 245, $3 A$ ). The integument will be a feature in all the succeeding groups and it has been compared to a highly modified indusium. It originates, however, from the base of the sporangium rather than from the epidermis as in the common forms. As in Selaginella, only one of the mother cells takes part in the formation of spores and but one megaspore (instead of four) is formed. This megaspore does not escape from the sporangium, owing to the large

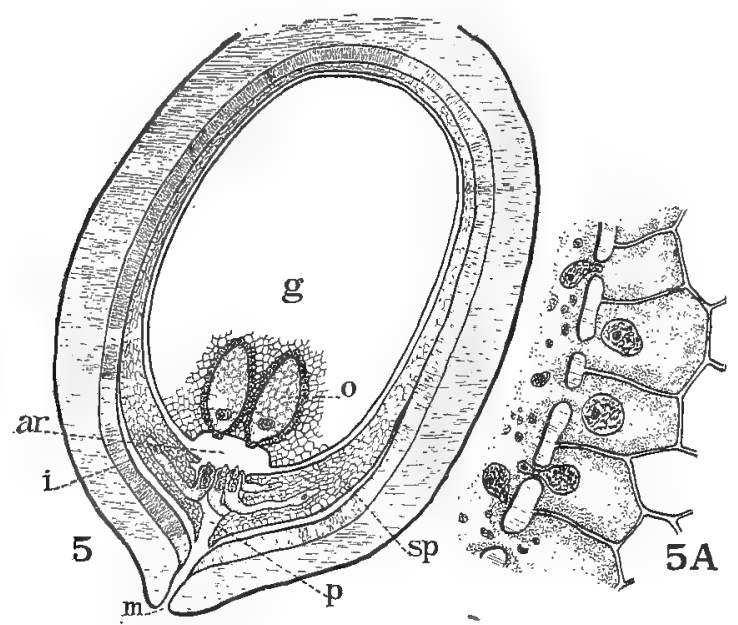

FIG. 246. Section of a megasporangium of Zamia, showing the female gametophyte just before fertilization: $i$, integument differentiating into a fleshy outer and hard inner coat; $m$, micropyle; $p$, cavity in which three microspores are shown germinating; $g$, female gametophyte which has developed from the single megaspore. At the micropylar end of the gametophyte are two archegonia opening into the archegonial chamber, ar. Two neck cells lead to large female gamete, $o ; s p$, remains of the sporangium not yet consumed by the growth of the gametophyte. At the right a few of the jacket cells which supply the female gamete with food are enlarged.-After Webber.

number of cells surrounding it and consequently it does not form a thick protective coat. It has been suggested that these cells enveloping the megaspore are due to the transformation of the spore mother cells, which make up the bulk of the fern sporan- 
gium, into nourishing cells. This structure of the megasporangium is characteristic of all the spermatophyta and the arrangement is of decided advantage since it provides the megaspore during its formation and germination with an abundance of food and moisture.

(b) The Gametophyte of the Cycads.-The megaspore germinates as in Selaginella. Numerous free nuclei are first formed that are arranged around the walls of the spore and by the later formation of walls a tissue is developed that gradually fills the enlarging spore. Archegonia now appear at the micropylar end of this gametophyte and become sunken in pits, called the archegonial chamber, owing to a continued growth of the adjacent cells of the gametophyte (Fig. 246). While this female gametophyte is very suggestive of the one noted in Selaginella it should be observed that the archegonia are more simple in structure, usually possessing but two neck cells and that the central canal cells of the neck are entirely lacking. The female gamete is also much larger (Fig. 246,o) than any heretofore noticed and it is nourished by specialized cells, the so-called jacket cells, that surround it and supply it through minute pores with an abundance of food.

It is evident that the buried position of the archegonia must necessitate some new departure in order to bring the male gametes to the archegonia. The microspores have already begun their germination at the time when they are discharged from the sporangium and being very light, they are carried by the winds to strobili containing megasporangia. When the megasporophylls are mature, they spread apart slightly, permitting the microspores to rattle down to the sporangia where they are caught, at least in some forms, by a mucilaginous secretion from the micropyle. This substance in drying contracts and pulls the spores in large numbers through the micropyle into a chamber formed in the upper part of the sporangium (Fig. $246, p)$. As has been stated, the microspore begins to germinate in its own sporangium and by the time that it reaches the cavity of the megasporangium its nucleus has already divided twice, forming a rudimentary male gametophyte of three cells that may 
be compared with that of Selaginella (Fig. 247, A); the cell (g) representing the small cell, and the cell $(a)$ corresponding to the large antheridial cell of the gametophyte of Selaginella (Fig. 243, I), while the cell $(t)$ called the tube cell, represents a new departure in the evolution of the male gametophyte. The tube cell

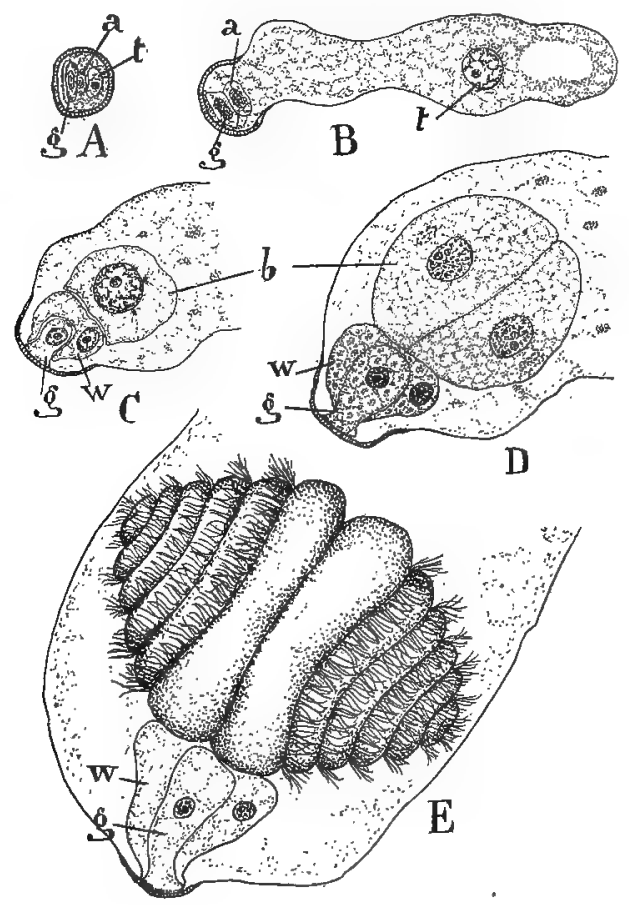

Fig. 247. Male gametophyte of Zamia: $A$, stage of germination of the microspore attained in the sporangium. See text for explanation of figures. $B$, formation of tube for absorbing of food from megasporangium. $C$, spore end of gametophyte showing the antheridial cell dividing into a body cell, $b$, and a single wall cell, $w$. $D$, the body cell has divided, forming two cells which become the male gametes. $E$, spore end of male gametophyte, showing the spirally ciliated gametes.-After Webber.

grows out into the tissues of the megasporangium, forming a tubular structure, often branching extensively, and absorbs food for the nourishment of the antheridial cell (Fig. 247, B). This latter cell finally divides, forming a rudimentary antheridium consisting of but a single wall cell $(w)$ and a body cell $(b)$. The body 
cell usually divides but once forming two cells, in each of which are organized two huge male gametes with spirally arranged cilia (Fig. 247, C-E). Owing to the growth of the numerous tube cells, the tissues above the archegonial chamber become disorganized and absorbed so that the end of the gametophyte containing the gametes bends into the cavity thus formed and comes into close proximity to the archegonia (Fig. 246). Owing to the swelling of the cells $(g)$ and $(w)$ assisted also by the accumulation of fluids in the tube, the male gametophyte is ruptured at its basal or spore end and the male gametes are discharged into the archegonial chamber where they swim about in the fluids probably emitted from the tubes at the time of their discharge: This fluid has been observed by Chamberlain to cause a shrinking of the neck cells in one species of Dioon and so we see how the male gametes may enter the archegonia.

The most noticeable departure in the sexual generation of the cycads is the very considerable reduction of the male gametophyte which consists of a delicate tube containing a few cells from one of which the male gametes are formed as in the ferns. You also notice that the gametophytes have become entirely parasitic upon the sporophyte, the male gametophyte at first upon the sporophyte which bore it and later upon the megasporangium. Attention may be called to a suggestive departure in the development of the female gametophyte that has been observed in one of the cycads. In case fertilization is not effected, the gametophyte ruptures the sporangium and projects as a green tissue, as in certain heterosporous ferns.

(c) Development of the Sporophyte.-The germination of the gametospore differs in two important respects from the ferns. Its nucleus gives rise by repeated divisions to numerous nuclei which arrange themselves around the walls of the gametospore, becoming especially numerous at its lower end, and finally form cell walls (Fig. 248, A). This structure is called the pro-embryo. From the lower cells of the pro-embryo is organized a massive suspensor (Fig. 248, B), which pushes the outermost cells of the pro-embryo deep into the tissues of the gametophyte where they develop the young sporophyte or embryo, which consists of a 
rudimentary root, stem and two cotyledons (Fig. $248, C$ ). In the ferns the gametospore divided into two cells which by further division formed the sporophyte. The second departure now appears. The sporophyte or embryo ceases to grow and it is admirably protected during its resting period by the integument which has become differentiated into a stony middle layer and into a fleshy inner and outer layer. This completed structure, con-
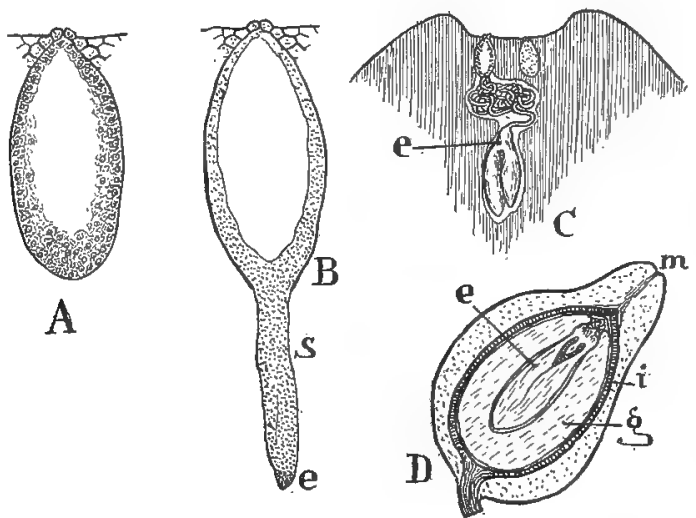

FIG. 248. Development of the sporophyte or embryo of Cycas: A, section of archegonium, showing a large number of cells lining the walls of the germinating gametospore. This is the pro-embryo stage. $B$, later stage in which the pro-embryo has developed a suspensor, $s$, which pushes the embryo-forming cells, $e$, into the nourishing tissues of the gametophyte. $C$, still later development, showing the greatly coiled suspensor and the young sporophyte or embryo, $e$, with two cotyledons. $D$, section of a seed of $Z a m i a$ : $i$, integument which is fleshy without and stone-like within; $m$, micropyle; $g$, gametophyte; $e$, dormant sporophyte or embryo.-A-C after Treub.

sisting of the modified integument, the embryo, and the gametophyte, which has increased in size until it has absorbed all the tissues of the sporangium, we call the seed (Fig. 248, D). At this stage of development, the seed falls from the strobilus and may remain in a dormant condition for years.

The formation of the seed is the most characteristic feature of the Spermatophyta and the most important advance that is to be noted in the evolution of plant life. This variation has given the seed plants an advantage over all other terrestrial groups and made them the dominant plants upon the earth. Not 
only are the male and female gametophytes better provided for than in Selaginella, owing to their complete parasitism on the well developed sporophytes, but the formation of the young sporophyte or embryo is also ensured by the abundance of food placed at its disposal. The most important advantage, however, possessed by the seed plant appears in the modification of the integument which renders it impervious to gases and fluids. This change so effectually seals up the embryo as to protect it for years in some cases against conditions unfavorable for growth. The modification of the integument was doubtless the chief factor that led to the seed habit, since it cuts off the supply of
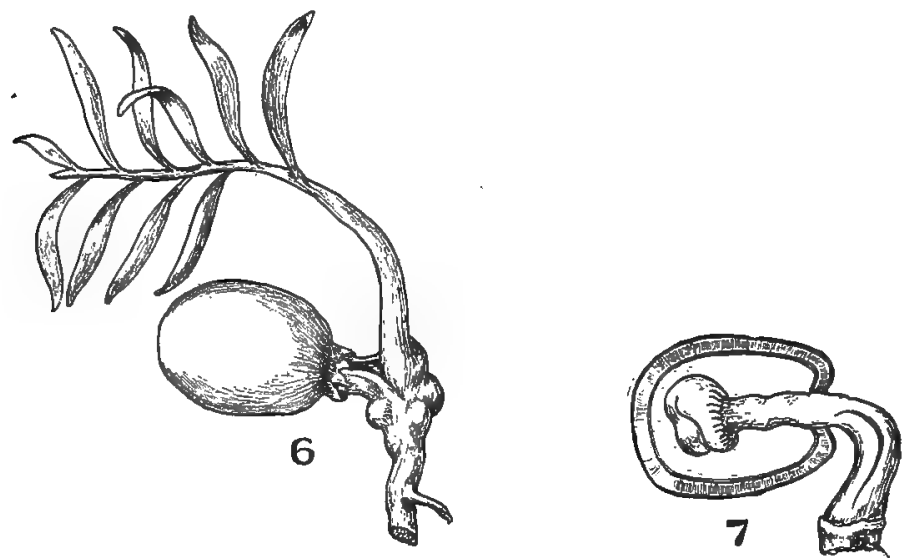

FIG. 249. Renewal of growth of the sporophyte or embryo in the seed. 7 , section of the seed, showing the base of the cotyledons extending from the seed, thus pushing out the stem and root, the latter organ (shown in part) curving down into the ground. The free ends of the cotyledons are enlarging as they absorb the food stored in the gametophyte. 6, seedling six months old with first normal leaf.-After Sachs.

oxygen and fluids from the sporophyte or embryo and thus stops its growth. When conditions are favorable for growth (see page I29), the integument becomes permeable to fluids and gases and the embryo continues its development. The cotyledons remain in the seed to absorb the food stored in the gametophyte, but their basal portions elongate, pushing out the root which soon becomes established in the soil, while the stem which is carried out with the root extends up into the air, and de- 
velops the leaves (Fig. 249). This renewal of growth of the embryo, or sprouting of the seed, is often erroneously termed the germination of the seed.

The maidenhair tree, Ginkgo biloba, a native of China and Japan and now extensively cultivated throughout the world, is the sole survivor of another ancient order of gymnosperms that have many points in common with the cycads and ferns. The tall shaft of the stem, wide-spreading branches and the arrangement and character of the tissues are more suggestive of the next order, the cone-bearing trees. The leaves, however, are fernlike in appearance and are deciduous, unlike most of the Gymnospermae. The arrangement of the sporangia, the development of the gametophytes, and fertilization are of the same nature as in the cycads. It is noteworthy that fertilization may be effected after the megasporangia have fallen, thus approaching the condition seen in Selaginella.

I2I. Order b. Pinales or Cone-bearing Trees.-This order is by far the largest group of gymnosperms and includes our wellknown evergreen or cone-bearing trees. They are largely confined to temperate regions and are more numerous in the northern than in the southern hemisphere. The shores of the Pacific are especially favorable for their development and on our western coast they attain dimensions equalled only by the giant Eucalyptus of Australia. Though less ancient in origin than the cycads, they have declined in the same way as the latter order and only a remnant of this very extensive group survives today. However, their variations have been more beneficial than in the case of the cycads and as a result nearly 300 species are adapted to present conditions upon the earth and constitute an important part, and commercially the most valuable part of our forest vegetation.

(a) Structural and Adaptive Features of the Pinales.-One of the variations that is of great benefit to many of these plants is their habit of forming buds (see page $7 \mathrm{I}$ ), which appear in this order in more perfect form than any of the preceding. By means of the scale leaves of the buds all the organs that are to be produced each season are protected against drying winds. The terminal bud of the tree is frequently the most vigorous and 
as a result spire-like stems with very symmetrically arranged branches are often formed. The growth of the Pinales is usually prolonged and vigorous, the age of some of the giant trees of California being estimated at over 5,000 years, and they may attain the height of over 300 feet and a diameter of 30 feet. The elongation of the stem is effected by a group of actively dividing cells at the apex, while the increase of girth is brought about by the activities of a cambium, as in the dicotyledons (see page 89): In fact, all the features seen in the cross-section of the stem as the cork, cortex, phloem, cambium, xylem with its annual rings of growth and medullary rays and the pith are suggestive of the dicotyledons, save that the tissues are more simple. This is particularly noticeable in the xylem, which is composed
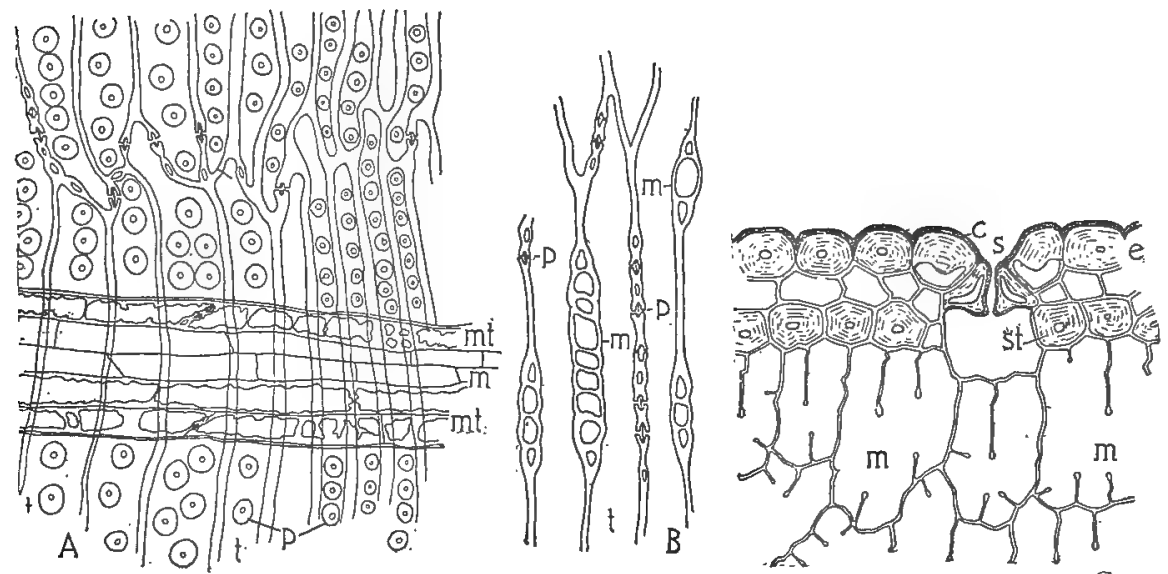

C

FIG. 250. $A$, radial section of the xylem of Pinus-t, tracheids; $p$, border pores or thin places in cell wall to promote transfer of fluids; $m$, medullary ray of two cells accompanied by tracheids, $m t$. $B$, tangential section, showing medullary rays, one cell broad and from three to nine cells high. $\quad p$, bordered pores. $C$, cross-section of the outer cells of pine leaf, showing heavy epidermal cells, $e$; well-developed cuticle, $c$; sunken stoma, $s$; strengthening stereome cells, st, and chlorenchyma, $m$.

of very regularly formed tracheids with peculiar bordered pores on their radial walls to promote the rapid transfer of fluids to and from the medullary rays (Fig. $250, A, B$ ). The characteristic uniform and even grain of pine, spruce, etc., is due to the simplicity of the tracheids which compose the wood. This struc- 
ture of the wood explains the ease with which the timber is worked and the common name of "soft wood" that is applied to it. The leaves are xerophytic in character and usually rather small and often needle-like. The strongly thickened epidermis is strengthened with strands of stereome that give them a leathery character (Fig. 250, C). The stomata are sunken and the centrally-placed vascular bundles communicate with the rather irregular chlorenchyma cells by means of tracheids, and thinwalled parenchyma cells instead of small veins as in the higher plants. The leaves in the majority of the genera remain on the branches for several years, and for this reason the members of the Pinales are commonly called "evergreens."

These plants generally flourish in localities where there is an abundance of moisture and at first sight the modifications of the leaves noted above are not in harmony with such surroundings, being decidedly characteristic of plants growing in arid regions. The minute tracheids which constitute the conducting system of the Pinales cannot, however, transport the fluids absorbed from the soil as rapidly as the large cells noted among the dicotyledons. Consequently smaller amounts of water are placed at the disposal of the leaves, and were it not for the fact that they are admirably adapted to lessen transpiration these plants would doubtless have disappeared from the earth long ago. The ability of the leaves to diminish the loss of water may also account for the common occurrence of the cone-bearing trees in northern and mountainous districts where the soils are cold and root absorption is therefore lessened and where the vegetation is especially exposed to the drying winds of winter (see page $3^{8}$ ).

Nearly all the Pinales are characterized by the presence of resin passages or ducts in the stems and leaves. Whenever the stems are cut or injured these passages pour out a thick resinous liquid that effectually heals the wound. This doubtless explains in part the freedom of these trees from the attack of insects and wood-destroying fungi. It may possibly account for the inability of many of these trees to sprout from the stump when cut. Hardwood forests will very generally perpetuate themselves by means of sprouts that arise from the stumps, but our evergreen 
forests are rapidly disappearing, because with few exceptions the trees are able only to develop from seeds. Possibly the rapid covering of living cells of the stump by the resinous substances excludes the atmosphere so effectually as to prevent any further growth (page 75). This resinous liquid is obtained in large quantities from certain species of pine by removing the bark and a little of the wood from the side of the trees when the liquid exudes and is caught in a pan placed at the bottom of the cut surface or in a pocket made in the tree. This substance is removed from time to time and distilled, yielding turpentine and resin. Balsam is a resin obtained from the balsam fir (Abies).

(b) The Sporangia of the Pinales. - The sporangia resemble those of the cycads in origin and structure and are developed upon sporophylls that are usually grouped in strobili (Figs. 25I,

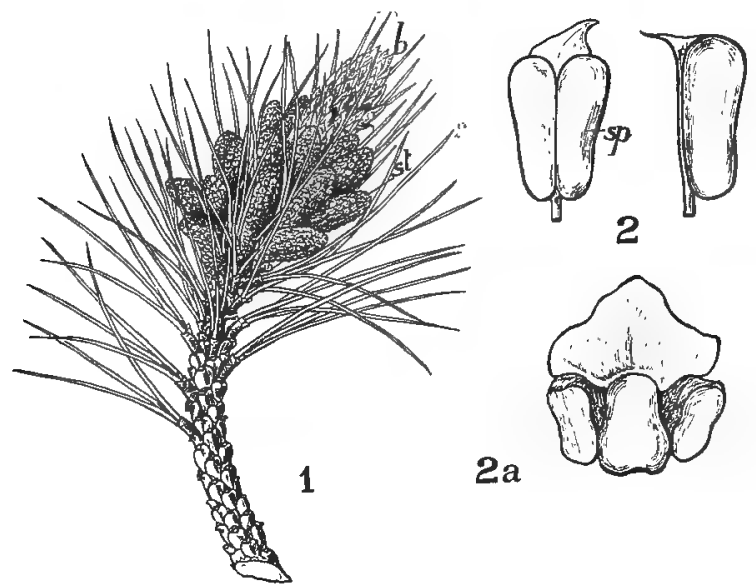

FIG. 25I. Microsporophylls of the pine: I, branch of pitch pine with leaves spirally arranged in fascicles of three and also with several strobili, st. At tip of branch the bud, $b$, is shown elongating and bearing numerous fascicles of leaves that are still enclosed by paper bracts. 2, surface and side view of microsporophyll, showing arrangement of sporangia, sp. $2 a$, microsporophyll of juniper bearing three sporangia.-H. O. Hanson.

252). The microsporangia are formed on rather small, delicate and often brightly colored sporophylls that perish as soon as the spores are scattered (Fig. 25I, 2). The microsporophylls bear one or several sporangia on their under surface and are hygro- 
scopic, curving away from each other when the sporangia are ripe, thus permitting the opening of the sporangia and the gradual distribution of the spores by the wind and closing when moistened to protect the spores against wetting. In some of these genera the outer coat of the microspore is lifted away from the inner coat in such a way as to form two sac-like outgrowths which render them more buoyant and adapted to distribution by the wind (Fig. 254). The miscrospores are produced in such enormous numbers that the ground in the vicinity of the ever-
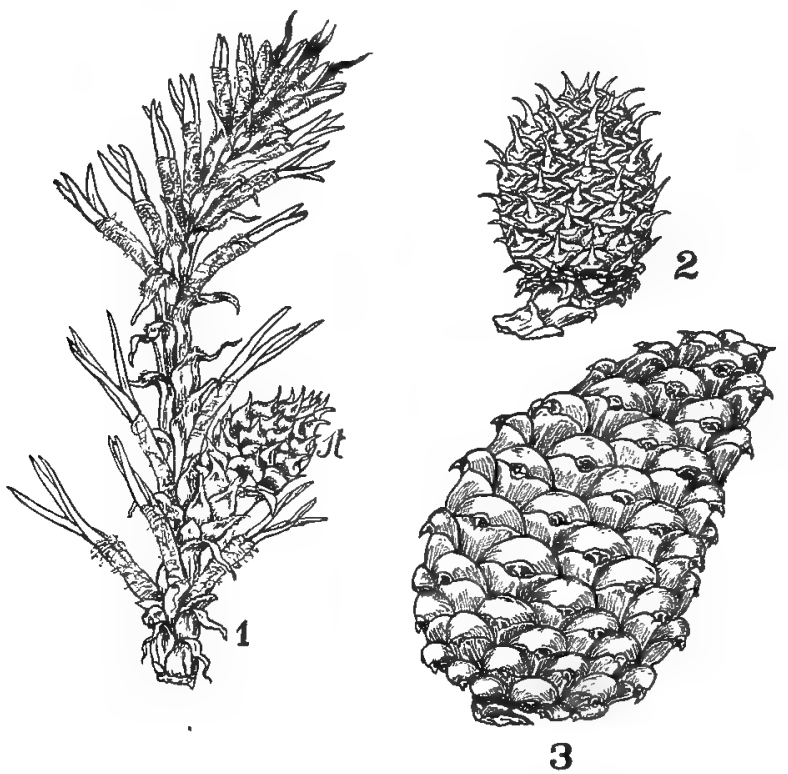

FIG. 252. Strobili of megasporophylls: I, a branch that has developed in the spring from a bud. The fascicles of leaves are just emerging from their papery bracts and at the right is shown a strobilus, st, consisting of minute spine-tipped scales. 2, growth of strobilus shown in I, twelve months later. 3, appearance of strobilus shown in 2, six months later.-H. O. Hanson.

green forests is often covered with the yellow spores, the socalled "sulphur snow." This extravagant formation of microspores is a necessity owing to the small chance of any one of the microspores being carried to the megasporophylls and so ensuring fertilization. Were it not for the fact that the microspores need be carried only comparatively short distances, this order 
would doubtless become extinct. The gymnosperms, however, live in colonies and the strobili of mega- and micro-sporophylls usually occur upon the same plant, thus necessitating but a short transfer of microspores. The megasporophylls ustually endure for a year or more and become quite large, forming the leathery or woody scales of the cone- or strobilus (Fig. 252). The megasporangia are usually developed on the upper side of the sporophyll (Fig. 253, A), the number formed varying in the different genera. In the majority of the Pinales, the sporangia appear upon curious outgrowths which become large and form the conspicuous scales of the cone. This structure is generally regarded as a greatly modified branch or shoot with which two sporophylls are fused. It generally arises from the axil of a bract just below it and with which it may be more or less unitedsee the spruces, pines, firs, etc. (Fig. 253, B). The origin and structure of the megasporangium and megaspore are essentially as noted in the cycads. There is only slight indication, however, in a few of the forms of the development of a cavity for the reception of the microspores. Several mother cells may form megaspores, but only one of these megaspores ever develops and germinates.

(c) The Gametophyte of the Pinales and Fertilization.-The female gametophyte is formed as previously noted in the cycads. By the repeated divisions of the nucleus of the megaspore numerous free nuclei are formed that become arranged around the walls of the megaspore. Later cell walls are developed about these nuclei, and by further division the entire space within the enlarging spore is filled with tissue (Fig. 253, C). A few or a large number of archegonia are developed at the micropylar end of the gametophyte. The archegonium consists of two or several neck cells, and a large female gamete which is surrounded by nourishing cells as in the cycads. It is noteworthy in a few of the forms that the archegonia begin to appear very early in this growth outlined above and that the bulk of the female gametophyte is developed subsequent to their origin. The possible significance of this will be more apparent in the Angiosperms, where we will see the female gamete arising with the third division 
of the nucleus of the megaspore, the gametophytic tissue being developed at a later period. You have noticed that there is no chamber formed above the archegonia, and it would be a natural inference that the male gametophyte must be of a somewhat different character from that of the cycads in order to met this

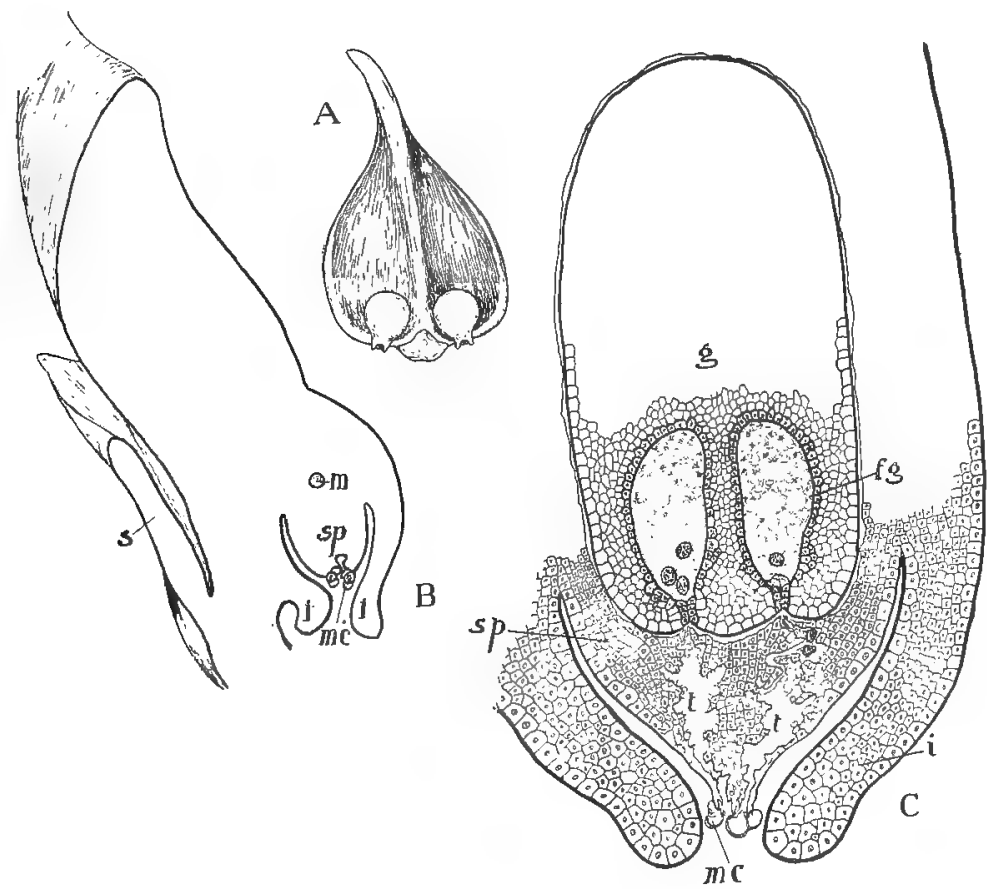

FIG. 253. Megasporangia of pine: $A$, scale-like outgrowth of sporophyll bearing two sporangia. $B$, section of $A$, taken through one of the sporangia, showing a small bract, $s$, and large scale-like outgrowth which bears the sporangia, $s p$. The sporangium is surrounded by an integument, $i$, and contains a single megaspore, $m$, as in the Cycads. $m c$, microspores that have been drawn through the micropyle to the sporangium, into which their tube cells are growing. $C$, section of megasporangium enlarged and diagrammatic, showing the female gametophyte at the time of fertilization- $g$, female gametophyte, showing two archegonia with large female gametes, $f g$. At the left the tube of the microspore, $m c$, has entered the neck of the archegonium and the two male gametes have been discharged into the large sac of the fernale gamete. On the right the tube cell with male gametes is seen approaching the neck of the archegonium. $i$, integument; $s p$, remains of sporangium not disorganized by the gametophyte; $t$ shows the disorganization caused by the tube cells as they grow towards the archegonia. 
new departure. The microspores which have already begun to germinate when discharged from their sporangia are carried by the wind to the megasporophylls which are slightly spread apart at this time, permitting the microspores to rattle down to the megasporangia. The microspores fall into the micropyle either by reason of the position and construction of the megasporangia, which may be so placed that the spores naturally roll down into the micropyle, or the microspores may be drawn through the micropyle by mucilaginous excretions as in the cycads. The
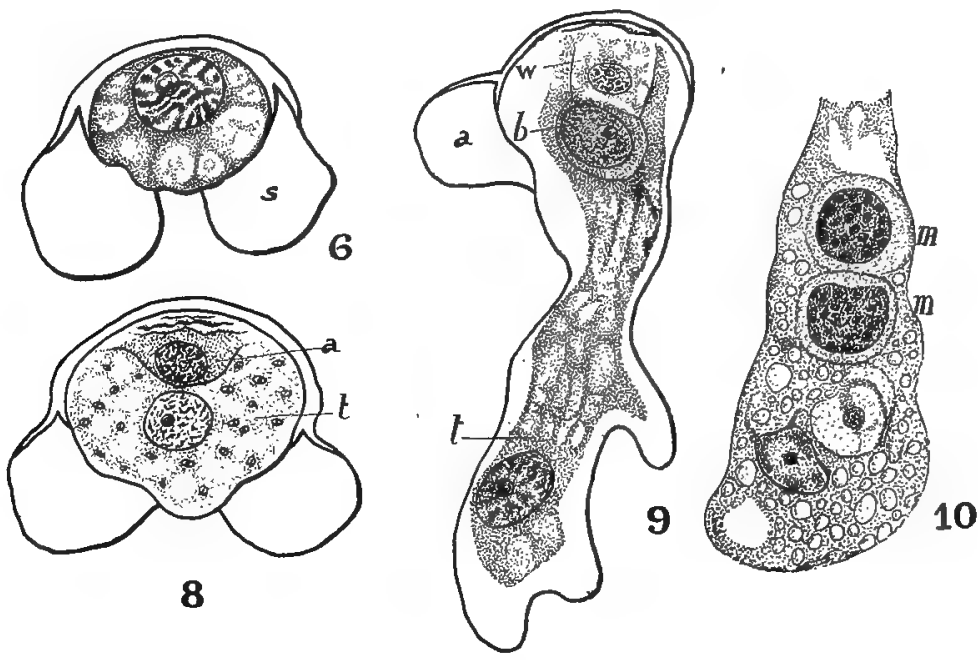

FIG. 254. Male gametophyte of the pine: 6, section of microspore, showing the two air sacs, $s$, formed by the lifting up of the outer wall of the spore. 8 , stage of germination of the spore at time of discharge from its sporangium $-t$, tube cell; $a$, antheridial cell, above which are seen two black lines, the remains of cells formed by earlier division of the nucleus of the microspore. 9, continuation of germination of the microspore after reaching the mega. sporangium- $t$, tube cell forming a branching tube that disorganizes and absorbs the cells of the megasporangium. The antheridial cell (a) of 8 has divided into a wall cell, $w$, and a body cell, $b$. Io, end of tube cell as it approaches the female gamete- $m, m$, male gametes. The nuclei of the tube cell and wall cell are also seen (somewhat disorganized) in the end of the tube. -After Coulter and Chamberlain.

early stages in the germination of the microspore are essentially as in Cycas, though generally more reduced. The microspore on reaching the megasporangium has germinated, forming a tube 
cell and an antheridial cell, but the one or two cells, which correspond to the cell $(\mathrm{g})$ of the gametophyte noted in the cycads, are quickly disorganized and appear as faint lines (Fig. 254, 8). In some forms several of these prothallial cells are formed so that the male gametophyte is more primitive in this respect than the cycads. On the other hand other groups do not apparently form a prothallial cell at all. So the tendency is towards the elimination of these cells because they are no longer of service in setting free the gametes. The tube cell develops as in the cycads, but it is directed in its growth so that one of its branches finally reaches one of the archegonia, when it pushes aside the neck cells and fuses with the cell membrane of the large female gamete (Figs. 253, $C ; 255, A$ ). In the meantime the antheridial cell has divided into a wall cell and body cell (Fig. 254, 9), and two motionless male cells are formed from the body cell." It is to be noted here that the body cell does not divide, forming cells in which male gametes are organized, as in all preceding cases. It forms two free nuclei and these with their associated cytoplasm function as gametes. It is now apparent why the tube cell extends to the female gamete and also why the archegonial chamber is not developed. The male gametes and the wall cell, now quite unattached, are carried down to the end of the tube (Fig. 254, 10) by the cytoplasmic currents and pass into the cytoplasm of the female gamete through an opening that is formed in the end of the tube. Chemical attraction now draws one of the male gametes to the nucleus of the female and their fusion results in the formation of the gametospore. The remaining cells of the male gametophyte are apparently disorganized (Fig. 255, A). Several instances have been reported where the male cells differ in size, indicating the loss of function in one of these cells. On the other hand in those group; where the archegonia are closely associated and where, therefore, the tube cell may spread over more than one archegonium, no such reduction appears. The functions performed by the tube cells in the Pinales will be a constant characteristic of all the members of the next subdivision or Angiospermae, and it should be noted that this important modification of the male gametophyte probably 
arose at first as an absorbing organ to supply the antheridial cell with food, as is the case in the cycads. In the more advanced types the archegonia became more effectually enclosed in the sporangial tissues and the tube cell assumed in addition the function of a conduit for the male gametes which lost their
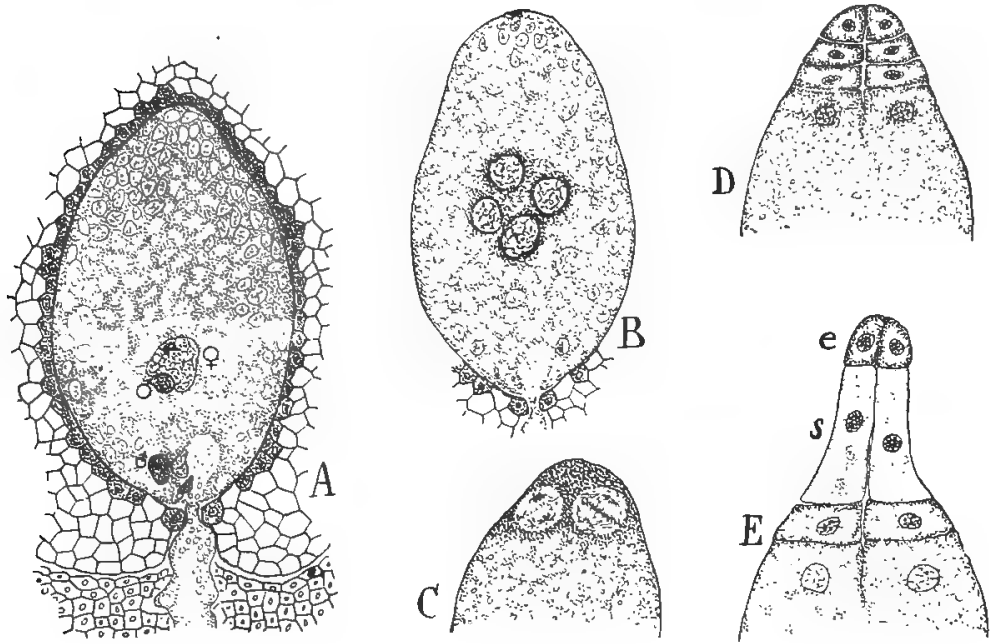

FIG. 255. Development of the pro-embryo of pine: $A$, section of an archegonium at time of fertilization. One of the male gametes, $\sigma^{7}$, is seen fusing with the female, $ᄋ$. The second male gamete, o $\sigma^{7}$, the tube nucleus, and the wall cell are also shown near the neck of the archegonium. $B$, the gametospore has germinated, forming four cells, which are passing to the upper end of the sac. $C$, the cells shown in $B$, arranged at end of sac and in process of division (only two cells in this sectional view). $D$, later stage, the pro-embryo of four plates of cells. $E$, the second plate or suspensory cells, $s$, of the pro-embryo elongating, thus pushing the embryo-forming cells, $e$, into the tissues of the female gametophyte. $-A$ after Ferguson; $B-E$ after Coulter and Chamberlain.

motility as a result of this new method of transport to the female gamete.

(d) Development of the Sporophyte.-The germination of the gametospore of the pine will illustrate the more important features in the process. The nucleus of the gametospore divides a varying number of times, commonly forming four nuclei (Fig. $255, B)$, which pass to the upper end of the spore and arrange 
themselves in a plate. By successive division these cells are increased until usually four plates of four cells each are formed
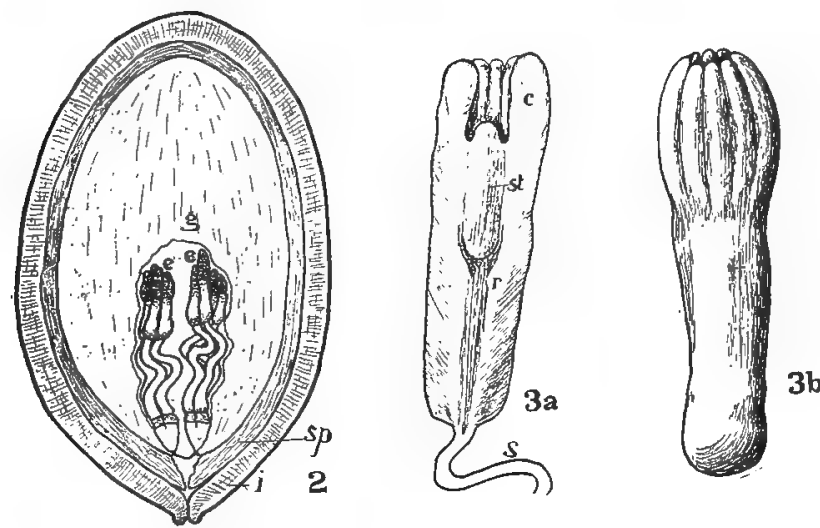

FIG. 256. Development of the young sporophyte or embryo: 2, diagram of a section of a megasporangium, showing the formation of elongated suspensory cells and numerous embryos, $e$; $i$, integument; $s p$, sporangium nearly consumed by the growth of the gametophyte; g, gametophyte, the central portion of it disorganized by growth of embryos, $e .3 A$, section of a nearly mature embryo; $s$, suspensor; $r$, root cap; $c$, cotyledons; st, stem. $3 B$, external view of embryo.

which become surrounded by cell walls save in the case of the lower plate, which is in direct contact with the rich food of the spore (Fig. 255, C-D). This meager growth corresponds to the

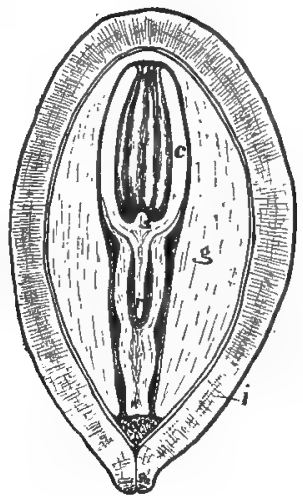

FIG. 257. Sectional view of pine seed: $i$, hard integument; $g$, gametophyte, often called the endosperm, which has completely consumed the sporangial tissues. The embryo consists of a root, $r$, ensheathed in a large root cap, cotyledons, $c$, and stem, $s$. 
pro-embryo of Cycas (Fig. 248, $A$ ). In this connection it should be noticed that only a portion of the gametospore, as in the cycads, is used in forming the embryo. In all the preceding groups, as the mosses, ferns, etc., the gametospore in germinating behaves-as an ordinary cell, dividing into two cells which continue the process. In the Pinales the larger portion of the gametospore serves as a storehouse for food, cell formation being confined to the upper end of it (Fig. 255, B,C). With one exception this is the only group characterized by this peculiar germination which is more suggestive of the growth of the animal egg where a large portion of the egg is reserve food for the nourishment of the embryo. The nourishment of the female gamete by the jacket cells is also suggestive of certain animals in which the egg cells are formed in a similar manner. The embryo is developed from the uppermost plate of cells which are pushed into the cells of the gametophyte by the elongation of the suspensory cells just below them (Fig. 255, E). Each of these four cells may form an embryo (Fig. 256,2 ) or they function collectively in this growth. The result is the same in all cases, rarely more than one embryo being found in a seed. The mature embryo consists of a stem bearing two or several laterally-placed cotyledons and a root with root cap (Fig. 256, 3). Attending this formation of the embryo, pronounced changes occur in the sporangium. It steadily increases in size and the integuments become modified into a hard coat, or the outer layer may be pulpy, as in some of the cycads. The gametophyte also increases in size, and as the embryo matures it absorbs all the tissues of the sporangium, thus filling the space within the integument (Fig. 257). The cells of the female gametophyte are often called the "endosperm." By these growths the seed is formed and pre- . pared for its dormant state, as in the preceding order. In some cases the integument forms a membranous outgrowth, which assists in the distribution of the seeds (Fig. 258, C). It is interesting to note that the seeds are so attached to these wings that they rotate in falling to the ground, thus retarding their fall and making possible a wider flight. The stimulus resulting from the fusion of the gametes also produces extensive changes outside of 
the sporangia. The sporophylls or their outgrowths often become greatly enlarged, forming the hard, woody scales of the cones (Fig. 258, B), or they may become fleshy and fuse, forming a berry-like fruit, as in the juniper (Fig. 260, 7). When this growth has been completed, the woody sporophylls or scales of the strobilus dry out, and becoming hygroscopic, they spread apart on dry days, thus permitting the scattering of the seeds by the winds (Fig. 258, A). Many of the fleshy fruits are eaten by birds and the hard nut-like seeds are distributed in this way.
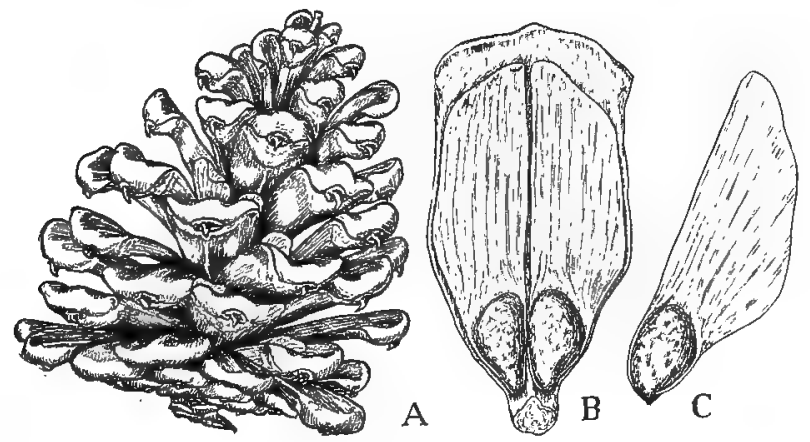

FIG. 258. $A$, mature strobilus of pine with open scales to permit the scattering of the seeds. $B$, scale from strobilus showing the winged seeds developed from the two sporangia, $C$, a seed with wing-like outgrowth, as it escapes from strobilus.

The stages in the development of the seed, outlined above, are very much prolonged in many of the pines. The microspores on reaching the megasporangia, in the spring, develop only a short tube cell during the first season and not until about the first of July of the following season are the male and female gametes mature and ready for fertilization. The seeds are matured during the following season, over two years after the appearance of the strobilus. Accordingly, three stages in the development of the strobilus of megasporophylls may be seen on certain species of pine in the early summer-very small ones that received the microspores in the spring, larger ones in which fertilization and the formation of the embryo is being effected and older strobili in which the seeds are approaching maturity (Fig. 252). When the conditions are favorable the embryo renews its growth. 
The root is pushed out through the micropyle and bends down into the soil, the hard integument often being cracked open by the swelling of the cells. The cotyledons remain within the seed until they have absorbed all the food from the gametophyte, when they are withdrawn and become erect (Fig. 259).

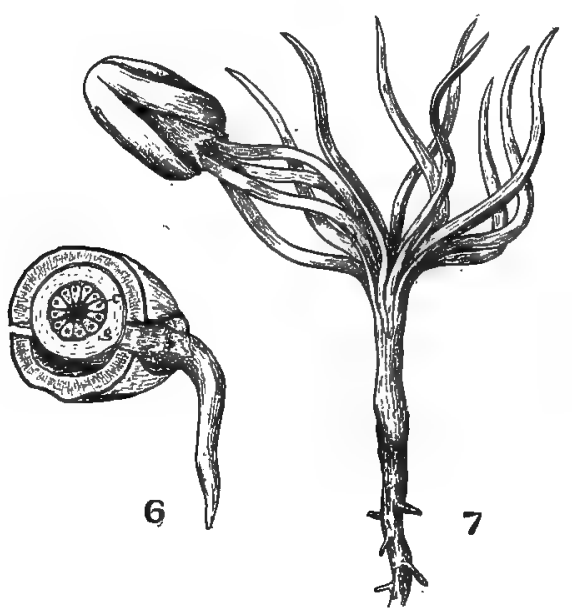

FIG.259. Renewal of growth of the embryo. At the left a seed has been cut across to show the relation of parts during the early growth The integument has been ruptured by the swelling of the seed and the protrusion of the root which is curving down into the soil. The cotyledons, e, remain in the seed absorbing the food from the gametophyte or endosperm, g. At the right a later growth with the cotyledons partially withdrawn from the seed after the absorption of its food.

(e) The Principal Genera of Pinales.-The more important genera of Pinales may be distinguished as follows: Pinus or pine, leaves long and needle-like, borne in fascicles on short stems that are quite concealed by papery sheathing scales (Fig. 25I, I). Larix or larch, short needle-like leaves clustered in tufts on short lateral branches. This is the only northern member of the order with deciduous leaves. Picea or spruce, leaves angled or foursided, radiating from all sides of stem, petioles remaining on branchlet after leaves fall, thus causing the rough appearance of the branchlets (Fig. 260, 9). Tsuga or hemlock, leaves flat in two rows, the petiole remaining on the stem after fall of leaf; 
the strobilus is ovoid with rather leathery scales. The spruce and hemlock have pendent strobili. Abies or fir, leaves flat in two rows, the stems being smooth after leaf fall, strobili erect on the branches. Taxodium or bald cypress, leaves flat in two rows
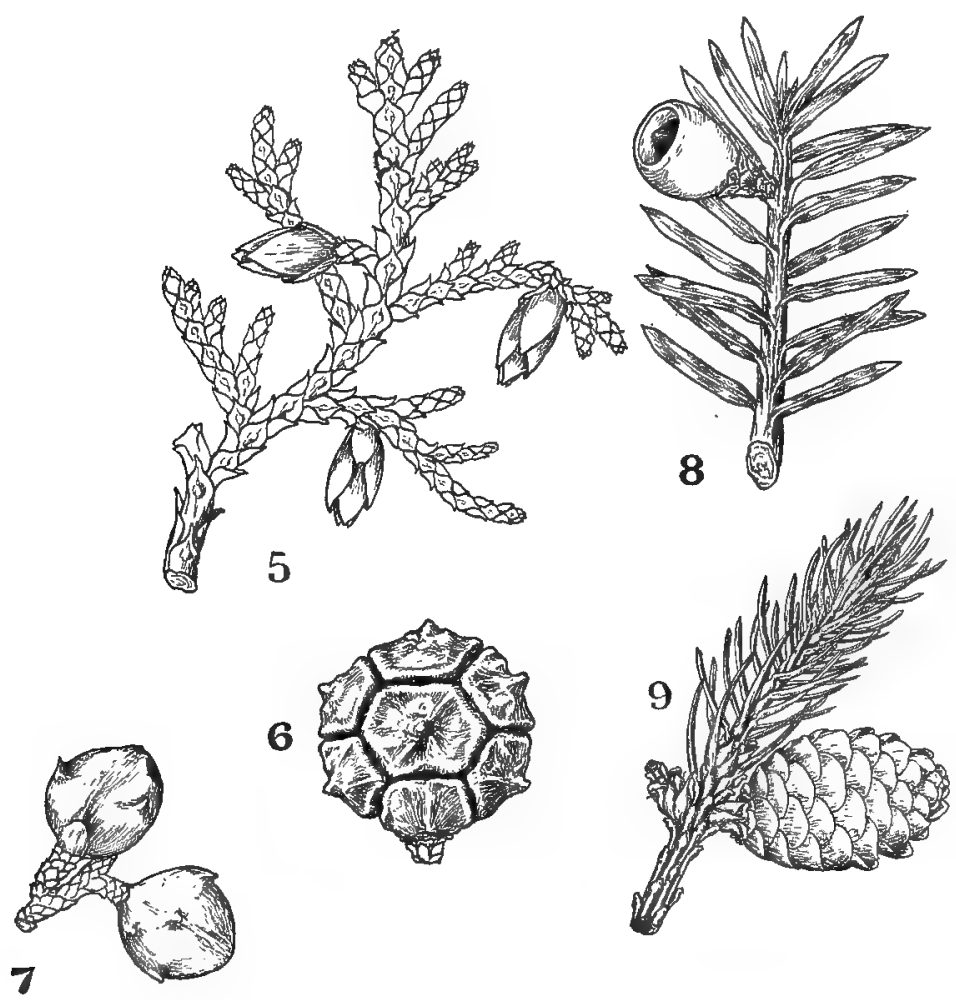

FIG. 260. Common examples of the Pinales: 5, Thuja or arbor vitae. 6. Strobilus of Chamaecyparis or southern white cedar. 7 , strobilus of Juniperus or red cedar with fleshy scales fused into a berry-like fruit. 8 , branch of Taxus or yew. The seeds are produced singly in the axils of leaves on short lateral branches and nearly enveloped by a thick fleshy cup that becomes bright red. 9, Picea or spruce.

and deciduous, strobilus globose with thick, spirally-arranged and shield-like scales. Thuja, arbor vitae, or northern white cedar, leaves scale-like, closely appressed to the branches in four rows, strobili ovoid with flat tough scales (Fig. 260,5). Chamaecyparis 
or southern white cedar, leaves resembling Thuja, but cones globose with shield-like opposite scales (Fig. 260, 6). Juniperus or juniper, pointed scale-like leaves, opposite or in whorls on stem, scales of strobili becoming fleshy and fusing to form a berry-like fruit (Fig. 260, 7). 


\section{CHAPTER $\mathrm{X}$}

\section{SUBDIVISION 2. ANGIOSPERMAE. PLANTS WITH ENCLOSED SEEDS}

I22. Origin of the Angiospermae.-These plants, like the Gymnospermae, produce seeds, but they differ so essentially from the latter group in the character and structure of the sporophyte and gametophyte as to justify their separation into a distinct division. They are retained here as a group coördinate with the gymnosperms out of deference to common usage. It has been noticed that the seed habit arose quite independently of the Spermatophyta (see page 35I) and it appears probable that the Angiospermae represent an independent line of development. Though the most recently evolved plants, their origin is uncertain and the meager evidence points to their derivation from a stock related to the more primative Filicales rather than to the Gymnospermae. The variations of this modern group of plants have been many and so successful that they have crowded out many of the lower forms and become the dominant plants upon the earth. They exceed all other groups combined in variety and number of forms, approximately, 125,000 species-certainly a striking contrast to the other vascular plants which comprise about 450 gymnosperms and 4000 pteridophytes. The angiosperms are adapted by their variations to practically all conditions that will sustain life, ranging from aquatics to xerophytes, from terrestrials to epiphytes and from photosynthetic to saprophytes and parasitic plants. The important features of the plant body have been considered in the opening chapters of the book.

I23. The Sporophylls of Angiosperms.-The flower is often considered as one of the most characteristic features of the angiosperms, but this structure contains as its essential organs one or more sporophylls and the term flower could be applied quite as well to the association of these organs in the Pteridophyta and gymnosperms. 
The sporophylls, like all organs of the plant, show a wide range of variation and they are generally associated with more or less modified leaf-like organs which serve to protect them. These leaf-like organs are known as the floral envelope or perianth and doubtless arose in many forms through the sterilization and modification of the sporophylls (Fig. 26I $A, \mathrm{r}$ ). The microsporophylls, often called stamens, usually consist of a stalk or filament and a four-lobed spore-bearing part, the anther (Fig. 26I $A$, 2). In cross-section, the anther is seen to consist of four spo-
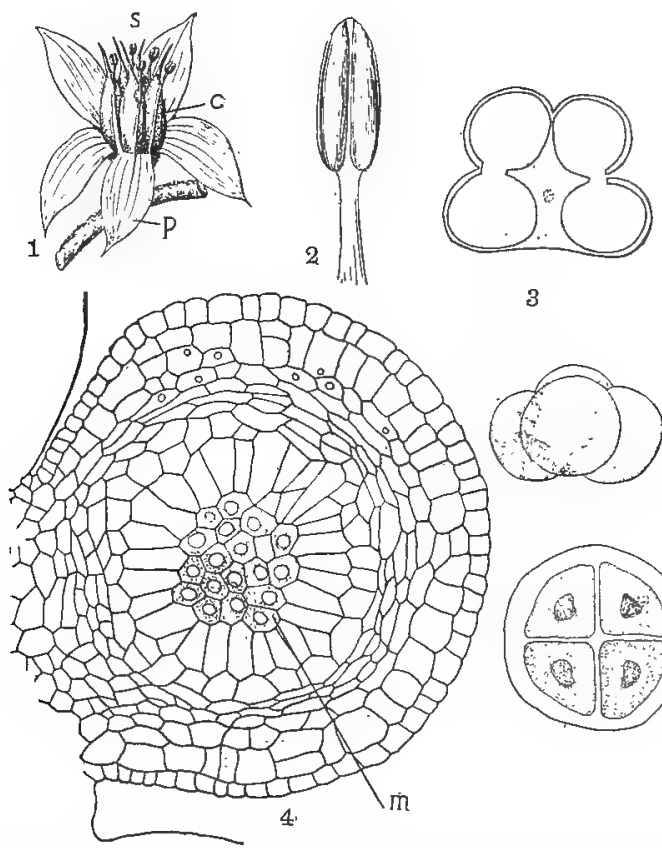

3

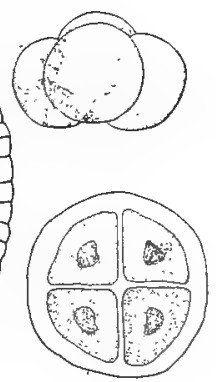

FIG. 26IA. Flower and sporophylls of Angiosperms: I, flower of Sedum with leaf-like perianth, $p$; 'microsporophylls, $s$; megasporophylls, c. 2, microsporophyll of the buttercup, showing four-lobed anther and flament. 3 , diagram of a cross-section of an anther, showing the breaking down of the tissue about the four sporangia and the beginning of the opening of the anther. 4 , one of the sporangia from a young anther, as seen in cross-section- $m$, spore mother cells. The large cells surrounding the mother cells are nourishing cells, known as the tapetum, and disorganize as the spores mature: At the right a mother cell forming four microspores, the upper one being characteristic of dicotyledons and the lower of monocotyledons. 
rangia in which the microspores originate in fours as in the preceding groups (Fig. 26I $A, 3,4$ ). At maturity, the two sporangia on each side of the anther usually merge into one cavity, owing to the breaking down of the intervening tissue. The anther opens in a variety of ways, as by slits and pores, permitting the scattering of the spores (Fig. 261 $A, 3$ ). The
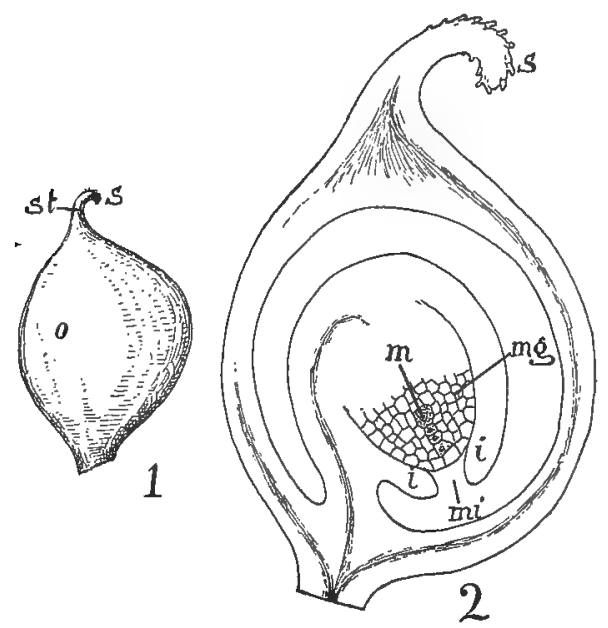

FIG. 26I $B$. Megasporophyll and megasporangium: I, megasporophyll of buttercup- $s$, stigma; $s t$, style; 0 , ovary. 2 , longitudinal section of megasporophyll-mg, megasporangium; $m$, megaspore, the mother cell having formed four spores in series, but the end one only develops; $i$, integument; mi, micropyle.

microsporophylls are often externally quite suggestive of those noted in certain of the Pinales, but the megasporophylls are essentially different from any other group considered, in that the sporangia are inclosed in a cavity formed in the sporophyll. This peculiarity is one of the important characteristics of the angiosperms, as the name indicates. The megasporophyll, often termed the pistil or carpel, is usually a rather elongated, flaskshaped organ with a hollow swollen base and consists of a stigma, style and ovary (Fig. 26I $B$, I) within which are produced the megassporangia or ovules. Such a structure would result if the edges of the leaf-like megasporophylls of previous groups were inrolled so as to form a closed organ. The megaspores originate 
in these sporangia as already noted in the gymnosperms and usually but one megaspore is developed in each sporangium (Fig. 26I $B, 2)$.

124. Development of the Flower of Angiosperms.-The sporophylls are variously associated in groups that are commonly called flowers. In its simplest form, the flower may be defined as a minute branch or receptacle bearing one or more sporophylls. Such a type is illustrated in the cat-tail (Fig. 262, B,C)
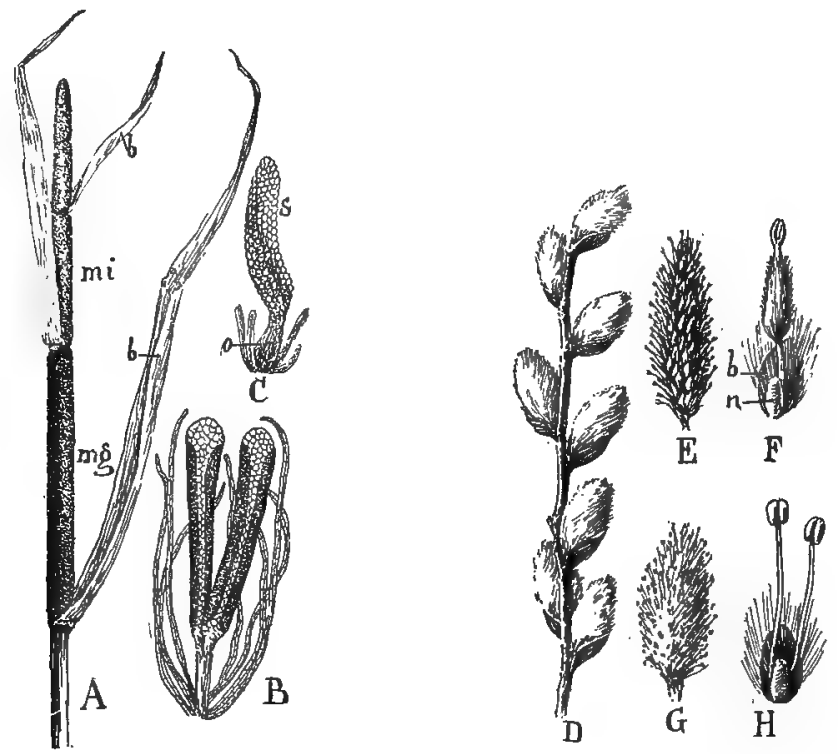

FIG. 262. Forms of primitive flowers: $A$, inflorescence of Typha or cattail- $m i$, region bearing only flowers with microsporophylls; $m g$, flowers with megasporophylls; $b$, bract. $B$, flower consisting of two microsporophylls which are sessile on a short stalk that has numerous hairs. $C$, flower consisting of one megasporophy!l-s, stigma; $o$, ovary surrounded with hairs. $D$, early appearance of the inflorescence of Salix or willow. $E$, inflorescence bearing only megasporophylls: $F$, flower, of a single megasporophyll with forked stigma- $b$, bract; $n$, nectar gland. $G$, inflorescence bearing only microsporophylls. $H$, flower of two microsporophylls.

where the flower consists of one or a few sporophylls associated with hairs, and also in the willow where the sporophylls are developed in the axil of a minute bract (Fig. 262, $F, H$ ). It should be noted in the cat-tail that numerous spirally arranged 
hairs are associated with the sporophylls. These are supposed to represent sterile sporophylls and this is borne out by the fact that primitive flowers are characterized by just such an arrangement of their sporophylls, and also by the fact that in an allied genus spirally arranged sporophylls actually occur. These simple types of flowers are often developed in large numbers upon an elongated stem (Fig. 262, $A, D-G$ ) and are rather suggestive of a strobilus although the individual flower really corresponds to the strobilus, as will be seen especially in those types where the sporophylls are numerous and arranged spirally upon the receptacle of the flower (Fig. 264). A group or cluster of flowers is called an inflorescence in contradistinction to the solitary flower developed at the end of a branch or stem. It is noticeable in these primitive angiosperms that the micro- and megasporophylls are usually borne in separate flowers or inflorescences (compare Pinales) which are developed on separate plants as in the willow or on different parts of the same plant as in the cat-tail. This arrangement is probably associated with the fact that the advantages of crossing or the transfer of the microspores of one flower to the megasporophylls of another is effected by the wind. In higher types, which include the great majority of angiosperms, the micro- and mega-sporophylls are developed in the same flower which is therefore said to be perfect since it contains both of the organs essential for seed production (Fig. $26 \mathrm{I} A, \mathrm{I})$. A type like the willow is termed imperfect because the flower lacks one kind of sporophyll. Crossing is effected in the perfect type of flower by the earlier ripening of the microor mega-sporophylls and often also, by the arrangement of the organs of the flower which is of such a nature that the microspores cannot readily reach the mega-sporophylls of the same flower. Insects are usually the agents for the transport of the microspores in such cases. Flowers in which the microspores mature and are shed from the anthers before the stigmas of the megasporophylls are ready to receive them, are called protandrous, meaning that the microspores which develop the male gametes, are the first to mature. If the mega-sporophylls become receptive before the anthers open, the flower is said to be protogynous, 
meaning that the pistil matures first. It must also be borne in mind, although the devices for effecting a crossing are almost universal among the various groups of angiosperms, that there are equally elaborate provisions for the transference of the microspores of perfect flowers to the stigmas of their own flower. This is called autogamy and would appear to be a provision for setting seed in case crossing fails.

From the above discussion we might characterize the primitive

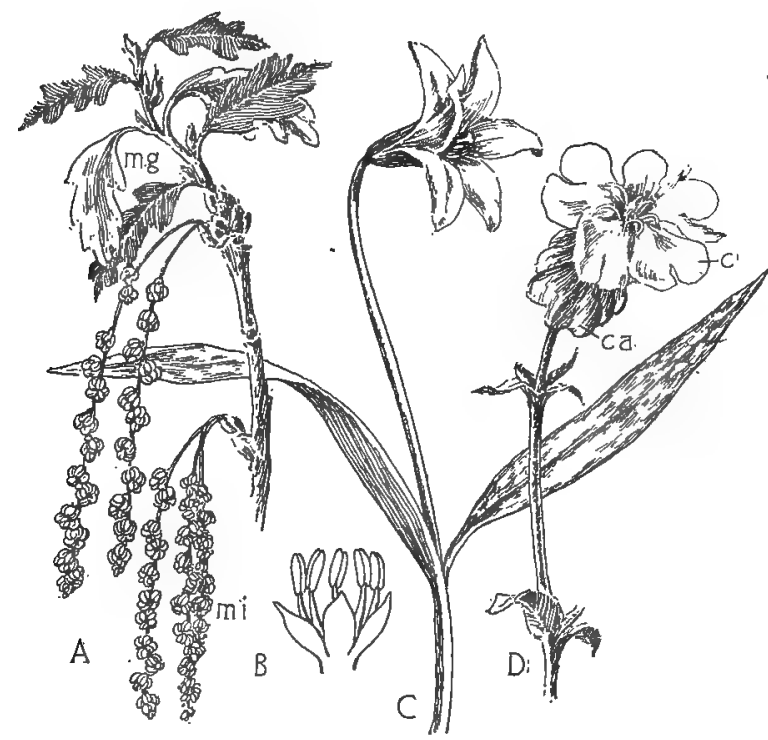

FIG. 263. Development of the perianth: $A$, inflorescence of Quercus or oak-mi, inflorescence with flowers bearing only microsporophylls; $m g$, inflorescence with flowers bearing megasporophylls. $B$, flower of oak, enlarged, consisting of several microsporophylls and a perianth of minute scalelike organs. $C$, flower of Erythronium or fawn lily. The perianth of six conspicuous leaf-like organs. $D$, flower of Melandryum or day pink-ca, calyx of green sepals; $c$, corolla of five delicate petals.

flowers as consisting usually of a large and indefinite number of sporophylls, spirally arranged upon the receptacle which is sufficiently elongated as to permit the separate attachment of each organ. Following the development of this type of flower, there appeared as the next advance, minute outgrowths about the sporophylls, known as the perianth. In its simplest form this 
consists of a few scales as in the sweet flag, oak, etc. (Fig. 263, B), but in higher forms, the perianth appears as the conspicuous leafy portion of the flower as in the lily (Fig. 263, C). Finally flowers appear in which the leaves of the perianth become differentiated into an outer calyx composed of several green sepals and a corolla of larger, more delicate and often brightly-colored leaves, called the petals (Fig. 263,D). We have now reached a point where the flower is said to be complete, consisting of all the organs that are normally associated in the flower.

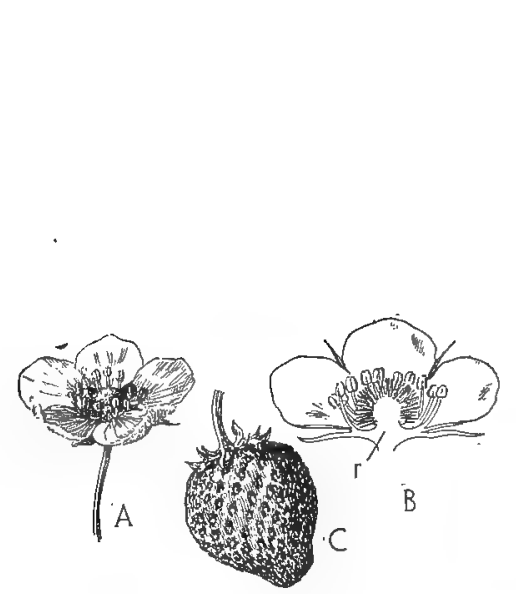

FIG. 264 .

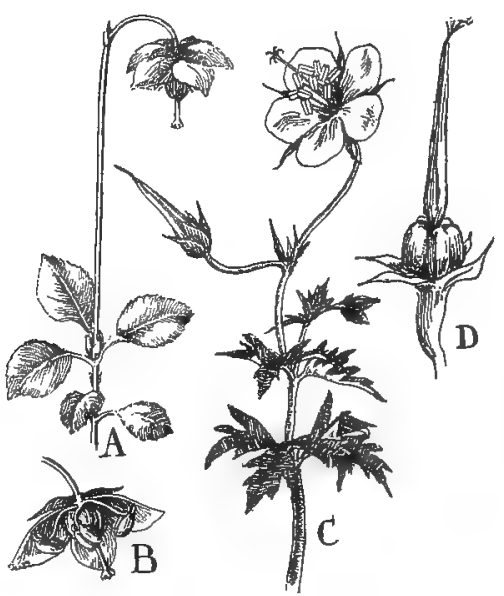

FIG. 265 .

FIG. 264. Flower of strawberry with elongated receptacle bearing numerous spirally arranged sporophylls: $A$, open flower. $B$, flower in section, showing arrangement of parts upon receptacle, $r$, which forms a shallow cup at base bearing the perianth and microsporophylls. $C$, the fruit or enlarged receptacle bearing the minute spirally-arranged megasporophylls.

Fig. 265. Flowers with shortened receptacles: $A$, flower of Pyrola with calyx and corolla arranged in whorls or cycles. $B$, section of flower, showing all the organs in cycles. $C$, flower of geranium. $D$, flower with corolla removed to show the coherence of the five megasporophylls that results from the shortening of the receptacle.

As stated above the simpler type of flower is characterized by numerous sporophylls, spirally arranged and separately attached to an elongated receptacle. One of the most important variations that appeared in the evolution of the flower is associated with the shortening of this receptacle. This is brought 
about by the checking of the apical growth of the receptacle and is often associated with a more or less extended growth of its basal region. These changes affected the flower in a most profound way. A crowding resulted, organs were reduced in number and their spiral arrangement upon the receptacle became so flattened that the various sets of organs appear to arise in whorls or cycles (Fig. 265, A,B). These cyclic flowers are characteristic of all the higher orders of angiosperms and no one character is of
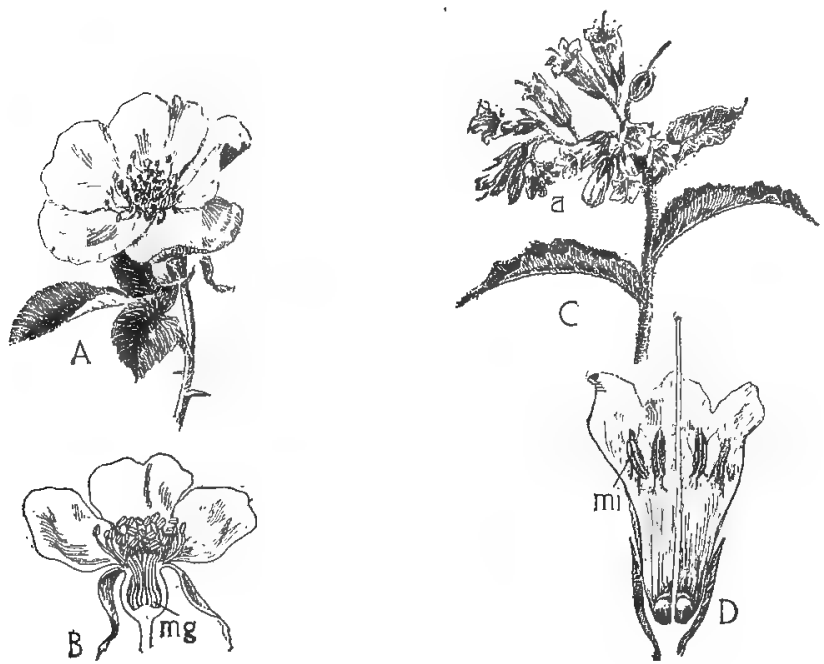

FIG. 266. Forms of adhesion that result from shortening of receptacle: $A$, flower of rose. $B$, section of flower, showing the lower portion of receptacle forming a cup about the megasporophylls, $m g$, and bearing the other organs of the flower. $C$, inflorescence of comfrey, Symphytum. $D$, flower enlarged in section to show adhesion of microsporophylls, mi, to the tubular corolla.

more value in enabling us to state whether a plant is of high or low rank. As the cyclic habit became established, so the number of organs in each whorl became constant. Thus at a certain point in the evolution of the monocotyledons you will find the organs usually in threes, whereas in cyclic dicotyledons whorls with four or five organs are the rule.

The crowding of the organs on the receptacle also caused them to develop en masse (as a unit), not as separate organs. This 
tendency is especially noticeable in the megasporophylls, which very frequently form a compound megasporophyll (Fig. 265, $C, D$ ), and in the same way the sepals and petals may appear as a more or less tubular calyx and corolla (Fig. 266, C). The crowding also led to the mass growth of the organs of adjacent sets or whorls. This is often seen in the case of the petals and microsporophylls, the latter organs appearing to arise from the corolla (Fig. 266, D).

The receptacle plays an important role in all cases of mass growth. As stated above, its apical portion ceases to elongate at an early period while the basal part continues active, forming a cup about the ovaries. The sepals, petals, and even the microsporophylls are often so associated with this basal growth of the receptacle that they arise en masse about the ovaries. This growth may be so slight that a careful examination of a section of a flower is required to detect it or a conspicuous cup-like structure may be formed, as in the rose (Fig. 266, $A, B$ ). This type of flower is termed perigynous, meaning that the receptacle and other organs form a more or less conspicuous cup about the ovaries. In simpler types, as the spiral flowers, it can be seen that the megasporophylls arise at the top of the receptacle and that each of the other organs arises at a point just below the next inner one. Such flowers are called for this reason hypogynous, meaning below the ovaries.

Very frequently the basal growth of the receptacle also involves the ovaries which becomes distinct from the mass growth at various stages in their development. Consequently the other organs of the flower appear to arise from the sides or from the top of the ovaries; the flowers being partially or completely epigynous, meaning that the organs of the flower are developed upon the ovary (Fig. 267, B, D). Often in completely epigynous flowers the receptacle elongates very slightly and the basal portion grows up around the apex forming a cup-like cavity which is roofed over by the megasporophylls. The sporangia or ovules usually arise from the walls of the cavity thus formed and not from the walls of the megasporophylls at the top of the cavity (Fig. 267, D). The calyx, corolla and microsporophylls 
arise from the top of the structure thus formed and these organs may be developed separately or there may be varying degrees of mass growth as noted in the perigynous flower.

Another feature to be noted in connection with the evolution of the flower is its symmetry. In the lower types, the organs

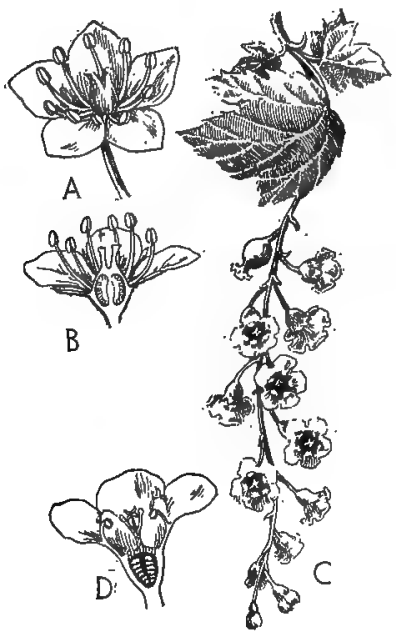

FIG. 267.

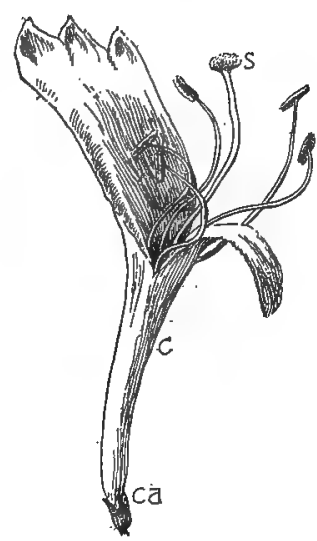

FIG. 268.

FIG. 267. Adhesion due to basal growth of receptacle: $A$, flower of saxifrage. $B$, section of flower, showing megasporophyll partially inclosed by receptacle. $C$, inflorescence of red currant. $D$, section of flower, showing: the receptacle forming a sporangial cavity that is covered at the top by the megasporophylls. The other organs arise from the top of this structure, the microsporophylls adhering to the corolla.

FIG. 268. Irregular or zygomorphic flower of honeysuckle: $c a$, calyx; $c$, corolla of five unequal cohering petals, $s$, stigma.

of a set are alike and radially arranged about the center of the flower (Fig. 267, A). This is the regular or actinomorphic type of flower, meaning radially symmetrical. In many of the orders of angiosperms one or more members of a set are different from the others, thus destroying the radial symmetry (Fig. 268). This is the irregular or zygomorphic type of flower, meaning yoke-form. Such flowers can be cut into two similar halves in but one plane.

It must not be understood that evolution of the flower has 
progressed steadily through the various changes outlined above and that consequently in the following lessons we can begin with the most primitive type and proceed by regular steps to the highest forms. The various orders of angiosperms have doubtless been derived from several distinct stocks and they have not only varied in different degrees but especially will it be noted that some orders have a tendency to emphasize certain forms of these variations, while in other alliances, the variations will proceed along quite different lines. These various modifications have been retained because they were of advantage to the plant (p. I44). The cause of the variations is unknown. Similar lines of variations also appear among the insects, and singularly these modifications of the flower and insect have been mutually beneficial the one to the other. In the simpler forms of flowers the microspores are carried by the wind, as in the gymnosperms. In the higher types odor and nectar glands appear and bright colors which serve to attract insects. This type of flower becomes modified so that it is adapted to special types of insects-all others being excluded. In this way the microspores are carried with greater certainty from one flower to another of the same kind.

I25. The Gametophyte of the Angiospermae.-The angiosperms have developed along quite distinct lines, but they show such a remarkable uniformity in the development and character of the gametophyte generation that this feature of their life history may be considered at this point, as it applies to all forms. The megasporangium, also called the ovule, originates in the cavity of the ovary at various points known as the placenta (Fig. $269, A)$. The structure of the sporangium and the formation of the megaspore is very similar to that of the gymnosperms. More often two integuments are formed and the sporangium or the stalk which supports it becomes curved so that it very frequently is turned completely over (Fig. 269, B). The germination of the megaspore results in a female gametophyte which is very much more reduced than in the case of the gymnosperms. As the megaspore enlarges, disorganizing the cells of the sporangium, also called the nucellus, its nucleus divides and the daugh- 
ter nuclei move to each end of the spore (Fig. 270, $A$ ). Each of these nuclei divides twice, forming four nuclei at either end of the spore (Fig. 270, $B, C$ ). This generally completes the nuclear divisions in the gametophyte. Only a few cases are

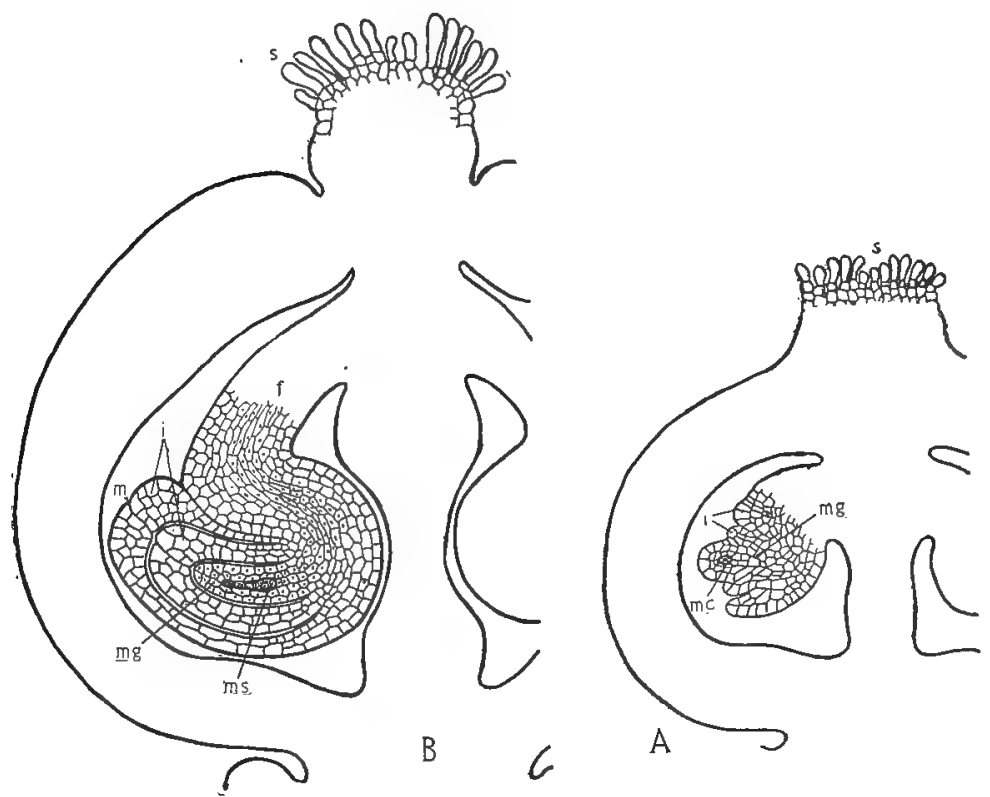

FIG. 269. Development of the megasporangium and megaspore: $A$, sectional view of the pepper-grass, Lepidium. This flower has two cohering sporophylls, only a portion of the right-hand one being shown. $s$, stigma with protruding cells to receive the microspores; $m g$, megasporangium containing a single spore mother cell, mc. Two integuments, $i$, are growing up about the sporangium. $B$, later stage of development, the megasporangium, $m g$, becoming inverted and completely covered by the integument. The mother cell of $A$ has formed four daughter cells in series and not in tetrads as in the Pteridophyta. The innermost cell of the series, $m s$, only matures as a megaspore; $m$, micropyle; $f$, stalk or funiculus of sporangium.

known where a larger number of nuclei are formed-compare with the gymnosperms. A nucleus from each of these groups; called the polar nuclei, now approach each other and fuse, forming a single large nucleus that is usually called the endosperm nucleus. This rudimentary growth represents the female gametophyte. The three outer or micropylar cells are not pro- 
vided with walls and consist of a rather larger cell, the female gamete, and two nourishing cells, the synergids or helpers (Fig. 27I). The inner group or antipodal cells usually have walls and they are either soon disorganized and absorbed by the enlarging gametophyte or they may remain as permanent features of the gametophyte for a long time and even increase greatly in number, serving to nourish the gametophyte by absorbing food from the sporangium. The endosperm nucleus plays a very important role in the development of the sporophyte, for as soon as fertiliza-

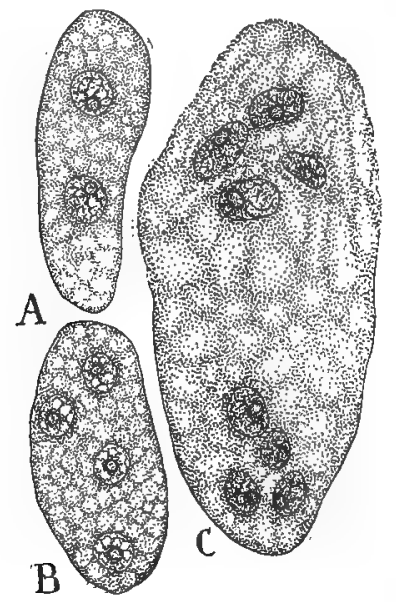

FIG. 270. Germination of the megaspore: $A$, first division of the megaspore. $B$, second division of the nuclei. $C$, final division of the nuclei.

tion has been effected it forms by repeated division a mass of cells that completely fills the entire space within the enlarging spore, thus providing food for the nourishment of the sporophyte. At first sight it would appear impossible to compare the various cells of this peculiar gametophyte with the tissues of the female gametophyte of the gymnosperms or ferns. It has been suggested that the female gamete and the synergids are the remains of three archegonia, only one of which is usually capable of being fertilized, and that the antipodal cells are a remnant of the numerous vegetative cells of the gametophyte. The peculiar formation of the endosperm nucleus through the fusion of the two polar cells is looked upon as a nourishing device to give the endosperm nucleus 
the power to 'grow and form a tissue that supplements the antipodal cells and 'so"takes the place of the nourishing gametophyte of the gymnosperms. According to this view, the endosperm is a delayed prothallial growth which does not take place until fertilization is effected. There is considerable evidence to justify

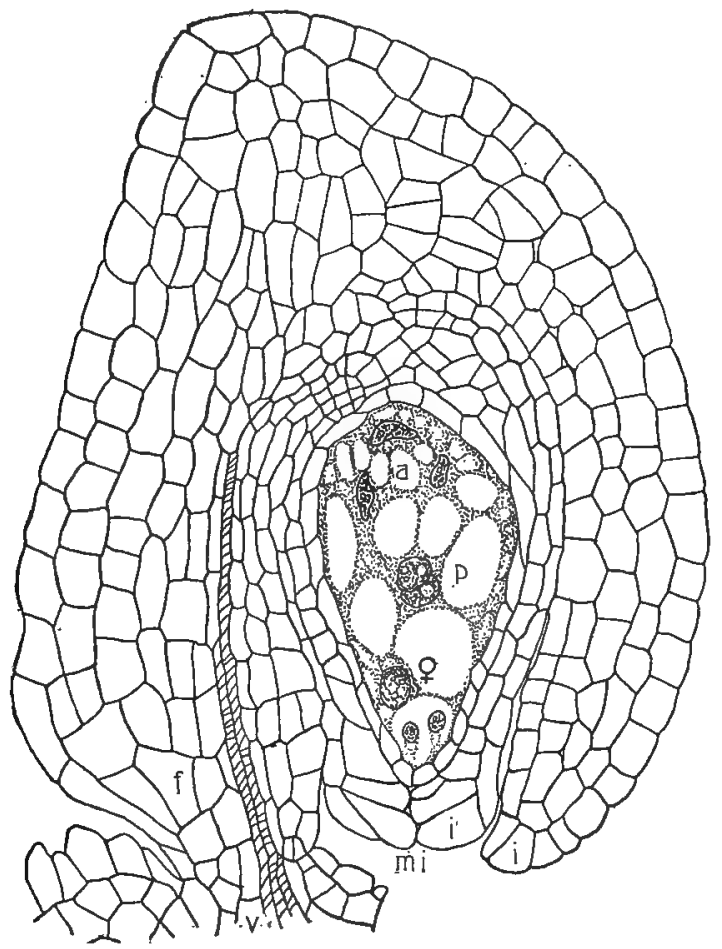

FIG. 27I. Section of a megasporangium of lily, showing the mature female gametophyte: $o$, female gamete, below which are two synergids; $p$, the two polar nuclei uniting to form the endosperm nucleus; $a$, antipodal cells; mi, micropyle; $i$, integuments; $f$, funiculus in which a vascular bundle, $v$, has been formed to transport foods to the sporangium.

this conclusion. In the Pteridophyta the archegonia are formed at the close of the prothallial development. Among the species of the Gymnospermae there are several examples indicating that the archegonia are formed at earlier and earlier stages in the development of the gametophyte (p. 367). Possibly we have in the Angiospermae a final condition where the homologues of the 
archegonia are developed at the very start of the gametophytic growth. The nicety of such a sequence of development is altogether admirable. In the ferns, if fertilization is not effected, the prothallial growth is wasted, but in the angiosperms there is no prothallial growth without fertilization.

The male gametophyte presents several features suggestive of the gymnosperms. The germination of the microspores usually begins within the sporophylls, and by the time that they are shed and carried to the stigma, their nuclei have already divided once and each spore consists of a large tube cell and an antheridial cell (Fig. $272, B$ ). There is very rarely a trace of the vegetative

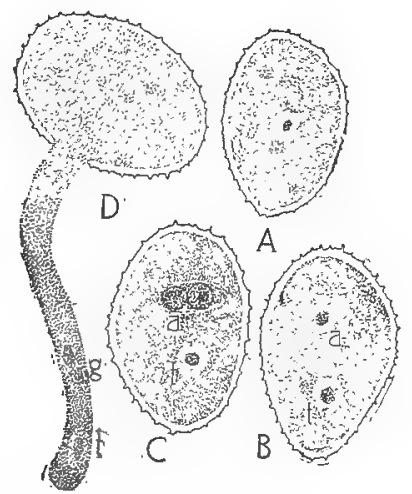

FIG. 272. Germination of the microspore: $A$, mature microspore of lily, $B$, first stage of germination- $t$, tube cell; $a$, antheridial cell. $C$, final division, in this case effected while in the microsporangium- $t$, tube cell; $a$, antheridial cell forming directly two male gametes. $D$, diagram showing the formation of the tube which grows down the style and finally reaches the female gametophyte. The two male gametes, $g$, are shown passing down the tube; $t$, tube nucleus. All the figures in sectional view.

cells of the gametophyte, as in the cycads and pines, since the necessity for these cells no longer exists. The stigma is generally provided with minute outgrowths or papillae derived from the epidermal cells which serve to hold the microspores (Fig. 269, s). These cells of the stigma usually secrete a sugary solution which nourishes the microspores and causes a continuation of their germination. It is noteworthy that these microspores may be made to germinate by placing them in sugar solutions, but the approxi- 
mate strength of the solution on the stigma must be determined in order to prepare a solution suitable for their development. The tube cell, stimulated by the secretion of the stigma, ruptures the outer wall of the spore, which is provided with one or more thin places to favor this growth, and protrudes as a delicate tube. This tube, owing to the fact that it is repelled by the oxygen of the air, grows down into the tissues of the style which are really a continuation of the stigma. These tissues of the style are usually looser and provided with abundant foods which are deposited in the cells just ahead of the elongating tube to nourish and direct it in its growth. In this way the tube is directed down the style to the cavity of the ovary where, owing to the attractive influence of the organic substances in the sporangium, possibly in the synergids, it usually turns out into the cavity of the ovary, enters the micropyle and works its way through the sporangium, and, unlike the Pinales, enters the female gametophyte generally alongside of one of the synergids (Fig. 273). 'The antheridial cell usually divides, forming directly two motionless male cells during the elongation of the tube, and in other cases these two cells are already formed when the microspores are discharged from their sporangia. In none of these cases is there any indication in the division of the antheridial cell of the formation of a wall cell as in the gymnosperms, so that the male gametophyte of the Spermatophyta presents a very regular series of reductions from the cycads to the pines and thence to the angiosperms, where it consists of a tubular growth containing three naked cells (Fig. 272,D). This development of the male gametophyte requires from a day to several months and is quite independent, apparently, of the distance that it has to traverse in reaching the female gametophyte. The male cells are often somewhat elongated and even spirally coiled and carried to the end of the tube, as in the Pinales.

I26. Fertilization.-The end of the tube finally ruptures, owing to the tension of the fluids that gradually accumulate in it, and the male cells are forcibly expelled into the sac-like cavity of the female gametophyte (Fig. 273). One of the male cells passes over to and fuses with the female gamete, thus forming the gametospore; and the other male cell unites with the polar 
nuclei, thus forming the endosperm nucleus through a triple fusion. While this process is probably in the nature of a reinforcement, enabling the endosperm nucleus to perform its work, it is noteworthy that the qualities of the male parent are trans-

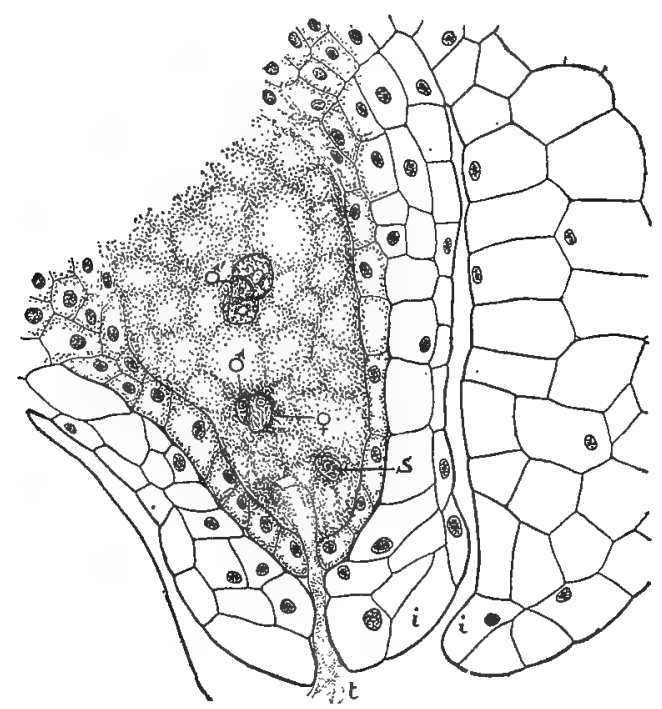

FIG. 273. Section of the micropylar end of the megasporangium, show: ing the process of fertilization. The tube, $t$, has passed through the micropyle, entered the female gametophyte and ruptured, discharging the male cells. One, $\sigma^{x}$, is shown fusing with the female gamete, $q$, and the other one, $\sigma^{\prime \prime}$, is uniting with the two polar nuclei, thus making a triple fusion in the formation of the endosperm nucleus; $s$, one of the synergids; $i$, integuments.

mitted to the endosperm cell just as though this fusion were a sexual process.

127. The Germination of the Gametospore.-After fertilization the endosperm nucleus divides repeatedly, and usually the resulting nuclei become arranged about the walls of the sac-like gametophyte which may now be called the embryo sac (Fig. 274). Later the endosperm cells develop walls and by further division completely fill the embryo sac with cells. This mass of cells is called the endosperm and the method of its development is exactly similar to that of the female gametophyte of the gym- 
nosperm, and it serves the same purpose, namely, to nourish the young sporophyte or embryo. Recall, however, that it originates in a different manner and at a different time in the life cycle.

The germination of the gametospore and the formation of the embryo vary so greatly that only a very general statement can be made. Following fertilization, the gametospore becomes surrounded by a cell wall and attached to the wall of the embryo sac (Fig. 275, $A$ ). It now begins to elongate and its nucleus divides several times, forming a row of cells (Fig. 275, $A, B$ ). This is the proembryo, the terminal cell being known as the embryo cell and the remaining cells as the suspensor. Less

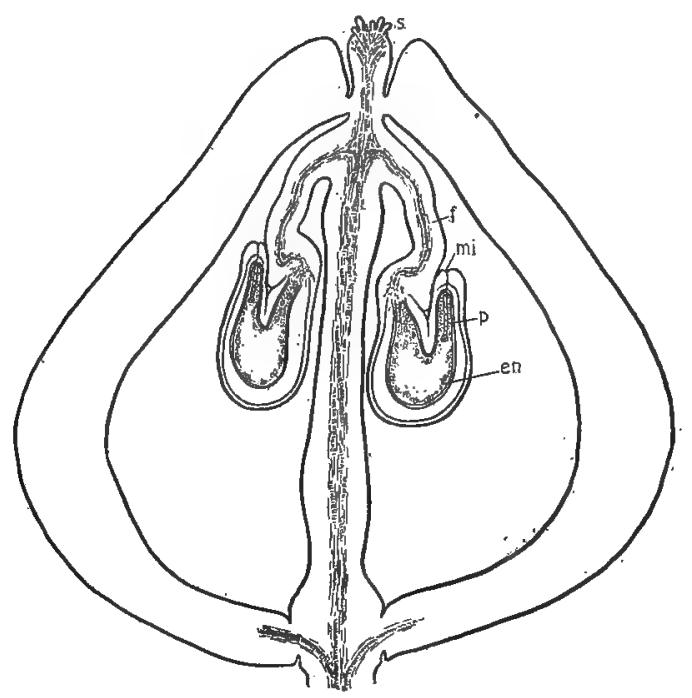

FIG. 274. Sectional view of megasporophylls of Lepidium shortly after fertilization (see Fig. 269); en, early development of endosperm cells about wall of embryo sac; $p$, young sporophyte developing from gametospore; mi, micropyle; $s$, stigma; $f$, funiculus.

commonly the proembryo is a mass of cells without any differentiation. This appears as a radical departure from the gymnosperms where the formation of free nuclei characterized the germination of the gametospore. But in passing from the cycads to the pines there is a steady decline in the number of free cells formed and indeed in one case in the latter group the proembryo 
consists of a row of cells. The synergids, which are partly consumed during the entrance of the tube cells and the process of fertilization, usually become entirely disorganized and absorbed during these early stages of germination. The embryo is formed by the repeated divisions of the embryo cell of the pro-embryo,

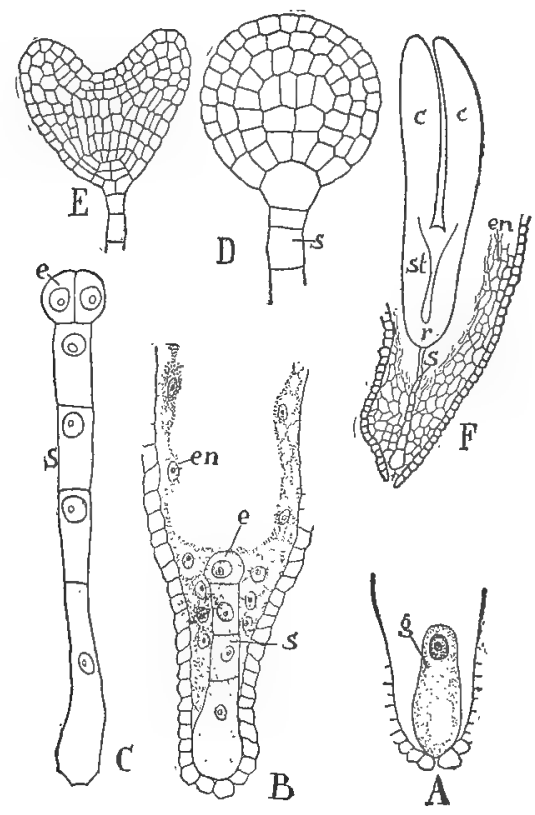

FIG. 275. Stages in the germination of the gametospore of Lepidium, sectional view: $A$, micropylar end of embryo sac, showing the enlarging gametospore provided with cell wall and attached to wall of sac. $B$, later growth-s, suspensor; $\epsilon$, embryo cell; en, endosperm cells. $C$, pro-embryo after first division of embryo cell. $D$, further divisions of embryo cell, showing formation of an epidermis and a central stem region. $E$, later growth, two growing regions, the cotyledons, appearing on the sides of the stem. $F$, micropylar end of the embryo sac in which the embryo cell has formed a small plant or embryo, consisting of two cotyledons, $c$; stem, st, which terminates in the root, $r$; the endosperm cells, en, are being absorbed by the enlarging embryo; s, suspensor.

assisted to a varying extent by one or more of the adjoining cells of the suspensor (Fig. 275, C-F). The remaining cells of the suspensor are ultimately disorganized or they may increase greatly in size and themselves become the principal means of 
absorbing food and transferring it to the embryo. The structure of the mature embryo varies greatly. In some genera, as in the orchids, Indian pipe, etc., it remains rudimentary, consisting of only a few cells. Among the monocotyledons, the embryo cell frequently produces the single cotyledon, while the next underlying cell of the suspensor forms the root and the laterally-placed growing point of the stem (Fig. 279). The pro-embryo of dicotyledons is frequently a filament of cells of varying length and the embryo cell, by a regular series of divisions, gives rise to the stem, two laterally-placed cotyledons and all of the root, save the tip, which is formed from the cells adjoining the embryo cell (Fig. 276, A).

I28. The Fruit and Seed.-Various changes occur in the sporangium during the growth of the embryo. More frequently, perhaps, the embryo sac enlarges, absorbing all the cells within the integument, and it becomes filled with endosperm cells. In a case like this, the embryo either remains small and embedded in the endosperm (Fig. 279), or the embryo may entirely consume the endosperm, the food in this case being stored in the cotyledons (Fig. 276, A). Less commonly, the embryo sac absorbs only a portion of the sporangial tissue (often called the perisperm) and consequently the embryo is associated with a varying amount of endosperm, which in turn is surrounded with sporangial cells or perisperm, as in the water lily (Fig. 276, $B$ ). The integument usually undergoes pronounced changes during this growth, becoming hard and tough to protect the parts within, and often developing appendages of various kinds, as hairs and wings, to promote the distribution of the seed (see gymnosperms, page 374 ).

The stimulus of fertilization extends beyond the changes wrought in the sporangium. This is particularly noticeable in the megasporophyll and often in adjacent parts which keep pace with the growth of the sporangium and often undergo remarkable transformations. The result of this total growth is called the fruit, while the term seed is restricted to the modified sporangium with its integument and embryo. The megasporophyll may form a firm coat that is closely attached to the seed, as in the corn and 
other grasses. Such a fruit is called a grain. Again the tough walls of the megasporophyll are free from the seed, as in the buttercup, forming a fruit known as the akene. The sporophylls may become papery or hard and split open to scatter the seed. Where a single megasporophyll behaves in this way and opens by two valves, the fruit is called a pod or legume, example the bean,
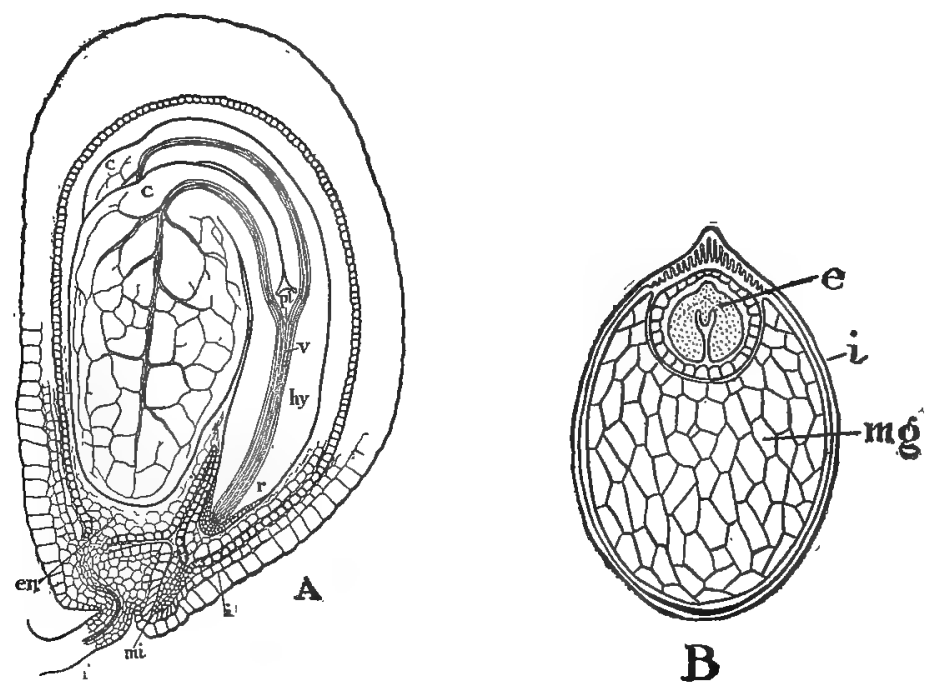

FIG. 276. Seed structure: $A$, section of a nearly mature seed of Lepidium. The stem of the embryo is differentiated below into a hypocotyl, hy, and above into an epicotyl, $p l$, commonly known in the seed as the plumule, $r$, root with root cap; $c$, the two cotyledons, which are bent over, lying one upon the other; $v$, vascular bundles extending through the stem into the cotyledons, where they form a network of veins; en, remains of endosperm. $B$, section of seed of water lily (after Conard)- $e$, embryo, surrounded by a layer of endosperm cells; $m g$, cells of the megasporangium; $i$ integument.

or if by one valve the fruit is termed a follicle, example the peony. Frequently wing-like processes develop from the megasporophyll, as in the maple and ailanthus, which are of service in distribution and in other ways, as in the manufacture of foods, these organs often being green during the development of the embryo. Such fruits are known as key fruits or samaras. In other cases the sporophyll becomes fleshy, forming a berry as in the currant or the inner layer forms a pit or stone, while the outer 
layer forms the pulp and skin, as in the cherry and peach, fruits known as drupes. In many fruits the receptacle becomes fleshy and forms the major portion of the fruit, as in the fig, apple, strawberry, etc., and in the pineapple, the axis of the inflorescence, as well as parts of the flower, become fleshy. These various devices serve primarily to preserve the life of the embryo and some of them also assist in distributing the seed.

When conditions are favorable for growth, which may not be till several years after the seeds have been scattered, the embryo renews its growth. The region below the cotyledons, the hypocotyl, or base of the cotyledon itself, elongates and pushes out the root which grows down into the soil, and by a later growth the stem tip, with or without the cotyledons which may remain in the seed, elongates and develops the characteristic stem, branches, leaves and sporophylls of the parent plant. The structure and variations of the mature sporophyte have been presented in the first part of the work (pages $7-145$ ), and will be further considered in the following studies. The terms sporangium, microsporophyll and megasporophyll have been retained up to this point in the work in order to keep clearly before you the progress and relationship of the variations that have attended the evolution of plant life. Now that we have arrived at the highest and largest group of plants, where the sporophylls have become highly modified and curiously associated in clusters called flowers, more familiar names will be used in discussing them, $i$. $e_{\text {., ovule }}$ for the megasporangium and its integument, stamen for microsporophyll and pistil for megasporophyll. The terms "carpel" and "pistil" are synonymous when these organs are distinct$i$. $e$., free from one another; but when they cohere to form a compound pistil the term "carpel" is employed to indicate the number of pistils that are united, as in the willow the pistil is composed of two carpels, in the lily of three carpels, etc.

While the sexual generation, mode of reproduction, and the character of the tissues are very similar in all angiosperms, two very distinct lines of variation or classes are to be noted: A, the Monocotyledones, represented by the grasses, lilies and orchids; $\mathrm{B}$, the Dicotyledones, represented by our common trees, roses, mints and daisies. 


\section{Class A. Monocotyledones}

I29. General Characteristics.-This group of angiosperms contains about 25,000 species that constitute a very natural alliance, owing to the uniformity and simplicity of their structures. These features may be due to the uniform conditions under which these plants live. The majority of Monocotyledones are moistureloving plants and are therefore exposed to very constant conditions, which would naturally result in less stimulation and consequent variation than in the case of plants exposed to the varying conditions of drier soils. Some, to be sure, have become adapted to dry and even arid regions, owing to peculiar modifications of their leaves or stems, as in the grasses, certain bulbous plants, etc.

The leaves are smooth and simple, lance-shaped or linear in outline, sessile and often attached to the stem by sheathing bases. The veins do not end in free branches on the margins of the leaves, and as a result of this closed venation the leaves are usually entire and destitute of teeth or lobed margins. In many instances the principal veins are quite parallel, but whatever the arrangement, the prominent veins are connected by very minute veinlets that form an inconspicuous network or reticulation throughout all parts of the leaf (Fig. 277). The stems are composed largely of parenchyma, through which are scattered numerous vascular bundles as in some ferns (Fig. 278) - see page 324 . These bundles rarely develop a cambium (Fig. 60) and consequently the stem does not increase materially in diameter, and usually it is columnar in appearance. In many instances the stems are reduced in size and are subterranean, the bulb and rhizome being common forms of stems which send up annually short-lived aerial branches. As a rule the stems do not branch, owing to the failure of the buds in the axils of the leaves to develop.

The flowers are also of rather simple and uniform structure, in the simplest cases being imperfect and consisting of either spirally arranged stamens or pistils without perianth. In the higher types spiral flowers with perianth and both kinds of sporophylls appear, and these give place to forms in which the organs are arranged in successive whorls of three parts each, the latter 
type of flower being especially common. Perigynous, epigynous and irregular flowers are of less common accurrence. The most conspicuous feature of the monocotyledons is the embryo, which has a single terminal cotyledon and a laterally developed stem tip

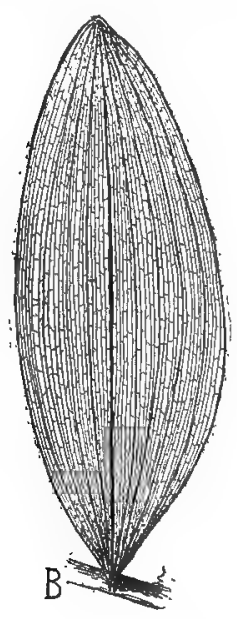

FIG. 277.

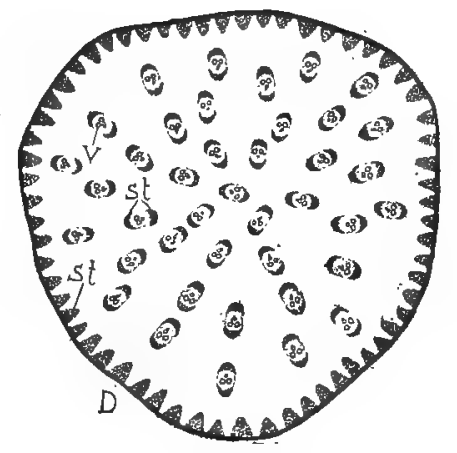

FIG. 278.

FIG. 277. Leaf of Solomon's seal with closed venation, entire margins, and sessile upon the stem, $i$. $\epsilon$., without petiole.

FIG. 278. Cross-section of stem of rush: $v$, vascular bundles; st, stereome.

(Fig. 279). Generally the root and stem tip are set free from the seed by the elongation of the basal portion of the cotyledon, while the cotyledon remains in contact with the endosperm as a food-absorbing organ, being often highly modified to perform this work. An examination of a few of the more important orders will give a better idea of the characteristics and variations of the monocotyledons.

r30. Pandanales, the Cat-tail Order.-The cat-tail, Typha, may be taken as an illustration of this order (Fig. 280). These plants live in wet and marshy places and present several variations that adapt them to such conditions. The main stem is a rhizome that branches through the mud and sends up each spring leafy stems. The rhizome grows on from year to year, and owing to the decay of the older portions, the branches become independent plants. In this way a single plant may spread and 
thickly populate an extensive marsh. The aërial stems live but for a year and are rather weak, but owing to the sheathing bases of the leaves they become sufficiently rigid to support a heavy foliage and withstand the winds. Notice also the extreme lightness of these organs. This is due to the larger air spaces which also permit a ready interchange of gases from the leaves to all parts of the plant, even throughout the submerged rhizomes. You would naturally expect to find this structure in all aquatics since the roots at least are submerged and all living cells require an interchange of gases (see page 54). The leaves are long

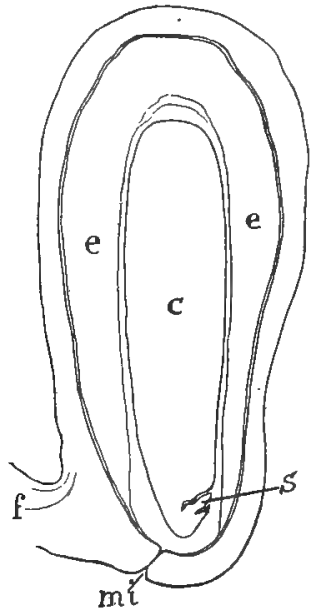

FIG. 279. Sectional view of seed of Veltheimia. The embryo consisting of a large cotyledon, $c$, and laterally placed stem, $s$, below which is the root, $e$, endosperm; $m i$, micropyle; $f$, funiculus.

and narrow and point nearly straight up in the air. This prevents shading and permits the association of the plants in dense colonies. The leaves are covered with a waxy coating or bloom to prevent the adhesion of water and the plugging of the stomata. This device is often to be seen on the leaves of plants that are subject to heavy dews or rains. Moisture is frequently not evaporated from the leaves until near midday, and if the stomata become filled with water, there can be no interchange of gases for photosynthesis during this time.

The flowers are of a very primitive type, consisting of naked 
sporophylls arranged in a compact inflorescence that assumes a spike-like structure at the tip of the stem. The sporophylls are protected until mature by modified sheathing leaves (Fig. 280, $A$ ). Each flower in the upper portion of the spike contains only two or three stamens supported upon a short stalk, which is associated with hair-like outgrowths (Fig. 28o, B), while the lower flowers of the spike bear a single pistil each (Fig. 280, C), which

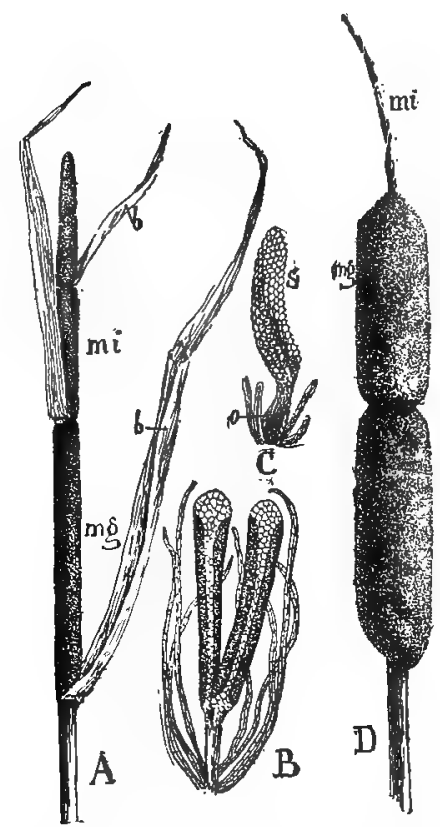

FIG. 280.

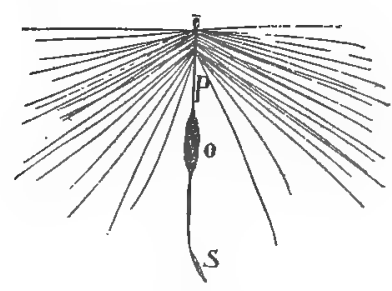

FIG. 281 .

FIG. 280. Inflorescence and fruit of Typha: $A$, inflorescence-- $b$, protecting bracts curving away from the sporophylls; $m i$, region of staminate flowers; $m g$, region of pistillate flowers. $B$, staminate flower consisting of two stamens sessile upon a short stem. $C$, pistillate flower of one carpel$s$, stigma; $o$, ovary containing a single ovule. $D$, appearance of $A$ in the fall-mi, region occupied by staminate flowers; $m g$, the pistils have increased greatly in size during the ripening of the seed.

FIG. 28I. The mature fruit of Typha: $s$, remains of the stigma; $o$, ovary $p$, elongated pedicel bearing numerous hairs. Compare Fig. 280, $C$.

consists of a large flat stigma, style and ovary containing a single ovule and supported upon a hairy stalk or pedicel. Note the 
association of numerous hairs with both the stamens and pistils. These organs are supposed to be sterile sporophylls so that we have here a very good illustration of a primitive type of flower. The microspores are carried to the stigmas of the pistils by the wind.

Such wind pollinated flowers are characterized by several features well illustrated in the cat-tail. The microspores must be produced in large numbers since the chance of one reaching the stigma of another plant rapidly decreases as the distance traversed by the spores increases. This probably accounts for the growth of such plants in dense colonies since the close proximity of the plants greatly increases the chance of the microspores reaching the stigmas. The Pinales, grasses, willows, oaks, etc., are other illustrations of a very large series of plants, some Io,ooo in number, that have a similar habit. Wind pollinated flowers are inconspicuous and simple in structure. You will notice that showy perianths, nectar and perfume glands are developed only in such flowers as utilize insects for the distribution of the microspores. The stigmas of these flowers are usually large and hairy or brush-like and conspicuously exposed so as to increase the chances of catching the microspores, thus reducing the dangers of this rather risky method of crossing. You will also observe that wind pollinated flowers are usually characterized by having imperfect flowers, the stamens and pistils being developed on different parts of the plant, or on different plants. By this arrangement, the advantages of crossing are secured and it also happens that the microspores are either scattered before the stigmas of neighboring flowers are mature, or, more frequently after they have withered and are therefore no longer capable of catching and nourishing the spores. In this way it comes about that the microspores, even when close to the pistillate flowers as in Typha, are often only of service when carried to some earlier flowering plant whose stigmas are mature. In the cat-tail, the microspores are shed a day or so before the stigmas on the same spike are mature and so there must result the benefit that comes from crossing two more or less widely separated plants (page I44). The stamens soon 
perish after the discharge of their spores, but the pistils increase greatly in size during the ripening of the seed and form conspicuous brown cylinders (Fig. 280,D). As winter approaches, the pedicel below the ovary and the hairs attached to it become greatly elongated and the sporophyll is thus transformed into a very stable parachute that is easily detached from the spike and capable of floating the seed in even the lightest winds (Fig. 28I). If this fruit chances to fall in a marsh, the torpedo-like seed after a time falls from the ruptured ovary and sinks in the water. When the growth of the seed is renewed, the base of the cotyledon elongates, pushes off the lid at the end of the seed and curves down so as to bring the root of the embryo in contact with the mud. Hairs now develop from the lower part of the cotyledon, anchoring the young plant to the ground while the tip of the cotyledon remains in the seed until the food is absorbed, when it is withdrawn. In the meantime, roots have developed and penetrated the soil and the stem tip begins to elongate, lifting up the cotyledon and making possible the formation of other leaves. The curious screw-pines, Pandanus, a large group from the oriental tropics and frequently seen in conservatories, belong to this order, also the bur reed (Sparganium). common about marshes and water ways, which is the highest member of the order.

I3I. Graminales, the Grass and Sedge Order.-This is one of the largest groups of the Spermatophyta, some 7,000 species being known, and in number of individuals it exceeds all others (Fig. 282). These plants are almost universally distributed over the earth and have become adapted to almost every,condition of climate and soil. The ability of these plants, which are of aquatic origin, to establish themselves upon the drier and more diversified land surface doubtless promoted variations and accounts in part for the enormous display of forms. The Graminales and the palms (Principales) which belong to an order related to Typha are about the only groups of monocotyledons that are associated in sufficient numbers to form striking features of the vegetation of a country. This is particularly true of the Graminales in all lands, where they constitute the principal vege- 
tation of hills, plains, meadows and marshes. These.plants are also of the greatest economic importance, furnishing a variety of foods, as wheat, rye, barley, oats, rice, corn, hay, etc. The bamboo also belongs to the order. The stem in the majority of forms is a rhizome (as in Typha), which branches extensively through the soil and sends up numerous aërial branches (Fig. 282, $B$ ). These interwoven rhizomes, with their numerous roots, form the firm swards of meadows and prairies. The aërial stems are models of mechanical construction. The ability of the long

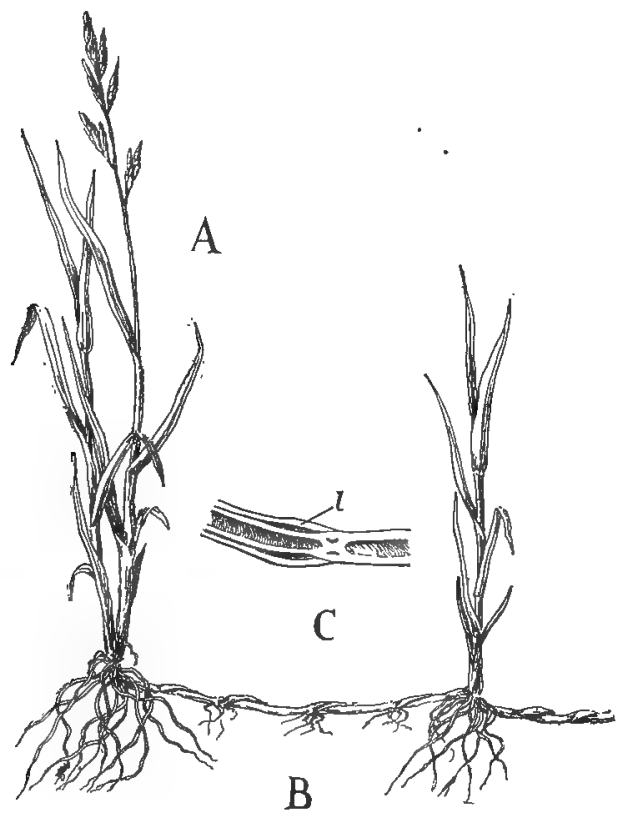

FIG. 282. Habit of growth of one of the grasses: $A$, aërial stem terminating in a branched inflorescence. $B$, underground stem or rhizome sending up a new shoot from one of the nodes. $C$, section through the node of a stem that has been placed horizontal, showing the sheathing leaf base, $l$, and the beginning of the upward curvature of the stem.

hollow stems of the grasses to support the heavy head of grain must appeal to every one. An examination of Fig. 282 will show you how the stem is reinforced by the long sheathing base of the leaves while tough, elastic strands of stereome fibers are so distributed as to give the best mechanical support. An un- 
usual localization of the growing regions also characterizes the grasses which enables them to lift up again their stems if they by any means become prostrate. In case the stem becomes prostrate, the stimulus of gravity causes a renewal of growth in the cells at the base of the node on the side of the stem next to the ground, thus causing the stem to curve up (Fig. 282, C). You can easily demonstrate this peculiar localization of growth by cutting. off a growing stem of grass and placing it horizontally with one end embedded in moist sand and noting the curvature

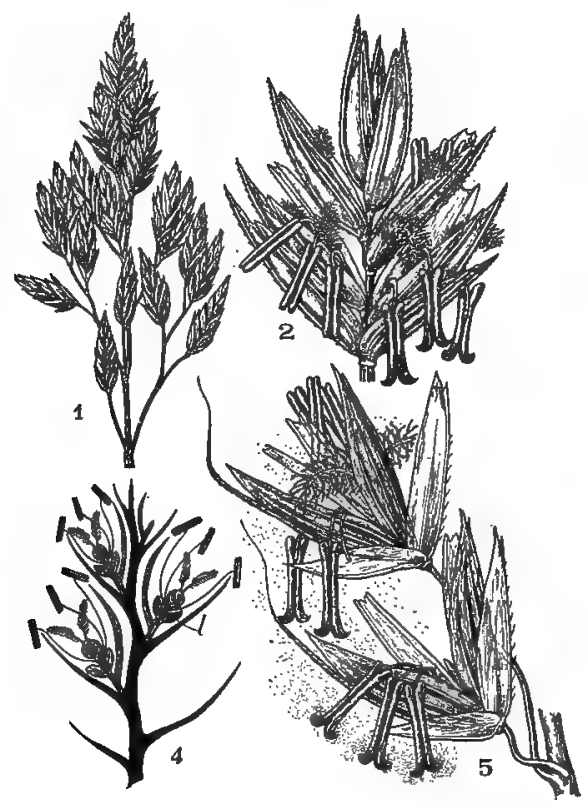

FIG. 283. Inflorescence of a grass: I, tip of stem with flowers arranged in spike-like inflorescences. 2, a single spike enlarged at time of flowering. 4, diagram showing structure of spike. At base two sterile bracts, above three flowers, each enclosed by an outer firm bract and an inner more delicate bract. $l$, lodicules. At apex of spike a sterile flower. 5, another species of grass, showing the scattering of the microspores.

of the node after a day. 'The leaves show wide variation in structure and are doubtless one of the factors that have enabled these plants to live under a variety of conditions. For example, where the plants are exposed to drought or drying winds the 
epidermal cells are very much thickened, stomata often sunken in narrow furrows and practically all species have the power of rolling up the leaves in dry seasons and thus reducing the leaf surface and lessening transpiration.

The flowers are exceptionally alike in structure and show about the same state of floral development. While resembling those of Typha in some particulars, they present several features that indicate a decided advance over the previous group. Fig. 283 illustrates the common types of inflorescence found among the grasses. The flowers are arranged on elongated branches, but instead of a large bract ensheathing the inflorescence (see Typha), each flower is inclosed by one or more small bracts so arranged as to form a spike-like structure of overlapping bracts (Fig. 283, 2). The two kinds of sporophylls may be arranged in separate spikes or on different parts of the same spike, or, as in many grasses, the stamens and pistils are developed in the same flower. One or more of the lower bracts of a spike are usually without flowers and above them are one to several flowers enclosed by secondary bracts (Fig. 283, 4). Removing the secondary bracts, the flower proper is seen (Fig. 284, 3A, $3 B$ ). This consists in many of the grasses of three stamens and one pistil and usually two small scale-like organs, the lodicules, which assist by their expansion in forcing open the protecting bracts at the time of flowering. The stamen consists of a long filament attached to the middle of the anther so that the latter organ can swing at the end of the filament, an arrangement known as the versatile anther. The stigma is often brightly colored and of a delicate feathery character, indicating that the plants are wind pollinated. The ovary contains a single ovule. The manner of flowering of the numerous genera of this order varies. In many cases the stigmas are first extruded from the bracts and can therefore be crossed only with the microspores from some earlier flowering plant. In other instances, stigmas and anthers are extended together and in some genera no injury results from the transfer of the microspores to the stigmas of the same flower. It is worth any one's time to note the time of flowering, the region on the spike where 
it begins and the manner of opening of the bracts and extension of anther and stigma. Many open between 6 and 7 A. M. on pleasant days. Owing to the swelling of the lodicules, or of the base of the bracts, these latter organs are forced apart, per-

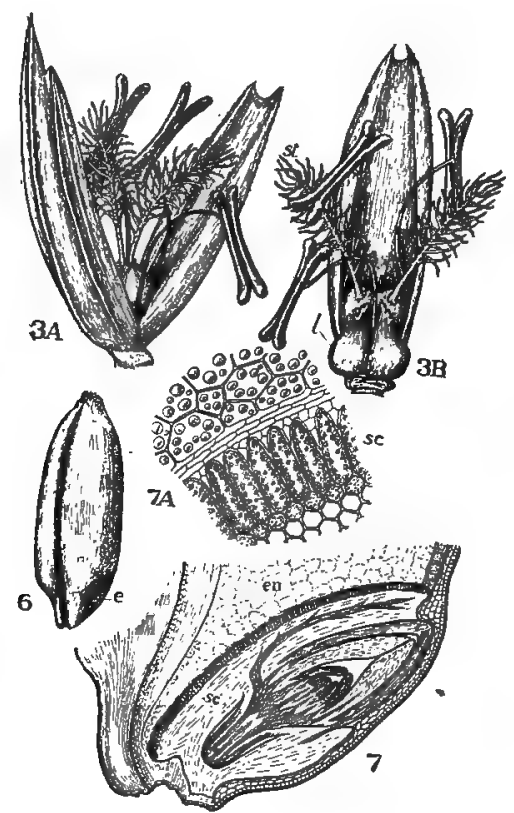

FIG. 284.

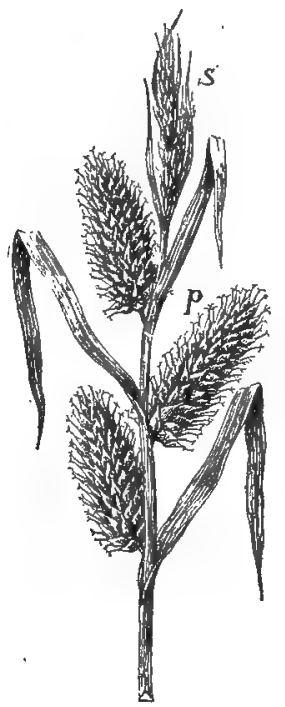

FIG. 285.

FIG. 284. Flower and fruit of grass: $3 A$, a single flower with the two enveloping bracts opened, exposing the stamens and pistil with feathery stigmas. $3 B$, flower with outer firm bract removed- $l$, lodicules; st, stigma. 6 , mature fruit or grain-e, region of embryo. 7 , section through base of grain, showing the root, stem leaves, and scutellum, $s c$, or absorbing organ of the embryo; en, endosperm. $7 A$, diagram of a few of the outer cells of the scutellum, sc.

FIG. 285. Inflorescence of one of the sedges, Carex: $p$, spike of pistillate flowers, each pistil is surrounded by a papery sac, through which the style and stigma protrude; $s$, spike bearing staminate flowers. Note the triangular stem, a characteristic of this large genus of over 1,000 species.

mitting the extension of the stigma and anthers. The filament quickly elongates and soon curves so as to allow the anther to swing back and forth in the wind. The two lobes of the anther now curve apart and open at their ends by a narrow slit, forming 
a cup in which the microspores collect (Fig. 283, 5). As the rocking of the anther in the wind sifts out the spores, more rattle down into the cup and so a very gradual scattering of the spores is effected. This entire process may be effected in a few minutes, and in the case of the wheat each flower is said to last for only I5 minutes. The Graminales includes two families: The Graminaceae, or grass family, and the Cyperaceae or sedge family. The grass family is by far the more important and is distinguished by the usually hollow aërial stems, two rows of leaves with sheathing bases split and the fruit is generally a grain (Fig. 284, 6). The sedges are largely paludose and of little value, the stems and leaves being often silicified. They usually have solid stems, three rows of leaves with sheathing bases entire, more simple flowers and the fruit is usually an akene (Fig. 285).

I32. Arales, the Aroid Order.-These plants are largely tropical and are characterized by large and generally net-veined leaves and showy inflorescences and fruit (Fig. 286). They present an odd series of striking forms quite different from other monocotyledons. Many of them are familiar plants owing to their extensive cultivation in green-houses, as the calla lily (Richardia), Caladium, often with variegated leaves, and the gigantic leaves of Dracontium and Colocasia, known as the elephant ear, and the curiously perforated leaves of the Monstera. Many species of Anthurium are climbers and reach to the top of the highest trees, sending out with great regularity from the successive nodes, naked branches that may reach the ground and form roots. The order is represented in temperate regions by a few very familiar genera as jack-in-the-pulpit (Arisaema), skunk cabbage (Spathyema), golden club (Orontium), sweet flag (Acorus), water arum (Calla). The duckweeds that float upon nearly every pond are extremely reduced allies of the order, representing the smallest seed plants known, Wolffia being an oval, rootless plant scarcely one millimeter in diameter.

The inflorescence is usually covered, as in Typha, with a bract known as the spathe. This organ is variously colored and often the most attractive feature of the plant. The coloration and the 
odors and glands that are developed in some of the forms indicate that these plants are pollinated by insects. The flowers are arranged upon a fleshy axis, the spadix, and in the simplest forms are quite comparable to those of Typha, consisting of one or a few stamens or a single pistil (Fig. 286, B-D). These im-

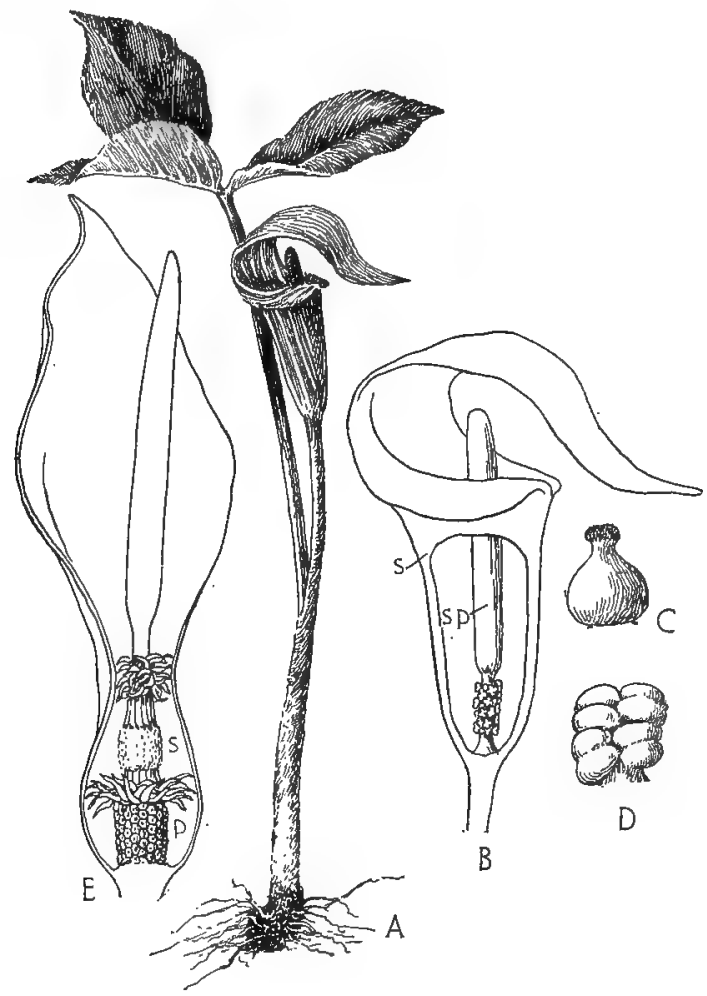

FIG. 286. Inflorescence of the Arales: $A$, habit of the jack-in-the-pulpit. $B$, diagram of the inflorescence with spathe, $s$, opened on one side to show the spadix, $s p$, bearing 'staminate flowers at the base. $C$, a pistillate flower consisting of a single naked carpel. $D$, a staminate flower of four two-lobed anthers. $E$, section of the inflorescence of one of the arums- $p$, compartment containing pistillate flowers; $s$, staminate flowers.

perfect flowers may be developed on different parts of the same spadix or on different spadices. In more advanced types, the flowers are perfect, containing one or several pistils that may be united and stamens which are surrounded by a very rudimentary 
perianth. The relation of these plants to insects is a very interesting one. The brightly colored spathe serves as an allurement and it also protects the microspores against wetting. The spores of comparatively few plants can endure water and it will be interesting to observe in the following lessons the devices that appear to guard against this danger. The spathe also affords shelter to the insect and the temperature is higher within the spathe since the food is being rapidly oxidized while the spores are forming. The temperature of the larger spadices may approach blood heat, being Io to $25^{\circ} \mathrm{C}$. higher than the outside air. Insects are not slow to avail themselves of these advantages and they also find an abundance of food in the microspores and glands that are often developed upon the spathe. Many aroids are characterized by the foul odors of decaying flesh and it is noteworthy that the coloration of the spathe is in singular harmony with these odors, resembling the hues of putrid meat. As a result of these variations, the lower orders of insects visit these flowers in great numbers and unwittingly serve in the transfer of the microspores; 250 carrion beetles and over I,000 midges have been reported as taken from a single spathe. You can readily demonstrate that small insects are attracted to the spathe by examining the inflorescence of the skunk cabbage and jackin-the-pulpit.

Common Examples of the Arales.-In the skunk cabbage (Spathyema foetida), which is of common occurrence along muddy streams, the inflorescence may appear as early as February, while the leaves are still rolled up into a compact bodkin to enable them to penetrate the soil. Later the leaves unroll and become very large, being good types of aroid leaves with broad blades, strongly net-veined and evidently adapted to abundant moisture and rapid transpiration. The spathe is shell-like, mottled with purple, green and yellow and encloses a fleshy oblong spadix that is entirely covered with flowers. You will find that small insects are attracted to these spathes in great numbers and spiders often take advantage of this fact and spin their webs out of sight in the darker recesses of the spathe. In this plant, the flowers are decidedly in advance of those noted in Typha, 
being perfect, and in addition containing a perianth of four sepals which arch over the sporophylls. The crossing of the flowers is effected in a variety of ways. In some cases the inconspicuous stigmas first push out from between the sepals so that microspores must be brought from another earlier flowering plant. In other cases, the stamens at the top of the spadix are first extruded and shed their spores; while at the bottom of the spadix the reverse condition obtains, the stigmas being in a receptive condition. This might result in a crossing of the upper flowers with the lower, and later, when the lower flowers put out their stamens and the upper their stigmas, insects could effect a reverse crossing. As the seeds mature the spadix and sepals become large and spongy, enclosing the ovaries which are finally set free by the decay of the spadix, as fleshy berries. This fruit is admirably adapted to the aquatic habit of these plants and readily floats in the water, owing to the spongy outer tissues, and so bring about the distribution of the seeds. The jack-in-thepulpit has a surer method for effecting a crossing, since the sporophylls are usually borne on separate spadices. You will often find, however, spadices with a few stamens situated just above the pistillate flowers. The flowers are very simple, consisting of a single naked pistil or of four nearly sessile stamens (Fig. 286, C-D). The fruit is a shining bright red berry.

In some of the tropical genera the insects are held in the spathe by hairs that extend obliquely downwards, thus permitting the entrance but blocking the exit of the insects until crossing of the flowers has been effected. In one of the species of Arum there are two sets of hairs that divide the spathe into two compartments containing respectively staminate and pistillate flowers (Fig. 286, E). As soon as the spathe opens the insect ladened with microspores from another flower makes his way to the lower chamber, where the stigmas are in a receptive condition. Here he is held a prisoner and rubs the microspores upon the stigmas as he wanders about in the compartment. When the microspores in the upper chamber begin to discharge, the lower set of hairs wither, giving him entrance to this chamber, where he feeds upon the microspores and becomes covered with them. 
Finally the upper set of hairs wither and he is free to leave the spathe and repeat his work in another inflorescence.

I33. Liliales, the Lily Order.-The members of this order comprise nearly 5,000 species that are widely distributed and extensively cultivated for their showy flowers. We have now reached a point in the evolution of the flower where it has become perfect and the protective spathe of preceding orders is replaced by a well-developed perianth. The floral axis also becomes short-

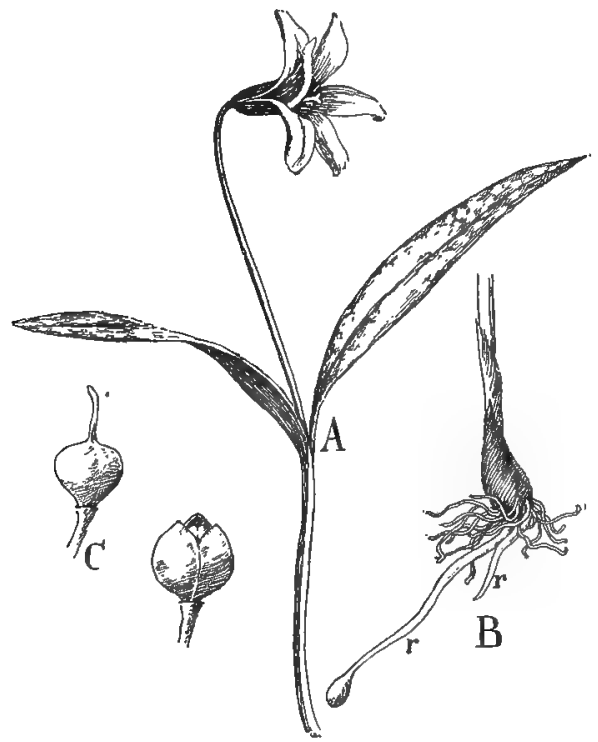

FIG. 287. The fawn lily, Erythronium americanum: $A$, habit of the plant. $B$, the bulb, showing the origin of the stem and leaves shown in $A ; r$, runners that penetrate the soil forming new bulbs at their tips. $C$, pistil of three carpels, at the right the fruit, a capsule, opening to scatter the seeds.

ened and we pass from the spiral series of flowers with a variable number of organs to the cyclic flowers with a definite number of organs arranged in whorls. In the lily order there are five whorls of organs of three members each, the stamens being arranged in two whorls. Note also that this crowding usually results in a compound pistil of three carpels (Fig. 287, C). These plants are largely perennial, with underground stems in the form of bulbs or rhizomes. This feature adapts 
many of them to dry and steppe regions, from which source many of our cultivated lilies have been obtained. It will be seen that this habit of storing food in underground stems enables these plants to develop their leaves, flowers and fruit during the short rainy season, after which the entire aërial portion withers away and their life lies dormant in the buried stems. This habit is equally serviceable if these plants come into competition with larger forms, as in forests where plants with bulbs and rhizomes may complete their annual growth before the grosser vegetation that would crowd them out is fairly started (see page 44).

(a) The Fawn Lily, Erythronium americanum.-This species may be examined as typical of the order (Fig. 287). This plant has received the atrocious name of adder's tongue, which is offensive and far-fetched, and also of dog-tooth violet, although it is not a violet at all. Burroughs has suggested the very appropriate name of trout lily, since the mottled leaves often form conspicuous beds on shady banks of streams; but to those who have experienced the spring time in the north country, the term fawn lily seems singularly appropriate. The leaves of the fawn lily spring from deep-seated bulbs that are formed in a peculiar way. The seed germinates on the surface of the soil and forms a very small bulb and a single grass-like leaf. During each succeeding season a larger leaf and bulb are formed, and when of sufficient size, the bulb sends out one or more runners that penetrate the soil and develop new bulbs at their tips (Fig. 287, B). In this way the bulbs become deep-seated and rapidly increase in numbers, and after several years they attain sufficient size to develop two leaves and a flower. The mottled leaves have the same habit of rolling up in emerging from the ground, as noted in the skunk cabbage. It is to be observed that the position assumed by the mature leaf of many plants is often strikingly correlated with the extent of the root system. In the Liliales generally, which do not have extensive lateral roots, the hang of the leaves is such as to direct the water that falls upon them towards the center of the plant, a feature doubtless of considerable advantage to plants living in semi-arid regions. The flower is of a decidedly higher type than any previously studied and it 
presents several features of special interest. The flower is laterally placed or slightly pendulous. The perianth is conspicuously developed, consisting of two whorls of three numbers each though these organs are not as yet fully differentiated into calyx and corolla. The stamens are also arranged in two whorls of three members each and the three carpels form a single whorl appearing as a compound pistil. The members of these whorls alternate

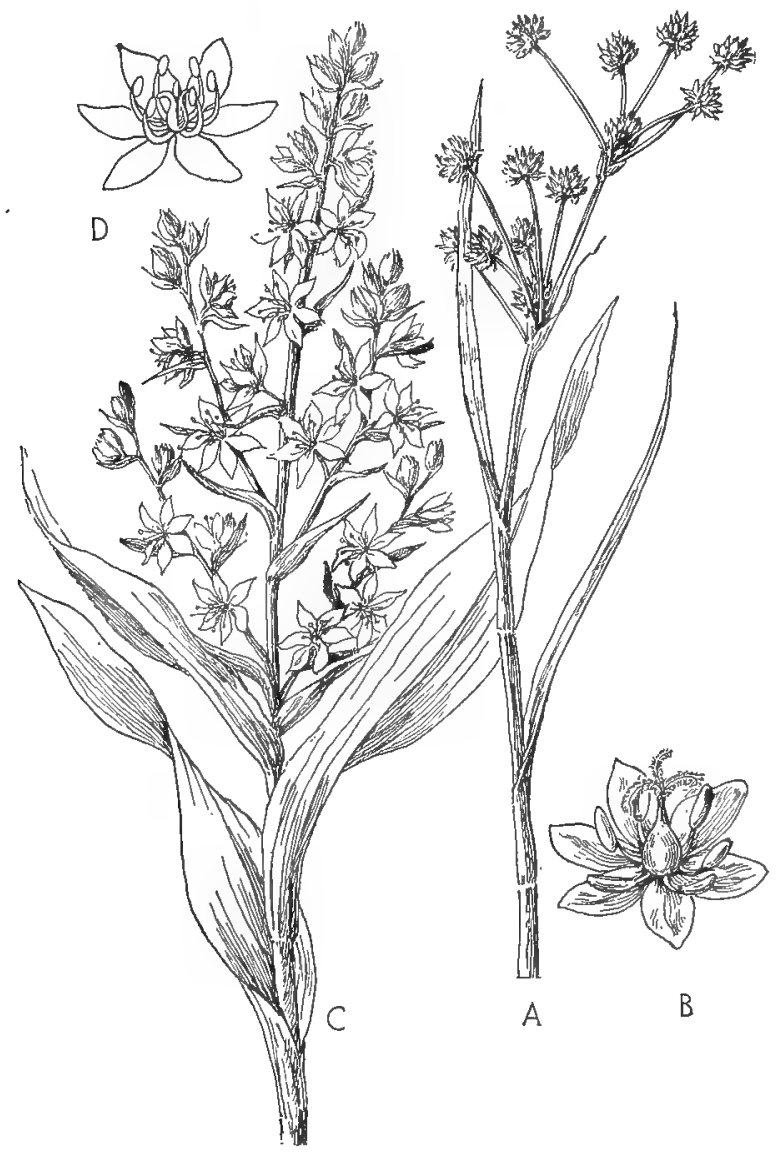

FiG. 288. Lower forms of the Liliales: $A$, a common rush, Juncus, showing grass-like appearance of the stem and inflorescence. $B$, a flower enlarged, showing a lily type. $C$, white hellebore, Veratrum. $D$, flower enlarged, showing the partial coherence of the carpels of this primitive type of the Liliales. 
with each other, so that the flower has three planes of symmetry. At maturity the walls of the ovary become papery and split down the side, thus freeing the seeds. This form of fruit is known as the capsule, and is of very common occurrence in the order (Fig. 287,C). The development of a conspicuous perianth is a noteworthy departure. This structure protects the microspores and replaces the bracts and spathe of preceding orders, but owing to its peculiar coloration and form, it also serves as an attraction to special kinds of insects. In the preceding forms that attracted insects, the inducements were usually in the nature of shelter and foods, which were largely the microspores that were offered freely to all. Such flowers are principally visited by a low order of stupid flies and beetles that are rather promiscuous feeders and are quite as likely to go from a flower of one species to that of a different kind, or to some other object and so defeat the principal object of the flower. With the development of the perianth, however, the flower is equipped with a device that primarily serves to exclude these less desirable visitors and to attract the more intelligent ones. In Erythronium the perianth is in a horizontal position, so that it offers a natural landing place for the insect, and the inducement is a sugary solution secreted by nectar glands concealed at the base of the perianth. It is an easy task for the more intelligent long-tongued insects, like the bees, wasps and butterflies, to reach the nectar in this type of flower. Such insects come to know by experience how to gather the food from a particular form of flower and consequently they will often confine their attention to a single species during their entire flight; consequently the flower by excluding the less intelligent and slothful insects is more certain of being properly crossed. The development of nectar and also of odor glands is among the important variations that appear in the evolution of the flower. It is chiefly by means of the perfumes derived from these organs that the insect is directed to the flowers. The coloration is also of service, when the insect is near to the flower, thus supplementing the perfume glands by directing him to the proper entrance. Some of the larger and more brightly colored members of this and other orders appa- 
rently depend entirely upon the attraction of their colors, while other forms rely upon perfumes, the flowers being small and inconspicuous and often hidden. So we have reached a point in the evolution of the flower where it presents a number of variations that are adapted and of benefit to special kinds of insects. Insects have likewise varied and some have become of special use to flowers owing to their peculiar form. In this way certain insects and flowers have become dependent upon each other, and as à result of their mutually beneficial variations, the flowering plants and insects have greatly increased in numbers and exceeded all other groups in the plant and animal kingdoms (p. 388).

(b) Other Forms of the Lily Order.-This order comprises an extensive series of plants that present nearly all the variations that occur in the flower. At the bottom of the series is the Rush family with grass-like stems and leaves (Fig. 288, $A, B$ ). The flower has the same structure as noted in Erythronium, but the perianth is composed of small scale-like leaves destitute of nectar glands, and as you would expect, is wind pollinated. The Bunchflower family is a somewhat higher type. The perianth is somewhat larger and more delicate then in the rushes and the carpels are often but partially fused (Fig. $288, C, D$ ). The flowers gain in conspicuousness by being associated in compact inflorescences, but do not develop as a rule the bright colors characteristic of large flowers. The family is represented by Tofieldia, swamp pink (Helonias), blazing star (Chamaelirium), Zygadenus, hellebore (Veratrum), bellwort (Uvularia), autumn crocus, etc. The Lily of the Valley family is characterized by rather larger flowers than those of the previous family, and they are less clustered and often provided with tubular perianths owing to the mass growth of the perianth segments. The fruit is a berry, unlike the majority of the families of this order. Here belong the asparagus, the false and true Solomon's seal, Indian cucumber, Trillium, and the closely related Smilax, etc. The Lily family includes nearly one half of the members of the order and occupies a medium position in the evolution of the group. The flowers are large and of the Erythronium type. Here belong some of the most showy of our native and cultivated plants; the 
day lily, Erythronium, tulips, hyacinths, lilies, Fritillaria, onion, aloes and Spanish bayonets $(Y u c c a)$ of arid regions. Among the higher genera of the Lily family the organs of the perianth often form a tubular structure. In the Amaryllis family we find the same type of flower and fruit as in the Lily family, but the basal growth of the receptacle has enveloped the ovary so that the flower has become epigynous (Fig. 289, A). This

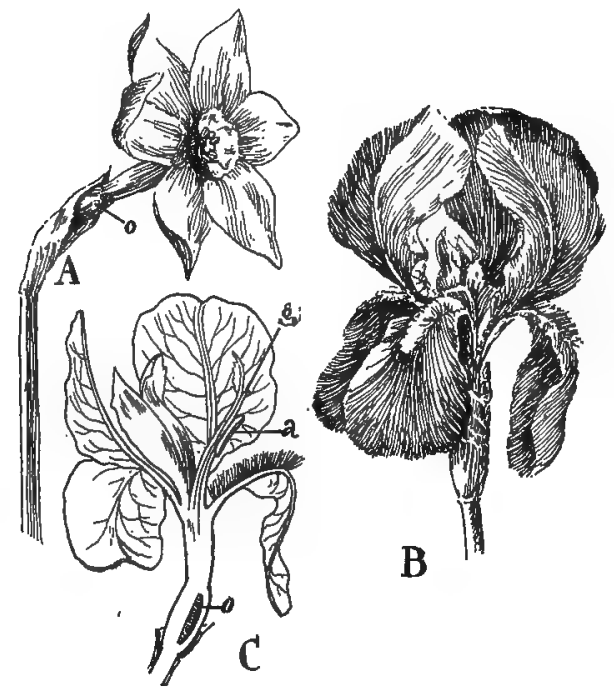

FIG. 289. Advanced forms of the Liliales: $A$, Narcissus with inferior ovary, $u$. The six sepals cohere at their base, forming a tube and they also develop an outgrowth at the mouth of this tube, which surrounds the anthers and stigma like a cup. $B$, flower of Iris. $C$, section of same, showing inferior ovary, $o$; stigma, $g$; and anther, $a$.

large family furnishes a number of showy flowers, as the jonquil and daffodil (Narcissus), amaryllis, snowflakè, Crinum, star grass, century plant, etc. The flowers of some genera become irregular through the unequal development of certain leaves of the perianth. The Iris family marks the culmination of the variations noted in the order. The types of flower and fruit are like those of the previous family, but the crowding on the receptacle has resulted in the obliteration of one whorl of stamens. The structure of the flowers often shows a series of variations that adapt them to insect visitors and crossing, as is well illustrated 
in the iris (Fig. $289, B, C$ ). The styles have a very unusual form, resembling a leafy organ with the stigma on the upper side of a small projecting shelf. Beneath each of these curving styles is a stamen. The insect naturally alights upon the broad leaf of the outer whorl of the perianth and the peculiar coloration of this leaf probably directs him to the nectar secreted at the base of the perianth. In reaching this food he crowds down into the tube and rubs off the microspores upon his back. In leaving the flower he cannot hit the stigma, but in visiting another flower it can readily be seen that he will deposit some of the spores upon the stigma situated upon the top of the shelf, thus effecting a crossing. This order includes a large number of showy cultivated forms, as the iris, fleur-de-lis, crocus, gladiolus, Friesia, blue-eyed grass, etc.

I34. The Scitaminales.-This order is confined largely to the tropics and includes such familiar plants as the banana, the traveler's tree, ginger plant, canna, etc. It is mentioned here as furnishing an interesting illustration of the variations that often appear in epigynous flowers as a result of the crowding of the organs upon the receptacle. Tendencies toward irregularity appeared in the epigynous families of the Liliales, but in this order these variations become very marked and make less abrupt the transition to the next order. The flowers of the banana are suggestive of the Amaryllis family, though somewhat irregular. All of the perianth leaves but one are united and only five perfect stamens are developed. These flowers are united into groups in the axils of bracts that form large buds at the ends of the stem. As the bud elongates, the basal or lower bract is first curved back from the bud, thus exposing the flower cluster, and this expansion goes on until all the flowers are exposed. The lowest flowers in the inflorescence are imperfect, containing only pistils, the central are perfect and the upper ones bear only stamens. Only the ovaries of the lower flowers of the inflorescence develop, each "hand" of bananas representing the matured ovaries of the flowers in the axil of the bract. Singularly, seeds do not develop in the edible banana, although you can see minute dark-colored ovules forming three radiating lines in a cross-section of the 
fruit. The ability of these plants to propagate themselves by means of buds developed on the underground rhizomes may have resulted in the loss of the seed habit. A great many plants are so successful in propagating themselves by buds, bulbs, runners, etc., that they have ceased to produce seed. In the higher members of the order, as in the ginger and canna families, the flowers become very irregular through the unequal development of the leaves of the perianth or in some forms on account of the abor-

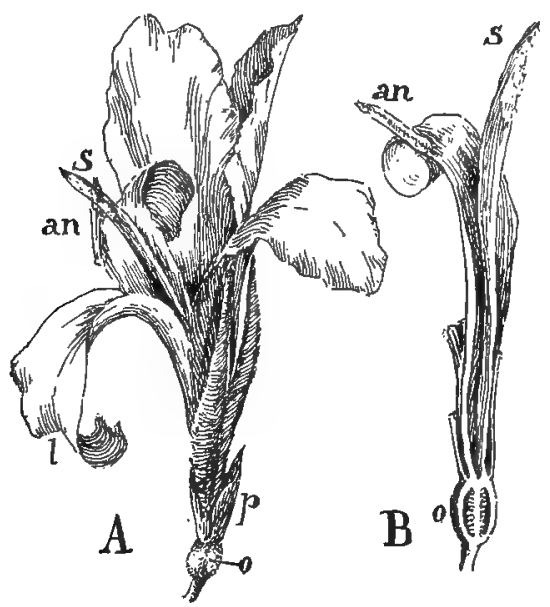

FIG. 290. Flower of Canna, the showy petal-like organs being modified stamens (staminodia) while the perianth proper, $p$, is reduced to green bractlike organs: $l$, labellum; $a n$, anther on petal-like organ; $s$, stigma; $o$, ovary. $B$, section of flower, showing ovary, $o$, the modified stamen, an, and stigma, $s$, the other organs being removed.

tion or transformation of all the stamens save one into petal-like organs termed staminodia. Usually one of the leaves of the perianth, or one or more of the staminodia, are highly modified and known as the labellum. This organ is so placed as to afford a natural landing place for the insects visiting the flower and also to necessitate crossing (Fig. 290). Observe a bee visiting the flowers of the canna and determine the significance of the position and movement of the labellum and its relation to the stamen and stigma.

I35. Orchidales, the Orchid Order.-The orchids are the 
highest group of the monocotyledons and their flowers are a source of wonder and admiration, owing to the singular beauty and delicacy of their mechanical construction. Variation in this order has occurred on a gigantic scale, resulting in a larger number of species (over 7,000 ) than is found in any of the preceding orders. Nevertheless these elaborate variations have not been very successful in enabling them to compete with other plants, and as a result the orchids are rather rare and not at all comparable in number of individuals with the lilies and grasses. Though more widely distributed than any of the other monocotyledons, their variations have adapted them as a rule to peculiar conditions. They are especially abundant in the mountainous districts of the tropics, where they more commonly appear as epiphytes upon the trunks of trees and in the crevices of rocks. Such conditions are met by the development of a thick mantle of cells about the aërial roots, the velamen, which absorbs the moisture from the air and doubtless the enlargement of the leaf base in some of these plants into a bulbous storage organ enables them to anticipate in this way the heavy demands that will be made upon them in the flowering season (Fig. 29I). The terrestrial forms are largely parasitic or saprophytic and associated with mycorrhiza, and this has resulted in some of the forms in the suppression of various organs of the plant as the primary root or even of the entire root system, as is illustrated in the coral root orchid, where the leaves have also become reduced to mere scales and the chlorophyll has disappeared. The dependence upon fungal life has reached such a stage in some forms that the seeds do not germinate unless hyphae come in contact with them (p. 69). The organs of the flowers are subject to such remarkable variations that the various parts may appear at first somewhat difficult to recognize. It is evident that the same line of variation noted in the higher families of the Liliales has been continued, for the perianth is arranged upon a compound ovary, but its parts are often sharply differentiated into calyx and corolla. The sepals and petals comprising these two whorls differ greatly in form, but especially to be noted is the oddly constructed petal known as the labellum (Figs. 292, 293, l). This 
organ is the most striking feature of the orchid and it assumes an almost endless variety of forms and colorations, being a good illustration of Wallace's law that the most highly modified part shows the greatest variation in coloration. In Cypripedium (Fig. 292, A) the labellum assumes the form of a moccasin, in other genera it resembles a vase, boat, tongue, body of insect, etc. It

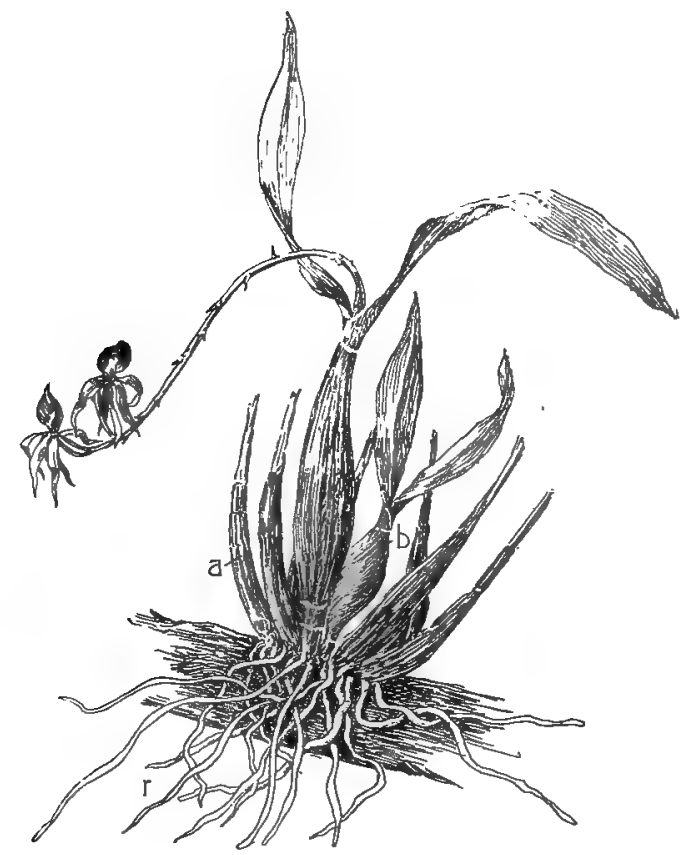

FIG. 291. An epiphytic orchid growing upon the branch of a tree. The coarse roots, $r$, are surrounded by a mantle of cells which takes up the moisture from the atmosphere. $-b$, storage organs formed from the base of the leaves, enabling the plant to produce flowers and fruit. The smaller stalks, $a$, are the shriveled remains of these organs after flowering and fruiting.

is entire or variously lobed, slit, fringed and often prolonged into a tube for the concealment of nectar. The stamens and stigmas are reduced in number and greatly modified, the former organs usually being reduced to one and so fused with the style that the anther is sessile upon it (Fig. 292, B). One or two of the stigmas are generally modified into a mucilage-secreting organ, called the rostellum (Fig. 293, $A$ ). The microspores are usually united 
into a waxy mass, pollinium (pl. pollinia) which is attached to a sticky part of the rostellum (Fig. 293, B, C). The remarkable feature about these gaudy flowers is the relation that the labellum, anther, rostellum and stigma sustain to each other. The position of these organs is such that an insect visiting the flower touches with some part of his body the sticky part of the rostellum and the pollinia are thus made fast to him and carried to the stigma of another flower. These devices are so elaborate in many orchids that the microspores can only reach the stigma through the agency of an insect. In the lower types of orchids, as the moccasin flower (Fig. 292, B), a somewhat different

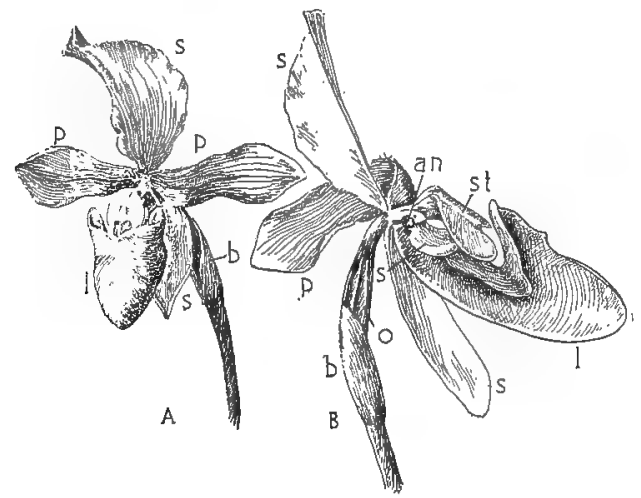

FIG. 292. A simple type of the Orchidales: $A$, the moccasin flower, $C y$ pripedium- $l$, labellum; $p$, the two unmodified petals; $s$, sepals, two being united below the labellum; $b$, bract, partially concealing the inferior ovary. $B$, section of the flower- $l$, labellum; $s$, stigma; $a n$, anther; st, shield-like sterile stamen covering the two anthers and stigma; $o$, ovary; $b$, bract.

arrangement is found. The bee enters the opening in the upper part of the labellum and feeds upon the glands distributed along the bottom. In leaving the flower he forces his way through the small opening on either side of the style and so he first comes into contact with the stigma and later with the anthers, which are two in number and located back of the stigma. In this flower the anthers are surrounded by a sticky mass and the microspores are thus fastened to the insect's body to be carried to another flower. In the higher types of orchids, the insect probing for the nectar touches the sticky discs of the rostellum, to which the 
pollinia are attached, and in this way they are fastened to his body and drawn out of the open anthers when he leaves the flower (Fig. 293, C). In some cases the pollinia quickly curve after being withdrawn from the anther, with the result that this change of position brings them into line with the stigma of the next flower visited. In other genera certain cells are irritable and in a high state of tension. A touch causes an explosion that results in hurling out the pollinia which always land on the end to which the sticky disc is attached and so become fastened to the

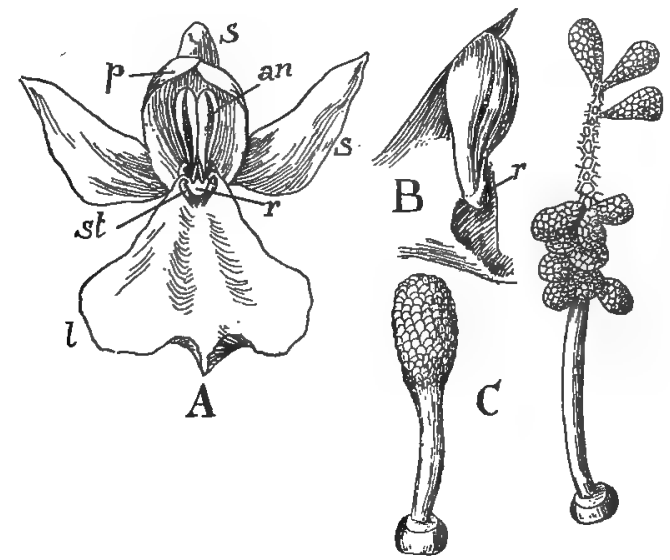

FIG. 293. Higher type of the Orchidales: $A$, flower of Orchis-l, labellum; $p$, the two unmodified petals; s, sepals; $r$, rostellum to which the two pollen masses, pollinia, in the two-lobed anther, an, are attached by sticky discs; st, stigma. $B$, enlarged lateral view of the anther which has opened, exposing the pollinia. $C$, one of the pollinia withdrawn from the anther showing adhesive disc at base which is attached to the rostellum. At right a pollinium enlarged, showing the small masses of microspores, massula, that may be separately detached from the pollinium.-After Warming.

insect. (See Darwin's Fertilization of Orchids for a discussion of the multiplicity of these arrangements.)

The seeds are among the most rudimentary of the Spermatophyta, consisting of an undifferentiated, few-celled embryo without endosperm and surrounded by a delicate bladder-like integument. They are exceedingly small and produced in enormous numbers; in fact, the seeds of the rattlesnake orchid, Peramium, weigh but two millionths of a grain each and float in the air like 
dust particles. The fringed orchis (Blephariglottis), Arethusa, ladies' tresses (Gyrostachys), rattlesnake plantain (Peramium), grass pink (Limodorum), rose pogonia, showy orchis (Galeorchis), moccasin flower (Cypripedium) are among the common and more showy of our native orchids.

\section{Class B. Dicotyledones}

136. General Characters.-The structure of these plants is more complex than that of the monocotyledons and their variations have been more extensive and successful, over I00,000 species being known. For this reason they are adapted to a greater range of conditions and have become the dominant plants, forming the conspicuous and characteristic features of the vegetation of the earth.

The dicotyledons may be short-lived annual plants, or perennials, and they include a great variety of climbers, epiphytes, parasites, and saprophytes and comparatively few aquatics. The most extreme forms of xerophytes are also found in this group. The leaves are highly differentiated, usually consisting of a blade and petiole which is often associated with small leaf-like organs, the stipules (Fig. 294). The blade varies in form and is often characterized by teeth and various forms of lobing. This is due to the fact that the veins usually differ from those of the monocotyledons in that they repeatedly branch, becoming smaller and smaller and thus forming a network or reticulated venation with free ends on the margins and other parts of the leaf. The stems are markedly different from the previous class, owing to the arrangement of the vascular tissues in a circle about the pith (p. 76) and the formation of a cambium cylinder which brings about an increase in the diameter of the stem (Fig. 295). This arrangement gives the plant a great advantage, permitting the extensive system of branching that characterizes the group and the consequent increase in the display of foliage.

The flower is subject to the same modifications as noted in the monocotyledons. Among the lower orders, the flowers are quite as simple as those of the primitive monocotyledons and the development of imperfect and wind pollinated flowers is of common 
occurrence. The spiral arrangement of the numerous organs of the flower will also be noted. The majority of the orders of the dicotyledons, however; are characterized by perfect, cyclic flowers and the various sets of organs usually consist of four or five members each. The perianth, when present, is generally differentiated into a green calyx and a variously colored corolla.

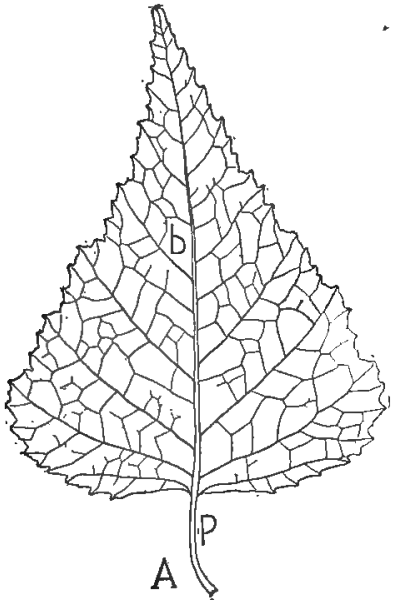

FIG. 294.

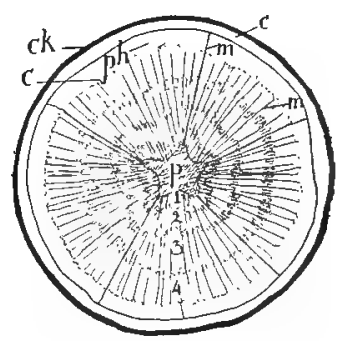

FIG. 295.

FIG. 294. Leaf of white birch, the blade, $b$, traversed by a network of veins that end in free branches (the margin irregularly toothed or dentate) and supported upon a petiole, $p$.

FIG. 295. Diagram of a cross-section of a stem of black oak four years old: $p$, pith; $1,2,3,4$, annual rings of xylem; $c$, cambium cylinder; $p h$, phloem; $c$, cortex; $c k$, cork; $m$, medullary rays.

The stamens are more frequently arranged in one or two whorls, equalling or twice the number of the sepals, and the pistils usually form a single whorl, equalling or less than the number of sepals. The crowding of the various organs, and the lateral growth of the receptacle results in the reduction in the number of organs and in their mass growth so that in the higher types the calyx and corolla become more or less tubular and the carpels form a compound ovary. The basal growth of the receptacle also causes the frequent occurrence of the perigynous and epigynous typts of flowers. Irregularity of the flower is more common than in the 
monocotyledons and this feature will be seen to characterize the higher members of many of the orders. .

The most characteristic feature of the dicotyledons is the embryo which usually consists of a root, stem, and two laterally attached cotyledons. The region of the stem above the attachment of the cotyledons is known as the epicotyl and frequently appears as a minute bud, the plumule. The region of the stem below the cotyledons, the hypocotyl, terminates in the root (Fig. 296).
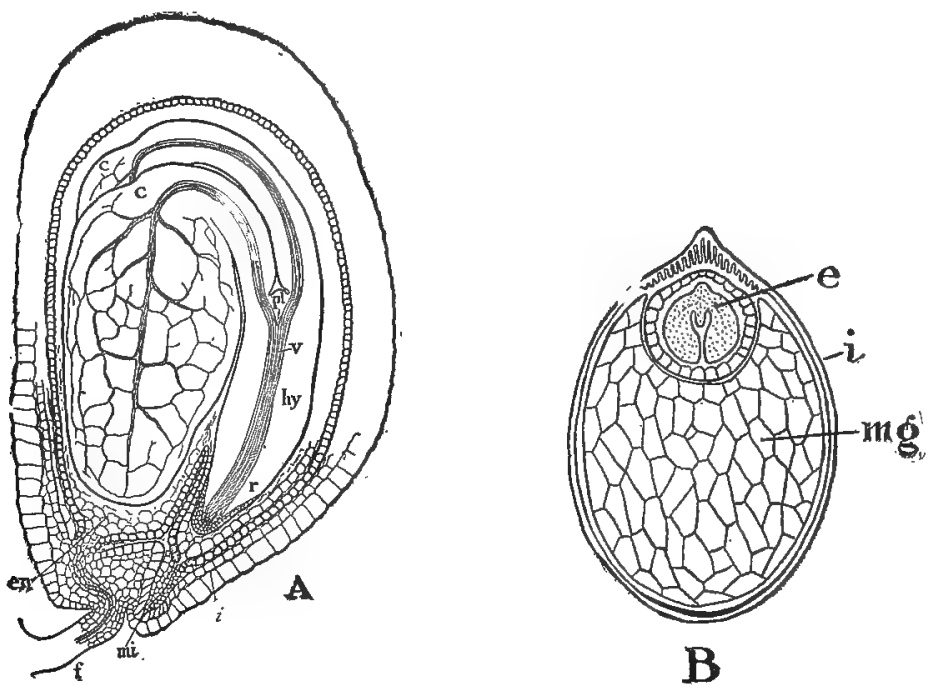

FIG. 296. Structure of dicotyledonous seeds: $A$, nearly mature seed of Lepidium. The embryo consists of the hypocotyl, hy, ending below in the root, $r$, and the root cap and above the epicotyl, $p l$. Two cotyledons, $c$; arise laterally from the stem; $f$, funiculus; $m i$, micropyle; in, integuments, $e n$, remains of endosperm. $B$, section of seed of water lily-e, embryo with two cotyledons attached laterally to the minute stem of the embryo and surrounded by a layer of endosperm cells; $m g$, sporangial cells or perisperm; $i$, integument.

The elongation of the basal portion of the hypocotyl frees the root from the seed and the growth of the upper region of the hypocotyl pushes up into the air the cotyledons and growing point or epicotyl. The formation of the stem is sometimes due to the elongation of the epicotyl alone, the cotyledons frequently containing the storage foods for the nourishment of the young plant and remaining buried in the seed. 
In endospermous seeds it should be noted that the cotyledons are not developed as digestive and absorbing organs as observed in the monocotyledons (page 40I). The primary root often persists, forming the main or tap root of the plant, which manner of growth is not so common in the monocotyledons. The Dicotyledons include two rather distinct series: $a$. The Choripetalae, distinguished by their free petals or lack of perianth. $b$. The Sympetalae, with united petals.

\section{Series a. Choripetalae}

I37. General Characters.-This group comprises about 6I,000 species and includes the majority of the trees and shrubs found in the temperate regions. The flowers as a rule are of a simple type but exceedingly variable in structure, so that it is not possible to separate them into so sharply characterized orders as in case of the monocotyledons, or in the following group of Sympetalae. Furthermore, these orders doubtless represent many parallel lines of development that are imperfectly understood. For this reason, the order of the presentation in the following pages does not attempt to represent the real relationship of the groups.

138. Salicales, the Willow and Poplar Order.-The willows are almost universally distributed along water ways, as though demanding for their existence only light and water. The poplars are less restricted and some can endure moderately arid conditions. Few plants have greater vitality. A bit of a twig and often a portion of a root is capable of developing buds and so starting the shoot. Trees are often pointed out that have originated through the careless sticking of a twig in the soil and several of the willows are naturally propagated by their twigs which are easily broken off by the winds. Their unusual ability to form numerous buds is well shown in the pollarded willows where the branches have been cut back and a large number of shoots develop about the wound. Perhaps the stimulus of the wound also awakens some of the dormant buds (page 75). The flowers, as in Typha, are arranged on an elongated axis forming a compact inflorescence known as an ament or catkin (Fig. 297, 
$C, E)$. The distinguishing feature of this kind of flower cluster is seen in the scale or bract that protects each flower (Fig. 297, $D, F)$. The aments and also the leaves are concealed in buds that are peculiar in that they are protected by a boat-shaped scale (Fig. 297, A). These plants flower very early in the spring and as the ament emerges from the bud the overlapping bracts with their hairy coats form the "pussy willow" stage of the
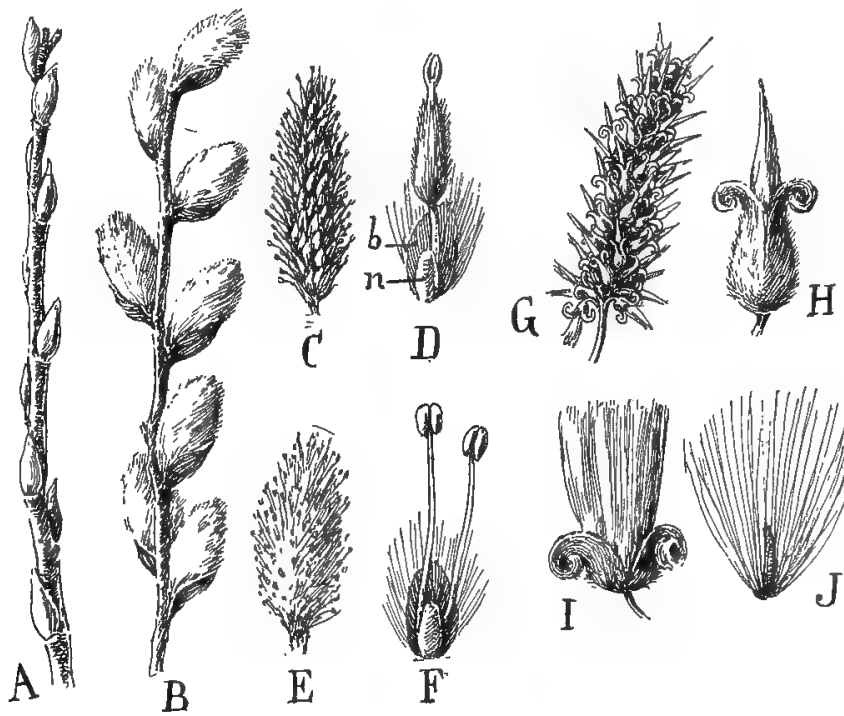

FIG. 297. Flowers and seed of the willow (Salix): $A$, winter appearance of a flowering twig, each boat-shaped scale concealing an ament. $B$, pussy willow stage of flowering, the aments emerging from the scales and exposing the hairy bracts that conceal the flowers. $C$, ament of pistillate flowers in full bloom. $D$, pistillate flower, consisting of a compound pistil of two carpels- $b$, bract; $n$, nectar gland. $E$, ament of staminate flowers. $F$, staminate flower of two stamens. $G$, ament of mature pistils which are opening to discharge the seeds. $H-I$, successive stages in the opening of the pistil. $J$, a seed with circle of hairs at base forming a parachute for dissemination.

inflorescence (Fig. 297, B). Soon the bracts spread apart, exposing the flowers which are nearly as primitive as the simplest of the monocotyledons, being without perianth, imperfect and usually the two kinds of sporophylls are arranged on different plants. The pistil is compound and composed of two carpels, each of which contains numerous ovules, so that the pistillate 
flowers are not as primitive as those of the cat-tails, where the pistil is simple (Fig. 297, D). The staminate flowers show the same primitive characters (Fig. 297, F), consisting of one or more naked stamens. The absence of showy perianth, the extravagant production of microspores and the formation of the flowers before the leaves become large and so interfere with the distribution of the microspores are all characteristics of wind pollinated flowers. It is noteworthy, however, that nectar glands are developed in the flowers of the willow (Fig. 297, D, n) and that the microspores are sticky. Perhaps we have here an illustration of one of the earliest variations of the flower that served as an allurement to insects. Certainly, the nectar glands and the conspicuous display of microsporophylls are a very efficient attraction, as is attested by the variety of insects that swarm about the aments.

The most efficient factor in the distribution of the willows and poplars is found in the seed. The pistils mature in the early summer, when the two carpels spread apart (Fig. 297, $G-I$ ), permitting the discharge of the seeds, which are provided with a circle of hair at the base (Fig. 297, J). This parachute is not so nicely constructed as in Typha, but it is so efficient that myriad numbers of minute seeds are carried a considerable distance and cover everything in the neighborhood of the trees with their lint-like masses. The name cottonwood is popularly applied to several of the poplars because of the cotton-like clusters of seeds that emerge from their aments.

139. Fagales, the Beech Order.-This order includes many of the most important hard-wood trees of the temperate regions, comprising the family of the birches, with such representatives as the American hornbeam (Carpinus), hop hornbeam (Ostrya), hazel (Corylus), birch (Betula), alder (Alnus) and the Beech family, which includes the chestnut (Castanea), beech (Fagus) and oak (Quercus). The inflorescence is more commonly an ament as in the preceding order (Figs. $298, A ; 299, A$ ), although in the hazel and in the Beech family only one or a few pistils are developed in the bud-like clusters of overlapping bracts (Fig. $299, p)$. The flowers are imperfect and the two kinds of sporo- 
phylls are usually developed upon the same plant. Several bracts are usually associated with sporophylls (Figs. 298, $B-F ; 299$, $B-E)$ so that the flowers are of a higher type than the willows. The innermost of these bracts is often of a delicate structure and has been referred to as a primitive form of the calyx (Fig. 298, $B, p r)$ and when present in the pistillate flowers it adheres to

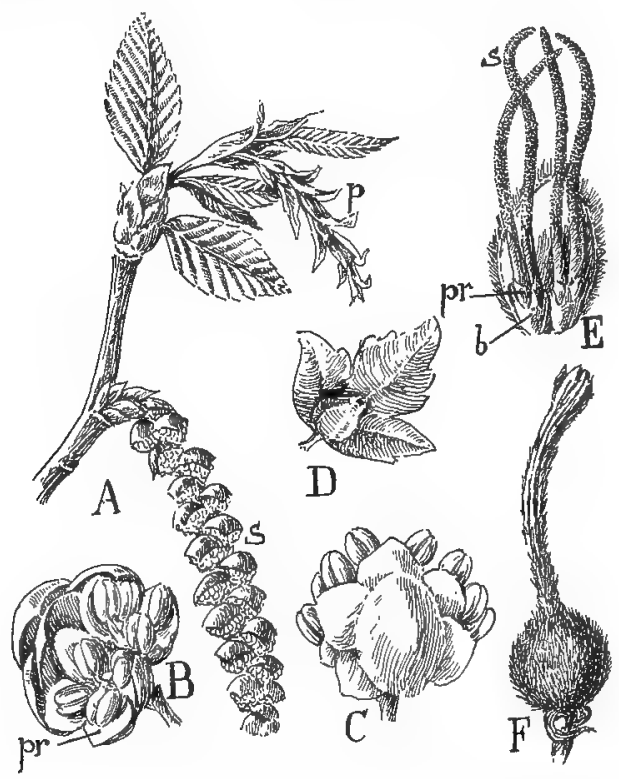

FIG. 298. Flowers and fruits of the birch family, order Fagales: $A$, inflorescence of hornbeam (Carpinus) - $s$, staminate ament; $p$, pistillate ament. $B$, staminate clusters from ament of alder (Alnus), each flower consisting of four stamens attached to a four-parted perianth, pr. $C$, upper view of the same cluster, showing the numerous bracts associated with the flowers. $D$, fruit of Carpinus attached to the greatly enlarged three-lobed bract. $D$, fruit cluster of hazel (Corylus) $-b$, bract encircling the ovary and within a more delicate bract, $p r$, adnate to the ovary; $s$, stigma. $F$, fruit of Corylus, the bract, $b$, in $E$ has grown out into a tubular beaked structure that completely envelops the nut.

the ovary (Figs. 298, E, pr; 300, B, pr). The pistils are provided with long delicate stigmas and are compound, containing several ovules but only one usually matures. The wall of the ovary develops into a tough coat about the seed, forming a fruit 
known as the nut. Certain bracts of the flower increase greatly in size as the ovary matures and form a conspicuous part of the fruit. Thus in the hornbeam (Fig. 298, D), one of the bracts develops into a large, three-lobed green leaf, in the hop hornbeam the bract forms a papery sac about the nut, in the hazel a leafy husk (Fig. 298), in the birch and alders a woody peglike structure. In the chestnut and beech the pistils are completely enveloped by prickly bracts or outgrowths that form the bur (Fig. 300, $A-C$ ), while in the oak these structures only cover the lower portion of the ovary, forming the cup (Fig. 299, $C-E$ ). The flowers of this order are typical of those that are wind pollinated. Note the small and simple flowers, absence of showy perianth, nectar, and odor glands, dry and light microspores lavishly produced to ensure seed formation and the delicate bushy stigmas for catching the spores. The stigmas appear a day or so before the adjoining microspores are being shed so that a crossing from an earlier flowering plant is necessitated. These plants form the larger part of our deciduous forests and their association in colonies is doubtless connected with the distribution of pollen by the wind, as is also the appearance of the flowers before the leaves are fully developed. The positions assumed by the staminate aments is of service in protecting the microspores against wetting and also to assist in their distribution. During the winter, these aments are quite erect but as the flowering stage approaches they become pendulous, the larger bracts protecting the sporophylls, like the shingles on a roof (Fig. 298, A). These bracts, being hygroscopic, remain closed during wet weather but on dry days they curve back, each bract forming a shelf which serves to catch the spores when no winds are stirring and thus prevent their falling to the ground.

I40. Other Tree Orders Suggestive of the Fagales.-Closely allied to the Fagales is the order of the walnuts, Juglandales, including the black walnut and butternut (Juglans) and the hickories (Hicoria, Fig. 30I). These trees are of very common occurrence in the northern United States and are characterized by aromatic oils and large compound leaves. The flowers are very similar in structure and arrangement to those of the beech 
order, but at maturity the outer part of the wall of the ovary becomes transformed into a fleshy rind and the inner portion forms a hard shell. In the walnut this pulpy, aromatic rind about the nut is finally destroyed by decay, while in the hickories

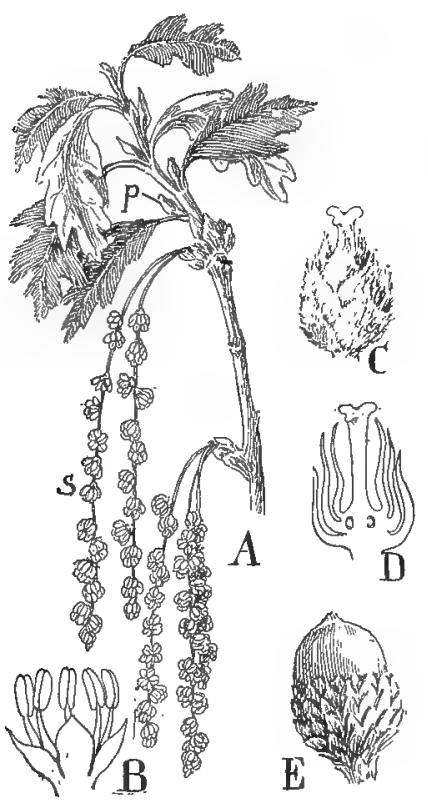

FIG. 299.
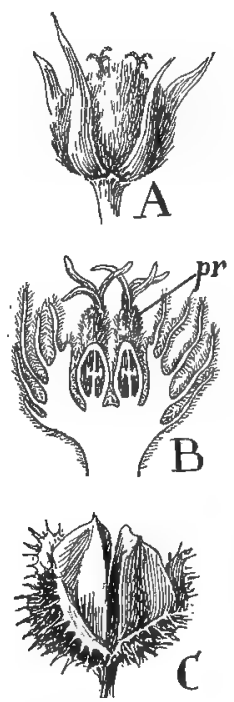

FIG. 300 .

FIG. 299. The Beech family, order Fagales: $A$, inflorescence of oak (Quey$c u s)-s$, staminate ament; $p$, pistillate inflorescence. $B$, staminate flower surrounded by a perianth of slightly united bracts. $C$, pistillate flowers with numerous bracts surrounding base of ovary. $D$, section of flower, the pistil being composed of three carpels and the inner bracts adnate to the ovary. $E$, fruit of oak, the cup consisting of the modified outer bracts shown in $C$ and $D$ and the nut has developed from the ovary and one of its ovules.

FIG. 300. Flower and fruit of the beech (Fagus), order Fagales: $A$, pistillate inflorescence, the three-lobed stigmas projecting beyond the bracts. $B$, section of the inflorescence- $p r$, inner bracts or perianth surrounded by an outer spiny set. $C$, the fruit, the outer bracts of $B$ have become hard and spiny and are splitting into four valves, exposing the three-angled nuts.

the rind becomes leathery and splits into valves, freeing the nut (Fig. 30I, C).

The order of the nettles, Urticales, also has many points in 
common with the beech order and contains several of our common trees as the elm (Ulmus, Fig. 302), hackberry (Celtis), mulberry (Morus), osage orange (Toxylon), numerous tropical forms, as the India rubber trees, banyan tree, etc., as well as a variety of valuable herbaceous plants, as the hop and hemp. These plants very generally contain a milky juice, latex, which

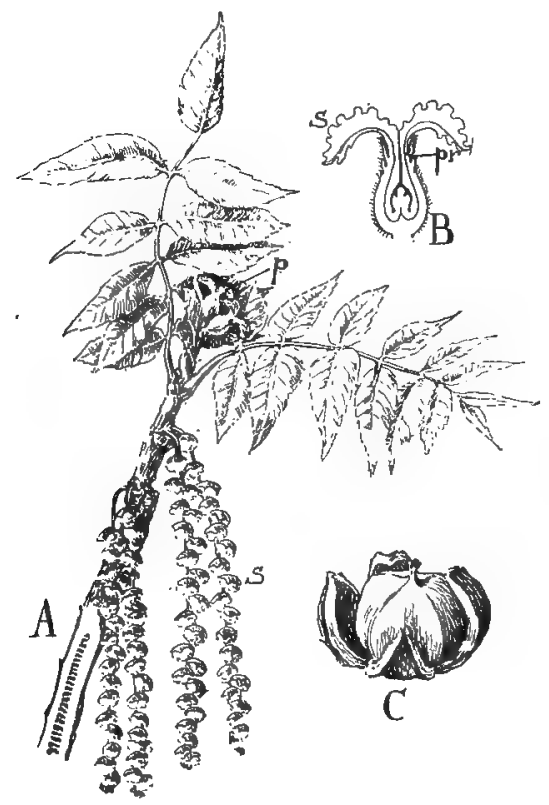

FIG. 30r. Flower and fruit of the Juglandales: $A$, inflorescence of butternut- $s$, staminate ament; $p$, pistillate inflorescence. The butternut and black walnut (Juglans) may be recognized by the chambered pith, as shown at bottom of twig. $B$, section of a pistillate flower- $p r$, perianth adnate to the two carpels composing the pistil; $s$, stigma. $C$, fruit of hickory, the outer part of ovary wall splitting into four valves and exposing the hard inner part, the shell of the nut.

in the case of Ficus and Castilloa, two of the india rubber trees, furnishes the raw material of india rubber and in the cow tree of South America yields a saccharine, nutritious milky juice. Tough stereome fibers are characteristic features in many of these plants and furnish the hemp derived from the Cannabis, and in Japan paper is manufactured from the fibers of the paper 
mulberry. The leaves are often provided with rough hairs which sometimes contain irritating acids, as in the nettles (page 40). The flowers are of a somewhat higher type than in the preceding orders, and associated in a variety of dense inflorescence. They are rarely perfect, though rudimentary (sterile) stamens may be developed with fertile pistils or vice versa, thus giving the appearance of perfect flowers (Fig. 302, $B-D$ ). The calyx does

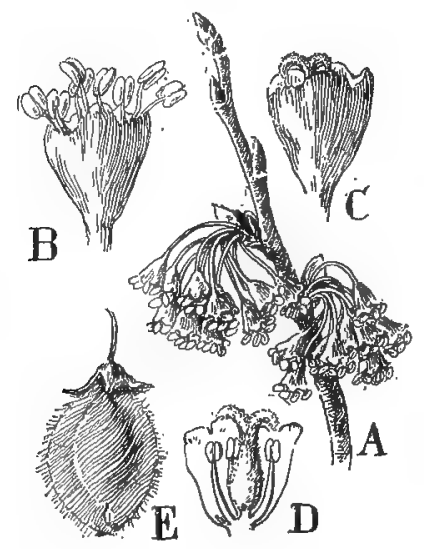

FIG. 302.

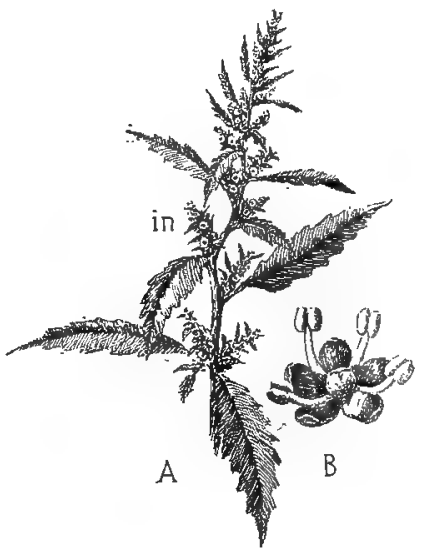

FIG. 303.

FIG. 302. Inflorescence and fruit of elm, order Urticales: $A$, twig of elm bearing principally staminate flowers. $B$, a staminate flower enlarged, showing lobed perianth enclosing numerous stamens. $C$, pistillate flower, twolobed stigma projecting from perianth. $D$, section of pistillate flower, showing aborted (sterile) stamens and pistil (fertile) of two carpels, as indicated by the two stigmas. $E$, the fruit with perianth still attached. A wing has grown out from the sides of the ovary.

FIG. 303. A simple type of the Chenopodiales: $A$, shoot of Mexican tea (Chenopodium), showing character of inflorescence, in. $B$, flower enlarged, showing the perianth, stamens and pistil of three cohering carpels.

not adhere to the ovary as in the Fagales, though the sepals often cohere (Fig. 302, D). The ovary usually matures as a nut, but in many cases a kind of drupe (page 399) is formed, owing to the perianth becoming fleshy and enveloping the nut. The fruit of the mulberry is an aggregation of drupes. In the fig the stem envelops the minute curious flowers and becomes fleshy, forming the edible portion of the fruit.

I4I. Orders Showing an Advance over Preceding Forms.- 
The buckwheat order, Polygonales, containing such familiar weeds as the sorrel, dock (Rumex), and knotweed or smartweed (Polygonum), has perfect regular flowers with a distinct perianth. These characters also appear in the allied goosefoot order, Chenopodiales, with its great array of common weeds, as the goosefoot (Chenopodium), orache (Atriplex), tumbleweed and pigweed

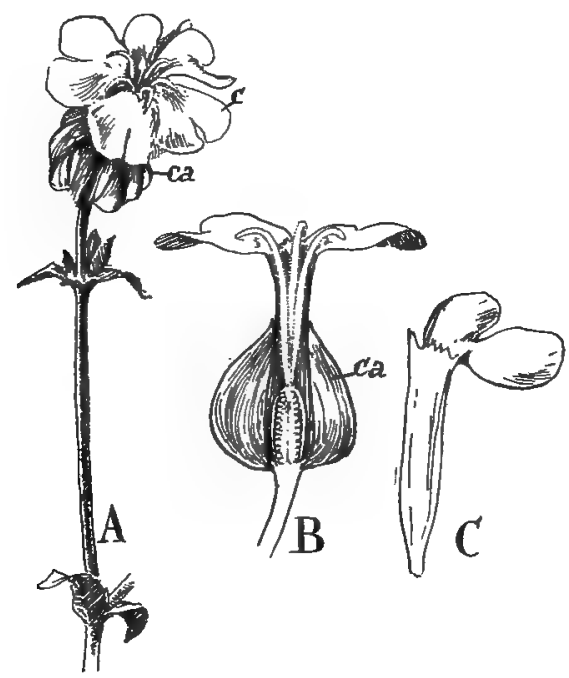

FIG. 304. Advanced type of the Chenopodiales: A, shoot of Melandrynum bearing flower with perianth differentiated into calyx, $c a$, and corolla, c. $B$, section of flower, showing the relation of calyx to corolla and the concealment of the nectar glands at the base of the ovary. Access to the corolla tube is guarded by an outgrowth on the petals, as shown in $C$, which, assisted by the styles or stamens, so effectually closes the mouth of the tube that only insects with long tongues can reach the honey.

(Amaranthus). The flowers are arranged in loose clusters and are for the most part small and wind pollinated (Fig. 303). However, it is noteworthy that some of the genera are adapted to insects, the calyx becoming larger and brightly colored and nectar glands are associated with it. In the higher members of the order, as in the purslane and pink families (which include the spring beauty, Claytonia), the perianth becomes differentiated into a calyx and showy corolla, and the flowers have become in a marked degree adapted to insect visitors (Fig. 304). These 
orders form a natural transition from the primitive flowers of the willows and beeches to the large flowers of the next order with their showy perianths, though the structure of the flower is not very indicative of a relationship between them.

142. Ranales, the Buttercup or Crowfoot Order.--This large and interesting order includes a great variety of our common plants, herbs, and trees, as the white and yellow water lilies (Nymphaea and Castalia), buttercups (Ranunculus), marsh marigold (Caltha), windflower (Anemone), Hepatica, rue (Thalictrum), columbine (Aquilegia), larkspur (Delphinium), monks-

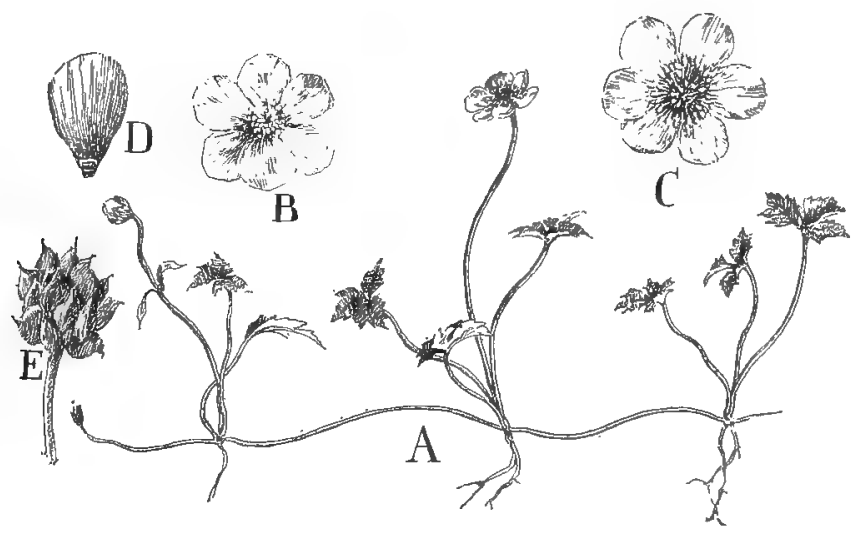

FIG. 305. A common type of the Ranales, Ranunculus repens: $A$, habit of the plant. $B$, early stage of flowering, the stamens clustered about the stigmas. $C$, late stage of flowering, nearly all the stamens bent over towards the petals, having discharged their spores. $D$, petal with nectar gland at base. $E$, fruit consisting of numerous spirally-arranged akenes.

hood (Aconitum), may apple (Podophyllum), magnolia, tulip tree (Liriodendron), Sassafras, spice bush (Benzoin), etc. In this order we have again reached the point, just as in the monocotyledons (see Liliales), where the flowers are more usually solitary and conspicuous, owing to the development of large, showy perianths. While the perianth is more differentiated than in the lilies it is noteworthy in the majority of the forms that the flower has not reached the state where the calyx is clearly separable from the corolla. The flowers are very simple, as is indicated by the regular and hypogynous arrangement of the parts (Fig. 
305). The receptacle is frequently elongated and consequently the organs of the flower, especially the sporophylls, are numerous and indefinite in number and spirally arranged. Were it not for the perianth, such a type of flower would be quite as primitive as any of the preceding orders.

(a) The Buttercup, Ranunculus.-The flower of the buttercup illustrates the more characteristic features of the Ranales (Fig. $305, A, B)$. Here the perianth is apparently differentiated into calyx and corolla. The petals, however, are sometimes regarded as stamens that have become highly modified for the production of nectar. The sporophylls are indefinite in number and spirally arranged. It is interesting to note the relationship of the various parts of this simple flower and their behavior during the period of blooming. When the flower first opens, the anthers are still closed and clustered around the receptive stigmas, affording a natural landing place for the insects (Fig. 305, $B$ ). Thus crossing may only be effected with the spores carried from older flowers. At a later period the outermost filaments elongate, curving over towards the petals, so that as their anthers discharge there is little chance of autogamy (Fig. 305, C). This position also brings the anther into the pathway leading to the nectar gland at the base of the petal (Fig. 305, D), so that the insect in probing for the nectar is sure to receive some of the sticky microspores on his body. Each day, for about a week, successive series of stamens behave in this manner, and it is not until the innermost anthers are discharging on the last day of blooming of the flower that there is an opportunity for autogamy. In many members of this and other orders you will find that the stigmas and anthers of the innermost stamens actually meet, owing to the peculiar curvature of the styles and filaments, thus ensuring autogamy in case crossing has failed. It should be borne in mind that the devices for effecting autogamy, as a last resort, are quite as general and often as elaborate as the provisions for bringing about crossing. The microspores are protected against dews and rains by the folding of the perianth and also by the downward curvature of the pedicel at night, whereas on each succeeding bright day the perianth apens again and the 
flower becomes nearly or quite erect and turned towards the light, so that it is in a position from which the insect will naturally come. The opening of the flower is due to a growth in the morning of the basal, inner portion of the petals thus bending them away from the center of the flower and thus effecting the opening; while a corresponding growth towards evening of the basal outer part of the petal bends them towards the center of the flower. This growth slowly increases the size of the flowers, as may readily be observed by comparing the freshly opened flowers of the anemone, buttercup, etc., with those several days old. All these features are of common occurrence in a great variety of orders. The furit of the buttercup is an akene, each carpel containing but a single ovule (Figs. 305, $E$; 26I $B$ ).

(b) Some Variations of the Order.-Many variations of this simple structure appear in other members of the order. The
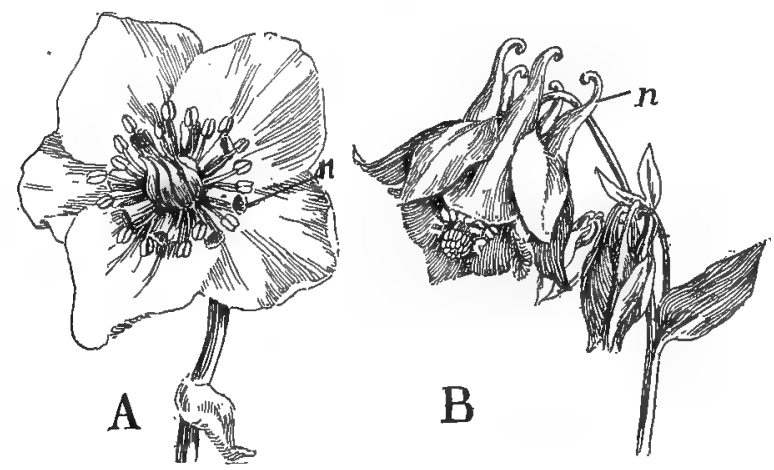

FIG. 306. Modifications appearing in the Ranales: $A$, flower of Helle. borus - $n$, nectar glands due to modifications of stamens. $B$, columbine$n$, honey leaves due to modifications of the petals or possibly of the stamens.

carpels may be reduced to one, as in sassafras and other groups, and in the green hellebore (Fig. 306, A) they are partially compounded and even united with the receptacle in some water lilies, etc. (flowers perigynous and epigynous). The stamens are sometimes few in number and they are frequently modified into nectar glands and assume a variety of odd shapes (Fig. 306, A). The showy nectar-bearing petals, honey leaves, of many of the genera are regarded by some as modified stamens, as in the monkshood, columbine, larkspur, etc. (Fig. 306, B). 
The parts of the perianth, which are more frequently in threes or indefinite in number than in fives, are also subject to considerable variation. Very frequently the corolla is not developed or partially suppressed, and the sepals become colored and petaloid, as in the marsh marigold, hepatica, certain windflowers, rue, spice bush, larkspur, etc. In a few of the genera the perianth becomes greatly modified and even irregular, as in the columbine (Fig. 306, $B, n$ ), where five of the petals, often regarded as modified stamens, are transformed into tubular honey leaves or

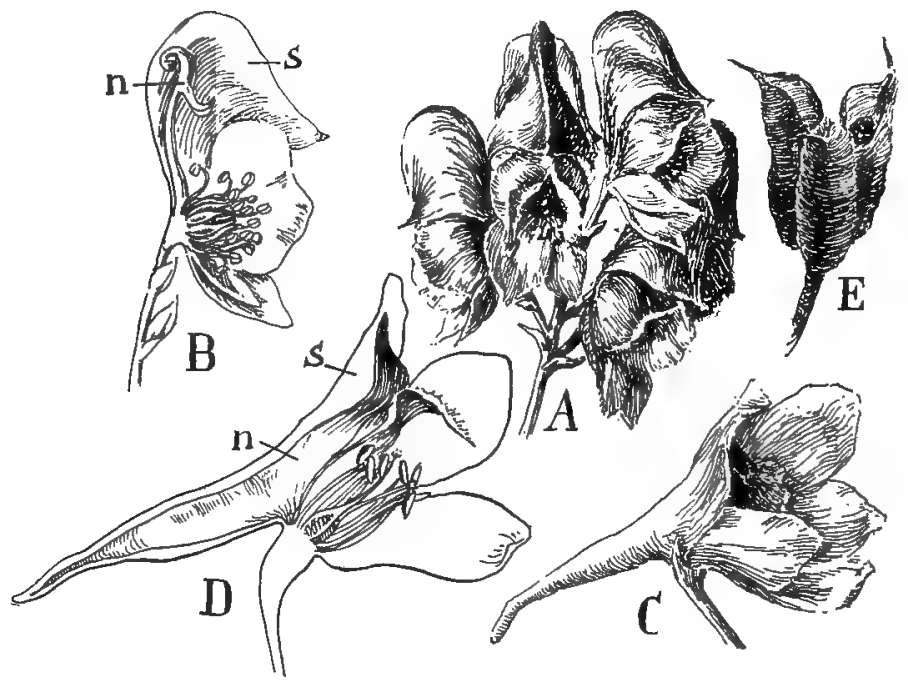

FIG. 307. Highest type of the Ranales: $A$, inflorescence of monkshood. $B$, section of a flower-s, helmet-like sepal enclosing nectar organ, $n . C$, flower of larkspur. $D$, section of flower-s, spurred sepal enclosing twospurred nectar organs, $n$. $E$, fruit of larkspur consisting of 3 pistils maturing as follicles.

into spurs and hoods, as in the larkspur and monkshood (Fig. $307, B, D)$. These flowers illustrate very well the progressive coloration that is often associated with the variation of the perianth. The simpler forms are usually yellow or white, while flowers with more highly modified parts are pink and pale blue (columbine), blue in higher types (larkspur) and ultra-marine blue in the most irregular and highly modified type (monkshood). Any of these flowers may take on by reversion the lower 
grades of color so that a blue-colored form may vary and its offspring may produce white or yellow flowers, as in the columbine. The remarkable brilliant yellow of the flowers, as seen in the buttercup and marsh marigold, etc., has been regarded as the primitive coloration of the perianth, and it is to be noted that the flowers showing reversion to this color assume a duller yellow. This order furnishes a great variety of showy ornamental plants, but none with fragrant flowers. Many contain acrid juices and poisonous alkaloids, some of which are of medicinal value, as aconite, hydrastin, helleborine, etc. Others are of value for the volatile oils, as sassafras, cinnamon, camphor, nutmeg, etc. The simple structure of the more characteristic flowers indicates that this order is a very ancient one and the pronounced tendency to vary would suggest that possibly many of the higher orders of the Choripetalae have been derived from this group. The origin of the monocotyledons from this order has also been suggested, owing to the structural features of the embryo and vascular bundles of certain groups.

I43. Papaverales, the Poppy Order.-This group includes two very well known families: (I) The poppies, with such familiar plants as the poppy (Papaver), sea poppy (Glaucium), celandine (Chelidonium), soldier's cap (Bicuculla), fumitory (Adlumia), corydalis (Capnoides) (Fig. 308). (2) The mustards, including the peppergrass (Lepidium), hedge mustard (Sisymbrium), white and black mustard (Sinapis and Brassica), yellow rocket (Barbarea), cress (Roripa), toothwort (Dentaria), shepherd's purse (Bursa), whitlow grass (Draba), rock cress (Arabis) (Fig. 309). The families of the caper and mignonette are also included in the order. These plants are closely related to the Ranales, as is indicated by their simple and showy flowers, the various organs usually being in multiples of two and quite distinct (flowers hypogynous) save in the case of the carpels. These organs are compound as in the water lilies and more commonly reduced to two, thus forming a sharp contrast with the preceding order. Note also that there is a sharp distinction between calyx and corolla.

(a) The Poppy Family, Papaveraceae.-The Bloodroot, San- 
guinaria, is typical of the simpler members of this family (Fig. 308). These plants form colonies in rather open, rich woods owing to their fleshy rhizomes, and like many plants with storage organs, flower very early in the spring. The flowers endure for about two days, but the large-lobed leaves are conspicuous features of the forest "carpet for several weeks while they are manu-

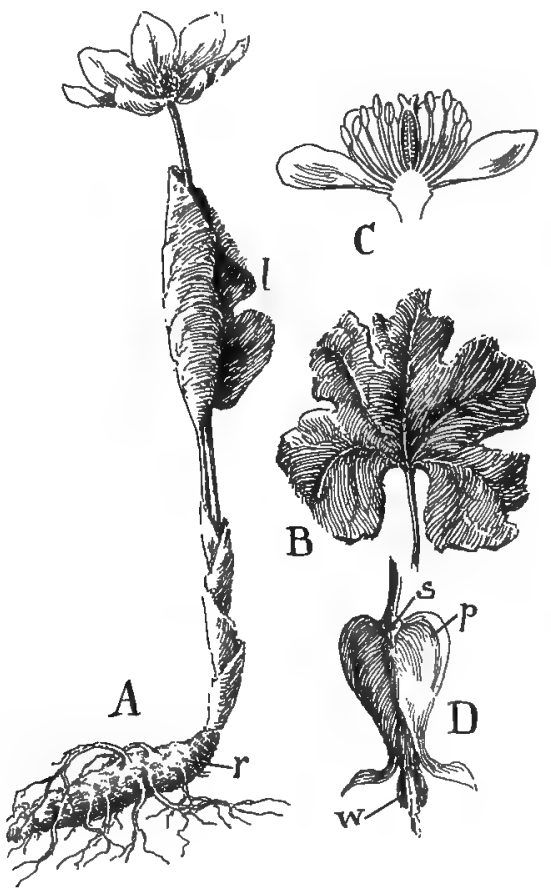

FIG. 308. Examples of the poppy family, order Papaverales: $A$, habit of the bloodroot at time of flowering $\rightarrow r$, rhizome; $l$, leaf folded about flower stalk. $B$, leaf unfolded. $C$, section of flower, showing its hypogynous structure with numerous stamens and pistil of two carpels. $D$, flower of fumitory (Adlumia) $-s$, sepal; $p$, inflated petals; $w$, winged petals which conceal the sporophylls.

facturing the food for the next season. The large leaves are tightly rolled about the solitary flower and enveloped in a papery sheath as they emerge from the soil. A juice, latex, is found in the majority of the plants of this order, and in this example it is of a blood-red color, thus giving the latin and popular name to the 
plant, Sanguinaria, or bloodroot. The flowers are of the simple open type noted in the buttercup, having two sepals (a characteristic of the family) which fall with the opening of the flower, petals 8-I2, stamens indefinite and a compound pistil of two carpels, as is indicated by the two stigmas and two rows of ovules (Fig. 308, C). The stigmas are receptive as soon as the flower opens, but the anthers remain closed, and so the spores must be carried from an older flower. The petals close during the late afternoon and when opened on the following day the anthers shed their spores and complete the flowering.

In higher types of the poppies we find the flowers becoming irregular and the various parts reduced in numbers. Thus, in the soldier's cap (Fig. 308, D), there are two scale-like sepals, four petals in two pairs, the two outer heart-shaped and spurred at the base, while the two inner are narrow and winged on the back, enclosing the sporophylls. The six stamens are somewhat united and arranged into two groups opposite the spurred petals. The carpel has the same structure as in the bloodroot. It is evident that the nectar concealed in this closed type of flower can only be secured by some long-tongued insect. Find out how the bee procures the honey, the purpose of the wings on the narrow petals and the position of the nectar glands. Is the stigma mature before the anthers open? The structure of this higher type of the poppies makes the transition to the mustard family a simple one.

(b) The Mustard Family, Cruciferae.-Here we find the sepals and petals four in number, and the latter arranged crosswise (Fig. 309, $A, B$ ), thus explaining the family name, Cruciferae. The petals usually have rather long claws (Fig. 309, D) that are so associated with the sepals as to form a narrow tubular perianth that effectually conceals the nectar glands situated at the base of the ovary. There are usually six stamens, but the two outer ones are shorter than the others (Fig. 309, C). The ovary is divided into two compartments by a membranous partition. The fruit is generally a capsule that usually opens by two valves, as seen in Fig. 309, $F$. This large family of over $\mathrm{I}, 800$. species is almost universally distributed over the earth and of 
very common occurrence. These plants with their small white or yellow flowers aggregated in conspicuous inflorescences are among the most familiar weeds of waste places, fence rows and barren fields. The flowers are of a more specialized type than in the open blossoms of the buttercups and poppies, and present a variety of interesting devices that can only be hinted at in this lesson. More commonly, perhaps, the stigmas are receptive as soon as the flower opens and the anthers are still closed, thus

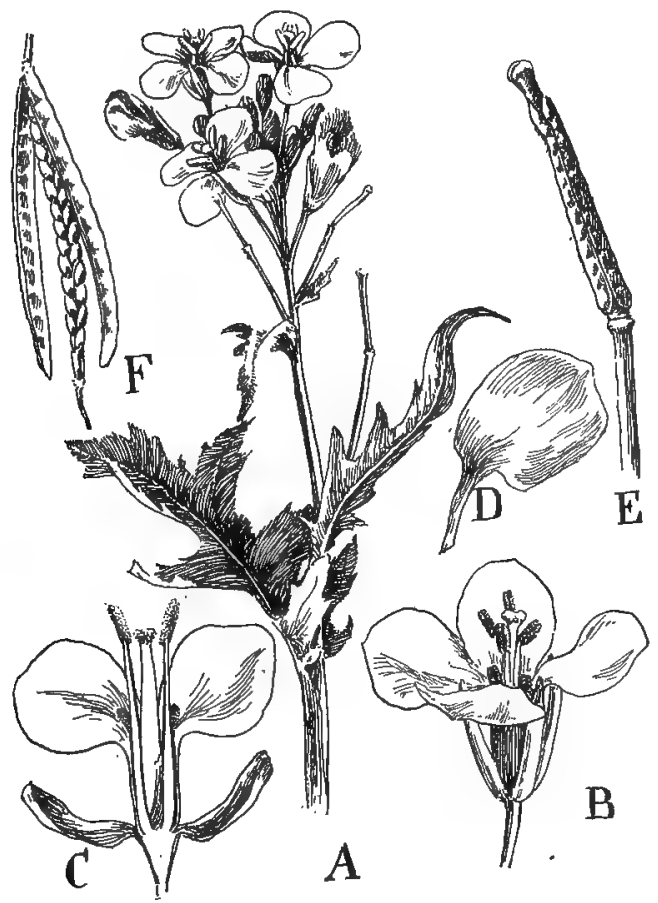

FIG. 309. Examples of the mustard family, order Papaverales: $A$, branch of Brassica, one of the turnips. $B$, a flower enlarged. $C$, flower in section. $D$, a petal, showing narrow claw and broad blade. $E$, pistil. $F$, fruit, the valves of the two carpels opened to show the seeds.

ensuring crossing. The short stamens are more frequently utilized only for crossing since they are below the stigma and so placed as to be in line with the nectar glands that are often located in sac-like enlargements of the perianth. The four long stamens 
are variously related to the stigmas. Sometimes they are below the stigma and when open are of service only for crossing, but later they elongate and bear some of the spores to the stigma. The reverse position of the sporophylls also occurs, but the outward opening of the anthers keeps the microspores from dropping by chance on the stigma until the stigma is finally lifted up to the anther by the elongation of the style, where it is sure to be dusted with spores, as the anthers open wider and wider. Certain species are characterized by an extraordinary twisting of the filaments, so that for a time the anther is turned away and bent over towards the perianth so as to be in line with the nectar glands, and later, at the close of the flowering period, a reversal of this bending brings the anther in contact with the stigma. These illustrations are sufficient to show that the flowers have many arrangements and exact movements that result in crossing, or, if this fails, in autogamy. You would naturally expect that specialized flowers like the mustards would show higher types of coloration. This is indeed the case in some forms where pink and purple colors appear, but in the majority of the species the unfavorable situations in which they grow have resulted in a reduction in the size of the flowers and also in a decline in color to white and pale yellow. It is noteworthy that the flowers of the radish when cultivated on barren soil develop white, but upon rich soil, pink. These minute flowers have a decided advantage in being grouped in compact inflorescences, a device that you will see copied again and again in the higher orders because it ensures crossing and makes them conspicuous. It should be stated that several of these plants get along very well without crossing.

Many products of great commercial value are derived from various members of this order. Opium, from which morphine and other alkaloids are obtained, is the dried latex obtained from the incisions of the unripe capsules of the Turkish poppy. The majority of these plants contain acrid or peppery juices that render certain parts of the plant or their seeds of value as spices, oils, foods, etc. Many of them are biennial, forming a close rosette of leaves the first year and flowers and fruit the second. 
By cultivation an abnormal development of one part or another of the plant has been induced. This feature is well illustrated in the cabbage, where the elongated stem of the wild plant has become shortened by cultivation and covered with fleshy leaves, forming a large bud or head. Brussels sprouts are a modification of the cabbage in which the stem becomes more elongated and covered with numerous small heads. The great variety of kales are really headless cabbages in which the leaves remain free from one another, assuming a variety of forms. The cauliflower is a variety of the cabbage in which the inflorescence has been transformed into a fleshy mass of tissue, and in the kohlrabi the stem becomes swollen and herbaceous. The turnip is a related species of the cabbage genus in which the underground portion of the plant is modified. Radish, cress, horse-radish, caper, spices and oils of mustard, etc., are other products of the order, as well as many cultivated flowers, as the wallflower, stock, mignonette, etc.

I44. Rosales, the Rose Order.-This enormous order, comprising over $\mathrm{r} 4,000$ species, is better known than any other, not only because of its great array of common field plants, but especially because of the large variety of our cultivated fruits and flowers that belong to it. The cultivated currant, blackberry, strawberry, apple, pear, cherry, peach, plum, pea, bean, hydrangea, syringa, rose, spiraea, wistaria, laburnum, as well as many native trees and shrubs, as the liquidambar, sycamore, witchhazel, locusts, etc., belong to the rose order.

These plants may be looked upon as the most typical of the Choripetalae, just as the Liliales were the most representative of the monocotyledons. The parts of the flower are more commonly in fives and cyelic (Fig. $310, A$ ) though the spiral arrangement still persists in nearly every family of the order. The most distinguishing feature of the group is seen in the basal growth of the receptacle, thus lifting up the corolla and stamens about the ovary (perigynous flowers) and this growth also frequently results in the epigynous type of flower. The simple forms of flowers that appear in many of the families are very suggestive of the Ranales, the sporophylls being free and often 
spirally arranged. Thus, in the live-forever (Sedum), we have a flower that has always been cited as the typical flower of the angiosperms. It is very regular with five whorls of alternating parts of five members each, $i$. e.: 5 sepals, 5 petals, 5 to Io stamens (one or two whorls) and usually 5 pistils (Fig. 3I0, $A$ ). This type

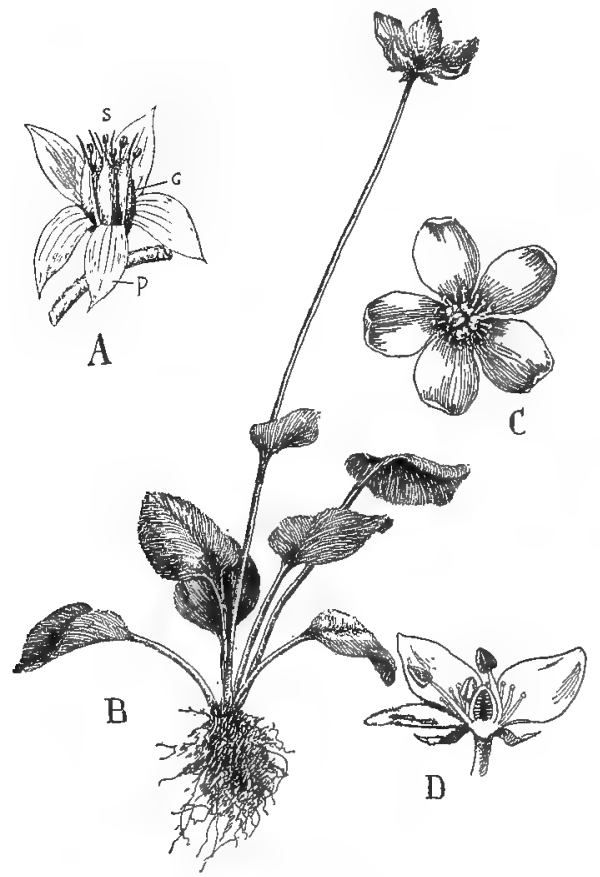

Fig. 310. Simple forms of the Rosales: $A$, flower of Sedum, showing the radial symmetry of the flower and five organs in each whorl. $B$, grass of Parnassus (Parnassia), a member of a closely-allied family. $C$, flower on first day of bloom, stamens converging over the pistil and encircled by row of modified stamens. $D$, section of flower, showing slight growth of base of receptacle and consequent adhesion to perianth. This flower is protandrous and the stamens in shedding the spores straighten up one by one on succeeding days and curve back towards the petals. The section shows three positions assumed by the stamens. You may calculate the significance of these features.

closely resembles the arrangement of parts in the buttercups, save for the slight adhesion of the calyx and receptacle (Fig. 3 Io, D). ? hese fleshy plants as illustrated in the houseleek (Fig. 69), hen and chickens, etc., are very common forms of xerophytes. 
Owing to their ability to retain moisture (page 45) they can exist in the crevices of rocks and upon dry soil, while the formation of roots from a bit of stem or even a leaf, as well as their habit of producing buds on short stems that afterward become detached and grow into new plants, brings about a sure distribution and explains their popular name, live-forever.

(a) Some Variations of the Rose Order.-The active growth of the base of the receptacle and the consequent crowding result in an interesting series of departures from the simple type noted

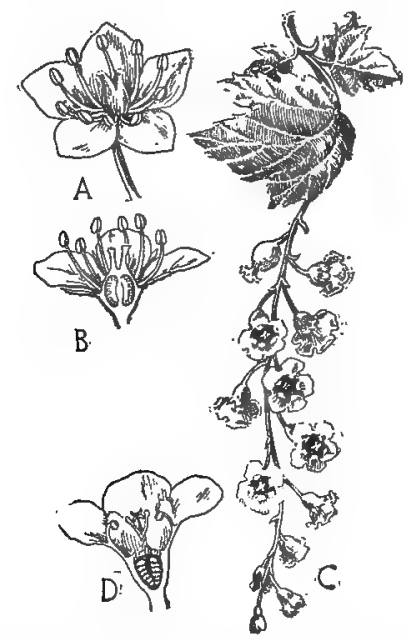

FIG. 3II. Higher forms of the Rosales: $A$, flower of the saxifrage. $B$, flower in section, showing the partial adhesion of receptacle to ovary. $C$. inflorescence of currant (Ribes). $D$, section of flower, showing receptacle forming the cavity for the ovules which is roofed over by the carpels, epigynous flower.

above that lead in very regular gradations to the highest forms of the order. In the higher family of the saxifrages, for example, which includes the saxifrage, false miterwort (Tiarella), heuchera, bishop's cap (Mitella), golden saxifrage (Chrysosplenium), the receptacle generally adheres to the ovary (Fig. 3 II , $A, B$ ). so that the flower is, in a measure, epigynous and the carpels are reduced to two and partly fused. Passing to the families of the hydrangeas, syringas (Philadelphus), currants (Ribes), etc., the receptacle and carpels are quite fused (Fig. 3II, $C, D$ ) and 
the flower is strictly epigynous. In the Rose family, which is very closely connected with the preceding group, this story of change in the evolution of the flower is repeated. In the simpler forms the mass growth of the receptacle and calyx, forms a cuplike structure (perigynous flower). This cup may be rather broad and shallow as in the strawberry, cinquefoil and blackberry (Fig. 3I2), but in higher types the receptacle more or less completely surrounds the pistils as in the spiraea, avens, rose, agrimony (Fig. 3I3). In the Apple family, including the apple,

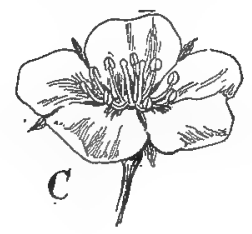

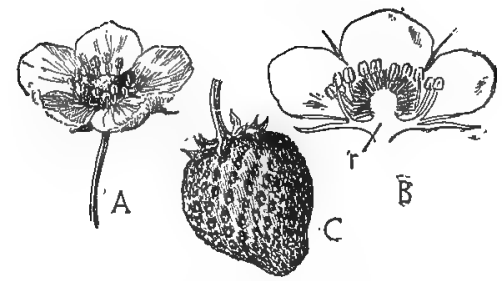

FIG. 3I2.

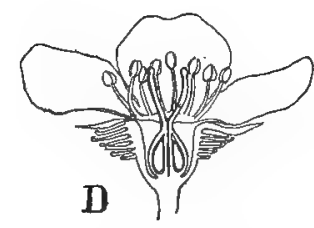

FIG. 3I3.

FIG. 3I2. A member of the Rose family with the simple structure of the saxifrages: A, flower of the strawberry (Fragaria). B, section of flower showing slight adhesion of receptacle to calyx and the spiral arrangement of the sporophylls. $C$, the fruit, akenes spirally arranged on the enlarged and fleshy receptacle.

FIG. 313. Higher forms of the Rose family: C, flower of Agrimonia. D, section of flower, showing the bristle-covered receptacle completely surrounding the pistils.

peach, quince, shadbush, thornapple, hawthorn, the ovules are completely enveloped by the receptacle (Fig. 3I4, A-C) as in the currants, while in the Plum family, with its plum, prune, cherry, peach, almond, apricot members, the pistils are reduced to one and are quite distinct from the cup-like receptacle (Fig. 3I $4, D-F)$.

The Senna family has essentially the same type of flower as the plum save that the pistil usually contains many seeds (nor- 
mally but one develops in the plum) and splits at maturity into two valves, a form of fruit called a pod. For example, in the honey locust (Gleditsia) and the Kentucky coffee bean (Gymnocladus), the receptacle forms a shallow cup which bears the regular sepals, petals and usually ten stamens about a single pistil (Fig. 3I5, A). The flowers are really monoecious, but in other respects are very suggestive of the plum flower. In the coffee bean tree, however, the petals are not quite equal and this irregularity becomes more noticeable in the sensitive pea (Cassia)

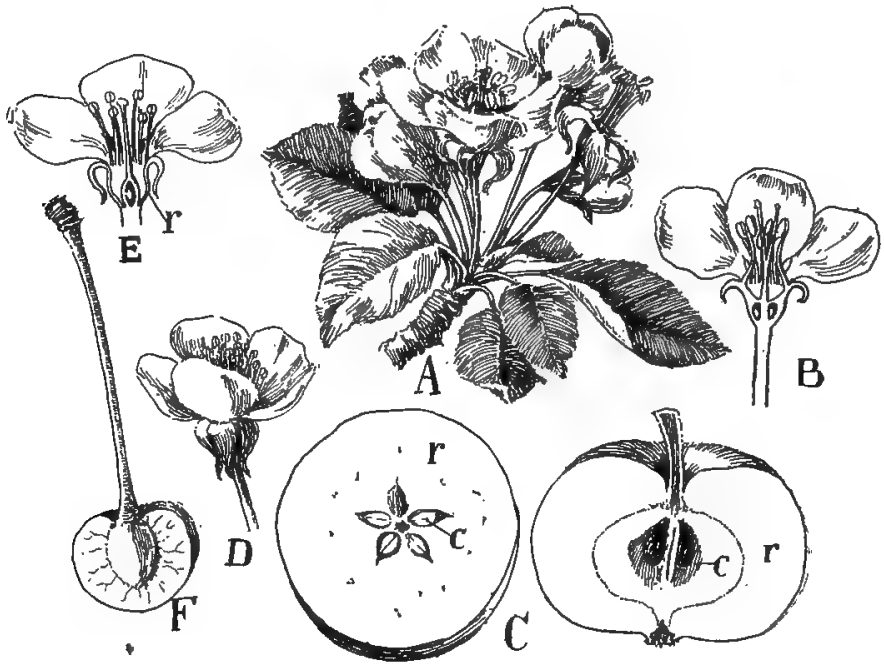

FIG. 3I4. Flowers and fruits of the apple and plum families: $A$, inflorescence of the apple (Malus). $B$, section of flower, showing adhesion of receptacle to the ovary, epigynous flower. $C$, sections of the fruit- $c$, carpels of the pistil; $r$, fleshy receptacle. D, flower of cherry (Prunus). E, section of flower $-r$, cup-like receptacle which falls off as fruit matures. $F$, fruit in section, showing the outer part of the wall of the ovary as a fleshy rind and the inner part forming the stone or pit which enclosed a single seed.

(Fig. $3 \mathbf{I}_{5}, B-D$ ). In the redbud, or Judas tree (Cercis), the petals are very irregular, two of them being insecurely united into a boat-like structure, known as the keel, which encloses the ten distinct stamens and single pistil, while two laterally placed petals, the wings, inclose the fifth petal known as the standard (Fig. 315, E, F). These three examples from the Senna family 
make a very easy transition from the regular flower of the plum to the highly modified flowers of the Pea family.

(b) The Pea Family, Papilionaceae.-The Pea family (Fig. $3 \mathrm{I} 6)$ is the highest of the rose order and the largest family, with one exception, of all the angiosperms, comprising over I I,000 species. Here we find the same type of flower as in the redbud.

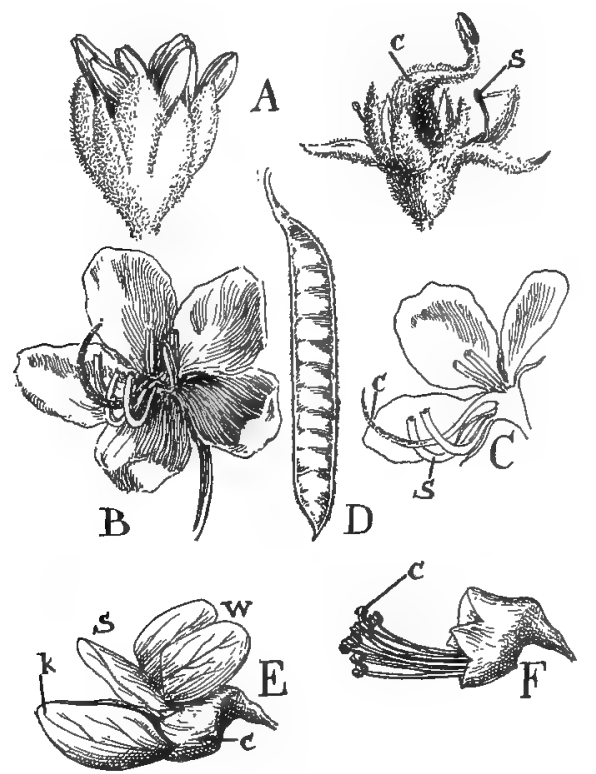

FIG. 3I5. Development of the irregular type of flower in the rose order: $A$, regular flower of the honey locust (Gleditsia). At left staminate flower. At right pistillate with single pistil, $c$, which develops into long flat pod, $s$, rudimentary stamens. $B$, flower of Cassia, showing slightly irregular corolla. $C$, section of flower-s, stamen; $c$, pistil. $D$, the fruit or pod. $E$, irregular flower of redbud (Cercis)—c, calyx; $k$, keel enclosing stamens and pistil; $w$, wings which arch over the standard, s. $F$, corolla removed, showing the ten stamens surrounding the simple pistil, $c$.

The standard in this family, however, incloses the wings and the stamens, usually ten in number, may be distinct as noted above or united by their filaments into a sheath about the solitary pistil; more frequently a single stamen remains free, an arrangement called diadelphous (two brotherhoods). This type of flower is called papilionaceous from its fancied resemblance 
to a certain genus of butterfly, Papilio. The more important characteristics of this form of flower are very well illustrated in the pea (Fig. 3i6). The standard is the conspicuous and most highly-colored organ of the flower, overlapping the two wings which in turn practically cover the keel. By carefully removing the keel and wings, it will be seen that these organs are attached to the calyx and receptacle by rather narrow claws (Fig. $316, C$ ) and that they are also locked together by a little process on each wing that fits into a groove on the keel. Nine of the filaments, the tenth being free, form a sheath about the

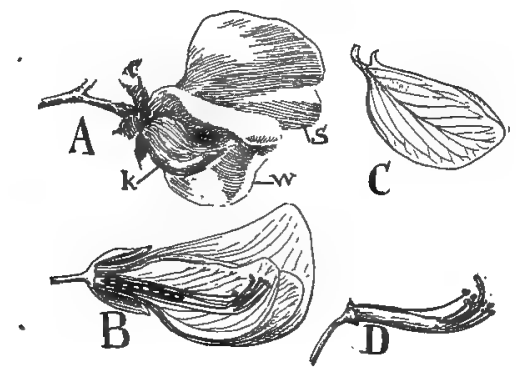

FIG. 316. Structure of the sweet pea (Lathyrus): $A$, flower of the pea $-c$, calyx; $s$, standard enclosing the two wings, $w ; k$, keel. $B$, section of flower, showing the sporophylls concealed in the keel. $C$, one of the wings. $D$, perianth removed, showing relation of sporophylls.

ovary which terminates in a stylar brush of upwardly pointing hairs and in a stigma. The anthers and style are confined in the tip of the keel (Fig. $316, B, D$ ). The significance of these features will be discovered if you watch a bee probing into the sheath of filaments after the nectar secreted at the base of the ovary. The standard serves to attract and also direct his approach to the flower so that he alights at the proper place, $i . e$, on the keel and wings. The weight of his body causes a slight depression of the keel and the stylar brush sweeps some of the microspores upon his body. It should be added that the flower is ready for the insect as soon as opened since the spores are discharged before the flower blooms. Only a portion of the spores are swept out by the insect and the dusting may be repeated on several visitors. The stigma does not mature until a 
later period and it is evident that there is a good chance of autogamy as soon as the stigma is mature. Some genera are always autogamous, but it has been observed in many cases that the spores grow more vigorously upon the stigma of another flower than upon the stigma of their own flower, so that if the stigma receives spores from its own and other flowers, the latter spores would develop better and effect fertilization. This is called the prepotency of foreign spores. In some species, autogamy is impossible owing to the failure of the spores to germinate except when transported to other flowers. There was a good illustration of this fact in Australia when the English clover was introduced and flourished exceedingly well, but produced no seed until bees from England were introduced for crossing. Plants transported to foreign countries are often sterile owing to the absence of the insect to which their variations are adapted. There are many variations of the mechanism shown in the pea. In some genera the style and stigma act like a piston, pushing out some of the spores from the apex of the keel with each visit of the insect and in some of these forms the wings are unlocked by the insect when the stamens that have been retained in the keel under considerable pressure are liberated by the dropping of the keel and spring up, scattering the spores with an explosive effect.

In many of these plants the pod splits at maturity into two valves, each of which twists with a sudden snap in opposite directions, hurling the seeds to a considerable distance (Fig. 3I7, A). This reaction is due to the tension set up by the difference in the drying of the three strata of cells which compose the walls of the pod. The Papilionaceae contain very many nutritious food plants as the pea, bean and lentils, and also forage plants as the clover, alfalfa and vetches. In temperate regions the majority of the forms are herbaceous, only a few trees and shrubs as the locust (Robinia), broom (Cytissus), dye weed (Genista), false indigo (Amorpha) belong to the family, but the tropics are richly represented by a great variety of woody forms that are valuable for lumber, resins and dyes, as the red sandalwood, licorice root, gum tragacanth, balsam of tolu, 
indigo, etc. Related to the Pea family are the curious sensitive plant (Mimosa) and the acacias. One of the species of the Acacia develops enormous spines that are tunnelled by ants that were supposed to protect the trees against leaf-destroying insects. Gum arabic is obtained from African and Australian species of Acacia.

One of the most interesting features of the Rosales is the variety of changes to which the receptacle and ovaries are subject in the ripening of the fruit. In the majority of cases, the pistil ripens as an akene or follicle (splitting along one side to free
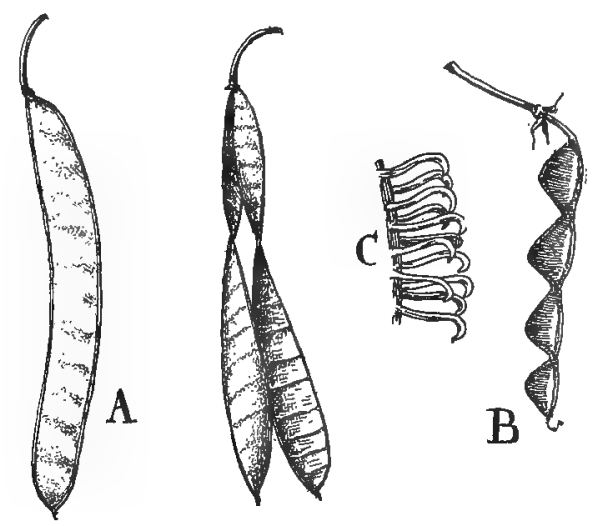

FIG. 317. Fruits of the Pea family: $A$, fruit or pod of the ground nut, showing the manner of seed dissemination by the snapping back of the valves with a twisting motion. $B$, fruit or lomentum of tick-trefoil (Meibomia). The lomentum breaks into as many nut-like parts as there are seeds in the fruit. $C$, hooked bristles on the surface of lomentum.

the seeds) or as a pod, without any considerable modification in the form of the ovary. In many instances, however, this growth is attended with pronounced alterations of the parts as in the currants and gooseberries where the receptacle forms the ovary and the entire structure becomes succulent, forming a berry. The same organs in the witch-hazel develop into a horn-like capsule, the walls of which, after splitting open, contract and pinch out the hard, smooth seed with great force. In the raspberries, the ovaries are transformed into drupes which may be lifted off from the convex receptacle like a thimble, while in 
the blackberries, the drupes remain attached to the receptacle which becomes the most edible portion of the fruit. The attractive portion of the strawberry is the enlarged succulent receptacle while the objectionable hard particles on its surface are the akenes. The receptacle surrounds the pistils in the agrimony and rose, but in the former genus it is hard and covered with hooked bristles for distribution of the nut-like fruit, while in the rose it is fleshy and often brightly colored, serving in some cases as food for birds and thus effecting seed distribution (Fig. 3I3, $B, D)$. The most pronounced changes are seen in the apple and plum families. In the former group, the carpels become tough, forming the "core" (Fig. 314,C) and the edible part is the greatly enlarged receptacle. The plum, cherry, peach, etc., represent the ovary alone, the cup-like portion of the receptacle is cast off as the fruit matures and the ovary becomes a drupe (Fig. 3I4, F). In the Pea family, the ovary usually becomes a pod with elastic valves but it is also variously modified. In the peanut, after the withering of the flower, the pistil is thrust into the ground where it develops as a pod that does not open at all. In other genera, the pod is nut-like as in the clovers, spirally coiled in alfalfa, or separable into nut-like joints that are provided with hooks as in the tick trefoil (Meibomia) (Fig. $3 I 7, B)$. Doubtless these methods of distribution, the welldeveloped seeds with their exceptionally firm integuments, the symbiotic relation of these plants with the bacteria (page I6I) and the elaborate mechanism of the iregular flowers have been the causes that have led to the abundance and wide distribution of these plants. It will be noticed in the following orders as in the preceding Orchidales, that the irregular and more highly constructed flowers are generally represented by a great number of genera and, barring some weakness, as for example, the poorly developed embryos of the orchids and their peculiar habitats, by a great number of individuals in each species.

I45. Sapindales, the Soapberry Order. - This group includes principally shrubs and trees, as the box, sumac (Rhus), smoke tree (Cotinus), holly (Ilex), burning bush (Euonymus), climbing bittersweet (Celastrus), maple (Acer), horse-chestnut and 
buckeye (Aesculus), etc. The flowers are more commonly small, of a yellow-green color and variously grouped into inflorescences (Fig. 3I8, A). We noticed in the rose order as the dominant characteristic the tendency towards the development of the basal region of the receptacle which was associated with the checking of its apical growth. In the Sapindales a.similar shortening of the axis without its basal growth leads to quite a different series of variations. As a result of the crowding of the parts of the flower upon the shortened receptacle, the distinguishing

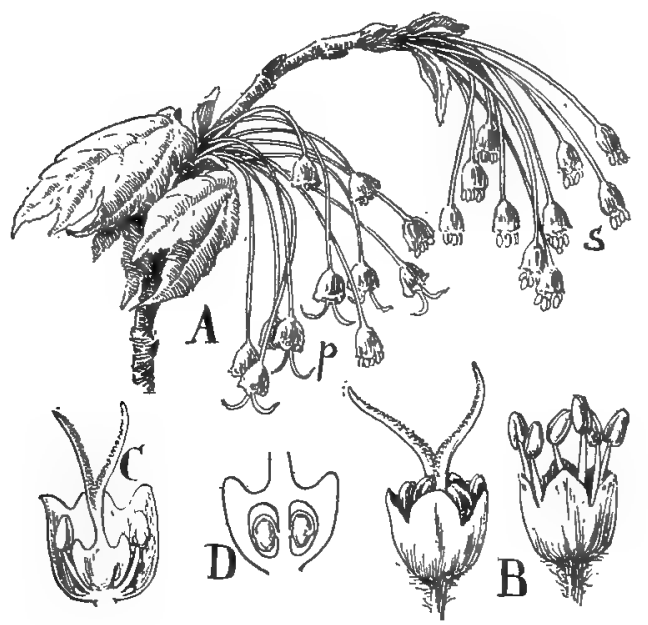

FIG. 318. A common form of the Sapindales: $A$, inflorescence of sugar maple (Acer saccharum) $-s$, staminate flowers; $p$, pistillate flowers. $B$, staminate (right-hand) and pistillate flower enlarged. $C$, section of a pistillate flower, showing the two sterile stamens and nectar disc at base of filaments. $D$, section of ovary, showing early development of the wings of the fruit and the perpendicular ovules with micropyle pointing down.

features of the order are seen in the reduction of the number of the organs of the flower, a tendency towards the cyclic arrangement of parts and an adhesion of the carpels. For example, the sepals and petals are four to five in number, usually distinct and the corolla may be entirely suppressed. There are two whorls of stamens, five to eight in number, rarely ten, while the pistils are reduced in number, ranging from two to more commonly three or rarely five. Thus we see that the spiral 
type of flower so often noticed in the rose and preceding orders has become reduced as a rule to the cyclic type and that fivenumerous sets of organs are not of common occurrence. This reduction of the flower and the suppression of parts is well illustrated in the maples (Fig. 3r8). The sepals form a fivelobed calyx. The petals are often suppressed and a nectar disc is developed outside the stamens, a distinguishing feature of the order (Fig. 318,C). The two whorls of stamens are suppressed to a varying degree so that from four to eight commonly appear and the pistils are normally reduced to two. Morefrequently the flowers are imperfect, either the pistils or stamens of each flower being aborted (Fig. 318, B). These two kinds of imperfect flowers are arranged on the same or different trees and they are adapted to small short-tongued lapping insects which visit these open types of flowers. The intelligent long-tongued bees and butterflies generally avoid such flowers, having learned by experience with colors and odors that a surer supply of food is to be found in those flowers that conceal their nectar and so exclude the promiscuous crowd of insects that swarm about the simpler types. It should be stated that the development of imperfect or incomplete flowers appearing in many of the orders is not to be looked upon as a primitive condition, though common in the lower monocotyledons and dicotyledons, since, throughout the Angiospermae, forms will constantly appear in which one or another set of organs fails to develop. The formation of windpollinated flowers, however, as in the box maple, is a return to a primitive condition.

The stimulation of fertilization results in a green wing-like outgrowth on each of the ovaries that assists at first in the manufacture of food for the embryo and later becomes a dry, membranous organ for seed distribution. This fruit, known as a schizocarp or samara, is at first partly loosened from its support and remains attached only by a small stalk (Fig. 3I9, B), which requires a rather strong wind to snap it. Thus the fruit is freed under conditions that will result in the widest dissemination of the seed. The development of the chlorophyll-bearing tissue in immature fruits to assist in the work of food produc- 
tion is an economical arrangement of tissues often to be seen. It is noteworthy that these green fruits are often protected by bitter, acrid juices and poisonous properties that finally give place to attractive flavors, odors and colors, variations that are of considerable assistance to seed protection and distribution.

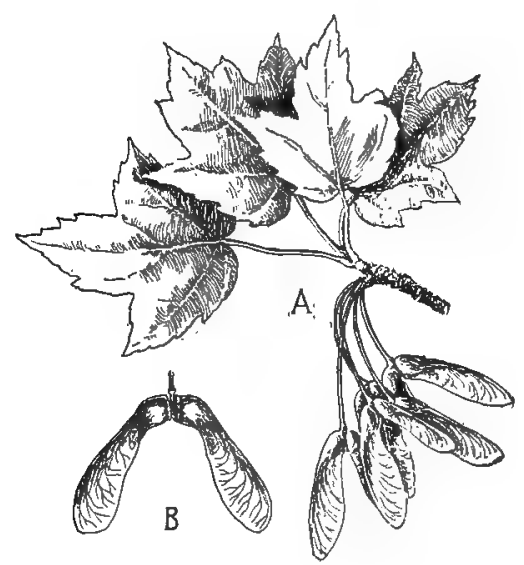

FIG. 3I9. Fruit of the maple: $A$, mature fruit of red maple (Acer rubrum). $B$, schizocarp of Norway maple. The fruit split in half is still attached to the receptacle by delicate stalks.

Many of the members of this order contain acid or poisonous juices, as in the scarlet fruit of the sumac, which were a source of acetic acid to the early settlers of this country, or poisonous oils, as in the poison ivy or poison oak (Rhus radicans) and the poison sumac ( $R$. Vernix). The former species is a climbing vine or sometimes a shrubby plant with leaves divided into three leaflets and with nut-like fruits (Fig. 320, B), while the poison sumac is an erect coarse shrub ten to fifteen feet high, with large pinnate leaves with reddish petioles and fruit clusters, as in the poison ivy (Fig. 320,A). Both of these plants contain volatile oils that cause the poisoning. The oil may readily be removed by washing in water containing baking soda, which saponifies the oil, or in alcohol which dissolves it. With alcohol the washing must be thorough in order not to spread the infection. Applications of alcohol containing sugar of lead (50 or 70 per cent. alcohol) are also recommended, which treatment is followed by 
thorough washing in alcohol. As in the preceding orders, the lower members of this group are characterized by a regular alternation of the members of each whorl, but in the higher types the sets of organs vary in number and the flowers become irregular, as in the horse-chestnut and balsam weed or touch-me-not.

I46. Orders Suggestive of the Sapindales.-The geranium order, Geraniales, shows essentially the same type and range of variation in the flower as the Sapindales, but there is this rather singular difference, namely, that the ovules, usually pendulous,

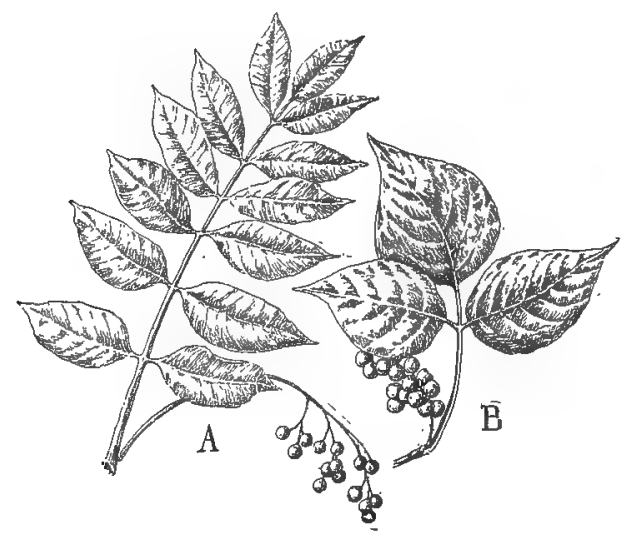

FIG. 320. Two poisonous species of the Sapindales: A, Rhus Vernix, poison sumac. $B$, Rhus radicans, poison ivy.

are always turned away from the axis of the ovary with micropyle directed upwards, while in the Sapindales the opposite arrangement is to be found, micropyle pointing down (Figs. 3 I8, $D$; $32 \mathrm{I}, D)$. This order ranges from the regular flowers of the oxalis, flax and geranium families to irregular forms like the nasturtium, milkwort (Polygala), etc. Many of these plants are known by their peculiar juices, oils, gums, as in the spurges (Euphorbia), castor bean (Ricinus), citron, lemon, orange, etc. The fruit of the lemon and orange is a berry in which the outer part of the ovary becomes leathery. The juicy pulp, which envelops the seeds, is formed from hair-like structures that arise on the inner side of the carpellary walls and by degrees entirely fill them. The navel orange is a chance variation in which a 
secondary receptacle, bearing compartments like the normal fruit, is introduced. This never reaches very large dimensions and may readily be seen at one end of the orange. The original stock from which the navel oranges grown in our country have been derived, was obtained from Brazil.

The Buckthorn order, Rhamnales, is very closely allied to the

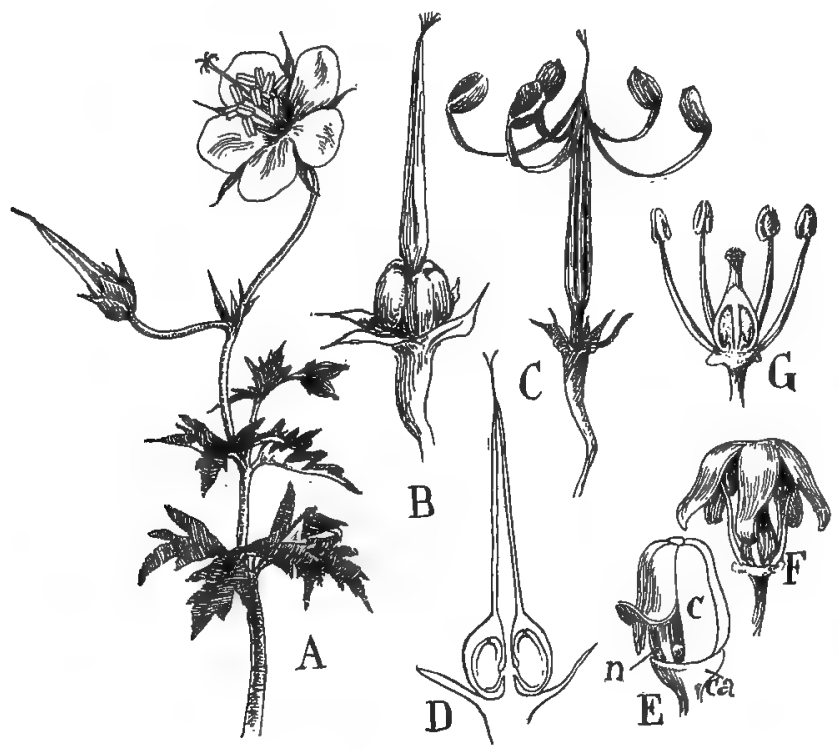

FIG. 321. Flowers of the Geraniales and Rhamnales: $A$, inflorescence of Geranium. B, nearly mature fruit consisting of five united carpels. $C$, discharge of the seed. The carpels snap apart, owing to the tension set up by the drying out of the tissues. $D$, section of pistil, showing the ovules with micropyle directed upwards. $E$, flower of the grape (Vitis), a common form of the Rhamnales - $c a$, calyx, reduced to a rim; $c$, corolla, which opens at base and falls off as a cap; $n$, nectar glands within stamens. Compare Sapindales. $F$, corolla free from the receptacle. $G$, flower freed from corolla, ovary in section, showing micropyle pointing down as in Sapindales.

Sapindales and includes such familiar plants as the buckthorn (Rhamnus), Jersey tea (Ceanothus), used in revolutionary times as a substitute for tea, the grape (Vitis), Japanese ivies, Virginia creeper (Parthenocissus), etc. The minute green or white flower shows a further reduction in parts, the petals not only being frequently suppressed, but the stamens are reduced to one whorl 
and placed opposite the sepals, whereas they alternate with the sepals in the Sapindales (Fig. 33I, E-G), and the nectary is within the filaments.

I47. Myrtales, the Myrtle Order.-This order marks a decided advance in the evolution of the flower over preceding groups, owing to the mass growth of the calyx and receptacle and usually of the ovary, the flowers being perigynous and usually epigynous. Another important character is that the flowers are always cyclic, the organs being regularly arranged in five whorls of four or less

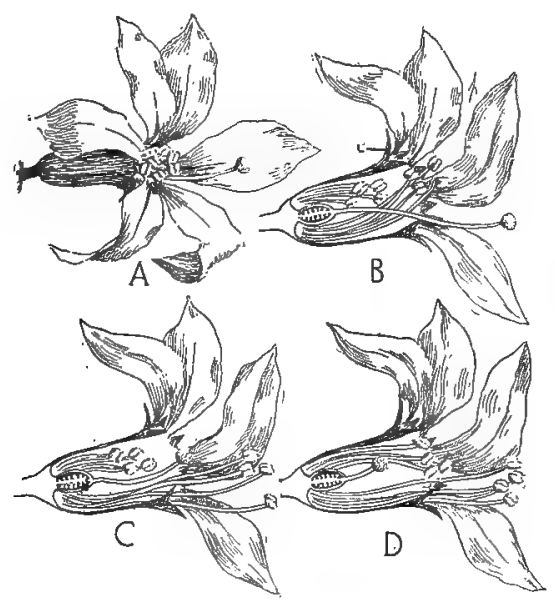

FIG. 322. Lower form of the Myrtales, flower perigynous: $A$, flower of Lythrum. $B$, flower in section- $-c$, lobe of the tubular calyx, from the margin of which arise the petals, $p$. This flower has the long form of style and the short and medium form of stamens. C, flower with medium style and with short and long stamens. $D$, flower with short style and with medium and long stamens.

commonly of five members each, though the number of stamens may be greatly increased by the splitting of the original number of the set. The petals are frequently suppressed and the calyx is often highly colored, a variation to be seen in many groups when the corolla is wanting. The carpels, as a rule, contain numerous ovules (Figs. 322, 323). The Myrtales is an important tropical order and represented with us by many familiar plants, such as the meadow beauty (Rhexia), willow-herb (Epilobium), the large 
Evening Primrose family, with one of which, Oenothera (Fig. 323, $A, B)$, deVries worked out his theory of mutation, and the common ditch and pond aquatics-the water milfoil (Myriophyllum) and mermaid weed (Proserpinaca).

The purple loosestrife (Lythrum) illustrates the characters of the lower members of the order before epigyny has become established (Fig. 322). The wand-like branches of this introduced plant with their terminal spikes of purple flowers are becoming rather common around the borders of marshes and water ways. The cup formed by the calyx and receptacle bears on its rim alternately with calyx lobes the rather twisted petals and at its base eight to twelve stamens. The pistil is composed of two carpels. This flower has become historic because of the attention that has been given to its devices for crossing. Fig. 322 shows that the sporophylls are of three lengths, short, medium and long, an arrangement called heterostyly. It can readily be seen that the three different lengths of the styles correspond exactly with the position of the anthers, consequently whatever part of the proboscis or body of the bee or butterfly in visiting these flowers comes in contact with one of the sets of open anthers, exactly the same region of their bodies will touch the stigmas as soon as they visit another flower with a corresponding length of style. The spores from the three lengths of stamens differ in size and color, and it has been demonstrated that better results follow when crossing is effected between sporophylls of the same length, $i$. e., long with long, short with short, etc. Heterostyly arose in many of the orders, as among some of the knotweeds, buttercups and rose families and in the gentians, primroses, forget-nue-not, etc.

A higher and more characteristic type of the order is seen in the Oenothera and in the great willow-herb (Chamaenerion, Fig. 323). This latter plant flourishes in rather dry soils, forming large colonies by its underground stems and gaining in conspicuousness through its terminal racemes of large deep purple flowers. The parts of the flower are in fours. The receptacle forms the ovary and the mass growth of perianth and stamens results in the development of a long tube which forms at its 
mouth the linear segments of the calyx alternating with the round spreading petals and the stamens. At the time of the opening of the flower the eight anthers are shedding their spores and are in line with the nectaries, while the lobed stigma is closed and bent backward (Fig. 323, C, s). A day later the stigmas assume the position shown in the lower flowers, the lobes curving backward so as to lie in the pathway leading to the nectaries (Fig. 323, C, o). It is evident that these positions

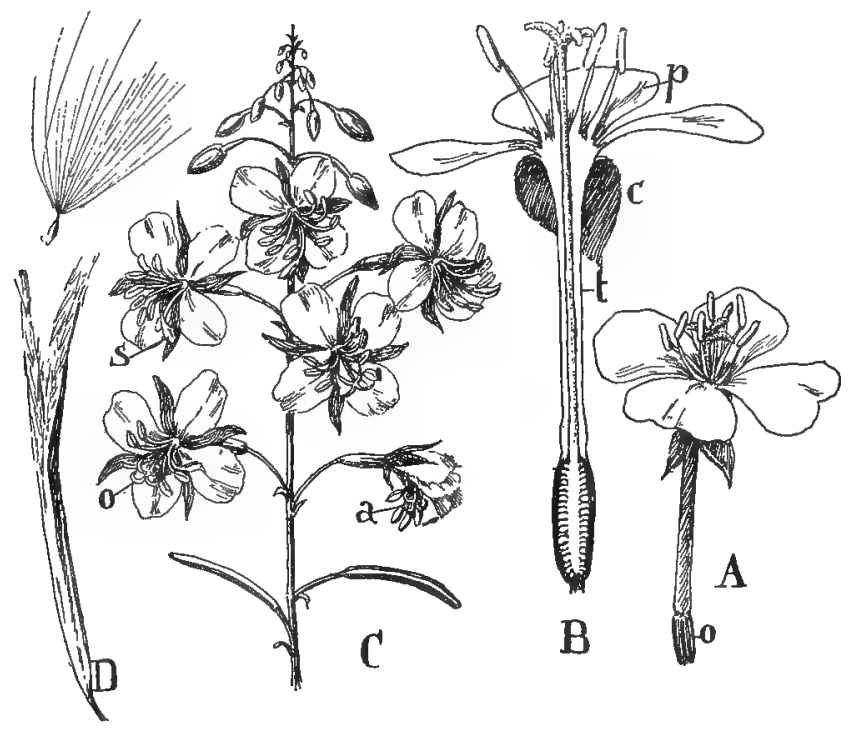

FIG. 323. Higher forms of the Myrtales, flowers epigynous: $A$, flower of Oenothera-o, ovary. $B$, enlarged sectional view of flower, showing the receptacle enveloping the ovules. The receptacle grows above the ovary, forming a tube, $t$, that bears at its summit the lobes of the calyx, $c$, the petals, $p$, and stamens. $C$, inflorescence of the great willow herb (Chamaenerion) $-s$, closed stigma in young flowers; 0 , opened stigmas in older fflowers; $a$ stigma touching anthers in withered flowers. $D$, capsule opening and discharging the seeds. $E$, a seed enlarged.- $C$ after Kerner.

must necessitate a crossing if the flowers receive the proper visitors. If, for any reason, crossing should fail autogamy results, owing to the continued curvature of the stigmas, which are finally brought in to contact with the anthers, in which work the positions of the flowers and stamens coöperate, as shown in the lowest 
flower (Fig. 323, C, a). The microspores are fastened together in threads by a sticky substance, viscin, so that they adhere to the insect's body and are drawn out from the anthers in net-like skeins. This may be tested by applying the moistened finger to the opened anthers; this is also true of the related plants, as the fuchsia, evening primrose, firewood (Epilobium), enchanter's nightshade (Circaea).

The numerous seeds developed in the capsule are provided at the end with tufts of long white hair (Fig. 323, D,E), which readily transport them and explains the quick appearance of these plants in forest lands that have been devastated by fire or cutting. In addition to the native plants mentioned above, many wellknown tropical plants are represented in this order, as the mangrove of our southern swamps and the large Myrtle family, often characterized by leathery leaves and aromatic oils. This family furnishes the clove, which is a flower bud, the pomegranate, guava, bay rum, the Brazil nut and the eucalyptus trees, some of which (Australian) attain the greatest height of any tree, over four hundred feet, with a diameter of twenty-four feet.

148. Umbellales, the Carrot Order.-This order marks the consummation in the reduction and mass growth of parts that we have seen steadily progressing through the various orders of the Choripetalae. Notice that the strictly epigynous, cyclic flowers (Fig. $324, C, D$ ) are now reduced to four whorls, the five lobes of the calyx alternating with the five petals and these in turn with the four to five stamens. The reduction also appears in the pistil which usually consists of two carpels that contain but a single ovule each. The order contains two rather small families, the Ginseng family (Araliaceae) represented by the sarsaparilla or spikenard (Aralia), the ginseng (Panax) and the Dogwood family (Cornaceae), including the pepperidge or sour gum trees ( Nyssa), dogwood or cornel (Cornus); and the large Carrot family (Umbelliferae) of 2,roo species. The Carrot family contains many familiar native and cultivated plants which may be recognized by the hollow internodes of the stems, leaves variously lobed and attached by conspicuous sheathing petioles, peculiar odors derived from oils and resins, small flowers that are 
usually white or yellow and grouped into flat-topped inflorescences (umbels), which are usually surrounded by bracts, called the involucre (Fig. 324, $A, B$ ). These features are well seen in the wild carrot which has become a troublesome weed in pasture lands and meadows. The calyx lobes are very small, a feature likely to be seen in any epigynous flower. The incurved petals alternate with the five stamens and in the center of the flower, the

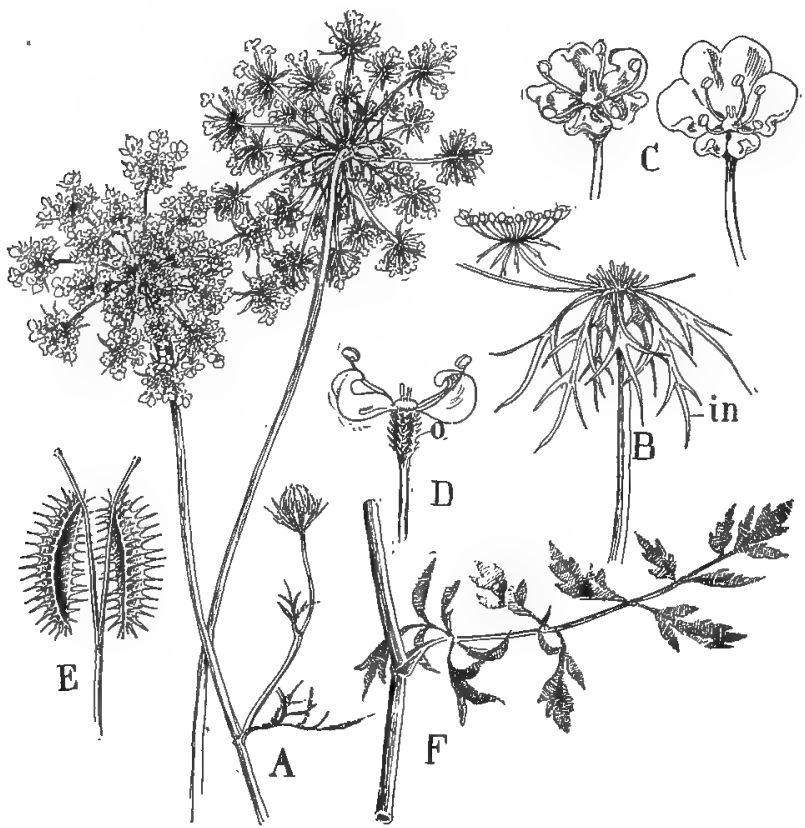

FIG. 324. A common form of the Umbellales: $A$, stems of wild carrot (Daucus) with flowers arranged in compound umbels. $B$, inflorescence with all the umbels removed but one-in, bracts of the involucre. $C$, forms of flowers, the one on the right being a flower from the margin of the umbel. The corolla is enlarged and irregular, thus adding to the conspicuousness of the inflorescence. $D$, corolla partially removed to show the epigynous character of the flower and the cushion-like nectary' at' the base of the styles; $o$, ovary. $E$, fruit splitting into two nutlets. $F$, portion of hollow stem with sheathing of leaf base.

two styles broaden out into a conspicuous nectary above the ovaries. The fruit is a schizocarp, splitting into two nut-like parts after the manner of the maple (Fig. 324,E). The flowers 
on the outside of the umbel become somewhat irregular, owing to the unequal enlargement of the outermost petals. These small flowers that individually cannot be seen at a distance of a few feet become the most conspicuous feature of our fields owing to their association in large numbers into compact, lace-like umbels. The aggregation of flowers has been noticed in various groups, as in the mustards, various families of the Rosales, in the Sapindales and buckthorns, of which latter simple regular type the carrot flower would appear to be a natural sequence (compare Figs. $32 \mathrm{I}, G ; 324, D)$. But in no group has so successful and varied an arrangement of the flowers been achieved. The advantages of this umbellate arrangement are apparent. The crowding of the flowers is attended with the reduction in their size and in saving of material while they have gained in the number of flowers and in conspicuousness. This arrangement also increases the chances of seed production since the insect in a single visit may cross a score of flowers in crawling over the umbel. Autogamy is prevented at first by the difference in the maturation of the anthers and stigmas, frequently one or more days intervening between these two conditions and in many genera the flowers are imperfect, the stamens and pistils being arranged on different parts of the umbel and so further assist in crossing. But even if the great variety of small lapping insects that swarm over these flowers were absent the construction of the umbel is such that the flowers are usually able to effect pollination unassisted. The variety of devices for the accomplishment of this work is without parallel in any other group. The opening of the flowers of an umbel proceeds either from the circumference towards the center or from the center outwards. In some genera, as Eryngium, the flowers on the margin open first and the stigmas are ready for crossing while the anthers are closed and bent down upon the petals. On the following day, the inner adjoining set of flowers is in the same condition while the anthers of the marginal flowers have been lifted up by their filaments so that they reach out and come in contact with the stigmas of the adjacent inner flowers, the curvature of the styles often assisting in bringing the two organs together. In this way, ample oppor- 
tunity for crossing with the older flowers of another umbel is first given and later a crossing between the adjacent flowers of the same umbel is almost sure to result. In other cases, as the snakeroot (Sanicula) a few of the simple flowers are perfect while the remaining flowers of the umbel bear only stamens. The perfect flowers are the first to open, being in the same condition as the marginal flowers of the preceding example. Later the filaments straighten out, curve away from the stigmas and the anthers discharge their spores and finally drop off. Now the adjoining flowers open and extend their filaments so that the anthers are pushed over to the stigmas of the perfect flowers. In the chervil, a similar crossing is effected after the perfect flowers have shed their anthers by the numerous imperfect flowers growing above them and extending their anthers so that the microspores will drop straight down upon the stigmas (Fig. 325).
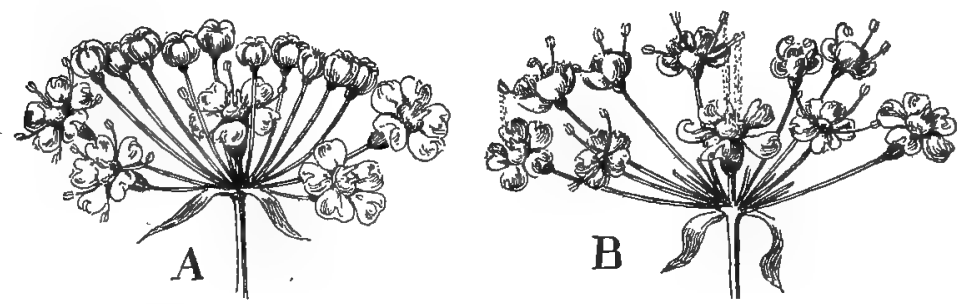

FIG. 325. Flowers of chervil: $A$, perfect flowers only in bloom. The anthers are discharging their spores before the stigmas are receptive. $B$, later stage - the staminate flowers are now in bloom and shedding their spores upon the mature stigmas of the perfect flowers.-After Kerner.

In the water parsnip (Sium), and beaked parsley (Anthriscus), etc., there are two kinds of umbels, one containing principally perfect flowers and the other only staminate flowers. The perfect flowers blossom first, and shed their spores and anthers before the stigmas are receptive. After all the anthers have been shed, the stigmas mature and continue in this condition for two days, during which time the umbels of imperfect flowers have grown above them and assume such a position that when the anthers finally open there results a rain of microspores upon the stigmas below.

The members of the Carrot family are characterized by the 
presence of essential oils and resins in the roots, stems, leaves o especially in the fruits which usually contain oil cavities between the ribs of the ovary. These substances are the sources of the peculiar odors that make easy the recognition of these plants. These oils give the commercial value to several fruits, as in the caraway, parsley, fennel, anise, coriander. Several species contain very poisonous alkaloids, as the water hemlock (Cicuta), among the most poisonous of our native plants, and the hemlock (Conium) which perhaps furnished the potion drunk by Socrates. Several valuable food plants, as the carrot, parsnip, celery, parsley, are cultivated species of the family.

\section{Series b. Sympetalae.}

149. General Characteristics.-This group contains the most common and abundant of our flowering plants, approximating 42,000 species, and ranks as the most specialized of the angiosperms. The variations of these plants have been very successful, especially to be noticed are the development of underground stems, special types of flower structures and the massing of the flowers in dense inflorescences. As a result of these advantages, they exceed all other groups in the number of individuals, though. they comprise fewer orders as a consequence of the strikinguniformity in the floral structure.

While a few of the simpler members of this group have distinct petals, the crowding of the organs on the receptacle has resulted, in nearly all the forms, in the sympetalous type of corolla, in the cyclic arrangement of the parts, and in the reduction in the number of stamens, so that each whorl does not exceed the number of petals, and more frequently one whorl of stamens is partly or entirely suppressed. The pistils are usually less numerous than the petals. The flowers range from regular hypogynous forms to epigynous and irregular types through the same series of variations, as noted in the Choripetalae. The Sympetalae are the most recently evolved of the Angiospermae, as is apparent from their uniformity of structure and they appear to be adapted to temperate and northern conditions where they have preëmpted the open country and flourished exceedingly, 
forming the most characteristic features of the herbaceous flora. Aquatics are of rare occurrence and but few tree forms appear; notably the ash, persimmon, catalpa, paulownia, etc. Heathlike shrubs, however, are widely distributed in northern regions. The invasion of the tropics with its favorable conditions has led to an enormous increase in some of the groups and the development also of a great variety of woody plants, as trees and climbers.

I50. Ericales, the Heath Order.-This order is the simplest of the Sympetalae and includes a great variety of plants that are largely northern in their distribution. Many are cultivated, as the azaleas, rhododendrons and laurels (Kalmia), and others are familiar plants of bogs and woods as the sweet-pepper bush

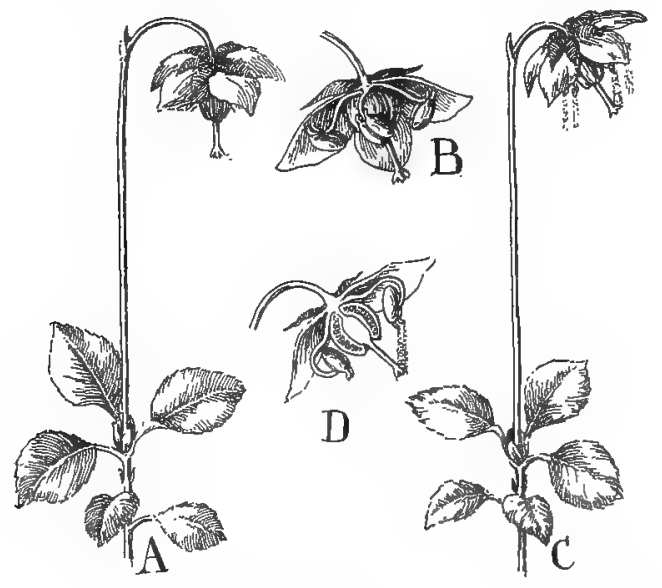

FIG. 326. A simple form of the Ericales: $A$, the shin leaf (Pyrola) with flower just opened. $B$, flower with part of perianth removed to show the retention of the anthers by the petals. $C$, later stage of flowering. The anthers have been released by the spreading of the petals and the flower stalk has inclined so that the spores sprinkle down on the stigma. $D$, flower in section, showing the relation of parts in autogamy.-After Kerner.

(Clethra), wintergreen (Chimaphila), Labrador tea (Ledum), Rhodora, Leucothoe, rosemary (Andromeda), leather leaf (Chamaedaphne), arbutus (Epigaea), checkerberry (Gaultheria), bearberry (Arctostaphylos), huckleberry (Gaylussacia), blueberry (Vaccinium), heather (Calluna), cranberry (Orycoccus). The flowers of the heaths are very characteristic and sharply dis- 
tinguished from other orders. More frequently they consist of five regular whorls of five members each, anthers usually opening by pores and often provided with two horn-like appendages, and the pistil is composed of five carpels, the ovary maturing as a capsule or berry (Fig. 326). The separate origin of each whorl of organs is an important feature of the order as contrasted with other Sympetalae, each set being as a rule separately attached to the receptacle. While the sympetalous corolla is a step in advance of previous types, it is evident that these regular hypogynous flowers are in other respects of a rather simple character. This feature is further illustrated in some of the genera like Clethra, Monotropa and Pyrola where the free or slightly fused petals form a very natural transition from the Choripetalae (Figs. 327, $A ; 326$ ).

The simpler forms of flowers are illustrated in Pyrola with its regular hypogynous and polypetalous flowers, though some species show a slight tendency to sympetaly. The stigmas are mature with the opening of the flower while the anthers are bent back out of the way, their filaments being held under considerable tension by the petals (Fig. 326, A, B). A bee laden with spores would effect a crossing as soon as he alighted upon the flower, but in probing after the nectar he presses back the petals, thus releasing the anthers which snap down, spilling the spores upon him. Doubtless autogamy results in many of these forms if crossing fails owing to the expansion of the petals which would release the stamens, and the drooping of the flower which would bring the falling spores in line with the stigma (Fig. 326, $C, D$ ).

Other genera show varying degrees of sympetaly but in the majority of cases, tubular corollas appear (Fig. $327, C$ ) as in the Leucothoe, bearberry, Andromeda, blueberries, etc. The majority of such forms have horned anthers which are shaken by the insect and so assist in sifting out the spores. In the Blueberry family, we note that a mass growth of the receptacle and ovary has begun (Fig. $327, D$ ) while in Rhodora, rhododendron and azaleas another line of variation appears in the irregular corolla (Fig. 327, F). In the two latter genera, the styles and stamens 
extend far out, furnishing a natural landing place for hovering animals as moths and humming birds. In this position the spores cannot be sifted out and we find them fastened together in fours, just as they were formed in the mother cell, by sticky threads which cause them to adhere on the insect's body in fringe-like masses (Fig. 327, D). One of the lower basidiomycetes (Exobasidium) infests the leaves and flowers of the azalea and other genera, causing large watery outgrowths that are

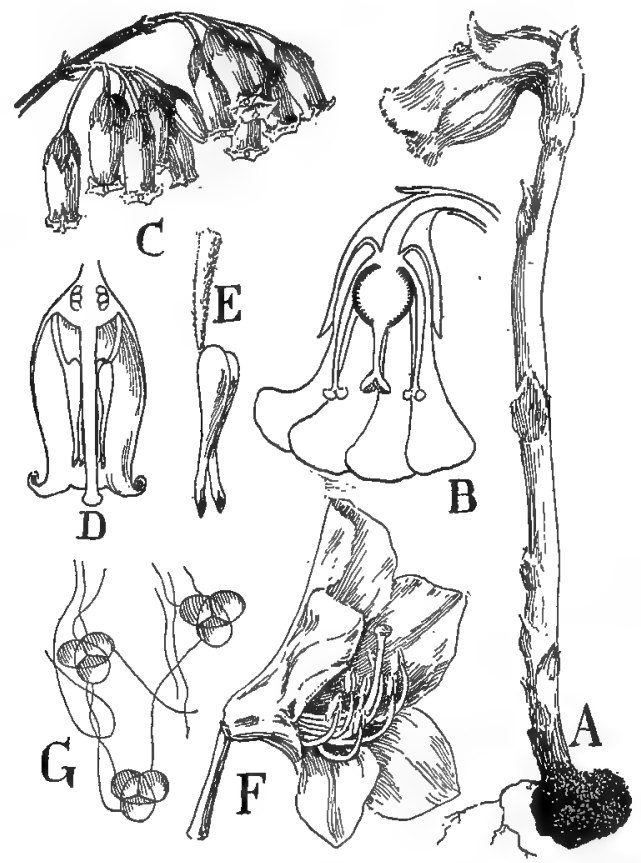

FIG. 327. Common forms of Ericales: $A$, Indian pipe (Monotropa). Leaves reduced to scales and without chlorophyll, owing to saprophytic habit of plant. $B$, section of flowers, showing polypetalous corolla. $C$, inflorescence of the blueberry (Vaccinium). $D$, section of flower, showing sympetalous corolla and epigynous type of flower. $E$, a stamen enlarged, opening by pores at end of anther. F, Azalea, showing irregular type of flower. $G$, spores attached by viscid threads.

often eaten under the impression that they are the fruit of the plant. The members of this order are adapted to a wide range of conditions though more characteristic of north temperate and 
arctic regions where they constitute the conspicuous features of the tundras, bogs, heaths and moors. These plants are often characterized by their thick, leathery, evergreen leaves of pronounced xerophytic character and their common distribution in wet moors and bogs presents a most puzzling problem in the association of plants. Many of the heaths have been cultivated from very early times and they have lent themselves so readily to crossing that perhaps no order furnishes so many forms for decorative and landscape effects. Several yield valuable fruits, as the blueberries, huckleberries and cranberries.

I5I. Orders of a Higher Type than the Ericales. - The primrose order (Primulales) forms a very natural transition from the Ericales. As the next step in advance, we note the slight association of the stamens and the corolla (Fig. 328, $A$ ) and their frequent reduction in number. The occurrence of staminodia, page $42 \mathrm{I}$, in certain forms marks the first transition to the reduction of the number of stamens. The pistil is generally composed of five carpels forming a capsule without partitions (unilocular) and containing a central placenta, bearing numerous seeds, that is attached only to the base of the ovary (Fig. 328, A). This is the so-called free central placenta and only occurs elsewhere in the small Bladderwort family of aquatics. This order includes the loosestrife (Lysimachia and Steironema), star flower (Trientalis), shooting star (Dodecatheon) and cultivated forms of the cyclamen and primroses.

Proceeding to the gentian order (Gentianales), it will be noted that the flowers are variable and not as clearly characterized, the corolla being sometimes wanting or polypetalous. The reduction of the stamens to a single whorl and the pistils usually to two in number indicates points of advance that are to be associated with the twisting of the petals in the bud and the opposite arrangement of the leaves as distinguishing features of the order (Fig. $328, B-D$ ). Note should be made of the fact that the two pistils are often quite distinct, doubtless a survival of a more primitive condition. The Gentianales include the ash (Fraxinus), lilac (Syringa), Forsythia, olive (Olea), valued. for fruit and oil, fringe tree (Chionanthus), privet (Ligustrum), jas- 
mine, Strychnos, yielding the alkaloid strychnine, oleander (Nerium), the gentians, marsh pink (Sabbatia), the aquatic floating heart (Limnanthemum) and the highly specialized plants of the dogbane and milkweed families. The latter family is dis tinguished by the microspores being united into club-shaped pollinia that are attached, one from each of the two adjoining anthers, to a peculiar hook, so that the leg of the insect becomes caught in the hook and withdraws the pollinia in pairs.

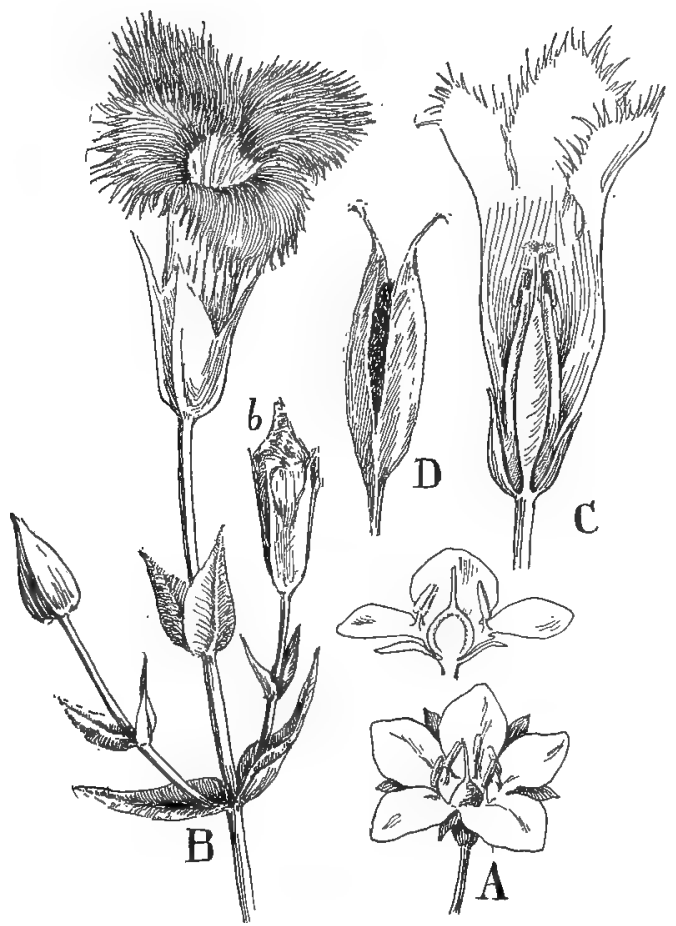

FrG. 328. Primulales and Gentianales: $A$, flower of loosestrife (Steironema). Above flower in section, showing cohesion of single row of stamens to base of corolla and the numerous ovules on a free central placenta. These are the most important characteristics of the order. $B$, fringed gentian (Gentiana), showing leaf arrangement and twisting of petals in bud, $b$, char. acteristics of the order. $C$, section of flower. $D$, fruit, the two carpels separated.

152. Polemoniales, or Phlox Order.-This group is the richest in the number of species, over 14,600, of any order of angio- 
sperms. The advance over previous orders is seen in the more prolonged mass growth of the corolla and stamens, the filaments appearing to rise at a higher point on the corolla (Fig. $330, D$ ) and the stamens are reduced to a single whorl, and frequently less than five in number. The pistils are completely compound and usually composed of but two carpels. This reduction is asso-

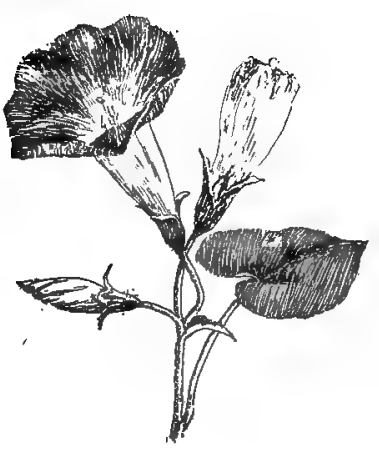

FIG. 329.

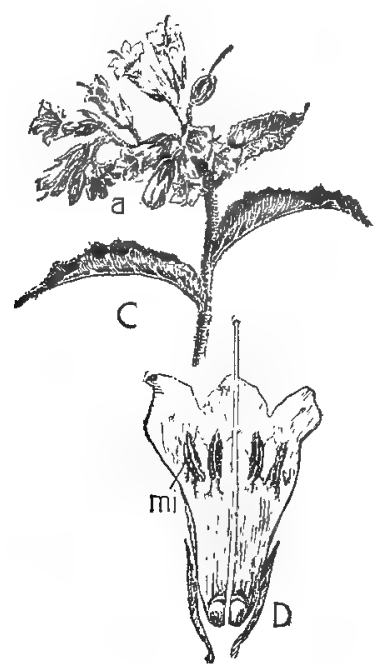

FIG. 330 .

FIG. 329. Flower of the morning-glory (Ipomoea), showing the tubular corolla characteristic of the Polemoniales.

FIG. 330. Boraginaceae: $C$, inflorescence of comfrey (Symphytum). Note the coiled inflorescence, $a$, a feature of this family. $D$, section of flower, showing the deeply four-lobed ovary and the stamens cohering high on the corolla and alternating with small tongue-like scales.

ciated with a pronounced irregularity of the corolla in the higher families and a high degree of specialization in the construction of the flower which in part accounts for the occurrence of the large number of individuals. The order is noted for its great number of showy flowers and the large tubular corollas which attain their highest perfection in several of the families.

(a) The More Important Families of the Phlox Order.-The flowers of the lower families are regular, as in the morningglory, sweet potato, dodder (Cuscuta), a yellow thread-like para- 
site that twines about various plants, and the phlox (Fig. 329). The flowers of the rough-leaved borages (Boraginaceae) are also regular but they are distinguished by having the ovary of the two carpels deeply lobed so that the fruit appears as four nutlets and also by their coiled inflorescences as shown in Fig. 330. This family includes the heliotrope, hound's-tongue (Cynoglossum), forget-me-not (Myosotis), comfrey (Symphytum), and the blueweed (Echium) in which the corolla becomes irregular.

The Mint family, Labiatae, is world-wide in its distribution and the largest of the order with 3,000 species. These plants are sharply characterized by square stems, opposite leaves, aromatic oils, nut-like fruits as in the borages, but the corolla is very irregular and usually two-lipped. The stamens, usually two short and two long ones, together with the two lobed style are more frequently concealed under the upper lip of the corolla (Fig. 33I). The flowers are generally so placed that the lower lip serves as a landing place for insects and in entering the flower, the top of their bodies rubs against the stigmas or anthers. Crossing is secured by the difference in the time of the maturation of the anthers and stigmas, assisted by a variety of movements, such as the alternate curving down of the anthers and stigmas which brings first one set of organs and then another into the pathway of the insect. One form of this arrangement is seen in the sage, where there are but two strangely modified stamens, the two anther lobes being connected by a long-curved rod which is fastened near one end to a short filament so that the anther becomes a lever with the filament as a fulcrum (Fig. 332). Only the anther lobes concealed under the upper lip are fertile. As the bee enters the flower, he pushes up the short arm of the lever, thus causing the long arm to swing down, pressing the fertile anther.upon his back and dusting him with spores. Later, the style which is at first immature and above this apparatus, grows out and curves down and at maturity comes to lie in such a position as to rub upon the back of a visiting insect at the same point as the anthers. The peculiar forms of the corolla, the relation of the anthers and stigmas and the frequent occurrence of hairs and bristles that direct the in- 


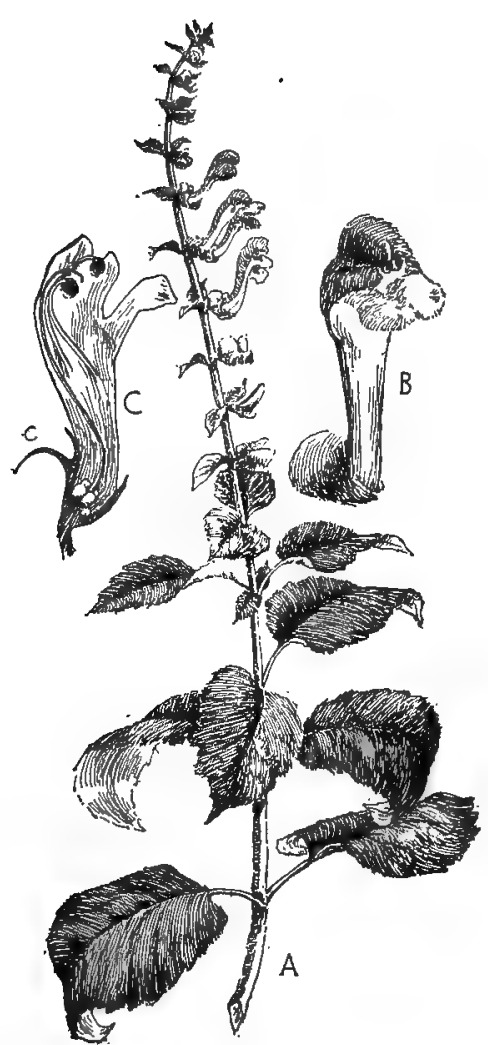

FIG. 33I.

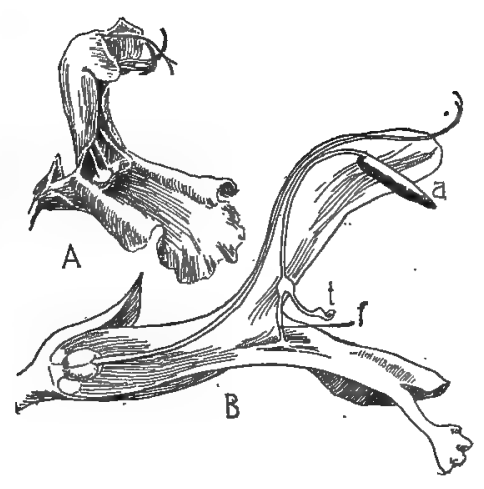

FIG. 332.

FIG. 33I. A common species of the Mint family: $A$, inflorescence of the skullcap (Scutellaria). Note the square stem, opposite leaves. Why are all the flowers facing one way? $B$, flower enlarged, showing the two-lobed under lip and the three-lobed upper lip which conceals the sporophylls. $C$, section of the flower. Ovary four-iobed, stamens cohering with the corolla and anthers concealed with the stigma beneath upper lip. Purpose of the crest, $c$, on the calyx?

FIG. 332. Flower of the sage (Salvia): $A$, flower after the anthers have shed their spores. The two-lobed stigma is bending down into the position occupied by them. $B$, sectional view of the flower, showing four-lobed ovary with nectar glands at the base; stigma not receptive and bent back. As the insect enters the flower he pushes against the sterile lobe of the anther, $t$, and thus causes the fertile lobe, $a$, to swing down upon his back. $f$, filament of anther. 
sect with the greatest precision to particular parts of the flower with a view to crossing, mark this family of the mints as the most specialized of the order. A fine series of devices are seen in such common mints as the blue curls (Trichostema), skullcap (Scutellaria), hyssop (Agastache), ground ivy (Glecoma), catmint (Nepeta), selfheal (Prunella), motherwort (Leonurus), dead nettle (Lamium), hedge-nettle (Stachys), sage (Salvia), bergamot (Monarda), pennyroyal (Hedeoma), mountain mint (Koellia), bugle weed (Lycopus), etc. Many of these plants are of commercial importance. Mentha yields valuable oils as spearmint, peppermint, and menthol and from other genera are derived oils used in perfumery, medicine and as condiments, as rosemary, lavender, origanum, thyme. Several are cultivated for their flowers and foliage, as the coleus, monarda, stachys, etc.

The large family of figworts, Scrophulariaceae, with its 2,400 species, closely resembles the mints, but is distinguished by the ovary being undivided and containing many seeds on a central axis (Fig. 333, C): While the simpler forms have almost regular corollas and five stamens, the higher forms are bilabiate with two to four stamens as in the mints. This family contains some of the most showy of our cultivated plants, as the foxglove (Dasystoma and Digitalis), Gerardia, snapdragon (Antirrhinum), rattlebox (Rhinanthus), toadflax (Linaria), Paulownia, beardtongue (Pentstemon), monkey flower (Mimulus); and the allied Catalpa and trumpet creeper; also many other attractive plants that are not cultivated as the mullen (Verbascum), figwort (Scrophularia), turtle head (Chelone), hedge hyssop (Gratiola), speedwell (Veronica), painted cup (Castilleja), lousewort (Pedicularis), cow-wheat (Melampyrum). These plants are among the most characteristic features of our flora, the family being largely confined in its distribution to the north temperate regions. The flower of the toadflax (Linaria) illustrates a common type of the. Figwort family (Fig. 333). Such flowers are said to be personate, that is bilabiate but with the under lip arched so as to meet the upper lip and entirely closing the mouth of the corolla. This arrangement very effectively protects the microspores and conceals the nectar and it requires a rather 
muscular insect alighting upon the knobbed lower lip to force his way into the flower. It is worth any one's time to sit by this plant and examine the mechanism of the flower while the bee is at work. The sporophylls present the same variety of arrangements for crossing as noted in the mints. The nectar glands are situated at the base of the carpels but the nectar does not remain upon the glands as in the majority of flowers, but runs down through a narrow duct between the filaments and collects in the spur-like prolongation of the corolla (Fig. 333, s).

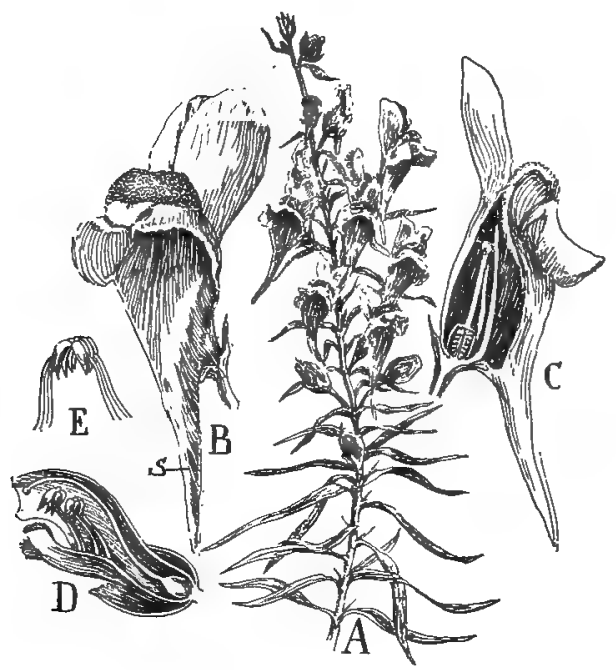

FIG. 333. Examples of the Figwort family: $A$, inflorescence of the toadflax (Linaria). $B$, flower viewed from beneath, showing the under lip arching up against the upper, two-lobed lip-s, nectar spur of the corolla. $C$, section of the flower viewed from the side, showing the undivided ovary with central ovules. Note the stigma and anthers concealed at the lips of the corolla. $D$, sectional view of flower of Rhinanthus with the four stamens arranged in pairs. $E$, appearance of the stamens as viewed from the mouth of the corolla. The filaments have been pressed apart, thus separating the opened anthers.

The yellow rattlebox (Rhinanthus, Fig. $333, D, E$ ) shows another form of the flower, common in this family. The general arrangement of the floral organs is the same as in Linaria, but the anthers are in pairs so that when they open, owing to the rigidity of the filaments or the pressure of the upper lip, they 
are kept tightly pressed together like a pair of sugar tongs, thus preventing the shedding of the spores. Owing to the form of the corolla and often because of numerous hairs and bristles, the insect is directed in such a definite way to the flower that he comes in contact with appendages of the anthers, or causes a slight deflection of the rigid filaments or of the lip of the corolla, any of which movements are sufficient to separate the anthers and bring down upon him a shower of spores. These flowers are largely protogynous so that at first only a crossing is possible. In many species, autogamy results from the downward bending of the corolla and style, accompanied by a loosening of the anthers so that during the last days of flowering the spores may fall directly upon the stigma.

Many of these flowers are characterized by mottlings and blotches. It appears to be a rather general law that the most highly modified parts are variegated in this manner-compare the mints and orchids. Less specialized flowers present an association of various colors or veinings, a feature that is illustrated in many families, as violets, peas, geraniums, etc., whereas the simplest types of flowers are usually of a uniform color. The figworts have been called a suspicious group, and if not actually poisonous, none at least serve as food. Several are medicinal, as Digitalis, Veronica, Gratiola, etc. Many are parasitic, as the foxglove, Gerardia, eyebright (Euphrasia) and the related and reduced brownish rapes (Thalesia and Orobanche), beech drops (Leptamnium) and squawroot (Conopholis).

The curious family of the bladderworts is closely related to the figworts. The bladderwort (Utricularia) is a very common aquatic in still waters and ponds. Certain leaves become modified into elaborate sacs with trapdoors for enticing and capturing small insects which die and decay in these prisons and are ultimately absorbed and so contribute to the nourishment of the plant. The butterwort (Pinguicula) is another member of this family found in the northern countries and also in our southern states. It has more the appearance of a violet with a rosette of leaves which are provided with glands that secrete a viscid substance for the capture of insects and also digestive fluids. 
The contact of the insect acts as a stimulus, causing the leaves to roll up and so bringing to bear upon him a larger surface of digestive glands. One of the species of Pinguicula is used in northern countries to curdle'milk in place of "rennet" which contains the similar digestive fluids of calves' stomachs.

The Potato family (Solanaceae) shows many of the irregularities of the figworts, but the majority of its $I, 700$ species have regular flowers as illustrated in Fig. 334. While the family
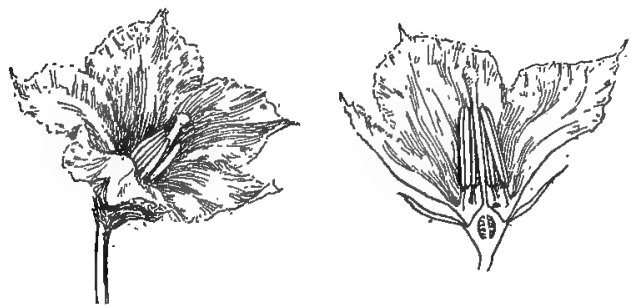

FIG. 334. Flower of the potato (Solanum tuberosum), showing the stamens inserted on the tube of the corolla and encircling the style.

is largely tropical, many of the species are cultivated, as the potato, eggplant, tomato, cayenne pepper (Capsicum). Poisonous, acrid and narcotic properties are characteristic features of the family. Belladonna and atropine from Atropa, stramonium from Datura and nicotine from Nicotiana Tabacum are characteristic drugs. Ground cherry (Physalis), nightshade (Solanum), Petunia, etc., are cultivated forms.

I53. A Transitional Order.-It would appear that all the changes possible in the hypogynous type of flowers had been wrought in the members of the Polemoniales and that the next step in advance must be to the epigynous flower. This is seen to be the case with the madder order, Rubiales. Here the flowers are epigynous and the parts are generally in fives though the carpels vary greatly in number. 'The simplicity in the structure of the flower and often also the form of the inflorescence, as in the elderberry (Sambucus), bedstraw (Galium) and arrowwood (Viburnum) is strikingly suggestive of the Umbellales (Figs. $335, A, B ; 324$ ). It appears that each step in advance is attained in a very simple way and that only gradually are 
alterations made that lead up to the specialized types. Look back over the preceding groups and orders and note that many of the irregular types of flowers are preceded by a long series of regular forms. So in the madder order, this new departure of the flower is attended with such a simplicity of structure as to render difficult the separation of some of the genera from the open flowers of the Umbellales which have also arrived at the

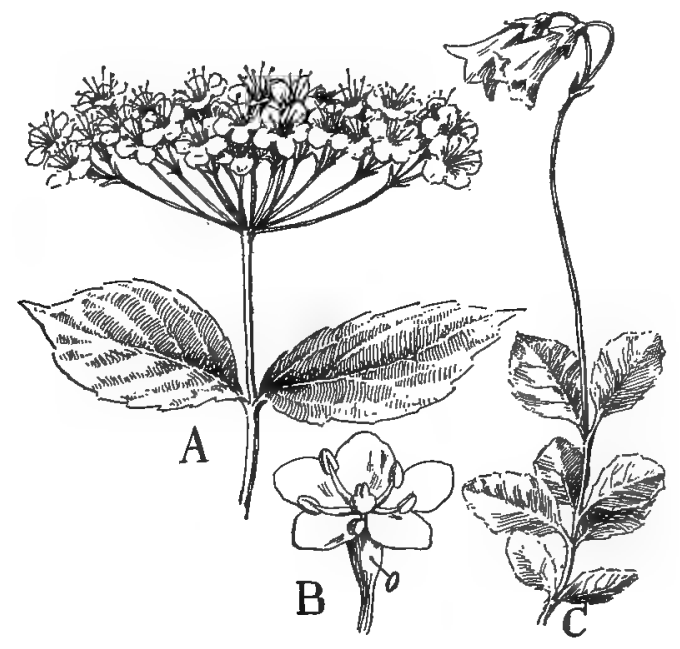

FIG. 335. Simpler forms of the Rubiales: $A$, inflorescence of the arrowwood (Viburnum). $B$, simple, epigynous flower of the elderberry (Sam. bucus)-o, ovary. $C$, the twin flower (Linnaea).

same stage of development, page 465 . This would not necessarily imply a relationship, since it repeatedly happens both among plants and animals that identically similar structures arise in groups in no way related. From these simple flowers, that may be no more sympetalous than certain genera of the carrot order, we pass to more pronounced tubular forms in the bluets (Houstonia), buttonbush (Cephalanthus), twin flower (Linnaea, Fig. $335, C$ ), snowberry (Symphoricarpus) and finally to irregular and even labiate types as in the honeysuckle (Lonicera, Fig. 268), valerian, teasel (Dipsacus) and scabious (Fig. 336). It is noteworthy that in the three latter genera the flowers become massed in a dense inflorescence, known as a head, which are sub- 
tended by modified leaves, the involucre (Fig. 336) and the pistils are reduced to a single fertile carpel with two-lobed style. These variations will become very prominent in the next order. The Rubiales are an important tropical group and furnish the coffee (Coffea) and the cinchonas which yield such drugs as quinine and calisaya.

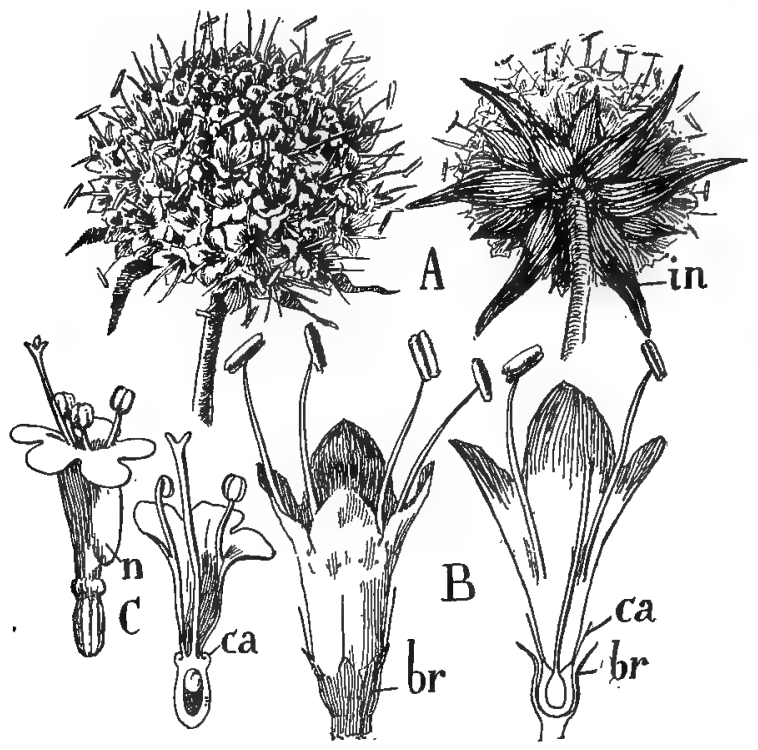

FIG. 336. Advanced forms of the Rubiales: $A$, inflorescence of Scabiosa, at the right showing the involucre, in. $B$, a single flower enlarged, showing the somewhat irregular corolla. At the right the sectional view of the flower shows the calyx, $c a$, terminating in bristle-like teeth; $b r$, bract-like cup surrounding the calyx. $C$, irregular flower of valerian- $n$, nectar sac; $c a$, rudimentary calyx, which matures in the fruit as a mass of delicate feathery organs, known as the pappus.

I54. Campanulales, the Bellflower Order.-This order marks the culmination of the tendencies that we have seen steadily progressing through the monocotyledons and the dicotyledons. The variations have been of so peculiar and successful a nature that no group of plants are so widely distributed and in the more specialized families of so common occurrence. Over I 4,500 species are known. The parts of the epigynous flowers are arranged in four whorls of usually five members each. The 
anthers are aggregated and usually cohere, forming a sheath about the style which is frequently covered with hairs and acts like a piston rod in the cylinder of anthers. The flowers are protandrous with few exceptions, the anthers opening on their inner sides and discharging the spores upon the style which later sweeps them out as it elongates. The pistils are generally reduced to a single one-ovuled carpel that ripens as an akene. Leaving out of consideration the gourds which include the melons, pumpkins, cucumber and gourd, as a family of uncertain

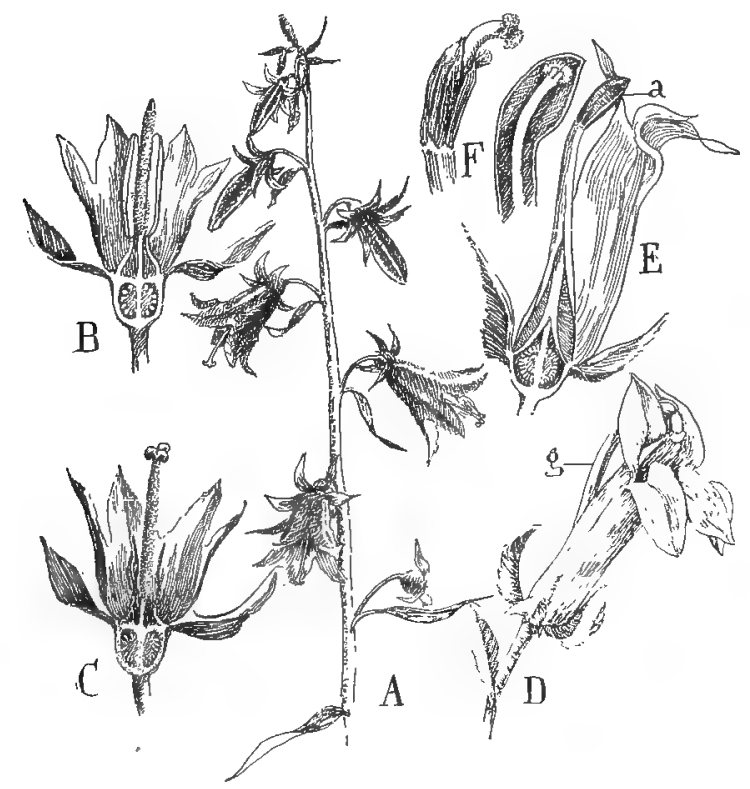

FIG. 337. Lower forms of the Campanulales: $A$, inflorescence of the bellflower (Campanula). $B$, section of a young flower. The hairy style is pushing up between the encircling anthers and sweeping the spores out of them. Note the closed stigmatic lobes. $C$, older flower. The anthers are withering and the stigmas are curving back towards the spore-covered style. $D$, flower of Lobelia. The tubular corolla is opened at one side, permitting the style and encircling stamens, $g$, to protrude. $E$, section of flower, showing the anthers, $a$, united about the style and stigma. $F$, relation of stigma to anthers. At right the section shows the anthers cohering about the bushy style, which acts later as a brush sweeping out the spores. At the left the style has grown beyond the anthers and the stigmatic lobes are spreading apart. 
alliance, we find a very natural sequence leading to the higher families. For example the lower members of the Bell-flower family have nearly or quite regular flowers, parts in five, anthers grouped about the style but not united, fruit a capsule with many seeds as in the harebell (Campanula) and Specularia (Fig. 337, $A, C)$. In the Lobelia the corolla usually becomes irregular and slit down one side, thus approaching the form assumed in the highest groups of the order. The anthers are united about the style which is two lobed and provided with a whorl of hairs to sweep the spores from the cylinder of anthers. The fruit is a capsule of two carpels (Fig. 337, D-E). This brings us to that great group of familiar plants that were formerly known as the Compositae, but that are now separated into the Chicory family (Cichoriaceae) of I,400 species, the Ragweed family (Ambrosiaceae) of 55 species, and the Thistle family (Carduaceae) of over II,000 species. The most conspicuous feature of these three families is the aggregation of numerous small

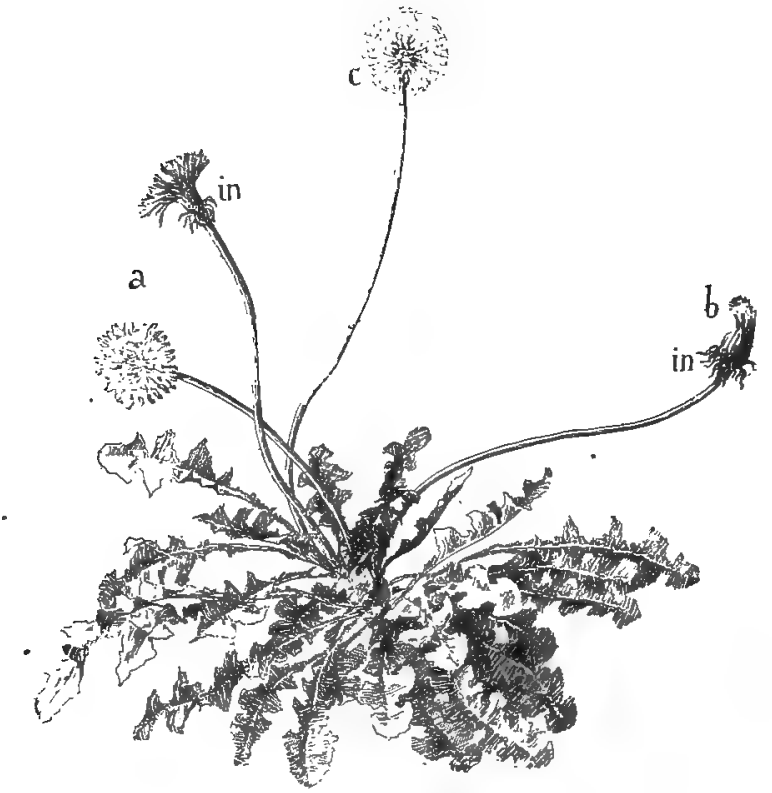

FIG. 338. Habit of the dandelion (Taraxacum), an example of the Cichoriaceae: $a$, appearance of the inflorescence or head; $b$, appearance of the head during the ripening of the seed; in, involucre; $c$, appearance of the fruit. 
flowers in heads subtended by one or more rows of bracts that form a calyx-like involucre (Fig. $338, i n$ ). This type of inflorescence might readily be mistaken for a single flower as the buttercup, rose, etc. This tendency to group the flowers in heads and compact clusters has been attained in several orders, notably the mustards, peas, Umbelliferae, mints, scrophularias, and especially in the Teasel family, page 482. But in no group has the aggregation been so successful and coupled with such efficient types of flowers. Leaving out of consideration the degenerate ragweeds the individual flowers of a head are very

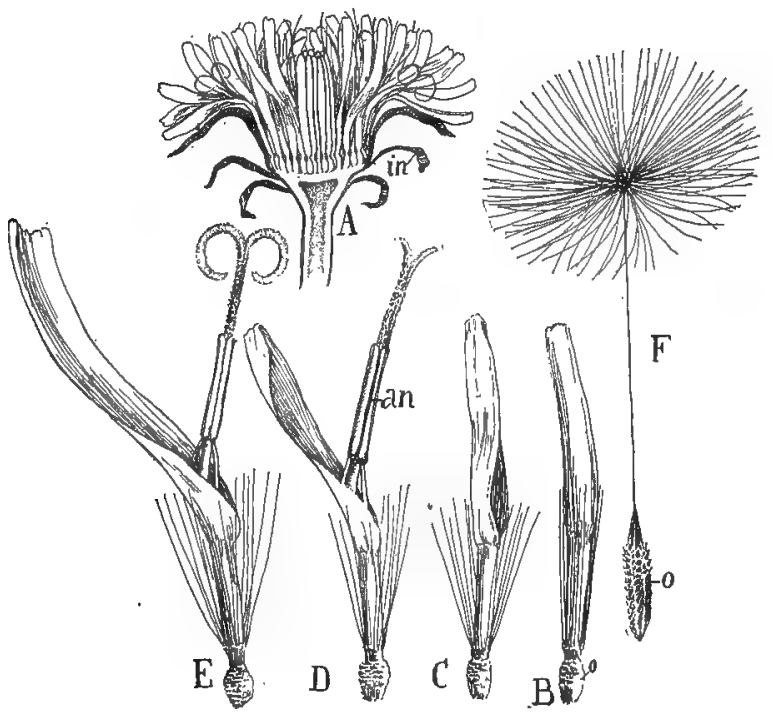

Fig. 339. Flowers and fruit of Taraxacum: $A$, sectional view of inflorescence-in, involucre. The flowers in the center of the head not as yet in bloom. $B$, an unopened flower. The thread-like calyx (pappus) and corolla arising from the ovary, $o . \quad C$, corolla opening. $D$, later stage, the style has elongated, sweeping the spores from the sheath of anthers, an, and the two stigmatic lobes are beginning to open. $E$, flower in full bloom, the stigma lobes recurving. $F$, mature fruit. The pappus is lifted up on a long, slender outgrowth of the ovary, $o$.

uniform in structure. They are epigynous, parts usually in fives, calyx wanting or more often appearing as tufts of hairs, plumose or barbed bristles, and known as the pappus (Figs. 339, 34I). The corolla is tubular or partially split open, forming a strap- 
shaped blade known as the ligulate corolla (Fig. 339, E). The anthers are united about the style which is often hairy and pushes out the microspores like a piston (Fig. 34I, $B-D$ ). The style is two-lobed, the stigma usually appearing as a line on the inner surface of the lobes and the single, one-ovuled carpel matures as an akene. Scale-like bracts, the chaff, are often associated with the flowers (Fig. 34I, B). The nectar formed from the glands at the base of the style is concealed at the bottom of the corolla tube.

(a) The Chicory Family.-This family is distinguished by all the flowers of the head being ligulate (Fig. 339) and mostly yellow in color and by the possession of milky, bitter or acrid juices. Here belong the goat's beard (Adopogon), hawkbit (Leontodon), sow thistle (Sonchus), hawkweed (Hieracium), rattlesnake root (Nabalus), as well as several introduced and native plants that are cultivated, as the dandelion (Taraxacum), species of chicory (Cichorium), salsify (Tragopogon), lettuce (Lactuca). The character of the head, flower and fruit of this family are well shown in the dandelion (Fig. 339). All the flowers are ligulate, the five lobes frequently to be seen on the margin of the corolla indicating the number of petals, and the calyx assumes the form of minute hairs (Fig; $339, B-E$ ). The five filaments adhere to the tube of the corolla while the anthers form a cylinder about the style and discharge their spores before the flower opens. The style begins to elongate as soon as the flower opens and pushes' out the spores which may be seen as little piles of dust at the top of the anthers in freshly opened flowers. The filaments of this genus are sensitive to touch and curve outward, pulling down the sheath of anthers, thus assisting in sweeping out the spores and exposing the style when an insect irritates them in his quest for nectar. This device appears in other genera and is sometimes the only means of exposing the microspores and styles. Autogamy is at first impossible owing to the fact that the two lobes of the style are closely pressed together effectually excluding the microspores from its inner, stigmatic, surface. Later the style grows considerably above the anthers and the lohes separate, exposing the stigmas for crossing (Fig. 339, E). The association 
of this type of flower is more effective than any as yet noticed, and it would appear impossible for any of the numerous insects which frequent these flowers to miss crossing a score of them at a single visit. Crossing between the flowers of a head is effected in some genera by the movements of the flowers. The inner leaves of the involucre fold over the flowers at night and in rainy weather, protecting them like a perianth. This results in crowd-

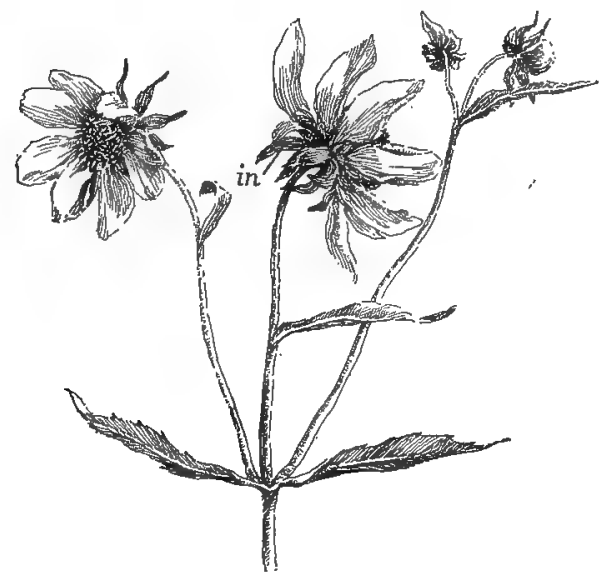

FIG. 340. Inflorescence of the bur-marigold (Bidens), a common ray form of flower of the Thistle family: in, involucre.

ing of the flowers together, and the stigmas are often brought in contact with the spores that have been dusted upon the various parts of adjoining flowers. The outward curving of the stylar lobes may also bring the stigmas in contact with the spore-covered parts of adjoining flowers with a like result. Autogamy is brought about in the dandelion, as in nearly all other members of the order, by the curvature of the lobes of the style which continue to bend back until the stigmatic surface is brought in contact with the spore-covered style (Fig. 341, D). The blooming of the flowers progresses from the margin to the center of the head so that during several days new sets of flowers are exposed for crossing. When the period of bloom is passed the involucre closes over the head and remains in this condition until the fruit is mature (Fig. $338, b$ ). During this period, the stalk 
bearing the head elongates considerably, so as to lift the fruit above the surrounding vegetation-the extent of its elongation depends upon the height of this vegetation. The corolla withers away and the hair-like calyx grows out into a white, delicate pappus, which is lifted upon a beak-like outgrowth of the ovary (Fig. 339, F). The fruit is now mature and in a position for distribution. The involucre opens, the hairs of the pappus expand, loosening the akenes so that the least touch or breath of air floats off the fruit as the most perfect type of parachute (Fig. $33^{8}, \mathrm{c}$ ).

(b) The Thistle Family, Carduaceae.-This is the largest family of the angiosperms. The flowers have the same arrangement and structure as in the Cichoriaceae, save that the corollas are either all tubular, as in the thistle and ironweed (Fig. 342), or the marginal flowers of the head may be ligulate, thus increasing the conspicuousness of the inflorescence, as in the asters, daisy, etc. (Figs. 340, 34I). The marginal ligulate flowers are termed ray flowers to distinguish them from the inner tubular or disc flowers. The ray flowers may be sterile, though more frequently imperfect and provided with pistils. The calyx may be wanting, but more often assumes the form of silky or plumose pappus or of membranous scales for wind transportation or of barbed bristles of various kinds for distribution by animals. In the case of the burdock (Arctium) the involucre is covered with hooks. The Carduaceae includes a great array of plants, many of which are among our troublesome weeds: Ironweed (Vernonia), thoroughwort (Eupatorium), blazing star (Lacinaria), golden-rod (Solidago), aster, fleabane (Erigeron), cat's-paw (Antennaria), everlasting (Gnaphalium), rosinweed and compass plant (Silphium), Spanish needles (Bidens), daisy (Chrysanthemum), groundsel (Senecio), thistle (Carduus). Cultivated for their showy flowers: Tickseed (Coreopsis), cone flower (Rudbeckia), sunflower (Helianthus), cornflower (Centaurea), cinerarias, etc. Medicinal: Wormwood (Artemisia), one species of which yields absinth, milfoil (Achillea), colt's foot (Tussilago), tansy (Tanacetum), chamomile (Anthemis), arnica, burdock (Arctium).

The Ragweed family, Ambrosiaceae, is a small group, princi- 
pally North American in its distribution, that have become separated from the Carduaceae through degeneration. The heads contain a few greatly reduced wind-pollinated flowers that are always imperfect and generally lacking in calyx or corolla, or

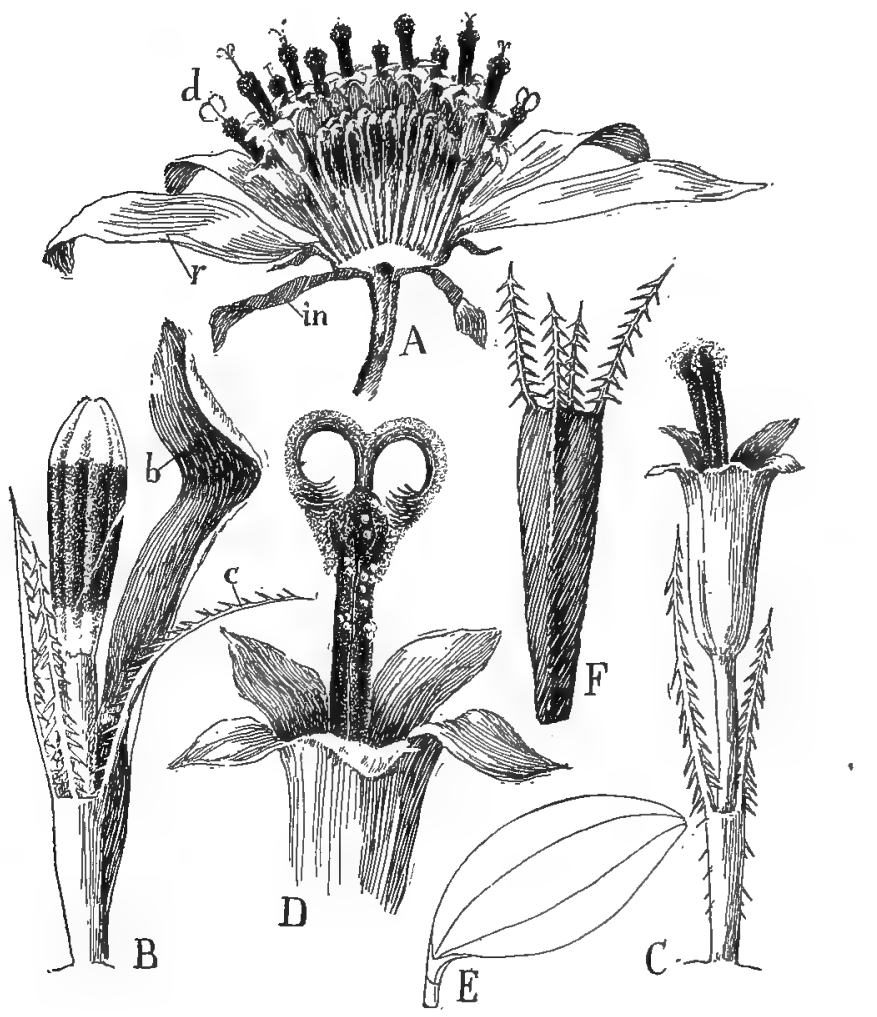

FIG. 34I. Flowers and fruit of Bidens: $A$, sectional view of the inflorescence $-r$, ray flowers; $d$, disc flowers; $i n$, bracts of the involucre. $B$, disc flower before opening, the shaded region showing the position of the anthers in the corolla- $c$, calyx in the form of downwardly barbed bristles; $b$, bract or chaff associated with the disc flowers. $C$, early stage in the opening of the flower. The stamens have been lifted beyond the mouth of the opened corolla by the growth of their filaments and the style is elongating, pushing out the spores, which appear in little piles at the top of the anthers. $D$, last stage in the bloom of flowers. The style has grown beyond the anthers and the stigmatic lobes have reflexed, touching the spore-covered style. $E$, a sterile ray flower, much less enlarged. $F$, the fruit, showing the barbed pappus for dissemination. 
both, and characterized by free anthers. The more familiar are: The marsh elder (Iva), ragweed (Ambrosia), and clot-bur and cockle-bur (Xanthium).

These three alliances are apparently the most recently evolved of the angiosperms, and owing to their numerous variations that have been so successful in meeting the present conditions upon

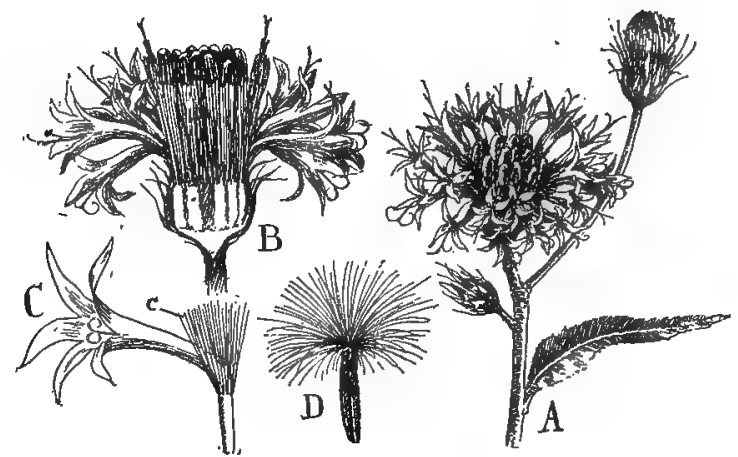

FIG. 342. A common tubular flower of the Thistle family: $A$, inflorescence of the ironweed (Vernonia). $B$, sectional view of the inflorescence, only. the outer flowers in bloom. $C$, enlarged view of one of the flowers $-c$, calyx or pappus. $D$, fruit.

the earth, they have become the dominant plants the world over. Their success can be traced to a variety of causes, as the occurrence in many genera of perennial underground stems, which make them to a degree independent of climate conditions and the depredations of grazing animals. A great many are avoided because of their protective armor of prickles, bitter, acrid juices or oils and resins. Especially to be noted is the seed-like fruit with its numerous devices for distribution. All these features, among others, explain their extensive distribution in open countries. Another advantage appears in the structure of the flower and the inflorescence. The highest type of a flower, as in the case of a machine, is the one that is most efficient. The flower is not so elaborate as the orchid or as those of some other groups, but it is superior because it accomplishes its work with greater certainty and more economically. Note the significance of these facts-the ovary of the orchid consists of three carpels 
which may produce thousands of seeds, whereas the simple ovary of one of the Compositae contains but a single seed. Reduction has been made in every part without loss of conspicuousness and variations have also appeared that practically eliminate the uncertainties of crossing and autogamy, and consequently the formation and distribution of the seed is ensured. In a word every evolutionary tendency that you have noticed in the development, of the flower finds its expression in this group of plants. 


\section{INDEX}

Abies, 376

Absorption, 12, 20, 5I, 54

Acer, 457, 459

Accompanying cells, 79, 80

Achlya, 219

Actinomorphic, 387

Adhesion, 385, 47 I

Adhesive discs, ro8, 109

Adiantum, 329

Adlumia, 443

Aecial stage, 252

Aeciospores, 252

Agaricaceae, 259, 260

Agaricales, 259

Agrimony, $45^{\circ}$

Air chambers, 273, 282, 283, 336, 402

Akene, 398, 438, 440

Albugo, 222, 223

Alder, 432

Algae, 173

blue-green, I64, 233

brown, 20I

colonial, 178

conjugating green, I 85

filamentous green, I90

green, 174

red, 2 ro

tubular green, I95

unicellular green, I74

Alga-like fungi, 2 I 8

Allen, 2 I 5

Ailelomorph, 14 I

Alnus, 432

Alternation of crops, 67

Alternation of generation, 136,137 ,

I94, 20I, 2 II-2I6, 256, 27I, 279,

281, 312, 319, 352

Amanita, 26I

Amaryllis family, 419

Ambrosiaceae, 485, 489

Ament, 429, 430

Ammonia, 66, I59, I60
Angiospermae, 378

Ankistrodesmus, 182

Annual rings, of scars, 75,73

of xylem, 91, 92

Annuals, 69

Annulus, 26I, 262, 300, 30I, 306, 307. $316,326,327,355$

Anther, II6, II7, 379 versatile, 408

Antheridial cell, I2 I, 122, 358, 369, 370,392

Antheridium, antheridia, I96, 208, 274, 303

Antherozoids, 196, 275

Anthoceros, 292, 294

Anthocerotales, 292

Antipodal cells, I I9, I20, 390

Antitoxin, I64

Apophysis, 305, 306

Apple, 450, 45I rust, 256,257

Aquatic plants, 39, 4I, 64

Arales, 4 IO

Aralia, 30, 465

Araliaceae, 465

Archangiopteris, 3 I6

Archegonium, 275, 276, 303, 350

Arcyria, I50, I5I

Âroid order, 410

Arrow-wood, 48I, 482

Arum, 4II, 4I3

Ascocarp, 229

Ascomycetes, 228

Asco-lichens, 232

Ascopores, 229

Ascus, asci, 229, 230

Asexual generation, 136, 137, I94, 204, 2I4, 256, 27I, 279, 28I, 3I9, 320

Asexual spore, 123, I72

Aspergillales, 240

Aspergillus, 24I, 242 
Asplenium, 324

Autoecious, 251

Autogamy, $383,439,446,454,470$, 480,488

Azalea, 471, 472

Bacillus, I55

Bacteria, I 54, I55 economic importance of, 157 exclusion of, 156

of decay, I $57, I_{5}^{8}$

of disease, I 57,162

iron, 161

nitrifying, $65,67,160$

nitrogen fixing, I6I

sulphur, I6I

synthetic, I 59

Banana, 420

Banyan tree, 70

Barberry rust, 25I

Bark, 86, 87

Basidial stage, 256

Basidiomycetes, 25I

Basidiospore, 255, 256

Basidium, basidia, 25I, 263, 255, 258, 262,263

Basswood stem, roo

Bean seed, I30, r3 I

Beard, 44

Beech, 43I, 434

orde $i, 43 I$

Begonia, 2

Bellflower, 484 order, 483

Berry, 398

Bidens, 488,490

Biennials, 69

Bilabiate flowers, 478

Birch leaf, 7,427 family, I 47,43 I, 432

Black knot, 239, 240

Bladderwort, 480

Bladderwrack, 206

Blade, 7, 8, 21, 27, 426

Blakeslee, 227

Bleeding, of plants, $6 \mathrm{I}$

Bloodroot, 442, 443

Blueberry, 47 I, 472
Blue green algae, 165

Body cell, 358, 369, 370

Bogs, 296, 473

Boletaceae, 265

Boletus, 265

Borages, 476

Boraginaceae, 475,476

Botrychium, 3I4, 3I5, 3I6, 3 I'7

Bower, 326

Brassica, 445

Bread making, 20, $25^{\circ}$

Bryales, 30I

Bryophyta, 269

Buckthorn order, 46I

Buckwheat order, 437

Buds, 7I-75, 73, 362 adventitious, 75 axillary, 74

Bulbs, I I 3

Buller, 264

Bunch flower family, 4 I 8

Bur-marigold, 488, 490

Burroughs, 4 I 5

Buttercup, $43^{8}$ order, 438

Butternut, 433, 435

Butterwort, 480

Cabbage, 447

Cactus, 44

Calcium cyanamide, 66

Callithamnion, 213

Callus, 75, Ior

Calyptra, 294, 299, 305

Calyx, II5, I I6, 384

Cambium, 79, 80, 82, 89, 314 cylinder, $89,90,91,314,426$

Campanula, 484

Campanulales, 483

Canal cells, 276, 303, 3I7, 3I8, 345

Canna, 42I

Capillitium, I50, I5I, I53

Capsule, 277, 305, 306, 307, 326, 4I4 $4 \mathrm{I} 7$

Carbohydrates, I I, I2

Carbon, I 5

dioxide, I2, I5, 2 I, 49, I59

Carbonic acid, $\mathrm{I}_{3}$ 
Carduaceae, 485,489

Carex, 409

Carpel, I I5, I I6, 399

Carpinus, 432

Carrot, order, 465

family, 465

wild, 466

Caruncle, I32, I33

Cassia, 35, 45I, 452

Castor bean, 76, 77, 90, 9I, 133

Catkin, 429, 430

Cat-tail, 38r, 40I, 403 order, $40 \mathrm{I}$

Cedar apple, 256, 257

Celery, blanching of, I4

Cell, crystals, 2 division of, $56,57,58$ intercalary, 253, 254

nature of, I

sap, I, 3, 33

wall, I, 57, 58

Cellulose, I I

Ceramium, 2 I I

Cercis, 45I, $45^{2}$

Chaetophorales, I90

Chaff, 487, 490

Chamaecyparis, 376

Chamaenerion, 463,464

Characters, nature of, 144

Chemical reaction, 3

Chemo-synthesis, 162

Chenopodiales, 436,437

Chenopodium, 436

Cherry, 450, 45I

Chervil, 468

Chicory family, 485,487

Chlamydomonas, I78, I79

Chlorenchyma, I1, I2, 76

Chlorophyceae, I74

Chlorophyll, I3-I5, I67

Chloroplasts, 2, 9, I0, I2, I3, I7

Chondrus, 2 I4

Choripetalae, 429

Chromatin, 56, 57

Chromoplasts, 2, 32

Chromosome, 56; 57

reduction of, I36, I37, 214-216, 280
Chromosome, homologous, I4I

Cichoriaceae, 485,487

Cilium, I5I, I52

Cladonia, 233

Class, 147

Classification of plants, I 46

Clavaria, 264

Clavariaceae, 264

Claviceps, 237, 238

Climbing plants, 106

Closterium, 188

Club moss, 34I

Club root, 153

Cluster-cup, 252

Cohesion, 385

Coenocytes, I95

Coleochaetes, 199, 200

Collateral bundles, 3r4, 354

Collecting cells, 9, 2 I

Collenchyma, 78, 83, 84

Colors of flowers, $417,423,441,446$, 480

Columbine, 440

Columella, 225, 293, 294

Comfrey, $385,475,476$

Commensalism, 68, 234

Compass plant, 33,34

Compositae, 485

Concentric bundles, 323, 324

Conducting system, $82,94,312$

Cone, $337,342,366$

Conidium, 228

Conn, I56

Consumption, 16.3

Contact, reaction to, 63 , 106, I07

Cordyceps, 238, 239

Cork, 42, 76, 86, 87, 3I4-3I5

cambium, 86, 87

Corm, II2, Ir3

Corn, root of, 57 seedling of, I34, I35

Corolla, II 5 , I I6, 384

Cortex, 59, 6o, 6I, 76, 3I4-3I5

Corylus, 432

Coscinodiscus, 169

Cosmarium, I89

Cotyledon, I24, I25, I26, I3 I, I32, $133,318,332,360,398,428$ 
Creeping stems, I09

Cribraria, I5o

Crossing, II5, I38, 382, 404, 4I $2,4 \mathrm{I} 3$, $445,446,463,467,476,487$

Crowfoot order, $43^{8}$

Crucibulum, 267

Cruciferae, 444, 445

Currant, 387,449

Cuticle, 10, 25, 36, 269

Cutin, ro, 36

Cyanophyceae, I65, I66

Cycadales, 353

Cycads, 353

Cycas, 353, 355

Cyclic flowers, $384,3^{85}$

Cymbella, 170

Cypcraceae, 4 ro

Cypripedium, 424

Cystocarp, 212, 2 I3

Cytoplasm, 2

Daldinia, 239, 24I

Dandelion, 485, 486

Darwin, 64, 132

Dasya, 2 I I

Daucus, 466

Decay, 158

Deciduous', 42

Decompositions, in living substance, 22-23

Decussate leaf arrangement, 27, 28

Delesseria, 2 I I

Dennstaedtia, 328

Desert plants, 44

Desmidium, 188

Desmids, I88, I89

De Vries, I 44,463

Diadelphous, 452

Diastase, 20, 250

Diatomaceae, 167

Diatoms, 167, r68

Dichotomy, 207, 27I, 272

Dicotyledons, 96, I25, 426

Dioecious, 284, 339

Diphtheria, I64

Disease, I 62

Disc flower, 489,490

Divisions, 148
Dodder, 64

Dodge, 229

Dominant factor, $\mathrm{I} 43$

Drupe, 398

Dryopteris, 324

Duckweed, 4 I0

Ducts, 79

Earth star, 267

Ectocarpus, 202, 203

Egg cell, I I9, I20, 197, 275

Elaters, 286, 287, 338, 339

Elderberry, 48I, 482

Elfvingia, 265

Elm, 436

Embryo, I24, I25, 359, 360, 396 cell, 124, 125, 395, 396 sac, 124, 394, 395

Empusa, 227

Endodermis, 59, 6r, 77, 316, 325

Endosperm, 124, 125, 133, 373, 39I, 394,398

nucleus, Ir9, 120, 123, 389, 390, 394

Energy of plant, I3, I5, 23, I62

Enzyme, I7, 20, I28, I 57

Epicotyl, I3I, I32, 398, 428

Epidermis, 8, 9, 26, 36, 272

Epigynous, 386, 387

Epiphragm, 305, 306

Epiphyte, 64, 422

Equisetales, 334

Equisetum, 335, 339

Ergot, 237, 238

Ericales, 470

Erysiphe, 244, 254, 247

Erythronium, 383, 4I4, 4I5

Etiolation, 14

Eucalyptus, 33

Eumycetes, 216

Euphyceae, I73

Evaporation, 25

Evening primrose, 29, 463, 464

Evolution of Algae, 174, I90 of Angiospermae, 378 of Bryophyta, 269, 290, 295, 309 of Eumycetes (true fungi), 218, 220 
Evolution of flower, 38I, 388, 426 of Gymnospermae, 353 of Pteridophyta, 312, 3 I9 of sex, 178, 180, 194, 198, 204, 340 of sexuality, I7I, I77, I8I, I85, 204

Excretion, 20, 22, 53

Exoascales, 248

Exoascus, 248

Exobasidium, 472

Eye spot, I75, I76

Factor, hereditary, 138

distribution of, 139

dominant, 143

nature of, $\mathrm{I} 44$

recessive, 143

Fagales, 43I, 432

Fagus, 434

Fairy rings, 259, 260

Family, I47

Farmer, 209

Fecundation, 122, 123

Felix, 328

Fermentation, $157,158,249$

Ferments, see enzymes.

Ferns, 3II

adder tongue, 3I4, 3I5

Christmas, 3 II, 322

common, $32 \mathrm{r}$

flowering, 328

grape, 315

shield, 324, 325

Fertilization, 122, 123, 209, 276, 393

significance of, I37, I44

Fertilizers, of soil. 66

Fibrillae, of spindle, $\mathbf{5 7}, 5^{8}$

Ficus, 435

Figwort, 478

Filament, I16, I65, 379

Filicales, 321

Flower, 338, 378, 38 I

coloration of, $417,423,441,480$

cyclic, 384,385

development of, $38 \mathrm{r}$

perfect and imperfect, 382

spiral, 383
Flower, structure of, II 5, II6

Foliar gaps, 314, 325

Follicle, 398

Food of plants, Ir, 48

distribution of, 16

storage of, 17,18

Foods, formation of, I2

Foot, 286, 287

Formaldehyde, I3

Formative regions, 58, 60, 98, 99

Formic acid, I3, 40

Forsythia, 28, 29

Fragaria, 450

Fruit, 127, 374, 397-399

Fucus, 206, 207, 208, 209

Fumitory, 443

Funaria, 294, 300, 303, 307

Fungus, 216

alga-like, 218

basidia-forming, 25I

bird's nest, 267

black, 239, 240

blue-green, 240

brown, 240

coral, 264

cup, 229

fly, 227

gill, 263,265

pore, 264,265

prickly, 264

sac, 228

Funiculus, I I8, 389, 395

Gametangium, 192, 196, 202, 203, 208

Gamete, I1 8, I72, 178, I79, I87, 192, I98, 200, 211,275

female, II $8,120,178,389$

male, II8, I2I, I22, I78, 318, $332,342,358,392$

Gametophyte generation, I36, 194, $215,274,276,281,310$. $3 \mathrm{I} 2,3 \mathrm{I} 6-3 \mathrm{I} 7,320,33 \mathrm{O}$, $339,345,349,388$

reduction of, 3I3, 349-35I 359,393

female, II9, I20, 332, 339, 349,

$357,367,368,388,389$ 
Gametophyte, male, I22, 332, 339, $349,357,369,392$

Gametospore, I I8, I22, I72, 201 germination of, $123,124,187$, I88, I93, 197, I98, 200, 213, 2I 4,2 I $, 276,277,280,286$, $293,304,308,309,318,332$, $333,340,345,35 \mathrm{I}, 359,37 \mathrm{I}$, 395

Gasteromycetes, 266

Gemmae, 270, 33 I

Generations, alternation of, 136,137 , I94, 20I, 2 II-2I6, 256, 27I, 279 , 281, 319, 352

Gentian, 474 order, 473

Gentianales, 473

Genus, I46

Geoglossum, 232

Geraniales, 460

Geranium, 384, 46r order, 460

Germ tube, 278

Gills, 260, 261, 263

Ginkgo, 362

Ginseng family, 465

Gleditsia, 45I, 452

Gleocapsa, I 66

Groebel, 309

Goosefoot order, 437

Grafting, I OI, I02

Grain, I34, I35, 397, 398, 409

Graminaceae, 4 Io

Graminales, 405

Grape, 46I

blight, 222

Grass, 406, 407, 409

family, 4 IO

order, 405

Gravity, effect on plant, 62, 104, 106. I32, 407

Ground nut, 455

Growth, apical, 56, 98, 200, 270, 304, 3I 3

conditions of, $72,74,129$

definite, 72

nature of, 3

of stem, 89, I03, 106
Growth of root, $5^{6}$ relation of chemical changes to, 4 rhythm of, 93

Growing point, 56, 98, 270, 313, 346

Guard cells, 9, 10, 26

Gulf weed, 206

Gymnospermae, 353

Gymnosporangium, 256, 257

Hairs, plant, ro, $38,39,40$ root, $47,46,52$

Haustoria, 220, 22 I

Hazel, 432

Hazen, 177

Head, 482,485

Heath order, 470

Heartwood, 95

Helleborus, 440

Helvellales, 23I, 232

Hepaticae, $27 \mathrm{I}$

Hepatics, leafy, 288

Hepatics, thallose, 271, 272

Hereditary substance, I3 8

Heterocyst, I66, 167

Heteroecious, $25 \mathrm{I}^{\circ}$

Heterogamous, 178

Heterospory, 347, 352

Heterostyly, 462, 463

Hickory, fruit of, $\mathbf{4 3 5}$ branch of, 73 leaves of, 34

Hilum, I29, I30

Honey locust, $45 \mathbf{I}, 45^{2}$

Honeysuckle, $3^{87}$

Hop, twining, 106

Hormogonium, I66

Horizontal branches, 28, 29

Hornbeam, 432

Horsechestnut, 3I, 34

Horsetail, 334

Hybrid, 138

Hydnaceae, 264

Hydnum, 264

Hydrodictyon, $\mathrm{I} 84$

Hydrolysis, 20

Hydrophytes, 39

Hymenium, 230, 231, 262, 263

Hypha, 68, 2 I 7 
Hypocotyl, 125, I26, 398, 428

Hypocreales, 238

Hypogynous, 386

Hypoxylon, 239, 240

Hysteriographium, 24I

Immunity, I64, 245

Indian-pipe, 69, 472

Individuality of the plant, 7

Indusium, 324, 325, 328, 329

Inflorescence, 381 , 382

Insectivorous plants, 296, 480

Insects, crossing by, II5, 388, 412, 4I3, 4I7, 4I I, 42 I, 424, 439, $445,453,47 \mathrm{I}, 476,479$

sight and sense of smell, $4 \mathrm{I} 7$

Integument, II $7,118,356,361,398$, 425,428

Intercellular spaces, 9, II , 2I, 25, 32, 273

Involucre, $285,287,466,483$

Ipomoea, 475

Iris, 4 rg

family, 419

Ironweed, $49 \mathrm{I}$

Iron bacteria, I6r

Irritability, 33, 61, 104

Isogamous, 178

Isthmus, 189,190

Jacket-cells, 356, 357

Jack-in-the-pulpit, 4II

Jeffrey, 317

Judas tree, 45 I

Juglandales, 433

Juglans, 435

Juncus, 4I6

Jungermaniales, 288

Juniperus, 376,377

rust, 256,257

Keel; 45 I-453

Kelps, 205

Kerner, 70

Key fruit, 398, 459

Klebs, 185

Knot, roo

black, 239, 240
Labellum, 421, 422, 423, 424, 425

Labiatae, 476

Lactuca, 33, 34

Laminaria, 205

Larix, 375

Larkspur, 44I

Lateral roots, 59, 62, 63

Latex, 435,443

Lathyrus, 453

Leaf, arrangement of, $27-36$ color, 32 compound, 30, 3I

fall of, 42,43

forms of, $7,30,3 I$

growth of, 33

lobing of, $30,3 \mathrm{I}$

movement, 33-36

reduction of, 43,44

size of, 24,25

structure of, 7-II, 2I, 36-42

work of, I I -26

Leaf-scar, 43

Legume, 65,398

Lenticel, $7 \mathrm{I}, 76,87,88$

Leotia, 232

Lepidium, I24, 389, 395, 396, 398, 428

Lespedeza, 35

Lessonia, 205

Leucoplasts, 2, I9

Lichens, 232

Asco-, 232, 233

Licmophora, 168

Light, 4, 13-14, 17, 3I, 36, 4I, 63 . I04, I06, II2, I76

Ligulate flowers, 487

Lilac leä, 9

Liliales, 4I4

Lily, fawn, 383, 4I4

of the Valley family, 418

family, 4 I 8

Lily order, $4 \mathbf{1} 4$

Linaria, 478,479

Linin, 56, 57

Linkage of factors, 143

Linnaea, 482

Live-forever, 448-489

Liverworts, $27 \mathrm{I}$ 
Liverworts, horned, 292

Jiving substance, I-6

Livingston, 183

Lobelia, 484, 485

Lockjaw, bacillus, 155, I63

Lodicules, 407, 408

Lomentum, 455

Looseztrife, 473,474 purple, 462,463

Lycogala, $\mathbf{I}^{\circ}$

Lycoperdales, 266, 267

Lycoperdon, 266

Lycopodiaceae, 343

Lycopodiales, $34 \mathrm{I}$.

Lycopodium, 34I, 342, 343, 345

Lythrum, 462, 463

Macrocystis, 205

Madder order, 48I

Malus, 45 I

Maple, $457,458,459$

Marattiales, 516

Marchantia, 274, 282, 284, 285, 286, 287

Marchantiales, 27i

Massee, 245

Massula, 425

Mechanical structure, 78,83

Medullary ray, 92, 93, 94, 3I4-315

Megasporangia, $348,356,380,388$, 389,391

Megaspore, II7, II8, 339, 347, 348, $367,368,380,388,390$

germination of, II8, II9

Megasporophyll, II7, 348, 355, 367, $379,380,389,397$

Meibomia, 455

Melandryum, 383, 437

Melosira, 168

Mendel, I42

Mendel's Law, I42

Mesophyll, 9, Io

Mesophytes, 39

Metchnikoff, 158

Micropyle, II7, II8, 355, 356, 368, 380

Microsphaera, 247

Microsporangia, 348, 365, 379
Microspore, I I6, 339, 347, 348

germination of, $120,122,349$, $350,357,358,369,392,454$

Microsporophyl, II 7, 348, 355, 365 379

Micrasterias, 188

Mildews, downy, 220, 223 powdery, 244, 245

Mimosa, 35, 36

Minerals in soils, 48

Mint family, 476

Mistletoe, 64

Mnium, 302

Moccasin flower, 422

Monkshood flower, 44I

Monocotyledons, 96, 125, 400

Monoecious, 284

Monotropa, 472

Morchella, 231, 232

Morel, 23I, 232

Morning-glory, 475

Mosaics, 32

Moss, 295

bog or peat, 296

chloroplasts, I7

scale, 290

true, 301

Mould, black, 224, 225, 226

brown, 240

blue-green, 217, 240

water, 218

Movements, gases, I2, 2I, 45

leaf, 33-36

root, $6 \mathbf{I}$

stem, I04

water, $24,50,54$

Mucorales, 224

Mushrooms, 21 7, 259, 260

Mușci, 295

Mustard family, 444

Mutation, 144

Mycelium, 257

Mycorrhiza, 68, 243, 296, 317, 422

Myrtales, 462

Myrtle order, 462

Myxomycetes, I49, 150, I5I

Myxobacteriales, I 53 
Narcissus, 4I9*

Nectar glands, 38I, 388, 404, 430 , $43 \mathrm{I}, 437,439,440,457,458$

Nemalion, $2 x_{3}$

Nereocystis, 205

Netted veined leaf, 426,427

Nettle, 40, 434

Nidulariales, 267

Nitrate, 66, I60

Nitrite, 160

Nitrogen, 16, 65, 160

Nostoc, I66, 292

Nucleoli, 56, 57

Nucleus, I, 2, 56

Nut, 432,433

Nutations, 103, 104, I06

Oak, 3I, 383, 427, 434

Odors, 4I2, 4I7, 433

Oedogonium, $197, \mathbf{1 9} 8$

Oenothera, 29, 463, 464

Olive, I 54

Onoclea, 330

Ö̈gonium, I97, 208

Oösphere, 197, 275

Operculum, 299, 300, 305, 306

Ophioglossales, 3 I 3

Ophioglossum, 3I3, 3 I5

Orange, 460

Orchid order, 64, 42I

Orchidales, 42 I, 423

Orchis, 425

Order, I 47

Oscillatoria, I66, I67

Osmosis, 53

Osmunda, 326, 328

Ovary, 116, II7, 380

Ovule, II6, I I 7, I $8,380,388,389$, 399

Oxygen, 3, I 3, I $5,21,22,75$, I 2 I

Palisade mesophyll, 9, IO, 2 I, 40, 4I

Pallavicinia, 288

Palms, 405

Palmelloid state, I92

Pandanales, 40r

Pandorina, I79.

Papaverales, 442
Papaveraceae, 442

Papillae of stigma, 389,392

Papilionaceae, $45^{2}$

Papilionaceous flower, 453

Pappus, 483, 486

Paraphyses, 208, 209, 230, 231, 262 263,303

Parasites, 64, 68, 216, 244, 245, 350

Parenchyma, I I, 77, 8 I

Parmelia, 233

Parnassia, 448

Pasteur, I64

Pea, family, $45^{2}$. sweet, 453

Peach curl, 248

Pear, branch of, 73

Peat, 298 moss, 296

Pedicel, 403

Pediastrum, 184

Penicillium, 217, 228, 242

Perennials, 69

Perianth, II 5, II6, 286, 287, 288, 379, $3^{8} 3$

Periderm, 266, 267, 268

Perigynous, 385, 386

Perisperm, 397

Perisporiales, 244

Peristome, 294, 305, 306, 307

Perithecia, 229

Peronospora, 220, 223

Peronosporales, 220

Personate flower, 478

Petals, II5, II6, 384

Petiole, 7, 8, 29, 42, 43, I07, 426 427

Peziza, 231

Pezizales, 229

Phaeophyceae, 201

Phallales, 268

Phallus, 268

Phegopteris, 330

Philotria, 2

Phloem, 59, 79, 9I, 3I4-3I5

Phosphorescence, 259

Phlox order, 474

Phosphorus, I6

Photosynthesis, I1-16, 23 
Photosynthesis, economic importance of, I 5-I6

Phycocyanin, I65

Phycomycetes, 218

Phyllactinia, 247

Phylloglossum, 343, 344

Phytophthora, 22I, 223

Picea, 375,376

Pierce, I9o

Pigments, 32

Pileus, 260

Pilobolus, 226

Pinales, 362 classification of, 375

Pine, 365, 366, 368, 369, 371, 372, 374, 375 wood, 94,363

Pinguicula, 480

Pinnularia, 169, 172

Pistil, I I5, I 16, 399

Pit, 398

Pith, 76, 78, 314-315, 324, 342

Placenta, 388, 389 free central, 474

Plankton, I68, I69

Planktoniella, 169

Plant, nature of, I cell, I

Plasmodium, I51, I52

Plasmopara, 221, 222

Plastids, 2, I7

Pleurococcus, 182

Plowrightia, 239, 240

Plumule, I25, I26, 398, 428

Pod, I27, 130, 398, 45I, 454, 455

Poison ivy, 459,460 sumac, 459,460

Poisonous secretions, $39,40,53,265$, $442,459,469,48$ I

Polar nucleus, I I8, I I9, 389

Polemoniales, 474

Pollen grains, I I6, I20, I22

Pollinium, 424, 425, 474

Polygonales, 437

Polypodium, 329

Polyporaceae, 264

Polysiphonia, 2 I2

Polystichum, 31 I, 322, 328
Polytrichum, 302, 303, 306

Pond scum, I 85

Poplar, leaf arrangement, 28 order, 429

Poppy, family, 442 order, 442

Pore, II , 80, 8I, 94, 264, 265, 283, 363

Porella, 289

Potato, 481 rot, $22 \mathrm{I}$

Prepotency, of foreign spores, 454

Primitive plants, 46, I54

Primrose order, 473

Primulales, 473

Pro-embryo, 359, 360, 371, 395, 396

Prosenchyma, II

Protandrous, 283

Prostrate stems, I09

Protection of microspores, 412

Proteids, I6

Proteid grains, I8, I9

Prothallium, 312, 317, 330, 331, 370

Protogynous, 283

Protomyxa, I 53

Protonema, 308, 309

Protoplasm, function of, 3 nature of, 2,3

Protoplasmic connection of cells, 3

Pruning, I00, 102

Prunus, 45I

Pteridophyta, 3I I

Pteridium, 329

Ptomaines, I 59

Puccinia, 25I, 252, 253, 255

Puffball, 266, 267

Pulvinus, 35

Purposive reactions, 5, 36, 104

Pussy willow, 430

Pustules, 258

Pycnium, 252

Pycnidium, pycnidia, 233, 252

Pycnidiospores, 252

Pyrenoids, 185,186

Pyrola, 384, 470, 47I

Pyronema, 229, 230

Quarter-sawed oak, 95

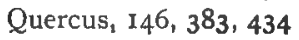


Ragweed family, 485,489

Ranales, 438, 440

Ranunculus, 438, 439

Ray, flower, 489,490 medullary, 92, 93, 94

Rattlebox, yellow, 479

Recessive factor, I 43

Receptacle, 38I-386, 439

Red algae, 2 I0, 2 I 8

bud, 45 I

snow, 176

Regeneration of stems, 364

Respiration, 8, 2I, 54, 88

Reproduction, I10, I36

Resin, 39, 364

Resurrection plant, 346

Rhamnales, 46I

Rhinanthus, 479

Rhizoids, 269, 273

Rhizomes, I IO, I II, 323, 324

Rhizopus, 224, 225, 226

Rhododendron, leaf, 4I

Rhodophyceae, 2 I0, 2 II

Rhus, 460

Ribes, 449

Riccia, 272

Ricciocarpus, 272, 273, 274, 276, 278, 281

Richards, 75

Ring, annual, 73, 75, 91, 92

Rivularia, I66

Rock, decomposition of, 49 disintegration of, 49

Rockweed, 206

Root, I, 4, 46, 298, 3I4 aerial, 64

anchoring and supporting, 69

bacteria on, 65

bending of, 62,63

binding action, 70

cap, $58,60,398$

contraction of, 70

growth of, $47,56-58,63$

hairs, $46,47,5^{2}$

lateral, 59, 62, 63

modification of, 64, I09

sensitiveness of, 61,109

storage organs of, 69
Root, structure of, 56, 59, 60, 61 surface of, 55 toxic substances from, 53

Rootstock, I Io, I I I

Rosales, 447

Rosette, 29

Rose, 385

family, $45^{\circ}$

order, 447

Rostellum, 423, 425

Rubiales, $48 \mathrm{I}$

Rush, 40r, 4I6, 4I 8

Rusts, 25 I

white, 220, 223

Saccharomycetes, 248,249

Sac fungi, 228

Sage, 477

Salicales, 429

Salix, 38x, 430

Salvia, 477

Saltpeter, 66, I60

Samara, 398, 458, 459

Sambucus, 48I, 482

Sanguinaria, 442, 443

Sap, 3, 33, 69, 7 I, 83

Sapindales, $45^{6}$

Saprolegnia, 219, 222, 223

Saprolegniales, 218

Saprophytes, I53, 2 I 7

Sapwood, 95

Sargassum, 206

Saxifrage, 387, 449

Scabiosa, 481, 482

Scenedesmus, 182

Schizocarp, 458, 459

Schizophyta, I 54

Scitaminales, 420

Sclerenchyma, 78

Sclerotium, 237, 238

Scouring rush, 336

Scrophulariaceae, 478

Scutellaria, 477

Scutellum, I35, 409

Secondary growth, 85

Sedge family, 4 IO order, 405

Sedum, Ir6, 379, 448 
Seed, 35I, 352, 360, 372, 397, 398 development of, 125, 126, 130 forms of, 126, 127 functions of, 127 growth of, $127-136$

Seedling, castor bean, I32, 133 corn, 134,135

Seed plant, $35^{2}$

Segregation of factors, I4 I

Selaginella, $346,347,348,350$

Selaginellaceae, 346

Senna family, $45^{\circ}$

Sensitive pea, 45I, $\mathbf{4 5 2}$ plant, $35,36,455$

Sensitiveness of leaf, 33 of protopla'sm, 4, 5, I 52 of root, $6 \mathrm{I}$ of stem, I04, 106 of zoöspores, i 76

Sepals, 384, 44I

Seta, 289, 29I, 309

Sex, evolution of, I78, I80, I8I, I82, 194, 198, 204

Sexual generation, $\mathbf{3}$ 6, $\mathrm{I37,} 279$

Sexuality, nature of, I7I, I72, I77, I 8I, I 85, 204

Shade plants, 4 I, 44

Shin leaf, $470,47 \mathrm{I}$

Sieve tubes, 79,80

Silicates, 48, I $70,-173,336$

Silk, of corn, I34

Siphonales, 195

Skull-cap, 477

Skunk cabbage, 4 I2

Sleep movements, 35

Slime mould, I49, I50, I5I

Smallpox, I63, I64

Smuts, 257

Soapberry order, 456

Soils, care of, 54,55 formation of, 48-50

nature of, $5^{0}-52$

retention of substances by, 52 sterility of, $53-55$

structure of, 5 I

texture of, $5 \mathrm{I}$

Solanum, 48I

Soldier's cap, 443, 444
Solomon's seal, leaf, $7,40 \mathrm{r}$

Soredium, 234, 235

Sorus, 316, 324, 325, 355

Spadix, 4 II

Spathe, 4IO, 4II

Spathyema, 4I 2 leaf structure, $4 \mathrm{I}$

Species, 146 biological, 245 ,

Sperm, 196, 275

Spermatophyta, 352

Sphaerella, I74, I75

Sphaeriales, 239, 240

Sphagnales, 296

Sphagnum, 296, 297, 299, 300

Spindle, of cell, $\mathbf{5 7}, \mathbf{5}^{8}$

Spiral leaf arrangement, 27, 28

Spirillum, 155

Spirogyra, 185, I86, I87

Spleenwort, 329

Spongy mesophyll, 9, I I, 2 I

Sporangia, II7, I50, I92, 224, 225 . $315,325,326$

Spore, I I 5, I I 8, I 5I, 270 differentiation of, 339 germination of, $278,300,301$, $330,331,338,349$

Sporophylls, II 5 , II6, II7, 337, 338, 379,381

Sporophyte generation, $136,194,2$ I5, 256,28 I

Sporophyte, development of, $28 \mathrm{I}$, 286, 29I, 293, 304, 3IO, 3I2, 3I8, $319,332-334,346,359,371,395$, 396,399

Squash, leaf, ro stem, 79,80

Stamen, II5, I I6, 379, 399

Staminodia, 42I, 473

Standard, 45I-453

Starch, 2, I2, 17, I8, I9 test for, I4

Staurastrum, I88

Steironema, 473,474

Stcm, branches of, 99, I00 dicotyledon, 84, 90, 93

function of, $7 \mathrm{I}$ growth of, 89, 90, 91 , 92, 93, 98,99 
Stem, healing of, IOI

modification of, 105

monocotyledons, $84,96,400$

sensitiveness of, I04

strengthening tissues of, 83

structure of, $71,73,77,90,91$,

92,93

Stemonitis, $\mathbf{5 0}$

Stereome, $37,38,39,78,79,84,85$, 323,325

Stereum, 264

Sticta, 233

Stigma, I I6, I I 7, 380

Stimuli, nature and effects of, 4 reaction to, $5,33-36,40,6 \mathrm{I}-63$, I04, I06, I2 I

Stink horns, 268

Stipe, 260

Stipules, 426

Stolon, I09, Iro

Stoma, 8, 9, ro, 21, 25, 26, 37, 88, 293

Stone fruit, 398

Storage organs, I8, 59, 77, IIO, III, I I3, I32

Strawberry, 384, 450

Streaming of protoplasm, 151, 152

Strobilus, 335, 337, 344, 347, 353 , $365,366,37.4$

Stroma, 238

Style, I I6, I I 7, 380

Suber, 86

Subdivision, I47

Subkingdom, I 48

Sugar, 12, I6, I7, 120

Sulphur, I6 bacteria, I6r

Surface reductions, 44 tension, 5I

Suspensor, I24, 125, 345, 346, 360, 37 I, 395, 396

Symbiosis, 68, 234

Sympetalae, 469

Symphytum, $385,475,476$

Synergid, II8, II9, I20, 390, 39I

Synthesis, I59, I60, I62

Tabellaria, I68

Tapetum, 379
Taraxacum, 485, 486

Taxodium, 376

Taxus, 376

Teeth, of peristome, 307,308

Telial stage, 254, 255

Teliospore stage, 255

Teliospores, 254, 255

Tendrils, 107, 108

Tetraspores, 2 I3

Thallophyta, classification of, 149

Thallus, I49, 270

Thaxter, 153

Thelephoraceae, 263

Thistle family, 485,489

Thuja, 376

Tissue, strengthening, 83

Toadflax, 478, 479

Toadstools, 259, 26o

Toxins, I $58, \mathrm{I} 62,163$

Tracheids, 9, 8I, 94, 363

Tradescantia, stoma, 38

Transpiration, 8, 24, 35

Transport of water, $59,79, \mathbf{I} 34$

Tree ferns, 325

Truffles, 243

Tsuga, 375

Tube, cell, I2I, I22, 358, 369-37I 392,393

Tubercles, 65, I6I

Tuberculosis, I63

Tubers, II I

Turgor, 83

Twigs, 73

Twining stems, 106

Typha, 38r, 40I, 403

Ulothrix, I90, I9I, I93

Umbel, 466

Umbellales, 465

Uncinula, 245, 247

Unilocular pistil, 473

Uredinial stage, 254, 255

Uredinales, $25 \mathrm{I}$

Urediniospores, 254, 255

Urticales, 434,436

Ustilaginales; 257

Ustilago, 258

Utricularia, 480 
Vaccinium, 472

Vacuoles, I, 2, 3, 60, 2 I7

Valerian, 483

Valves, of diatoms, 170

Vapor, from plants, 24

Variation, I05, I44, I76, I90, I97, 2 I $8,280,3$ I2-3i $3,320,388$

Variegated plants, I4, 32

Vascular bundles, II, I2, 16, 76, 77, $78,79,80,97,312,314,323,324$, $337,342,354$

Vaucheria, I95, I96

Veins, 7, 9, I I, 301, 302, 3I2

Velamen, 422

Veltheimia, 402

Velum, 260, 26I

Venation, 7, 400, 40I, 426, 427

Veratrum, 4I6

Vernonia, 49 I

Versatile anthers, 408

Vessels, 79, 80

Viburnum, 48I, 482

Vitis, $46 \mathrm{I}$

Volva, 26I

Volvocales, I74

Volvox, I80, I8I

Wallace's Law, 423

Wall cells, 277, 3I 8, 358, 392

Walnut order, 433

Ward, 24

Water-bloom, I65

Water, action on rock, 49

capillary, 50

composition of, I2

gravitational, 50

hygroscopic, 50

lily, 398,438

mould, 2 I 8

net, I 84
Watering of plants, 55

Wax of epidermis, 37,39

Weeds, 445

Willow, 38I, 430 order, 429

Wilting, cause of, 24

Wind, pollination by, $388,404,433$, $45^{8}$

Winged fruits, $373,45^{8}$

Wings, of flowers, $45 \mathrm{I}-453$

Witches' broom, 256

Wolffia, 410

Wood, heart, 95 oak, 95,427

pine, 363

sap, 95

sections, 93, 94, 95

spring, 91, 92, 95

summer, 9I, 92

Woodsia, 328

Woodwardia, 326, 328

Work of plants, 15

Working of ponds, I65

Xanthidium, 188

Xerophytes, 39, 45

Xylaria, 239, 24I

Xylem, 59, 76, 78, 79, 9I, 3I4-3I5

Yamanouchi, 2 I 5

Yeast, 248, 249

Yucca, 4 I9

Zamia, 353, 354, 355, 356

Zoöglea, I 55

Zoöspore, I5I, I 52

Zygnema, I85, I 86

Zygnematales, I85

Zygomorphic, 387 





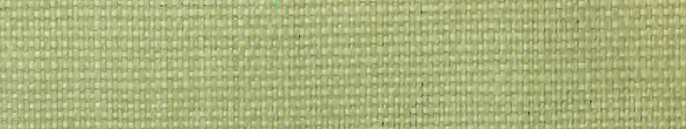

